


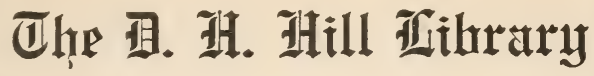

\section{Anarth Caralina State}

\section{Crallege}

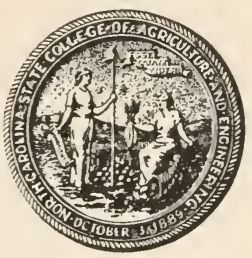

This book was presented by

$$
\begin{aligned}
\text { Dr. Z. P. Netcalf } \\
\text { QH366 } \\
\text { J6? }
\end{aligned}
$$




\section{9}

This book may be kept out TWO WEEKS ONLY, and is subject to a fine of FIVE CENTS a day thereafter. It is due on the day indicated below:

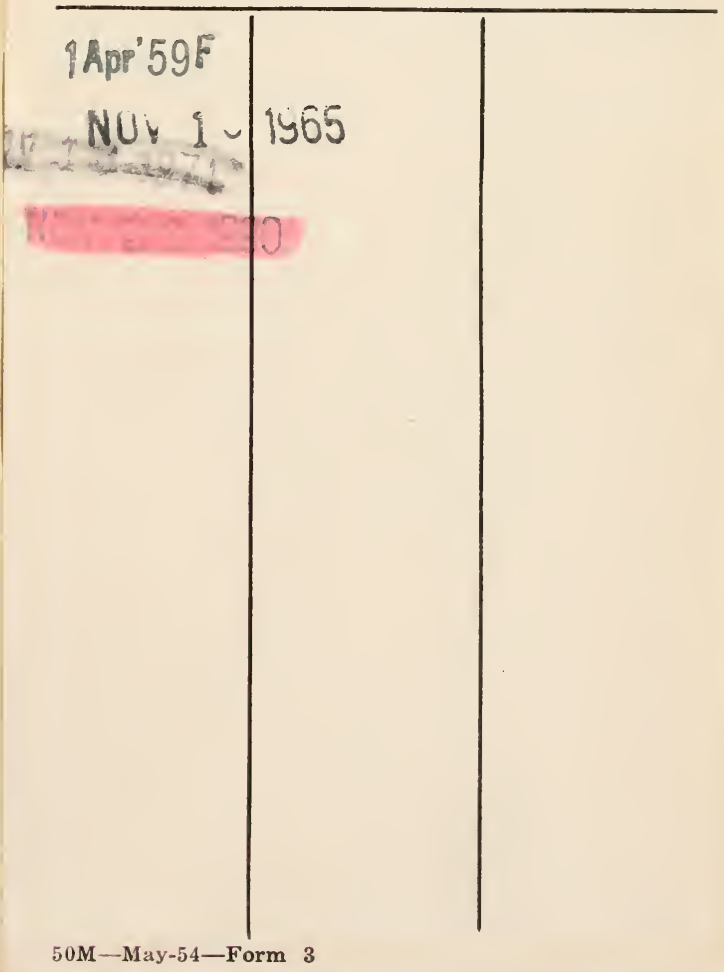



EVOLUTION AND ANIMAL LIFE 


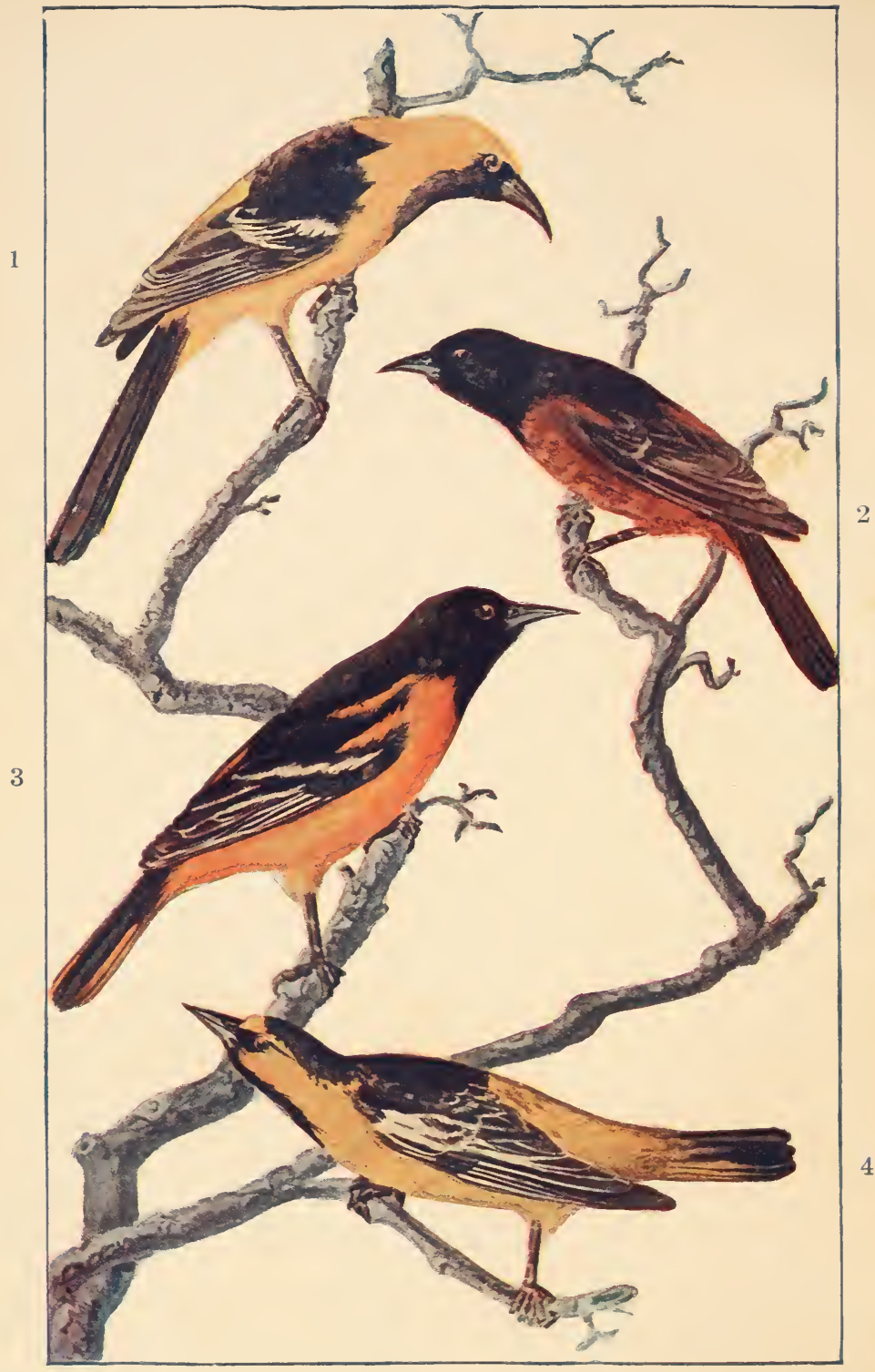

Plate I. - Four species of American orioles : 1, Nelson's oriole, Icterus nelsoni; 2 , orchard oriole, I. spurius; 3 , Baltimore oriole, I. galbula, 4, Bullock's oriole, I. bullocki. (From specimens.) 


\section{EVOLUTION AND ANIMAL LIEE}

AN ELEMENTARY DISCUSSION OF

FACTS, PROCESSES, LAWS AND THEORIES RELATING TO THE LIFE AND EVOLUTION OF ANIMALS

BY

DAVID STARR JORDAN

PRESIDENT OF LELAND STANFORD JUNIOR UNIVERSITY

AND

VERNON LYMAN KELLOGG

PROFESSOR OF ENTOMOLOGY, AND LECTURER IN BIONOMICS

IN LELAND STANFORD JUNIOR UNIVERSITY

Time, whose tooth gnaws away everything

else, is powerless against Truth.-HuXLEY.

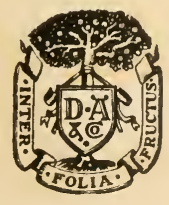

NEW YORK AND LONDON

D. APPLETON AND COMPANY 
COPYRIGHT, 190\%, BY

D. APPLETON AND COMPANY

Printed in the United States of America 


\section{PREFATORY NO'TE}

In the present volume the writers have tried to give a lucid elementary account, in limited space, of the processes of exolution as they are so far understood. We have turned to animals for illustrative purposes, nearly to the exchusion of refur:ences to plants, simply because both authors are zö̈logists and have made use of the facts most familiar to them.

The book is composed primarily of the substance of a university course of elementary lectures delivered jointly by the authors each year to students representing all lines of college work. This fact, and the desirable limiting of the book to a convenient size for the general reader and student, account for the extremely laconic treatment of various important mool points concerning the evolution mechanism, and for the omission of certain discussions which otherwise might well have been included. But on the whole the authors feel that the interested? general reader will find this small volume a fairly comprehensive irtroduction to our present-day knowledge of the factors and phenomena of organic evolution.

To the general reader we may perhaps with propricty address the following words, used to the students in the opening lecture of the course:

We cannot talk long without saying something others do not believe. Others cannot talk long without saying something we do not believe. We wish you to aceept no view of ours unless you reach it through your own investigation. What we hope for is to have you think of these things and find ont for yourselves.

$$
\begin{aligned}
& \text { 1). S. J. } \\
& \text { V. I. K. }
\end{aligned}
$$

Leland Stanford Jenior Univergity,

March 30, 1907. 



\section{TABLE OF CON'TENTS}

\section{CHAPTER I.-Evolution Defined.}

Organic evolution and bionomics, 1; Meaning of evolution, 2 ; Encasement theory, 2; Theory of epigenesis, 3; Evolution of the species or transmutation, 3; Cosmic evolution, 4; Spencer's formula of evolution, 5; Biologic evolution and cosmic evolution not the same, 6 ; Usefulness of the term bionomics, 7 ; The flux of nature, 7 ; Comprehensiveness of the science of organic cvolution, 8 ; The immanence and permanence of law, 9; Evolution not necessarily progress, 10; Theory of descent, 10.

\section{CHAPTER II.-VARIETY AND UNITY in Life.}

Range of variety, 12; Meaning of species, 13 ; Number of species, 14; Extinct species, 16; Changes of species with time and place, 18; Variety in life a factor in the history of the globe, 21; Unity in life, 22.

Chapter III.-Life, Its Physical Basis and Simplest ExpresSION.

Live things and lifeless things, 25; The basic distinetion between life and non-life, 26; Protoplasm, 26; Chemical make-up of protoplasm, 27; Physical make-up of protoplasm, 28; The cell, 30; The simplest animals, 32; Differentiation and animal types, 32: The genealogical tree, 36; Primary conditions of life, 35; Origin of life, 41; Spontaneous generation, 42; Where did life begin on the earth, 47.

YifAPTER IV.-Factors and Mechanism of Evolution.

The fact of descent, 48; Darwinism not synonymous with descent, 49; Factors in descent, 49; Variation, 50) Selection, 51: Prodigality of production, 52; Heredity, 53; Isolation, 53; Mutation, 54; Orthogenesis, 55; Lamarckism and inheritance of acquired characters, 55; Adaptation, 56. 
Chapter V.-Natural Selection and Struggle for Existence: Sexual Selection.

Natural selection the chief determining agent in adaptation, 57; Adaptation to conditions of life, 58; The crowd of animals, 59; Reproduction by multiplication, 59; Numbers of individuals almost stationary, 60; Struggle for existence, 60; Discriminate death, 61; Natural selection, 62; Interdependence of species, 63; Animal and plant invasions, 64; Doctrine of Malthus, 67; Limits to the capacity of natural selection, 68; Survival of the existing, 69; Actual standing of Darwinism, 70; Secondary sexual differences, 71; Classification of secondary sexual characters, 72; Theory of sexual selection, 75; Criticisms of the theory, 77; The sexual selection theory largely discredited, 78 .

\section{CHAPTER Vi.-Artificial Selection.}

Natural selection and artificial selection, 80; Steps in the production of new races, 81; Selected traits quantitative, 81; Race traits qualitative, 84; Hybridization, 88; Plant amelioration, 90; Work of Luther Burbank, 90; Panmixia, or cessation of selection, 104; Reversal of selection, 104; Transmission and heredity, 105; Artificial selection and natural selection, analogous processes, 106; Race-forming by sports, 107 .

CHAPTER VII.-VArious Theories of Species-Forming and Descent Control.

Segregation of isolation, 108; Geographic and physiologic isolation, 109; Romanes's championship of physiologic isolation, 109; The Lamarckian theory of species-transformation, 111; Orthogenetic evolution, 112; Species-forming by mutation, 114; The unknown factors of evolution, 115 .

\section{CHAPTER VIII.-Geographic Isolation and SPECIES-Forming.}

Migration and faunal distribution, 117; Closely related species not found in the same region, but in contiguous regions, 120; The American warblers, 120; Barriers, 122; The Hawaiian Drepanidæ, 124; Adaptive and non-adaptive characters, 127; The American orioles, 128; Species traits not necessarily useful, 129; The persistence of the sufficiently fitted, 130 .

\section{CHAPTER IX.-Variation and Mutation.}

Actuality and extent of individual variation, 131; Darwin's laws of variation, 137; Quetelet's determination that fluctuating variation follows the law of probabilities, 140; Discontinuous varia- 
tion, 141; Discontinuous and continuous variation, 141; Congenital and acquired variation, 142; Determinate variation, 150 ; The causes of variation, 154, 156; Variation as related to amphimixis and parthenogenesis as mutations of de Vries, 154.

\section{CHAPTER X.-HerEDity.}

Hereditary variancy defined, 163; Atavisin or reversion, 166; Telogony, 166; Prenatal influences, 167; Not all transmission is heredity, 168; Determination of sex, 170); Homologios and analogies, 172; Vestigial organs, 174; Significance of vestigial organs, 181 ; Heredity and its "laws," 1S1; Galton's law of ancestral inheritance, 184; Mendel's law of alternative inheritance, 187; Modification of Mendelism, 188.

\section{CHAPTER XI.-Inheritance of ACquired Characters.}

The Lamarckian principles of evolution, 196; Neo-Iamarckism and Neo-Darwinism, 197; Acquired characters, 198; Effects of use and disuse, 199; Environmental modifications not inherited, 2()(); Examples of non-inheritance of acquired characters, 201 ; Heredity unproved, 203; Convergence of characters and parallelism, 2().4; Actual effects of environment, 205; Ontogenetic species, 206.

\section{CHApter XII.-Generation, Sex, And Ontogeny.}

Generation and ontogeny, 211; Spontaneous generation or abiogenesis, 212; Simplest modes of generation, 213; Parthenogenesis, 215; Differentiation of reproductive cells, 217; Simplest manycelled animals, 218; Effects of sex, 220; Sex dimorphism, 221; The life cycle, 223; The egg, 224; Numbers of young, 2.25; Embryonic and post-embryonic development, 227; Developmental stages, 229; Continuity of development, 231; Metamorphosis or apparent discontinuity, 234; Significance of facts of developsment, 234; Divergence of development, 234; The duration of life, 240; Death, 241.

\section{SHAPTER XIII.-Factors IN Ontogeny, Ani Experimantal JEVELOPMENT.}

Processes in ontogeny, 244; Extrinsic and intrinsic factors, 24.5; Mechanism versus vitalism, 246; Functions of protoplasm, 247; Ultimate structure of protoplasm, 2 ss; Theories of organic units, 250; Cell division, 251; Mitosis, or karyokinesis, 252; somatic and germ tissues, 257; Reproduction in protozoa, 2(io): Maturation, 264; Fertilization, 267; Cleavage, 269; Reluction of the chromosomes, 269; Preformation versus epigenesis, 276 ; Examples giving 
evidence for each, 278; Mechanism versus vitalism, 281; Artificial parthenogenesis, 283; Regeneration and regulation, 285.

\section{CHAPTER XIV.-Paleontology.}

Fossils and thei: significance, 289; Fossil-bearing rocks and their origin, 292; Geological epochs, 296; Conditions of extinc'. life, 297; Divergent types and synthetic types, 299; Parallelism between geologic and embryonic series, 300; Orthogenesis, 301; Significance in evolution of the facts of paleontology, 301; Duration in time of species, 302; History of the vertebrates, 305; Man, 307.

\section{CHAPTER XV.-Geggraphical Distribution.}

Zoögeography, 309; Relation of species to geography, 311; Laws of distribution, 314 ; Species debarred by barriers, 315 ; Species debarred by inability to maintain their ground, 315; Species altered by adaptation to new conditions, 315; Effects of barriers, 316; Faunas and faunal areas, 316; Remains of animal life, 322; Subordinate remains of provinces, 323; Faunal areas of sea, 323; Analogies between language and fauna, 325; Geographic distribution and the theory of descent, 326 .

\section{CHAPTER XVI.-ADAPTATIONS.}

The principle of fitness and general adaptations, 327; Origin of adaptations, 327; Types and classification of species adaptations, 328; Adaptations for food-securing, 329; Adaptations for self-defense, 330; Adaptations brought about by rivalry, 331; Adaptations for defense of young, 338; Special adjustments to surroundings, 343 .

\section{CHAPTER XVII.-Parasitism and Degeneration.}

Parasitism defined, 347; Kinds of parasitism, 348; Simple structure of parasites, 350; Gregarina, 351; Parasitic hemosporidia: the cause of malarial fevers, 351 ; Tapeworm and other flat worms, 354; Trichina and other round worms, 355; Sacculina, 358; Parasitic insects, 359 ; Parasitic vertebrates, 361 ; Parasitic plants, 362 ; Degeneration through quiescence, 363 ; Degeneration through other causes, 363; Immediate causes of degeneration, 366; Advantages and disadvantages of parasitism and degeneration, 36 .

\section{CHAPTER XVIII.-Mutual A D and Communal Life among Ani-} MALS.

Man not the only special animal, 369; Animal societies, 369; Commensalism, 370; Symbiosis, 373; Symbiosis between animals 
and plants, 376; Social life, gregariousness, 3S0; Solitary and communal bees and wasps, 383; The honey-bee community, 357; Ants, 391; Termites, 394; Division of labor the basis of communal life, 395; Advantages of communal life, 397.

\section{CHAPTER XIX.-Color and Pattern in Animals.}

Color among animals, 398; Protection by color, 400; Protection f color, 402; Significance of color and pattern, $4(1) 4$; Table of insect colors, 405; General protective resemblance, 4(06; Variable protective resemblance, 407; Special protective resemblance, 411 ; Warning colors, 416; Terrifying appearances, 418; I)irective coloration, 419; Recognition marks, 420; Mimicry, 421; Criticism and general considerations of the theory of protective and minicking color pattern, 424 .

CHAPTER XX.-Reflexes, Instinct, and Reason.

Irritability, 426; Nerve cells or fibers, 427; Brain or sensorium, 427; Mechanical reflexes, 428; The tropism theory, 42!): The theories of the method of trial and error, 429; Instincts, 430; Instincts of feeding, 432; Instincts of self-clefense, 43:3; Instinct of play, 435; Climatic instincts, 436; Environmental instincts, 435; Instincts of courtship, 438; Instincts of reproduction, 439; Instincts concerned with the care of the young, 439; Variability of instinct, 442; Reason, 443; Mind, 448.

\section{Chapter XXI.-Man's Place in Nature.}

Post-Darwinian conception of humanity, 452; Man's place among the other animals, 453; Classification of the primates, 45.5 ; Evidences from comparative anatomy of man's relation to lower animals, 456; Special physiological evilence, 457; Evidence from embryology, 460; Evidence from paleontology, 461: ('onclusions from ethnology, 462; The earliest man, 46. The grenealogy of man, 466; Theology and Darwinism, 467. 



\title{
EVOLUTION AND ANIMAL LIFE
}

\author{
CHAPTER I
}

\section{EVOLUTION DEFINED}

Grau, theurer Freund, ist alle Theorie, Und grün des Lebens gold'ner Baum.

- CiokTHE.

Men of science repudiate the opinion that natural laws are rulers and governors of nature, looking with suspicion on all "necessary" and universal laws.-Brooks.

This volume treats of the elements of the sciense of Organic Evolution. To this science belongs the consideration of the forces which govern the changes in organisms. It includes the influences which control development in the inclividual and in the species which is the succession of individuals, together with the laws or observed sequences of events which development exhibits. From another point of view, this is the science of life-adaptation. The term Bionomies (Biōs, life, vópōs, order or custom), first suggested by Prof. Patrick Geddes, is essentially equivalent to the older term Organic Erolution, the science of the facts, processes, and laws involved in the mutation of organisms. For many reasons, this new name, Bionomics. with its technically exact meaning, should be preferred to the phrase Organic Evolution, as, unlike the latter, it involves no philosophic assumptions.

That organs and organisms do change from day to day, and place to place, and from generation to generation is an observed fact, which now admits of no doubt. The orderly arrangement of our knowledge of this process constitutes a branch of scicnee. To use the word evolution in regard to this process is to use it philosophic term in connection with a group of scientific facts. For the word evolution means unrolling. It carries the thought

\section{H. HILL LIBRARY,}


that something which was previously hidden is now brought to light. This leads naturally to the philosophic suggestion that whatever is evolved must be previously involved. This may be true as a matter of words, but not necessarily so as a matter of fact, unless we reduce these words to the simple meaning that the actual now must have been the possible before; whatever actually takes place was a possibility before it happened.

The word evolution, then, belongs to philosophy rather than to science. In the philosophy of nature the idea that present conditions are brought about through unrolling or unveiling has had a long existence. The word evolution has been frequently applied to the process of growth and maturity of the individual animal or plant, and again to the process of derivation of species from ancestral organisms, and again to the progressive changes in the forms of inorganic bodies, as planets or mountains. Each one of these meanings is essentially distinct from the others, and each is distinct from the theory of evolution which existed in the dawn of biological science. When men first began to notice the changes in the animal embryo, through which, from the formless egg, little by little, the individual was built up, becoming at each stage of the process larger, more specialized, and more like the parent from which it sprang, it was natural to regard this process as an unrolling. It was natural, too, to suppose that the egg was not really formless, but that the beginnings of each part of the final organism existed within it in fact, if we could see them. Hence evolution took the form of a theory of encasement. Men imagined that the egg of the chicken contained a minute chicken, and that within this chicken were the germs of the eggs the future hen would bear; and again, that encased within each of these eggs was an endless series of the eggs and chickens of all the future. In like fashion, men conceived that in the small human egg were the bodies and embryos of countless future generations. In some theories, this idea of encasement was applied not to the egg, but to the male germ, the homunculus or minute man in whom the generations of the future were enfolded and from which they unrolled.

The perfection of the microscope as an instrument of precision did not verify these theories of encasement. The egg still appeared essentially formless, a mass of undifferentiated 
protoplasm, or at least without traceable lineaments of the future embryo. It was a single cell, apparently essentially like any other cell, a single one of the units of structure of which living organisms are made.

Thence arose the theory of upbuilding or epigenesis ( $\epsilon \pi i$, upon, $\gamma^{\prime} \boldsymbol{v} \epsilon \sigma \iota s$, birth) of organisms, by the addition of cell upon cell, to the original germ or egg. Each egg cell by segmentation divides into two daughter cells, and these, through the influence of heredity, naturally arrange themselves so that a new organism is formed similar to the parent organism. It was recognized that the form was predetermined by the ancestry; but no longer that the embryo was literally released from encasement within the structure of the egg. The evolution of the individual is thus conceived as the realization of an hereditary tendency.

But "hereditary tendency" is again a metaphorical expression. In biology, we know no "influence" or "tendeney" which is not localized somewhere. Any act or modification of an act is a function of some particular organ. To account for the likeness involved in the facts of heredity, we must expect to find some form of organic mechanism.

Such mechanism must exist within the germ cell itself, and its existence as the "physical basis of heredity" is now well established. In a later chapter we shall discuss the nature of this physical basis, the structures within the nucleus of the germ cell which control or preside over the development of the individual. From our knowledge of the operation of the cell in heredity we recognize the facts of epigenesis, and with these a theory of individual evolution, much more subtle than the old theory of encasement.

We may therefore still imagine the maturing of the individual organ as a process of evolution, or unrolling, of the hereditary plan as hidden in the structure of its cells. We may also speak of the same process as a development. To envelop is to make snug. Development is its opposite. 'To develop) is to make free or independent.

From the evolution of the individual it is natural to extend the use of the word evolution or the word development to the changes which characterize the history of a species or other group of animals or plants, a process which has also been called transformism or transmutation. This word transmutation describes the process more literally than either evolution or 
development. That species do change their structure with time or with space is a matter of common scientific observation. With the lapse of time, generation following generation, directive influences combine to modify the line of descent. With the separation of individuals by barriers of land and water and varying climate, differing lines of descent are brought into existence. The fact of descent with modification large or small is a matter of common knowledge in the biology of to-day, verified in the hundreds of thousands of species of organisms now known and classified. To call this transmutation of species is but to state the fact. To call it evolution is to suggest a theory that all these changes are but the unrolling of the plan-a movement toward some predetermined end. That this is true we have no means of knowing, and the results as they appear to us seem to be determined by proximate causes alone. Among these proximate causes are differences in structure and in degrees of adaptability among individuals, the operation of the rule of the survival of the best adapted, the inheritance by individuals of the traits of the immediate ancestry, and the effects of climatic changes, and of migrations hampered and unhampered by the presence of physical barriers. The effects of influences like these are considered by most writers as the essential elements in "organic evolution." But a few writers give external influences a secondary place, confining the term evolution solely to the results of causes resident within the individual.

Speaking broadly we find as a fact that transmutation of species through the geologic ages has been accompanied by increasing divergence of type, by the increased specialization of certain forms, and by the closer and closer adaptation to conditions of life on the part of the forms most highly specialized, the more perfect adaptation and the more elaborate specialization being associated with the greatest variety or variation in environment. Accepting for this process the name of organic evolution, Herbert Spencer has deduced from it the general law that as life endures generation after generation, its character, as shown in structure and function, undergoes constant differentiation and specialization. In this view, the transmutation of species is not merely an observed process, but a primitive necessity involved in the very organization of life itself. 
A process of orderly mutation is observed not only in living things but in inaninate objects as well. The foatures of the surface of the earth pass through a slow process of unrollingfrom primitive chaos to the diversified earth of to-day. Manifestly we cannot imagine a homogeneous earth which rould forever retain its homogeneous eondition. At least our miverse and our earth have not done so. A cooling earth must lue its perfect rotundity, its surface must berome diversifuml, its relation to the sun must cause its equator to differ from its poiles. A single homogeneous form of life on this carth could not remain uniform because it would be thrown under varying conditions. It could not be the same under the tropical sim ats under the arctic cold, and the individuals aclapted to either would tend to reproduce individuals likewise arlapted. There must, then, exist in all things a "tendency " to become specialized and differentiated. In accordance with this tendency, it is conceived that nebulous masses have been concentrated into planets and the generalized creatures of geologic time have been succeeded by variant and specialized forms, their lineal descendants.

The universal formula of the process of evolution is compactly stated by Herbert Spencer in these famous words:

"Evolution is a continuous change from indefinite incoherent homogeneity to a definite coherent heterogeneity of structure and function, through successive differentiations and integrations. In its physical aspect evolution is further an integration of matter with concomitant dissipation of motion."

This formula applies more or less to all forms of orderly change, that is, change due to a persistent cause, a continuous force. Thus solar systems are conceivably formed from nebulit. Thus continents and mountain chains, islands and river basins are shaped. Thus organisms are derived from pirent organisms. Thus all the variant chemical elements may have been (hypothetically) derived through influences as yot not even imaginerl, from the unknown and probably unknowable primitive element, protyl. The general movement is from the simple to the complex, from the homogencous to the heterogeneous, from the inexperienced to the experieneed, from the undivided to the divided, from the inchoate to the integrated. Whaterer 
happens in time or is encountered in space promotes evolution. But the kind of evolution thus produced is very different in different kinds of objects.

Biological evolution and cosmic evolution are not the same. From the biological side a certain objection must be made to this philosophical theory of universal or cosmic evolution. In organic and inorganic evolution there is much in common so far as conditions and results are concerned; but these likenesses belong to the realm of analogy, not of homology. They are not true identities because not arising from like causes. The evolution of the face of the earth forces parallel changes in organic life, but the causes of change in the two cases are in no respect the same. The forces or processes by which mountains are built or continents established have no homology with the forces or processes which transformed the progeny of reptiles into mammals or birds. Tendencies in organic development are not mystic purposes, but actual functions of actual organs. Tendencies in inorganic nature are due to the interrelations of mass and force, whatever may be the final meanings attached to these terms or to the terms matter and energy. It is not clear that science has been really advanced through the conception of the essential unity of organic evolution and cosmic evolution. The relatively little the two groups of processes have in common has been overemphasized as compared with their fundamental differences. The laws which govern living matter are in a large extent peculiar to the process of living. Processes which are functions of organs cannot exist where there are no organs. The traits of protoplasm are shown only in the presence of protoplasm. For this reason we may well separate the evolution of astronomy, the evolution of dynamic geology and of physical geography, as well as the purely hypothetical evolution of chemistry, from the observed phenomena of the evolution of life. To regard cosmic evolution and organic evolution as identical or as phases of one process is to obscure facts by verbiage. There are essential elements in each not shared by the other-or which are at least not identical when measured in terms of human experience. It is not clear that any force whatever or any sequence of events in the evolution of life is homologous with any force or sequence in the evolution of stars and planets. The unity of forces may be a philosophical necessity. A philosophical necessity or corner in logic is un- 
known to science. We can rerognize no logical neressity until we are in possession of all the facts. No ultimatc fact is yol known to science.

For reasons indicated above the term evolution is not wholly acceptable as the name of a branch of science. Thu: term bionomics is a better designation of the changing of organisms influenced through unchanging laws. It is a name broader and more definite than the term organic: evolution, it is more euphonious than any phrase meaning life adint at inn, it involves and sugarests no theory as to the origin of the phenomena it describes.

It is a matter of common observation that organisms (hange from day to day, and that day by day some alteration in their environment is produced. It is a conclusion from scientific investigation that these changes are greater than they appear. Not only do they affect the individual animal or plant, but they affect all groups of living things, classes or races or species. No character is permanent, no trait of life without change; and as the living organism and groups of organisms are undergoing aiteration, so does change take place in the objects of the physical world about them. "Nothing endures," says Huxley, "save the flow of energy and the rational order that pervades it." The structures and objects charige their forms and relations, and to forms and relations once ahandoned they never return; but the methods of change are, so far as we call see, immutable. The laws of life, the laws of death, and the laws of matter never change. If the invisible forces which rule all visible things are themselves subject to modification and evolution we have not detected it. If these vary, their aberrations are so fine as to defy human observation and computation. In the control of the universe we find no trace of "variableness nor shadow of turning."

But the objects we know do not endure. Only the shortnest of human life allows us to speak of species or even of individuals as permanent entities. The mountain chain is no more nearly eternal than the drift of sand. It endures beyond the period of human observation; it antedates and outlasts human history. So may the species of animal (or plant outlast and antedate the lifetime of one man. Its changes are slight eren in the lifetinc of the race. Thus the species, through the persistence of its type among its changing individuals, has come to be regarded 
as something which is beyond modification, unchanging so long as it exists.

"I believe," said the rose to the lily in the parable, "that our gardener is immortal. I have watched him from day to day since I bloomed, and I see no change in him. The tulip who died yesterday told me the same thing."

As a flash of lightning in the duration of the night, so is the life of man in the duration of nature. When one looks out on a storm at night he sees for an instant the landscape illumined by the lightning flash. All seems at rest. The branches in the wind, the flying clouds, the falling rain, are all motionless in this instantaneous view. The record on the retina takes no account of change, and to the eye the change does not exist. Brief as the lightning flash in the storm is the life of man compared with the great time record of life upon earth. To the untrained man who has not learned to read these records, species and types in life are enduring. From this illusion arose the theory of special creation and permanence of type, a theory which could not persist when the facts of change and the forces causing it came to be studied in detail.

But when men came to investigate the facts of individual variation and to think of their significance, the current of life no longer seemed at rest. Like the flow of a mighty river, ever sweeping steadily on, never returning, is the movement of all life. The changes in human history are only typical of the changes that take place in all living creatures. In fact, human history is only a part of one great life current, the movement of which is everywhere governed by the same laws, depends on the same forces, and brings about like results.

Organic evolution, or bionomics, is one of the most comprehensive of all the sciences, including in its subject matter not only all natural history, not only processes like cell division and nutrition, not only the laws of heredity, variation, segregation, natural selection, and mutual help, but all matters of human history, and the most complicated relations of civics, economics, and ethics. In this enormous science no fact can be without a meaning, and no fact or its underlying forces can be separated from the great forces whose interaction from moment to moment writes the great story of life,

And as the basis to the science of bionomics, as to all other science, must be taken the conception that nothing is due to 
chance or whim. Whatever occurs comes as the resultant of moving forces. Could we know and estimate these forece, we should have, so far as our estinate is accurate and oml logrce perfect, the gift of prophery. Knowing the law, and knowing the facts, we should foretell the results. To be ahle in some degree to do this is the art of life. It is the ultimate and of science, v'hich finds its final purpose in human conduct.

"A law," according to Darwin, "is the ascertained sequence of events." "The actual sequence of events it is, in fact, but man knows nothing of what is necessary, only of what has buen ascertained to occur. Because human olservation and logre can be only partial no law of life can be fully stated. Burance the processes of human mind are human, with organic limitations, the study of the mind itself becomes a part of the science of bionomics. For it is itself an instrument or a combination of instruments by which we acquire such knowledge of the world outside of ourselves as may be needed in the art of living, in the degree in which we are able to prartice that art.

The necessary sequence of events exists, whether we are able to comprehend it or not. The fall of a leaf follows fixed laws as surely as the motion of a planet. It falls by chance because its short movement gives us no time for observation and calculation. It falls by chance because, its results being uninportant to us, we give no heed to the details of its motion. But as the hairs of our head are all numbered, so are numbered all the gyrations and undulations of every chance autumn liaf. All processes in the universe are alike natural. The creation of man or the growth of a state is as natural as the formation of an apple or the growth of a snowbank. All are alike supernatural, for they all rest on the luuge unseen solidity of the universe, the imperishability of matter, the conservation of energy, and the immanence of law.

We sometimes classify seicnees as exact and inexact, in accordance with our ability exactly to weich forese and results. The exact sciences deal with simple data accessible and apable of ineasurement. The results of their interactions can be reduced to mathematics. Becumse of their escential simplicity, the mathematical sciences have been carricel to great comparative perfection. It is easier to weigh an invisible planet than to measure the force of heredity in a grain of corn. The sciences of life are inexact leceanse the human mind can never 
grasp all their data. The combined effort of all men, the flower of the altruism of the ages, which we call science, has made only a beginning in such study.

But, however incomplete our realization of the laws of life, we may be sure that they are never broken. Each law is the expression of the best possible way in which causes and results can be linked. It is the necessary sequence of events, therefore the best sequence, if we may imagine for a moment that the human words "good" and "bad" are applicable to world processes. The laws of nature are not executors of human justice. Each has its own operation and no other. Each represents its own tendency toward cosmic order. A law in this sense cannot be "broken." "If God should wink at a single act of injustice," says the Arab proverb, "the whole universe would shrivel up like a cast-off snake skin."

The laws of nature have in themselves no necessary principle of progress. Their functions, each and all, may be defined as cosmic order. The law of gravitation brings order in rest or motion. The laws of chemical affinity bring about molecular stability. Heredity repeats strength or weakness, good or ill, with like indifference. The past will not let go of us; we cannot let go of the past. The law of mutual help brings the perpetuation of weakness as well as the strength of coöperation. Even the law of pity is pitiless, and the law of mercy merciless. The nerves carry sensations of pleasure or pain, themselves as indifferent as the telegraph wire, which is man's invention to serve similar purposes. Some men who call themselves pessimists because they cannot read good into the operations of natur? forget that they cannot read evil. In morals the law of competition no more justifies personal, official, or national selfishness or brutality than the law of gravitation justifies the shooting of a bird.

The science of bionomics centers about the theory of descent, the belief that organs and species as we know them are derived from other and often simpler forms by processes of divergence and adaptation. According to this theory all forms of life now existing, or that have existed on the earth, have risen from other forms of life which have previously lived in turn. All characters and attributes of species and groups have developed with changing conditions of life. The homologies among animals are the results of common descent. The differences 
are due to various influences, one of the leading forces ancug these being competition in the struggle for existence between individuals and between species, whereby those best adapted to their surroundings live and reproduce their kind.

This theory is now the central axis of all biological inve-tigation in all its branches, from ethics to histology, from anthropology to bacteriology. In the light of this theory avery peculiarity of structure, every character or quality of individual or species, has a meaning and a cause. It is the work of the investigator to find this meaning as well as to recort the fact. "One of the noblest lessons left to the workd hy I) arwin," says Frank Cramer, "is this, which to him amounted to a profound, almost religious conviction, that every fact in nature, no $1 \mathrm{tatter}$ how insignificant, every stripe of eolor, every tint of flowers, the length of an orchid's nectary, unusual height in a plant, all the infinite variety of apparently insignificant things, is full of significance. For him it was an historical record, the revelation of a cause, the lurking place of a principle." It is therefore a fundamental principle of the science of bionomics that every structure and every function of to-day finds its meaning in some condition or in some event of the past. 


\section{CHAPTER II}

\section{VARIETY AND UNITY IN LIFE}

"L'espèce, c'est un être qui dans ses générations successives présente toujours les mémes caractères d'organisation; il faut ajouter dans les mêmes localités, et les mêmes circonstances extérieures."RAMBUR, 1812 .

"That mystery of mysteries as it has been called by one of our greatest philosophers "- - this is Darwin's phrase regarding

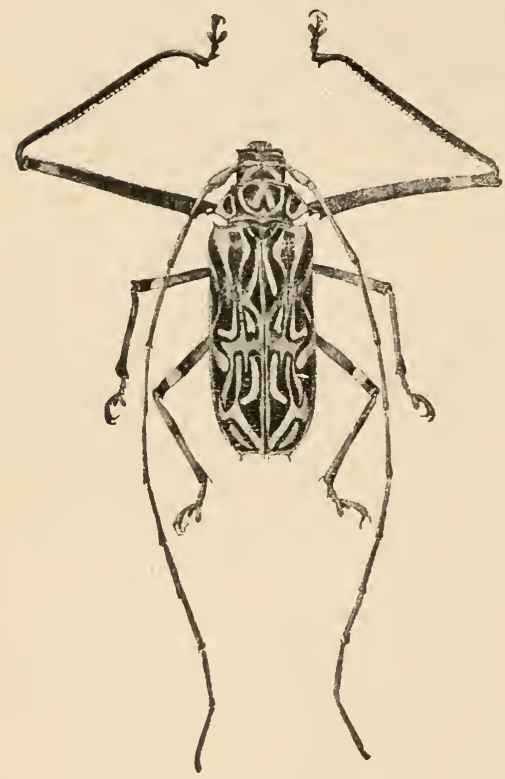

F'IG. 1.-Jong-horned horing beetle from Central America (one-half natural size). ${ }^{1}$ the problem before us, the origin of species - the or igin or cause of variety in the life of the globe.

That variety exists, that there are many kinds and types, grades and grada. tions in animal and regetable life is evident to all. Birds and trees, beetles and butterflies, fishes and flowers, ferns and blades of grass, all these are objects of constant recognition. The green cloak which covers the brown earth is the shield under which myriads of organisms, brown and green, carry on their life work, and still farther below the level of our ordinary notice exists a range of life scarcely less

${ }^{1}$ This figure and the others in this chapter are introduced simply to illustrate graphically the variety of animal form. 


\section{VARIETY AN INITY IN I.III.}

varied. Pasteur has defined fermentation as "life " it liont air." A host of ehemical changes in organic nuatter, formentation, putrefaction, infection of discase-all these are the work of minute organisms none the less real becante invisible and at -aried in form and structure as in the differing efferts the ir presence may produce.

Each kind of animal or plant, that is, cicch set of form which in the changes of the ages las divereerl tancribly from it neighbors, is called a species. There is no absolute definition for the word species. The word kind rejuresents it exactly in common language, and is just as susceptible to cxact definition.

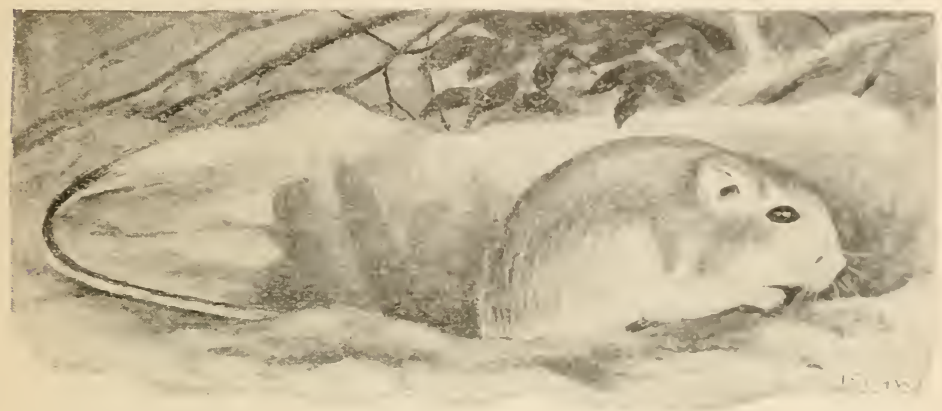

Fia. 2.- Kangaroo rat from the California-MIojave desert (one-half natural -1ze .

The scientific idea of species does not differ materially from the popular notion. A kind of tree or bird or squirrel is a speries. Those individuals which agree very closely in structure and function belong to the same species. There is mo absolute tert, other than the common judgment of men competent to deride. Naturalists recognize certain formal rules as assisting in such ib decision. A series of fully intergrading formis, however varieul at the extremes, is usually regarded as forming a single species. There are certain recognized effects of climate, of climatic irolation, and of the isolation of domestication. These do not usually make it necessary to regarrel ats distinct syecien the extreme forms of a series concemed.

In the words of the entomologist Rambur, "I sprecies is a group of beings which in suecessive generations show the sunce characters of organization, unchanged so long as the locality and external conditions 1 cmain unchanged." 
The number of species actually existing is far beyond ordinary conception. The earliest serious attempt to catalogue the species of animals and plants was made by Linnæus. In the tenth edition of his "Systema Naturæ " in 1758, in the 823 pages

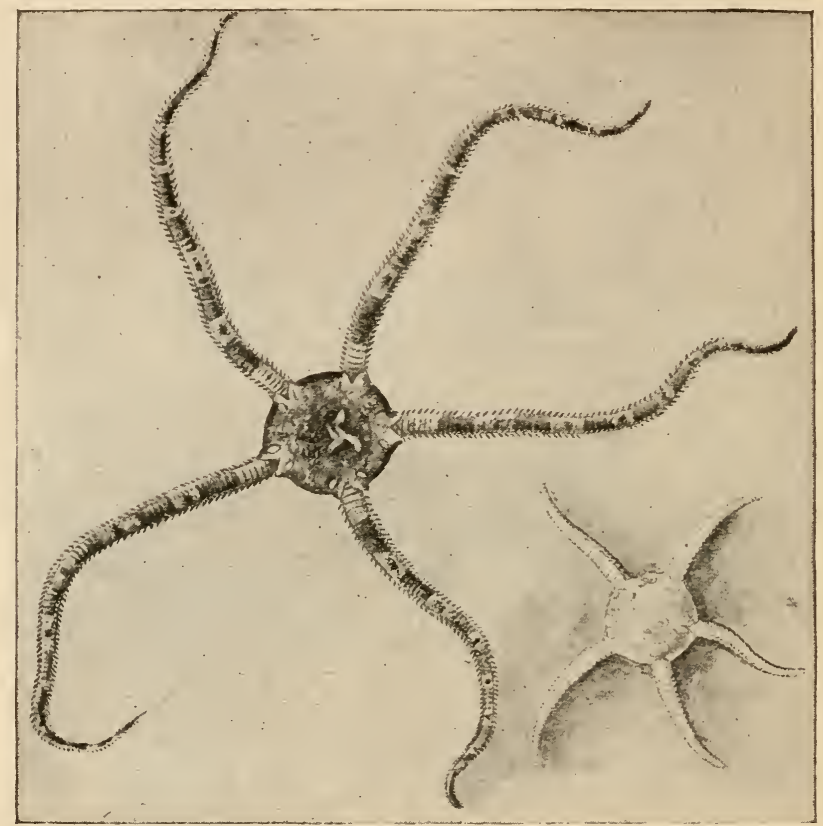

FIG. 3.-Brittle or serpent stars-species undetermined. (Natural size.)

devoted to animals, he describes and names some four thousand different kinds. Great as this number seemed, Linnæus rentured to suggest that probably his pages did not include half of those kinds of animals actually existing.

To-day our records contain descriptions of more than one hundred and fifty times as many linds of animals as were known to Linnæus and all his predecessors and all his associates of a century and a half ago. Each year, since 1S64, there has been published in London a volume called the "Zoölogical Record." Each of the volumes-larger than the whole "Systema Naturæ" - contains the names of the animals new to science which have been added to the system in the year of which it treats. In the 
record of each year we find about twelve thousand specrict, aluntent three times as many animals as in the whole " Nystomat Natmir." Yet the field shows no signs of exhaustion. As the rolumen of the "Zoölogical Record" stand on the shelves, it is easy in fore that the later volumes are the thickest; and those of the new century, with a general revival of interest in systematic zoolongy

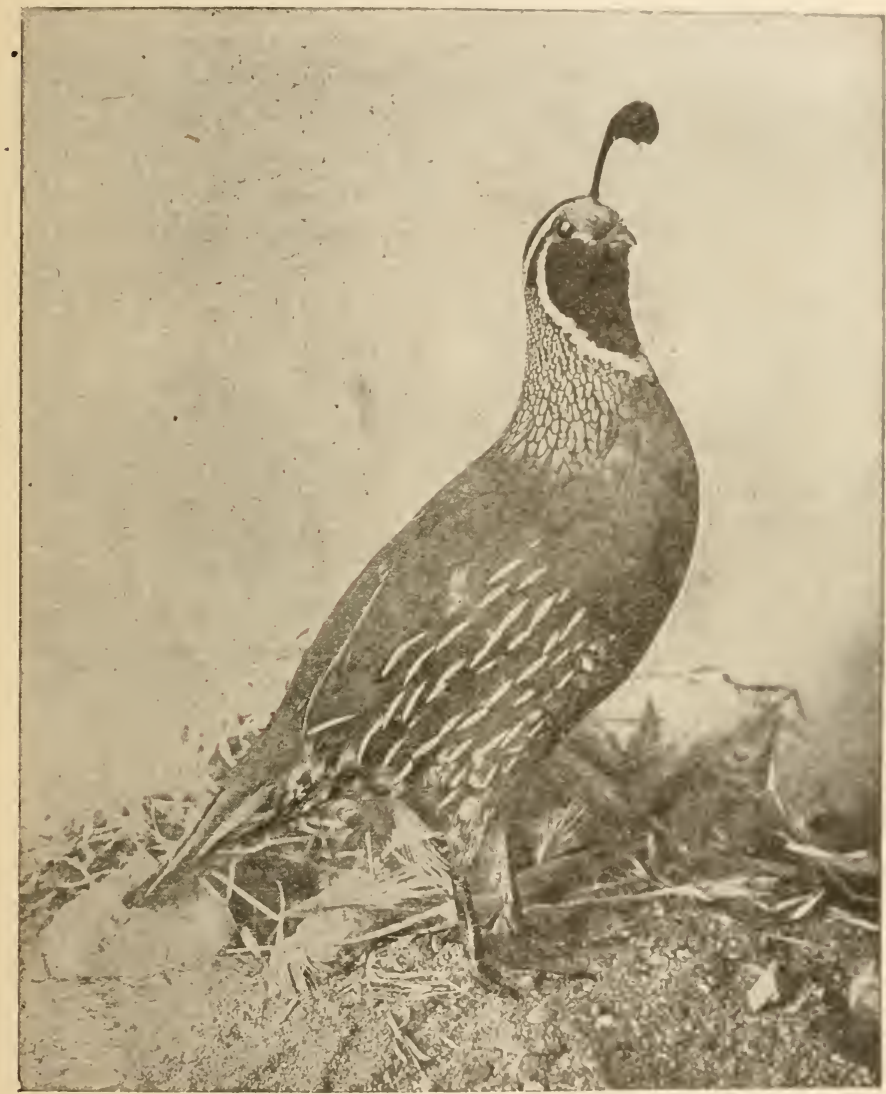

FIg. 4.-California quail, Lophortyx culifornicus. (Two-thirds natural size.)

and the study of geographical distrihution, are the thinkist of

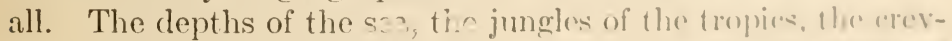
ices of the coral reefs, the tundras of the north, the limbs of 
trees, the hair of mammals, the feathers of birds, the body tissues of mosquitoes, all places where animal life is found, are being examined with an eagerness not less than that of the early explorers, while the investigators of to-day are armed with every appliance that science can devise. Yet now, as in Linnæus's time, it is certain that not half of the number of species of animal organisms is yet known. The 600,000, more or less,

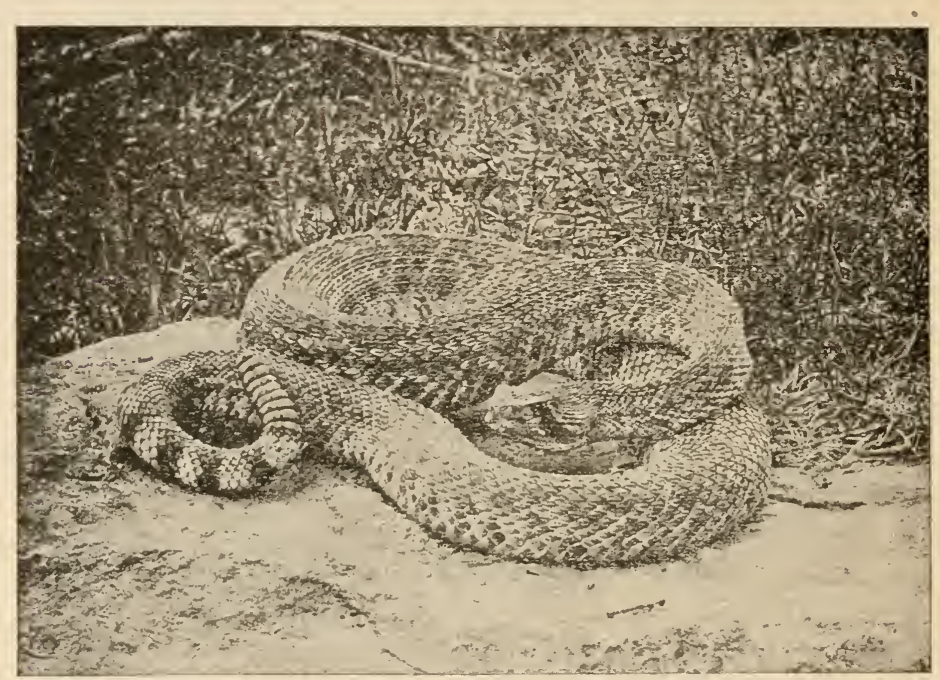

FIG. 5.-Diamond rattlesnake, Crotalus adamanteus. (Photograph by W. H. Fisher.)

on our registers to-day are certainly far less than half of the millions which actually exist.

In botany we find the same conditions. There are ferer known species of plants than animals by half, and they are more easily preserved and handled, while the work of collection and investigation proceeds on a scale even more extensive, yet it would be a bold statement to say that we know to-day half the species of plants that exist.

All this refers to the forms now living, without reference to the host which composes their long ancestry, extending backward toward the dawn of creation. The species have come down through the geological ages, changing in form and function to meet the varying needs of changing environment. This 
enumeration takes no account of the still vaster myriule of forme almost endlessly varied which have perished utterty in the pressure of environment, leaving no trace in the line of derecul.

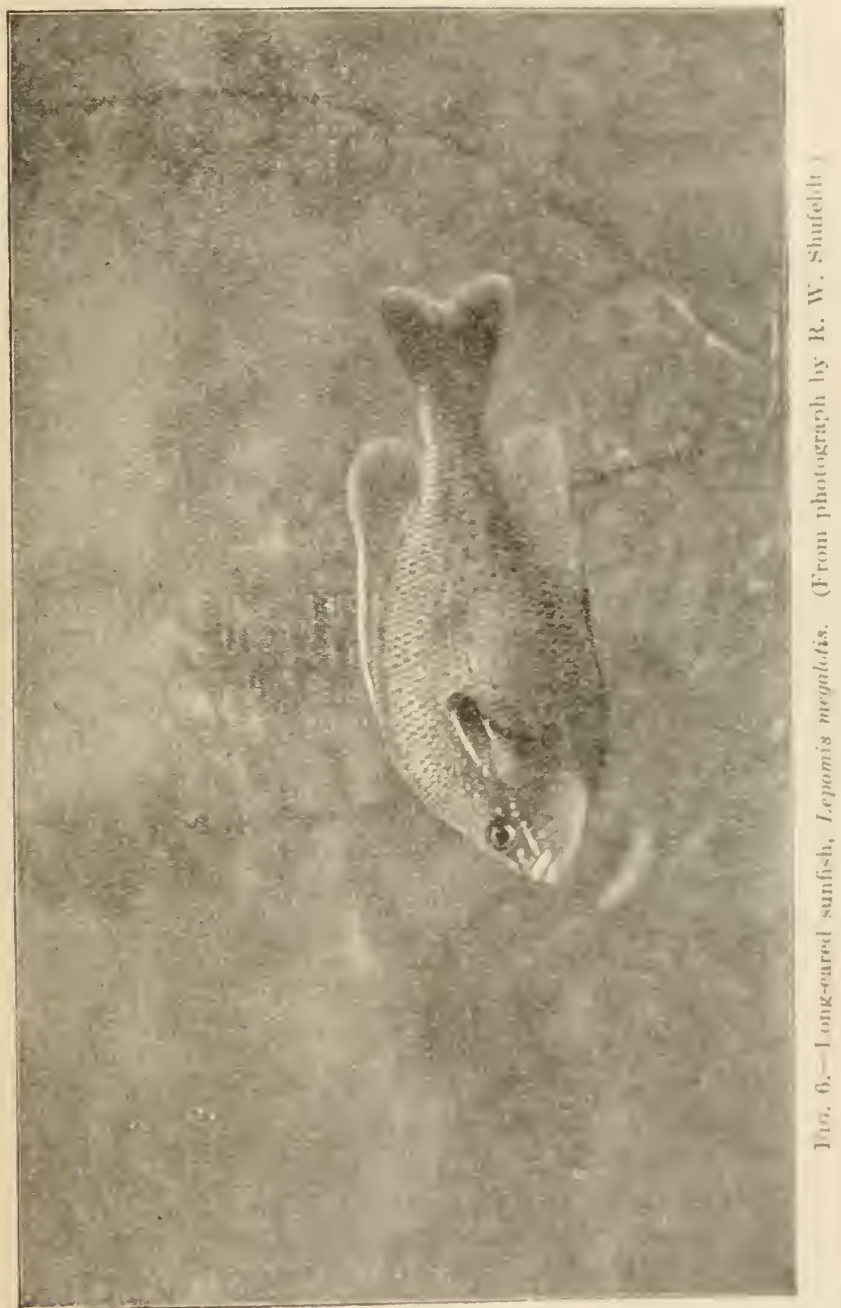

Of these extinct forms of animals and plants we know a few; one here and another there: here a bone, there a tooth, here a 
mass of shells, there a piece of petrified wood, an insect in the marl bed or a leaf preserved flat in the shale. Each of these fossils is a record of past life, true beyond impeachment, but the fragments are so few, so scattered, so broken, as to give only hints of the history they represent.

Moreover, as we extend our studies of species we find that they change with space as well as with time. These changes

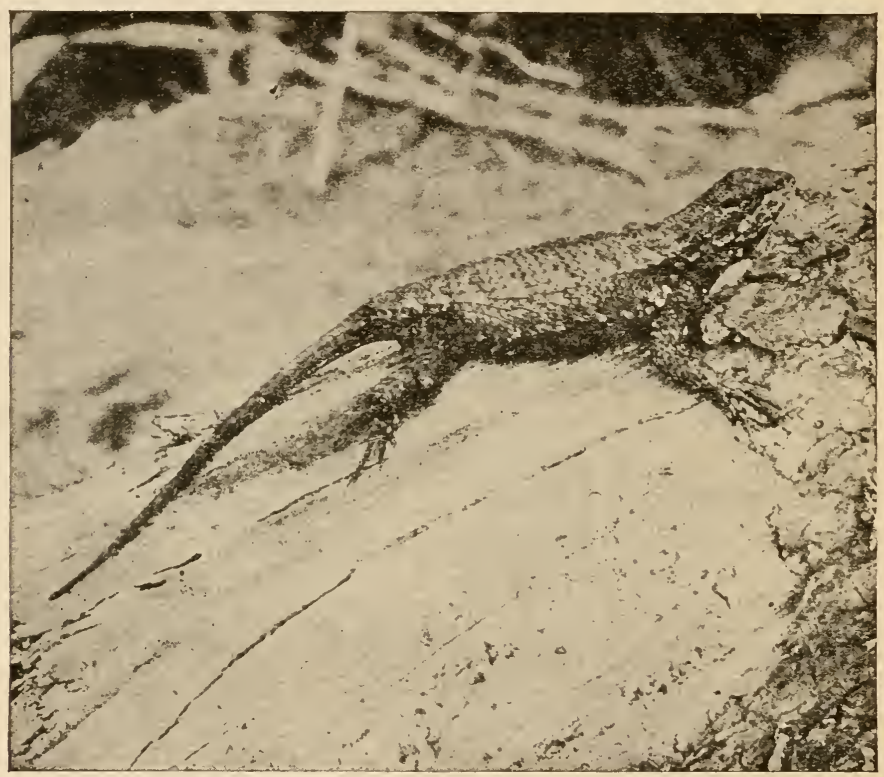

FIG. 7.-Common lizard or swift, Sceloporus undulatus. (Photograph by W. H. Fisher.)

are in large degree a response to external conditions. As conditions change, so do forms change to fit their surroundings. A movement over the surface of the earth, any movement in space, brings organisms in contact with barriers. A barrier means a change in conditions of life. As distance in space brings barriers, so does the passage of time bring events which are barriers also. Time brings new events; events mean changes in conditions, and change brings about divergence. Neither time nor space flows evenly.

Variations in turn become greater with lapse. of time and 
space, for these again bring other erents and aliselose of luer barriers. A closer observation will show us that the range of variety is far greater than is indicated by the number of spreaice. There is not one blade of grass in the meadow exactly like any other blade. There is not a sepuirrel in the forest like any other squirrel, not a duck on the pond like any other duck in every detail of its structure. If we coupluare two rose leatres we shall find differences in size, in serration of the matrin, in the length of the stalk, in the hairs on the surface, in the intensity of the green, in the number of breathing pores on the lower side. In every structure and function where difference is possible variation will appear. The squirrels or the ducks will differ in shade of color, in distinctness of marking, in length of limb, in breadth of organ, in every way in which there is play for individualism.

Nor are these differences limited to nuatters of color or form. There are like variations in function, in tendency, in disposition, in endurance. No two men ever bore the same features, no two ever held the same character, no two ever lived the same life. The traits of the individual, however small, appear on every hand. It is by little traits of

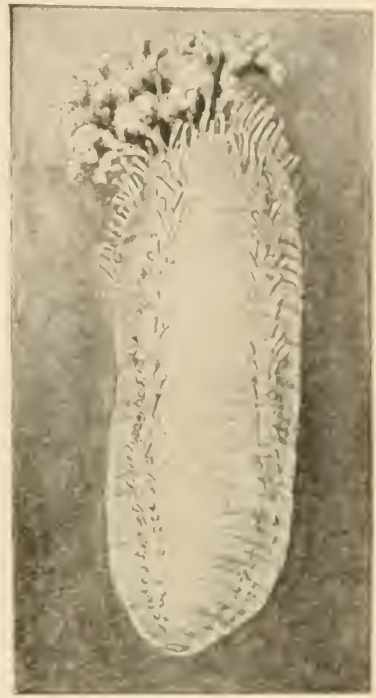

Fic. S.- Sca mucumber, rucumaria, s). (Xatural size.) emphasis that we recognize our friends. The same individualism is possessed by the lower animals and hy plints, though the differences in stress and emphasis in color and figure are most marked in ercatures of the nost highly specoializod organization. In all animals and all plintis like differeneres obtatio. No two individuals of any species are erere quite the sitme. Do two germ cells of the same parent ale "reve yuite alike. Lotwo cells in the body are ever exactly inlentical. Among flumts of the same kind in the field, some are cout down hy from while others persist; some are destroyed hy dromerht while others endure; some are immune to attacks of rust while others are ex- 


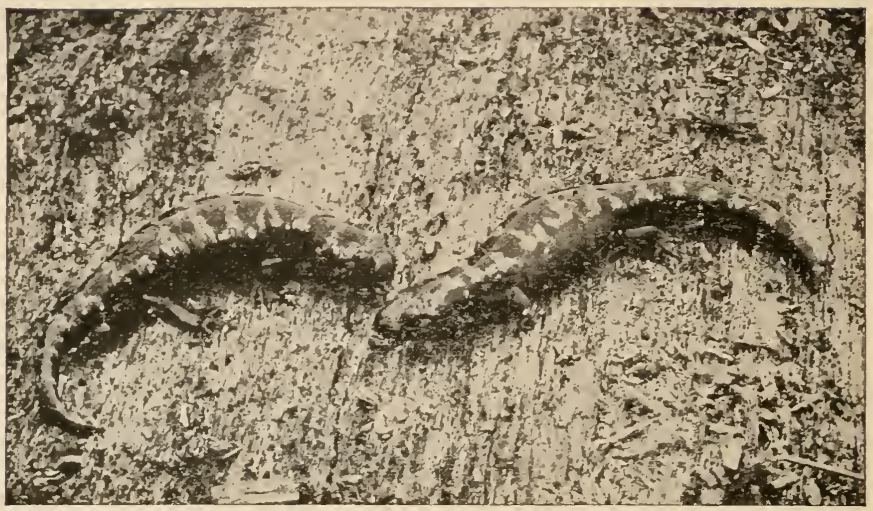

F. IG. 9.--Blunt-nosed salamander, A mblystoma opacum. (Photograph by W. H. Fisher.)

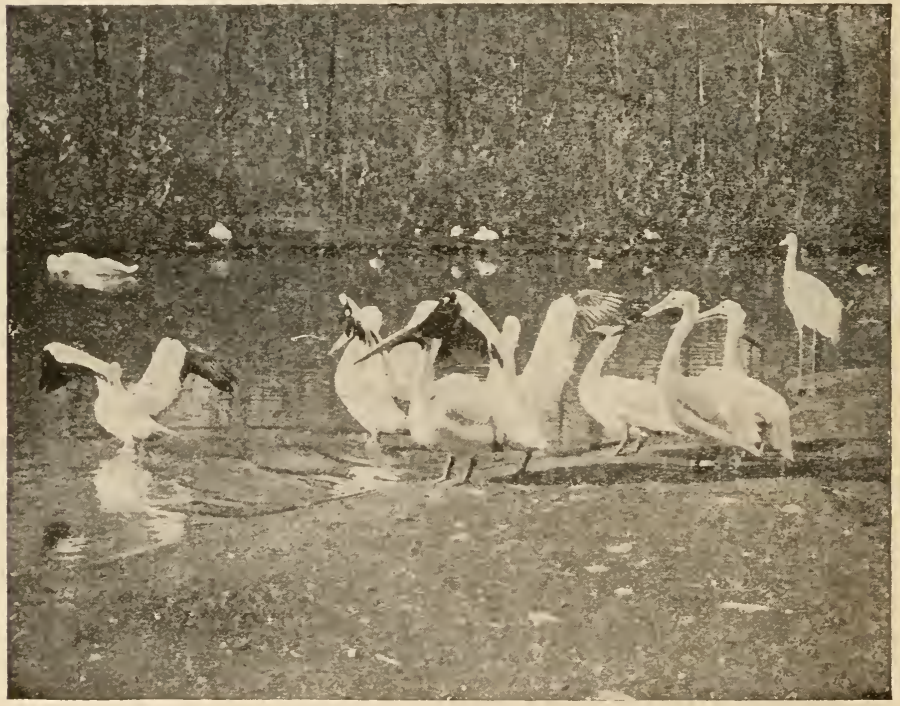

FIG. 10.-White pelicans, Pelecanus erythrorhynchus, and whooping-crane, Grus americana. (Photograph by W. H. Fisher.) 
terminated by such parasites. Fill a hottle with flies. All in time will die of suffocation, but a certitin few will ontlast tluc many. Bring in a number of wolf culss. Some will hecoms. relatively tame-some will remain wolves, and between the most fierce and the most docile we shall find all ranges of variation. "What is one man's food is another man's poison." This proverb is a recognition of the principle of individuality which accompanies everywhere the formation of specics, and being everywhere present, it must be an integral part of the

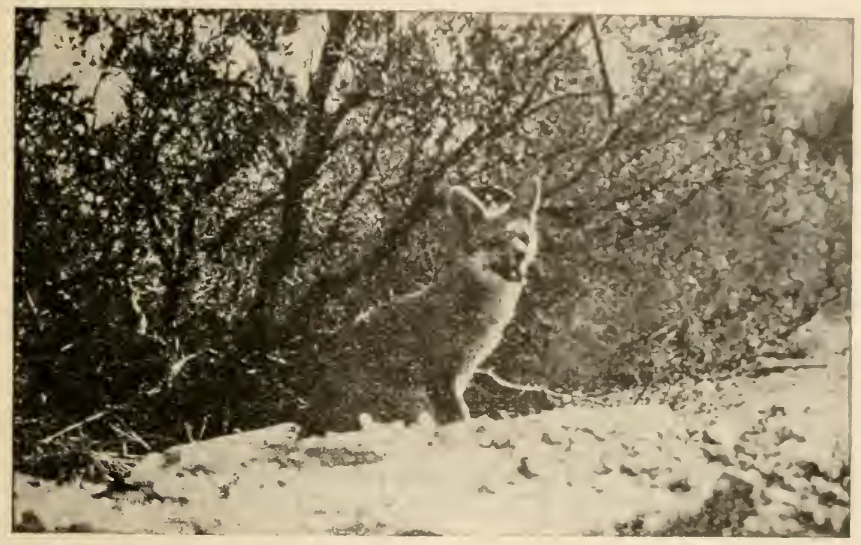

FIG. 11.-Silver fox, V'ulpes pennsylvanicus argentatus. (1'hotograph by W. H. Fisher.)

process. Such differences are not matters of structure alone. Psychological differences, differences in instinct, in andantability, in rate of nerve processes are just ats marked als difforences in anatomy. They may separate ome specios from another. They may be just as decided within the lin its of the species itself. Moreover, the beginning of valriation is not with the individual organisms. No two cells are absolutely alihe. and in the variance of the germ colls, from which irdividusts spring, all the elements of their future variation are involved.

Without further discussion, it is evilent that varicty in lifo is a factor in the history of our globe, that it may he axpmesed in terms of number of species, but that the actual range of variation is far greater than the number of species, and that if canses are to be judged by range of effects, we must find in the origin of 
species the operation of world-wide forces, the coöperation of great influences, far-reaching in time and space, as broad as the surface of the globe and as enduring as its life. To consider these causes so far as known is the purpose of this work. Our problem is no longer the "mystery of mysteries," for in a large way by the work of Darwin and his successors the influences promoting variety in life are already known. We know many of the different factors which produce divergence in form and adaptation to conditions. But the relative value of these factors is less certain, and from time to time other and more

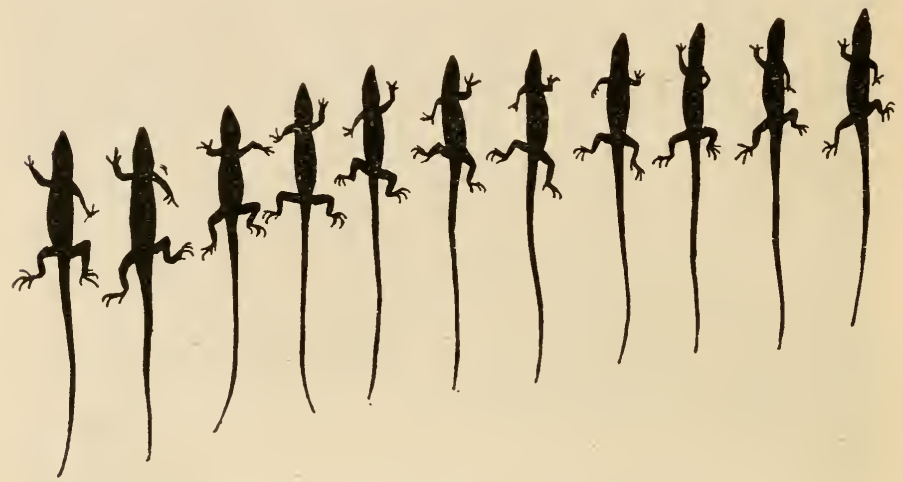

Fig. 12.-Lizard walking. (After Marey.)

subtle factors are brought to light, or the great forces themselves are analyzed into finer component elements.

But with all that we may say of the universality of variation and the prevalence of individualism, we are equally impressed with the underlying unity. There are only a few types of structure among animals, and in these few the beginnings in development are the same. The plants show similarly a few modes of development, and all the range of families and forms is hased on the modification of a few simple types. Horeover all living forms, plants and animals alike, agree in the fundamental elements. All are made of a framework of cells, each cell a source of energy, containing in all cases a semifluid network of protoplasm, which is found wherever the phenomena of life appear. In all the cells is the mysterious nuclear substance which seems to direct the operations of heredity. The same laws or methods of heredity, variability, and response to 
outside stimulus hold in all the organic worlel. We call animals and plants "organic" because they are male up of organs, cells, and tissues so grouped that like structures perform like functions. We could not use a generic term like organic, were it not for the structural resemblances existing in each individual in great groups of organisms. All organisms have the impulse to reproduction. All are forced to make concession after concession to their surroundings and in such concessions progress in life consists. At last each organism or each alliance of organisms is dissolved by the process of death.

The unity in life is then not less a fact than the diversity. However great the emphasis we lay on individuality or diversity, the essential unity of life must not be forgotten. Whatever solution we may find to the problem of the origin of species, must also explain why species and individuals may be so much alike in all large details of structure. To know the origin of species we must also know why species admit of natural classification. Why is variety in life based on essential

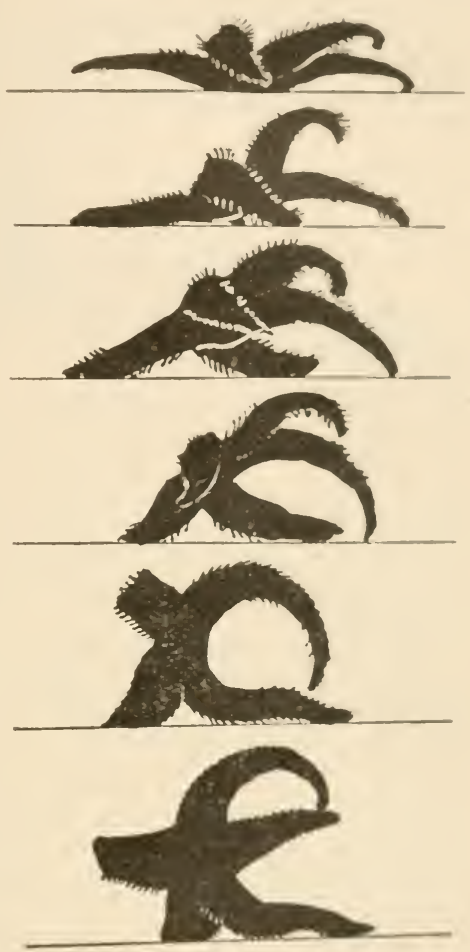
unity?

From the fundamental unity of the speecies of to-daly, wo may infer the similar unity of species in past time. From the knowledge of variety in unity comes the likening of specice of 
animals or plants to the separated twigs of a tree, of which the trunk is more or less concealed. "We can only predicate and define species at all," says Dr. Elliott Coues, "from the mere circumstance of missing links. Our species are twigs of a tree separated from the parent stem. We name and arrange them arbitrarily, in default of a means of reconstructing the whole tree, in accordance with nature's ramifications." To continue

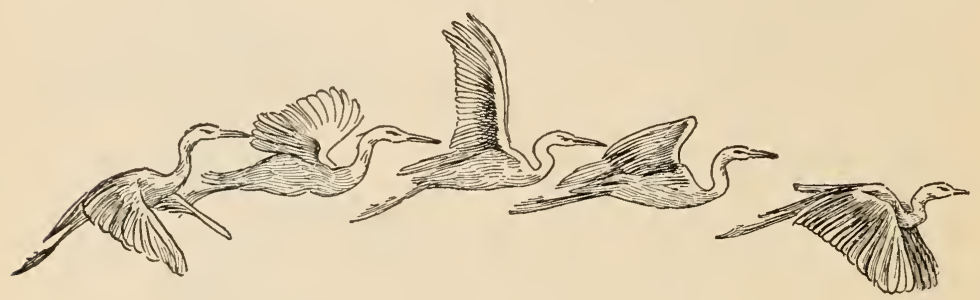

Fig. 14.-Heron flying. (After Marey.)

the figure, in our studies of the origin of the twigs of the tree, the existence of the trunk must not be forgotten. In the life of the earth variety in unity, unity in variety are nowhere separated.

Another equally striking simile is this: A species is an island, a genus, an archipelago, in a sea of death. The species is clearly definable only as its ancestors and cousins have disappeared, only in the degree that the stages in its development are unrepresented in our records. The genus is a group of species, an archipelago of islands, and there may be every conceivable degree of width or breadth of channel which scems to separate one island or group of islands from another. 


\section{CHAPTER III}

\section{LIFE, ITS PHYSICAL BASIS AND SIMPLEST EXPRESSION}

There can be little doubt that the further science advances the more extensively and consistently will the phenomena of nature be represented by mathematical formulie and symbols. But the man of science who, forgetting the limits of philosophical inquiry, slides from these formulæ and symbols into what is commonly understond by materialism, seems to me to place himself on a level with the mathematician who should mistake the x's and y's with which he works his problems for real entities, and with this further disadvantage as compared with the mathematician, that the blunders of the latter are of no practical consequence, while the errors of systematic materialism may paralyze the energies and destroy the beauty of a life.HuXley.

IN practice the distinction between a live thing and a lifeless one is usually of the simplest, but to define this distinction in terms so precise that the definition may be used as an invariable criterion is a problem of considerable difficulty. The sheep grazing in the field and the soil under its feet; the grass and flowers on the one hand, and the stones on the other hand, in the same pasture; there are no difficulties in the distinction here. Nor, indeed, even when we come to consider the simplent kinds of organisms, the tiny one-celled plants and animals that teem in stagnant waters of the wayside puddle. As we exan ine a drop of this water under the mierosenpe we know without question what in it is alive and what in it is dead.

But let us attempt to put into words, into definite declaratory: phrases, the characteristics of organisms and we find ourselves curiously impotent. When we come to study analytically: organic nature and inorganic nature, things animate and 
things inanimate, we find structures and behavior among inorganic things which cannot be readily distinguished in defining words from structures and behavior that are usually taken as characteristic of organisms. On the other hand we shall find in organic nature the very same chemical elements, and for the most part the same combinations of elements, that we find in the great mass of inorganic world substance. So that some biologists by a detailed and keen, if somewhat sophisticated, analysis of the alleged differences between animate and inanimate matter show that these differences are not absolute, and leave you with a stone in one hand and a grasshopper in the other logically unable to define the fundamental difference between the two, and yet morally certain of this absolute difference.

As a matter of fact there is one distinction between living matter and non-living matter which even the cleverest of the modern physicochemical school of biologists has as yet been unable to explain away. And that is the inevitable presence in living matter and the inevitable absence in non-living matter of certain highly complex chemical combinations of carbon, hydrogen, oxygen, nitrogen, and sulphur, called proteids or albuminous compounds.

The actual presence of these chemical substances in living matter is made manifest to us by the physicochemical behavior of these substances: that is, by our observation or recognition of their peculiar attributes. This behavior or these peculiar attributes or activities are those fascinating ones which we are accustomed to call the essential life processes. What these activities are we indicate in a not very precise way by the words organization, assimilation, growth, reproduction, motion, irritability, and adaptation. These essential life processes we have come by constant experience to associate always and only with a substance called protoplasm. Huxley long ago called protoplasm, therefore, the physical basis of life.

But protoplasm we have found to be a complex of substances or chemical compounds. Of these, a certain few are indispensable and fundamental, while others may be absent or present without affecting the particular capacities which make protoplasm the physical basis of life. This protoplasm too must be organized in a particular way in order that life may persist in the organism. It must appear in two conditions, and proto- 
plasmic stuff representing these two conditions must be disposod in certain definite relations. Protoplasm must oceur as a ceell or cells to be capable of performing the necessary activitics of life. Hence we must consider at the very beginning of any discussion of life the two things, protoplasm and the ceell.

The elements that compose protoplasm are the faniliar ones, carbon, nitrogen, hydrogen, oxygen, sulphur, flusplurus, potassium, sodium, etc.; but these elements, or some of them, are found in protoplasmic cells in certain complex combinations which arc not found elsewhere in nature, and which therefore actually and absolutely distinguish chemically liviner protoplasm from all lifeless matter. These particular comblinations are certain albuninous compounds or proteids, componed of $\mathrm{C}, \mathrm{H}, \mathrm{O}, \mathrm{N}$, and $\mathrm{S}$, and their complexity is extreme: the atoms in a single molecule often number more than a thousand. The molecules also are very large, which is probably the reason of their characteristic nondiffusibility through animal membranes or artificial parchment.

In addition to these characteristic albuminous compounds and various derivatives of them, protoplasm usually contains certain native albumins and certain other characteristic compounds known as aarbohydrates and fats (which differ essentially from the albuminous substances in lacking nitrogen as a composing element). There are also various salts and gases and always water to be found in living substances. Water is absolutely necessary to the physical condition of half fluility which gives to protoplasm its essential capacity for motion on it: lf. The commoner salts found in living substances are compounds of chlorine as well as the carbonates, sulphates, and phosphates of the alkalies and alkali earths, especially common salt (sodium chloride), potassium chloride, ammonium chloride, and the carbonates, sulphides, and sulpliates of solimm, pot:assium, magnesium, ammonium, and calcium. The gases found in living matter are oxygen and carbon clioxide. 'Thes, when not in chemical combination, are almost always di-colved in water, although rarely they may be in the form of gas bublites.

To sum up the relation of living matter to chemistry we mas say that life is always associated with protoplasm, and that this protoplasm is made up of a few familiar inorganic elements. particularly those of lowest atomic weight: that it does not include any special so-called vital or life element, that is any 
elementary substance other than occurs in the inorganic world. These elements are combined in protoplasm into certain most extremely complex compounds, which are always present where life is, and never elsewhere, and hence the essential chemical characteristic of living matter is the presence of these complex as yet unanalyzed, albuminous compounds.

It is obvious that this chemical half-knowledge of protoplasm makes no satisfying revelation to us explanatory of the qualities of this life stuff. How is it then with the physical structure of protoplasm? We know that many simple chemical substances put together in particular physical relationship to each other will give a capacity of performance or function quite different from and beyond that which they possess when simply brought together without definite order or arrangement. Is protoplasm a machine with a capacity for doing extraordinary things, with its powers due primarily to its physical make-up? Unfortunately we have no satisfying answer to this question. While chemists are balked in their analysis of the protoplasmic make-up by the complexity of the compounds they meet, a complexity too much for their present technic to resolve, physicists are similarly balked in their attempt to resolve and expose the ultimate physical structure of protoplasm.

This ultimate structure of protoplasm is ultramicroscopic, and its study is checked by the limitations of microscopes. When we examine protoplasm with the highest powers of the microscope we see plainly that it is not as it appears under lower powers, structureless and homogeneous. On the contrary it reveals an apparent granular or fibrillar or alveolar or reticular structure. We find that protoplasm varies in its physical make-up at different times or in different cells. We also find that the difficulties of interpreting just what one sees when using the highest microscopic powers make it impossible to be really certain of understanding what is seen. But however various our interpretations of the finer structure of protoplasm, they agree that any bit of protoplasm is a viscous colloidal mass composed of at least two substances of somewhat different physical make-up. One of these substances is evidently denser than the other and is arranged in the form of grains, rods, threads, or droplets scattered through a ground mass. Concerning this dimorphic condition of protoplasm practically all biologists are agreed. The names, hyaloplasm, paraplasm, or others of sim- 
ilar significance are applied to the viseous hyaline groumd substance, while the denser parts are variously ("alled microssomes, granules, fibrils, spongioplasm, etc.

The important part of all this is the fact that all the hiologing are not agreed on any certain kind of intimate strueture of

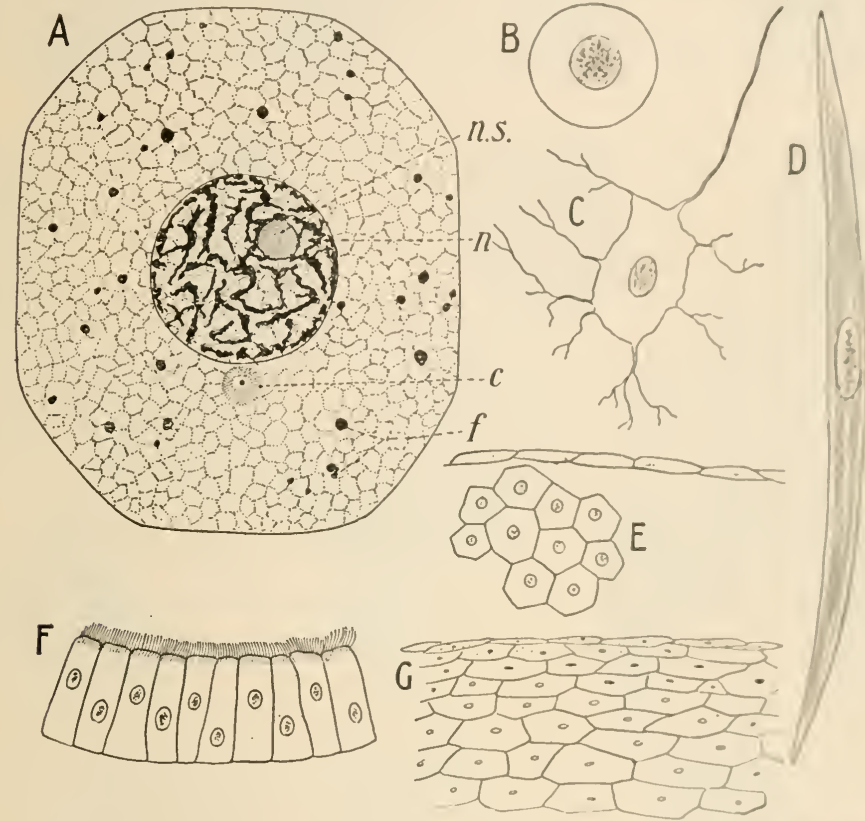

FIG. 15.-Different types of cells composing the body of the squnirrel or other h thls developed animal: $A$, liver cell; $f$, fool materials; $n$, nuclems; 13 , complete w is C, nerve cell, with small part of its fiber; 1), muscle fiber; L; (eells lmug the hats cavity; F, lining of the windpipe; G, section through the skin. (Highly magr finen

protoplasm as revealed by the highest powers of the microserth: but they all agree that there is a fine and roal structural organization of what at first glance appoars to be homogenemente structureless life stuff. That is, as l)elage expresces it it is - in that protoplasm is not simply an organic chemical conponnt. but that it is an organized substanee; that is, it prosersen structure of a higher order than the antomatic structure of these chemical molecules which empose non-living so-called organy substances. But at the same time we are derecived if we expret 

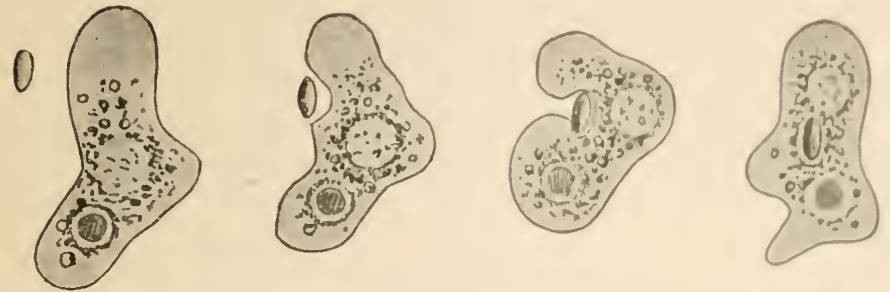

Fig. 17.-Amoba eating a microscopic onc-celled plant. (After lierworn.)
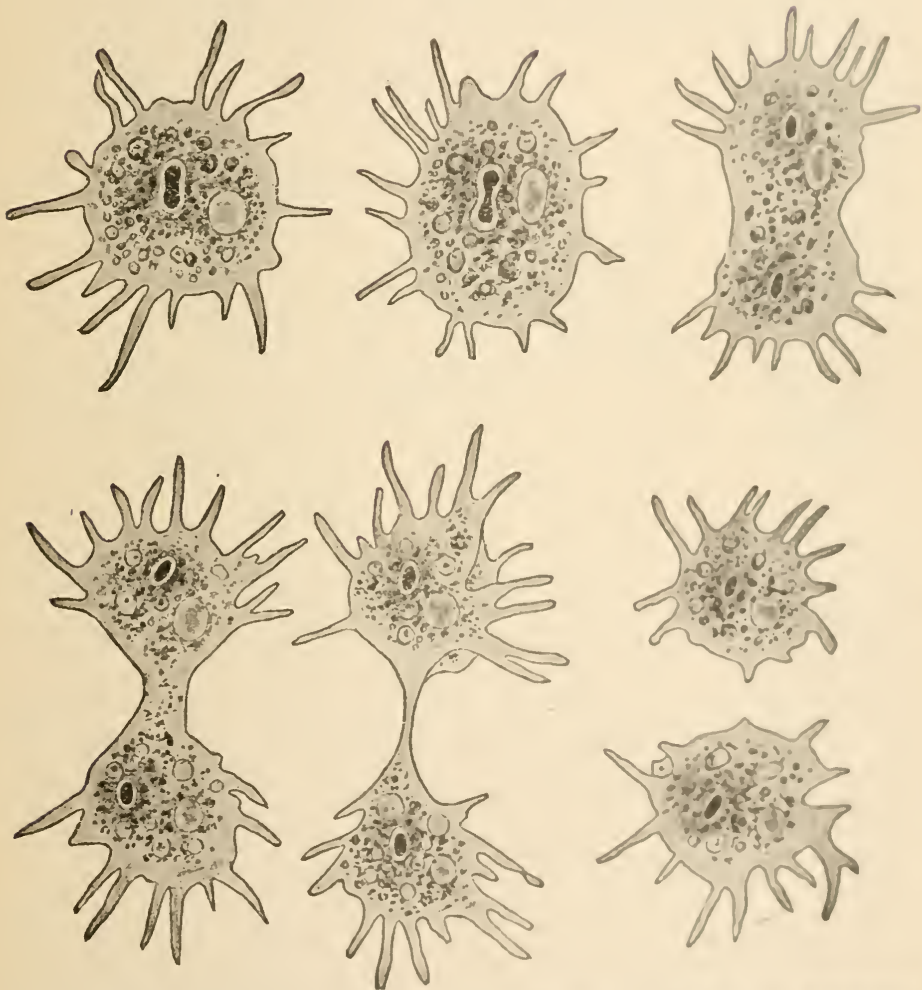

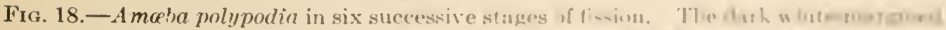

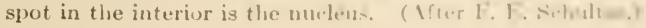


if such protoplasmic cells, composed of nucleus and cytoplasm, exist singly they form living units. And we have actual exemplifications of this condition in the structure and life of the simplest organism.

The simplest organisms are independently living, single protoplasmic cells (Figs. 16-21). There are thousands of kinds of
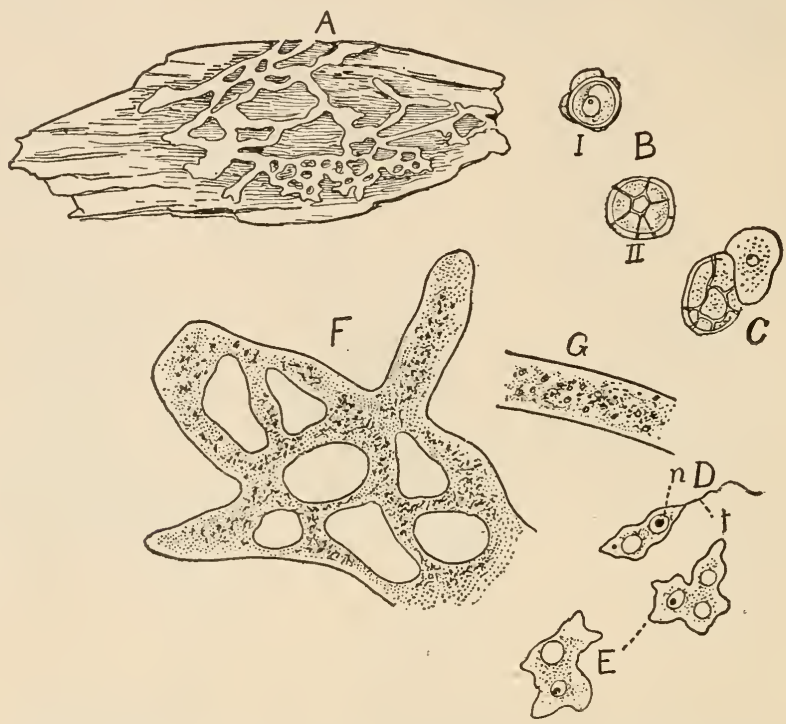

FIG. 19.-Plasmodium of a slime mold on wood, Trichia faraginea: A, plasmodium $\times 2$; $B$, spores; C, spore with contents escaping; D, ciliated swarm spore, showing flagellum, $f$, and nucleus, $n$; $\mathrm{E}$, two amœboid swarm spores; $F$, part of plasmodium under glass slide; G, a part of F, more highly magnified. (After Campbell.)

these single-celled organisms recognizably different by characteristics of shape and size, habit and habitat. We try to distinguish them as single-celled animals (Protozoa) and single-celled plants (Protophyta), on the basis of alleged differences in their habit of food-taking and general nutrition. This distinction is often most arbitrarily made, and botanists and zoölogists are constantly claiming the same organisms as belonging to their respective fields of study. Many naturalists, conspicuously Haeckel, have repeatedly suggested the convenience and even the necessity of grouping most of these unicellular organisms into a phylum or lingdom to be called the Protista, the members 
of which shall not be recognized as sufficiently specialized to lo called either plants or animals, but simply organisus. But this suggestion seems to meet with little practical farof from students of systematic biology.

For a basis, therefore, of any sturly of the crolution of life. an acquaintanceship with the life and structure of the simplest organisms is a necessity. As the authors have already tried in another" book ("Animal Life") to present a simple account of this life together with an account of certain less simple or slightly complex organisms (Figs. 22-26) whose physiology and structure reveal successive stages in organic complexity and specialization, and as the space in this book is limited, the authors must refer their present readers to chapters I, II, and III of "Animal Life" for an account of the life of the simplest and slightly complex organisıns.

The differentiation and growing complexity of the body of those many-celled animals which differ from and are, we may say, beyond and higher than the simple manycelled forms, are by no means always along the same line (Figs. 27-37). It is familiar knowledge that animals can be classified or grouped into a number of great divisions called branches or phyla. For example, the starfishes, sea urchins, sea cucumbers, ete., constitute one phylum, the Echinorlermata; the crustaceans, insects, spiders, etc., constitute another phylum. the Arthropoda, and all the animals with a backbone or with a notochord constitute another, the Chordata. Now for each of these phyla there is a fundamental or type structure (Fig. 27). All of the Echinodermata, for eximple, are huilt on the radiate plan. They recall the starfish with its five or more arms radiating from a central disk. The Arthropols are all animals with a body composed fundamentally of at strice of successive segments, some or all of these segments bearing pairs of jointed appendages; and so on. We need not pursue 


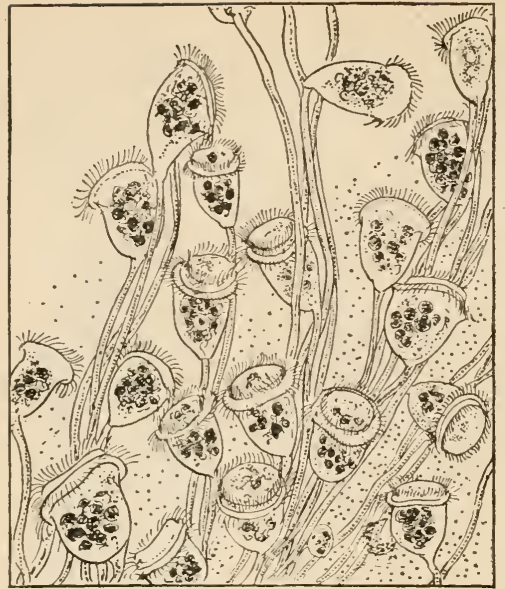

FIG. 21.-A group of stalked one-celled animals, Carchesium. sn. (Adapted from Davenport, from a photograph of the living animals.)

grouped into two regions and the appendages limited to the anterior one of these two. The Mrriapods, which are also Arthropods, have a structure more in conformity with what may be called the racial or typical plan for the whole phylum; that is, the body is made up of a series of many successive similar segments, each segment bearing a pair of jointed appendages. In that general line of descent to which man belongs, and which is distinguished by the name of the phylum Chordata, there are of course various subordinate lines which we recognize under the names further the general classification of animals into phyla. Nor need we explain in any detail the structural types or fundamental structural plans which distinguish the various principal lines of descent in the animal kingdom.

Branching out from each of the principal lines are hosts of subordinate lines. Some of the Arthropods, is the insects, have their body segments grouped into three regions and their jointed sppendages confined to tlie anterior two of these $\mathrm{rc}$ gions. Others, as the spide:s, have the body segments
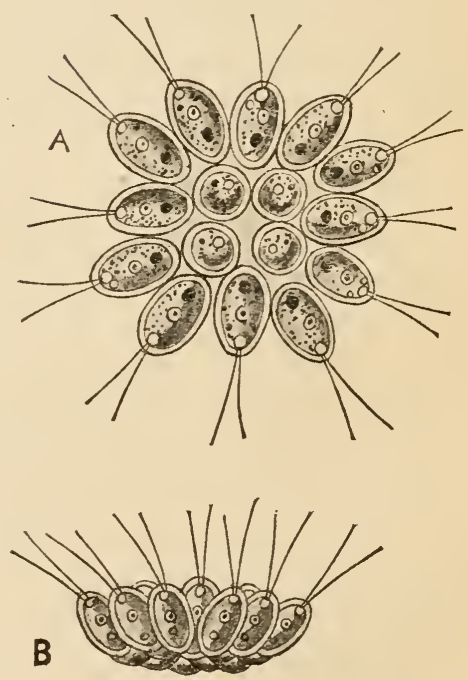

FIG. 22.-Gonium pectorale, a coionial protozoön: A, seen from above; $B$, seen from the side. (After Stein.) 
LIFE, ITS PHYSICAL BASIS ANT SIMPLENT HAPRESION 3.j

of fishes, amphibians, reptiles, birds, and mammals.

In all the subdivisions of the main groups there are also to he recognized differentiated and divergent lesser lines of descent, and within these still lesser ones. While, as already noted, the main divisions of the animal kingdom are called phyla and the divisions of the phyla, classes, the subdivisions of the classes are usually called orders. The next subdivision is that into families, each in turn being a cluster of genera.

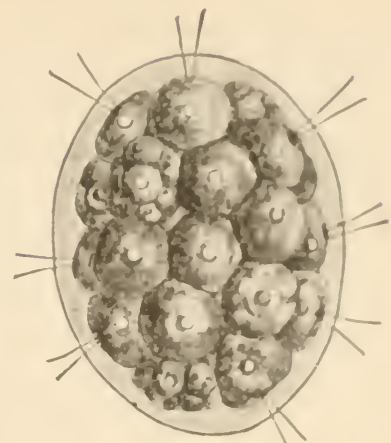

Fig. 23.-Panderina sL. a reain al protuzons. (Jlighls magnife d The genera are composed of species and the species finally of sub-species, varieties, and individuals. Fatch one of thes

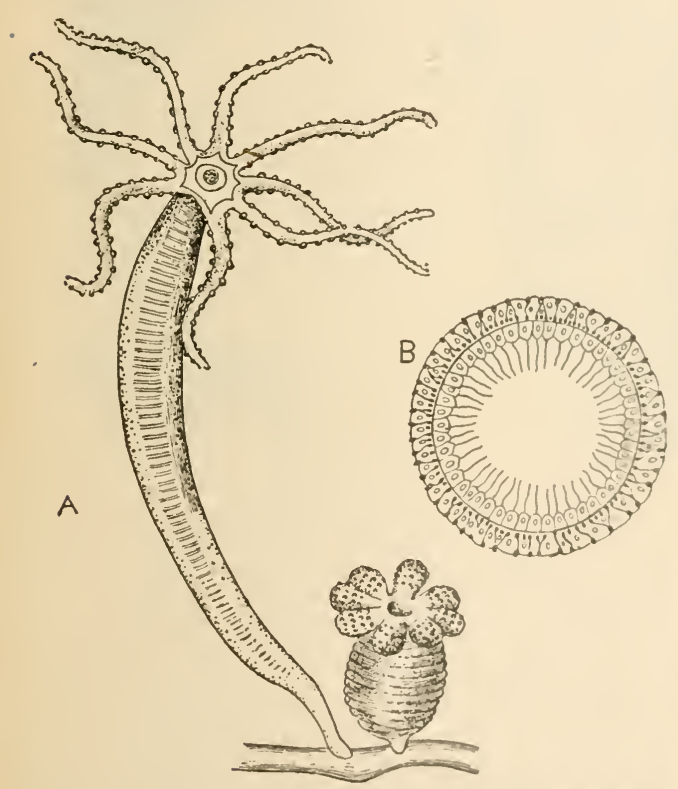

FIG. 24.-A fresh-water polyp, IIydra vulgaris: 1, in extended condition and in contracted comderon; 13, cruss section of body, showing the two layers of cells which make up the body wall. natmes refers p.imarily to a s sperial line or nucole of differentiation :'nul at the same time refers to the fact that the members of each of these different iatral gromps are geneticially relatiol to each other. that is, related hy blood, ly aretu: ancestral descrint. All these differentiater erromlet indicate diverging lines of evolution. somer of themr short. amel hut slightly divergent from the matn line from which 
they arise; others, on the contrary, long, important, and widely divergent.

The traditional tree which is drawn to explain animal classification illustrates at the same time the two fundamental facts upon which this classification is based, namely, differentiation of structure, and corresponding divergence of descent. All the branches of this genealogical tree lead back, as they do in a real tree, to its trunk, and the trunk of this tree springs from the simplest of the many-celled animals, namely, from those primitive forms which resemble in essential characters animals. like the

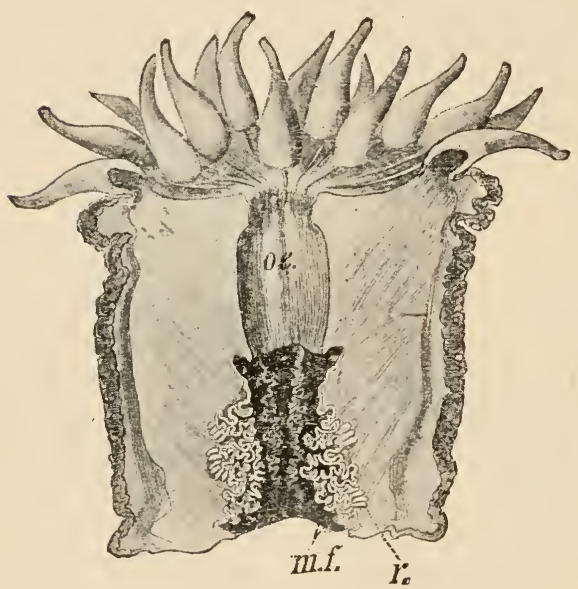

FIG. 25.-Longitudinal section through the body of a sea anemone: oe., oesophagus; m.f., mesenterial filaments; $r$., reproductive organs.

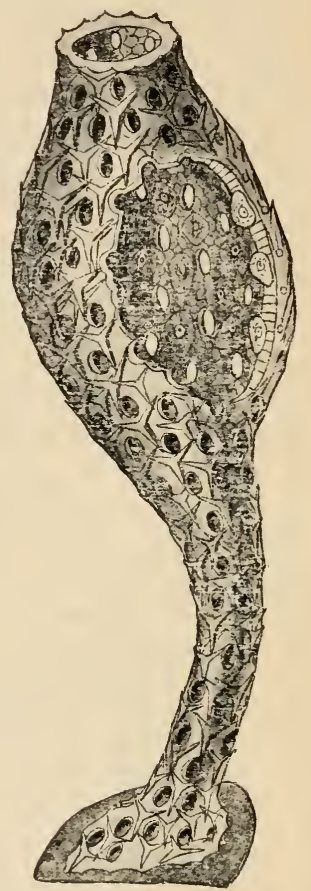

FIG. 26.-One of the simplest sponges, Calcolynthus primigenius. A part of the outer wall is cut away to show the inside. (After Haeckel.)

simpler polyps. Indeed it seems certain that this tree trunk can be traced farther back; that it must spring in the beginning from forms essentially like the lowest organisms that we know to-day, namely, single, simple cells living independently. From the Amœba to Man; that is the history of descent, or ascent if one prefers. The course has been a continuous one, both in point of time and in point of gradual transformation. 


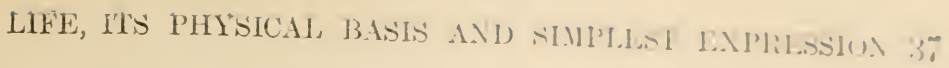

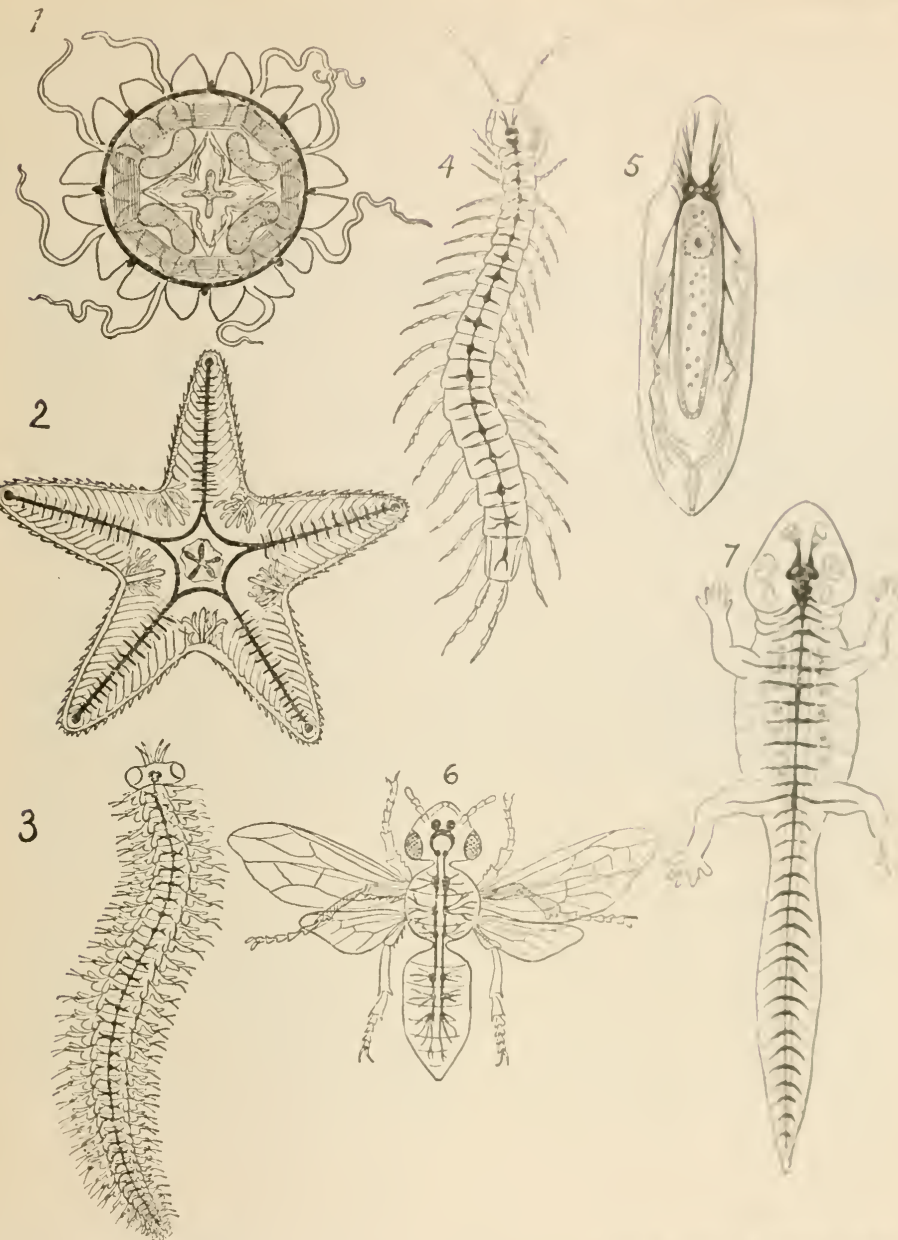

FIG. 27.-Diagram showing fundamental structure of typen of wereral whisul phis:

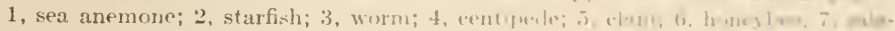

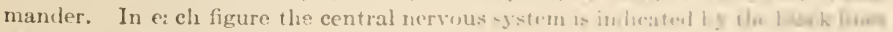
(After Haeckel.)

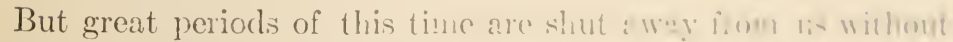
record of their duration, amel honer serice of lle sradually changing forms are lost to us witlunt l of o w di-cosery. Inil get in its large outlines we knows the listory of all thin libe and the character of all these graded sorici, 
We should give at least brief attention to what may be called the primary, or necessary, conditions of life. We know that fishes cannot live very long out of water and that birds cannot live in water. These, however, are conditions which depend on the special ecological habits of these two particular linds of animals. The necessity of a constant and sufficient supply of oxygen is a necessity common to both. It is one of the primary conditions of their life. All animals must have air. Similarly both fishes and birds and all other animals must have food. This, then, is an-

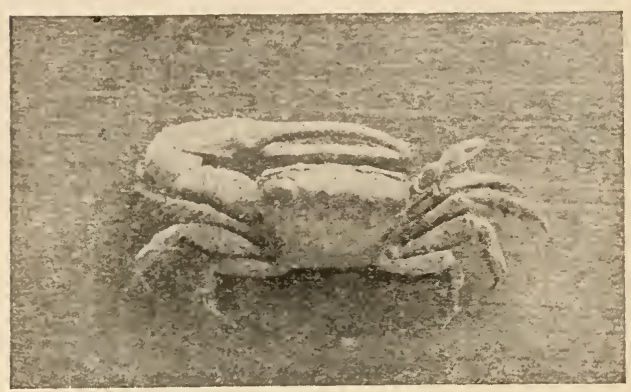

FIg. 28.-The fiddler crab, Gelasimus. (Photograph by Miss Mary Rathbun.) other of the primary conditions of animal life.

If water be held not to be included in the general conception of food, then special mention must be made of the necessity of water as one of the primary conditions of life. Protoplasm, the basis of life, is a fluid, although thick and viscous. To be fluid its components must be dissolved or suspended in water. In fact, all of the really living substance in an animal's body contains water. This water, so necessary for the animal, may be derived from the general food, all of which contains water in greater or less quantity, or it may be taken apart from the other food by drinking or by absorption through the skin.

We know, too, that if the temperature is below a certain minimum point or above a certain maximum, these points varying for different animals, death takes the place of life. It is familiar knowledge that many animals can be frozen without being killed. Inscets and other small animals may lie frozen through winter and resume active life again in the spring. An experimenter kept certain fishes frozen in blocks of ice at a temperature of $-15^{\circ} \mathrm{C}$. for some time and then gradually thawed them out unhurt. 'There is no doubt that every part of the body, all of the living substance, of these fish was frozen, for specimens at this temperature could be broken and pounded up 
into fine icy powder. But a temperature of $-20^{\circ}($. killed the fish. According to I. J. Turner, the Alaska mud-fish (I)illia), was fed frozen to Esquimaux dogrs. One of these thawing in the stomach of the animal made its escape alive. Frogrs lived after being kept at a temperature of $-2 \mathrm{~S}^{\circ} \mathrm{C}$., centiperles, at

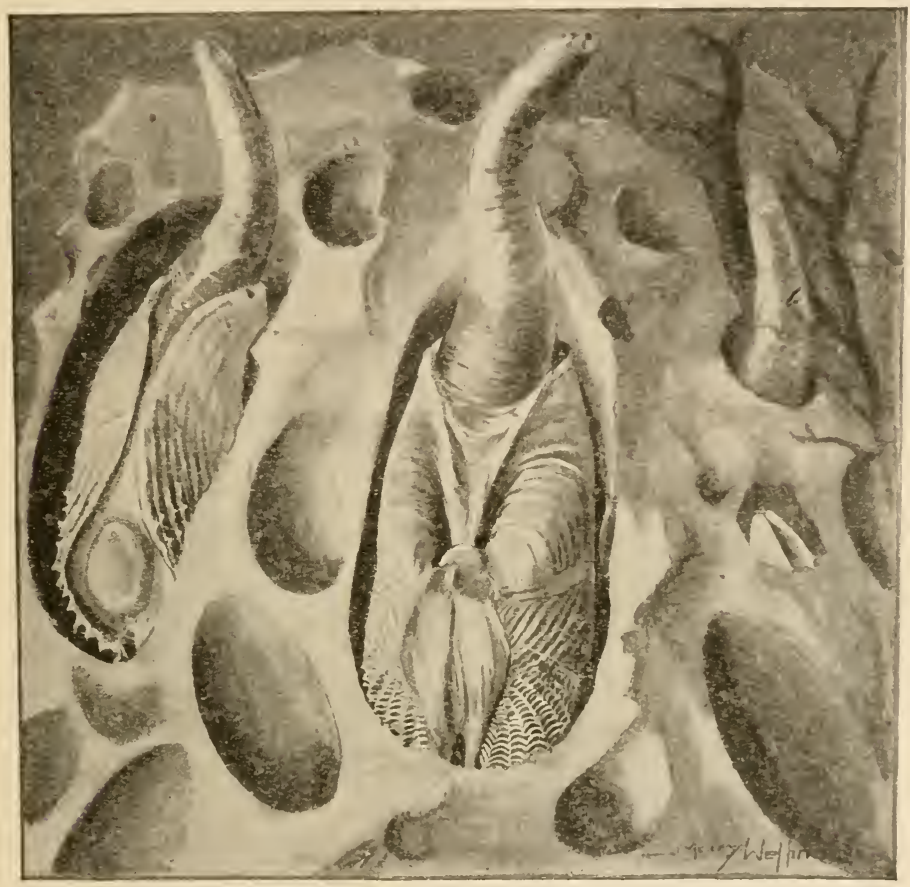

FIG. 29.-The piddock, Zirphœa crispata, a rock-boring mollusk. F(Natural size, from life.)

a temperature of $-50^{\circ} \mathrm{C}$, and certain snails endured a temperature of $-120^{\circ} \mathrm{C}$. without dying.

At the other cxtreme, instances are known of animals living in water (hot springs or water gradually heated with the organisms in it) of a temperature as high as $50^{\circ}$ ( $'$. Experiments with Amobre show that these simplest animils contract and cease active motion at $35^{\circ} \mathrm{C}$, but are not killed until a temperature of $40^{\circ}$ to $50^{\circ} \mathrm{C}$. is reached.

Variations in pressure of the atmosphere also constitute 
conditions which may determine the existence of life. The pressure or weight of the atmosphere on the surface of the earth is nearly fifteen pounds on each square inch. This pressure is exerted equally in all directions so that an object on the earth's surface sustains a pressure on each square inch of

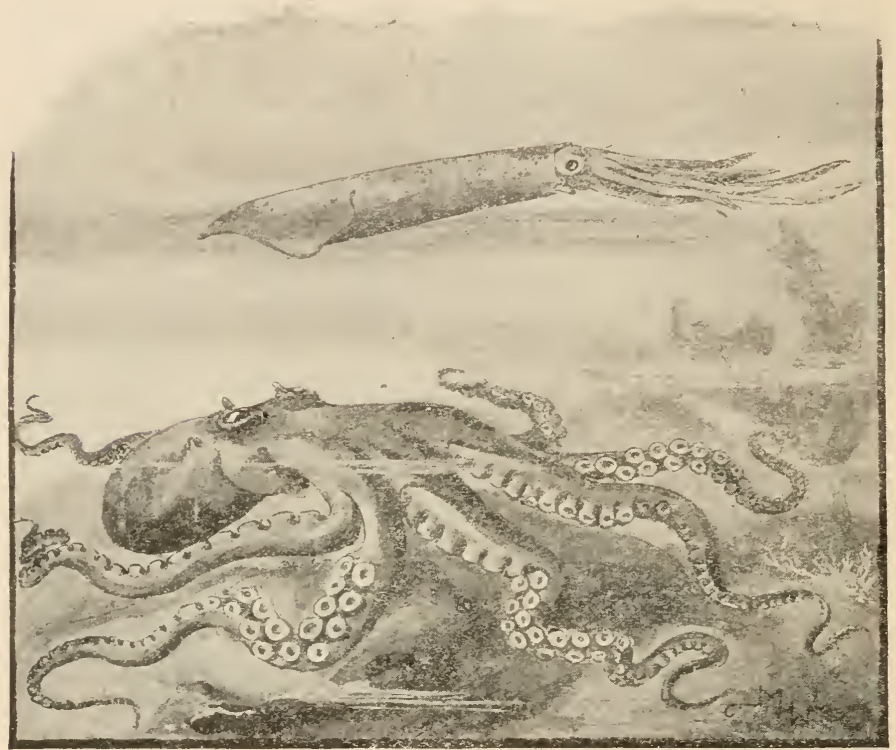

F1G. 30.-Cephalopods. Lower figure, the devil-fish or octopus, Octopus punctatus. The upper figure represents the squid, Loligo pealii, swimming backward by driving a stream of water through the small tube slightly beneath the eyes. (From life, one-third natural size.)

its surface of fifteen pounds. That is, all animals living on the earth's surface or near it live under this pressure and under no other condition. The animals that live in water, however, sustain a much greater pressure, this pressure increasing with distance. Certain ocean fishes live habitually in great depths, at from two to nearly fire miles, where the pressure is equivalent to that of many hundred atmospheres. If these fishes are brought to the surface their eyes bulge out, their scales fall off because of the great expanse of the skin, and the stomach is thrust wrong side out. Indeed the body itself sometimes bursts. Cn 
the other hand if an animal which lives normally on the surface of the earth is taken up a very high mountain or is carried up in a balloon to a great altitude where the pressure of the atmosphere is much less than at the earth's surface, serious consequences may ensue, and if too high an altitude is reached, death occurs.

Some animals require certain organic salts or compounds of lime to form bones or shells, etc. These salts may be regarded as necessary articles of nutrition, though their function is not that of ordinary food. These are peculiar demands of special kinds of animals. There might also be included smong primary life conditions such necessities as the light and hewt of the sum, the action of gravitation, and other physical condition:s

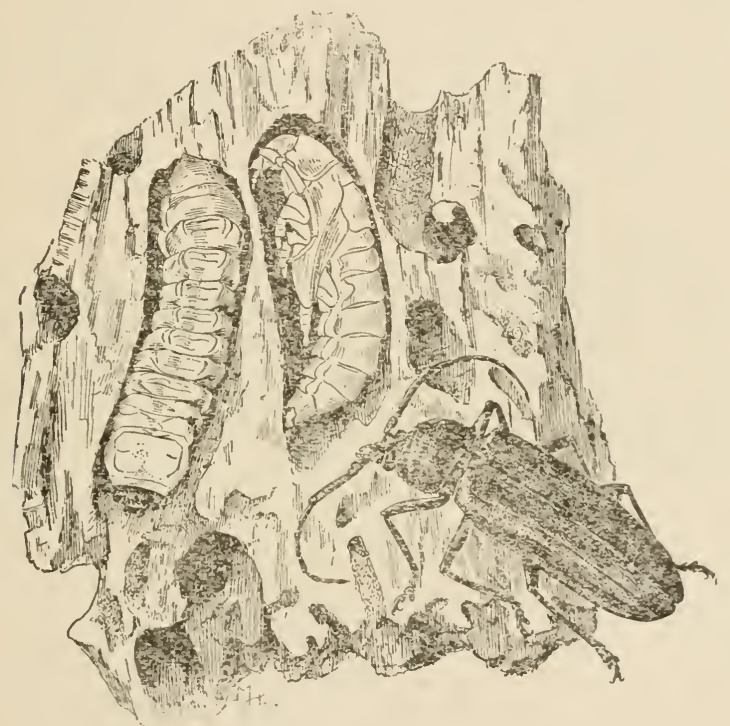

Frg. 31.-Long-horned boring beetle, Ergates sp.--larva, pupa and adult insect.

without which existence of life of any lind would be impossible on this earth.

Finally we may refer briefly to the "grand problem" of the origin of life itself. Any treatment of this question is hound to be wholly theoretical. Wre do not know : single positive thing about it. We have some negative eviclener. That is, we have 
no resorded instance-and men have searched diligently for examples-of spontaneous generation. No protoplasm has been seen, or otherwise proved, to come into existence except through the agency of already existing protoplasm. All life comes from life. All those former beliefs of spontaneous appearance of bees from the carcasses of oxen, flies from decaying flesh, hair worms

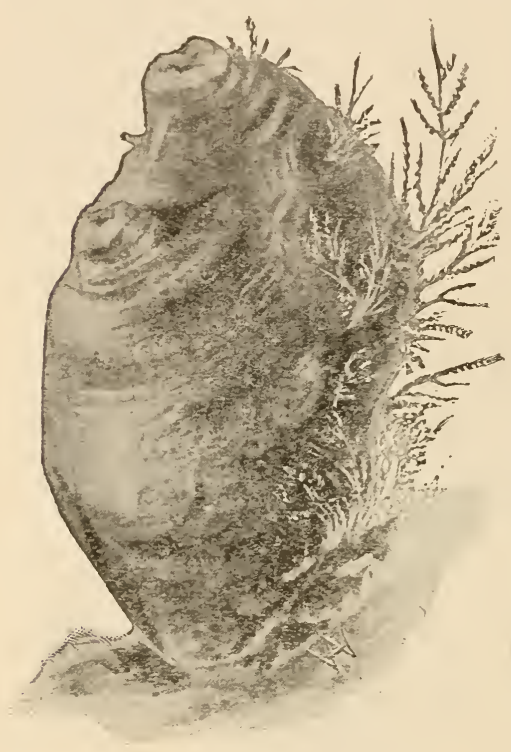

FIg. 32.-Ascidian or sea squirt. from horse tail hairs in water troughs, and bactei ia and infusoria in infusions of beef or hay have been shown on scientific investigation to be utterly without basis of fact.

But if protoplasm and life do not appear, are not being generated spontaneously in this earth epoch, may they not have bcen in earlier ages? Geologists and biologists attempt to explain most of the things that happened in ealier geologic ages by what they observe to be happening now. They would answer, on this basis, that what evidence we now have should lead us to believe that the generation of life has nerer occurred. But there must have been a beginning. Life has not always been. The accepted geological theory of the making of our earth precludes the existence of life on it until the globe was cool enough for organisms to exist. We know that there is a maximum of temperature beyond which protoplasm inevitably coagulates. When and where was this beginning of life? The biologist cannot admit spontaneous generation in the face of the scientific evidence he has. On the other hand he has difficulty in under. standing how life could have originated in any other way than through some sort of transformation from inorganic matter.

As a matter of curiosity we may glance at a few of the 


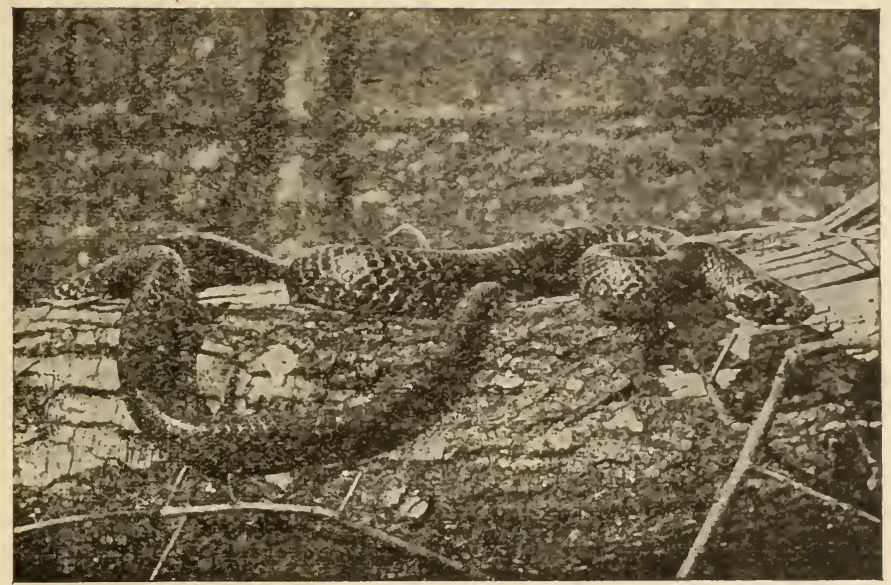

FIG. 33.-Blacksnake, Bascanion constrictor. (Photograph by W. H. Fisher.)

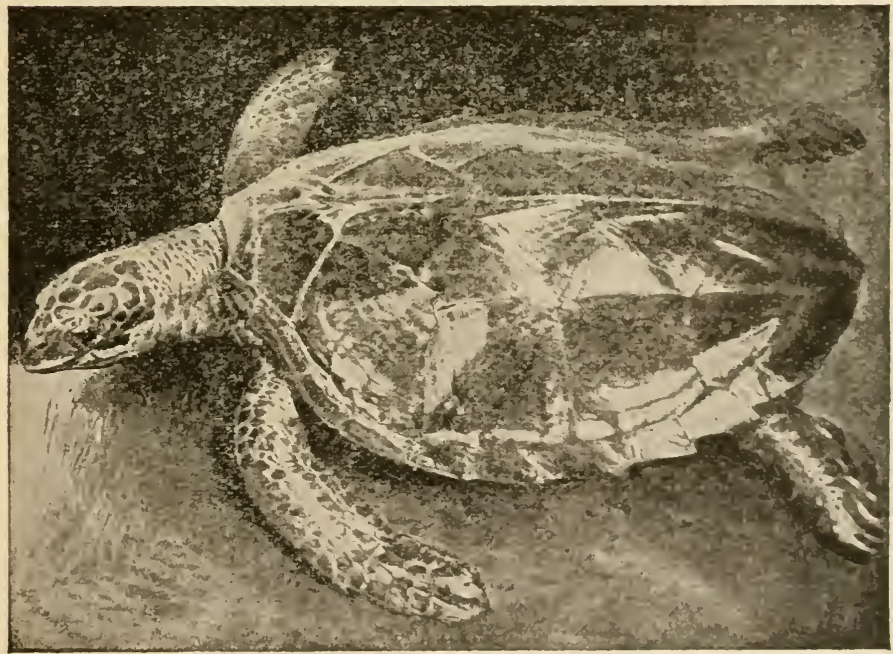

Fig. 34,-Hawkbill turtle, Eretmochelys imbricata. 
speculations that biologists have allowed themselves concerning the origin of living substance on the earth. A speculation that is interesting only because it was suggested by a great scientific

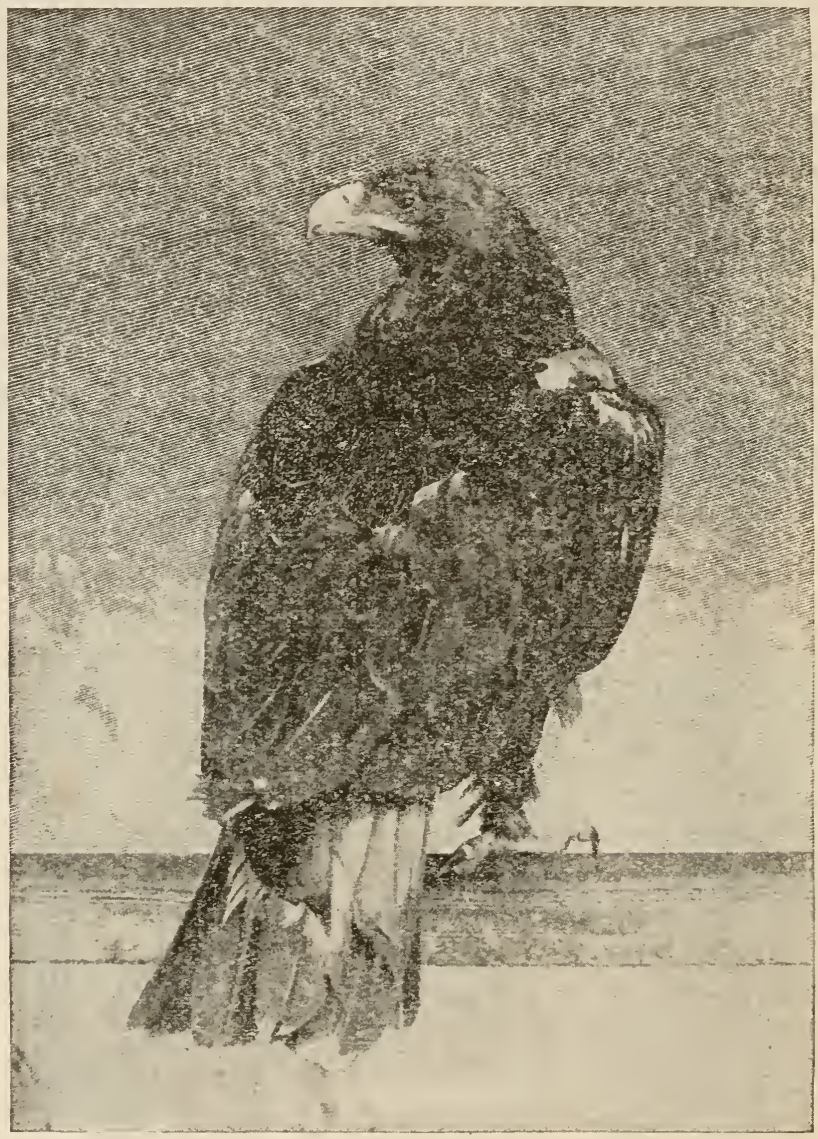

FIG. 35.-Golden eagle, Aquila chrysaetus.

man-a physicist, however, not a biologist - is Lord Kelvin's theory that living substance was brought to this earth from celestial regions by meteorites. A more acceptable theory is that at some earlier geologic age the conditions of earth, atmosphere, temperature, etc., were at one time of such a favorable 
LIFE, ITS PHYSICAL BASIS ANI SIMPLEST EXPRESSION t气̂

nature that just that fortunate coincidence of all necessary conditions and elements oceurred which allowed C', I, O, N, to unite in those gieat, almost infinitely complex, molecules which compose the alluminous compounds whose existence is the only real chemical characteristic peculiar to living natter. I3ut we lave

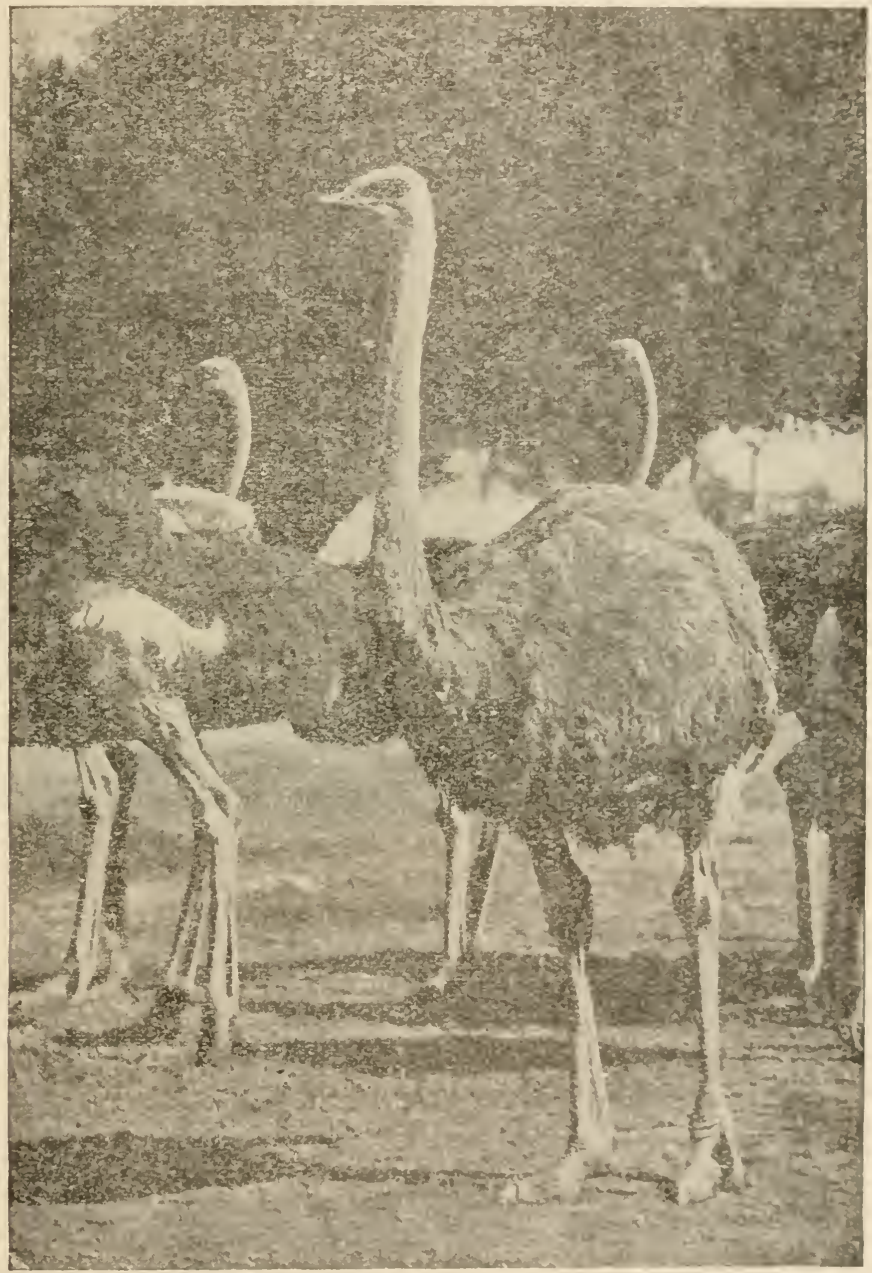

FIG. 36.-African or two-toed ostrich, Struthio camelus. (Plootograph by William Graham.) 
already indicated that the production of such compounds would not necessarily be the production of protoplasm. What of the complex definitive physical organization of protoplasm on which we predicate so much of its capacity?

The botanist Schaffhausen believes that water, air, and the necessary mineral substances have been directly combined under the influences of life and heat and have given birth to an

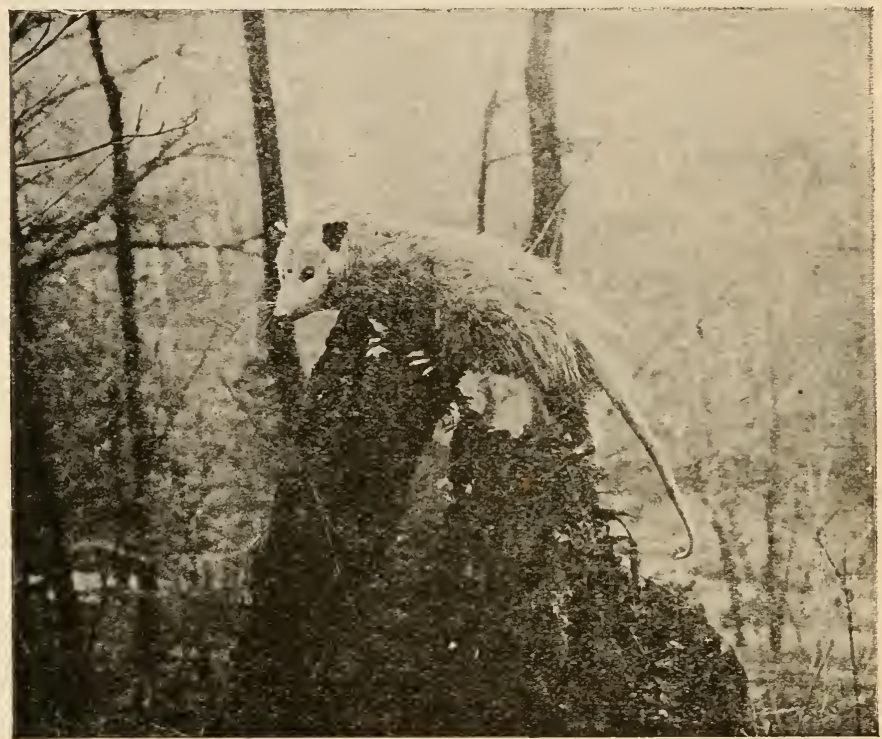

FIG. 37.-Opossum, Didelphys virginiana. (One-tenth natural size; photograph by W. H. Fisher.)

uncolored protococcus which next became Protococcus viridis. Delage asks: "If the thing is so simple why does not the author produce one of these protococei in his laboratory? On lui ferait grâce de la chlorophylle!" Nägeli holds that when the albuminous compounds had their birth in an aqueous liquid, as they were not soluble in water, they were precipitated. This precipitate was formed of minute particles, a sort of crystal which he calls micellæ. These micellæ are the materials from which organisms were formed. An inorganic crystal deposited in a saturated solution of the same nature determines a deposit on its surface in the form of tiny crystals, by which means it 
increases in size. In the same way, when some of these alluminous micella are formed anywhere, they facilitate further precipitation within their sphere of influence in such a way that the formation of other micellæ, instead of going on uniformly in the liquid mass, is localized at certain points. Thus are found aggregates of an albuminous nature which constitute the primitive protoplasm. This is Nägeli's suggestion, and Nägreli is one of the most thoughtful biologists who has erer lived!

Granting that protoplasm must have had a natural, spontaneous beginning on this earth, being neither brought to it from other worlds nor created extranaturally on this world, biologists indulge in some speculations as to the probalsle whereabouts of this first appearance of life, and as to whether living substance was formed spontaneously but once only or several times, and perhaps in several places. It is not necessary here to follow up such speculations. The only one of them with any scientific evidence at all for it is the theory that life began at the poles or perhaps particularly at the north pole. The evidence for this is based, first, on the fact that in accordance with the cosmic theory of world evolution, the poles of the earth must have been first in a condition under which life might exist, and, second, on facts revealed by the study of the geographical distribution of living and fossil organisms. There seems to be some slight scientific foundation for the claim that the first organisms lived in polar regions. 
alike. This refers not only to individuals of different species of plants and animals, but to individuals of the same species and even (and this in a way is most important of all) to individuals born of the same parents. It is indeed this last condition that is the actual basis and fundamental beginning for species change. That this variation does exist is absolute fact, and there is no discussion of it.

To what extent or degree, what parts of an organism are chiefly affected, whether or no this variation shows a regularicy in its occurrence or a determinateness of tendency or direction, whether or no this variation is based on inheritance and if so in what degree of similarity or identity-all these and a dozen other questions are the moot problems in connection with the great factor variation. These are undecided things, which means, on the whole, that variation, apart from the observed and admitted actuality of the occurrence, is itself a great evolution problem.

The variation alone, however, presumably does not make new species nor maintain lines of descent. If this variation is, as it seems to be, almost unlimited in its range of appearance, then as species are of definite character and number and as lines of descent are even more definite and more limited as to number, there must be some factor which determines what kinds or lines of variation may or shall persist and what shall be extinguished. Is there something incident to the causes of variation that determines what lines of descent shall be established by it or based on it, or is there some added factor which, having no control over the initial appearance of variation, has absolute control over its persistence and headway? Darwin's factors of selection, more particularly natural selection, is the explanation of this control offered in the famous "Origin of Species." And natural selection has been in the minds of biologists until to-day, at least, undoubtedly that factor in evolution which has been believed to have the chief control in the forming of species and the direction of descent lines.

But in reference to this particular factor three schools of biologists have gradually grown up; namely, first the school headed by Weismann, who has believed and contended that natural selection is almost the only factor which, on a basis of fortuitnus, that is, uncontrolled, variation, has produced the species and lines of descent as we know them; second, the 
school which holds that natural selection has practically nothingr to do with species-forming but only, and in a large general way, with the control of descent; and, third, the compromise school, which attributes to natural selection an important part in both. species-forming and control of general descent lines, but recognizes the simultaneous existence and the considerable importance of several other species-forming and descent-modifying factors. In addition to these three schools one must note that a number of active working biologists repudiate the factor of natural selection entirely, holding it to be a vagary and an artifact of logic.

Associated with natural sclection in the general theory of selective action is Darwin's conception of sexual selection. 'This factor was presumed by Darwin to play a part only in the formation and control of those often very obvious but never wellunderstood characteristics of a secondary sexual character which distinguish the sexes in many species of animals. Let one recall these characters in the pea fowl, the bird of paradise, the pheasant, some of the butterflies, the lamellicorn beetles, many fishes, and so on. According to the theory of sexual selection the females have chosen for their consorts those males best endowed by variation with these ornamental characteristics, so that by this selection there has come about a gradual cumulation of the characteristics culminating in such bizarrerie as we are familiar with in numerous living animals.

The word selection will certainly bring to the mind of the reader also a third kind of selective process, namely, that called artificial selection, and this kind of sclection is, of course, a factor, and an important one, and has been such for some eighty centuries, in the modification of plant and animal forms. But however widely differing and extraordinarily modified cultivated and domesticated kinds of animals and plants may be, these different kinds are not looked on by biologists as having the validity, that is, the stability and characteristics of origin, that the different species of animals and plants found in nature have.

All the different kinds of pigeons, for example, are known to be due primarily to the artificial modification of a single wild kind, the rock dove of Europe, and all of these different artificially produced kinds agree in an important physiological characteristic, namely, that of being able to mate freely with each other and with their common ancestor. As this plyssiological char- 
acteristic is precisely one of the ite ia largely used in determining species limits in nature, naturalists call the artificially produced kinds by another name than species; they call them races or varieties, meaning by this to indicate obvious structural and functional differences. Thus artificial selection, while a factor in determining the extent and character of the modification of many kinds of animals and plants, is not considered a factor in the determination of natural lines of descent. Its value in this regard lies in the clew it gives to natural processes of the same kind.

Selection by nature among the variations which appear is made possible only by several other factors or actually existent conditions. One is the "prodigality of production" or the constant tendency to overpopulation due to reproduction by multiplication or in a geometrically progressive ratio. Every mature female or hermaphroditic plant or animal produces, at least in the condition of eggs or germ cells, more than one new individual like itself. (There are a very few exceptional cases, compensated for, however, in other ways.) Most produce many new individuals and some reproduce enormously. Certain fishes lay millions of eggs; so do certain oysters; many insects produce thousands of young; many plants produce myriads of seeds. But not all can grow up: there is neither room nor food for all. There must inevitably be a selection by active or passive, guided or fortuitous, means.

It is a necessary assumption, for the effectiveness of the natural selection factor', that this selection is actually based on the fitness or advantage of some of the variations as compared with others. The trying out or determination of the advantage of these variations comes about as an inevitable active or passive competition for life among the overabundantly appearing new individuals. This is the "struggle for existence," and the "survival of the fittest" is the expression of the assumed fact of the success of the individuals advantageously (i. e., most fitly) varying. The unfit and the less fit are assumed to compose the thousands and hundreds of thousands who must die where only tens or hundreds can live at one time.

But if natural selection, which is, so far, obviously one of but individuals alone, is to produce new species and control descent lines, it has to depend on a further factor, one named by a familiar word, but not at all explained by it, namely, the factor 
heredity. Although we can rely in our theory building on the fact that no two individuals are exactly alike, yet we can equally certainly rely on the fact that the offspring of any individual will be much more like other individuals of the species to which the parent belongs than like individuals of other species, and also, in the main, more like the parent than like other individuals of the same species. Heredity is the name we use for expressing this fact of likeness of young to parent.

Some biologists seem to mean by heredity a force or doninating influence which brings about this likeness; while others use the word heredity to name rather the processes which are gone through with by the young in becoming, in its total development, like the parent. The essential connotation of the word is, however, simply the fact that this likeness does exist and that we may rely on its continuing to occur. So that when the struggle for existence weeds out, if it does, those individnals of a too abundant population which possess variations of disadvantage or of no special advantage, leaving those to survive and produce offspring which do possess specially advantageous or fit variations, the fact of heredity permits us to assume the almost certain perpetuation of these advantageous variations by insuring their reappearance in the offspring of the "saved" individuals. Thus while we may liken the causes that produce ever-appearing variations to a centrifugal force making for difference and instability, heredity (if used as the name for the causes that produce likeness) may be conceived as a centripetal force, making for stability and sameness.

But at least one other factor scems to be necessary in species-forming and that is the factor of isolation, separation, or segregation, as it is variously named. By this is meant that those individuals showing similar variations must in some way be segregated, made to live and breed together, in order that the particular variations (which from the point of view of the student of species-forming may be called also the particular varietal differences that are to become in time so developed and fixed as to be true species differences) may be maintained.

For it is obvious that if an individual possessing certain particular variations mate with another of its species possessing different variations, the offspring of this union will likely not possess in pure form the variations of that particular parent 
we are for the moment interested in. The offspring may show a blend of the different characters of the parents, or a mosaic of them, or may show the characters of either one alone, or, indeed, characters of wholly new type. The important thing is, however, that there is no certainty-indeed there is almost certainty of the opposite-that any particular variation will be fostered and fixed if miscellaneous interbreeding is allowed. So that a segregation of individuals having certain common variations or varietal characters is necessary for the perpetuation of these characters.

Now the most usual way, probably, in which this segregation or isolation is brought about is by topographic or geographic barriers; a group of individuals gets isolated from others of their species by some physical barrier, and the variations that appear among them, due often to some cause incident to the special locality and hence common to all of them, are readily preserved and fostered by the enforced breeding among themselves. But such an isolation may conceivably be brought about in several other ways, and observation has shown that probably in some cases so-called biologic isolation occurs, that is, that a restriction of miscellaneous interbreeding among individuals of one species, and an enforced selective breeding among certain ones possessing certain variations or differences in common, does really obtain. Such isolation is also called physiologic, or sexual, isolation.

Many biologists, and the number of them has increased rapidly in the last few years, due primarily to the activity and leadership of the botanist de Vries (Amsterdam), believe that species-forming is achieved without the aid of the selection factor; that the actual production of species is a function of variation ("mutation" the special kind of variation efficient in species-making is called), and that the influence of selection is only of a more remote and generally restraining, and thus directive, nature. Such biologists may be said to believe in species-forming by heterogenesis or saltation, as contrasted with species-making by slow, gradual transmutation. And de Vries and his followers have adduced a few apparently undeniable examples of species-forming by heterogenesis. At least this influence seems to have produced forms to all intents and purposes apparently similar to natural species. So the particular kind of variation called mutation, which is the 
hasis of this sort of species-making, must be arlded to our list of evolution factors.

Some other biologists, of whom the botanist Nügeli, the zoölogist Eimer, and the paleontologist Cope are representatives (all thrce of these men, however, having evolution theories and beliefs distinct and peculiar to each), believe in what may be called orthogenetic evolution. 'That is, that the lines of descent are determined by the appearance of certain special determinate lines or tendencies of variation or change, this nonfortuitous and determinate variation being itself determined by certain causes either (in Nägeli's belief) inherent in life, or (in Eimer's belief) extrinsic to life but imposed upon it, as for example the influence of climate, etc. So that orthogenesis or determinate variation should also find a place in any list of assumed evolution factors.

While it is apparent that variation is ever present and also apparent that heredity or the fact of likeness is always ever to be relied on, the exact relationship or correlation of these two evolution factors is not so apparent. That heredity often preserves or perpetuates variations after they have oceurred is well proved, but it is also proved that some variations appearing in the parent are not handed on to the parent's offspring, nor indeed to any future generations of the line. And the general answer to the natural query raised by this condition is that variations which are congenital or blastogenic, that is, are determined at birth for it (although they appear of course only after development), are heritable (that is, will be passed on from parent to offspring); but that variations or modifications acquired during the lifetime of the individual, that is, those which are impressed on it by extrinsic influences during its "growing up " or development, will not be heritable. Thus such modifications in body parts as may be produced by use or disuse, or by other functional stimulation or lack of it, changes caused by mutilation or disease, etc., are believed by most biologists to be non-heritable. Hence it is that only the congenital variations are looked on by these hiologists as of importance in the matter of species-forming. Yet the whole pre-Darwinian evolution theory of Lamarek was founded on the assumption that the modifications in individuals due to use, disuse, and other functional stimulation, in a word that all body change and adaptation, all characters acquired during the lifetime of an individual, 
can be, in some degree at least, handed on by inheritance to the offspring. And there are to-day many Lamarckian evolutionists. So that in our list of possible evolution factors the so-called Lamarckian factor should not be omitted. And in connection with it may be considered, by and large, the immediate influence or non-influence on individuals and on species of all environmental conditions; and particularly the results of such influence during development. In fact the study of development has come largely to be a study of the actual influences or factors that determine and guide growth, instead of one purely descriptive and comparative as in the older days of embryological study. Some of these factors are apparently strictly inherent in the protoplasmic germ cells and in the embryo substance: others are as obviously extrinsic or epigenetic. And the determination of the relative influence and power of these two sets of developmental factors and of the various members of each set is one of the most eagerly worked-at problems of modern biological study.

Finally, the general term adaptation should be mentioned in any list of evolution factors; although it is more usually looked on, not as a factor, but as an evolution problem and indeed one of the greatest of the problems. Adaptation is precisely one of the things evolutionists are trying to find the causes or causal factors of. But nevertheless the adaptability of life stuff, its plasticity and capacity of advantageous reaction, is, to many biologists, a fundamental fact in organic nature, like gravitation or chemical affinity in inorganic nature: a thing basic and inexplicable, and in itself a factor whose consequences are to be determined but not further to be questioned as to their cause. 


\section{CHAPTER V}

\section{NATURAL, SELECTION AND THE STRUGGLE FOR EXISTENCE; SEXUAL SELECTION}

The tendency to regard natural selection as more or less unnecessary or superfluous which is so characteristic of our clay, seems to grow out of reverence for the all-sufficiency of the philosophy of evolution, and pious belief that the history of living things flows out of this philosophy as a necessary truth or axiom.-BRooks.

La selection naturelle est un principe admirable et parfaitement juste. Tout le monde est d'accord aujourd'hui sur ce point. Mais oú l'on n'est pas d'accord, c'est sur la limite de sa puissance et sur la question de savoir si elle peut engendrer des formes specifiques nouvelles. Il semble bien demontre aujourd'hui qu'elle ne le peut.

-Delage.

OF all the various factors of organic evolution the one which has been most relied on as the great determining agent is that called Natural Selection, the survival of the individuals best fitted for the conditions of life, with the inheritance of those species-forming adaptations in which fitness lies. The primal initiative is not in natural selection, but in variation, germinal and individual. This may be slight variation (fluctuation) or large deviation (saltation), but in any case all difference in species or race must first be individual. The impulse to change, once arisen, is continued through heredity. From natural selection arises the choice among different lines of descent, the adaptive tending to exclude the non-ardaptive, while traits which are neither helpful nor hurtful, but simply indifferent, may be borne along by the current of adaptive characters. Finally separation or isolation tends to preserve a special line of heredity from being merged in the mass which constitutes the parent stock or species.

Without individual variation, no change could take place; all organisms would be identical in structure. Without heredity, 
if we could conceive such a condition, no change would persist. Without selection, there would be no premium placed on adaptive characters, and organisms would persist in every degree of variance with their surroundings. Without some degree of isolation, every change would be lost by cross-breeding with the mass. In a world of varying conditions with varying organisms, it is not conceivable that species should, through all their generations, undergo no change. Nor in the changes of any species is it possible that any one of the factors or conditions named above should be wholly absent. But the effects of each one may show themselves in many different ways, and each may be modified by other facts or conditions. We have compared the history of species to the flow of a river. A single rock may change the course of a stream. In like manner incidental circumstances may determine the evolution of a species. Or using a different metaphor we may compare the course of a species with that of a glacier. The movement of a glacier depends on the law of gravitation "resident" within its molecules. Its course is determined by the topography of its bed. To this bed it is perfectly fitted, but the condition of its surface depends on circumstances related neither to the law of gravitation nor to the form of its bed. A species of animai or plant is well fitted to its conditions in life. This natural selection rigidly enforces; but its surface characters, which are not essential to its life, are determined by other influences, and in this both selection and environment play but a minor part.

All animals feed upon living organisms or upon that which has been living. Hence each animal throughout its life is busy with the destruction of the other organisms or with their removal after death. If these creatures, animals, or plants on which animals feed, are to hold their own, there must be an excess of birth and development to make good the drain upon their numbers. If the plants did not restore their losses the animals that feed on them would perish. In like fashion flesheating animals are dependent on those which feed on plants.

But throughout nature there is a vast excess in the process of reproduction. More plants sprout than could find standing room were all to grow. More seeds are developed than can find place to sprout. Nore animals are born than can possibly survive. The process of increase anong animals is rightly called multiplication. Each species tends to increase in geo- 
metric ratio, but as it multiplies it finds the world already rrowded with other multiplying species. A single pair of any species whatsoever, if not checked by adverse conditions, would soon fill the whole earth with its progeny.

An annual plant producing two seeds only would have 1,048,576 descendants in twenty-one years, if each seed sprouted and matured. But most plants produce hundreds or thousands of seeds. The ratio of increase is a matter of minor importance. It is the ratio of increase above loss which determines the fate of species. Those species increase in numbers in which the gain exceeds the rate of destruction through the influence of other species or the adverse conditions of life. Where few enemies exist the ratio of increase need not be iarge. One of the most abundant of birds is the fulmar petrel of the midPacific. It lays but one egg yearly, but it has few enemies and the low rate of increase suffices to cover the sea with fulmars within the region it inhabits.

It is not easy to realize the inordinate numbers any species would attain were it not for the checks produced by the presence of the activity of other organisms. Certain protozoa, at their normal rate of increase-if none were devoured or destroyedmight fill the entire ocean within a very short time. It is said that the conger cel lays $15,000,000$ eggs yearly. If each hatched and the conger grew to maturity, in a few years there would be no room for any other kind of fish in the sea. The codfish has been known to produce 9,100,000 eggs each year. If each egg were to develop, in ten years the sea would be solidly full of codfish.

The female quinnat salmon of the Columbia, Oncorhynchus tchawytscha, ascends the river at the age of about four ycars, and lays 4,000 eggs, after which she dies. Half these egres develop into males. If each female egg came to maturity, we should have at the end of fifty years $\$, 000,000,000,000,0(00,-$ $000,000,000,000,000,000,000,000,000$ female salmon and as many males as the offspring of a single pair. It takes about one hundred of these salmon to weigh a ton. Could all these fishes develop, in a very short time there would be no room for them in all the rivers $c^{f}$ the North, nor in all the waters of the sea.

If each egg of the common house fly should derelop and each of the larva should find the food and temperature it nealed 
with no loss and no destruction, the people of the city in whices it happened would suffocate under the plague of flies. Whenever any species of insect develops a large percentage of the egge laid, it becomes at once a plague. Thus originate plagues of locusts, grasshoppers, and caterpillars. But the crowd of life renders these plagues rare. Scavenger-beetles and bacteria destroy the decaying flesh where the fly would lay its eggs. Minute creatures, bacteria, protozoa, other insects, are parasitic within the larva itself. Millions of flies starve to death. Millions more are eaten by birds and predaceous insects. The final result is that from year to year the number of flies does not increase. Linnæus once said that "three flies will devour a dead horse as quickly as a lion." Quite as soon would three bacteria with their descendants reach the same result. "Even slow-breeding man," says Darwin, "has doubled in twenty-five years. At this rate in less than a thousand years there literally would not be standing room for his progeny. The elephant is reckoned the slowest breeder of all animals. It begins breeding when thirty years old and goes on breeding until ninety years old, bringing forth six young in the interval and surviving to be a hundred years old. If this be so, after about $\$ 00$ years there should be 19,000,000 elephants alive descended from the first pair." A few years of still further multiplication without check, and every foot of the earth would be covered by elephants.

Similar calculations may be made in regard to any species of animal or plant whatsoever. Each one increases at a rate which without checks would make it soon cover the earth. Yet the number of individuals in a state of nature in any species remains about stationary. With the interference of man, in many species the numbers slowly diminish; very few increase. There are about as many squirrels in the forest one year as another, as many butterflies in the field, as many frogs in the pond. Wolves, bears, deer, ducks, singing birds, fishes, all suf-fer from man's attacks or man's neglect and grow fewer year by year. It is manifest that the tendency to reproduce by geometric ratio meets everywhere with a corresponding check. This check is known as the Struggle for Existence.

The struggle for existence is threefold: (a) Among individuals of one species, as wolf against wolf or sparrow against sparrow, (b) between individuals of different species, as rabbit with wolf or blue-bird with sparrow; $(c)$ with the conditions in life-as 
the necessity of the robin to find water in summer or to kecp warm in winter. All three forms of the struggle for existence, intraspecific, interspecific, and envirommental, are constantly operative and with every species. In some regions or under some conditions the one phase may be more destructive, in others another. Any one of these may be in various ways modified or ameliorated. When the conditions of life are most easy, as with most species in the tropies, there the conflict of individuals and the conflict of species is most severe. It is not possible to say that any one of these three forms of struggle and selection is more potent than the others. In fact, the first ancl the second are in a sense forms of the third. All struggle is, strictly speaking, with the conditions of life. Those individuals

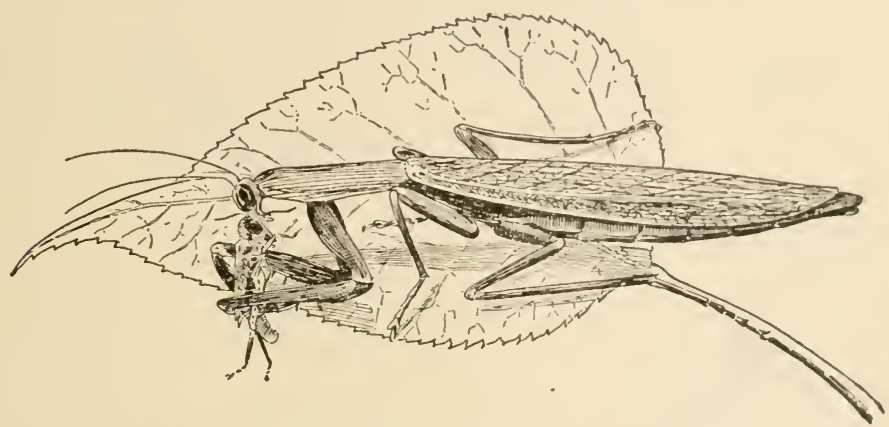

FIG. 38.-Praying mantis, eating a grasshopper. (Adapted from photograph from life by slingerland.)

which endure this struggle survive to reproduce themselves. The rest die and leave no progeny.

Because of the destruction resulting from the struggle for cxistence, more individuals in each species are born than can mature. The majority fail to reach maturity because for one reason or another they cannot do so. All live that can. Each animal tries to feed itself: many try to take care of their young. Bit in self protection and in propagation of the species very few individuals succeed in comparison with the rast number which the process of reproduction calls into being.

The destruction in nature is not indiscriminate. In the long run and for the most part, those creatures least fitted to resist are the first to perish. It is the slowest animal which is soonest overtaken by the pursuers. It is the weakest which is 
crowded aside or trampled on by its associates. It is the least adaptable which suffers most from extremes of heat and cold. By the process of Artificial Selection the breeder improves his stock, destroying his weakest or least comely calves, reserving the strong and fit for parentage. In like fashion, on an inconceivably large scale, the forces of nature are at work modifying and fitting to the demands of their surroundings the different species of animals. Because the processes and results of the struggle for existence seem parallel with those of artificial selection, Darwin suggested the name of Natural Selection for the sifting process as seen in nature. To the general result of natural selection, Herbert Spencer has applied the term

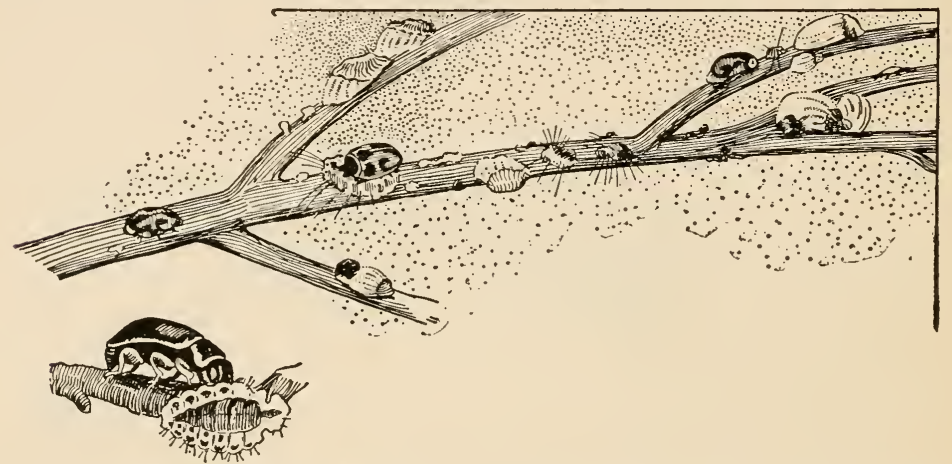

FIG. 39.-The Australian ladybird, Vedalia cardinalis, feeding on cottony cushion scale, Icerya purchasi. (From life.)

Survival of the Fittest. By fitness in this sense is meant only adaptation to surrounding conditions, for the process of natural selection has no necessary moral element, nor does it necessarily work toward progress among organisms. With changing conditions species undergo change. Some individuals, by the possession of slight advantageous variations of structure or of instinct, meet these new demands better than others. These survive, the others die. The survivors produce young sharing in part, at least, their own advantages, and with renewed selection the degree of adaptation increases with successive generations.

To the process of zatural selection we must, in most cases, probably ascribe the adjustment of species to surroundings 
Natural selection does not creste species, it enforces adaptation. If a species or a group of individuals cannot fit itself to its environment, it will be crowded out by others which ean do so. It will then either disappear entirely from the earth, or it will be limited to that region or to those conditions to which it is adapted. A partial adjustment tends to become more perfect, for the individuals least fitted are first destroyed in the struger for existence. Very small variations may sometimes, therefore lead to great changes. A side issue apparently unimportai may perhaps determine the fate of a species. Any adrantuge however small may possibly turn the scale of life. "Battle within battles must be continually recurring, with varying success, yet in the long run the forces are so nicely balanced that the face of nature remains for a long time uniform, though assuredly the merest trifle would give the victory to one organic being over another."

\section{Darwin says:}

"I have found that the visits of bees are necessary for the fertilization of some kinds of clover; for instance, twenty heads of white clover (Trifolium repens) yielded two thousand two hundred and ninety seeds, but twenty other heads protected from the bees produced not one. Again, one hundred heads of red clover (Trifolium pratense) produced two thousand seven hundred seeds, but the same number of protected heads produced not a single seed. Humble-bees alone visit red clover, as other bees cannot reach the nectar. . . . Hence we may infer as highly probable that, if the whole genus of humble-bees became extinct or very rare in England, the heartsease and red clover would become very rare or wholly disappear. The number of humble-bees in any district depends in a great measure on the number of field mice, which destroy their combs and nests; and Colonel Newman, who has long attended to the habits of humble-bees, believes that more than two-thirds of them are thus destroyed all over England. Now the number of mice is largely dependent, as everyone knows, on the number of eats; and Colonel Newman says: 'Near villages and small towns I have found the nests of humble-bees more numerous than elsewhere, which I attribute to the number of cats that destroy the mice.' Hence it is quite credible that the presence of feline animals in large numbers in a district might determine, through the intervention first of mice and then of bees, the frequency of certain flowers in that district." 
Huxley carries this calculation still further by showing that the number of cats depends on the number of unmarried women. On the other hand, clover produces beef, and beef strength. Thus in a degree the prowess of England is related to the number of spinsters in its rural districts! This statement would be true in all seriousness were it not that so many other elements come into the calculation. But whether true or not, it illustrates the way in which causes and effects in biology become intertangled.

There was introduced into California from Australia, on young lemon trees, twenty-five years ago, an insect pest called the cottony cushion scale (Icerya purchasi). This pest increased in numbers with extraordinary rapidity, and in ten years threatened to destroy completely the great orange orchards of California. Artificial remedies were of little avail. Finally, an entomologist was sent to Australia to find out if this scale insect had not some special natural enemy in its native country. It was found that in Australia a certain species of ladybird beetle attacked and fed on the cottony cushion scales and kept them in check (Fig. 39). Some of these ladybirds (Vedalia cardinalis) were brought to California and released in a scale-infested orchard. The ladybirds, having plenty of food, thrived and produced many young. Soon they were in such numbers that many of them could be distributed to other orchards. In two or three years the Vedalias had become so numerous and widely distributed that the cottony cushicn scales began to diminish perceptibly, and soon the pest was nearly wiped out. But with the disappearance of the scales came also a disappearance of the ladybirds, and it was then discovered that the Vedalias fed only on cottony cushion scales and could nui live where the scales were not. So now, in order to have a stock of Vedalias on hand in California, it is necessary to keep protected some colonies of the cottony cushion scale to serve as food. Of course, with the disappearance of the predaceous ladybirds the scale began to increase again in various parts of the State, but with the sending of Vedalias to these localities the scale was again crushed. How close is the interdependence of these two species!

There is little foundation for the current belief that each species of animal has originated in the area it now occupies, for in many cases our knowledge of palæontology shows the reverse of this to be true. Even more incorrect is the belief that each 
species occupies the district or the surroundings best fitted for its habitation. This is manifested in the fact of the extraordinary fertility and persistence shown by many kinds of animals and plants in taking possession of new lands which have become, through the voluntary or involuntary interference of man, open to their invasion. Facts of this sort are the "enormous increase of rabbits and pigs in Australia and New Kealand, of horses and cattle in South America, and of the sparrows of North America, though in none of these cases are the animal. natives of the countries in which they thrive so well " (Wallace). The persistent spreading of European weeds to the exclusion of our native plants is a fact too well known to every iarmer in America. The constant moving westward of the white weed and the Canada thistle marks the steady deterioration of our grass fields. The cockroaches in American kitchens represent invading species from Europe. The American cockroaches live in the woods. Perhaps a majority of the worst insect pests of the United States are of European or Asiatic origin. Especially noteworthy are cases of this type in Australia and New Zealand. In New Zealand the weeds of Europe, toughened by centuries of selection, have won an easy victory over the native plants.

Dr. Hooker states that, in New Zealand "the cow grass has taken possession of the roadsides; dock and watercress choke the rivers; the sow thistle is spread all over the country, growing luxuriantly up to 6,000 feet; white clover in the mountain districts displaces the native grasses." The native Maori saying is: "As the white man's rat has driven away the native rat, as the European fly drives away our own, and the clover kills our fern, so will the Maoris disappear before the white man himself."

Prof. Sidney Dickinson gives the following notes on the rabbit and other plagues of Australia:

"The average annual cost to Australasia of the rabbit plague is $£ 700,000$, or nearly $\$ 3,500,000$. The work which these enormous figures represent has a marked effect in reducing the number of rabbits in the better districts, although there is little to suppose that their extermination will ever be more than partial. Most of the larger runs show very few at present, and rabbit-proof fencing, which has been set around thousands of square miles, has done much to check further inroads. Until this invention began to be utilized it was not uncommon to frod 
as many as a hundred rabbiters employed on a single property whose working average was from three hundred to four hundred rabbits per day. As they received five shillings a hundred from the station owner, and were also able to sell the skins at eight shillings a hundred, their profession was most lucrative. Seventy-five dollars a week was not an uncommon wage, and many an unfortunate squatter looked with envy upon the rabbiters, who were heaping up modest fortunes, while he himself was slowly being eaten out of house and home.

"The fecundity of the rabbit is amazing, and his invasion of remote districts swift and mysterious. Careful estimates show that, under favorable conditions, a pair of Australian rabbits will produce six litters a year, averaging five individuals each. As the offspring themselves begin breeding at the age of six months, it is shown that, at this rate, the original pair might be responsible in five years for a progeny of over twenty millions. That the original score that were brought to the country have propagated after some such ratio, no one can doubt who has seen the enormous hordes that now devastate the land in certain districts. In all but the remoter sections, the rabbits are now fairly under control; one rabbiter with a pack of dogs supervises stations where one hundred were employed ten years ago, and with ordinary vigilance the squatters have little to fear. Millions of the animals have been killed by fencing in the water holes and dams during a dry season, whereby they died of thirst, and lay in enormous piles against the obstructions they had frantically and vainly striven to climb, and poisoned grain and fruit have killed myriads more. A fortune of $£ 25,000$ offered by the New South Wales Government still awaits the man who can invent some means of general destruction, and the knowledge of this fact has brought to the notice of the various colonial governments some very original devices.

"Another great pest to the squatters is developing in the foxes, two of which were imported from Cumberland some years ago by a wealthy station owner, who thought that they might breed, and give himself and friends an occasional day with the hounds. His modest desires were soon met in the development of a race of foxes far surpassing the English variety in strength and aggressiveness, which not only devour many sheep, but out of pure depravity worry and kill ten times as many as they can eat. When to these plagues is added the ruin of thousands of acres from the spread of the thistle, which a canny Scot brought from the Highlands to keep alive in his breast the memories of Wallace and Bruce; the well-nigh resistloss inroads of furze; and, in New Zealand, the blocking up of rivers by 
the English watereress; which in its new home grows a dozen feet in length, and has to be dredged out to keep navigation open, it may be understood the colonials look with jaundiced eye upon suggestions of any further interference with Australian nature.

"Not to be outdone by foreign importations, the country itself has shown in the humble locust a nuisance quite as potent as rabbit, fox, or thistle. This bane of all men who pasture sheep on grass has not been much in evidence until within the last few years, when the great destruction of indigenous birds by the gun and by poisoned grain strewn for rabbits has facilitated its inerease. The devastation caused by these inseets last year was enormous, and befoll a clistrict a thousand miles long and two thousand wide. For days they passed in clouds that darkened the earth with the gloomy hue of an colipse, while the ground was covered with crawling millions, devouring every green thing and giving to the country the appearance of being carpeted vith scales. It has been discovered, however, that before they attain their winged state they can easily be destroyed, and energetic measures will be taken against them throughout all the inhabited districts of Australia whenever they make another appearance."

The conditions of the struggle for existence are not necessarily felt as an individual stress to the individuals which survive. The life they lead is the one for which they are fitted. The struggle is painful or destructive only to those imperfectly adapted. Men in general are fitted to the struggle endured by their ancestors as they are adapted to the pressure of the air. They do not recognize the pressure itself but only its fluctuations. Hence many writers have supposed that the struggle for existence belongs to animals and plants and that man is or should be exempt from it. Competition has been identified with injustice, fraud, or trickery, and it has been supposed that it could be abolished by acts of benevolent legislation. IBut competition is inseparable from life. The struggle for existence may be hidden in social conventions or its effects more evenly distributed through processes of mutual aid, but its necessity is always present. Competition is the source of all progress.

The first suggestion of the doctrine of natural sclection came to Darwin through the law of population as stated by Thomas Malthus. The law of Malthus is in substance as follows: Man tends to increase by creometrical ratio-that is, by multiplication. The increase of food supply is by arithmetical 
ratio-that is, by addition; therefore, whatever may be the ratio of increase, a geometrical progression will sooner or later outrun an arithmetical one. Hence sooner or later the world must be overstocked, did not vice, misery, or prudence come in as checks, reducing the ratio of multiplication. This law has been criticised as a partial truth, so far as man is concerned. This means simply that there are factors also in evolution other than those recognized by Malthus. Nevertheless, Malthus's law is a sound statement of one great factor. And this law is simply the expression of the struggle for existence as it appears among men.

The doctrine of organic evolution was first placed on a firm basis by Darwin, because Darwin was the first who clearly defined the force of natural selection. Darwin, however, recognized other factors, known or hypothetical, and was interested more in showing the fact of descent and one cause of modification than in insisting on the all-sufficiency of the cause especially defined by himself.

In later times, Weismann and his followers have laid more exclusive stress on natural selection and its Allmacht or exclusive power in bringing about organic evolution. This view is known as Neo-Darwinism and the school of workers who profess it as Neo-Darwinians. Few investigators question the far-reaching influence of natural selection, but there are many phases in organic evolution which cannot be ascribed to it. Hence the scarch for other factors has been assiduously prosecuted, and doubts of Darwinism have been widely expressed; but this doubting has been thrown not so much on the Darwinism of Darwin, nor, as a rule, on the law of natural selection, but rather on the Allmacht claimed for it by Weismann and his associates.

Without attempting any elaborate discussion of questions still far from settled we may venture these suggestions:

1. Given the facts of individual variation, of inheritance, and some check to freedom of migration, natural selection would accomplish some form of organic evolution; species would be formed by the survival of the adapted, adaptations would be perpetuated, and minor differences would develop in time into deep-seated differences.

2. With natural selection alone, however, the actual facts in organic evolution as we know them would apparently not be achieved. 
3. In other words, while natural selection furnishes the motive force of change, other influences, extrinsic: and intrinsic, help to direct the channels in which life runs. It is necessary to consider other causes for the great body of indifferent characters or traits not produced by adapt ation, and apparently not yielding either advantage or disadvantage in the struggle for life.

4. The formation of species of animals and plants through natural selection finds an analogy in the formation of rivers through gravitation. Gravitation is the motive power carrying the waters from the uplands to the sea. The courses of streams are determined by a number of minor influences acting in concurrence with gravitation, the final result far more complex than the single cause would produce.

5. In like fashion, while natural selection is the motive element in descent or evolution, the total result is due to a concurrence of causes, and is too complex to be explained by natural selection, by the principle of utility, or the survival of the fittest alone, and the varying effects must be ascribed to a variety of causes.

Certain minor traits, as color patterns, relative proportions of parts, survive - apparently without special utility, but because these traits were borne by some ancestors or group of ancestors. This has been called the Survival of the Existing. In making up the fauna or flora of any region those organisms actually present when the region is first stocked must leave their qualities as an inheritance. If they cannot maintain themselves their breed disappears. If they maintain themselves in isolation their characters remain as those of a new species. In hosts of cases, the survival of characters rests not on any special usefulness or fitness, but on the fact that individuals possessing these characters have inhabited or invaded a certain area. The principle of utility explains survivals among competing structures. It rarely accounts for qualities associated with geographic distribution. The nature of the animals which first colonize a district nuust determine what the future fauna shall be. From their actual specific characters, largely traits neither useful nor harmful, will be derived for the most part the specific characters of their surecsisors.

It is not essential to the meadow lark that he should have a black blotch on the breast or the outer tail feathers white. Yet all meadow larks have these marks, as all shore larks possess 
the tiny plume behind the ear. Any character of the parent stock, which may prove harmful under new relations, will be eliminated by natural selection. Those especially helpful will be intensified and modified. But the great body of characters, the marks by which we know the species, will be neither helpful nor hurtful. These will be meaningless streaks and spots, variations in size of parts, peculiar relations of scales or hair or feathers, little matters which can neither hely nor hurt, but which have all the persistence heredity can give.

In regard to natural selection our knowledge seems positive. In regard to most other factors of organic evolution we have to deal so far not with clearly demonstrated facts but with "probabilities of a higher or lower order," their value to be ultimately shown by experiment.

In this connection the following words of Dr. Edwin Grant Conklin are very pertinent:

"On the whole, then, I believe the facts which are at present at our disposal justify a return to the position of Darwin. Neither Weismannism nor Lamarckism alone can explain the causes of evolution. But Darwinism can explain those causes. Darwin endearored to show that variations, perhaps even adaptations, were the result of extrinsic factors acting upon the organism, and that these variations or adaptations were increased and improved by natural selection. This is, I believe, the only ground which is at present tenable, and it is but another testimony to the greatness of that man of men that, after exploring for a score of years all the ins and outs of pure selection and pure adaptation, men are now coming back to the position outlined and unswervingly maintained by him."

Finaily we ought not to suppose that we have already reached a satisfactory solution of the evolution problem, or are, indeed, near such a solution.

"We must not conceal from ourselves the fact," says Roux, "that the causal investigation of organisms is one of the most difficult, if not the most difficult, problems which the human intellect has attempted to solve, and that this investigation, like every causal science, can never reach completeness, since every new cause ascertained only gives rise to fresh questions concerning the cause of this cause." 
In order to explain certain important phenomena outside the apparent range of natural selection, a theory of another sort of selective activity is recognized hy many biologists. This is the theory of Sexual Selection first propounded hy Darwin.

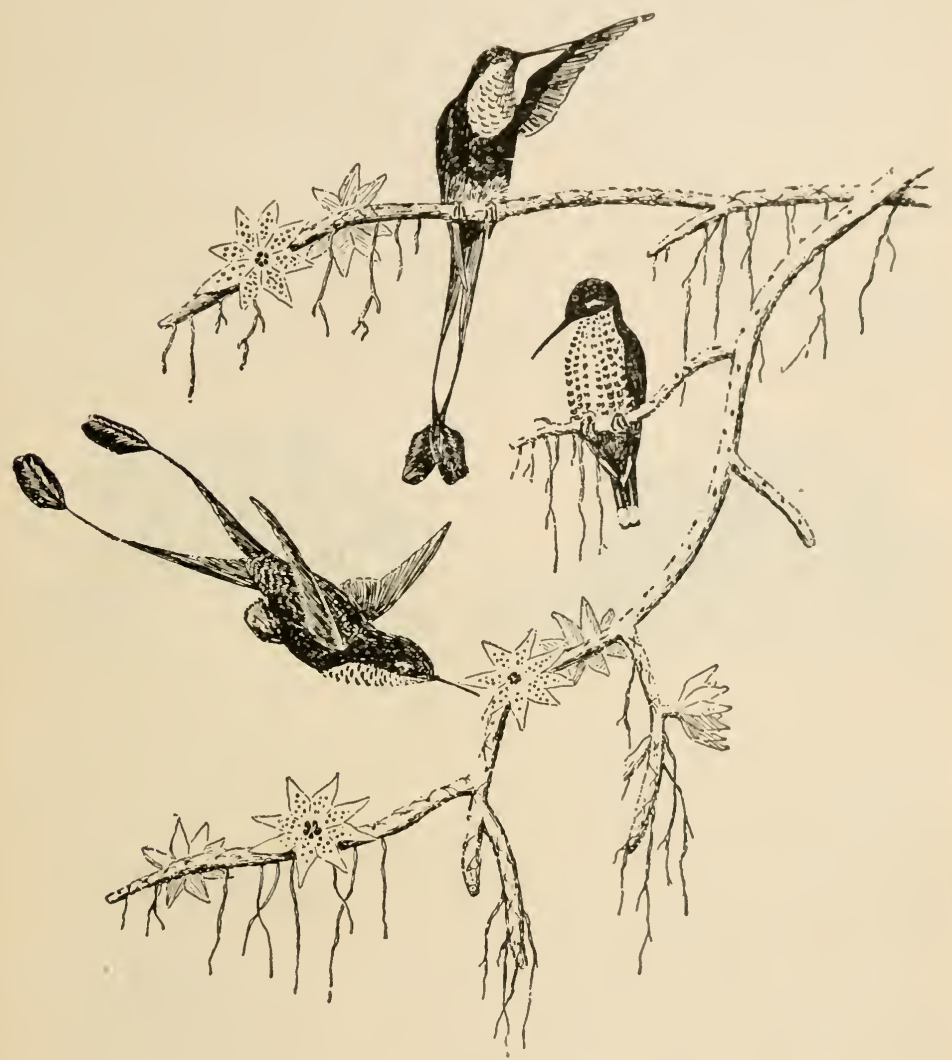

Frg. 40.-Male and female humming bird; showing sex dimorphism. (After Gould.)

Differences between male and female individuals of the same species are the rule rather than the exception (Fig. 40). Many of these differences are what might be called the necessary ones due to the particular functions assumed by each individual in this differentiation of sex. Of this nature are, besides those fundamental ones of the primary reproductive ones, such others as 
those specially connected with the care and rearing of the young; as the mammæ of female mammals, the brood pouches of the female kangaroos and opossums, etc. But a moment's reflection calls to mind the existence of a host of other differences between males and females of the same species which plainly have no such immediate relation to the distinct functions or duties assumed by each in the business of production and care of young. For example, the long plume feathers of the male bird of paradise, the curious chitinous horns of the male leaf-chafer beetles (Fig. 41), the brilliant plumage of many male birds as contrasted with the sober dress of the females, and a host of other distinguishing characteristics of the sexes in many animal species. Now these differences are all conveniently named by the phrase "secondary sexual differences," and the explanation of their origin has come to be one of the most
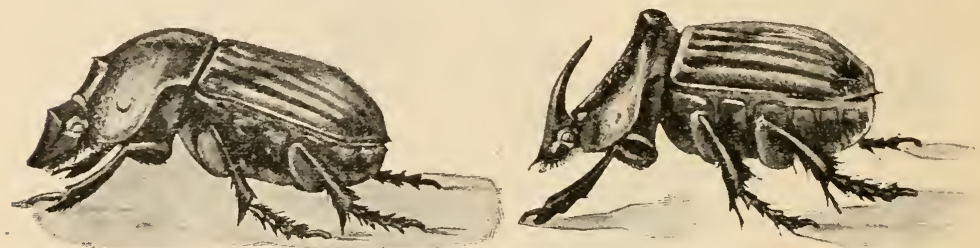

FIG. 41.-Male and female Scarabeid beetles, Phaneus mexicanus, showing sex dimorphism; the male with prominent dorsal horn on head. (From specimens.)

puzzling of biological problems. The most familiar and, for many years, a widely accepted solution of this problem, is that embraced in the theory of sexual selection proposed and fought for by Darwin and Wallace, but later discarded by the latter of these great naturalists.

Before taking up the sexual selection explanation of distinguishing sex characters, it is well to pay a little further attention to the characters themselves. And for this purpose a rough grouping or classification may be attempted.

The characters may be of special use to the possessor (male or female) or for the benefit of the young, such as weapons of offense and defense (antlers of male deer, stings of female bee and wasp, tusks of male swine, etc.), or special organs for mating (seizing and holding organs of certain male crabs, suckerlike holding pads on the feet of male water beetles (Fig. 42), or special locomotory organs (presence of wings in the male and their 
absence in the female in numerous insect species), or special sense organs (the much more expanded antenne of male eccropia, promethea, polyphemus, and other bombycine moths, as compared with those of the female), or special structures for the care of the young (milk glands of female mammals, brood pouches of female marsupials, pits on the back of the male of the frog Pipa (Fig. 43), for carrying the cggs, etc.), or recognition marks (the eye spots, collars, wing bands, tail blotches, and such other conspicuous color spots and markings possessed by the males and wanting in the females of various bird species), or, finally, characters connected with special habits of one sex differing from those of the other (the pollen

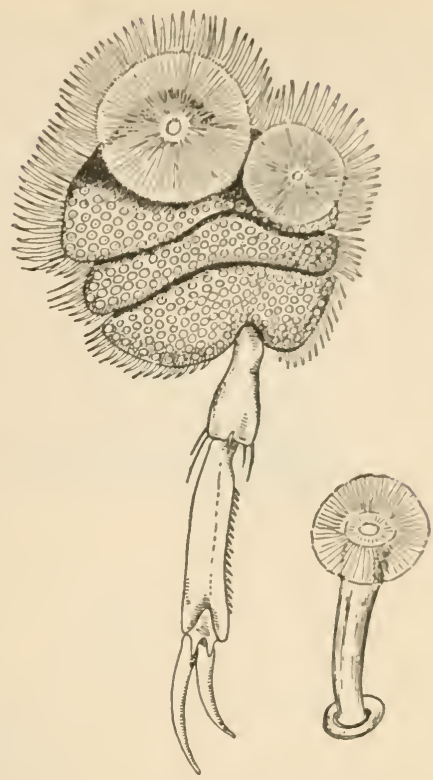

Fig. 42.-Fore leg of male water beetle, Dyticus, showing special suckerlike expansion of the leg. (After Miall.) baskets and wax plates of the worker female honey bees, the winglessness of certain female parasitic insects, the males being nonparasitic and winged, cte.).

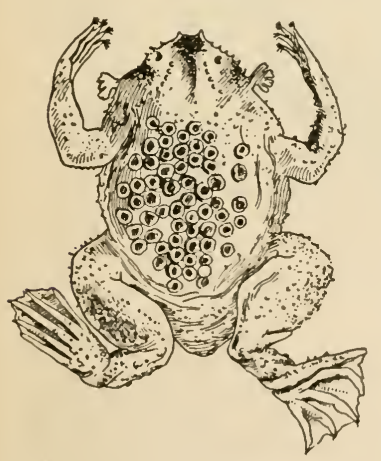

Fig. 43.-A male frog, Pipa americann, carrying eggs in pits on its back. (After Darwin.)

The special characters may be apparently for the purpose of attracting or exciting the other sex, as the brilliant colors, markings, and other ornamentation of many male birds, some manmals, and some reptiles and very many fishes, and the cries and songs, special odors, and curious antics or dancing of the males of various animals (mammals, hirds. spiders, insects, etc.). In many of these cases the special secondary sexual characters appear only during the breeding season; in others they are persistent. 
The characters may also we of the type called reciprocal, that is, organs which exist in functional condition in one sex, but in the other appear in rudimentary and often nonfunctional forms, as the reduced horns of female antelopes and goats, the undeveloped stridulating organs of female crickets and katydids, small spurs on the female pheasant, reduced mammæ of male mammals, undeveloped mimicry of male butterflies, etc.
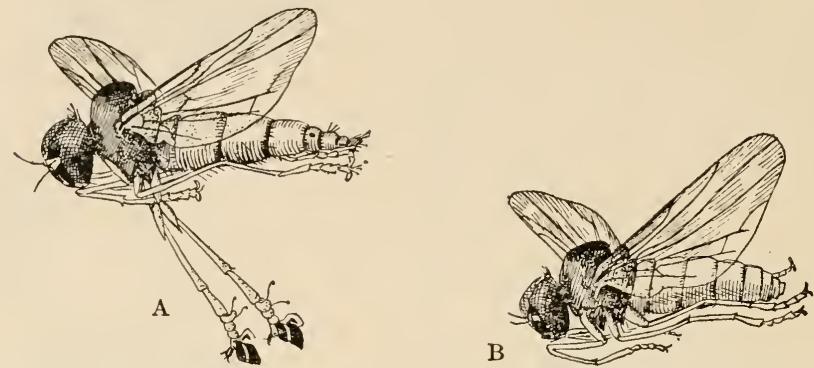

Frg. 44.-Male (A) and female (B) of the fly, Calotarsa insignia Ald., showing secondary sexual characteristics on the feet of the male. (After Aldrich.)

Finally the characters may be indifferent, that is, without any apparent utility; as the reduced wings of numerous female insects, the rudimentary alimentary canal of the male Rotatoria, absence of antlers of female deer, loss of wings in insect females,'small differences in size and markings between males and females, slight differences in wing form in hummingbirds, dragon flies, and butterflies, differences in number of tarsal and antennal segments in insects, etc.

The explanation of these various differences between males and females plainly cannot be a single one. The extreme variety of the secondary sexual differences of itself makes it necessary to find more than one explanation for their existence. To take the most obvious case, it is apparent that the useful character's, such as the fightirig antlers of the male deer, can be explained probably by natural selection. At least these characters fall readily into line with precisely that type of useful specialization for whose explanation we rely on natural selection. So practically all those secondary sexual characters of our first category, namely, those obviously useful to the possessor or to its young, sucin as organs of offense and defense, brood pouches, food-producing or gathering organs, special 
means of locomotion, etc., may be considered to offer no specia! problem. Although indeed the reason why these useful characteristics should be possessed by but one sex is by no means always, or perhaps even often, plain to us.

But the real problem presented by secondary sexual (haracters is that thrust on us by the nomuseful and even apparently disadvantageous differenees. Why the male bird of paradise should be decked out in a plumage certain to make it a conspicuous object to every enemy it has, and of a weight and difficulty of manipulation that must mean a constant demand on the strength and attention of the bird, is a question that demands a special answer. In the same case with the bird of paradise are the peacock, the gorgeous male pheasant (Fig. 45 ),

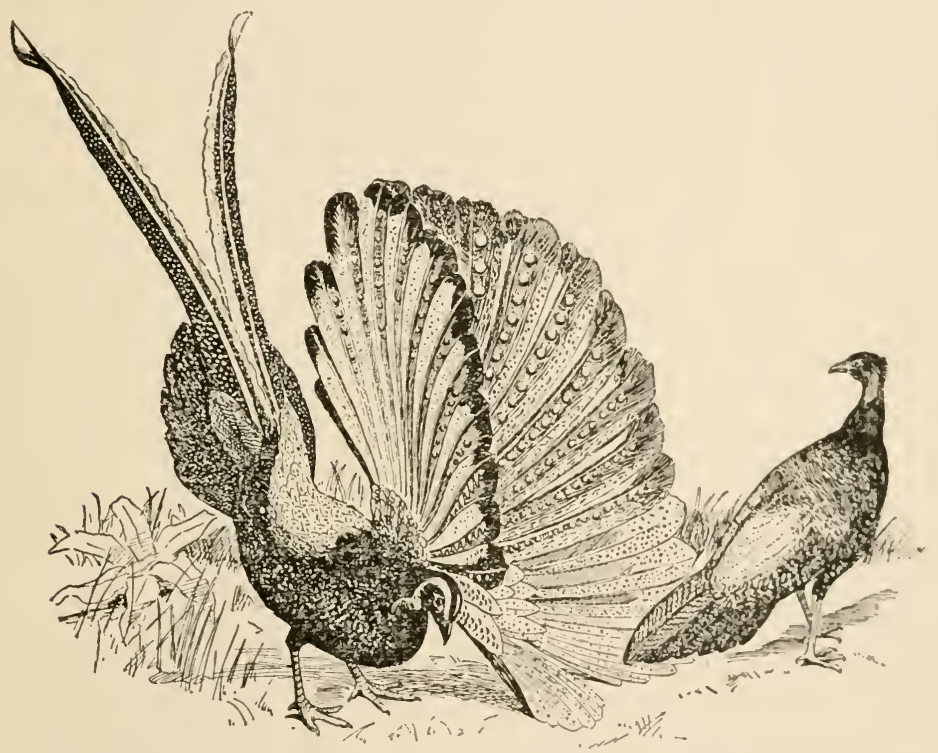

FIG. 45.-Male and female argus pheasant; the male is shown in characteristic "courting attitude." (From Tegetmeicr's "Pheasants.")

many humminghirds (Fig. 40), etc. Now to explain these extraordinary secondary sexual differenees the theory of sexual selection has been devised.

This theory, in few worc's is that there is practically a competition or struggle for mating, and that those males are 
successful in this struggle which are the strongest and best armed or equipped for battle among themselves, or which are most acceptable by reason of ornament or other attractiveness to the females. In the former case mating with a certain female depends upon overcoming in fight the other suitors, the female being the passive reward of the victor; in the second case the female is presumed to exercise a choice, this choice depending upon the attractiveness of the male (due to color, pattern, plumes, processes, odor, song, etc.). The actual fighting among males, and the winning of the females by the victor is an observed fact in the life of numerous animal species. But a special sexual selection theory is hardly necessary to explain the development of the fighting equipment, antlers, spurs, claws, tusks, etc. This fighting array of the male is simply a special phase of the already recognized intraspecific struggle; it is not a fight for room or food, but for the chance to mate. But this chance often depends on the issue of a life and deatl struggle. Natural selection would thus account for the development of the weapons for this purpose.

For the development, however, of such secondary sexual characters as ornament, whether of special plumage, color, pattern, or processes, and song, and special odors, and "love dancing," the natural selection theory can in no way account; the theory of sexual selection was the logical and necessary auxiliary theory, and when first proposed it met with quick and wide acceptance. Wallace in particular took up the theory and applied it to explain many cases of remarkable plumage and pattern development among birds. Later, as he analyzed more carefully his cases, and those proposed by others, he became doubtful, and finally wholly skeptical as to the theory.

The theory as proposed by Darwin was based on the following general assumptions, for the proof of each of which various illustrations were adduced. First, many secondary sexuai characters are not explicable by natural selection; they are not useful in the struggle for life. Second, the males seek the females for the sake of pairing. Third, the males are more abundant than the females. Fourth, in many cases there is a struggle among the males for the possession of the females. Fifth, in many other cases the females choose, in general, those males specially distinguished by more brilliant colors, more conspicuous ornaments, or other attractive characters. Sixth, 
many males sing, or dance, or otherwise draw to themselves the attention of the females. Seventh, the secondary sexual characters are especially variable. Darwin believed that he had observed certain other conditions to exist which helped make the sexual selection theory probable, but the conditions noted are sufficient if they are real.

Exposed to careful scrutiny and criticism, the theory of sexual selection has been relieved of all necessity of explaining any but two categories of secondary scxual characters; namely, the special weapons borne by males, and special ornaments and excitatory organs of the males and fcmales. For examination has disclosed the fact that males are not alone in the posscssion of special characters of attraction or excitation. Regarding these two categories Plate in his able recent defense of J)arwinism, says "the first part of this theory, the origin of the special defensive and offensive weapons of males through sexual sclection, is nearly universally accepted. The second part of the theory, the origin of exciting organs, has given rise to much controversy. Undoubtedly the presumption that the females compare the males and then choose only those which have the most attractive colors, the finest song, or the most agreeable odor, presents great difficulties, but it is deubtful if it is possible to replace this explanation by a better." Some of these difficulties may be briefly enumerated.

The theory can be applied only to species in which the males are markedly more numerous than the females, or in which the males are polygamous. In other cases there will be a femalc for each male whether he be ornamented or not; and the unornamented males can leave as many progeny as the ornamented ones, which would prevent any accumulation of ornamental variations by selection. As a matter of fact, in a majority of animal species, especially of the higher vertebrates, males and females exist in approximately equal numbers.

Observation shows that in most species the female is wholly passive in the matter of pairing, accepting the first male that offers. Note the cock and hens in the barnyard, or the fur seal in the rookeries.

Ornamental colors are as often a characteristic of males of kinds of animals in which there is no real pairing, as among those which pair. How explain by sexual selection the remarkable colors in the breeding season of many fishes, in which the 
female never, perhaps, sees the male which fertilizes her dropped eggs? In many fishes the spring ornamentation of the males is just as marked and just as brilliant as in the birds or other animals of much higher intelligence and corresponding power of choice. Witness the horned dace, chubs, and stone rollers in any brook in spring.

Choice on a basis of ornament and attractiveness implies a high degree of æsthetic development on the part of the females of animals of whose development in this line we have no other proof. Indeed, this choice demands æsthetic recognition among animals to which we distinctly deny such a development, as the butterflies and other insects in which secondary sexual characters of color, etc., are abundant and conspicuous. Similarly with practically all invertebrate animals. Further, in those groups of higher animals where æsthetic choice may be presumed possible, we have repeated evidence that preferences vary with individuals. Certainly they do with men, the animal species in which such preferences certainly and most conspicuously exist.

In some human races hair on the face is thought beautiful; in others, ugly. Besides even if we may attribute fairly a certain amount of æsthetic fecling to such animals as mammals and birds, is this feeling so keen as to lead the female to have preference among only slightly differing patterns or songs? Yet this assumption is necessary if the development of ornament and other attracting and exciting organs is to be explained by the selection and gradual accumulation through generations of slight fortuitously appearing fluctuating variations in the males.

There are actually very few recorded cases in which the observer believes that he has noted an actual choice by a female. Darwin records eight cases among birds. Since Darwin, not more than half a dozen other cases, all doubtful, have been noted. Also a few instances, all more illustrative of sexual excitation of females resulting from the perception of odor or actions, than any degree of choice on their part, have been listed.

In numerous cases the so-called attractive characters of the males, described usually from preserved (museum) specimens, have been found, in actual life, to be of such a character that they cannot be noted by the female. For example, the brilliant colors and curious horns of the males of the dung beetles are, in 
life, always so obscured by dirt and filth that there can be no question of display to the female eye about them. The dancing swarms of many kinds of insects are found to be composed of males alone with no females near enough to see; it is no case of an excitatory flitting and whirling of many males before the eyes of the impressionable females. Of many male katydids singing in the shrubbery will not for any female that particular song be loudest and most convineing that proceeds from the neurest male, not the most expert or the strongest stridulator? Sinilarly with the flitting male fireflies; will not the strongest gleam be, for any female, that from the male which happens to fly nearest her, and not from the distant male with ever so much better, stronger light? Even in the human speeies, propinquity is recognized as the strongest factor in the choice of mates.

Several other serious objections can also be urged against the sexual selection theory, but the most important one of them all is that all the evidence (though it is little in quantity as yet, although of good quality) based on actual experiment, is strongly opposed to the validity of the assumption that the females make a choice among the males based on the presence in the males of ornament or attractive colors, pattern, o. speci: 1 structures. Such experiments have been undertaken by I)üi igen and Douglas with lizards, and by Mayer with moths.

It must be said, however, in closing this brief discussion of the sexual selection theory, that no replacing or substitute theory of anything like the same plausibility has yet been offered to take its place.

There is no question that, in many cases, brilliancy of breeding colors, development of processes, and the like, is often correlated with superior vigor. This is especially true among fishes and birds. This reason could, howerer, not at all account for such structures as the highly specialized stridulating organs of certain insects. The problem of the sccondary sexual characters, especially of those which seem to stand in opposition to the natural selection theory, is one of the most pressing in present-day biology. 


\section{CHAPTER VI}

\section{ARTIFICIAL SELECTION}

We can command Nature only by obeying her laws. This principle is true eren in regard to the astonishing changes which are surerinduced in the qualities of certain animals and plants in domestication and in gardens.-LYELL.

VARIETIES are the product of fixed laws, never of chance. With a knowledge of these laws we can improve the products of nature, by employing nature's forces in ameliorating old or producing new species and varieties better adapted to our necessities and tactes. Breeding to a fixed line will produce fixed results. There is no evidence of any limit in the production of variation through artificial selection; especially if preceded by crossing.-Luther BurbaNk.

THe name Selection has been long used for the process by which breeds or races of domestic animals or plants have been formed in the past, and for the process by which the skillful breeder can develop new forms at will. This latter process, called by Youatt "the magician's wand," by which the breeder can summon up any form of animal which may meet his needs or please his fancy, has been especially designated as Artificial Selection. By it we have derived all of our familiar hosts of varieties of domesticated animals and plants. The similar process in nature was accordingly designated by Darwin, Natural Selection. It refers to the development or increase of traits adaptive or advantageous in the life of a species, through the survival for reproduction of a greater proportion of individuals possessing the characters in question than of those which do not. In any race, it is the individual which succeeds in reaching maturity which determines the future of the race. The qualities of the multitude which die prematurely are naturally not repeated in heredity. In general, the forms pro- 
duced in artificial selection are not those which could arise or even exist in nature. In nature, hardiness or power of resistance in competition or the struggle for existence is all important. In artificial selection stress is laid chiefly on characters useful or attractive to man. From the standpoint of self dependence, the improvements due to artificial selection constitute a sort of retrogression.

In general, the production of a new race of animals or plants in domestication is the outcome of the work of a number of factors, in which human or artificial selection plays a leading part, a part which increases in importance with the degree of intelligent choice concerned in it.

In the formation of a new race of animals or plants, we may have the following stages or factors:

1. Unconscious selection with more or less complete isolation.

2. Conscious selection of the most desirable individuals.

3. Conscious selection directed toward definite or special ends.

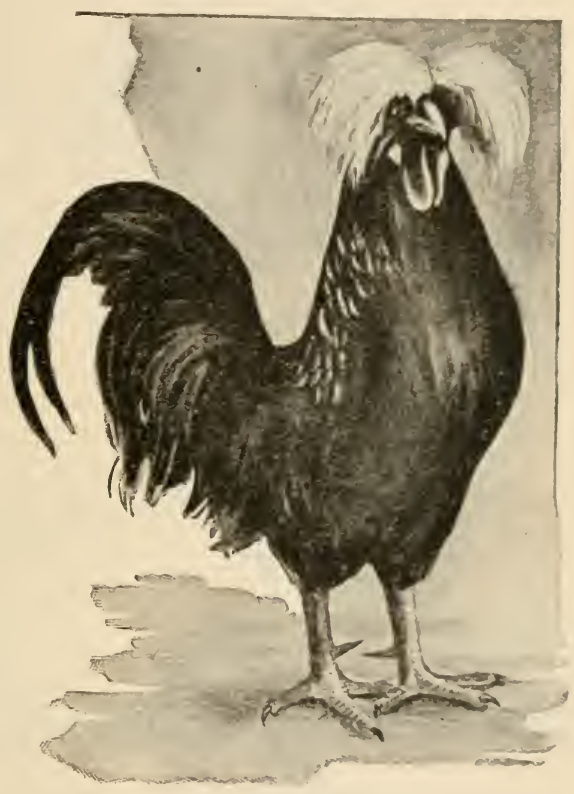

FIG. 46.-White-crested black Polish cock. (After photograph.)

4. Crossing with other races or with other species (known as hybridizing), in order to increase the range of variation, or to add or combine certain specific desirable qualities or to eliminate those undesirable, this accompanied by conscious selection directed toward definite ends. On this series of processes breeding as a fine art must depend.

Taking as an illustration some of the breeds of medium wool sheep found in Southern England: we have (1) the domestication of sheep in each of the different counties or natural 
areas. In the beginning men are satisfied with sheep as sheep. Little attention is paid to the distinction among individuals. Those which are feeble, ill nourished, untamable, scant-fleeced, or otherwise unfit will be eliminated, a process which will tend to improve the stock, without giving the race distinctive qualities, except as compared with the wild original. To form disinct races, the factor of isolation must enter. Those in one county, for example, will be, at the beginning, somewhat different from those in an-

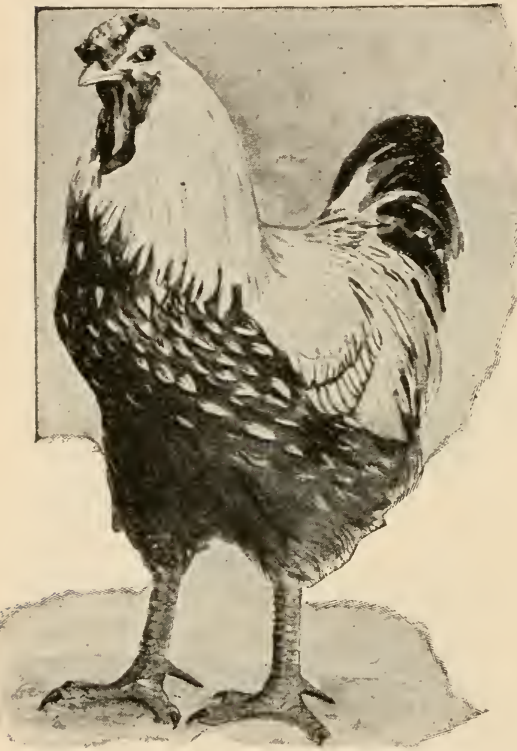

FIG. 47.--Silver-laced Wyandotte cockerel. (After photograph.) other. Each herd will show its own traits in time, these due primarily to differences in the original stock, secondarily to the predominance of one form of variation over others. Exchanges of sheep will, by cross-breeding, tend to unify the type of sheep in some one county, or on some side of a barrier across which sheep are not driven. With this, there will be also variations in the character of the unconscious selection. One type of sheep will flourish in a meadow county, another on a moor, and still another on the rocky hills. At any rate, - as the environment varies, so will the character of the selection. Thus as a final result, in Southern England, the Southdown sheep of Sussex have tawny faces and legs; the sheep of Hampshire have black faces, ears, and legs, with a black spot under the tail; this black spot is lacking in the sheep of Devon. In the Cheviot sheep the face and ears are white, the head free from wool, while the ears, unlike those of most of the others, stand erect. In the dun-faced Shropshire sheep, the faces are more or less covered by wool. All these are hornless, while the more primitive Dorset sheep with white face and ears 
have almost always small curved horns which are white, not black, as in the still more primitive Irish breed. Most of these distinctive traits offer neither advantages nor disadvantages either to the sheep or its owner. They are nonadaptive or

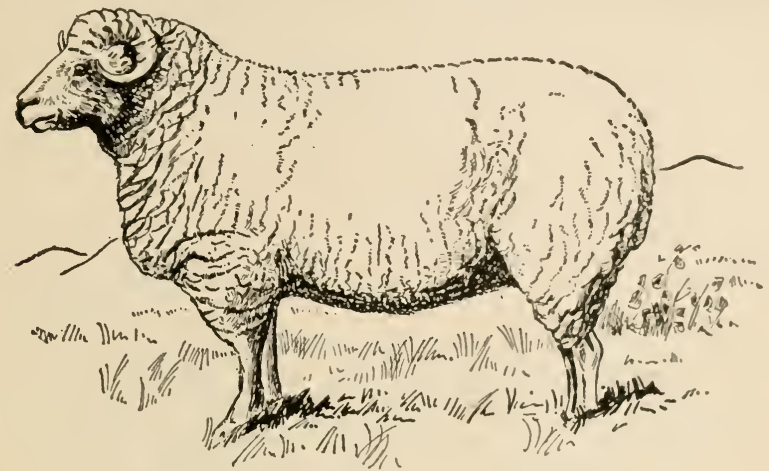

FIG, 48.-Typical Dorset ewe, horned. (After Shaw.)

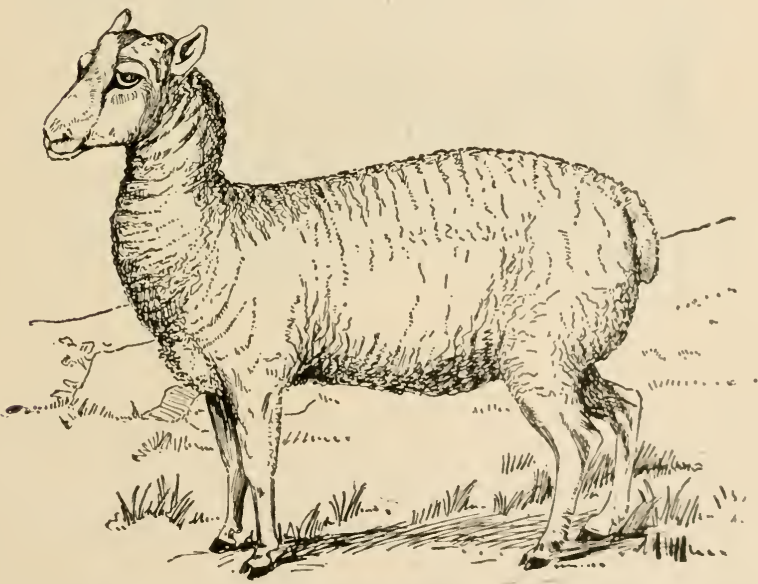

FrG. 49.-Polled Welsh sheep, a primitive type, lean and scant wooled. (After Youatt.) indifferent characters. These characters are therefore associated with the hereditary traits of the original stock. They are preserved through segregation and they are lost when herds from different counties frecly intermingle. Free interbreeding would give a new and relatively uniform race of sheep over the whole area occupied by these separate breeds. 
At this point we may conceive that (2) conscious selection of the more desirable individuals appears. Through its agency, Hampshire, Shropshire, Cheviot, and Southdown sheep alike, and the others in their degree, tend toward larger size, more wool, plumper bodies, earlier maturity, greater docility, greater fertility, or whatever virtues the average shepherd may prize in a sheep. While in race traits, the breeds (uncrossed) tend to diverge from one another, in these adaptive qualities, their tendency is to run parallel-or even to converge toward greater resemblance.

With conscious selection (3), there is first a tendency to emphasize the qualities of desirable breeds. If, for example,

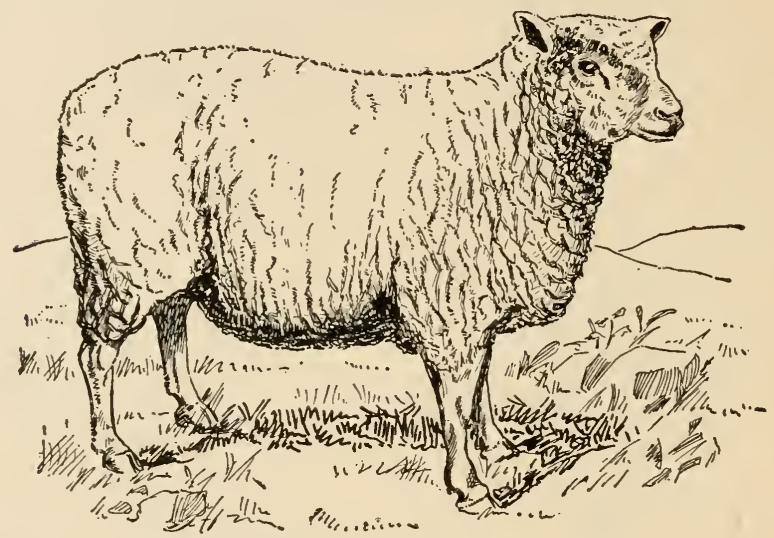

Frg. 50.-Typical Southdown ewe. (After Shaw.)

the Hampshire is a favorite breed, the individuals showing most distinctly black ears, legs, and face will be preferred by breeders to those having these parts pale. Again, new points of special excellence will appear in the breed and these will be deliberately emphasized, and perhaps by continuous selection a new breed will be formed having one or more of these as a distinctive trait. According to Somerville, one may chalk out on a wall any form or type of sheep he may like, and then in time reproduce it through selective breeding.

In Nova Scotia, Mr. A. Graham Bell has developed a new breed of sheep by selection, its distinctive character being in the increased milk flow, with an increased number of teats. 
At Chillenham, in England, is still preserved a herd of the original wild white English cattle, from which most or all of the British breeds are said to be descended. It is stated that Lord Cawdor has offered to reproduce this herd, by selection alone, in three or four generations, using the relatively primitive Welsh eattle as his base of operations.

In general, those characters which are usually affected by selection, whether natural or artificial, are characters of degree. They are matters of more or less, a greater or less degree of strength, swiftness, size, endurance, fertility, capacity to lay

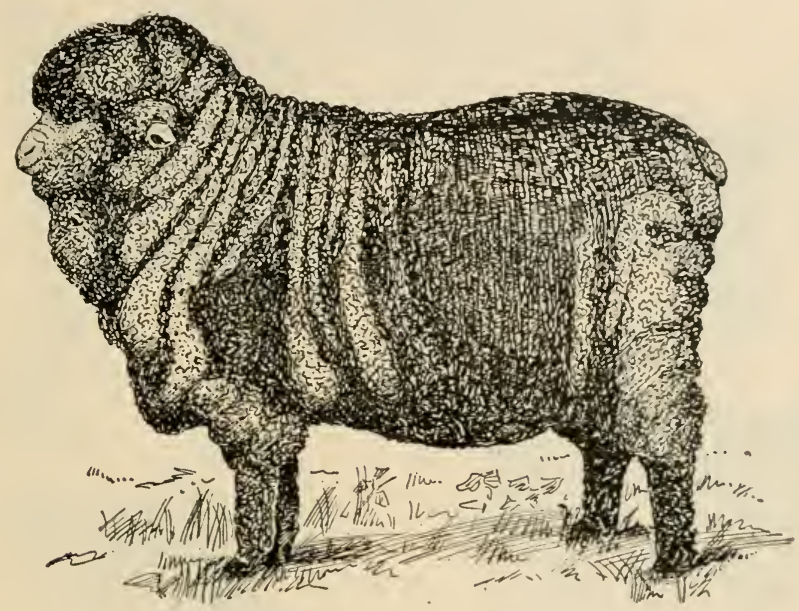

Fig. 51.-Typical American merino ewe, a highly specialized breed with fine close-set wool. (After Shaw.)

on fat, docility, intelligence, or of whatever it may be. [nder ordinary conditions these characters selected are not traits of quality. They do not represent a new thing, a new acquisition, but a different degree of development of an old one, or at most, a change in their relative arrangement, an alteration of biological perspective.

The characters which distinguish true breeds as well as true species are not of this order. They are in their essenee qualitative and not quantitative. They are not, as a rule, adaptive. One set of species or race traits is as good as another, if the good qualities or adaptive qualities are represented in an equally 


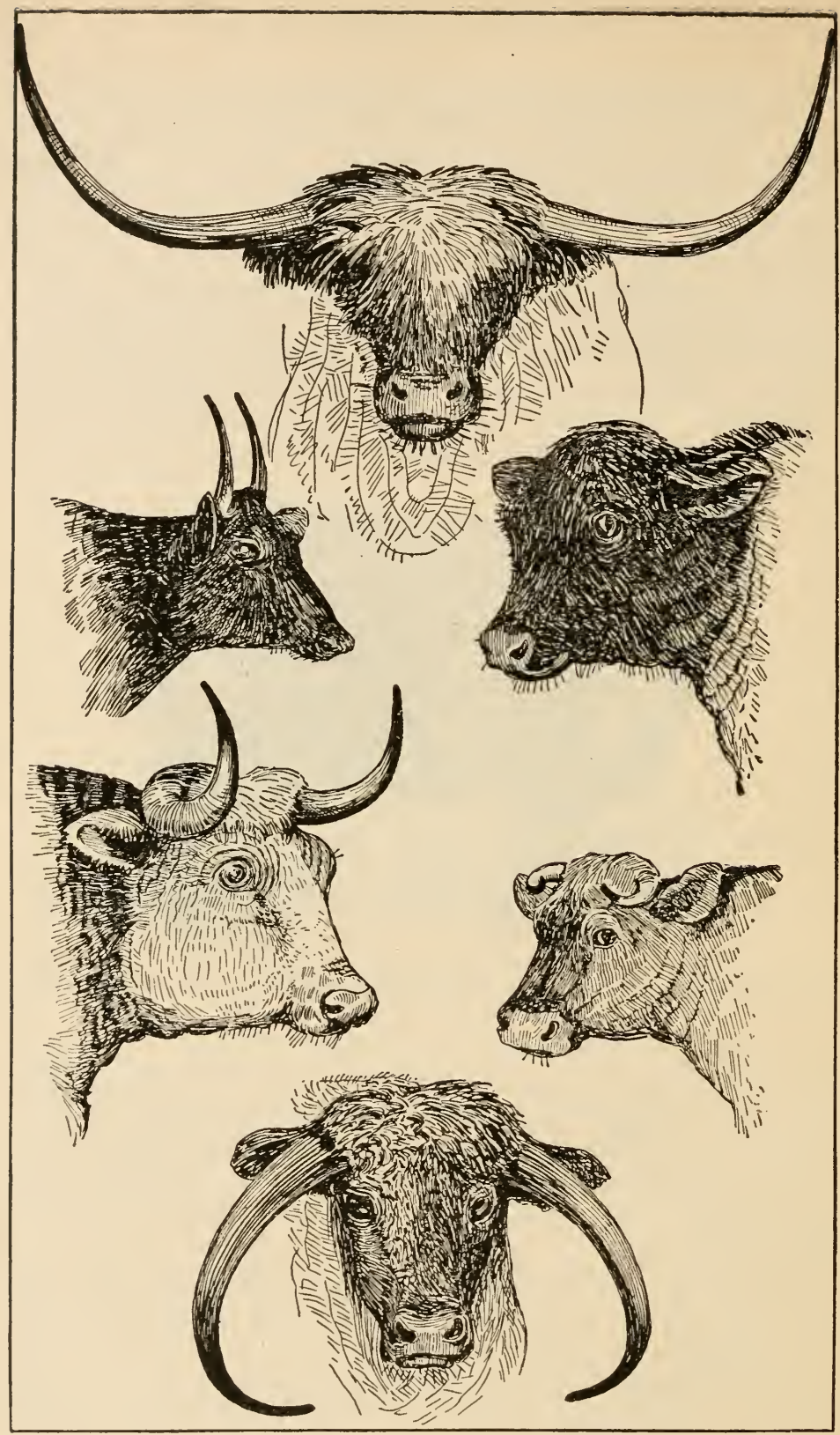

FIG. 52,- Heads of various British breeds of domestic cattle, showing variations is shape of head and condition of horns. (After Romanes.) 


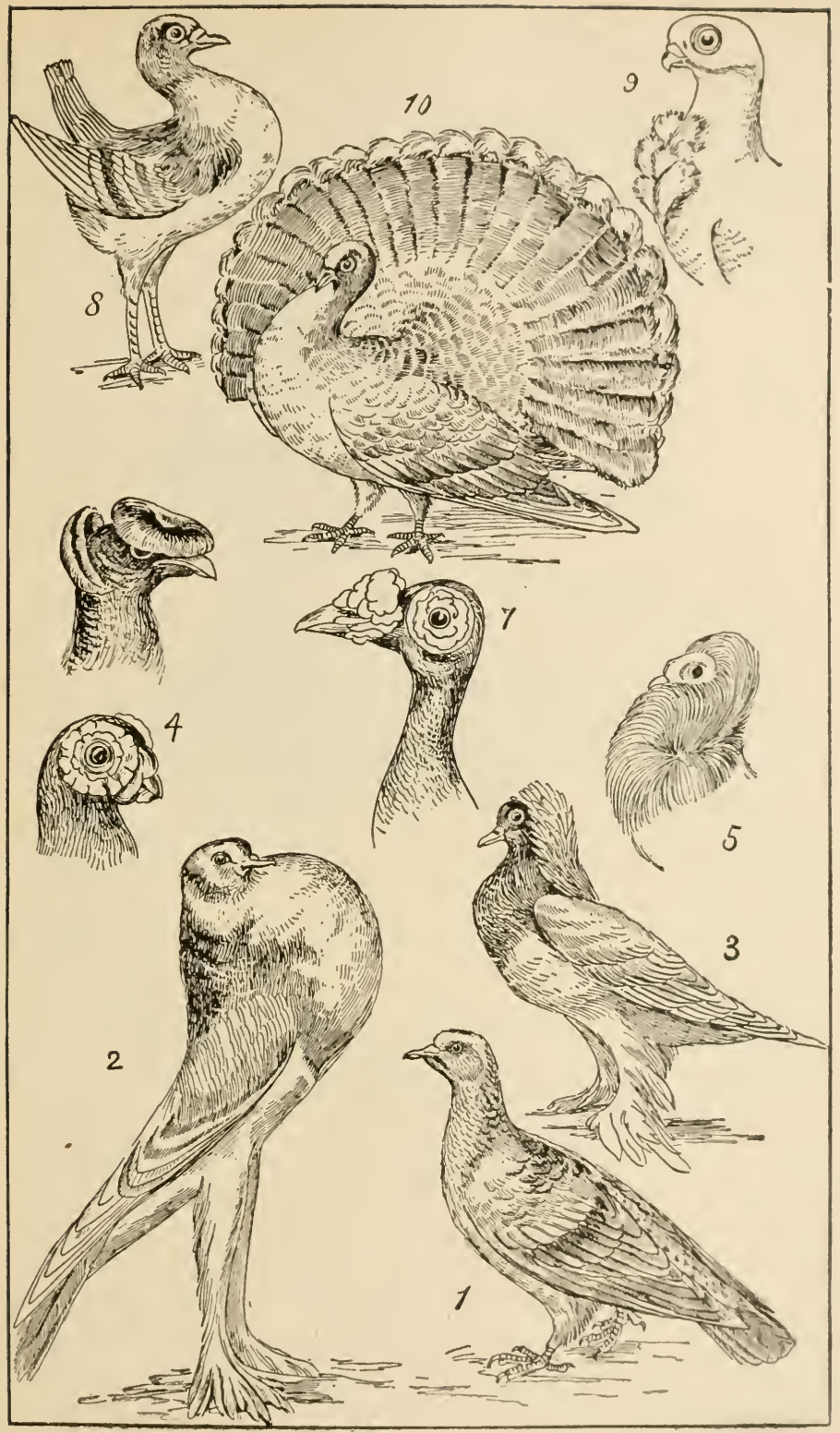

Fra. 53, - Yarious races of pigeons, all probably descended from the European rock dove, Columba livia, (After Haeckel.) 
high degree. The Southdown sheep are valued-not for their Southdown traits, but for the excellence of their mutton, a trait with which middle length of wool, tawny legs, naked faces, drooping ears, and absence of horns have nothing necessarily to do. We value these race traits only for the other qualities

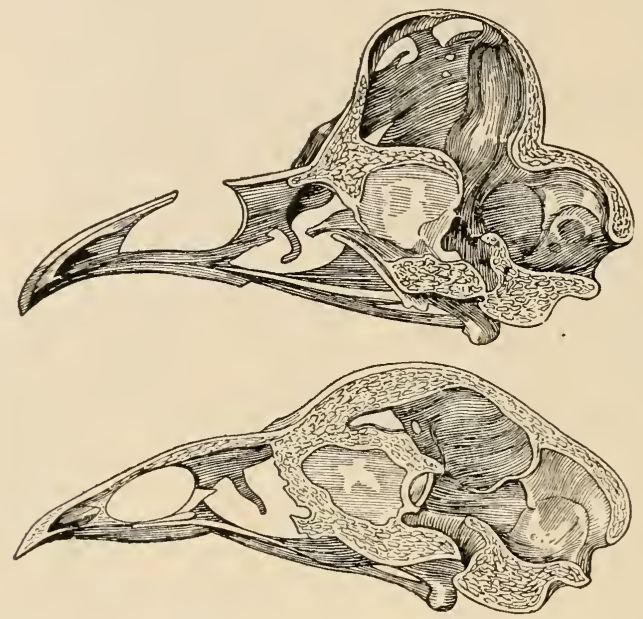

Frg. 54.-Skulls (in longitudinal section) of two breeds of domestic fowl, showing the large modification in the cranium: upper figure, Polish cock; lowcr figure, Cochin cock. (After Darwin.)

which have been in a high degree associated with them in the heredity of the race.

Under crossing and selection, much bolder attempts are possible. When parents widely divergent are crossed, many very different results are attained. In general the progeny, at least after the first generation, diverge very widely from one another. Some will have the good traits of both parent stocks; some will have the undesirable ones; some will show a mosaic of parental characters; some a more or less perfect blenà of characters, this blend being definable as a finer type of mosaic. Some will diverge widely from either stock, often showing traits either remotely ancestral or wholly new. From desirable variations of this sort new races may be developed, each succeeding generation tending to give greater fixity.

In general, wide crosses or hybrids are more successful with plants than with animals, because the mutual adjustment 
traits become more important in the more highly specialized organisms. Among animals, related species often cannot be crossed at all; the germ cells refuse to interningle. Sometimes there is a very imperfect mingling and the resultant animal is divided within itself and does not live long. An example of this is seen in Dr. Moenkhaus's cross of the silverside (Menidiri) with the killifish (F'undulus). The unnixed chromosomes of the germ-cell nucleus are seen unblended, through several segmentations of the egg.

In the case of the mule, the cross of the horse with the ass, the hybridization is readily effected, but the resultant offspring is sterile. Presumably the hereditary difference in the repro-

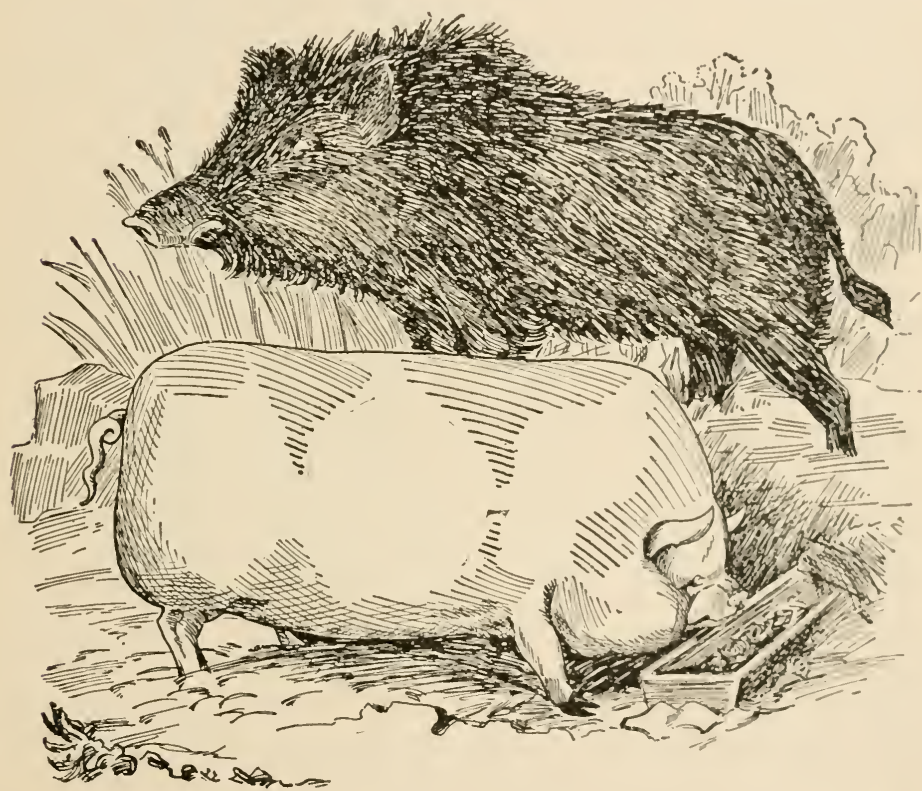

FIG. 55.-Wild boar contrasted with modern domestic pig. (After Romanes.)

ductive organs in the two parental strains is too great to allow the normal development of generative organs in the progeny.

In general, crosses between closely related species are fertile, the degree of fertility being less as the parent species are more widely differentiated. Among animals, any great difference 
between the parent stocks renders hybridization impossible. But among plants, when hybrids are actually formed, fertility rather than sterility may be taken as the rule. This is the case with Mr. Luther Burbank's Primus berry, a cross between the Siberian raspberry (Rubus cratcogifolius) and the Californian dewberry or blackberry (Rubus ursinus). In this form the fruit excels in size and abundance either parent, and the hybrid breeds true from the seed, and ripens before either parent begins to bloom. It was fixed in the first generation, being in this regard a rare exception to the general rule of the aberration of hybrids. In this and in other respects the Primus, known to be an intentional cross of two species, behaves as though it were a distinct species. In like fashion, the Iogan berry, the product of an accidental cross at Santa Cruz, in California, of the European raspberry with the native dewberry, behaves also like a distinct species, and is also much superior in productiveness to either parent.

The fine art of the horticulturist is seen in the selection and fixing of the variations produced by crossing and hybridization. While most of the forms thus obtained are worthless, a few will show decided adrances. Often as much progress may be made in a single successful cross or hybridization as in a dozen or even a hundred generations of pure selection.

By selection alone, however, important results may be obtained, with time and patience. Given a variation in a desired direction there is perhaps no actual limit bounding the possibilities of selection unless arising through external or mechanical conditions. Thus selection for speed of horses is limited by the strength of the material of which a horse's leg is composed. The increase in the number of petals may be limited by the space on which petals can stand, and the number of leaflets in a leaf by the length of the rhachis. Still there are known cases in which a positive limit has been reached in attempting to modify organisms by selection alone.

Accidental crossing within a species may form a useful basis for selection. Thus from the seeds in a single potato ball of the Early Rose variety, crossed by insects with an unknown parent, Mr. Luther Burbank reared potatoes of many different sorts: red potatoes, white potatoes, elongate potatoes, potatoes relatively smooth and potatoes all eyes and "eyebrows." Among ail these, one form, long, white, smooth, and mealy, seemed far 
superior to the others. From the subdivision of the tubers of this seedling arose the Burbank potato, the most valuable variety in its economic relations now cultivated in America. But with the choice of this form for preservation, selection ceased, as all plants of the Burbank potato in cultivation are

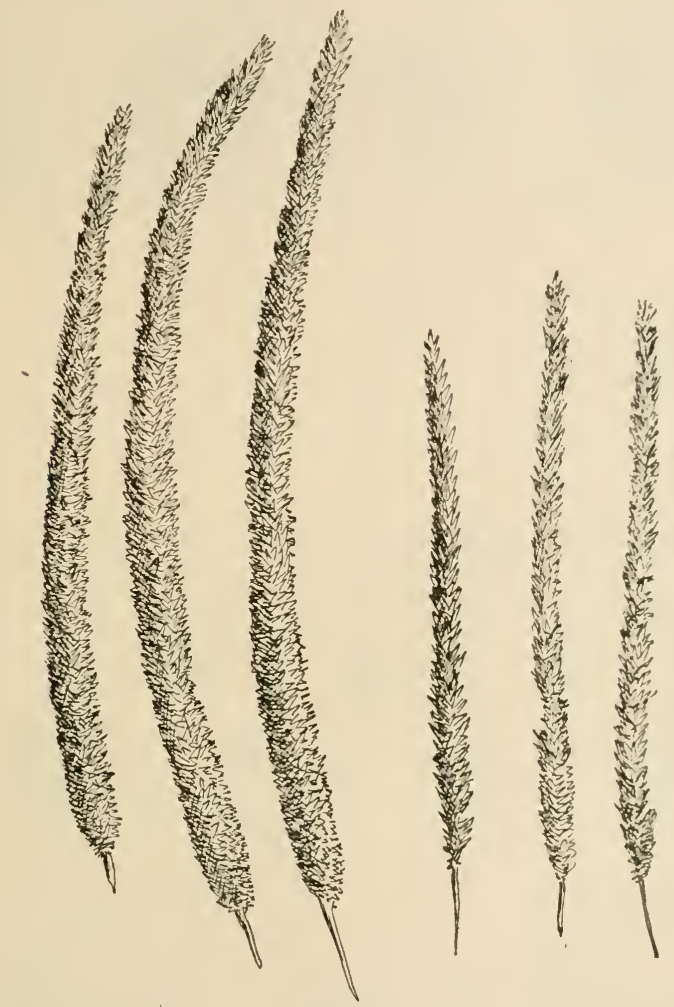

FIG. 56.-Heads of timothy, showing improvement by selection.

(After Hays.)

subdivisions of a single original plant. New forms would come from further selection of the Burbank potato seed.

As illustrations of the nore complex art of hybridization and selection, we give in the following paragraphs a brief account of the work of Luther Burbank, the most ingenious and successful of all recent experimenters in plant breeding. 
Burbank has originated and introduced a remarkable series of plums and prunes. No less than twenty varieties are included in his list of offerings, and some of them, notably the Gold,

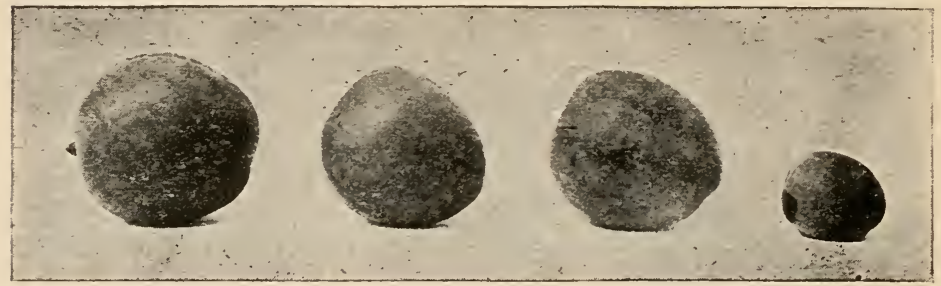

FIG. 57.-Four types of plumcot: colors, red and yellow of various shades. (Photograph by Burbank; about one-hali diameter.)

Wickson, Apple, October Purple, Chalco, American, and Climax plums and the Splendor and Sugar prunes, are among the best known and most successful kinds now grown. In addition, he is now perfecting a stoneless plum, and has created the inter-

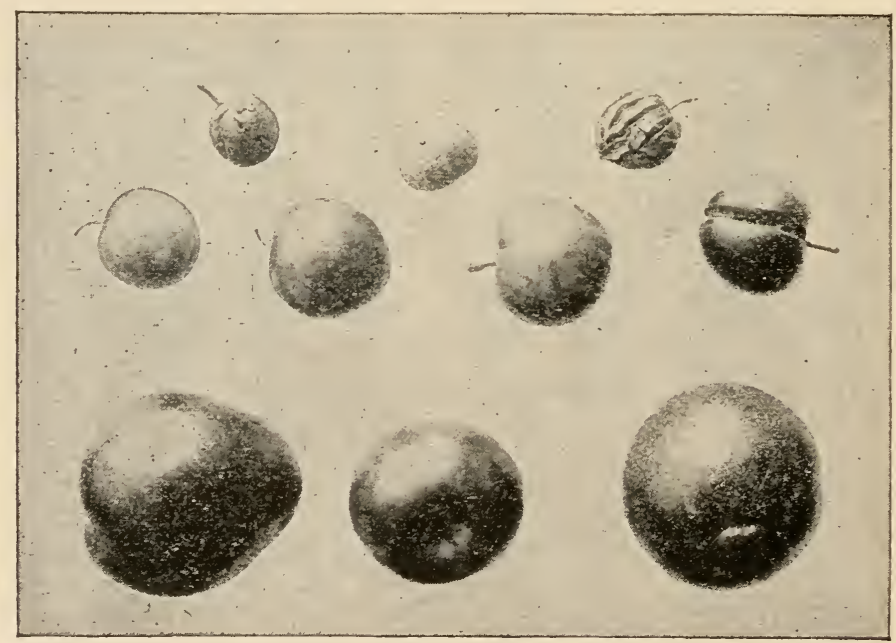

FIG. 58.- Seedlings from one hybrid plum. (After photograph by Burbank.)

esting plumeot by hybridizing the Japanese plum and the apricot. The plumcot, however, has not yet become a fixed variety and may never be, as it tends to revert to the plum. 
The stoneless and seedless pium is being produced by selection from the crossing of the descendants of a single fruit in a small wild plum with only part of a stone with the French prune; the percentage of stoneless fruits is gradually increasing with succeding generations. The sugar prune, which promises to supplant the French prune in California, is a selected product of a second or third generation varicty of the l'etit d'Agen, a very variable French prune. The Bartlett plum, cross of the bitter Chinese simoni and the Delaware, a Burbank hyloricl, has a fragrance and flavor extraordinarily like that of the Bartlett pear. The Climax is a cross of the simoni and the Japanese triflora. The Chinese simoni produces almost no pollen, only a few grains of it ever having been obtained, but these few grains have enabled Burbank to revolutionize the whole plum shipping industry. Most of Burbank's plums and prunes are the result of multiple crossings, in which the Japanese Sutsuma has played an important part. Hundreds of thousands of seedlings have been grown and carefully worked over

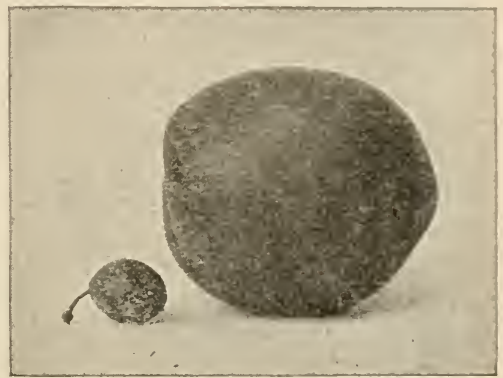

FIG. 59.-The larger plum is the direct seedling of the smaller, produeed by crossing the trifoliala (Japan) plum and the little maritima (Atlantie Coast) plum. (After photograph by Burbank.)

in the twenty years' experimenting with plums, and single trees have been made to carry as many as 600 varying seedling grafts.

Burbank has originated and introduced the Van I)eman, Santa Rosa, Alpha, P'ineapple "No. S0," the flowering Dazzle, and other quinces; the Opulent peach, cross bred from the Muir and Wager; the Winterstein apple, a seedling variety of the Gravenstein; and has made interesting, although not profitable, crosses of the peach and nectarine, peach and almond, and plum. and almond.

Next in extent, probably, to his work with plums is his long and successful experimentation with berries. This work has extended through twenty-five years of constant attention, has involved the use of forty different species of Rubus, and hats 
resulted in the origination and introduction of a score of new commercial varieties, mostly obtained through various hybridizations of dewberies, blackberries, and raspberries.

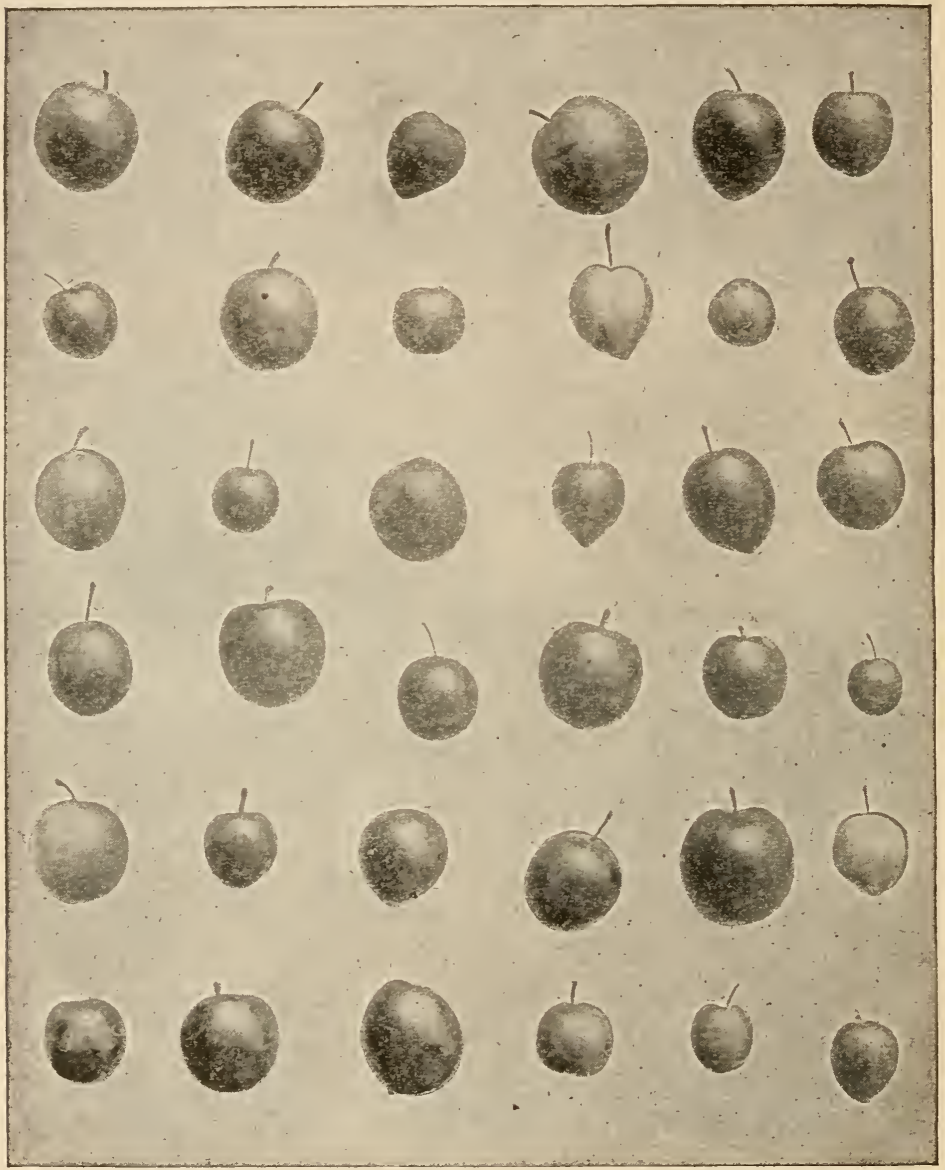

FIG. 60.--Seedlings of one kind of hybrid plum: colors almost black, deep crimson, light crimson, scarlet, deep yellow, and shades of orange and yellow, green striped, spotted and speckled; long and short stems; sweet. sour, bitter, good, bad, and indifferent, firm and soft; flesh, yellow; white; pink, red, crimson, striped, and shaded; stones of various shapes and sizes, large, small, oval, round, of different colors, some clingstones, some freestones; foliage varying as much as the rest, and grow th from short and stalky and dwarf to rampant exuberance. (Photograph by Burbank, ahout one-quarter diameter.) 
Among these may especially be mentioned besides the Primus already spoken of, the Iceberg, a cross-bred white blackberry derived from a hybridization of the Crystal White (pistillate parent) with the Lawton (staminate parcnt), with

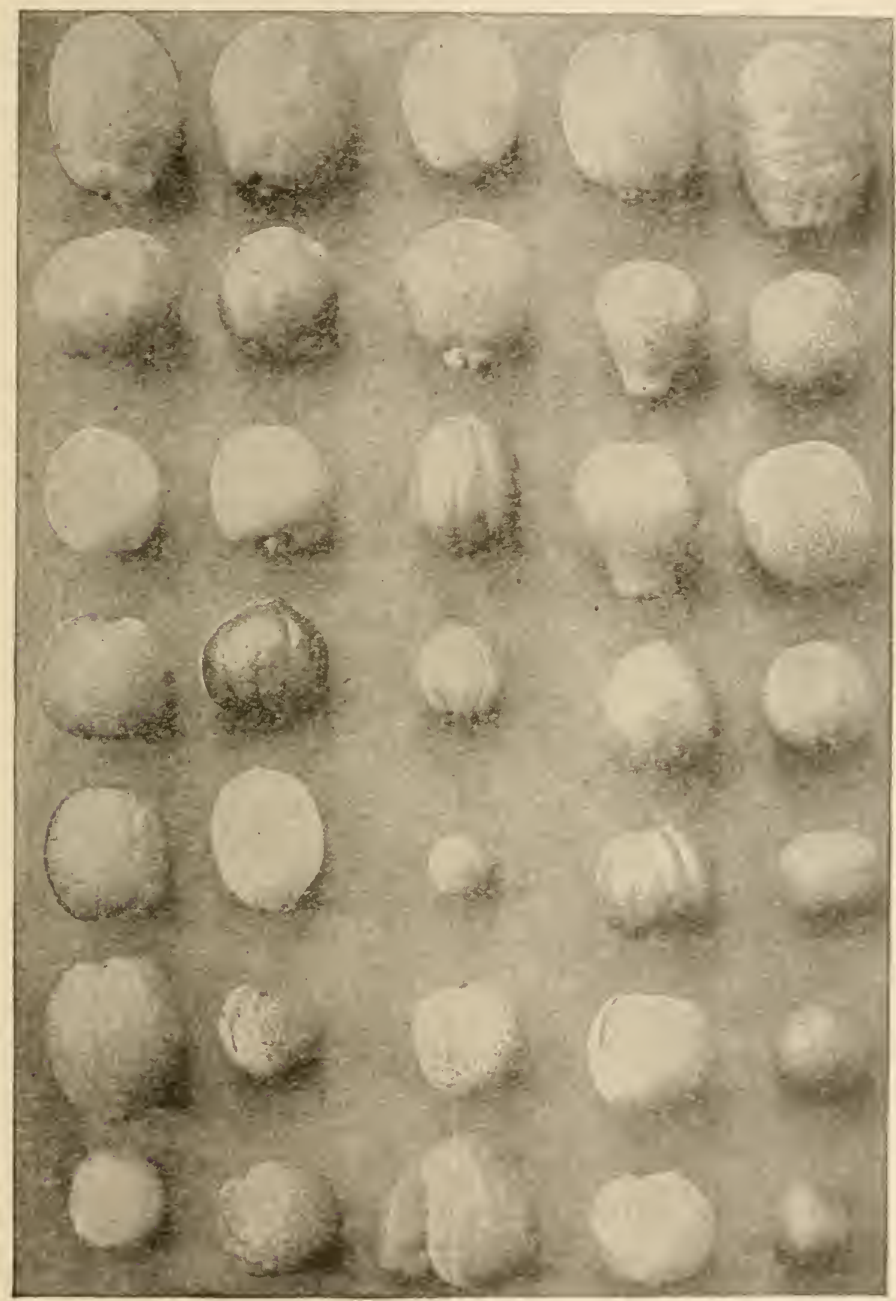

Exg. 61.-Seedlings of the Japanese qunce, Pyrus Japrmica colors, orange yellow, or almost white, with crmimson dots and splashes. (Foun photograph hy Burbank) 
beautiful snowy-white berries so nearly transparent that the small seeds may be seen in them; the Japanese Golden Mayberry, a cross of the Japanese $R$. palmatus (with small, tasteless, dingy yellow, worthless berries) and the Cuthbert, the hybrid growing into treelike bushes, six to eight feet high, and bearing great, sweet, golden, semitranslucent berries which ripen before strawberries; the Paradox, an oval, light-red berry, obtained in the fourth generation from a cross of Crystal White Blackberry and Shaffer's Colossal Raspberry. While most of the plants from this cross are partly or wholly barren, this particular outcome is an unusually prolific fruit producer.

An interesting feature of Mr. Burbank's brief account, in his

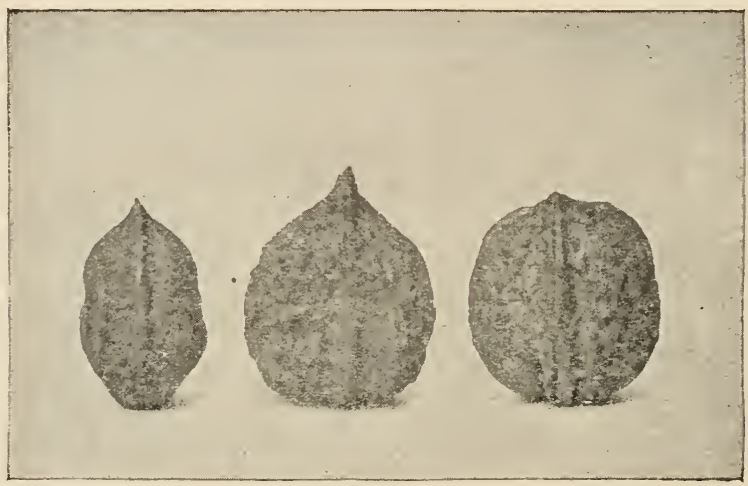

FIG. 62.- Three walnuts: at left Japanese walnut, at right English walnut, and in middle a hybrid of these two. (From photograph by Burbank.)

"New Creations" catalogue of 1894, of the berry experimentation is a reproduction of a photograph showing "a sample pile of brush 12 feet wide, 14 feet high, and 22 feet long, containing 65,000 two- and three-year old seedling berry bushes ( 40,000 Blackberry X Raspberry hybrids and 25,000 Shaffer X Gregg hybrids), all dug up with their crop of ripening berries." The photograph is introduced to give the reader some idea of the work necessary to produce a satisfactory new race of berries. "Of the 40,000 Blackberry-Raspberry hybrids of this kind 'Paradox' is the only one now in existence. From the other 25,000 hybrids two dozen bushes were reserved for further trial." 
Leaving Burbank's other fruit and berry creations unnoticed, we may refer to his curious cross-bred walnut results (Fig. 63), the most astonishing of which is a hybrid between

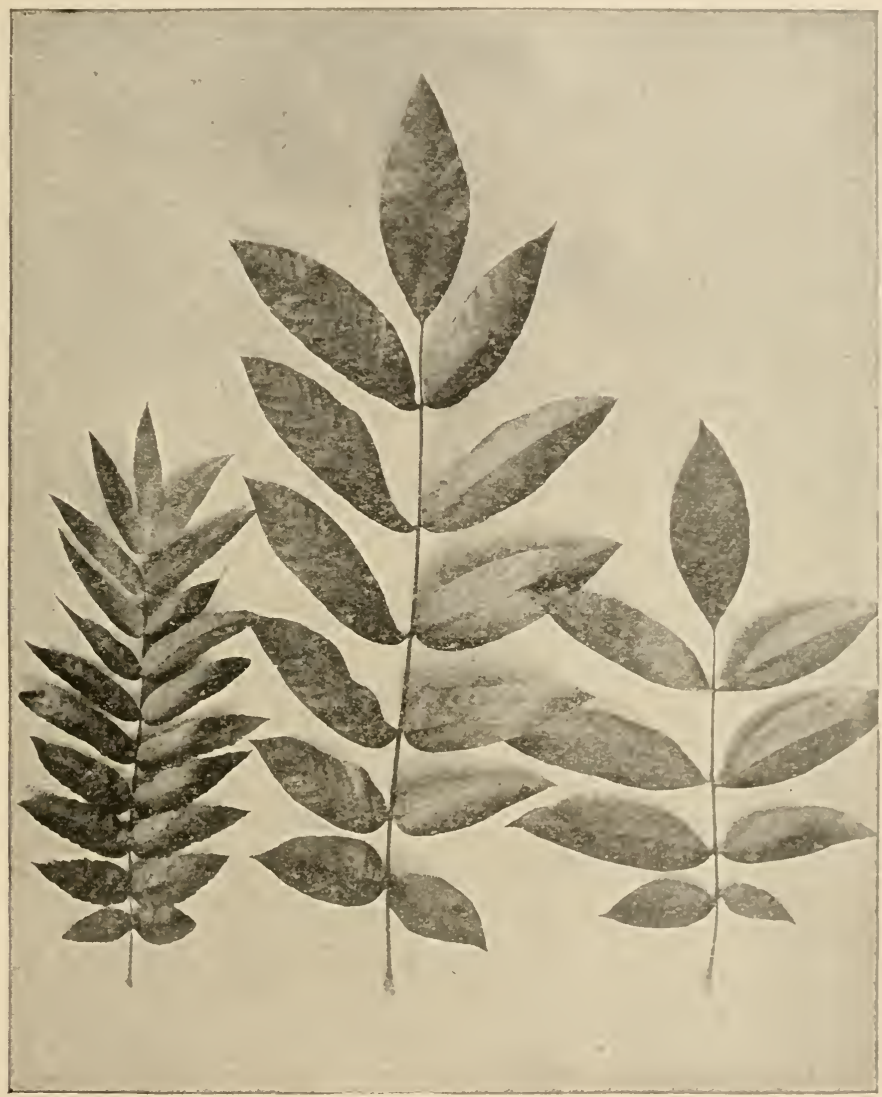

FIG. 63.-At left, leaf of English walnut, Juglans regia; at right California black walnut, Juglans californica; and in the middle a leaf of the hybrid Paradox, first generation. (From photograph by Burbank.)

Juglans Californica (staminate parent) and J. nigra (pistillate parent), which grows with an anazing vigor and rapidity, the trees increasing in size at least twice as fast as the combined growth of both parents, and the clean-cut, glossy, bright green 
leaves, from two to three feet long, having a sweet odur like that of apples. This hybrid produces no nuts, but curiously enough the result of the reverse hybridization (i. e., pollen from nigra on

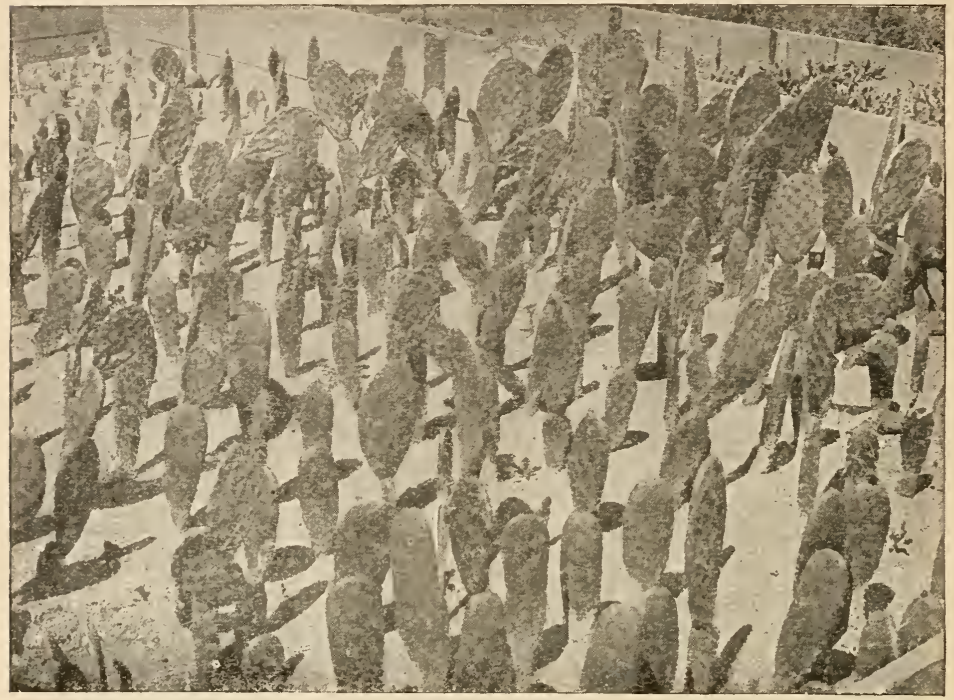

Fig. 64.-Hybrid seedling cactuses, Opuntin, after six months growth, showing numerous varieties. (From photograph by Burbank.)

pistils of Californica) produces in abundance large nuts of a quality superior to that possessed by either parent.

Of new regetables Burbank has introduced besides the Burbank and several other new potatoes, new tomatoes, squashes, ssparagus, etc. Perhaps the most interesting of his experiments in this field is his attempt, apparently destined to be successful, tc produce as spineless and spiculeless and unusually nutritious cactus (the spicules are the minute spines, much more dangerous and harder to get rid of than the conspicuous long thornlike spines) edible for stock, and indeed for man. This work is chiefly one of pure selection, for the cross-bred forms seem to tend strongly to revert to the ancestral spiny condition.

Among the many new flower varieties originated by Burbank may be mentioned the Peachblow, Burbank, Coquito, and Santa Rosa roses, the Splendor, Fragrance (a fragrant form), and Dwarf Snowflake callas, the enormous Shasta and Alaska 
daisies, the Ostrich plume, Waverly, snowdrift, and 1)ouble clematises, the Hybrid Wax Myrtle, the extraordinary Nicotunia, a hybrid between a large, flowering Nicotiana and a Petunia, several hybrid Nicotianas, a dozen new gladioli and ampelopses, several amaryllids, various dahlias, the Fire polpy (Fig. 65), (a brilliant, flame-colored variety obtained from a cross of two white forms), striped and carnelian poppies, and a blue Shirley (obtained by selection from the Crimson field poppy of Europe), the Silver Line poppy (ohtained by selection from an individual of Papaver umbrosum, showing a streak of silver

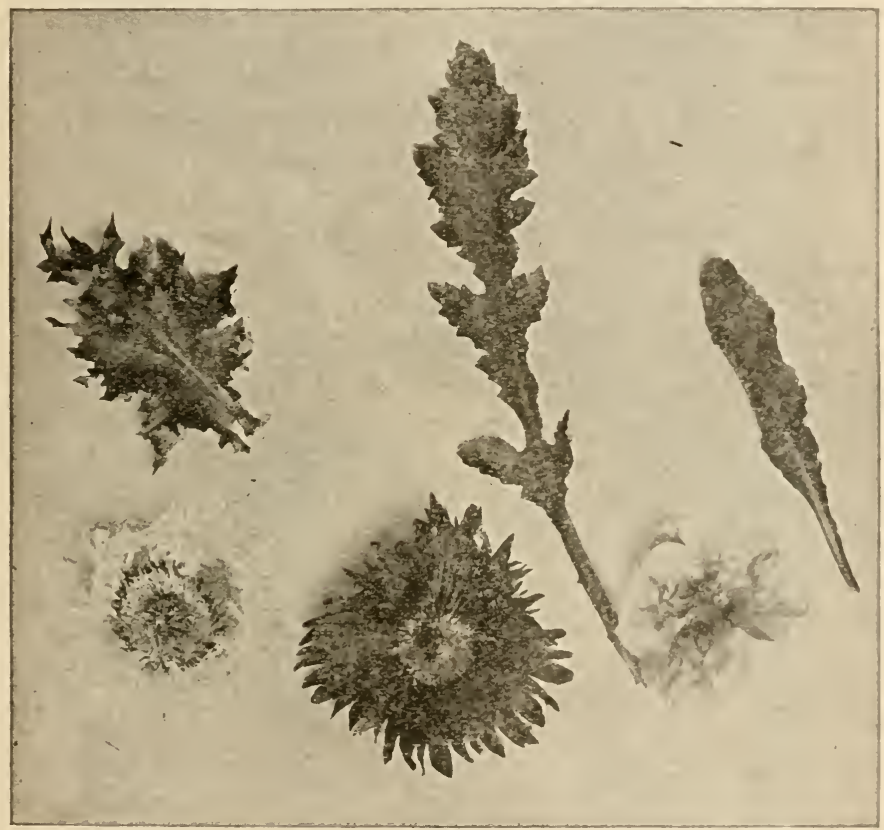

FIg. 65.-At left, leaf and flower of the pale yellow poppy, Paparer pilusum; at right leaf and flower of the snow white poppy, Paparer somniferum; and in the midlle, leaf and fire-crimson flower of the first generation hybrid of these two. (From photograph by Burbank.)

inside) with silver interior and crimson cxterior, and a Crimson California poppy (Eschscholtzia), obtained by selection from the familiar golden form.

Perhaps his most extensive experimenting with flowers has 
been done in the hybridizing of lilies, a field in which many plant breeders have found great difficulties. Using over half a hundred varieties as basis of his work Burbank has produced a marvelous variety of new forms (Fig. 66). "Can my thoughts be imagined," he says, in his "New Creations" of 1893, "after so many years of patient care and labor [he had been working over sixteen years], as, walking among them [his new lilies] on a dewy morning, I look upon these new forms of beauty, on which

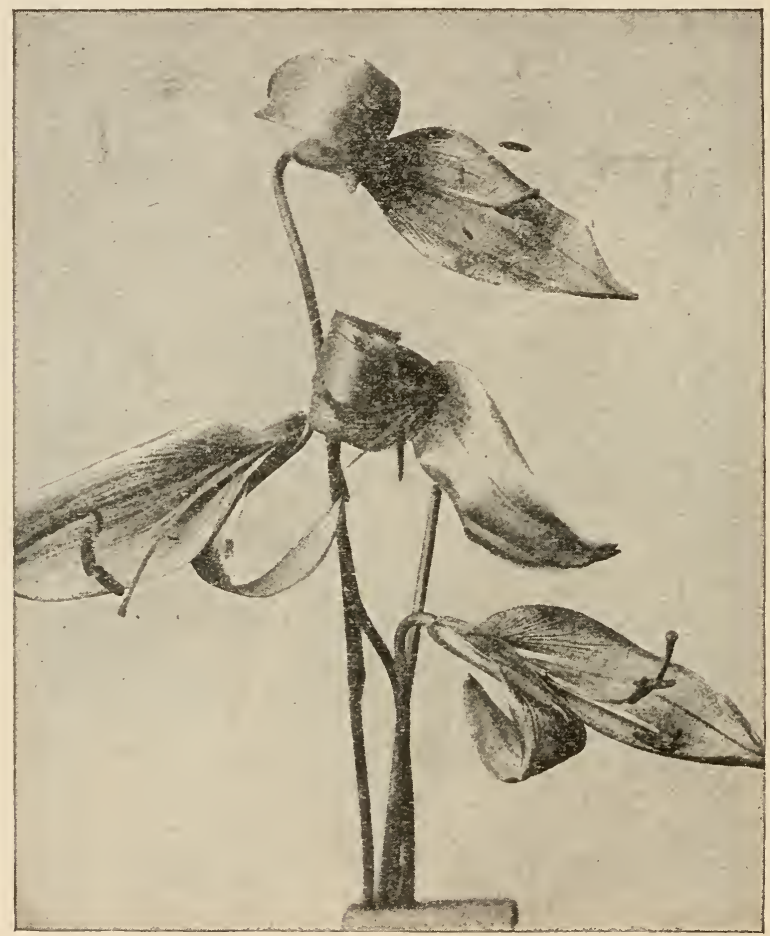

FIG. 66.-An improved seedling lily with two petals. (From photograph by Burbank.)

other eyes have never gazed? Here a plant six feet high with yellow flowers, beside it one only six inches high with dark red flowers, and further on one of pale straw, or snowy white, or with curious dots and shadings: some deliciously fragrant, 
others faintly so; some with upright, others with nodding flowers; some with dark green, wonlly leaves in whorls, or with polished light green, lancelike, seattcred leaves.

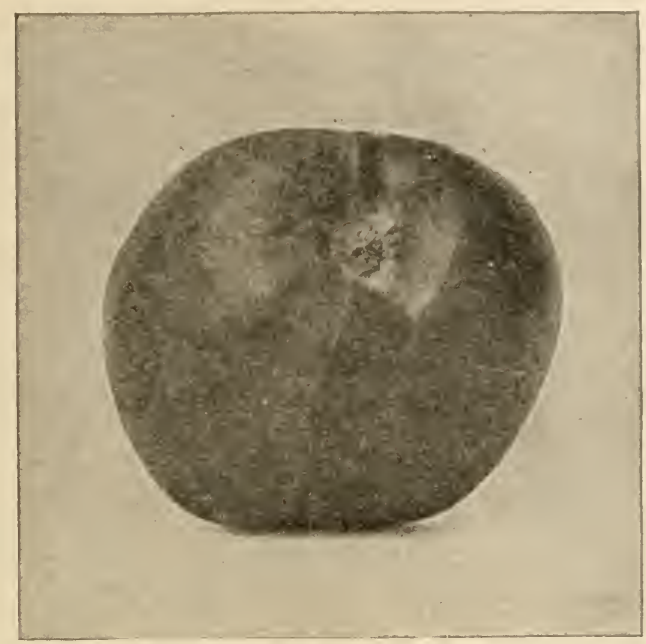

Frg. 67.-An extraordinary apple, one-half being bright red and sour, and the other half greenish yellow and sweet; note in photograph the sharp line of demarkation between the different halves. (From photograph by Burbank.)

So far no special reference has been made to the more strictly scientific aspects of Burbank's work. Burbank has been primarily intent on the production of new and impreved fruits, flowers, vegetables, and trees for the immediate benefit of mankind. But where biological experimentation is being carried on so extensively it is obvious that there musi be a large accumulation of data of much scientific value in its relation to the great problems of heredity, variation, and speciesforming. Burbank's experimental gardens may be looked on, from the point of view of the biologist and evolutionist, as a great laboratory in which, at present, masses of valuable data are, for lack of time and means, being let go unrecorded.

Of Burbank's own particular seientifie beliefs touching the "grand problems" of heredity we have space to record hut two: first, he is a thorough believer in the inheritance of acquired characters, thus differing strongly from the Weismann school of evolutionists; second, he believes in the constant 
mutability of species, and the strong individuality of each plant organism, holding that the apparent fixity of characteristics is a phenommin wholly dependent for its degree of reality on the

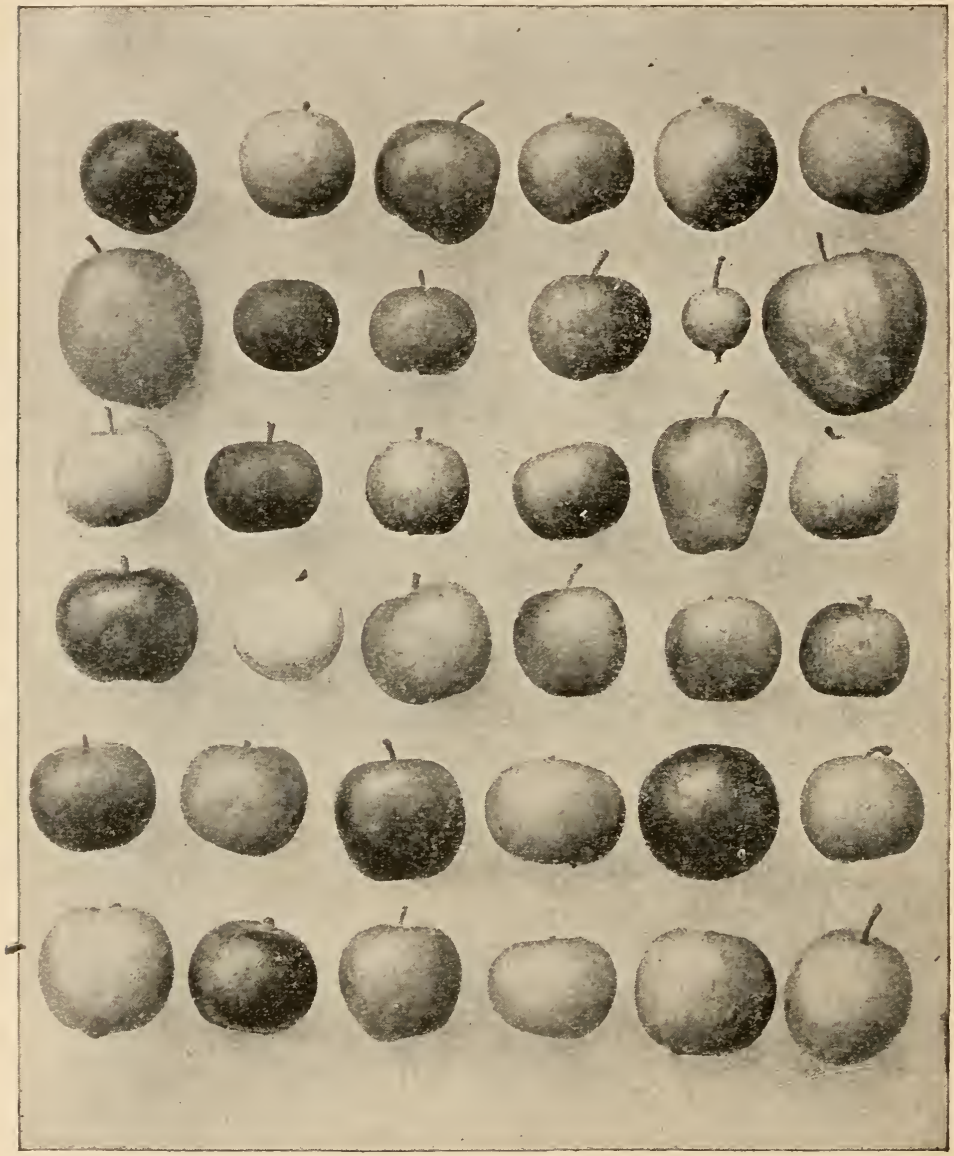

FIG. 68. - Seedlings of the Williams early apple. showing all the colors ever found in apples. (From photograph by Burbank.)

length of time this characteristic has been ontogenetically repeated in the phylogeny of the race.

In like fashion to this working with plants, breeds of animals have been established by crossing and selection with a 
view to the preservation of the best traits of both. In establishing the stock fam at Palo Alto, Lelund Stanford had the

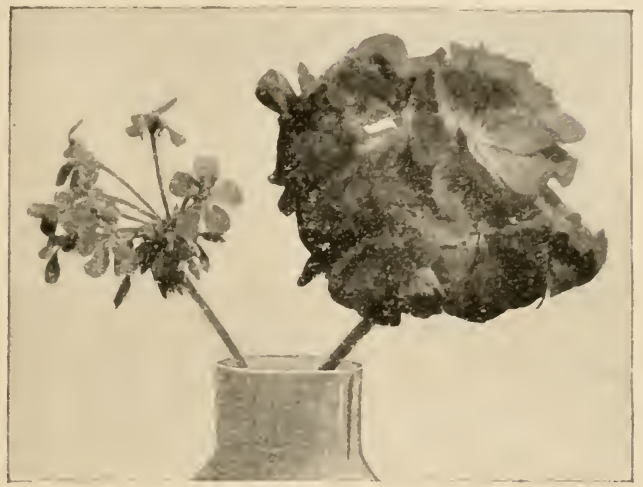

FIG. 69.-Improvement in geranium: at left, the original wild form, and at right the latest improved form. (From photograph by Burbank.)

conception of strengthening the trotting horse by a cross with the larger running horse or thoroughbred. The result was the formation of a peculiar type of horse, large, strong, supple,

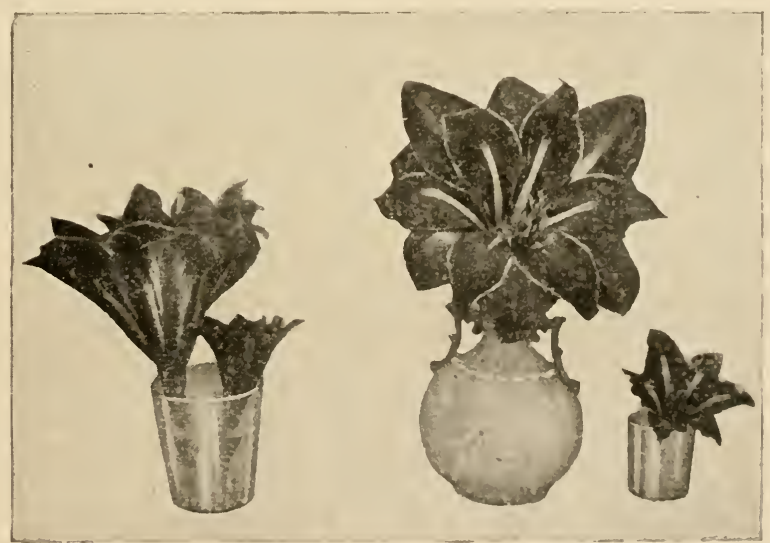

FIG. 70. - Sports found among crosised amaryllids, the size and form markedly changed; the flowers are three inches in diameter. (From photograph by Burbank.)

and intelligent, very clean of limb and sleek of coat. This group of horses held for some years the world's records for 
speed in their various classes and ages, and the experiment was in the highest degree successful. In one sense such attemnta we not experiments. The skillful breeder knows that out of the many combinations possible in crossing, some few will fall in line with his plans. He has only to preserve these, and to clinch them by in-and-in or segregated breeding to bring about a result he may have deemed possible or desirable. It is possible, by intentional selection, to turn a nonessential or race character into a selective or adaptive one. The Hampshire sheep have black ears, but by persistent selection the ears could probably be made white. Probably also the horns of the Dorsets could be bred on Hampshires by making use of possible occasional reversions to the horned stock. This result could be attained very rapidly by a crossing with Dorset stock, but this triumph of the breeder's art has rarely any homologue in the wild state or in the condition of unconscious selection.

When selection ceases, the adaptive characters are likely to decline or disappear. Under cessation of selection, called by Weismann panmixia, no premium is placed on traits of excelicnce, from the human standpoint, such as long wool, plumpness or symmetry of form; and only the purely vegetative arlvantages of the indiridual count. But while the traits of excellence disappear, the race traits or nonadaptive characters persist unchanged. A herd of neglected Hampshire sheep is still a herd of Hampshires. The black face, ears, and legs remain black, with no tendency to fade.

When the worst individuals are selected for breeding, we have the reversal of selection. A flock of Hampshire culls, feeble, loose-jointed, scant-rooled, unsymmetrical, could be used in breeding, and the adaptive characters usually sought for could be bred out of them. But they would still be Hampshires, for the hereditary characters which had persisted without the aid of selection would persist after selection ceases or even if it is reversed. When these same characters are made the object of selection, they are subject to the same laws as ordinary adaptive characters.

What is true of a breed of sheep-a product of geographical isolation with segregative breeding-is true in a general way of any wild species of animals or plants. Its adaptive characters are due to natural selection, These change more rapidly than 
the nonadaptive characters, and respond more readily to the conditions of panmixia or of reversal of selection.

In matters of breeding we must distinguish between animals actually best and those potentially best. An animal is at its actual best when in prime condition, at the prime of its life. Another of far finer heredity, of far stronger ancestry, may be at any given time actually the inferior of the first. It may be too old, too young, in too poor condition to represent its own best status.

It is generally recognized that, for all breeding purposes, the animal potentially best is superior to one which, otherwise inferior, may be actually best at the time. The tendency of heredity is to repeat the traits of the ideal individuals, which the parents ought to have been. More exactly, the tendency of heredity is to produce individuals which, under like conditions of food and environment, would develop as the parents have developed.

But it is also recognized that the actual physical condition of the parent affects the offspring. A sick mother is likely to bear an enfeebled child. Immature or declining sires do not beget offspring as strong as those begotten by them when they are in perfect strength and health. In this matter, apparently, we have to deal with two different elements, as Weismann and others have pointed out. The first is true heredity, the quality of the germ cell, which is not affected by the condition of the parent. Weak or strong, the offspring is of the same kind or type as the parentage.

The second element has been called Transmission. Its relations are with vegetative development. The embryo is ill nourished by the sick mother, and it enters on life with lowered vigor. The momentum, if we may use such a figure of speech, is reduced from the first, and the lost vitality may never be regained. The defects of the male parent are perhaps of less moment, but whatever their nature their results would be of the same kind. They would not enter into the heredity of the offspring, but they might play a large part in retarding its development. In the eategory of transmission, not of heredity, would belong the theme of Ibsen's "Ghosts" (Gjengängere), the development of softening of the brain in the son of a debauchee, the alleged cause being that the father's nervous system was vermoulu (worm-eaten), if we are to accept the ghastly drama. as an exposition of possible facts. 
The rôle played by the phenomena of transmission as distinguished from that of heredity has never been clearly ascertained. Many eminent writers ascribe to it a large importance. It is a central element in Mr. Casper Redfield's theory of heredity, and he brings together a considerable array of facts and statistics to justify his conclusions. But the value of statistics in such matters is easily exaggerated, because of the difficulty in ascertaining the real causes behind the phenomena we try to record. It is fair to say as a broad proposition that, as a sound mind requires a sound body, soundness both of mind and body are factors in giving to offspring the best possible start in life. The heredity unchanged, there is still a great value in vigor of early development.

Tre relation of these matters to the theory of organic evolution is mainly here: artificial selection as a process is of the same general character as natural selection; both represent a form of isolation or segregation, which prevents indiscriminate mating, and which holds certain groups of individuals as the agents of reproduction of the species within a given time or in $\therefore$ special area.

Artificial selection intensifies useful or adaptive characters, using these words in a broad sense. At the same time, it perpetuates a series of characters, in no wise useful, and in no fashion adaptive. These characters remain unchanged for long periods, and hence have more value in race distinction or in classification than the strictly adaptive characters have. A Southdown sheep is plump and fat, on the whole perhaps more so than any other type of sheep. Nevertheless, it is not by its plumpness that we know a Southdown. It is rather by the character of its wool, the color of its face and feet, the form o: its head. So it is with breeds and races generally. They are formed primarily by isolation in breeding, the separation of a few from the many by geographical or similar causes, by the perpetuation of the traits of these few (the "survival of the existing"), all this being modified by the new range of natural and artificial selection and the new reactions under the varying conditions of a new environment.

It interests us to know that a similar process takes place in nature. Geographical and topographical barriers are crossed in migration. These isolate a portion of a species under new conditions, with new reactions to the enviroument, and a 
new range of natural selection. Adaptive characters change rapidly, and in ways more or less parallel, with similar alterations in related species. Characters nonadaptive, often slight in appearance and bearing no relation to the life of the animal, become slowly but surely fixed as characters of the species. As two closely allied breeds of animals are never found in the same region unless purposely restrained from frec interbreceding, so two closely related species never develop in the same breeding area. As the nearest relative of some given breed of domestic animals is found in a given region nearly related geographically, so is the nearest relative to any given wild species found, in most cases, not far away. It is to be looked for on the other side of sone geographic, topographic, or climatic barrier. In other words, the interrelation of variation, heredity, geographie isolation and environmental features generally scems to be the same in the formation of domestic races as in that of the fornation of natural species. The principal new clement intordueed in the art of selective breeding is that of purposoful crossing, the removal of the barriers which separate welldifferentiated forms, for the purpose of beginning a new series to be selected toward a predetermined end.

It has been recently repeatedly stated that most races of domesticated animals or plants find their origin in a mutation or saltation of some sort. In our judgment, there is not sufficient evidence to prove this view. There are few cases of either races or species knowr to have originated in this way. That such is in fact the general law of race or species origin, we see little reason to believe. One of the few well-known illustrations of race-forming through saltation is that of the Ancon sheep. In 1791, in Massachusetts, a ran was born witl? unusually short legs. As this character was useful, preventing the sheep from leaping over stone walls, the owner of this sheep used the ram for breeding purposes, and suceeeded in isolating a short-legged strain of sheep known as the Aneon sheep. So far as known to us, this type of sheep differed in this character alone from the common sheep of Connecticut. With the later advent of the more heary-wooled, and therefore more profitable, Merino, the Ancon sheep disappeared. A recent similar case of race origin from a prepotent sport is that of the polled Herefords arising in Kansas from a hornless Hereford bull. 


\section{VARIOUS THEORIES OF SPECIES-FORMING AND DESCENT CONTROL}

The four factors named, variation, inheritance, selection, and separation, must work together in order to form different species. It is impossible to think that one of these should work by itself or that one could be left aside.-Ortmann.

As mentioned in the introductory chapter on the factors of evolution (Chapter IV), and as referred to several times in the chapter on natural selection, the factor of the segregation or isolation of groups of individuals must be taken into account in any discussion of species-forming causes. This factor has long been recognized by biologists, that phase of it, and undoubtedly the most important of its several phases, called geographic or topographic isolation or segregation being very clearly stated and its importance emphasized by Moritz Wagner in 1868. Alfred Russel Wallace gave much attention, in his years of active investigation, to the general subject of geographical distribution, and was a pioneer in calling the attention of naturalists to the great significance, in the light of the evolution theory, of the facts of the geographical distribution of both animals and plants. To-day, especially among American biologists, the factor of topographic segregation is recognized as one of the most important of species-molding influences. Indeed it seems self-evident to many naturalists that natural selection is impotent as an actual cause of species-forming without some effective sort of isolation factor to assist it. Because of the importance in the eyes of present-day naturalists of the geographic isolation factor we have given (Chapter VIII), a brief special discussion of this factor. In addition, in Chapter XIV, will be found a discussion of the more general subject of geographical distribution. 
But it is conceivable that isolation may be effected in other ways than by actual segregation or geographic separation of individuals. Anything that could lead to exclusive or discriminate breeding among certain individuals of a species would result in the isolation of these individuals from the rest of the species as effectively as their actual separation from others by a geographic or topographic barrier. Now there are various influences or conditions that might conceivably bring alosut such a state of affairs, and some of these have been actually observed to exist. It is of interest to note that this kind of isolation differs, in a rather important way, from purely geographic isolation in that the latter is almost sure to be wholly indiscriminate as regards the individuals comprised in an isolated group, while the former, which has been called physiological isolation, will be discriminate. That is, there will be a structural or physiological peculiarity common to all the "isolated" individuals, it being by virtue of this common peculiarity (something not common to other individuals of the same species) that the isolation actually exists.

Romanes has been the chief champion of the physiological isolation factor. And we may advantageously refer directly to his writings for a specific statement of different forms or phases of this kind of isolation. In "Darwin and After Darwin," III, p. 7 et seq., he writes:

"Now the forms of discriminate isolation, or homogamy, are very numerous. When, for example, any seetion of a species adopts somewhat different habits of life, or occupies a somewhat different station in the economy of nature, homogamy arises within that section. There are forms of homogamy on which Darwin has laid great stress, as we shall presently find. Again, when for these or any other reasons a section of a species becomes in any small degree modified as to form or color, if the species happens to be one where any psychological preference in pairing ean be exercised-as is very generally the case among the higher animals-exclusive breeding is apt to ensue as a resuit of such preference; for there is abundant evidence to show that, both in birds and mammals, sexual selection is usually opposed to the intercrossing of dissimilar varicties. Once more, in the case of plants, intererossing of dissimilar varieties may be prevented by any slight difference in their seasons of flowering, of topographical stations, or even, in the ease of flowers which depend on insects for their ferti- 
lization, by differences in the instincts and preferences of their visitors.

"But, without at present going into detail with regard to these different forms of discriminate isolation, there are still two others, both of which are of much greater importance than any that I have hitherto named. Indeed, these two forms are of such immeasurable importance that were it not for their virtually ubiquitous operation, the process of organic evolution could never have begun, nor, having begun, continued.

"The first of these two forms is sexual incompatibility-either partial or absolute-between different taxonomic groups. If all hares and rabbits, for example, were as fertile with one another as they are within their own respective species, there can be no doubt that sooner or later, and on common areas, the two types would fuse into one. And similarly, if the bar of sterility could be thrown down as between all the species of a genus, or all the genera of a family, not otherwise prevented from intercrossing, in time all such species, or all such genera, would become blended into a single type. As a matter of fact, complete fertility, both of first crosses and of their resulting hybrids, is rare, even as between species of the same genus; while as between genera of the same family complete fertility does not appear ever to occur, and, of course, the same applies to all the higher taxonomic divisions. On the othe ${ }^{\circ}$ hand, some degree of infertility is not unusual as between different varieties of the same species; and, wherever this is the case, it must clearly aid the further differentiation of those varieties. It will be my endeavor to show that in this latter connection sexual incompatibility must be held to have taken an immensely important part in the differentiation of varieties into species. But meanwhile we have only to observe that wherever such incompatibility is concerned, it is to be regarded as an isolating agency of the very first importance. And as it is of a character purely physiological, I have assigned to it the name Physiological Isolation; while for the particular case where this general principle is concerned in the origination of specific types: I have reserved the name Physiological Selection."

If the factors of variation, heredity, natural selection, and isolation are, in the minds of most naturalists, the chief factors in species-forming and descent control, and a combination of these factors is, in the belief of these same naturalists-the socalled selectionists or Neo-Darwinians-a sufficient causal explanation of organic evolution, there are many other natural- 
ists who have no such high esteem of the value of natural selection. These believe, variously, that $(a)$ to the selection factors other auxiliary or helping ones are to be added, or (b) that various other factors are equally potent in species-forming, or $(c)$ that these other factors are the more important ones, or finally $(d)$ that the selection factors are of no importance at all, that is, have no reality. Before Darwin, the French naturalist Lamarck had clearly enunciated an explaining theory of species transformation, and there are to-day many naturalists who believe that the Lamarckian explanation, or its fundamental assumption, is true, or, at least, that it is based on the more important and effective factors in evolution. These naturalists have been called Neo-Iamarckians. Some of these have formulated theories of their own based on Lamarckian fundamentals, but developed in directions more or less obviously away from characteristic Lamarckism.

Still other fundamental causal factors than the Darwinian ones of selection and the Iamarckian ones of accumulated effect of use, disuse, and functionsl stimulation are assumed in certain other theories of species change and general evolution. Nägeli, a botanist and natural philosopher, believed in a special inherent vitalistic principle or force in living matter which tends to produce progressive differentiation and evolution. Von Kölliker, Korschinsky, and de Vries believe that species-forming occurs by definite sudden small (or larger) fixed changes or mutations, so that for them a mutational or discontinuous variation is the fundamental causal factor in species transformation. Numerous paleontologists believe that variation follows determinate lines in its occurrence, so that evolution is orthogenetic, with its lines primarily fixed by determinate variation.

We may then examine briefly some of the more important special theories or groups of theories put forward by biologists either as auxiliary and subordinate to the more generally known Darwinian theory, or as alternative with or substitutes for this theory.

First to be mentioned should be the transmutation theory of Lamarck. In its simplest expression it is, that every individual organism is, throughout its lifetime, reacting to environmental stimuli and conditions in such ways as to change its structure and its habits in greater or less degree from the structure and habits of its parents and ancestors, this change 
coming about specifically from the varying effects of use or disuse of parts, and the functional stimulation of other parts in response to such extrinsic conditions as light, contact, temperature, pressure, color, etc., etc. The changes effected will, in the nature of things, be essentially adaptive. Now, these adaptive changes, these variations, or new characters acquired during the lifetime of the individual will be, in Lamarck's belief, inherited, if not in full, at least in partial degree, by the offspring. These in turn submitted to similar or to different environmental influences will continue the changes either cumulatively or diversely. By this steady direct change and adaptation to environment the species is ever modifying and transforming. Evolution marches, and marches adaptively and advantageously.

But modern naturalists find a most unfortunate impediment to this simple, direct, and sufficient explanation of speciesforming and evolution in the apparent untruth of the assumption that the characters acquired by an individual in its lifetime are transmitted by inheritance to its young. This question, fundamental to the Lamarckian theory, of the inheritance or noninheritance of acquired characters has long been one of the most hotly debated points in evolution biology. As we have devoted a number of pages to its particular discussion in our later chapter on heredity (Chapter $\mathrm{X}$ ), we need not anticipate that discussion here. It is sufficient to say that as far as scientific proof, that is, evidence from actual observation and experiment, goes, those naturalists led by Weismann, who deny this inheritance, have at present distinctly the better of the argument.

The orthogenetic evolution theories of various authors, based upon the assumed occurrence of variations in determinate lines or directions (a restricted and determinate variation as compared with the nearly infinite, fortuitous, and indeterminate variation assumed in the selection theory), are of several types. The mention of two will reveal pretty well the more important characters of all. Not a few biologists have always believed in the existence of a sort of mystic, special vitalistic force or principle by virtue of which determination and general progress of evolution is chiefly fixed. Such a capacity, inherent in living matter, seems to include at once possibility of specific adaptation and the possibility of progressive or truly evolutionary change. Not all evolution is in a single direct line, to be 
sure; ascent is not up a single ladder or along a single genealogical branch, but these branches are few (as indeed we actually know them to be, however the restriction may be brought about) and the evolution is always progressive, that is, toward what we, from an anthropocentric point of view, are constrained to call higher or more ideal life stages and conditions.

Other naturalists also seeming to see this course of determinate or orthogenetic evolution, but not inclined to surrender their disbelief in vitalism, in forces over and beyond the familiar ones of the physicochemical world, have tried to adduce a definite causomechanical explanation of orthogenesis. The best and most comprehensible types of this explanation are those essentially Lamarckian in principle, in which the direct influence on living matter of environmental conditions, the direct reactions of the life stuff to stimuli and influences from the world outside, are the causal factors in such an explanation. But while every naturalist will grant that such factors do change and control in considerable degree the life of the individual, most see no mechanism or means of extending this control directly to the species.

The stumbling block of heredity, the means and mode of inheritance, as we so far know them, are directly in the way of any general acceptance of such a theory of evolution under the direct control of such "primary factors of life." Ontogenetic species, that is, conditions of structure and habit common to many individuals of one kind, the conditions due to sameness of intrinsic and extrinsic factors in development, constitute a category of organisms which at any given time and place seem very real, and are for the moment truly real. But their environment is remaining fairly constant. We speak easily of the flux of Nature: her everchangingness. And in the large we are speaking only of the truth. But during our brief period of observation of the few generations of this or that kind of animal or plant that comes under our eyes and microscopes, the nature environing these generations may be nearly uniform. What are the changes in the desert in a score or a hundred or a thousand of years? What changes in life conditions on the barren storm-swept peaks of the mountain ranges? What in the waters of that brackish bay or sweet-water lake apart from the paths of man? Ontogenetic species have a seeming of reality, but so far as our present knowledge goes it is only a 
seeming: reality vanishes with the death of the individual: their young can perpetuate their specific peculiarities only if the environmental conditions of their development are identical with those which attended the growing up of their parents. Variations in this environment will determine variations in them, and their father's kind will exist no more.

The authors of this book believe that more characters of species than are commonly thought are of this shifty, ephemeral character; that not a few so-cilled true species are only ontogenetic species held for a number of generations true to a type simply because the environment, the extrinsic factors in the development of all the individuals in these successive generations, are the same. But how these individual characteristics and changes can be put into the heredity of the race we do not understand. "There is no fixity in species other than that due to the long-repeated ontogenetic reiteration of this or that characteristic," says Luther Burbank. And he speaks from the conviction forced on him through thirty years of the closest sort of observation and personal experience of the life of plants. And yet, however strongly our own minds respond to a desire to believe this-it would be so clarifying-the obstinate "no mechanism" objection stands boldly up to check our sympathetic reasoning.

Finally we should refer to the theories of heterogenesis or species-forming by mutations or saltations, which have been proposed at various times as a substitute for the theory of species-forming by the gradual transformation through selection. During the discussion in the first few years after the appearance of Darwin's "Origin of Species," the German zoölogist von Kölliker expressed the belief that the change from species to species would probably be found to be more sudden and more distinctive than Darwin's theory permitted one to assume. Later, the Russian botanist Korschinsky, on a basis of general observation and some not very extensive personal experimentation, definitely formulated a theory of speciesforming by heterogenesis which he placed strongly in contrast with Darwin's theory of gradual transformation by selection, which later theory he claimed should be wholly given up. But not until the publication of de Vries's work, Die Mutations. theorie, in which are recorded the results of close personal observation and experimentation for twenty years on race and 
species-forming in plants has the theory of species-forming by mutations, or sudden fixed changes (lesser or greater) had any considerable adoption or even general attention.

At the present moment, probably because of a strong reaction against the too blind acceptance and general overemphasis of the selection doctrines, and because, too, of the unusually extensive character of de Vries's experimentation and observation, and his trenchant criticism of the weak places in the other theories, with the generally weighty character of his work and reputation, because of all this the theory of speciesforming by nutations has at the present moment a fairly large body of adherents among reputable biologists. And yet the actual evidence of tested observation on which the theory rests is curiously meager. One hastens to admit, however, that similar evidence for the theory of direct speries-forming by selection is also meager. While apparently no one has ever seen a case of species-making by the natural selection of slight fluctuating variations, de Vries seems to be almost the only one who has observed actual cases of species-making by heterogenesis, and he has seen very few. And in the nature of things, the opportunities for this kind of evidence, that is, that of actual observation, ought to be much larger in the case of heterogenesis than in that of general transformation by the selection of slight variations. An account of the exact character of the de Vriesian mutations is included in our later chapter on variation and mutation. Our readers should realize, that however much they may see of this theory in present-day popular scientific literature, and however strongly the case may be put in favor of the mutation theory of species origin, this theory is not accepted by the great body of biologists as entitled to replace the Darwinian theory.

We may close this chapter with a reference to a pregnant sentence of the American paleontologist, Osborn, in a lecture entitled "The Unknown Factors of Evolution": "The general conclusion we reach from a survey of the whole field is that for Buffon's and Lamarck's factors we have no theory of heredity, while the original Darwinian factor, or Neo-Darwinism, offers an inadequate explanation of evolution. If acquired variations are transmitted, there must be, therefore, some unknown principle in heredity; if they are not transmitted, there must be some unknown factor in evolution." Our present plight seems 
to be exactly this: we cannot explain to any general satisfaction species-forming and evolution without the help of some Lamarckian or Eimerian factor; and on the other hand, we cannot assume the actuality of any such factor in the light of our present knowledge of heredity. The discovery of the "unknown factors of evolution" should be the chief goal of all present-day biologic investigation. 


\section{CHAPTER VIII}

\section{GEOGRAPHIC ISOLATION AND SPECIES- FORMING}

"For me, it is the chorology of organisms, the study of all the important phenomena embraced in the geography of animals and plants, which is the surest guicle to the knowledge of the real phases in the process of the formation of species."-Moritz WAGNer.

A FLOOD of light may be thrown on the general problem of the origin of species by the study of certain evidence as to the ${ }^{1}$ actual origin of species with which we may be familiar, or of which the actual history or the actual ramifications may in some degree be traced.

In such cases, one of the first questions naturally asked is this: Where did the species come from? Migration forms a large part of the history of any species or group of forms. The fauna of any given region is made up of the various species of animals living naturally within its borders. The flora of a region is made up of the plants which grow naturally within its limits. Of all these, animals and plants, the inhabitants of most regions are apparently largely migrants from some other region. Some have entered the region in question before acquiring their present specific characters; others come after having done so. Which of these conditions apply to any given case can sometimes be ascertained by the comparison of the individuals along the supposed route of migration.

Thus, Dr. C. Hart Merriam has undertaken to show the actual origin of nine species of Californian chipmunks (Eutamias) by an elaborate study of their distribution, adaptations, and transformations. He finds them closely related to one another,

${ }^{1}$ A paper published in "Science," 1906 , by the senior $2 u$ thor, under the title "The Actual Origin of Species," has been freely quoted from in this chapter. 

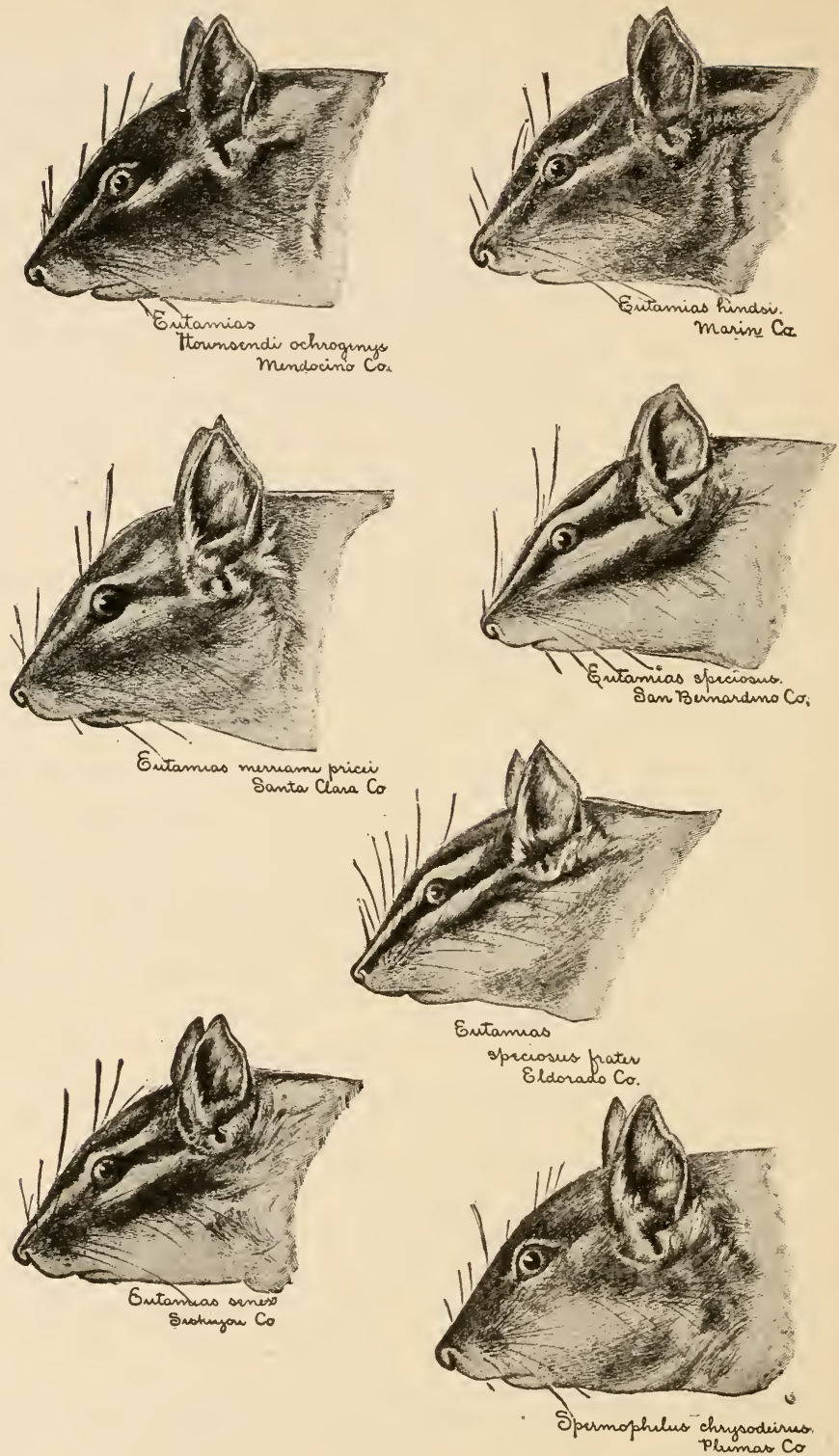

Frg. 71.-Some chipmunks of California, showing distinct species produced through isolation. (From nature, by William Sackston Atkinson.) 
but not derived from one another by direct lines of descent. A closer study indicates that some of them " "ame from closely related forms in remote geographic areas, others from anteredent forms now extinct, and not more than three or four from specics still inhahiting the region."

Thə nature of any fauna bears an immediate relation to the barriers, geographic, climatic, topographic, or bionomic, which may form its boundaries. IBy bionomic barriers we mean any condition of any sort which may check free interbreeding, or which may tend to rause divergence within a species. A thickly peopled level area may be in this sense a barrier, because it prevents the animals on the one side of the area from interbreeding with those on the opposite side. If the two extremes have diverged to become different species, the individuals in the middle area, whose presence in a sense constitutes the bionomic barrier, are usually variously intermediate in the characters and habits which they possess.

Whenever the individuals of a species move evenly over an area, its members freely interbreeding, the character of the species remains substantially uniform. Whenever freedom of movement and consequent freedom of interbreeding is checked, the character of the species is rapidly altered. It is changed even though external conditions seem to be absolutely identical on botl sides of the barrier, and if there is no visible distinction in the original stock on the two sides. Presumably, there are subtle differences in the environment, producing changes in the process of selection and adaptation. Doubtless, there are differences equally subtle produced by the processes of variation and their repetition by inheritance.

The pregnant phrase of Dr. Coues applies in these cases: "Migration holds species true: localization lets them slip." In other words, free interbreeding swamps incipient lines of variation, and this in almost every case. On the other hand, a barrier or check of any sort brings a certain group of individuals together. These are subjected to a selection different from that which obtains with the species at large, and under these conditions new forms are developed. This takes place rapidly when the conditions of life are greatly changed, so that a new set of demands is made on the species, and those individuals not meeting it are at once destroyed. The process is a slow one, for the most part, when the barrier in question interrupts the 
flow of life without materially changing its conditions. But this is practically a universal rule: A barrier which prevents the intermingling of members of a species will with time alter the relative characters of the groups of individuals thus separated. These groups of individuals are incipient species, and each may become in time an entirely distinct species if the barrier is really insurmountable. In the great water basin of the Mississippi, many families of fish occur and very many species are diffused throughout almost the whole area, occurring in all suitable waters. Once admitted to the water basin, each one ranges widely and each tributary brook has many species. In the streams of California, mostly small and isolated, the number of genera or families is much smaller. Each species, unless running to the sea, has a narrow range, and closely related species are not found in the same river. The fact last mentioned has a very broad application and may be raised to the dignity of a general law of distribution.

Given any species in any region, the nearest related species is not likely to be found in the same region nor in a remote region, but in a neighboring district separated from the first by a barrier of some sort, or at least by a belt of country, the breadth of which gives the effect of a barrier.

Always the species nearest alike in structure are not found together nor yet far apart, and always a check to interbreeding lies between. Where two closely allied forms are not found to intergrade, they are called distinct species. If we find actual intergradation, the occurrence of specimens intermediate in structure, the term subspecies is commonly used for each of the recognizable groups thus connected.

Widely distributed across the United States and from southern Canada to Arizona, we have the yellow warbler, Dendroica cestiva. This bird is chiefly yellow, olive on the back with chestnut streaks on the sides, the tail feathers colored like the body, and without the white spot on the outer feathers shown in most of the other wood warblers composing the genus Dendroica.

The yellow warbler throughout its range is very uniform in size and color. Its nearest relative differs in having a shade less olive on the back and the brown streaks on the sides narrower. This form is found in the Sonoran region, and, as along the Rio Grande it intergrades with the first, it is called 
a subspecies, Dendroica cestiva sonorana. Further south, in central Mexieo, this form luns larger $\mathrm{i}_{\mathrm{i}}$ size and is recorded as Dendroica astiva dugesi. Northward, through to Alaska, we have an ally of the parent bird, but smaller and still more greenish. 'This is Dendroica astiva rubiginosa.

In the West Indies, the golden warblers migrate not from noth to south, but from the shore to the mountains, and, possibly in consecpuence of the loss demand of flight, the wing is shorter and more rounded, while the tail is longer. As these forms do not clearly intergrade with those of the mainland, and, for the most part, not with each other, they are held to represent a number of distinct species, although doubtless derived from the parent stock of Dendroica astiva. Some of these West Indian forms are relatively large, the wing more than five inches long, and the longest known of these, the type of the species for this reason, found in Jamaica, is called I)endroica petechia. On the island of Grand Cayman is a similar bird, a little smaller, Dendroica auricapilla. Of a deeper yellow than petcehia, and equally large, is the golden warbler of the Lesser Antilles ranging from island to island, from Porto Rico to Antigua. This form, first known from St. Bartholomew, is Dendroica petechia bartholemica. A smaller bird, a little different in color, takes its place in the Bahamas. This is Dendroica petechia flaviceps.

In Cuba, the golden warbler is darker and more olive, with other minor differences from the form called bartholemica, of which it may be the parent. This is Dendroica petechia gundlachi. A similar bird, but with the crown distinctly chestnut, is Dendroica petechia aureola, the golden warbler of the Galapagos and Cocos Islands, off the coast of Ecuador and Peru. Scattered over other islands are smaller golden warblers with the wing less than five inches long, and with the crown tawny red, as in aureola. These are known collectively as Dendroica ruficapilla, the type being from Guadeloupe and 1)ominica. More heavily streaked, with the crown darker in color, is the rolden warbler of Cozumel, Dendroina ruficapilla fluvivertex, .nd with very similar but with darker crown is Dendroica ruficapilla flavida, of the island of st. Andrews. Always, the nearest form lies across the barrier, and among these island forms the chief barrier is the sea. With a darker chestnut crown is Dendroica ruficapilla rufopileata, of the island of 
Curaçao, and still darker bay is the crown of Dendroica ruficapilla capitalis, the golden warbler of the Barbadoes.

Still other golden warblers exist, with the chin and throat chestnut as well as the crown. One of these, olive green on the back, is Dendroica rufigula, of Martinique. The others are more yellow. One of these, with the sides heavily streaked, inhabits the isthmus region, Dendroica erythacoides, called a distinct species, because no intergradations have been made out. Another, more faintly streaked, replaces it on the Atlantic coast from Yucatan to Costa Rica, Dendroica bryanti, while the Pacific coast, from Sinaloa to Costa Rica, has another form, with still fainter narkings, Dendroica bryanti castaniceps. An extreme of this form with the throat and breast tawny, but not the crown, is found in Jamaica again and is known as Dendroica eoa. In this case, which is one typical of most groups of small birds, the relation of the species to the barriers of geography is so plain as to admit of no doubt or question.

Given the facts of individual fluctuation and of heredity, it is manifest that while natural selection may produce and enforce adaptation to cunditions of life, the traits which distinguish these species bear little relation to utility. The individuals which, separated from the main flock, people an island, give their actual traits to their actual descendants, and the traits enforced by naturil selection differ from island to island. If external conditions were alike in all the islands the progress of evolution would perhaps run parallel in all of them, and the only differences which would persist would be derived from differences in the parent stock. As some difference in environment exists, there is a corresponding difference in the species as a result of adaptation. If great differences in conditions exist, the change in the species may be greater, mor rapidly accomplished, and the characters observed will bear a closer relation to the principle of utility.

Doubtless, wide fluctuations or mutations in every species are more common than we suppose. With free access to the mass of the species, these are lost through interbreeding. Isolate them, as in a garden, or an enclosure or on an island, and these may be continued and intensified to form new species or races. Any breeder or any horticulturist will illustrate this.

It is not claimed that species are occasionally associated with physical barriers, which determine their range, and which 
have been factors in their formation. We claim that such conditions are virtually universal among species as they exist in nature. When the geographical relations of the origin of a species cannot be shown it is usually because the species has not been critically studied, from absence of material or from absence of interest on the part of naturalists. In a few eases, a species ranges widely over the earth, showing little change in varying conditions and little susceptibility to the effects of isolation. In other cases, there is some possibility that saltations, or suddenly appearing characters, may give rise to a new species within the territory alrealy occupied by the parent form. But these cases are so rare that in ornithology, mammalogy, herpetology, conchology, and entomology, they are treated as negligible quantities.

One of the most successful workers in this field is Rev. John T. Gulick, whose studies of the localization of species and subspecies of land snails in Oahu Island (Hawaii) have become classical. According to Mr. Gulick, the land snails of the wooded portion of Oahu have become split up into about 175 species of land shells represented by 700 or SCO varieties. He frequently finds a genus represented in several successive valleys by allied species, sometimes feeding on the same and similar plants. In every case, the valleys that are nearest to each other furnish the most nearly allied forms, and a full set of the varieties of each species presents a minute gradation between the more divergent types found in the more widely separated localities. Similar conditions are recorded among the land snails in Cuba and in other regions. In fact, on a smaller scale, the development of species of land and river mollusks has everywhere progressed on similar lines with that of birds and fishes. To recognize isolation as practically a necessary condition in the subdivision of species need not necessarily eliminate or belittle any other factor. Isolation is $\therefore$ condition, not a force. Of itself it can do nothing. Species change or diverge with space and with time: with space, because geographical extension divides the stock and brings new conditions to part of it; with time, because time brings always new events and changes in all environment. The beginning of each species must rest with its variability of individuals.

One of the most remarkable cases of group evolution is 
that of the song birds of Hawaii which constitute the family of Drepanidæ. In this family are about forty species of birds, all much alike as to general structure, but diverging amazingly from each other in the form of the bill, with, also, striking differences in the color of the plumage. In almost all other families of birds the form of the bill is very uniform within the group. It is correlated with the feeding habits of the bird, and these in most groups of wide range become nearly uniform within the limits of the family. With a great range of competition, each type of bird is forced to adapt itself to the specicl line of life for which it is best fitted. But with many diverging possibilities and no competition, except among themselves, the conditions are changed, and we find Drepanidæ in Hawaii fitted to almost every kind of life for which a song bird in the tropics may possibly become adapted. (Plate II.)

In spite of the large differences to be noted there can be little doubt, as Dr. Hans Gadow, Mr. Henry W. Henshaw and others have shown, of the common origin of the Drepanidx. A strong peculiar goatlike odor exhaled in life by all of them affords one piece of evidence pointing in this direction. There is, moreover, not much doubt that the whole group is descender from some stock belonging to the family of honey creepers, Ccerebidæ, of the forests of Central America. Each of the Hawaiian Islands has its species of Drepanine birds, some olive green in color, some yellow, some black, some scarlet, and some variegated with black, white, and golden. The females in most cases, like the young, are olive green. On each island, most of the species are confined to a small district, to a single kind of thicket or a single species of tree, each species being especially fitted to these localized surroundings. With the destruction of the forests some of these species are already rare or extinct. With high specialization of the bill they lose their power of adaptation. In each of the several recognized genera there are numerous species, mostly thus specialized and localized, relatively few species being widely distributed throughout the islands.

Most primitive of all, least specialized and most like the honey-creeper ancestry, is the olive green Oreomystis bairdi of the most ancient island, Kauai. This bird has a small straight bill, not unlike that of the slender-billed sparrows. It is said to be the most energetic and ubiquitous of the group, feeding 


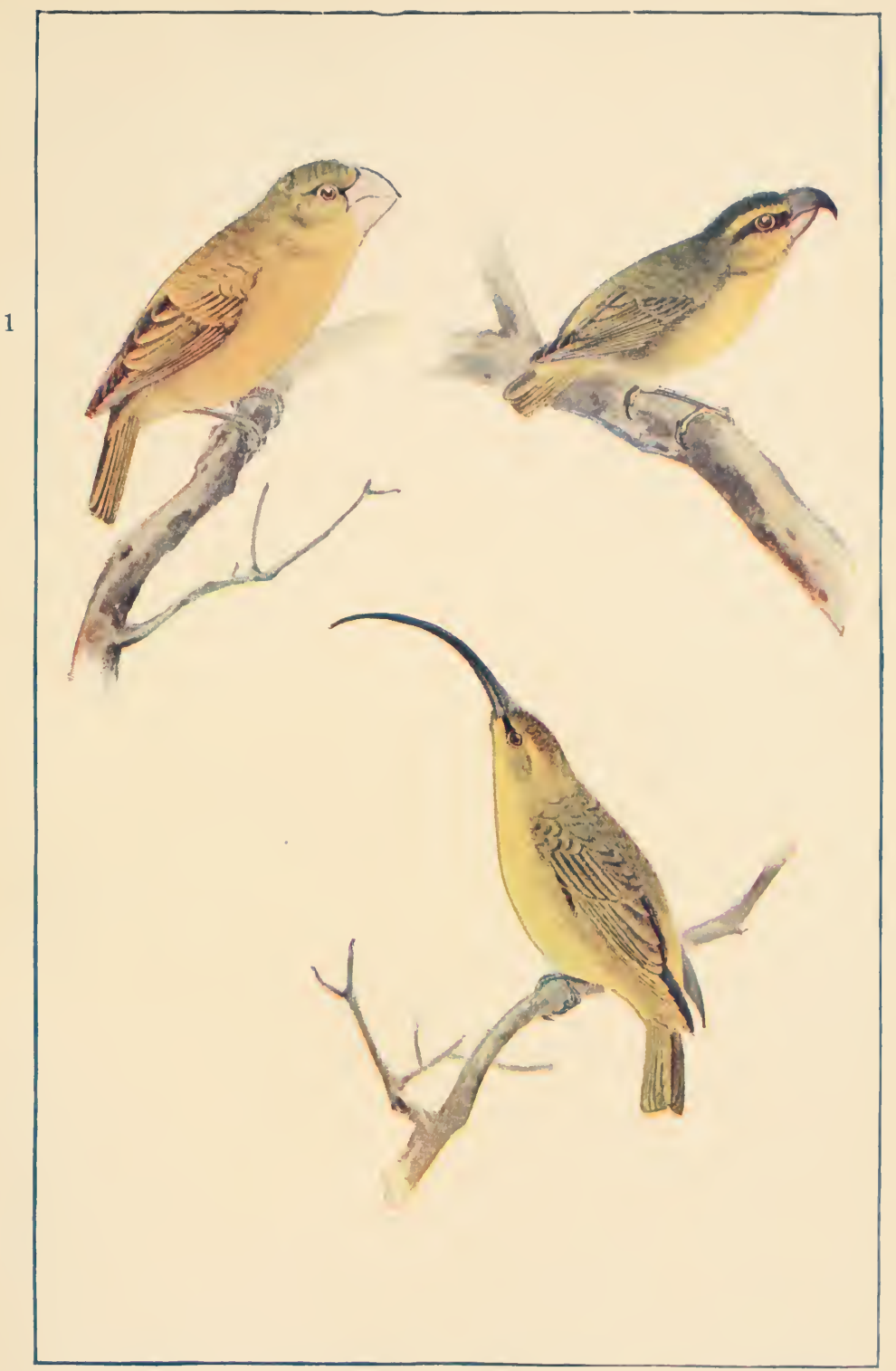

Pt.ATE II. -1, Chloridops kona Wilson, Hawaii; 2, I'seudonestor xanthophrys Rothschild: 3, Hemiqnathus procerus Cabani-, Kauai. (lrom sperimens.) 

on insects on the trunks of trees. If we assume that Orenmystis, or some other of the genera with short and slender bills, represents the original type of Drepanida, we have two lines of divergence, both of them in directions of adaptation to peculiar methods of feeding.

Next to Orcomystis, on the one hand, we have Loxops and Himatione, with the bill pointed, a little longer than in Orenmystis, and slightly curved downward. The species, red or golden, of these two genera are distributed over the islands, each on its own mountain or in its own particular forest. Testiaria, another genus, remarkable for its beautiful scarlet plumage, has the bill very much longer and strongly curved downward. Testiaria coccinea, the iiwi of the islands, lives among the crimson flowers of the ohia tree (Metrosideros) and the giant lobclia, where it feeds chiefly on honey, which is said to drop from its bill when shot. According to $\mathrm{Mr}$. S. B. Wilson, the scarlet sickle-shaped flowers of a tall climbing plant (Sirongylodon lucidus) found in these forests "mimic in a most perfect manner both in color and in shape the bill of the iiwi" so that the plant is called nukuiiwi (bill of the iwii).

ihe next genus, Drepanis, has the sickle bill still further prolonged, forming a segment of a circle, and covering nearly fifty degrees. Drepanis pacifica, one of the species, has the bill forming about one fourth of the total length. The species of this genus, black and golden in color, were very limited in range, and are now nearly or quite extinct. Still another group with sickle bills, Hemignathus, diverges from V'estiaria in having only the upper mandible very long and decurved, the lower one being straight and stiff. The numerous species are mostly golden yellow in color. The group contains longbilled forms like Hemignathus procerus of Kauai, and shortbilled forms like Heterorhynchus olivaceus of Hawaii. In the short-billed forms the two mandibles are quite unlike: the upper very slender, much curved and about one fourth the length of the rest of the body, the lower mandible half as long and thick and stiff. These birds feed chiefly on insects in the dead limbs of the koa trees in the mountain forests. Some or all of them use the lower mandible for tapping the trees, after the fashion of woodpeckers, while with the long and flexible upper one they reach into cavities for insects or insect larvie or suck the honey of flowers. 
Mr. S. B. Wilson remarks: "Nature has shown great symmetry in regard to the species of this genus (Hemignathus including Heterorhynchus) to be found in the Sandwich Archipelago, three of the main islands having each a long-billed and a short-billed form." This, of course, is most natural. Both long-billed forms (Hemignathus) and short-billed forms (Heterorhynchus) have spread from the island where they were originally developed to the other islands, each changing as it is isolated from the main body of the species and subjected to natural selection under new conditions. With the genus Heterorhynchus, the forms with slender bills reach their culmination.

Going back to the original stock, to which Oreomystis baird $i$ is perhaps the nearest living ally, we note first a divergence in another direction. In Rhodacanthis, the bill is stout like that of the large finch, not longer than the rest of the head, and curved downward a little at the tip. The species of this genus feed largely on the bean of the acacia and other similar trees, varying this with caterpillars and other insects. The stout bill serves to crush the seeds. In Chloridops, the bill is still heavier, very much like that of the grosbeak. Chloridops kona is, according to Mr. Robert Perkins, a dull, sluggish, solitary bird and very silent; its whole existence may be summed up in the words "to eat." Its food consists of the fruit of the aaka (bastard sandal tree), and as this is very minute, its whole time seems to be taken up in cracking the extremely hard shells of the fruit, for which its extraordinarily powerful bill and heavy head are well adapted.

"The incessant cracking of the fruits, when one of these birds is feeding, the noise of which can be heard for a considerable distance, renders the bird much easier to get than it otherwise would be. Its beak is always very dirty with a brown substance adhering to it which must be derived from the sandal nuts."

In Psittacirostra and Pseudonestor the bill suggests that of a parrot rather than that of a grosbeak. The mandibles are still very heavy, but the lower one, as in Heterorhynchus, is short and straight, while the much longer upper one is hooked over it. Pseudonestor feeds on the larva of wood-boring beetles (Clytanus) found in the koa trees. (Acacia falcata), while the 


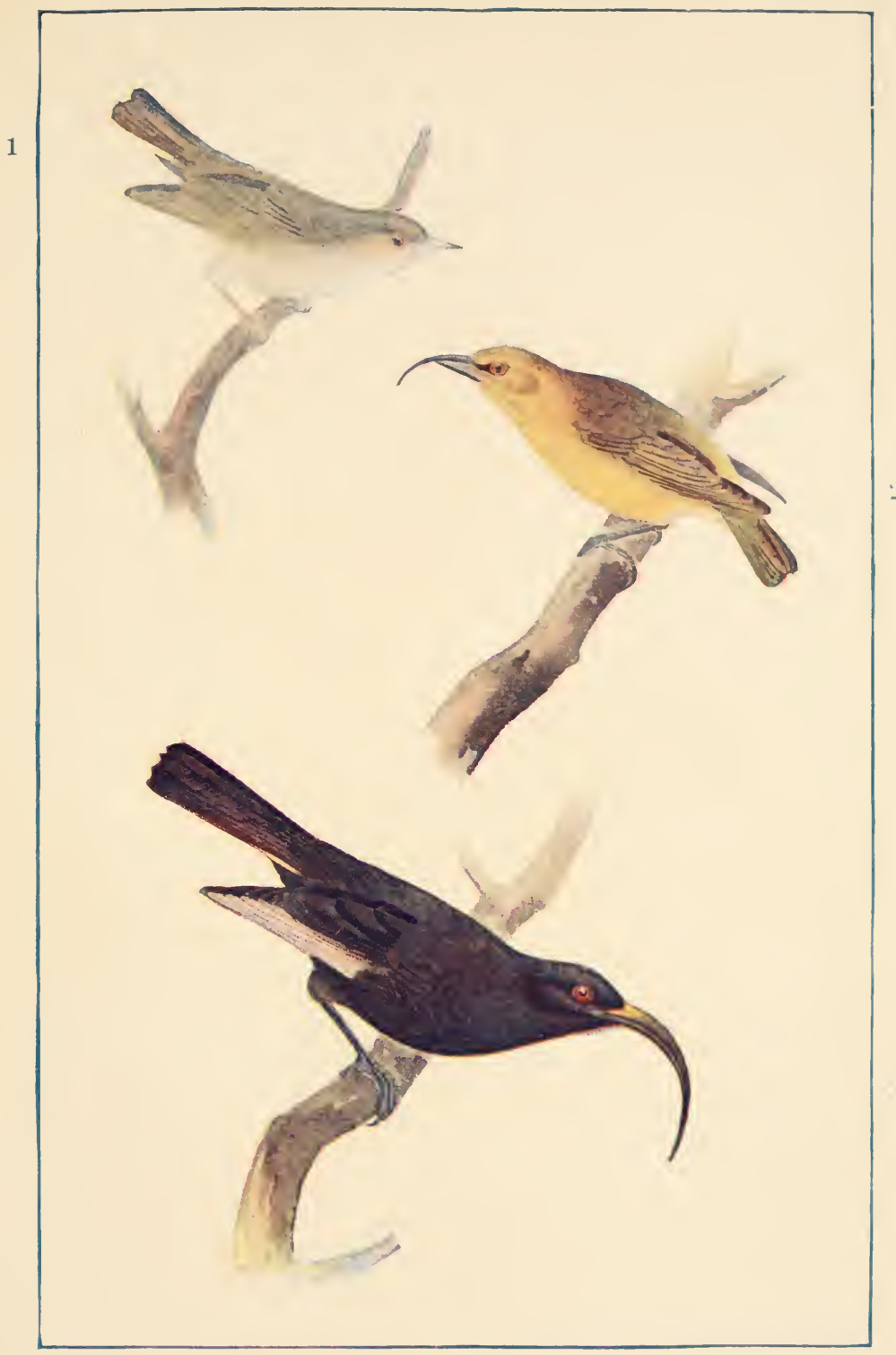

Plate III.-1, Oreomystis bairdii Stejneger, Kinuai 2, Hiterurhymehus dimceus La Fresnaye, Hawaii ; 3, Drepunis funerea Newton, Molok:ai. (Irom specimens.) 

closely related Psittacirostra eats only fruits, that of the ieie (Freycinetia arborea) and the red mulberry (Morus sapyrifera) being especially chosen. In all these genera, there is practically one species to each island, except that in some cases the species has not spread from the mountain or islarıd in which we may suppose it to have been originally developed.

There are a few other song birds in the Hawaiian Islands. not related to the Drepanida. These are derived from the islands of Polynesia and have deviated from the original types in a degree corresponding to their isolation. In the case of the Drepanidæ, it seems necessary to conclude that natural selection is responsible for the physiological adaptations characteristic of the different genera. Such changes may be relatively rapid, and for the same reason they count for little from the standpoint of phylogeny. On the other hand, the nonuseful traits, the petty traits of form and coloration which distinguish a species in Oahu from its homologue in Kauai or Hawaii, are results of isolation. These results may be analyzed as in part differences in selection with different competition, different food and different conditions, and in part to hereditary difference due to the personal eccentricities in the parent stock from which the newer species was derived.

In these as in all similar cases we may confidently af̣rrtr: the adaptive characters a species may present are rite to natural selection or are developed in connection with the demands of competition. The characters nonadaptive which chiefly distinguish species do not result from natural selection, but are connected with some form of geographical isolation and the segregation of individuals resulting from it.

The origin of races and breeds of domestic animals is in general of much the same nature. In traveling over England one is struck by the fact that each county has its own breed of sheep, each of these having its type of excellence in mutton, wool, hardiness, or fertility, but the breeds distinguished by characters having no utility either to sheep or tos man. The breeds are formed primarily by isolation. "The traits of the first individuals in each region are intensifmed by. the inbreeding resulting from segregation. Natural selectior preserves the hardiest, the most docile, and the most fertile: artificial selection those which yield the most wool, the best. mutton and the like. The breed once established, artificial 
selection also tends to intensify and to preserve its nonadaptive characteristic marks. The more pride the breeders take in their stock, the more certain is the preservation of the breed's useless peculiarities. Very few of the characters which usually distinguish a breed of domestic animals have the slightest physiological value to the species. Each of them would disappear in a few generations of crossing, and in each race prized by the breeder the actual virtues exist wholly independently of these race marks.

Analogous to the race peculiarities of domestic animals are the minor traits among the men of different regions. Certain gradual changes in speech are due to adaptation, the fitness of the word for its purpose, analogous to natural selection. The nonadaptive matters of dialect find their origin in the exigencies of isolation, while languages in general are explainable by the combined facts of migration, isolation, and the adaptation of words for the direct uses of speech.

In the animal kingdom generally we may say therefore: Whenever a barrier is to some extent traversable, the forms separated by it are likely to cross from one side to the other, thus producing intergradations, or forms more or less intermediate between the one and the other. For every subspecies, where the nature of the variation has been carefully studied, there is always a geographical basis. This basis is defined by the presence of some sort of physical barrier. It is extremely rare to find two subspecies inhabiting or breeding in exactly the same region. When such appears to be the case, there is really some difference in habit or in habitat: the one form lives on the hills, the other in the valleys; the one feeds on one plant, the other on another; the one lives in deep water, the other along the shore. There can be no possible doubt that subspecies are nascent species, and that the accident of intergradation in the one case and not in the other implies no real difference in origins.

For a final example, we may compare the species of American orioles constituting the genus Icterus. We may omit from consideration the various subspecies, set off by the mountain chains, and the usual assemblage of insular forms, one in each of the West Indies, and confine our attention to the leading species as represented in the United States. (See frontispiece.) 
The orchard oriole, Icterus spurius, has the head, back, and tail all black, the lower parts chestnut, and the body relatively small, as shown by the average measurements of different parts. In the hooded oriole, Icterus cucullatus, the head is all golden orange except the throat, which is black, the tail is black, and the wings are black and white. This species, with its subspecies, ranges through southern California and Arizona, and over much of Mexico. Our other orioles have the tail black and orange. In the common Baltimore oriole, Icterus galbula, of the east, the head is all black and the under parts orange. In the equally common Bullock oriole, Icterus bullocki, of the California region, the head is yellow on each side, the belly rather yellow than orange. The females of all the species are plain olivaceous, the color and proportions of parts varying with the different species, while in the males of each of the many species black, white, yellow, orange, and chestnut are variously and tastefully arranged. Each species again has a song of its own, and each its own way of weaving its hanging nest.

That which interests us now is that not one of these varied traits is clearly related to any principle of utility. Adaptation is evident enough, but each species is as well fitted for its life as any other, and no transposition or change of the distinctive specific characters or any set of them would in any conceivable degree reduce this adaptation. No one can say that any one of the actual distinctive characters or any combination of them enables their possessors to survive in larger numbers than would otherwise be the case. One or two of these traits, as objects of sexual selection or as recognition marks, hare a hypothetical value, but their utility in these regards is slight or uncertain. Naturalists now look with doubt on sexual selection as a factor in the erolution of ornamental structures, and the psychological reality of recognition marks is yet unproved, though not impossible. It may be noted in passing, that the prevalent dull yellowish and olivaceous hues of the female orioles of all species seem to be clearly of the nature of protective coloration.

It has been shown statistically that certain specific characters among insects have no relation to the process of selection. Among honey bees the variation in venation of the wings and in the number and character of the wing hooks is just as 
great among the bees which first come from their cells as in a series of individuals long exposed to the struggle for existence.

Among ladybird beetles of a certain species (Hippodamia convergens), eighty-four different easily describable "aberrations" or variations in the number and arrangement of the black spots on the wing covers have been traced. These variations are again just as numerous in individuals exposed to the struggle for life as in those just escaped from the pupal state. In these characters, there is, therefore, no rigorous choice due to natural selection. Such specific characters, without individual utility, may be classed as indifferent, so far as natural selection is concerned, and the great mass of specific characters actually used in systematic classification are thus indifferent.

And what is true in the case of the orioles and the ladybirds is true as a broad proposition of the related species which constitute any one of the genera of animals or plants. All that survive are sufficiently fitted to live, each individual, and therefore, each species, matched to its surroundings as the dough is to the pan, or the river to its bed, but all adaptation lying apparently within a range of the greatest variety in nonessentials. Adaptation is presumably the work of natural selection; the division of forms into species is the result of existence under new and diverse conditions. 


\section{CHAPTER IX}

\section{VARIATION AND MUTATION}

It becomes imperative that we should carry out the most exact research possible by means of experiment and also wean ourselves of the convenient, but, as it seems to me, highly pernicious habit of theoretical explanations from general propositions. Otherwise there is great danger that the bright expectation which Darwin has opened out to us by his theory may be baffled - the prospect of gradually bringing even organic Being within reach of that method of inquiry which seeks to discern mechanical efficient causes.-SEMPER.

Thus far in our diseussion of evolution factors and theorics we have taken for granted the actuality of the two fundamental factors, variation and heredity. No one disputes their reality; nor does anyone deny their fundemental and indispensable character in relation to the origin of species and the evolution of organisms. All the theories to explain evolution build on these two basic factors or vital conditions. The subjects of doubt or denial are such postulated factors as selection, mutation, orthogenetic progress, etc.; variation and heredity never.

But the character, the influence, the regularity or irregularity of variations, their behavior in heredity, whether transmissible or not, whether acquired or congenital, whether determinate or indeterminate, etc.- these are the problems that the facter variation or variability presents to biologists. Heredity, too, has its problems. These we shall take up in another chapter.

That variations exist is too obvious to everyone to need any discussion. Any litter of kittens or puppies, of mice or pigs. shows us the differences in pattern, shape, and physiology of individuals born at one time and of the same parents. In wild nature the variations among brothers and sisters are no less real than among these domesticated animals. 
Collect a few thousand individuals, at one time in one place, of a single species of insect, as a spotted ladybird beetle; then go over these carefully, looking for variation in some single characteristic, as the color pattern. What do you find? Let us
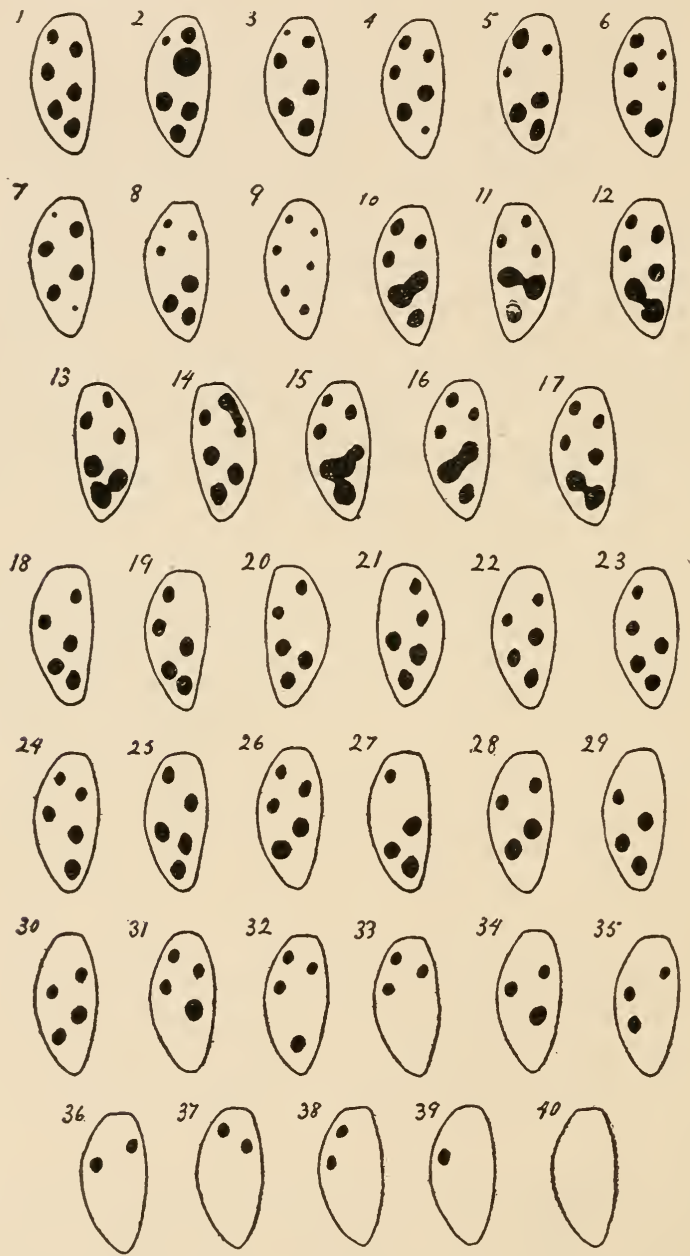

F.G. 72.-Diagram showing variation in elytral pattern of the convergent ladybird, Hippodamia convergens: 1 , Mode; $2-9$, variations in size of spots; $10-17$, variations by coalescence of spots; $18-40$, variations by reduction in number of spots. (After Kellogg and Bell.? 
answer by calling attention 10 Figs. 72, 73, and 74 and what these variations signify. Note-also Fig. 75, showing the
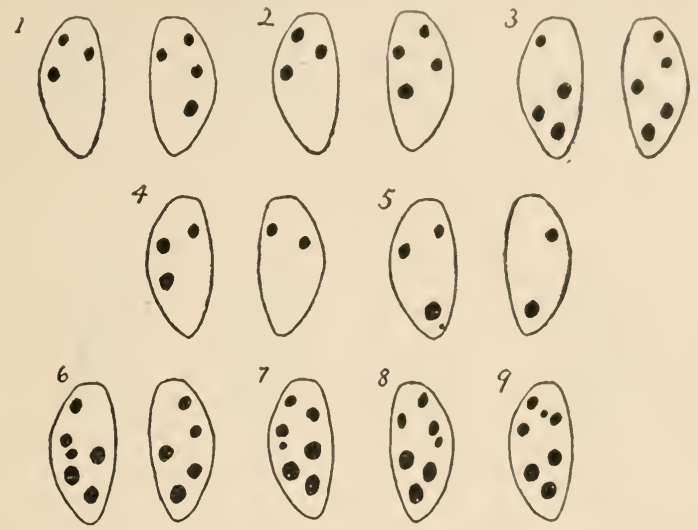

FIG. 73.-Diagram showing variations in elytral pattern of convergent ladybird, Hippodamia convergens: $1-5$, Variations by different reduction in number of spots in the two elytra; 6-9, variations by conditions of spots. (After liellogg and liell.)

variation in elytral blot ching to be found in a series of individuals of the California flower beetle, Diabrotica soror; see also Fig. 76, showing the variations in the black and yellow color pattern of the abdomen of the common

A

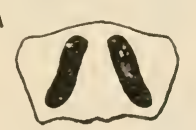
yellow jacket (Vespa sp.); and Fig. 77 showing the variation in the pattern of the prothorax in a series of 178 individuals of a common Californian flower bug, all these individuals collected at one time by swceping a net over a few rods of alfalfa and Baccharis on the campus of Stanford University.

These are all color and pattern variations; but in-

C
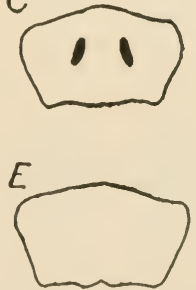

FIG. 74.-Diagram showing variations in prothoracie pattern of the convergent ladlybircl, Hippoxhmin convergens. (After Kellogg and Bell.)

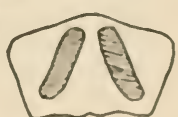

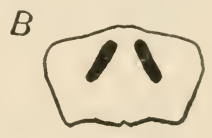

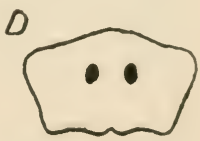

r sects show variations in structural parts as well. Fig. Ts shows a common red-legged locust and one of its hind tibise enlarged 

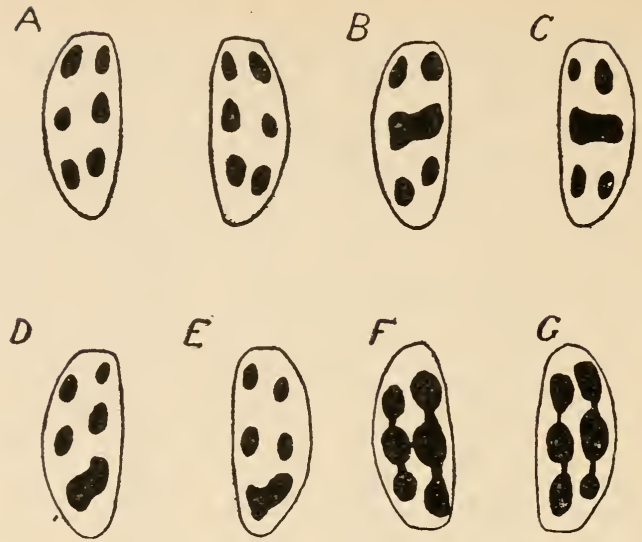

FIG. 75.-Diagram showing variations in elytral pattern of the California flower beetle, Diabrotica soror. (After Kellogg and Bell.)

to show the spines. In eighty-nine individuals of this ${ }^{\circ}$ species of locust collected at Ithaca, N. Y., the number of spines in the
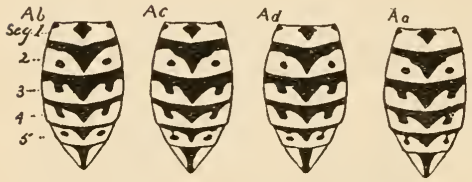

$$
\text { B6 }
$$
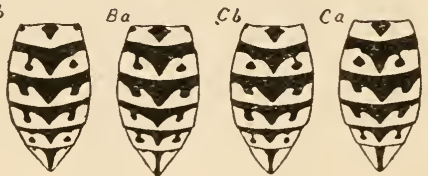

Da

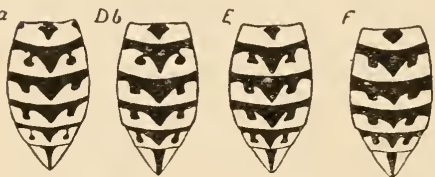

FIG. 76.-Diagram showing variation in pattern in the yellow jacket, Vespa germanica. (After Kellogg and Bell.) outer row of the right tibiæ varies from nine to fifteen, in the inner row from eleven to sixteen. One not given to the systematic study of insects may think spines on the hind legs very trivial structures indeed; but the entomologist, using exactly such characteristics as the number of these structures as a means in helping him to distinguish and define his species, knows how considerable this variation really is.

The dog-days cicada (Fig: 79) also has spines on its hind tibiæ, but only a few, usually, indeed, two. But in any series of individuals of this insect some individuals will be found with but a single spine, some with three, and a few with four even, although the very great majority will have two. For example, 
in a series of 98 male individuals collected at Indianapolis, Indiana, at one time, 12 individuals had one spine in the outer low of the right tibia, S3 had two spines, 22 had three spines, and one had four spines. In the outer row of the left tibie of the simme individuals, there were three spines in 6 individuals, two in 75 , and one in 17 . In the inner rows of tibial spines in these same
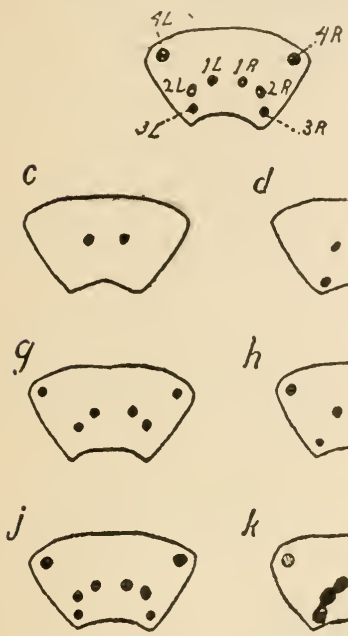

$m$

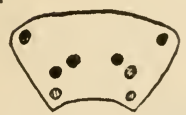

d

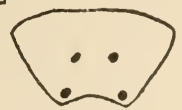

$h$

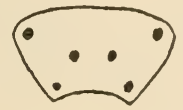

$k$

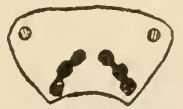

$n$

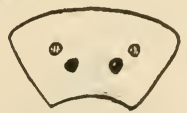

Cl

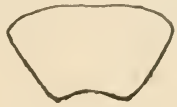

e

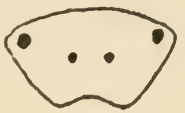

$i$

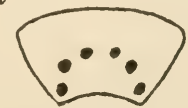

$k$

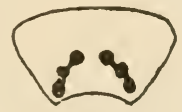

l
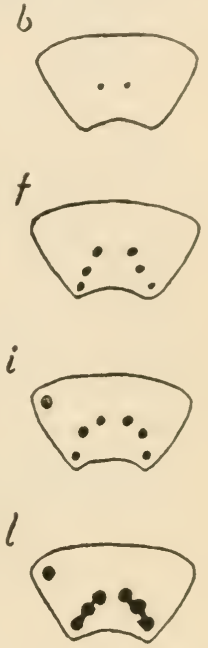

$i$

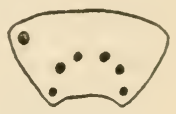

○ p
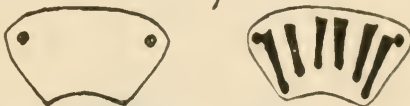

FIG. 77.-Diagram showing variation in pattern of the prothorax of a flower bug (After Kellogg and Bell.)

individuals there were in the right tibia, five spines in $\bar{j}$, four spines in 40, three spines in 43, two spines in 9, and one spine in 1 individual: in the left tibix, fire spines in 2 individuals, four spines in 48 , three spines in 39 , and two spines in $\mathrm{S}$.

In the paper from which we have taken these illustrations of the actuality of variation, studied and stat istically tabulated, are given the data showing the actual extent and frequency of variations in various characters, such as color patterns of head. thorax, and abdomen, character of antemnal segments, number of tibial spines, character of elytral striation, character of veri- 
tion, number of wing hooks, etc., in two dozen different insect species. Long ago Dr. J. A. Allen, of the American Museum of Natural History, gave similar data of the actual variation in
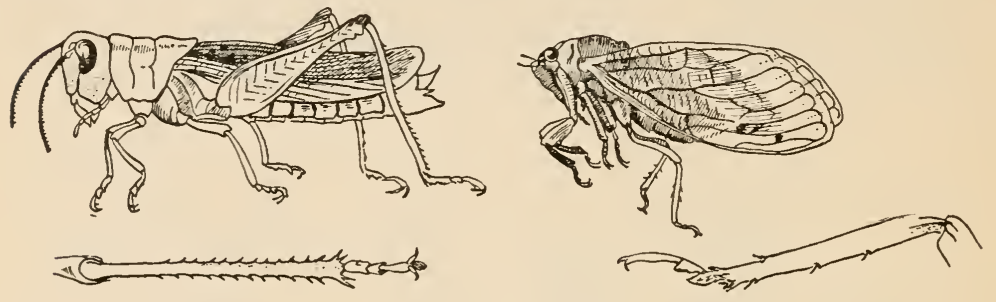

FIG. 78,-Red-legged locust, Melanoplus femur-rubrum, and hind tibia, showing inner and outer rows of spines. (After Kellogg and Bell.)

Fig. 79.--The seventeen-year locust, Cicada septendecim, and its hind tibia, showing inner and outer spines. (After Kellogg and Bell.)

various familiar American bird species, his data referring chiefly to variations in dimensions; as length of whole body, length of tail, of wing, of bill, of tarsus and claw, etc.

\section{CARDINALIS VIRGINIANUS 58 specimens, Florida.}

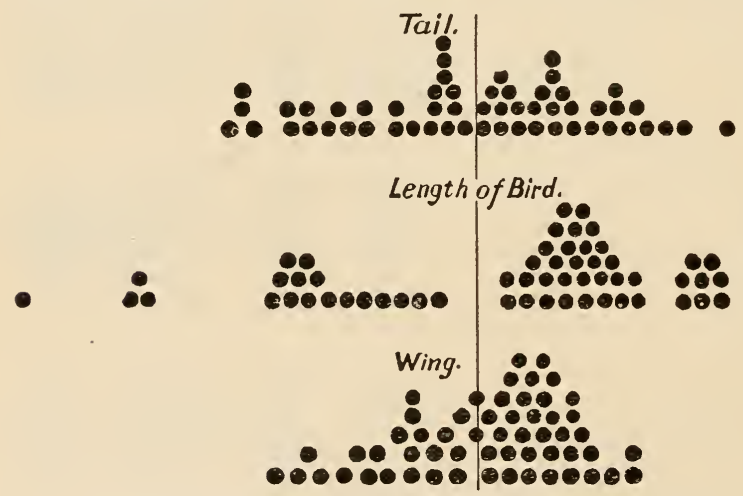

F:G. 80.-Diagram showing variation in length of tail, body, and wing in fifty-eighi specimens of the cardinal, Cardinalis (formerly called virginianus), from Florida. (After Allen.)

And anyone with means of collecting considerable series of individuals of single species can, if he but give the time and study to it, reveal similar variations in almost any part or characteristic of any species or kind of plant or animal. 
parts vary?" some one asks. All parts vary, but some more than others.

Darwin, in Chapter V of his "Origin of species," postulated certain so-called laws of variability, which attempt to answer this question, "What parts vary?" These so-called "laws" which to-day would hardly be dignified with the name of law, are summed up by Darwin at the end of this chapter as follows:

"Our ignorance of the laws of variation is profound. Not in one case out of a hundred can we pretend to assign any reason why this or that part has varied. But whenever we have the means of instituting a comparison, the same laws appear to have acted in producing the lesser differences between varieties of the same species, and the greater differences between speeies of the same genus. Changed conditions generally induce mere fluetuating variability, but sometimes they eause direct and definite effects; and these may become strongly marked in the course of time, though we have not sufficient evidence on this head. Habit in pro-

VARIATION OF

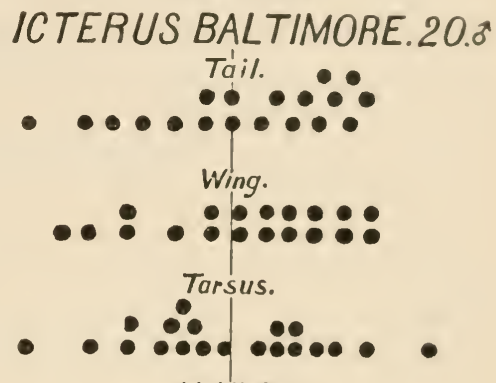

Middle Toe.

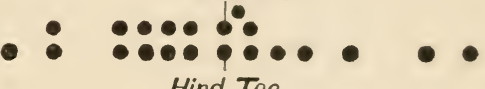

Hind Toe.

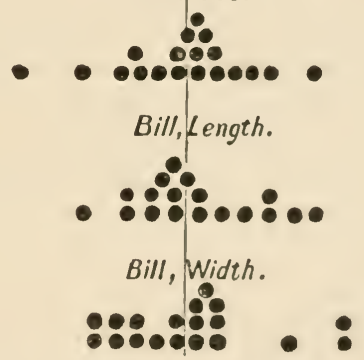

FIG. 81.-Diagram showing variation in dimensions in twenty male specimens of the Baltimore oriole, Icterus galbula (formerly called baltimore). (After Allen.)

ducing eonstitutional peculiarities, and use in strengthening, and disuse in weakening and diminishing organs, appear in many cases o have been potent in their effects. Homologous parts tend to vary ir the same manner, and homologous parts tend to cohere. Modifieations in hard parts and in external parts sometimes affect softer and internal parts. When one part is largely developed, perhaps it tends to draw nourishment from the adjoining parts: and every part of the structure which ean be saved without detriment will be saved. 
Changes of structure at an early age may affect parts subsequently developed; and many cases of correlated variation, the nature of which we are unable to understand, undoubtedly occur. Multiple parts are variable in number and in structure, perhaps arising from such parts not having been closely specialized for any particular function, so that their modifications have not been closely checked by natural selection. It follows, probably from this same cause, that organic beings low in the scale are more variable than those standing higher in the scale, and which have their whole organization more specialized. Rudimentary organs, from being useless, are not regulated by natural selection, and hence are variable. Specific characters-that is, the characters which have come to differ since the several species of the same genus branched off from a common parent-are more variable than generic characters, or those which have long been inherited, and have not differed within this same period. In these remarks we have referred to special parts or organs being still variable, because they have recently varied and thus come to differ; but we have also seen . . . that the same principle applies to the whole individual; for in a district where many species of a genus are found - that is, where there has been much former variation and differentiation, or where the manufactory of new specific forms has been actively at work-in that district and among these species we now find, on an average, most varieties. Secondary sexual characters are highly variable, and such characters differ much in the species of the same group. Tariability in the same parts of the organization has generally been taken advantage of in giving secondary sexual differences to the two sexes of the same species, and specific differences to the several species of the same genus. Any part or organ developed to an extraordinary size or in an extraordinary manner, in comparison with the same part or organ in the allied species, must have gone through an extraordinary amount of modification since the genus arose; and thus we can understand why it should often still be variable in a much higher degree than other parts; for variation is a long-continued and slow process, and natural selection will in such cases not as yet have had time to overcome the tendency to further variability and to reversion to a less modified state. But when a species with an extraordinarily developed organ has become the parent of many modified descendants - which in our view must be a very slow process, requiring a long lapse of time-in this case, natural selection has succeeded in giving a fixed character to the organ, in however extraordinary a manner it may have been developed. Species inheriting nearly the same constitution from a common parent, and exposed to similar 


\begin{tabular}{|l|}
\hline Lacerta ocellata \\
Lacerta viridis \\
\hline Lacerta agilis \\
\hline Lacerta muralis
\end{tabular}

FIG. 82,-Diagram showing variations in dimensions of lizards. (After Wallace.)

influences, naturally tend to present analogous variations, or these same species may occasionally revert to some of the characters of their ancient progenitors. Although new and important modifieations may not arise from reversion and analogons variation, such modifications will add to the beautiful and harmonious diversity of nature. 
"Whatever the cause may be of each slight difference between the offspring and their parents - and a cause for each must exist-we have reason to believe that it is the steady accumulation of beneficial differences which has given rise to all the more important modifications of structure in relation to the habits of each species."

Modern investigation of variation, which includes at least two phases of study that have been developed since Darwin's time, namely the statistical and quantitative, and the experimental

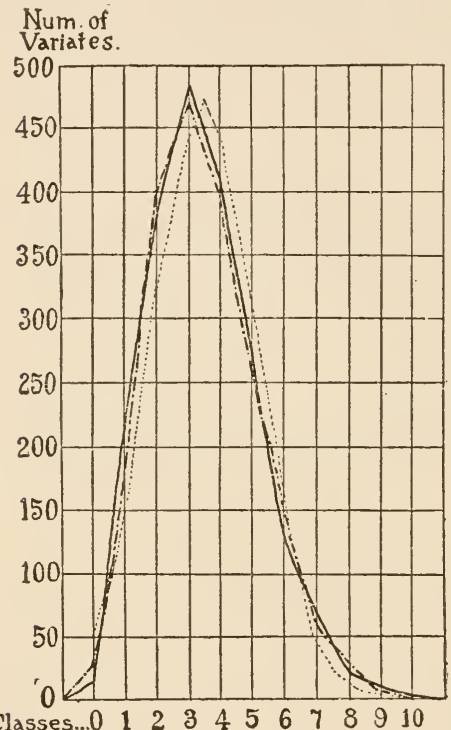

FIG. 83. - Diagram showing curves of distribution of frequency of variation in glands of swine. (After Davenport.) study of variation, has been able to add much information about the mode and the character of variations, and has effected a sort of classification of them which helps at once to express and to clarify and organize our knowledge of variability. But it has added as yet no great fundamental generalizations really worthy to be called laws.

One generalization there is, perhaps, of application and value far reaching enough to be called law (although it applies to only a single category of variation, but a large one), and that is the law formulated in 1846 (ten years before Darwin's "Origin of Species"), by the Belgian anthropologist, Quetelet, on the basis of the examination of the height and chest measurements of soldiers. As it applies only to what are variously called fluctuating, individual, continuous, or Darwinian variations, we may note before stating the law the current mode of classifying the variations which occur in plants and animals.

Variations may be either congenital or acquired: that is, may be such as are apparently determined in the organism 2.0 conception, or such as are imposed on it during its development 
by the influence of extrinsic factors. Or variations may be divided into determinate and indeterminate; that is, those (if there really are such) which are apparently (ontrolled by some, to us unknown, influences and are by these influences confined to certain definite lines or directions of change; and, on the other hand, those which are apparently wholly accidental, or rather which may represent any conceivably possible line or kind of change. Finally, variations may be distinguished as to their general character as discontinuous and continuous; that is, variations occurring irregularly, mostly large and comparatively rarely, and small, abundant variations occurring in graderl series. Among the former are to be ranked the occasional sports and monsters familiar to all breelers; while in the latter, Darwin believed himself to have at hand the necessary ever-present materials to serve natural selection as a basis for species transformation. Hence the slight but abundant and ever-present fluctuiting continuous variations are often called "Darwinian variations."

Now the law of Quetelet applies solcly to the Darwinian variations. The law is, that these variations occur according to the law of probabilities (or law of error): that is, that the slightest variations away from the modal or average type will be the most abundant, and that the number of varying individuals will be progressively less the farther away from the modal type the variations of these individuals are. That is, if the variations in some characteristic of a species be determined for, say, 10,000 individuals of the species, and tabulated, and a curve erected to express graphically the facts of this variability, this curve will practically coincide with that one which would similarly express the variation, if the variation actually occurred according to the mathematical law of the frequency of error; this theoretical curve being obtained by the formula deduced originally by Gauss at the beginning of the list century. Fig. 83 shows graphically how certain studied cases of continuous variation reveal the condition expressed by (2uetelet's law.

As compared with discontinuous and sport vatriation, continuous variation is by great odds the more common. Bateson, an English student of variations, has attempted to show that discontinuous variations are more common thatn is gencrally believed, and has filled a large volume with aterounts and illustrations of such alleged variations. But it has been proved that many of these are cases of teratogenie regeneration, or ab- 
normal restoration of injured parts. Others, too, are of a character which, to many people, will not seem to be discontinuous at all, but continuous. For example, differences in number of antennal or tarsal segments in insects are called by Bateson cases of discontinuous variation if the differences are only by one segment. But as the differences cannot well be less than a whole segment, variations in number of segments, if represented by all the successive numbers between the lowest and highest number of segments observed, may fairly be called continuous: that is, strictly gradatory.

It may be of interest to note, for the purposes of explaining by concrete examples the various phases or categories of variation already named, some specific examples exemplifying each category. The following are taken from a paper on variation in insects, which records a number of statistical studies of variability made by the junior author of this book and Mrs. BellSmith.

To distinguish absolutely between acquired variation and congenital (or blastogenic) variation is a matter which can be done in but comparatively few cases. Whether a variation be congenital or whether it be acquired during the development or life-time of the individual showing it, this variation cannot be recognized until after a considerable part of the development has been undergone; if it is a variation in an adult structure or function, all of the development must have been completed. The variation is apparent only after it is unfolded: only after the part it appears in has reached its definite stage of completed growth and development.

Now, who is to say whether this variation was or was not imposed on the individual showing it, during this long development and immature life as a result of some external influence brought to bear on the varying part during the development? We know that such extrinsic influences do modify parts and functions during individual development, and so we must be very careful when we claim that this or that variation is congenital and not acquired. Yet, how all-important it is to make the distinction is apparent when we recall the fact that most biologists are agreed that acquired characters (variations) cannot be inherited, so that new species can be built up only on the basis of congenital characteristics.

In the case of insect variations, a criterion for distinguishing 
between the congenital and acquired condition is at hand, thanks to the unusual character of the development of certain specialized insects, namely, all those that undergo a complex metamorphosis.

"Without by any means exhausting the subject of the postembryonic development of insects, entomologists have becomesufficiently well acquainted with the phenomena attending this development to be able to confirm absolutely (in essential (haracters) Weismam's discoveries in the larva of the 'imaginal dises' as the independent embryonic centers from which develop the wings, legs, antennæ, and some other parts of the winged adults (imagines) of insects with complete metamorphosis. That is to say, in all the insects which hatch from the egg in a larval condition markedly different from the definitive condition of the species in its fully developed, mature stage, many of the adult organs, as the external parts of the head, and the legs and wings, are produced not by a gradual development, growth, and transformation of the corresponding larval parts, but by a special development in late larval life and during the pupal stage, the final structures being formed from small groups of previously undifferentiated subembryonic cells. These cells are derived, in the case of the external parts just named chiefly from invaginations of the larval cellular skin layer. In the larva (maggot) of a house fly, for example, there are no functional legs or wings: there are no external signs (buds, pads) of these o"mans at any time in the larval stage.

"In the larval life there can be no possible molding influence on these future adult organs of the nature of a direct response or reaction to the immediate environment. We might assume such an influence possible if the wings and legs were slowly transforming external structures subject to attempts at or actual functional use in flight or crawlingr during the larval life. At pupation, the wings and legs suddenly appear as external parts, but still equally functionless, and now wholly concealed and protected by the opaque chitinized wall of the puparimm. With the final issue of the adult, the wings and legs appear for the first time in functional condition, and with the simple need of unfolding, expanding, and drying the outer wall, an operation requiring but few moments, they appear at this time in their définitive fully deveroperd condition. The wings have the arrangement of reins and number of spines and fringing hairs; the legs have the armature of spines and spurs and the number of segments which they retiin unchanged through the short or longer adult life. The wings and legs of the adult of all 
insects with complete metamorphosis-and the insects of this category include all the beetles (Coleoptera), two-winged flies (Diptera), moths and butterflies (Lepidoptera), ants, bees, wasps, gall flies and ichneumons (Hymenoptera), and some other orders-are exposed during their development to just one type of extrinsic influences, namely. those of nutrition, temperature, humidity, etc. These influences affect the whole body and metabolism of the body-developing insect. But they have no direct relation to specific parts.

"An important special environing condition of life, and one that certainly works direct and obvious influence on the body wall of certain animals, is what may be called the chromatic condition of the environment. Color and pattern adapted to the needs of protection or aggression are phenomena familiar throughout the animal series. Most of such color and pattern conditions, catalogued under the head of protective resemblance, mimicry, warning colors, etc., are fixed conditions as far as the individual is concerned, presumably brought about by the age-long action of natural selection.

"Not a few animals display the capabilities of achieving marked adaptive changes, i. e., acquired rariations, during their immature life (postembryonic development). But it is obvious that insects of complete metamorphosis, which possess in adult stage a color scheme and pattern wholly different from that of the larva or pupa and one which is not apparent until it appears in fixed definitive condition on the emergence (and drying) of the imago from the pupal cuticle, cannot be conceived to show, in their color pattern, variations due to individual adaptive changes. That is, variations in this color pattern among the individuals of a species are not acquired, but are strictly congenital, except in so far as they are produced by the general influences of nutrition, temperature, etc., working without reference to the external chromatic conditions of the environment.

"Even such all-pervading influences as nutrition, temperature, humidity, and light may be, and in many cases obviously are, so nearly practically identical for all the members of one brood, or even for all the individuals of the species, that they can have little or no influence in causing variations. For conspicuous example, the case of the honey bee may be noted. Here, all the larvæ live side by side under identical conditions (those of the hive) of temperature, humidity, and light, and the distribution of exactly similar food to them in similar quantity is probably as nearly exactly uniform as could be guaranteed under our most careful artificial experimental conditions. The pupæ are, moreover, under identical conditions of temperature, moisture, and light, so 
that when the adults issue, the variations to be found in any of their parts may with complete confidence be ascribed to prenatal influenees, to intrinsic causes. They are purely blastogrenic. Similarly, the ronditions of life of the developing individuals of all the other social insects, the termites, ants, and social wasps, are practically identical.

"The variations, therefore, in the color pattern of Diabrotica (Fig. 75), Hippodamia (Figs. 72, 73 and 74), and V $\operatorname{cspa}$ (Fig. 76) (insects of complete metamorphosis with all adult external structures never exposed to outside conditions until in definite unchangeable conditions), are congenital variations. Of the same nature are also the structural variations in the character of the venation and the number of wing hooks in the honey bee (see Fig. 94). But the variations in the pattern of the prothorax of the flower bug (Fig. 77), and in the number of spines on the tibiæ of the red-legged locust (Fig. 7S), and the circurla (Fig. 79), may be in part acquired. In these latter eases the insects, not having a complete metamorphosis, have during their immature life these color and structural characters in formative condition, and to some extent in use. They are therefore exposed to the continuous influence of their environment."

It might be thought that we could determine whether variations are congenital or acquired in eases in which we are thoroughly acquainted with the character of the enviromment or extrinsic influences which have surrounded the individuals during their development. In experimental cases we can control this environment and make it identical for all of a given lot of individuals, or measurably varying for different lots. Then by comparison we ean determine what characteristics still vary among those individuals exposed to identical envirommentthese variations should be congenital-and what new kincls of variations appear in those individuals exposed to different environments-these should be acquired variations. This has been done experimentally for silkworm moths. By varying the food supply, etc., marked variations have been produced in the size of larva and moths, weight of sillen cocoons, duration of larval stages (instars). These variations are manifestly acquired, and wherever in nature simple variations in dimensions are found among individuals of a species, this is due undoubtedly, to greater or lesser extent, to differing conditions of nutrition. But we know well that a practically identical food supply given to domesticated animals or human beings can 
never make all the individuals of a single brood or family of the same size. Part of the dimensional variation is due, therefore, to congenital causes. In a beehive, the condition of temperature, humidity, and food supply are practically identical for all the developing bees, and yet bees born of eggs laid by a

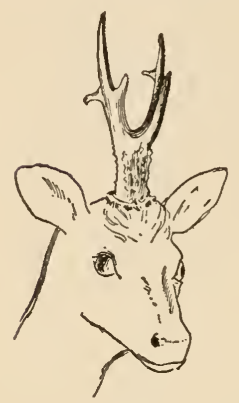

FIG. 84.- Head with one prong of horns markedly different from the other. (After Bateson.) single queen, reared at the same time in the same hive, vary largely in such easily determinable and important matters as venation of the wings, number of hooks used in holding the two wings of one side together, color pattern, etc. Undoubtedly, these variations are strictly congenital, hence inheritable, and therefore of a character to serve as a basis for species change.

With regard to examples of continuous and discontinuous variations, we take the following from the paper on "Variation in Insectis":

"By continuous variations we refer to those variations mentioned above, variously called fluctuating, individual, etc., which are present in any series of individuals of a species, and which cluster about the modal or most abundantly represented forms of the species, as would be expected from the law of error (law of probabilities) discussed above.

"Morgan, in 'Evolution and Adaptation,' objects to the use of 'continuous' as a descriptive name for these variations, on the ground that the word suggests persistence or continuity through successive generations. It seems to us, however, that the name is an apt one, if 'continuous' be taken to mean that the occurring variations in any (sufficiently large) set of individuals form a continuous series, the extremes being connected

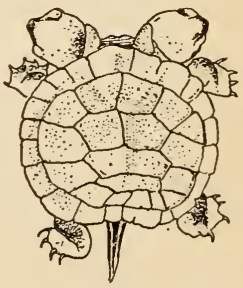

FiG. 85.-Turtle with two heads. (After Bateson.) or immediately merging into each other by a series of small gradatory steps. By 'discontinuous' variation, we would mean, in contrast to continuous, such considerable and radical changes as have been variously called single variations, sports, saltations, mutations, etc.; that is, variations which are not members of graded series and do not group themselves in orderly manner about the modal 
species form according to the law of error. Although often not large, they are yet rarely so minute as those differences which distinguish the adjacent members in any series of indivicluals arranged on a basis of continuous or fluetuating variation. Mutations, according to the usage of de Vries, diseontinuous variations may or may not be. Thus, all mutations might be ealled discontinuous variations, although not all discontinuous variations are necessarily de Vriesian mutations, that is, certain to breed true under varying conditions of environment.

"As a matter of fact, not all continuous variation follows the law of error: the curve or polygon of frequency is not infrequently an unsymmetrical one: 'skewness' prevails; that is, the highest part of the eurve may be

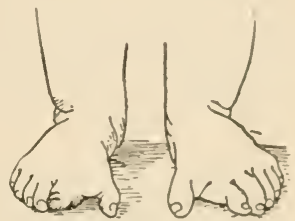

Frg. 86.-Child with six toes on each foot. (After Bateson.) nearer one end, or the eurve may even be bimodal. But nevertheless the 'continuity' of the variations is unmistakable. In a sufficiently large series the extremes of the range are perfectly connected with the mode or modes and hence with each other by gradatory steps very small in size. Whatever the largeness of the difference between the extremes, any two adjacent members of the series are hardly distin-

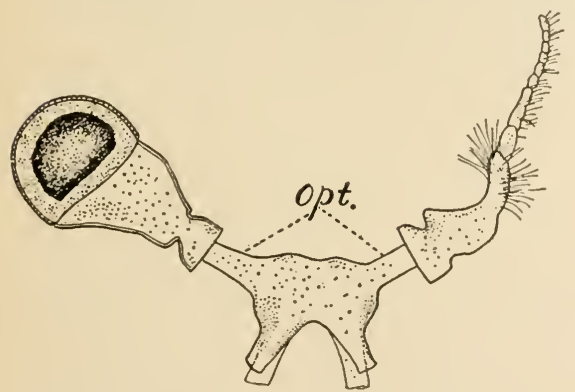

FIG. 87.-Eyestalks of a decapod dissected out: on the right an antenna has regenerated out in place of an amputated eye; opt., optic nerve. (After Herbst.) guishable. This gradual kind of variation, insensible, but yet effective (as regards widely separated members of the series), is most typicially illustrated in cases of what Bateson calls 'sub)stantive' variation, that is, where the varying characteristic is one of pattern, of length, width, or bulk, of the eurving of a vein or legr or spine. Exrellent examples of this

continuous substantive variation are presented by the abdominal and face patterns of Vespa (see Fig. 76), and the elytral pattern of I)iabrotica (see Fig. 75).

"According to Bateson, variations in number of antennal and tarsal segments, number of spines, hairs, or other processes, and other 
such numerical or, as called by him, meristic variations, must be looked on as different in kind from the substantive variations-those capable of perfect merging from one condition to another-in other words, practically incapable of quantitative measurements. These meristic variations are called discontinuous by Bateson. Typical examples are the variation in the number of the costal wing hooks in bees and ants, the number of tibial spines in the locust and cicada, the number of metathoracic tactile hairs in biting bird lice, etc. But when one stops to consider the fact that in all these cases variation could hardly occur

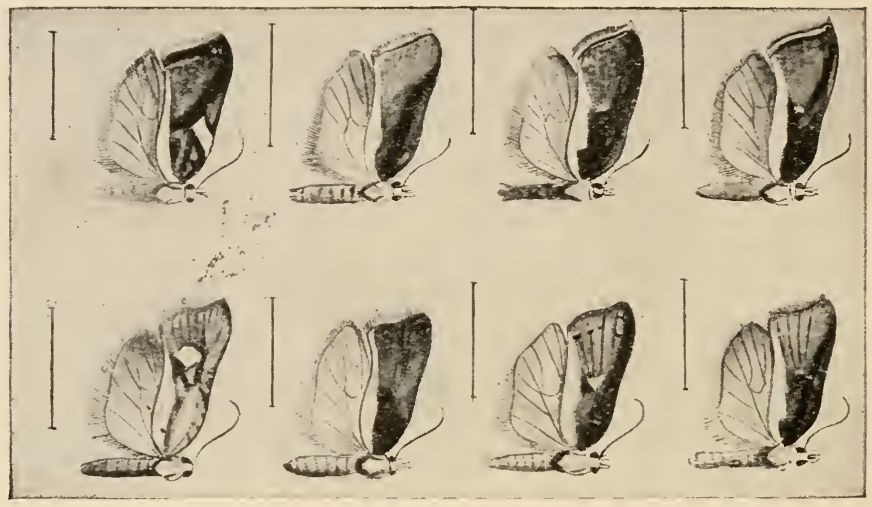

FIG. 88.-Variations in pattern of wings of Peronea cristana. (After Clark.)

by any steps less than those of one hook or one spine or one hair, that a half hook or half antennal segment is inconceivable, serious doubts as to the validity of Bateson's classification of variations as continuous and discontinuous will certainly result. The doubt is strengthened by the difficulty of a clean classification presented by such cases as that of Hippodamia convergens (Figs. 72, 73 and 74). Here we hate a substantive variation in pattern, appearing, however, in such a way as to demand numerical, i. e., meristic, expression. One specimen hes nine elytral spots, another ten, another eleven, and so on; the whole range is indeed from naught to eighteen, with every number between represented, each by various combinations of spots.

"But it is conceivable, and indeed is really the case among our specimens, that these spots might be either of normal size, or of any lesser size down to the limits of visibility. Some of the spots are of the diameter of pin points, some of the pin shaft, and some of pin heads. There is perfect gradation and continuity in this variation. 
And even in such cases as rariations in spines and hairs, this gradation might exist: and indeed it does. Although in our consideration of the variation in the number of the tibial spines of the locust and cirada and in the number of the tactile hairs of the bird lice, we lave referred to these variations only numerically, i. e., meristically, as a matter of fact there are obvious differences in the length, i. e., size, of the spines and hairs, so that it would be wholly fair to break down the unit differences and speak of differences by one quarter, one third, and two thirds of a spine. For the tibial spines of the locust, we have actually recorded the conditions in the form of fractions. But in the case of a hook or an antennal or a tarsal segment it is a unit or nothing.

"To our mind, the distinction between substantive and meristic variation is not at all equivalent to a distinction between continuous and discontinuous variation. It is a distinction between two categories of variation only in that one category includes such conditions as permit more readily of extremely slight, nearly insensible, practically unmeasurable differences, as those of pattern or shape or extent, while the other category inclucles particularly conditions in which any variation must of necessity be fairly obvious, and usually capable of numerical expression.

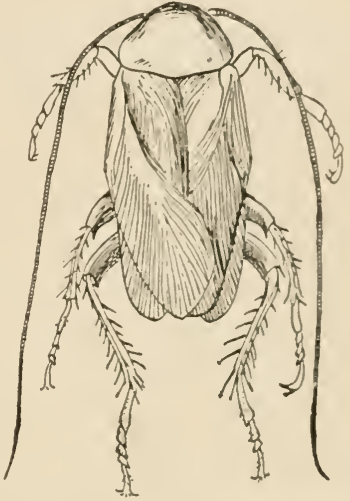

FIG. 89.-Cockroach, showing varying number of tarsal segments in legs. (After Kellogg and Bell.)

"But we believe, nevertheless, that variations really discontinuous occur among insects. For example, the occurrence of interpolated, wholly new, and complete cells (determined by the presence of new cross veins or branches of longitudinal veins) in the fore and hind wings of drone honey bees (Figs. 93 to 96 ) and the occurrence of curious malformations of venation among drone bees must be looked on as sports or truly discontinuuous variations. The regular occurrence of a four-segmented foot, perfectly complete, functional in those numerous specimens of cockroach (Fig. S9), in which natural regeneration has taken place, may be looked on as an example of discontinuous variation. Although no difference in tarsal segments less than that of one is conceivable, it is quite conceivable that the foot with one fewer than the normal number might be in such condition that it would be obviously a five-segmented foot with one segment dropped out: in 
other words, that when compared with a normal five-segmented foot it would appear to be a modification of such a foot with some one segment wanting. But that condition is not at all what appears after the cockroach regenerates a foot. The new foot is only very little, if any, shorter than the normal five-segmented foot (see Fig. 89):" one cannot say that it is precisely this or that segment which is lost. It is a new kind of foot, apparently just as capable, as 'fit,' as useful as the fivesegmented kind. We have regularly occurring, in these cases of regeneration, the development of an entirely changed organ, similar as a whole to the old one, but different from it in all its parts; this difference not being one of incompleteness, or serial addition or subtraction, but the difference of newness. It is the regenerative mutation of an organ!"

In five years of experimental rearing of the silkworms for the sake of studying phenomena of heredity and variation, the junior author has been able to record numerous cases of discontinuous or sport variation such as the absence of the usually well-developed caudal horn of the larva, melanism in larvæ, double cocooning or absence of cocoon in the pupal condition, congenital monstrous loss of a whole wing in the adult, striking aberration of the wing pattern in the adult, etc. But the great mass of variation ever present and readily observable among the scores of thousands of silkworm individuals reared and carefully scrutinized has been of the continuous (fluctuating or Darwinian) type.

A special type or kind of discontinuous variation, that exemplified by the so-called de Vriesian mutations, is discussed at the end of this chapter.

The matter of determinate variation is discussed as follows in the same paper:

"The theory of determinate variation is based on the hypothesis tnat fluctuating variations are not in all cases, nor necessarily in any case, purely fortuitous and scattering, but that because of some intrinsic or extrinsic influence they tend to occur along definite or determinate lines. The need for the theory rests on the claimed inadequacy of slight fortuitous variation in offering selection a sufficient 'handle' for action. The greatest logical difficulty with the theory is that none of the influences which are known is adequate to cause such an effect as that of producing persistent determinate variations. In the case of any developing individual, determinate variation can be 
attained by controlling the environment (kind and quantity of fond, degree of temperature, humidity, and light, etc.), but if such variations (modifications) acquired during development are not inherited, there will be $n o$ advance, generation after generation, along any line. There will be no cumulative effect of such determinate variation. The constant repetition of a rertain environment on generation after generation of a certain species would of course produce a constant repetition of certain individual modifications (orthoplasy), but we do not know as yet of any actual effect on the species of such persistent ontogenic variations.

"The need, however, for some such factor in species-forming as determinate variation is obvious and strongly felt. There are certainly few selectionists left who honestly believe that the minute fluctuating variations in pattern, in size, in curve of a vein, in length of a hair, etc., have that life-and-death value which is the sole sort of value that an 'advantageous variation' must have to be a serviceable handle for the action of natural selection. As a matter of fact, no systematist will have escaped having had it distinctly impressed on him that he recognizes differences in the pattern of ladybird beetles, in the number of fin rays in fishes, in the branching of a vein in flies' wings, that no enemy, no agent of natural selection, can recognize, at least to the extent of pronouncing sentence of death (or not pronouncing it) on its basis. And further, no biologist really satisfies himself with the worn statement: 'We must not presume to judge the value of these trivial, these microscopic differences, for we do not know all the complex interrelation and interaction of the organism and its environment.' We do not; but we do know for many cases that such differences are not actually of life-and-death selective value, and reason compels us to believe to a moral certainty that in other cases these fortuitous trivialities have similar lack of life-and-death importance.

"Directly touching this point are our data of the variation of series of honey bees collected from free-flying individuals after exposure as adults to the rigors of outdoor life, as compared with the variation in the series of bees, adults, but colleeted just when issuing from the cells before being exposed as adults in any way to the external dangers of living. Series of both drones and workers representing both exposed and unexposed individuals were studied. The results of this examination are, that the variation among the exposed individuals is no less than that among the unexposed individuals. This means that these various, mostly slight, blastogenic, variations (although in surh important organs as the wings), which occur among bees at the time of 
their issuance as active, winged creatures, are not of sufficient'adrantage or disadvantage to the individuals to lead to a weeding out by death or saving of such rarying individuals by immediate selective action. Whatever the rigor and danger of the outdoor bee life, these variations seem to be insufficient to cut any figure in the persistence or nonpersistence of any individual in the face of this rigor.

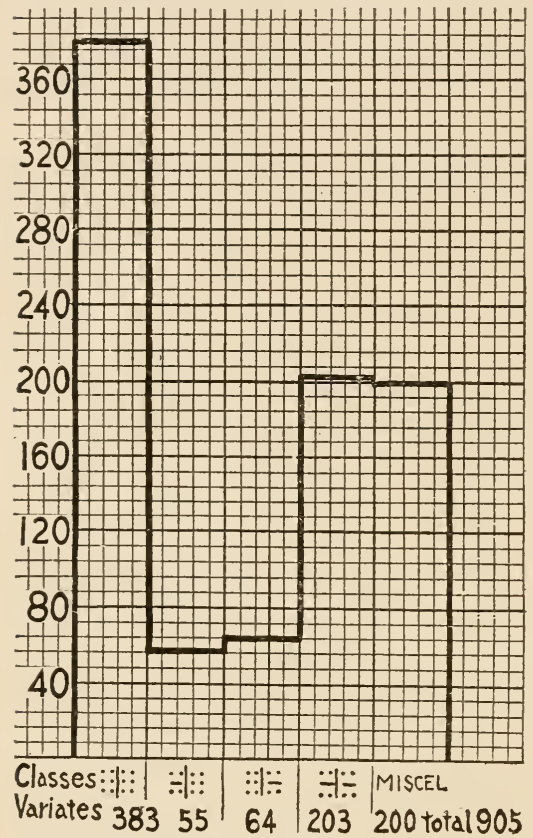

Frg. 90.-Frequency polygon of variation of elytral pattern in 905 specimens of the California flower beetle, Diabrotica soror, collected at Stanford University, 1895. (After Kellogg and Bell.)

"A case which really seems to illustrate determinate variation is that of the variation of the flower beetle, Diabrotica soror (Fig. 75). Among a thousand individuals collected on the University campus in 1895, a certain condition of variation in the elytral pattern exists, as represented graphically by Fig. 90. In 1901 and 1902, other thousands collected from the same place and examined to determine the condition of the variation in this pattern, show a distinctly different status, as illustrated in Figs. 91 and 92. (To be sure that a series of a thousand individuals really reveals the conditions of this pattern variation, repeated series of 1,000 individuals each were examined and found practically identical.) The difference in the variation status between the 1895 lot and the 1901-2 lots consists in the dominance in 1901-2 of one of the two modal conditions found to exist in the species, which in 1895 was not the dominant one. There has been a marked change in seven years, not in the pattern itself but in the prevalence or dominance of one type of pattern. Has the change been brought about by natural selection? Or is it the result of a determinate variation caused by we know not what intrinsic or extrinsic factors? 
"When one straightens up after a carcful microscopic examination of the pattern of I Dabrolica to determine its variation, one is sure that no other enemy of these flower bertles ran be concerved to use such discrimination as ours. Does the fly catcher swoop)ing from its station on fence post or tree branch determine which of two heavily flying Diabroticas shall be its prey on the basis of 'two midlle spots on left elytron partially fused' in one and 'these two spots not touching' in the other? To our minds the change in variation status, the dominance of one mode to-day which was the subordinate mode in 189.;, is not due to the action of selection. We do not indeed hesitate to believe in those 'unknown factors of evolution' which may produce, among other results, that rondition of affairs best named 'determinate variation.' This variation is not necessarily to be conceived of as purpeseful or even advantageous; if by its eumulation it becomes a disadvantage of life-and death value, natural selection, which is after all a

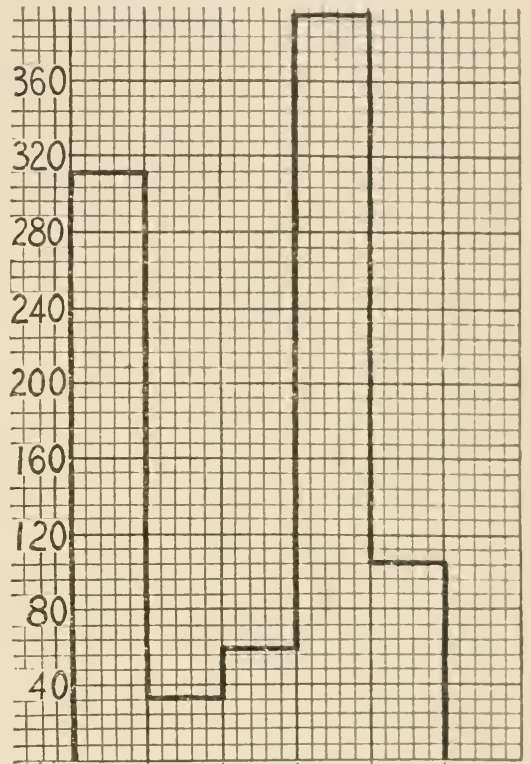

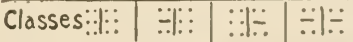
\begin{tabular}{ll|l|l|l} 
Variates 313 & 32 & 60 & 396 & 104 total905
\end{tabular}

FIg. 91.-Frequency polygon of variation of elytral pattern in 905 specimens of the California flower heetle, Dialrotica soror, cullected at stanford University, October, 1901. (After Kellogg and Bell.) logical necessity and undoubterlly an actual actively regulative factor in species control, will take care of it."

In the light of the foregoing discussion of the eategories and characters of variations, it is obvious that a well-grounded knowledge of variability and variations, a knowledge based on careful extensive statistical and experimental studies, is essential as a basis for any effective investigation of the factors and 
processes involved in species-forming, that is, evolution. The methods and phenomena of evolution are intimately linked with-indeed throughout are based upon-the methods and phenomena of variation. What causes variation is a contrib-

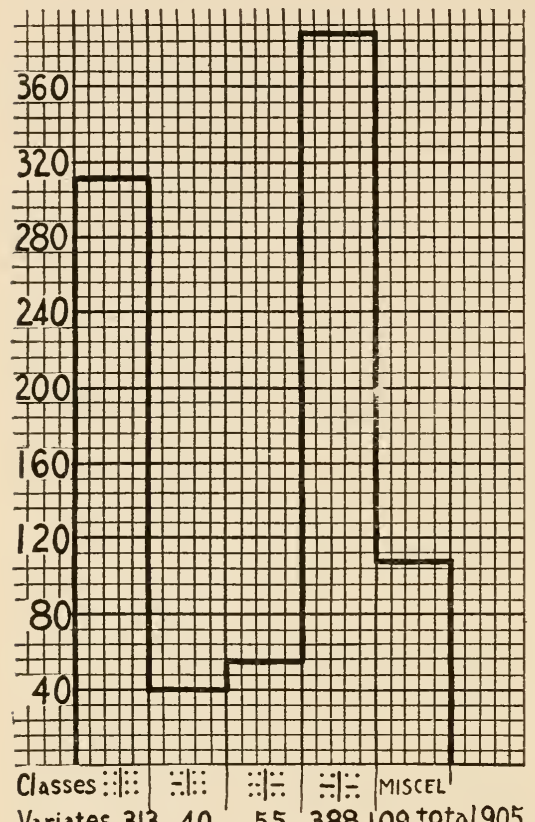

Variates $313 \quad 40 \quad 55 \quad 388$ 109 total 905

FIG. 92.-Frequency polygon of variation of elytral pattern in 995 specimens of the California flower beetle, Diabrotica soror, collected at Stanford University, October, 1902. (After Kellogg and Bell.) utory cause in evolution, and one of the fundamental and all-important causes.

Concerning the causes of variation, at least of those of congenital variation, we are almost wholly in the dark. Only such influences as can affect the actual germ cells are presumably potent to effect congenital variation. Such influences are not proved to the satisfaction of many biologists to be numerous. In the fusion of the germ cells of two individuals, the phenomenon called by him amphimixis, Weismann finds the most effective cause of variation. Now the wider apart the two parents are in structural and functional characteristics, the greater is the variation in their offspring likely to be. Hence hybridization, or the mating of unlike parents, even to the degree of race and species unlikeness, is a great resource of the breeder who would have in his hands large variation. But if the parents are too unlike, their mating, even if possible, proves sterile. Usually parents must be of the same species, although experiment has shown that considerable extraspecific hybridization is possible. Among cultivated plants and animals the artificially selected races differ very much, but these races are mostly easily hybridiz- 
able. The nature and results of fertilization and amphimixis are treated in Chapter XIII.

But parthenogenetically produced individuals (that is, young born from unfertilizerl eggs-as the honey-bee drones, certain whole generations of various gall flies, saw flies, aphids, etc., etc., regularly are) also vary. In the case of male bees, male ants, female aphids, etc., etc., the individuals differ quite as much as do individuals of the same species of bisexual parentage. Comparing the variation in drone bees (parthenogenetically produced) as compared with that of the workers (from fertilized eggs), we find that this is true. The organs examined

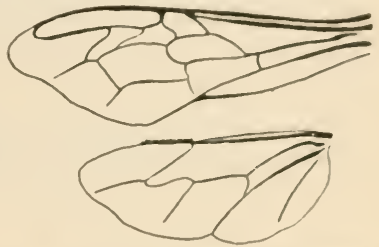

Fig. 93.-Fore and hind wings of honeybee (irone), showing normal venation. (After fellogg and Bell.)

for variation in these series of bees were the wings, organs used by both drones and workers, and having no immediate relation either structurally or physiologieally to the differentiation of those two castes or kinds of individuals of the honey-bee species. The workers are "incomplete" only in that most of them are infertile: in no other structural or physiological feature of their makeup are they less "complete" than the drones. They are indeed distinctly the more specialized of

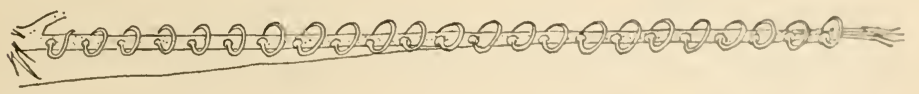

Fig. 94.-Part of costal margin of hind wing of honeybee, much magnified to show hooks. (After Kellogg and Bell.)

the two, and according to one of the early Darwinian canons of variation might be expected to differ more than the drones. But the drones are males and, according to another commonly accepted belief, this is the explanation for a larger variation on their part, if such larger variation occurs. As a matter of fact, it does. The drones, in all the many series studied, show markedly more variation in the venation of the wings than do the workers, while they show quite as much variation as the workers in the number of the hooks which hold the two wings together in flight. (See Figs. 93 to 96.) Both these characters, i. e., wing venation and wing hooks, are not so-called "male char- 
acters": they are not to be compared with those secondary sexual characters such as ornamental or aggressive spines, horns, patterns, etc., which are the characteristics that give males their special reputation for ultravariation.
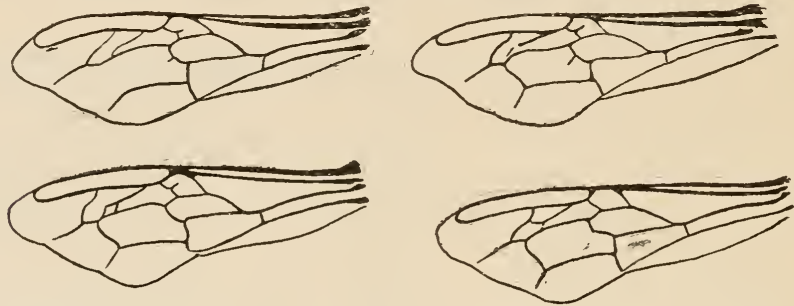

FrG. 95.-Fore wings of honeybee (drone), showing variations in venation. (After Kellogg and Bell.)

Finally, with regard to the causal influence in variation-producing of the "primary factors of evolution," such as temperature, light, humidity, pressure, and extrinsic physicochemical conditions generally, summed up commonly in the phrase climate and environment, we have one all-important considera-

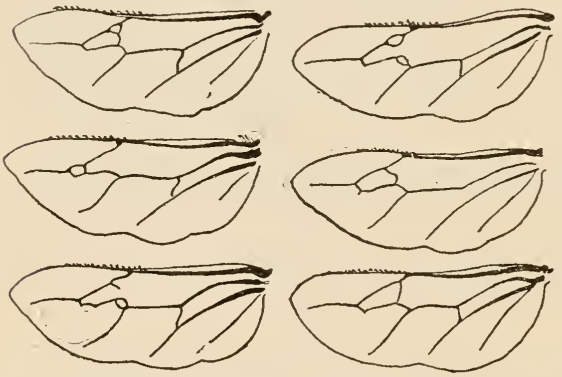

FrG. 96.-Hind wings of honeybee (drone), showing variations in venation. Note the interpolation of the cells. (After Kellogg and Bell.) tion to keep constantly in mind. However potent and obvious the effects of these influences are on the individual, we have no proof as yet of a nature to compel the general acceptance of biologists, that such effects can be carried directly over to the race or species.

Only ten years after Darwin published the "Origin of Species," von Kölliker, the great German zoölogist, in criticising the assumptions on which species-forming by natural selection was based in the Darwinian theory, proposed an alternative theory of heterogenesis or species-forming by leaps (saltations or mutations). These saltations need not of necessity to be large, but must be changes definite and fixed. Later, Korschinsky, a Russian botanist, outlined in some de- 
tail and with greater emphasis such a theory of species-forming by mutations; and finally in 1901 Hugo de Vries, the famous botanist of Ansterdam, published in catenso the details of many years of observation and experiment on the suljecet of mutations, and reformulated definitively a theory of speciesforming by mutational or saltational variation, the now familiar mutation theory.

The following paragraphs from Morgan ("Evolution and Adaptation," pp. 294-297, 1903) give a concise statement of the actual details of the mutations in the evening primmose observed by de Vries:

"We may now proceed to examine the evidence from which de Vries has been led to the general conclusions given in the precording pages. De Vries, found at Hilversam, near Ansterdam, a locality where a number of plants of the evening primrose, Einothera lamarcliiana, grow in large numbers. This plant is an American form that has bee: imported into Europe. It often escapes from cultivation, as is the case at Hilversam, where for ten years it had been growing wild. Its rapid increase in numbers in the course of a few years may be one of the causes that have led to the appearance of a mutation period. The escaped plants showed fluctuating variations in nearly all of their organs. They also had produced a number of abnormal forms. Some of the plants eame to maturity in one year, others in two, or in rare eases in three, years.

"A year after the first finding of these plants de Vries obscrved two well-characterized forms, which he at once recognized as new elementary species. One of these was $O$. brevistylis, which occurred only as female plants. The other new species wits a smooth-leaferl form with a more beautiful foliage than $O$. lamarcliana. This is $O$. lavifolia. It was found that both of these new forms bred true from self-fertilized seeds. At first only a few sperimens were found, each form in a particular part of the ficld, which looks as though each might have eome from the seeds of a single plant.

"These two new forms, as well as the common O. lamarrkiana, were collected, and from these plants there have arisen the three groups or families of elementary spercies that de Vries has studied. In his garden other new forms also arose from those that had been brought under cultivation. The la"gest group), and the most important one, is that from the o: iginal O. lamurelizana form. The aceompanying table shows the mutations that arose between 155 and 1899 
from these plants. The seeds were selected in each case from selffertilized plants of the lamarckiana form, so that the new plants appearing in each horizontal line are the descendants in each generation of lamarckiana parents. It will be observed that the species, $O$. oblongata, appeared again and again in considerable numbers, and the same is true for several of the other forms also. Only the two species, $O$. gigas and $O$. scintillans, appeared very rarely.

\section{"CENOTHERA LAMARCKIANA}

Elementary Species

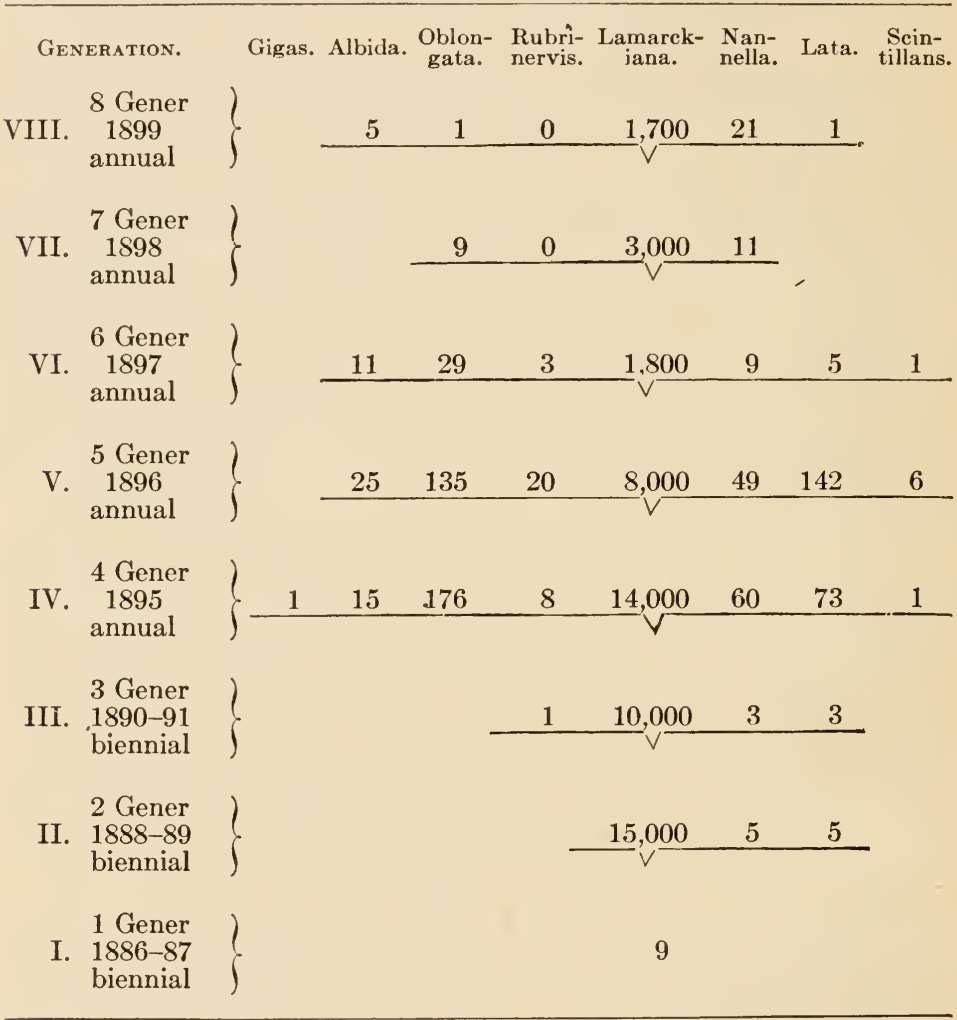

"Thus de Vries had, in his seven generations, about fifty thousand plants, and about eight hundred of these were mutations. When the flowers of the new forms were artificially fertilized with pollen from 
the flowers on the same plant, or of the same kind of plant, they gave rise to forms like themselves, thus showing that they are true elementary species. ${ }^{1}$ It is also a point of some interest to observe that all these forms differed from each other in a large number of particulars.

"Only one form, $O$. scintillans, that appeared eight times, is not constant as are the other species. When self-fertilized, its seeds pro-
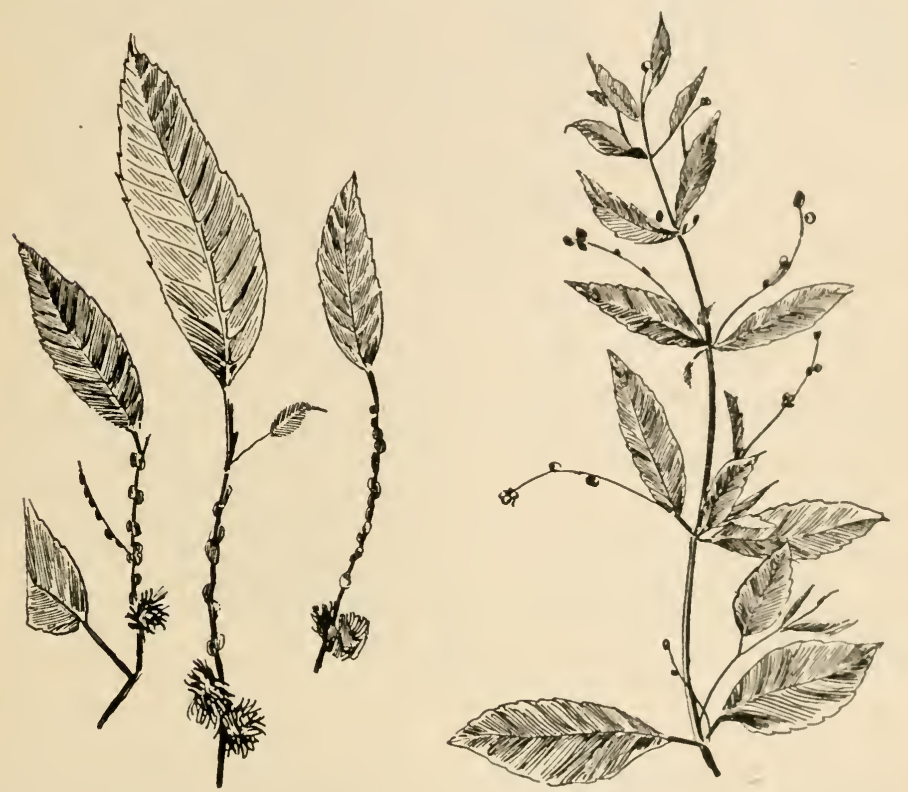

FIG. 97.-At left, section of chestnut, Castanea vesca, showing unusual variations; at right, a branch of Mercurialis annua, which presents several variations. (After de Vries.)

duce always three other forms, $O$. scintillans, $O$. oblongata, and $O$. lamarckiana. It differs in this respect from all the other elementary species, which mutate not more than once in ten thousand individuals.

From the seeds of one of the new forms, O. lavifolia, collected in the field, plants were reared, some of which were O. lamarchiuna, and others O. lavifolia. They were allowed to grow together, and their descendants gave rise to the same forms found in the lamarchiana

${ }^{1} O$. lata is always female, and cannot, therefore, be self-fertilized. When crossed with $O$. lamarckiana there is produced fifteen to twenty per cent of pure lata individuals. 
tamily, described above, namely, O. laia, cliipíica, nannella, rubrinervis, and also two new species, 0 . spatulata and leptocarpa.

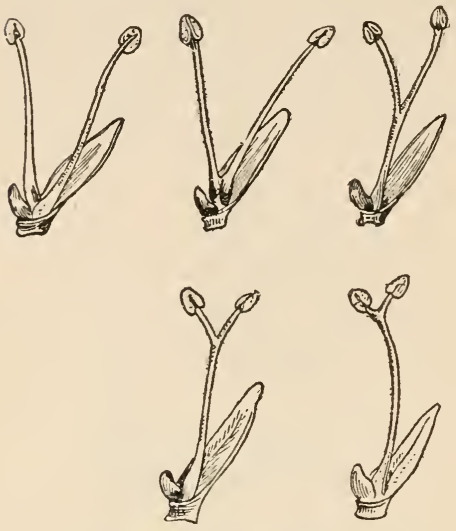

Frg. 98.-Stamens of a hybrid willow, Salix auritax purpurea, showing different degrees of varying.

"In the lata family, only female flowers are produced, and, therefore, in order to obtain seeds they were fertilized with pollen from other species. Here also appeared some of the new species, already mentioned, namely, albida, nannella, lata, oblongata, rubrinervis, and also two new species, elliptica and subovata.

"De Vries also watched the field from which the original forms were obtained, and found there many of the new species that ap. peared under cultivation. These were found, howerer, only as weak young plants that rarely flowered. Five of the new forms were seen either in the Hilversam field, or else raised from seeds that had been collected there. These facts show that the new species are not due to cultivation, and that they arise year after year from the seeds of the parent form, O. lamarcliana."

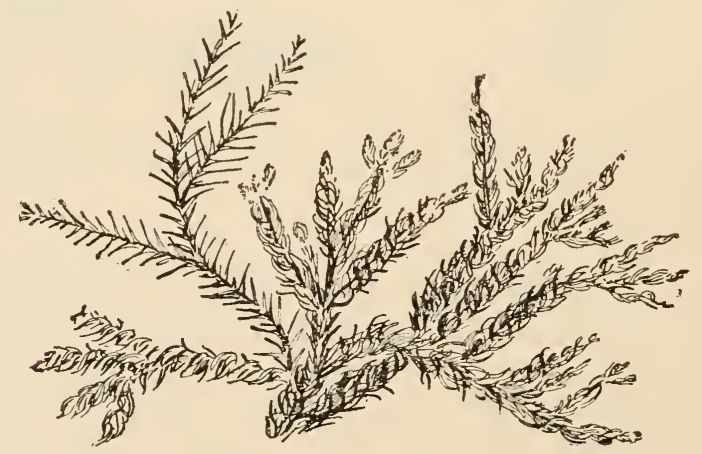

FIG. 99.-A branch of a Japanese tree, Cryptomeria japonica, showing an atavistic variation. (After de Vries.)

As to this we may observe: It has long been known that individual variations of an extreme degree sometimes occur, 
and that these may be to a degree persistent in heredity. Of such nature was the Ancon sheep, the Mauchamp sheep, the iceberg blackberry, and numerous other races or forms known in the domestication of animals, or the cultivation of plants. The generally normal structure of such individuals distinguishes

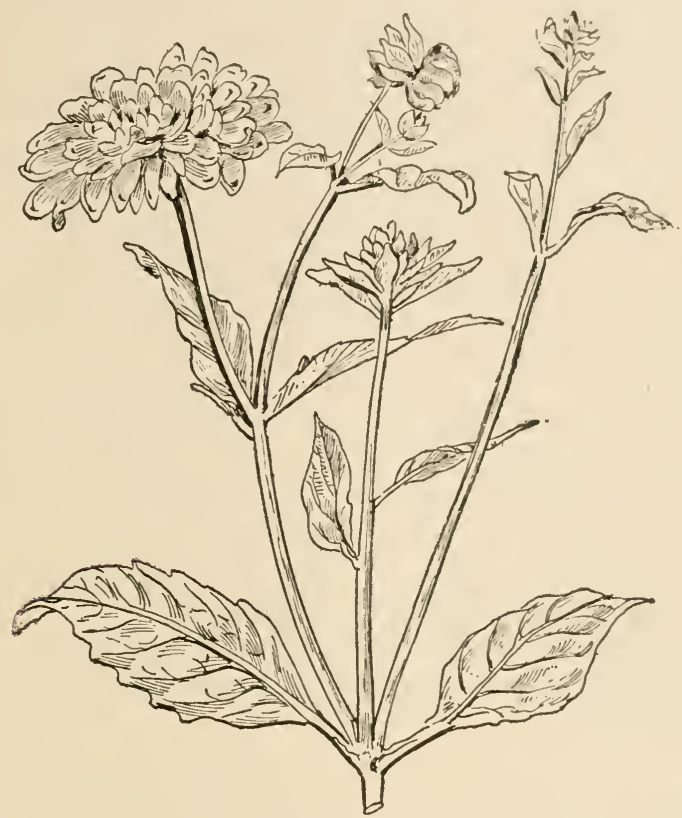

FIG. 100.-A branch of the green Georgine, in which the inflorescence leaves and some of one branch (the right-hand one) are green like the rest of the plant, while the other varieties are red and in normal condition. (After de Vries.)

them from monstrosities, which are usually frealis of derelopment rather than of heredity.

The name "saltation," or in recent years "mutation," has been applied to extreme fluctuation, the immediate cause of which is unknown. The experiments of de Tries on the saltations of the descendants of the evening primrose (called (Enothera lamarchiana) have drawn general attention again to tho possibility that saltation has had a large part in the process of

${ }^{1}$ The word mutation was firet used not for saltations but for the slow fluctuation in succesșive geological periods. 
formation of species. As to this it may be said that the possible variation within each species is much greater than the range of the individuals which actually survive. The condition of domestication favors the development of extreme variation, because such individuals may be preserved from interbreeding with the mass, and they may survive even if their characters are unfavorable to competition in the struggle for existence. Among plants it is noticed that new soil and new conditions seem to favor large variation in the progeny, although the traits thus produced are not usually hereditary. Cases more or less analogous to those noted by Dr. de Vries are not rare in horticulture. The cross breeding of variant forms favors the appearance of new forms. Among actual species in a state of nature, there are very few which seem likely to have arisen by a sudden leap or mutation. The past and the future of de Vries' evening primroses are yet to be shown. The species called by de Vries Enothera lamarckiana is not at present known in its wild state anywhere in North America, the parent region of all the species of evening primroses or Enothera; so that we have as yet no reason to assume that the various mutants of the evening primrose are really comparable to the wild species of the same group now existing in America.

While saltation remains as one of the probable sources of specific difference, the actual rôle of this process in nature is yet to be proved. 


\section{CHAPTER $\mathrm{X}$}

\section{HEREDITY}

"Vom Vater hab' ich die Statur, Des Lebens ernstes Führen;

Vom Mütterchen die Frohnatur Und Lust zu fabuliren.

Urahnherr war der Sehönsten hold, Das spukt so hin und wieder.

Urahnfrau liebte Sehmuck und Gold,

Das zuckt wohl durch die Glieder.

Sind nun die Elemente nicht

An dem Complex zu trennen;

Was ist denn an dem ganzen Wicht

Original zu nennen?"

-Goethe, " "Zahme Xenien," vi.

Heredity is the rule of persistence among organisms. The existence of such a law, or "ascertained sequence of events." is a matter of common observation. "Like produces like,"

1 "Stature from father and the mood

Stern views of life compelling;

From mother, I take the joyous heart

And the love of story-telling.

"Great-grandsire's passion was the fair.

What if I still reveal it?

Great-grandam's, pomp and gold and show,

And in my bones I feel it.

"Of all the various elements

That make up this complexity,

What is there left when all is done,

To call originality?"

BAYARD TAYLOR's translation in part. 
"Blood will tell," "Blood is thicker than water," these proverbs in all languages indicate the general fact that each organism is likely to resemble its parents, and that the basis of fundamental resemblance among organisms is found in kinship by blood. It is equally a matter of common observation that the law of heredity is inseparable from a law of variation. No one organism is quite an exact copy of another. The prevention of such a condition is one of the effects of the process of double parentage. Except in certain exceptional forms in which parthenogenesis or hermaphroditism appear, each complex organism springs from two organisms of the same species: the one male, the other female. The resultant organism partakes of the qualities of each of these in some degree, and through these to a degree also it partakes of qualities of the parents or ancestors of each.

The phrase, "Kinship by blood," used in connection with all studies of heredity, is a survival of an ancient theory that the physical basis of heredity is found in the actual blood. "Blood is quite a peculiar juice," as was observed by Mephistopheles, but its peculiarities are not concerned with heredity. The function of blood is concerned with the nourishment of tissues and the removal of their waste. The actual vehicle of transfer of hereditary qualities, the physical basis of heredity, is found in structures within the protoplasm of the germ cell.

The germ cells, male or female, are alike in all characters essential to this discussion. On the average, the potency of the male and the female cell is exactly the same, there being nowhere constant advantage of one sex over the other. Each cell, male or female, is one of the vital units, or body cells, set apart for the special purpose of reproduction. It is not essentially different from other cells in structure or in origin, but in its potentialities. Its function is that of repeating the original organism, "with the precision of a work of art."

Heredity is shown in the persistence of type, in the existence of broad homologies among living forms, in the possibility of natural systems of classification in any group, in the retention of vestigial organs, in the early development and subsequent obliteration of outworn structures once useful to individuals of the race or type.

In a general way, the individual inherits from both parents the common structure of organisms of the species to which it belongs. The special peculiarities of the individual organism 
are also inherited, but in much less certainty of degrce. These traits belonging to a member of a single generation have a smaller "inheritance fund" on which to draw. In each generation some of these individual qualities are liutent or "recessive," others are potent or "dominant." The recessive or ancestral characters reappear with a certain regularity. They may form a sort of mosaic, by mixing with other lominant traits, or they may make a more or less perfect blend. Resemblance to some remote ancestor occurs at times, being known as atavism. Each ancestor has some claim in the formation of the new individual, and behind the grandfather and grandmother dead hands from older graves reach in their direstion. The past will never let go, though with each generation there is a de'per crust over it. These old claims grow less with time, because with each new generation there are twice as many of these competitors. Moreover past generations can affect the heredity of the individual only through the agency of his immediate parents. Out of these elements Ir. Galton frames the idea of a "mid-parent," a sort of center of gravity of heredity, though, as Dr. Brooks has observed, it is doubtful if this mid-parent is more than a logical abstraction. The bluer the blood in any species, that is, the more closely alike the ancestors are, the more certain will be the personal resemblance among the descendants.

But characters actually latent are very real in heredity. Dr. Brooks says:

"When a son of a beardless boy grows up and acquires a beard, we may say that he has inherited his grandfather's beard, but this is only. a figure of speech, and he actually inherits the beard his father might have acquired, had he lived, nor would the case of a child descended from a series of ten or a hundred beardless boys be different."

It is, moreover, certainly true that a beard can be as well inherited from the mother-who has none-as from the futher. The inheritance is that of the beard the mother might hate developed had she been a man. And, in general, in matters of heredity, the child is not derived from the parents as they actually are, but from the parents as they might have heen. The traits transmitted in heredity are chosen from the whole line of parental possibilities. And with the process of conception, 
the union of the two parental germ cells, "the gate of gifts is closed." No trait or quality can ever be acquired of which at least the elements are not involved in the original inheritance.

"What is transmitted to the infant," observes Dr. Archdall Reid, "is not the modification [of the parent], but only the power of acquiring it under similar circumstances. The power to acquire fit modifications in response to appropriate stimulation is that which especially differentiates high animal organisms from low animal organisms."

Atavism or reversion is the process of "throwing back," by which in some degree an individual resembles a distant ancestor. Under the name of "atavism," according to Yves Delage, are included three very different things:

(a) The transmission in one family of individual characters, which, latent for several generations, suddenly reappear. This is family atavism, and its nature is readily recognized.

(b) The reappearance, more or less regularly in a race, of characters of an allied race, from which the first race may have been derived. This is race atavism. Of this nature are the zebra stripes sometimes seen in mules.

(c) The appearance of characters abnormal for the race in which they appear, but which are normal in other races supposed to be ancestral. This is atavism of teratology. An illustration is the occasional appearance in the modern horse of rudiments of additional toes, with partly developed hoofs.

"Everything is possible in heredity," observes Delage. "One may always find examples of election, of blending (of mosaic), of combination, of resemblance direct, and of resemblance reversed. To give to these groupings the name of laws would be an abuse of language, since not one of these rules is exclusively true. In reality there is no law of resemblance between a child and its parents. All is possible, from a difference so great that there is not a trait in common, to an almost perfect identity with one or the other parent, with every intermediate degree of blending of characters and combination of resemblances."

The name "telegony" is given to the supposed influence of the first male on the future offspring of the female. This theory of telegony rests mainly on a case of a mare which was first impregnated by a quagga, and whose subsequent colts from males of her own species had quagga-like markings. The supposed 
facts on which the theory is based are inalequate or umproverl, and it is probable that the phenomena called telegony have no real existence.

Equally uncertain are the phenomena known as "prenatial influences." In the process of evolution, the development of the female has brought her to be more and more the protector and helper of the young. She gives to her progeny not only her share of its heredity, but she becomes more and more a factor in its development. In the mammalia the little ego is retained long in the body and fed, not with food yolk, but with the mother's blood. The parent thus becomes an immediate and most important part of the environment of the young. In man, by the growth of the family the parental environment becomes a lifelong influence. The father as well as the mother becomes a part of it.

It has long been a matter of common belief that among mammals a special additional formative influence is exerted by the mother in the period between conception and birth. The patriarch Jacob is recorded as having made a thrifty use of this influence in relation to the herds of his father-in-law, Laban. This belief is part of the folklore of almost every race of intelligent men. In the translations of Carmen Silva, that gentle woman whom kind nature made a poet and cruel fortune a queen, we find these words of a Roumanian peasant woman:

"My little child is lying in the grass,

His face is covered with the blades of grass.

While I did bear the child, I ever watched

The reaper work, that it might love the harvests;

And when the boy was born, the meadow said,

"This is my child.'",

In the current literature of hysterical ethics we find all sorts of exhortations to mothers to do this and not to do that, to cherish this and avoid that on account of its supposed effect on the coming progeny. Iong lists of cases have heen reported illustrating the law of prenatal influence. Most of these records serve only to induce scepticism. Many of these are mere (o)incidences, some are unverifiable, others gressly impossible. There is an evident desire to make a case rather than to tell the truth. The whole matter is much in need of serious study, and 
the entire record of alleged facts must be set aside to make a fair beginning.

There are also many phenomena of transmitted qualities that cannot be charged to heredity. Just as a sound mind demands a sound body, so does a sound child demand a sound mother. Bad nutrition before as well as after birth may neutralize the most vigorous inheritance within the germ cell. A child well conceived may yet be stunted in development. Even the father may transmit weakness in development as a handicap to hereditary strength. The many physical vicissitudes between conception and birth may determine the rate of early growth or the impetus of early development. In a sense, the impulse of life comes from such sources outside the germ cell and outside heredity. All powers may be affected by it. Perfect development demands the highest nutrition, an ideal never reached. In such fashion the child may bear the incubus of Ibsen's "Ghosts," for. which it had no personal responsibility. "Spent passions and vanished sins" may impair germ cells, male or female, as they injure the organs that produce them.

In a thoughtful article on problems of heredity (The Horseman, April 17, 1906), Mr. C. B. Whitford maintains that better results in the trotting horse come from breeding from untrained horses of good blood than from horses which have been elaborately trained to the highest speed on the racecourse.

"Trotting horses that are overbred show the effects of their intensified breeding in a variety of ways. But the usual difficulty is extreme nervousness and want of ability to stand training. Sometimes a horse of this kind will show great promise when he is first hitched to a sulky. He will show great flashes of speed and will have a smooth, easy action and the trotting instinct well pronounced."

But he is overnervous, lacks constitutional strength and will not do well.

"The trouble with a horse of this kind is that he has not inherited the necessary fuel with which to create energy. He is 'burnt out' by heredity. That which he needed to train on was so largely used up by his ancestry in their process of development that they had not enough to transmit to their progeny." 

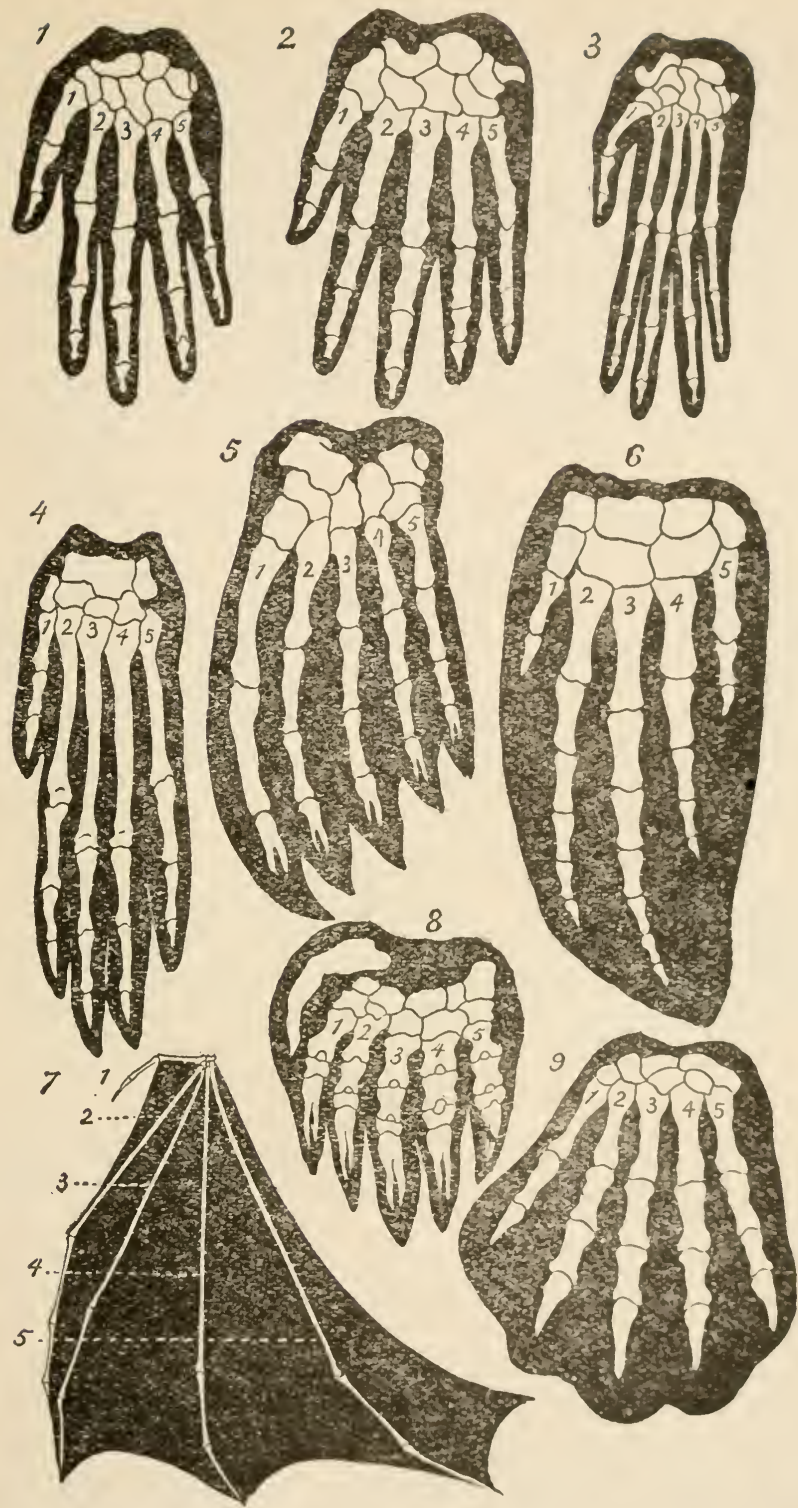

FIg. 101.-Diagram showing arrangement of hones in the hand or font of various animals: 1 , man ; 2 gurilla ; 3 , orang; 4 , dug ; 5 , soa lion; 6 , dolphin; 7, bat; 8, mole; 9, Ornithorhynchus. (.1fter Haeckel.) 
If this is true, it would appear that nervous overstrain of the parent is unfavorable to normal nerve development of the offspring. This would be apparently a case of transmission of parental conditions, as above indicated, and not one of true heredity.

It may be conceived that, at the moment of impregnation, the resultant germ cell is sexless. It begins its development at once, and, in the higher animals, turns very soon toward the formation of those structures which distinguish the one sex or the other. Each individual ultimately becomes either male or female. Relatively few animals, and those among the lower

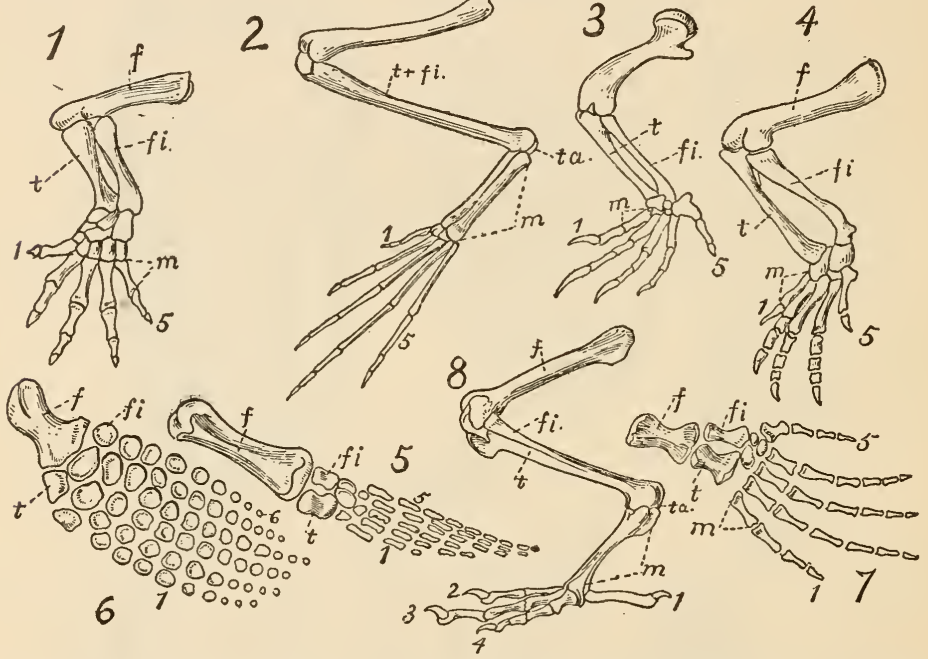

FIg. 102.-Limb skeletons of extinct and living animals, showing the homologous bones: 1 , salamander; 2 , frog; 3 , turtle; 4 , Aëtosaurus; 5 , Plesiosaurus; 6 , Ichthyosaurus; 7 , Mososaurus; 8 , duck.

forms, are ever really hermaphrodite, or representative of both sexes at once.

Among the invertebrate animals the numerical relations of the sexes are subject to great variation. Among vertebrates, in general, the sexes are practically equal in number, as is shown by count of large series of individuals. This is true whether the species be monogamous, polygamous, or promiscuous in its sex relations. It is therefore apparent that the sex tendencies in 
the germ are held on a very fine balance. A very slight impulse the one way or the other determines the sex direction the embryo shall take. Although much investigation and very much speculation have been devoted to this problem, it is still ${ }^{1}$ unsolved. We are not able, in the vertebrate animals, nor in fact in animals generally, to determine the nature of the stimulus, or of any of the various impulses, if more than one exists, which

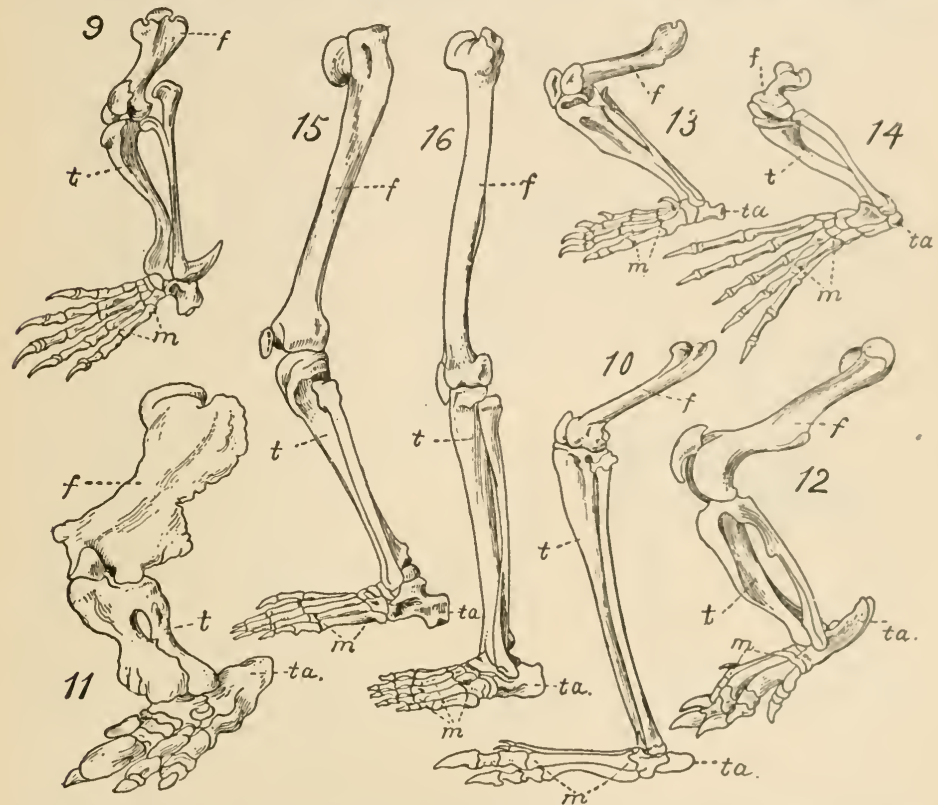

FIG. 103.-Limb skeletons of various animals, showing homologous bones: 9, Ornithorhynchus; 10, kangaroo; 11, Megatherium; 12, armadillo; 13, mole; 14, sea lion; 15, gorilla; 16 , man.

leads the individual germ cell to develop as male or female. It is also possible that each germ cell is really bisexual from the beginning. One sex or the other becomes dominant and the other recessive as the embryo develops. But in this event we are still in doubt as to the nature of the determining factor $\mathrm{O}_{i}$

${ }^{1}$ The latest studies of the problem are chicfly concerned with an attempt to determine whether or not thre exists a chromosome sex determinant. and whether sex determination may not be brought under Mendel's law of heredity (see later paragraphs in this chapter) in a modified form. 
stimulus. Among ants and the social bees and wasps the males develop parthenogenetically from unfertilized cells, the fertilized cells yielding either females or workers which are sterile females. But this specialized mode of development is peculiar to particular groups. For a few lower species it has been ascertained that variation in nutrition may be a factor in sex determination. Favorable nutrition seems to increase the number of females. Most higher plants are hermaphrodite, the central leaves (carpels) in the bud which becomes the flower, yielding ovules or fe-

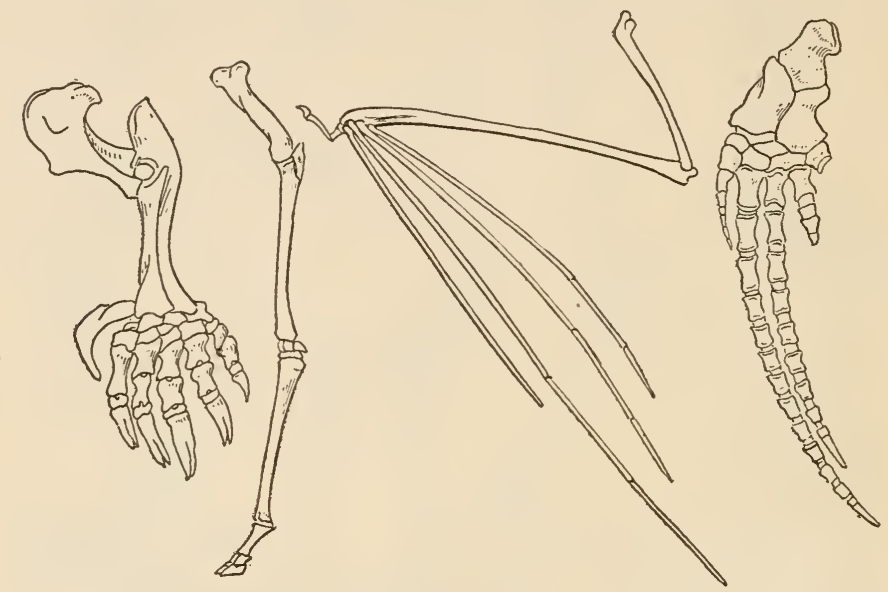

Fig. 104.-Limb skeletons of various animals, showing homologies of the bones; at left, mole; next, giraffe; next, bat; next, porpoise.

male germ cells. The next whorl (stamens) yields male germ cells or pollen. The outer whorls (corolla, calyx) serve as protective organs only, and are without sex.

The bonds of union among organisms which stand at the basis of all classification are known as "homologies" (Figs. 101104). A homology is a real likeness, as distinguished from one, merely superficial or apparent. To superficial likeness we give the name of analogy. Homology means fundamental identity of structure, as distinguished from incidental similarity of form or function. Thus, the arm of a man is homologous with the foreleg of a dog, because in either we can trace deep-seated resemblance or homologies with the other. In each detail of ach bone, muscle, vein, or nerve of the one we can trace the 
corresponding details of the other. But in comparing the arm of man with the "limb" of a tree, the arm of a starfish, or the foreleg of a grasshopper, we find no correspondence in details. In a natural classification, or one founded on fact, organisms showing the closest homologies are placed together. An artificial classification is one based on analogies. Such a clascification might place together a cricket, a frog, and a kingaroo, because they all jump, or a bird, a bat, and a butterfly, because they all fly, even though the wings are very differently made (Fig. 105) in each case.

The very existence of such terms as animals and plants, insects and mollusks imply relationships, and relationships in different degrees. Classification is the process of reducing our knowledge of these grades of likeness and unlikeness to a system. By bringing together those which are fundamentally alike, and separating those which are unlike, we find that
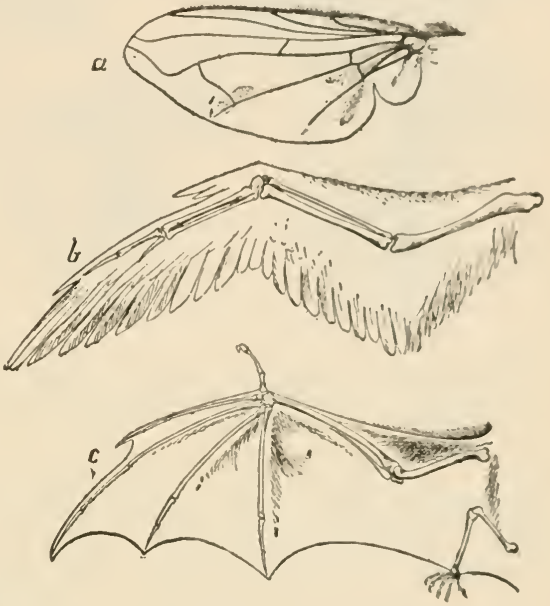

Frg. 105.-Diagram of wings, showing homology and analogy: $a$, wing of fly; $b$, wing of bird; $c$, wing of bat. these traits are the outcome of long-continued influences. Classification is defined as "the rational lawful disposition of observed facts." It rests on the results of the operations of natural laws, or forces which bring about inevitable results.

For it is a matter of common observation that the closest homologies are shown by those animals which have sprung from a common stock. The fact of blood relationship shows itself always in homology. So far as we know, homology is never produced in any other way, therefore the actual presence of homologies among animals or plants implies, as we shall see in a later chapter, their common descent from stock possessing these same characters. In our primitive use of the trunk of the tree to imply unity in life, we can see that this trunk represents 
homology, and that it is the representation of the current of heredity. The resemblances arise from common origin, the

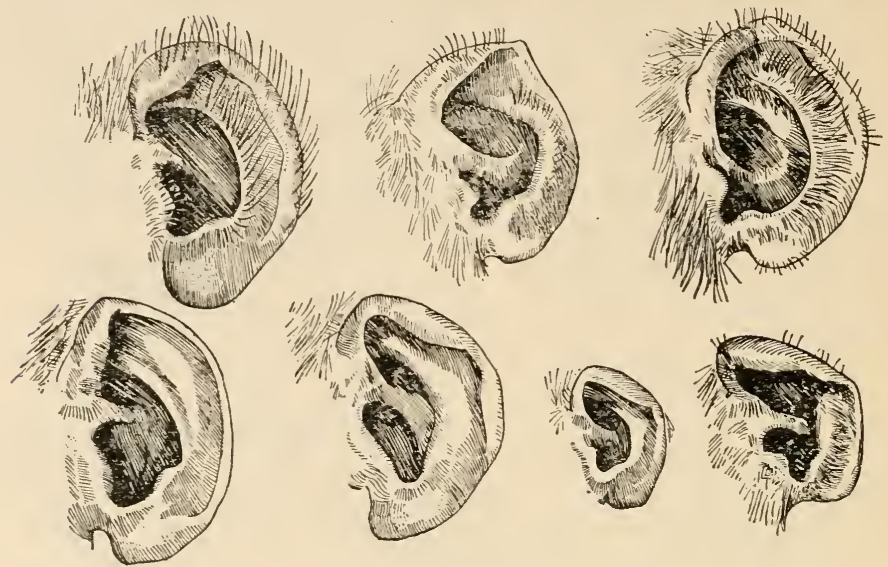

FIG. 106.-Ears of various anthropoid apes and of man, showing human vestigial characters: 1 , hairy human ear; 2 , Barbary ape; 3 , chimpanzee; 4 and 5 , human ears; 6 , ear of human foetus; 7 , orang-outang.

variations from the demand of differing external conditions. It may be said that the inside of an animal tells what it is, the outside where it has been. In the internal structure, ancestral

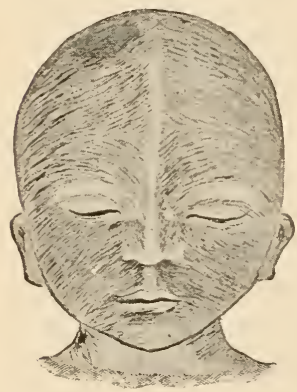

FIG. 107.- Head of a fivemonths human embryo showing embryonic haircovering. (After Ecker.) traits are perpetuated with little change through geologic ages. The external characters affected by every feature of the surroundings may be rapidly altered through response to demands of environment and through the destruction of individuals whose life fails of adjustment.

It is in the persistence of heredity that we find the explanation of vestigial organs. An organ well developed in one group of animals or plants may in some other be reduced to an imperfect organ or rudiment so incomplete as to serve no purpose whatever. Such rudimentary or functionless structures may be found in the body of any of the higher animals and in most or all of the higher plants. As a rule such structures are more fully 
developed in the embryo than in the adult, becoming atrophied with age. Familiar examples are the appendix vermiformis and the unused muscles of the ears in man, the atrophied lung, pelvis, and limbs of the snake, the air bladder of the fish, the "thumb" (or rather index finger), of the bird, the splint bone of the horse, and the like.

The anatomist Wiedersheim has recorded 180 vestigial organs in man. These structures occur in all the systems of organs, integument, skeleton, muscles, nervous system, sense organs, digestive, respiratory, circulatory, and urino-genital systems. Most of these remnants of structures are to be found completely developed in other vertebrate groups. Eleven of them are characteristic as functional organs of fishes only, four of amphibians and reptiles. The fact that structures are vestigial is shown often

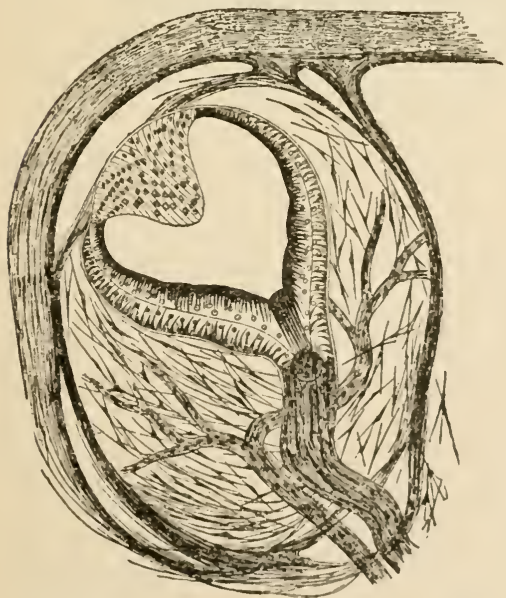

lig. 109.-Pineal eye of lizard, sphenodon (llatteria). (After Baldwin spencer.)

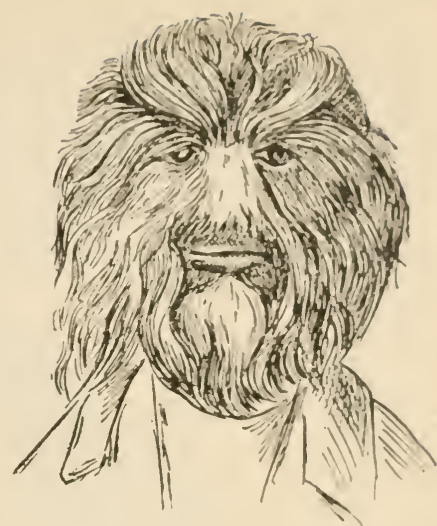

FIG. 108. - Andrian Jeftichjew, the Russian dog man, showing extraordinary covering of hair on the face. (After Wiedersheim.) by cases of atavistic development.

Within the brain of man, near the optic lobes, is a little spheroid structure scarcely larger than a pea, known as the "pineal gland" or conarium. It has no evident function, and Descartes once suggested that it might be the seat of the soul. It is larger in the embryo and still larger in the brains of some of the lower vertebrates. Recent investigattions have shown that it is especially developed in 
certain lizards, notably in a very primitive New Zealand lizard of the genus Sphenodon (Hatteria) (Fig. 109), and that, in these lizards, the pineal body ends in a more or less perfect eye-like structure placed between the true eyes in the center of the forehead. A trace of this eye is shown in the limbless lizard called slow worm (Anguis), of Europe, and in several American species. In the horned toad (Phrynosoma) (Fig. 110) its place

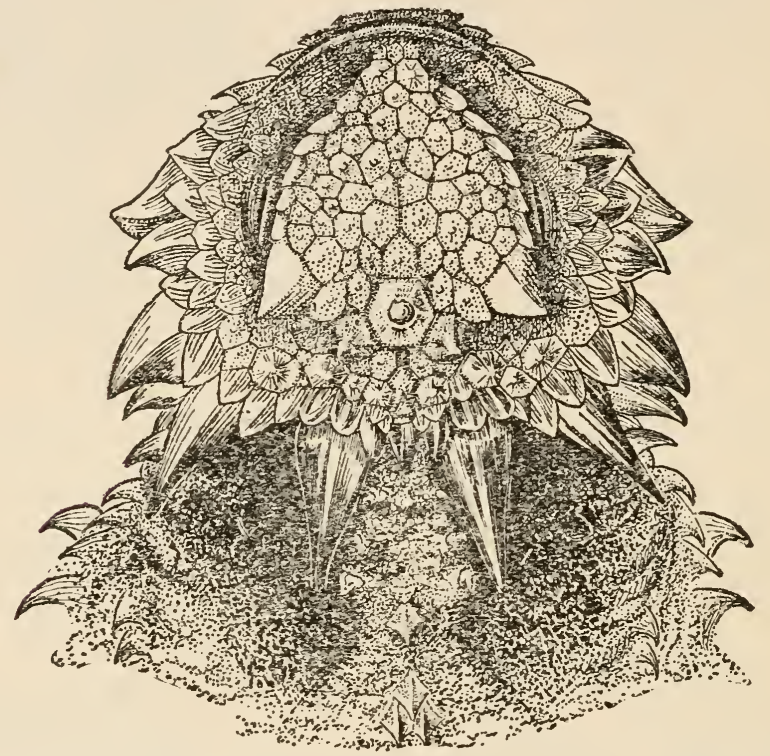

FIg. 110.-Head of lizard or horned toad, Phrynosom blainvillei, showing translucent pearly skin covering the pineal eye. (From specimen.)

is covered by a translucent pearly scale. These lizards have in fact three eyes, and the pineal body is the nervous ganglion from which the third eye arises. The natural conclusion from this that all vertebrates originally had three eyes, is probably a too-hasty one. Perhaps the pineal body was an organ of sense, which developed into an eye in the lizards and their ancestors only, not in any of the Amphibians or fishes, and not in any mammals or birds, although these are descended from reptilian stock. Whatever the origin or primitive function of the pineal ganglion, its existence in man as a vestigial organ is due to the persistence of heredity. 
In the living species of horse, Equus, there is but a single toe, with its basal bones. On each side of the base bone of this toe is a small bone known as a splint bone. The splint bones are apparently useless to the horse, but in extinct species of horse these bones are developed as digits, bearing small hoofs. Occasionally even now colts are born in which these splint bones bear rudimentary hoofs. In the museum of Stanford University is the leg of a high-bred colt from Milpitas, California, bearing a small hoof on each of the two splint bones.

The remains (Fig. 111) of over thirty different ancient horse-like animals have been found in the rocks of the
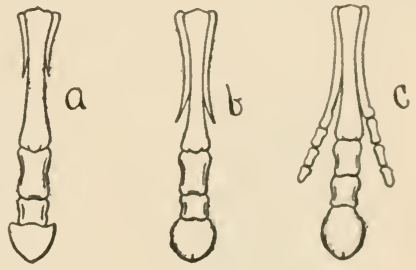

Tertiary era. The Eohippus, the earliest of these horselike animals, found in the oldest Tertiary rocks, was little larger than a fox, and its forefeet had four hoofed toes, with the rudiment of a fifth, while the hind feet had three hoofed toes. In the later rocks is found the Orohippus, also small, but with the rudimentary fifth toe of the forefoot gone. Still later appeared the Mesohippus and Miohippus, horses about the size of
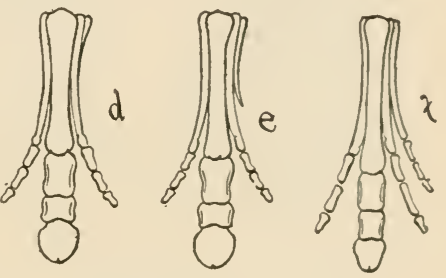

FIG. 111.-Foot changes in evolution of the horse: a, Equus, Quaternary (recent) ; $b$, Pliohippus, Pliocene; c, Protohippus, Lower Pliocene; $d$, Miohippus, Miocene; e, Mesohippus, Lower Miocene; f, Orohippus, Eocene. (After FIG. 254 of "Animal Studies.")

sheep, with three hoofed toes only, on both forefeet and hind feet, but with the rudiment of the fourth toe in the forefeet, of the same size in Mesohippus, smaller in Miohippus. Also, the middle toe and hoof of the three toes in each foot was distinctly larger than the others in both Mesohippus and Miohippus. Next came the Protohippus, a horse about the size of a donkey, with three toes, but with the two side toes on each foot reduced in size, and probably no longer of use in walking. The middle toe and hoof carried all the weight. Still later in the Tertiary era lived the Pliohippus, an "almost complete horse." The side toes of Pliohippus are reduced to mere rudi- 
ments or splints. This animal differs from the present horse somewhat in skull, shape of hoof, length of teeth, and other minor details. Lastly came the present horse, Equus, with the splint bones or concealed rudiments of the side toes very small and the hoof of the middle toe rounder. In spite of the great difference between the one-toed foot of the living horse and the dog's five-toed foot there was once a kind of horse which had a five-toed foot, and there is after all a close relationship between the foot of the horse and the foot of the dog.
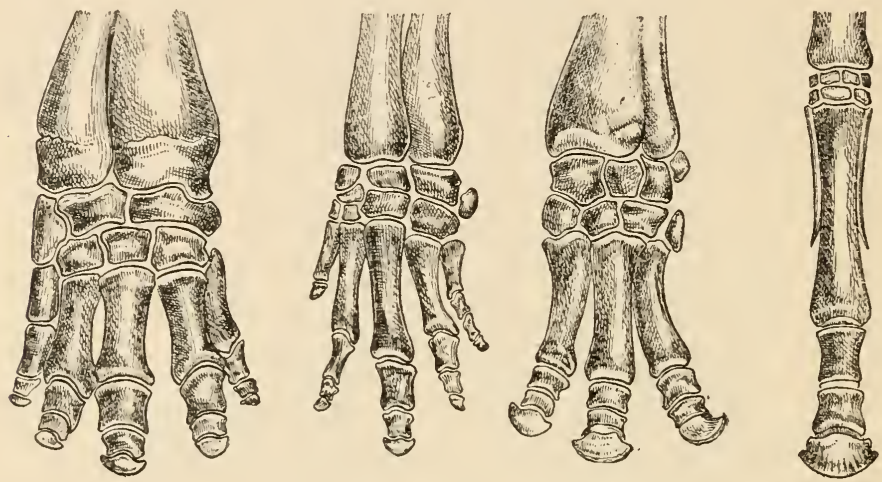

FIG. 112.- Homology of digits of four odd-toed mammals, showing gradual reduction in number and consolidation of bones above. (After Romanes.)

In man there is developed at the proximal end of the cæcum or blind sac of the large intestine a small structure as shown in Fig. 113. This appendage has no function, and it is subject to inflammation or suppuration, known as appendicitis. In the embryo the appendix rermiformis is notably larger than in the adult man; and in the lower animals, as in the dog or the kangaroo (see Fig. 113), it may be recognizable as a prolongation of the crecum, scarcely less in diameter than the intestine itself. The appendix vermiformis is therefore a vestige of a long cæcum which had its part in the process of digestion.

In the embryo of all chordate animals, without exception, respiratory or gill slits are developed, homologous with those seen in the embryo of the fish. The presence of theseslits or their vestiges is one of the most important secondary distinctive characters of the great group of Chordata, which includes the vertebrates. The human embryo is, in this regard, at certain 
stages essentially similar to the embryo of the fish. But in the course of development the gill slits in man and the higher vertebrates disappear. Their position is, however, indicated by the course of eertain blood vessels. These follow the lines blocked out in the embryo when they led to the gill slits, although no other trace of these slits persists in the adult, and this direction is not one which we could conceive as likely to have arisen except for the results of inheritance from the lower vertebrates.

In the veins of the higher animals valves are present, so arranged as to prevent the flow of blood backward and especially downward from the heart. In the lower animals, these valves are adjusted to the position on all fours. Their adjustment is the same in man, notwithstanding his erect posture. Apparently the adjustment of the valves was completed before the position on all fours gave way to the erect posture.
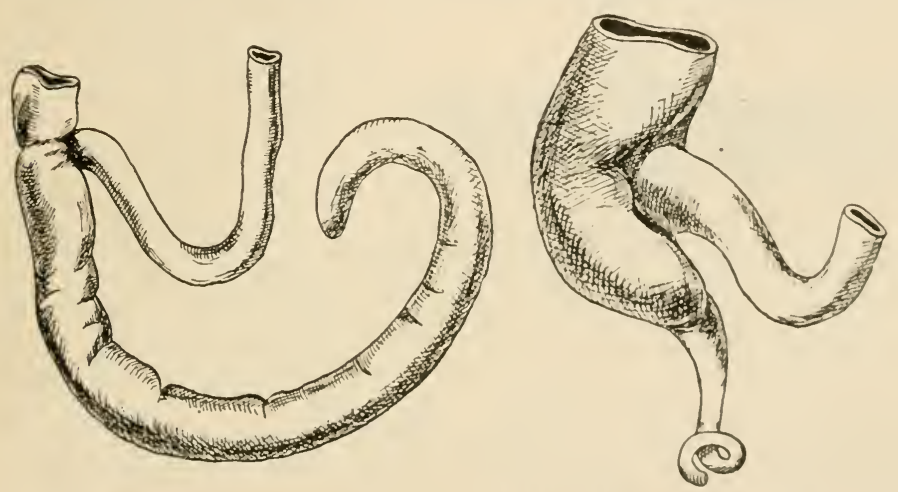

FIG. 113.-At left, appendix vermiformis of kangaroo; at right appendix vermiformis of human embryo. (After Wiedersheim.)

In the embryo of man there exists a regular tail, supported by eight distinct bones, like the tail of any other mammal. In the process of development, these bones are reduced in number and are joined, forming the coccyx or rudimentary tail.

In various species of fishes, lizards, salamanders, crayfishes, and other animals living in eaves or buried in the gromind, the eyes are atrophied. Numerous cases (Fig. 114) of this sort have been studied by Dr. Carl H. Eigenmann. He finds in general that the young cave fish have normally developed eyes, but that 
with growth atrophy sets in affecting different species differently, in some cases the muscles, in others the lenses, but in all cases reducing the size of the organ to a functionless structure more or less covered by the skin. In all cases, the ancestry of these blind species can be traced to forms with well-developed eyes inhabiting the same region. Among the species examined are the blind fish of Mammoth Cave (Amblyopsis spelceus), the cave blind fish of Kentucky and Indiana (Typlichthys subterra-

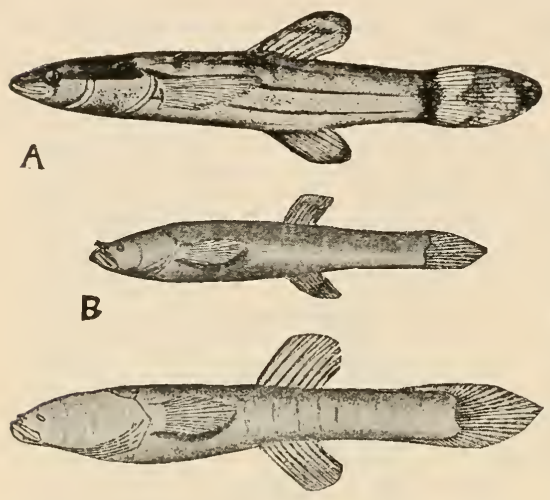

FIG. 114-Fishes showing stages in loss of eyes and color: $A$, Dismal Swamp fish, Chologaster cornutus, ancestor of the blind fish; $B$, Agassiz's cave fish, Chologaster agassizi; $C$, cave blind fish, Typhlichthys subterraneus. neus), descended from the Dismal Swamp fish (Chologaster cornutus), the Missouri blind fish (Troglichthys rose), the blind fishes of the caves of Cuba (Lucifuga subterranea, and Stygicola dentata) and the blind goby of Point Loma (Typhlogobius californiensis).

In Dr. Eigenmann's opinion, the retention of eyes in these species is due to the influence of heredity, the vestigial structures being each and all necessary

to life in the light. Their degeneration he ascribes to the inheritance of the individual effects of disease, a matter we discuss in another chapter.

Hundreds of cases of vestigial organs in plants have been recorded, among which we may mention the barren stamen in Pentstemon which completes the number of five usual in the group of Scrophulariaceæ to which Pentstemon belongs. Other illustrations are the rudimentary leaves, with rudimentary stomata, found on the joints of species of cactus (Opuntia), etc.; the cilia found on the spermatozoa of cycads, which would enable these structures to move freely in the water, although they are not deposited in the water, and these cilia are never actually used.

By the theory of special creation it was supposed that these 
rudiments were created in accordance with the tendency in creative processes to adhere to an ideal type. But it cannot be too clearly understood that tendencies in biology exist only as functions of particular organs. The tendeney to adhere to a type is a part of heredity, the function of the germ cell.

In the light of our knowledge of organic evolution it is clear that the presence of vestigial organs is simply a fact of heredity. They are organs once useful, but which through changed conditions of life have become needless.

It is a recognized fact that useless organs tend to dwindle away, but the cause of this phenomenon is not so clear. It may be due in part to (a) panmixia or cessation of selection, the organ being no longer held to a high grade of efficiency, to (b) reversal of selection, the advantage lying with those individuals in which the organ is no longer functional or $(c)$ the inheritance of the results of functional disuse. The latter offers an explanation which at first sight appears adequate, and its reality has been stoutly maintained by various witers of the Neo-Lamarckian school. In their views, changes in the individuals unquestionably due to individual or ontogenetic disuse are carried over to the species as phylogenetic disuse. Against this view is opposed its inconsistence with current theories of heredity, and also the positive fact that there is as yet no proof of the inheritance of acquired characters.

When we say that, through heredity, the offspring inherits the characters of the parent, we are speaking only a large and general truth. The details of this inheritance reveal in what regards this general statement must be modified. We have already noted the inevitable occurrence of at least small variations in all body parts in all individuals. In addition to this $\mathrm{ex}-$ ception to identical inheritance, certain characters of the parent may not, as just mentioned, appear at all in the offspring. And this may be due to any one of several causes.

First, certain parental characters are apparently really not heritable, namely, those new characters which have been acquired by the parent during its lifetime as the result of mutilation, disease, special use or disuse of parts, any change of parts due to direct reaction to a functional stimulus or to an environmental stimulus or cause, such as a bleaching due to lack of light, a thickening of the skin in certain places due to eon 
tact, etc. At least, there is not recorded any satisfactory proof of the inheritance of these acquired characters, and there is definite proof that many of them are not inherited. And most biologists, as helpful in many ways to a clearing up of the problem of adaptation and species-forming as the actuality of such inheritance would be, believe themselves unable to accept this fact, in the light of our present knowledge. (This matter of the inheritance of acquired characters is discussed in Chapter XI. The assumption of this inheritance is a fundamental part of the Lamarckian explanation of evolution.)

Second, certain characters peculiar to sex are inherited only according to sex and not by all the young. These characters include not only the differing reproductive organs themselves, but those many, various, and often most remarkably developed so-called secondary sexual characters, such as the tufts and plumes and brilliant plumage of male birds, the antlers of male deer, the specialized antennæ, skeletal processes, and color patterns of many male insects, and the reduced wings of many female insects, etc., etc. Even in cases of parthenogenetic reproduction (i. e., reproduction in which the male takes no part), sex and the sex characters of the offspring have no direct relation to the sex and sex characters of the mother. The queen honey bee produces, in fact, exclusively drones (male bees) when she lays unfertilized eggs, while on the contrary the parthenogenetic offspring of the Aphids (plant lice) are all females for several generations, and then in a single generation both males and females.

Finally, certain parental characters, even though blastogenic, may not appear in the offspring, but be inherited by them in latent condition, to appear in their young or perhaps even in a later generation. It is obvious, too, that where a certain character in the mother is represented in the father by one of opposite condition, as where the mother is very short, the father very tall, the mother a brunette, the father light-haired, a given child can inherit the character in only one condition. That is, in all cases of biparental reproduction, and they compose the majority of cases in both animal and plant kingdoms, the inherited characters cannot be all those possessed by both parents, but must be either those of one or the other, or a mosaic of them, or a blend or fusion of them. And this introduces us to that phase 
of the study of the results of heredity which to-rlay is being most investigated, the determination of the "laws" of inheritance of characteristics.

The similarity or dissimilarity of the two mating parents is a matter of much importance in regard to the results of inheritance. To produce a fertile mating the two parents have at least to be nearly allied. We are arcustomed to take this for

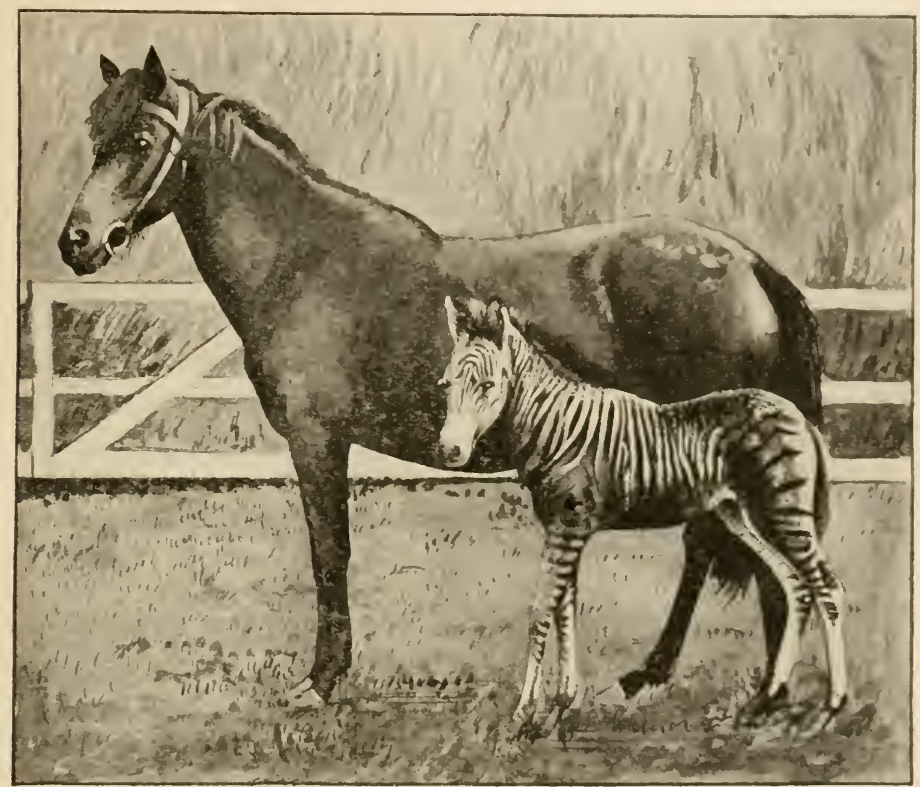

FIG. 115.-Romulus, the striped colt of a horse mother and zebra father. (After Ewart.)

granted, but the actual degree of phyletic relationship necessiury in fertile mating is a point of much biologic interest. In most cases both parents must belong to the same species of kiml, but among animals and plants there have been noted exceptions to this rule, these exceptions constituting the facts of hybridization.

Hybridism is practically limited to mating of different species of the same genera. Only in a few recorded cases have organisms of different genera mated in nature with the production of offspring. In zoölogical garlens and menageries the 
race feeling of the confined animals seems to break down, and unusual cases of hybridism are occasionally noted. Also mention must be made of the artificial induction of the fertilization of sea-urchin eggs by the sperm cells of starfishes (animals not only of different genera but of different classes), and a few other similar exceptional cases accomplished by Loeb and other experimenters. In many examples of hybridism the immediate offspring are unable to produce young and so no continuous series of generations results. In other fewer cases the offspring of hybridization are fertile, and thus constitute the beginnings of a new race or variety of animal or plant. Many of our domesticated animal races and cultivated plant varieties have originated by hybridism often artificially induced by man.

For the most part, however, both parents of any brood of young belong to the same species, and hence they are at least as like each other as the other members of the same species have to be. But this may still permit great superficial dissimilarity: many attributes, such as size, color, texture, outline. etc., of the body parts, especially the external ones, may be quite different. For within any species there may be several subspecies or varieties, the individuals of all of which are capable of fertile mating with each other. And even where there is no distinctly recognizable subspecific distinctions there may yet be much superficial dissimilarity among the individuals composing a single species. So in all studies of the results of heredity, of the actual inheritance of parental characters, the degree of likeness or unlikeness of the parents must be taken into account.

So that the "laws" of heredity, as formulated on a study not of its mechanism but of its results, refer to the character of the parental union, whether pure or crossed, and if crossed whether the parents are of different varieties of one species or of actually different species. As a matter of fact the crossing of parents with a few to many dissimilar characters has been the actual means of getting at some of the most important evidence as to the behavior of heredity that we have. For the very dissimilarity of the parental attributes makes it possible to trace in the progeny of succeeding generations the workings or results of heredity with reference to these particular characters.

Galton's Law of Ancestral Inheritance may be stated in few 
words, although for an understanding of the character of the evidence on which it is based, and for an appreciation of its whole significance some full account of it, preferably (ialton's own statement and discussion of it in his memoir entitled "The Average Contribution of Each Several Ancestor to the Total Heritage of the Offspring," published in 1897 , should be real. From a study of the carefully kept pedigree book of the kennels of the Basset Hounds Club, with records extending through twenty-two years, and a study of inheritance in the British Peerage made possible by the complete genealogic reeords kept for these families, together with a consideration of various other less detailed but at least helpful records of inheritance, Galton formulated the statement that any organisin of bisexual parentage derives one half its inherited qualities from its parents (one fourth from each parent), one fourth from its grandparents, one eighth from its great-grandparents, and so on. These successive fractions, whose numerators are one and whose denominators are the successive powers of two, added together equal one or the total inheritance of the organism: thus $\frac{1}{2}+\frac{1}{4}+\frac{1}{8}+\frac{1}{16}+\frac{1}{32}+\frac{1}{64}+\ldots=1$.

The English mathematician and natural philosopher, Karl Pearson, has made computations showing that Cralton's law thus simply expressed is only a close approximation to the actual inheritance relations, and that the fraction indicating the contribution of any given ancestor must be slightly modified by introducing into it another factor. In general, though, the Galtonian formula received a very general acceptance among biologists. And only recently, in the light of the disenvery of Mendel's investigations and conclusions and their confirmation in essential principle by the recent researches of variouls botanists and zoölogists, has Galton's law been looked on as altogether too simple and incomplete a formulation of the facts of inheritance. It is not yet quite certain whether Galton's formula is consonant with the Mendelian formula or not. But at best Galton's law only expresses a part of what may now with confidence be said to be known of the regular course of inheritance.

Before taking up the actual ITendelian results and conclusions, however, it is important for us to note the different modes or kinds of behavior of inheritance which characteristies maty show in their transmission. ('uenot has made a rough but 
suggestive classification of thase inheritance categories as follows:

In cross matings - and by " cross mating," students of heredity do not necessarily mean mating between distinct species or even varieties, but mating between parents which disagree in the condition of one or more specifically referred to characteristics-in cross mating between the parents $A$ and $B$, if we consider a single pair of corresponding characters $a$ and $b$ which differ in the two parents, the young produced by the crossing may (1) all present the same parental character $a$ without any trace of the character $b$, the character $a$ being then termed dominant or prepotent or prevalent, the other recessive or latent; or, (2) the young may all agree in presenting a new character differing from the parental characters $a$ and $b$, this new character apparently being a simple physical mixture or a real chemical combination or blending of $a$ and $b$; or (3), the young may differ from one another in regard to the parental characters $a$ and $b$, some showing the character $a$, some showing the character $b$; or (4) the young may differ among themselves in regard to the characters $a$ and $b$, some showing the character $a$, some the character $b$, and some various characters intermediate between $a$ and $b$; or (5) the young may show the characters $a$ and $b$ side by side in each individual in small separated parts, even in neighboring but distinct cells. These differences undoubtedly depend partly on the nature of the characteristics themselves, partly on the kind of organism, and partly on extrinsic influences. It is obvious also that for certain characteristics by no means all five of these ways are open. Many characters are so wholly antagonistic that no blend nor any mosaic of them can occur in a single individual, leaving only ways (1) and (3), viz., exclusive or alternative inheritance open to them.

To these five general categories of the actual transmission of certain obvious parental characters may here be added for consideration those cases of the appearance in the young of $c_{s}$ character or characters having no obvious relation to either $a$ or $b$, but sometimes explicable as reversions or reappearances of characters possessed by ancestors more or less remote and other times as obviously wholly new and heretofore never existent characters which, if pronounced, are called "sports" or sudden or discontinuous variations. Also must be taken into account the possible appearance among the young, of a few to 
many individuals showing many simultaneous, usually slight but real differences from the parents in various parts and functions. These are the differences called mutations by de Vries ,nd his followers, and are the basis of the at present considsr bly accepted theory of species-forming by heterogenesis or sudden complete fixed modifications of organic types. In the light of the observations and experiments of de Vries, these mutations are of special importance in any consideration of hereiity and variation. (See p. 157, Chapter IX, for a brief acenunt of these mutations.)

The Mendelian "laws" apply only, probably, to certain particular categories of inheritance, or rather categories of characters. That is, so far as worked out, the Mendelian principles seem to have definite application only to cases of inheritance in which the characteristies under observation are mutually exclusive or alternative in character; categrories (1) and (3) in our list in a preceding paragraph are the only ones under the rule of the Mendelian principles, and there are even some exceptions in these categories. The various other kinds of inheritance, called blended or combined (where the two characteristics fuse or blend to form a new condition), and mosaic or particulate (where both parental characteristics exist side by side in each individual among the young), apparently require for their explanation something besides the Mendelian principle.

At some time between 1855 and 1865 Gregor Joham Mendel, an Augustinian monk in the small Austrian village of Brünn, carried on in the gardens of his cloister pedigree cultures of peas and some other plants from which he derived data which he read. together with his interpretation of their significance, before meetings of the Natural History Society of Brimn, and which in the same year of their reading (1S65) were published under the title "Exporiments in Plant-hybridization," in the Abhamelungen (vol. iv), of the society. Mendel was the son of a peasant, and had been edueated in Augustinian foundations and ordained a priest. For two or three years he studied physies and natural science in Vienna, and refers to himself in one of his papers as a student of Kollar. He heeame abbot of his cloister. and was for a time president of the Brïm Nitural History Society. Such are the exisential details of the education and work of the man whose name will undoubtedly live forever in the annals of biological science. 
Mendel's principal data were derived from the crossing of varieties of peas (Pisum sativum) in which he found several pairs of well-marked contrasting characters. Bateson gives a clear and concise summary account of Mendel's methods and results which we quote in the following paragraphs. For the purposes of his experiments Mendel selected seven pairs of characters as follows:

1. Shape of ripe seed, whether round; or angular and wrinkled.

2. Color of "endosperm" (cotyledons), whether some shade of yellow; or a more or less intense green.

3. Color of the seed skin, whether various shades of gray and gray-brown; or white.

4. Shape of seed pod, whether simply inflated; or deeply constricted between the seeds.

5. Color of unripe pod, whether a shade of green; or a bright yellow.

6. Nature of inflorescence, whether the flowers are arranged along the axis of the plant; or are terminal and form a kind of umbel.

7. Length of stem, whether about six or seven feet long, or about three fourths to one and one half feet.

"Large numbers of crosses were made between peas differing in respect of one of each of these pairs of characters. It was found that in each case the offspring of the cross exhibited the character of one of the parents in almost undiminished intensity, and intermediates which could not be at once referred to one or other of the parental forms were not found.

"In the case of each pair of characters there is thus one which in the first cross prevails to the exclusion of the other. This prevailing character Mendel calls the dominant character, the other being the recessive character. ${ }^{1}$

"That the existence of such 'dominant, and 'recessive' characters is a frequent phenomenon in cross breeding, is well known to all who have attended to these subjects.

"By letting the cross-breds fertilize themselves Mendel next raised another generation. In this generation were individuals which showed

1 "Note that by these novel terms the complications involved by the use of the expression 'prepotent' are avoided." 
the dominant character, but also individuals which presented the recessive character. Such a fact also was known in a good many instances. But Nendel discovered that in this generation the numerieal proportion of dominants to recessives is on an average of ratise's approximately constant, being in fact as three to one. With very (onsiderable regularity these numbers were approached in the case of each of his pairs of characters.

"There are thus in the first generation raised from the crossbreds seventy-five per cent dominants and twenty-five per cent recessives.

"These plants were again self-fertilized, and the offspring of each plant separately sown. It next appeared that the offspring of the recessive remained pure recessive, and in subsequent generations never produced the dominant again.

"But when the seeds obtained by self-fertilizing the dominants were examined and sown it was found that the dominants were not all alike, but consisted of two classes: (1) those which gatve rise to pure dominants, and (2) others which gave a mixed offspring, composed partly of recessives, partly of dominants. Here also it was found that the average numerical proportions were constant, those with pure dominant offspring being to those with mixed offspring as one to two. Here it is seen that the seventy-five-per-cent dominants are not really of similar constitution, but consist of twenty-five which are pure dominants and fifty which are really eross-breds, though, like the cross-breds raised by crossing the two original varieties, they only exhibit the dominant charaeter.

"To resume, then, it was found that by self-fertilizing the original cross-breds the same proportion was always approached, namely:

25 dominants, 50 cross-breds, 25 recessives,

$$
\text { or } 1 \mathrm{I}): 2 \mathrm{DR}: 1 \mathrm{R} \text {. }
$$

"Like the pure recessives, the pure dominants are thenceforth pure, and only give rise to dominants in all succeeding generations studied.

"On the contrary the fifty cross-breds, as stated above, have mixed offspring. But these offspring, again, in their numerical proportions, follow the same law, namely, that there are three dominants to one recessive. The recessives are pure like those of the last generation, but the dominants can, by further self-fertilization, and examination or cultivation of the seeds produced, he again shown to be made up of pure dominants and cross-breds in the same proportion of one dominant to two cross-breds. 
"The process of breaking up into the parent forms is thus continued in each successive generation, the same numerical law being followed so far as has yet been observed.

"Mendel made further experiments with Pisum sativum, crossing pairs of varieties which differed from each other in two characters, and the results, though necessarily much more complex, showed that the law exhibited in the simpler case of pairs differing in respect of one character operated here also.

"In the case of the union of varieties $A B$ and $a b$ differing in ro distinct pairs of characters, $A$ and $a, B$ and $b$, of which $A$ and $B$ are dominant, $a$ and $b$ recessive, Mendel found that in the first cross-bred generation there was only one class of offspring, really $A a B b$.

"But by reason of the dominance of one character of each pair these first crosses were hardly if at all distinguishable from $A B$.

"By letting the $A a B b$ 's fertilize themselves, only four classes of offspring seemed to be produced, namely:

" $A B$ showing both dominant characters.

" $A b$ showing dominant $A$ and recessive $b$.

" $a B$ showing recessive $a$ and dominant $B$.

" $a b$ showing both recessive characters $a$ and $b$.

"The numerical ratio in which these classes appeared was also regular and approached the ratio

$$
9 A B: 3 A b: 3 a B: 1 a b \text {. }
$$

"But on cultivating these plants and allowing them to fertilize themselves, it was found that the members of the

Ratios

$1 a b$ class produce only $a b$ 's.

$3\{1 a B$ class may produce either all $a B$ 's,

$3\{1 A b$ class may produce either all $A b$ 's

$\{2$ or both $A b$ 's and $a b$ 's.

$9 \begin{cases}1 A B & \text { class may produce either all } A B \text { 's } \\ 2 & \text { or both } A B \text { 's and } A b \text { 's, } \\ 2 & \text { or both } A B \text { 's and } a B \text { 's, } \\ 4 & \text { or all four possible classes again, }\end{cases}$ namely, $A B$ 's, $A b$ 's, $a B$ 's, and $a b$ 's,

and the average number of members of each class will approach the ratio $1: 3: 3: 9$ as indicated above.

"The details of these experiments and of others like them made with three pairs of differentiating characters are all set out in Mendel's memoir," 
Perhaps the most striking thing about Mendel's work is the singularly suggestive and lumirsus interpretation which he gave of just why the pea characteristic's were transmitted exactly as they were; why, in general, tho peculiar numerical ratio between dominant and recessive should be, and why it should persist so uniformly. This interpretation or explanation is now well known in biology as the theory of the "purity of the germ sells," or, as Cuenot has called it, the theory of "gamites disjoints," or "la disjonction des charactères dans les gamètes des hybrides" (the separation of characters in the germ cell of hybrids), the Spaltungsgesetz of de Vries.

This interpretation is simply that in the young of the first generation after a cross-mating, although because of dominance but one of the contrasting pair of parental characters will show itself in the body make-up, yet when these young form their germ cells the two parental characteristics will be represented, but only one in any one germ cell; that is, in the case of Mendel's peas that the pollen cells and ovvule cells produced by the cross-bred young would carry each one of the alternative or mutually exclusive parental varietal characters. If this were the ease and if, on an average, the pollen cells and ovule cells were evenly divided as to the two characteristics, then by miscellaneous or random mating (mating according to the law of probabilities) between these cells we should get in the developed young just such conditions with regard to the contrasting characteristics as Mendel actually did get in his peas. For twenty-five per cent of the pollen grains representing the dominant character would unite with twenty-five per cent of the ovule cells representing the dominant character, twenty-five per cent of the recessive pollen grains with twenty-five per cent of the recessive ovule cells, and the remaining fifty per cent of each kind with each other; that is, of every four pollen grains and every four egg cells we should get by random pollination 1 pollen dominant $\times 1$ ovule dominant; 1 pollen recessive $\times 1$ orule recessive; 1 pollen dominant $\times 1$ ovule recessive; 1 pollen reeessive $\times 1$ ovule dominant. This condition would bring it about that the fully developed young would show the contrasting characteristics (remembering the dominance of one of the characteristies in those eases in which dominant and recessive are unitel), in this condition: 31), 1R. Which is exactly what occurred in Mendel's peas, and has since been noted to occu! 
in many other cases recorded by post-Mendelian observers and experimenters. These records are of both plants and animals, and are fast multiplying.

Thus the so-called Mendelian laws of heredity refer to two phases of the problem of inheritance-viz.: (1) how inherited characters are actually distributed, and (2) the fundamental cause, lying in the germ plasm, for this particular kind of distribution. Like Galton's formula, Mendel's law expresses the regularity of heredity based on actual recorded statistics of inheritance; but it also gives a satisfying fundamental reason for this regularity. Biologists, with few exceptions, see in the establishment of the Mendelian principles of heredity in biologic science the greatest advance toward a rational explanation of inheritance that has been made since the beginning of the scientific study of the problem.

The extraordinary fact that Mendel's work lay practically unnoted for thirty-five years (actually the only reference to it in scientific "literature" in all that time seems to have been one by Focke in 1881 in Die Pflanzenmischlinge, p. 109), has been partly explained by Bateson as due to the driving interest felt through all that time by biologists generally in other phases of investigation; but it remains a curious commentary on the possibilities of the temporary obscurity that may be in store for even the best scientific work. The "discovery" of Mendel's work seems to have been made in 1900 by three investigators almost simultaneously, who also discovered independently the same important facts of the transmission behavior in inheritance of exclusive or alternative characteristics. These men are de Vries, Tschermak, and Correns, and their published papers not only verify Mendel's particular work on the peas, but confirm his principles or laws on the basis of much added experimentation and observation on other plants. In the last five years zoölogists, notably von Gnaita working with mice, Cuenot, Darbishire, Davenport, Bateson and Castle with mice, rabbits, guinea-pigs and chickens, McCracken with certain beetles, and Toyama, Mrs. Bell and Kellogg with silkworms, have shown that Mendelian principles obtain in animal as well as in plant inheritance. For the results of all of these investigations in large measure confirm our confidence in the Mendelian principles of dominance and recessivity and of the purity of germ cells. But also in nearly all of these studies the investigators 
have found some inconsistencies and have caught glimpses of other principles which, when finally grisped, will undoubterlly considerably limit the application of Mendel's laws, but will, almost certainly, not detract from their importance, nor lessen in any degree the high place in science that belongs to the patient, persistent, clear-minded Augustinian monk of the cloister gardens of Brünn.

One of the modifications of the Mendelian behavior of hybrids which has been shown to exist in certain cases, is that the young of the cross-mated parents may not all exhibit in the same degree the dominant characteristic, although in the subsequent generations the regular Mendelian three-to-one splitting up into dominant and recessive appearance may occur. The young of the first generation may include a very few individuals showing the recessive character, as de Vries found in mating two varieties of Papaver somniferum (ninety-seven per cent showed the dominant character, three per cent the recessive). Or the first generation may show a sort of pseudoblend condition, approaching but not duplicating exactly the dominant characteristic, as occurs when Hyoseyamus pallidus is crossed with $H$. niger (de Vries, "Die Mutationstheorie," Bd. II., p. 162.)

When silkworm moths of the race Shanghai, with white cocoons, are crossed with moths of the race Yellow Var. with rose-yellow cocoons, the hybrid offspring make straw-yellow cocoons of a tint just between the two parent tints. The coloring matter of the grapevine Aramon has the chemical formula $\mathrm{C}_{46} \mathrm{H}_{36} \mathrm{O}_{20}$, and the coloring matter of the race Teinturier has the formula $\mathrm{C}_{44} \mathrm{H}_{40} \mathrm{O}_{20}$ : the hybrid offspring called PctitBouschet, of a crossing of these two, has coloring matter of the formula $\mathrm{C}_{45} \mathrm{H}_{38} \mathrm{O}_{20}$, exactly intermediate. These are specific cases of blended inheritance and there are many others known. Mendel once got as the result of a crossing betwern two pea races, one one foot in height and the other six feet, hybrids mcasuring from six to seven and one half feet high.

Also when the plant Mirabilis jalapa $q$, with red flowers, is crossed with a male variety with white flowers the hybrid offspring exhibit red flowers (maternal type), white flowers (paternal type), and flowers streaked with the two colors. so when corn with blue kernels is crossed with com with white kernels, a hybrid is obtained exhibiting on a single car blue 
kernels, white kernels, kernels of intermediate bluish-white tint and kernels streaked with blue and white. The streaked flowers and kernels of these two cases are due to mosaic inheritance.
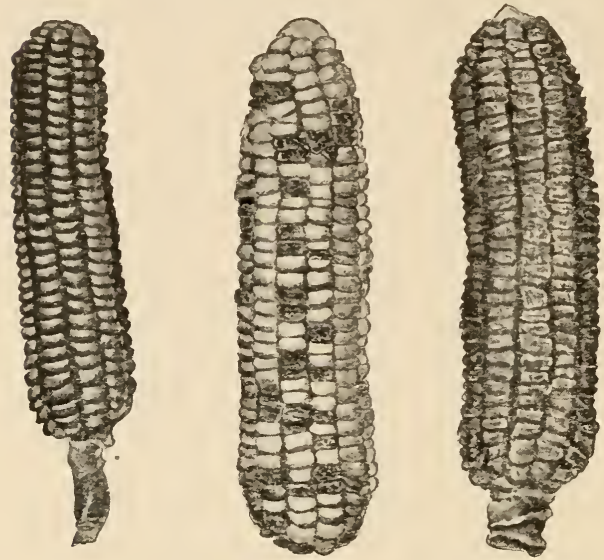

FIG. 116.-At left an car of fiel.l corn; at right an ear of sweet corn; and in the middle a hybrid of these two, showing alternation of kernels resembling those of each different parent. (After de Vries.)

Or the apparent dominance of the contrasting characteristics may be proved to have something of real dominance about it, as Miss McCracken has so clearly shown in her studies of the inheritance of dichromatism in the little beetles Lina lapponica (Fig. 117) and Gastroidea dissimilis. Here the first two or three generations behave in true Mendelian manner, but with successive generations the dominant character is plainly seen to be gradually extinguishing the recessive character in the crosibred groups, so that in the seventh generation after the origins cross-mating the Mendelian ratio of 2 to 1 in the cross-bred group is changed to 28 to 1 .

There may occur also a breaking up or decomposition of the parental varietal characters, which may mean that the dominant and recessive characters are not simple
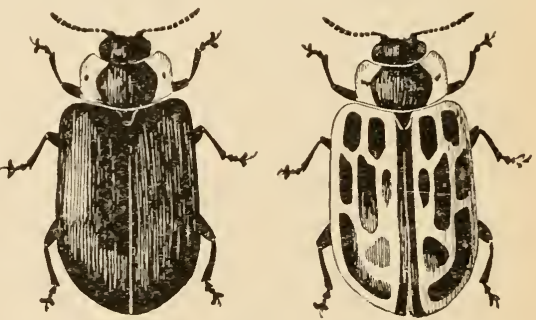

FIG. 117.-Lina lapponica, showing its two forms, one black and one spotted. (After McCracken.) ones but are complex-

i. e., really the resultant of several combined characteristics; or it may mean that there exists a real instability in the parent type and that the stimulus or influence of the cross-mating is all 
that is needed to break down this weak apparent stability of tl.c type and allow its component characters (the clementary units of de Tries) to recombine into various ney and differing types. This condition seems to be that which results in the extranrdinary variation so commonly observed by plant and animal breeders as brought out by hybridization, and which is (constantly made use of by these breeders. Luther Burbank depends very largely on this initial abundant and eccentric variation induced by wide hybridizations for "starters" for his work of producing "new creations."

So in accepting Mendel's laws of heredity we must bear clearly in mind that they by no means apply to all, or, at any rate, that our present knowledge of them does not include their application to all, cases and categories of inheritance. 


\section{CHAPTER XI}

\section{INHERITANCE OF ACQUIRED CHARACTERS}

Tout ce qui a été acquis, tracé ou changé dans l'organisation des individus, pendant le cours de leur vie, est conservé par la génération et transmis aux nouveaux individus qui proviennent de ceux qui ont eprouvé ces changements.-LAMARCK.

Heaven forfend me from Lamarck nonsense of a tendency to progression, adaptation from the slow willing of animals, etc.; but the conclusions I am led to are not wholly different from his, though the means of change are wholly so.-Darwin to Hooker, 1848.

The "fourth Law of Evolution," as expressed by Lamarck in his "Zoölogical Philosophy," reads as follows: "All that has been acquired, begun, or changed in the structure of individuals in their lifetime, is preserved in reproduction and transmitted to the new individuals which spring from those which have inherited the change."

This principle was used by Lamarck as one of the fundamental elements in his theory of the transmutation of species. For nearly a hundred years it attracted little attention, being accepted as a part of the law of heredity by most persons, even by those most opposed to the essential part of Lamarck's theory, the derivation or transmutation of species. Among others, Darwin accepted it as one of the factors in evolution of forms. With Herbert Spencer it became one of the fundamental principles of the philosophy of Evolution. Mr. Spencer states the proposition in this way: "Change of function produces change of structure: it is a tenable hypothesis that changes of structure so produced are inherited." For the supposed inheritance of characters produced by the impact of environment or by resultant activities of the individual the term progressive heredity has been devised. The fact of the existence of pro- 
gressive heredity, more or less taken for granted by writers of the last century, was ftatly denied by Dr. August Weismann, who insisted that it was necessary that the theory of the inheritance of characters acquired in the lifetime of the individual should no longer be aceepted without definite proof.

In the theory of heredity through the developunent of the germ cell controlled by influences exerted by structures within the mucleus, Weismann found no room for the inleritance of characters not preëstablished within this germ. External influences in general cannot reach the germ cells, and throughout nature the germ eclls are elaborately protected from the direct influence of external conditions.

This attack upon sn ancient theory roused its supporters to defend their faith and to search for evidence to support it. A temporary division of naturalists into two schools arose as a result of this discussion. Those who l:chl with lamarck and spencer that characters gained in the life time of the individual, and not received from ancestors possessing them, became hereditary, were known as Neo-Jamarckians. 'Those who, with Weismann, denied the existence of this factor and from a necessity, real or foncied, laid special st ress on the Darwinian principle of natural selection, assumed the title of Neo-Darwinians. In their hands the Darwinian principle became the all-powerful factor in evolution, a theory of Allmacht which was soon questioned from other quarters and by those not considered as Neo-Lamerckians. Prominent among the leaders of the NeoLamarckians were Herbert Spencer, Hacekel, Nïgeli, Cope, Fimer, Hyatt, Gadow, Dall, Packard, and others. Among the recognized Neo-Darwinians were Weismann, Wallace, Huxley, Giay, Brooks, Iankester, and others.

After some years of controversy, mostly theoretical, the discussion has been tacitly dropped by biologists generally. It is recognized that the sole crucial test is that of experiment, that experiment is not easy, inasmuch as it is rery diffeult to show that sny given trait in heredity really helongs to the categery" of acquired characters, and that in no ease has it been indubitably shown that any character not inborn has been inherited. Moreover the studies of the germ cell and the phrsical basis of heredity tend to show that the structures of the germ cell are more complex and that the processes of heredity are in a sense more mechanical than eould have been supposed in the time of 
Lamarck or even that of Darwin cir Spencer. The characters shown by any adult individual are all in a sense acquired characters, their development dependent largely on nutrition and on the influences of environment. The facts of heredity show that it is not the actual traits of the parents, but rather their potentialities which are inherited. Moreover, acquired characters are simply matters of degree of development. They represent in no case anything qualitatively new. Taking the modern theories of heredity, it is perhaps not conceivable that "all that is acquired, begun, or changed" in the physical or mental life of the individual should produce a corresponding change in the germ cells, or in the cells from which these are thrown off.

On the other hand, Dr. Weismann has admitted the possibility that one-celled animals and animals of simple structure in which the germ cell shares in the general relation of the body cells to the environment may be efferted by developmental conditions. In other words, the inheritance of acquired characters may be a reality in the development of Protozoa, the simpler Metazoa, and the lower types of plants, but this condition does not obtain among the higher forms.

In much of the discussion on this subject the term "acquired characters" is used with an uncertain or double meaning. The term should be limited to traits of the individual which were not inborn or blastogenic, and would not be exhibited in the natural or usual development of the individual. In general, such traits would arise either from the operation of use or disuse of parts, or other functional stimulation derived from the environment.

An illustration of an acquired character resulting from use and disuse would be the increased size of the arm in the blacksmith, or the decreased leg muscles of the tailor. The training of a musician or of a mathematician would give increased power along the lines of the training. The neglect of the musical or of mathematical ability would lead to the relative mediocrity of this form of ability. Education in a general way increases mental capacity: neglect of education allows it to become relatively less. The supposed inheritance of results of civilization forms an important part of the philosophy of Herbert Spencer. Is civilization the inheritance of the power gained by past successes, or is it simply the acquisition of the machinery which past successes have produced? As to this Herbert Spencer 
remarks: "Considering the width and dejth of the effects which the acceptance of one or the other of these hypotheses raust have on our views of life, the question, Which of them is true? demands beyond all other questions whatever the attention of scientific men."

Other illustrations of the supposerl effect of use and disuse are thus discussed by I)r. Edwin Grant Conklin:

"In the first place, this whole line of argument starts with the assumption that the individual habits of an animal are inherited, and that these habits ultimately determine the structure, an assumption which really begs the whole question; for, after all, the substratum of any habit must be some physical structure, and if modified hahits are inherited it must be because some modified structure is inherited. I take an example which will serve as an illustration of a whole class: Jackson says that the elongated siphon of Mya, the long-necked clam, is due to its habit of burrowing in the mud, or to quote his words: 'It seems very evident that the long siphon of this genus was brought about by the effort to reach the surface, induced by the inabit of deep burial.' It certainly would be pertinent to inquire where it grot this habit, and how it happened to be transmitted. It is surely as difficult to explain the acquisition and inheritance of habits, the basis of which we do not know, as it is to explain the arcuisition and inheritance of structures which are tangible and visible. Such a method of procedure, in addition to begging the whole question, commits the further sin of reasoning from the relatively unknown to the relatively known.

"This case is but a fair sample of a whole class, among which may be mentioned the following: The derivation of the long hind legs of jumping animals, the long forelegs of climbing animals, and the elongation of all the legs of ruming animals through the influence of an inherited habit. All such cases are open to the very serious objection mentioned above.

"Another whole class of arguments may be redueed to this proposition: Because necessary mechanical conditions are never violated by organisms, therefore modifications due to such conditions show the inheritance of aequired characters. Plainly, the alternutive propos sition is this: if aequired characters are not inhorited, organisms ought. to do impossible things.

"Many of the arguments advanced to prove the inheritance of characters acquired through use or disuse seem to me to prove eptirely 
too much. For example, Professor Cope argues very ably that bones are lengthened by both stretch and impact, and that modifications thus produced are inherited. Even granting that this is true, how would it be possible for this process of lengthening to cease, since-in active animals the stretch and impact must be continual? Professor Cope answers that the growth ceases when 'equilibrium' is reached. I confess that I cannot understand this explanation, since the assumed stimulus to growth must be continual. But, granting again that growth may stop when an animal's legs become long enough to 'satisfy its needs,' how on this principle are we to account for the shortening of legs, as, for example, in the turnspit dog and the ancon sheep and numberless cases occurring in nature? If any one species was able, by taking thought of mechanical stresses and strains, to add one cubit unto its stature, how could the same stresses and strains be invoked to decrease its stature?

"These evidences are, I know, not the strongest ones which can be adduced in support of the Lamarckian factors. There are at present a relatively smali number of such arguments which seem to be valid and the great force of which I fully admit. But the cases which I have cited are, I believe, fair samples of the majority of the evidences so far presented, and in the face of such 'evidence' it is not surprising that one who is himself a profound student of the subject and a convinced Lamarckian prays that the Lamarckian theory may be delivered from its friends." 1

As to the inheritance of the effects of extrinsic forces on the individual, we find little in the way of direct evidence.

In all the members of the large family of flounders and soles, the adult fish rests flat on the bottom and swims on its side, the cranium being twisted so that both eyes appear on the upper side. As a rule color cells are developed on the upper side only, the lower cells remaining largely uncolored or white. In the young of all species the head is symmetrical, both eyes being normally situated, and the fish swims vertically in the water. Little by little, as development goes on, the fish turns over to one side, and the eye of the lower side passes around or through the forehead to join its fellow on the upper side. On the upper side pigment cells develop, while on the lower side they remain

${ }^{1}$ H. F. Osborn, "Evolution and Heredity," Wood's Holl Biological Leitures, 1890. 
imperfect. Howerer, in a flounder reared under conditions in which the light falls on the lower side, pigment rells are developed also on that sicle.

It has been claimed by certain writers, as Cumninglam, that the twisting of the head in the flounder is due to the inleritance of an acquired character. A flat fish without air bladder, resting on the sea bottom, naturally falls on one side. The eye thrust into the sand is naturally twisted around to the upper side, and this tendency begum in rery young individuals becomes hereditary, while the lack of pigment on the under side is also transmitted by inheritance. I3ut it is just as easy to chaim that the furst trait of adaptation is due to natural seleretion, and that the whiteness of the blind side is ontogenetie, due to the absence of light in the growth of the individual. In : ny r.se, no specific theory of the origin of the twist of the flounder's head can be regarded as proved.

It is well known, as Dr. Conklin observes, that certain water snails "if reared in small ressels are smaller than when grown in large ones," and this case has been cited as sliowing the influence of environment in modifying species. Tlese is good evidence, however, that this modification does not affect the germinal protoplasm, for these same gasteropods will grow larger if placed in larger vessels. It scems very y:obable that the diminished size of these animsls is due to dicficicnt foor supply, but this has so little modified the somatir motoplasm that, although they may be fully developed as shom n hy sexual maturity, they at once increase in size as sonn a more a lundant food is provided, and this takes place by the active crowth and division of all the cells of the body. In higher an imals, once maturity has been reached, there is little (llonce for growth, apparently because many of the cells are sn higlly clifferentiated that they can no longer divide; conseguently tl e growth is limited, and hence the size of the adult may dejwnd in part upon the arount of nutriment furnished to the ambryo. This limitation of growth is due to the high degree of differentiation of the somatic cells. But as the germ colls are not highly differentiated and are capable of division, it follows that they would not be permanently modified by starving. It may be. as Professor Brewer argues, that long-contimued starving and consequent dwarfing of amimals may lave its mark on the germinal plasm; but, as he alio remarks, this influence must be 
very slight as compared with the cumulative efiects of selection in breeding, and it is safe to assert that there is no such wholesale and immediate modification of the germinal plasm due to nutrition as some people seem to suppose."

As a matter of fact experiment has shown that the results of dwarfing due to lack of food are shown for three generations in silkworms (these subsequent broods of larvæ being full fed but producing dwarfed moths). But with succeeding generations the moths became larger and resumed their normal appearance.

Mutilations of any sort are not inherited. The tails of sheep have been cut off for countless generations. Yet each lamb is born with a tail. This law holds good for docked tails, docked ears, pierced ears, and the many mutilations to which domestic animals and men have been subject since the beginning of civilization.

Influences of climate, of heat, of cold are not inherited so far as experiment shows, nor has it been made clear that any extrinsic influence exerted on the individual really modifies the forces of heredity. Even Lamarck admits this. He observes: "Circumstances change the forms of animals. But I must not be taken literally, for environment can effect no direct changes whatever upon the organization of animals."

In Spencer's view, the phenomena of instinct are to be explained as the inheritance of habits of the individual. The Neo-Darwinians see in the adaptations of instinct only the results of natural selection acting upon the endless variations to which individual instincts are subject. In most cases the latter view seems the most probable. In some cases it hardly offers a plausible explation.

The young mocking bird shows an inborn dread of owls and cats, while it is relatively indifferent to the presence of dogs or chickens. It seems hardly reasonable to suppose that all mocking birds without this instinct of dread for these fs-ticular animals have been destroyed, while the others have survived. Still more deep seated is the dread of snakes possessed by all the monkey species known to us, as well as by their human allies. Most men and most monkeys have a different feeling in regard to snakes from that exhibited toward any other sort of animals. This feeling is inborn. It may be suppressed, but not often wholly conquered. To call it an inherited experience is easy, 
but in default of other idence for the inheritanee of experiences, the explanation is not satisfactory. But it is not easy to believe that in early times those without this instinct fell victims to venomous snakes through their own fearlessness. It is perhaps not necessary to take sides on this question. Any view we may adopt rests for confirmation mainly on the improbability of what we conceive to be the opposite alternative.

Conklin further observes that the

"so-called facts [of progressive heredity] are merely probabilities of a higher or lower order, and to one man they seem more important than to another. No conviction based even upon a high degree of probability can ever be reached in this way. There is here a deadlock of opinion, each challenging the other to produce indubitable pronf. This can never be furnished by observation alone. Possibly even experiment may fail in it, but at least it is the only hope."

We shall not assist science, says Osborn,

"with any evolution factor grounded upon logic rather than upen inductive demonstration. A retrograde chapter in the history of science would open if we do so and should accept as established laws those which rest so largely upon negative reasoning."

Meanwhile we may regard the theory of the inheritance of acquired characters as a piece of useful scaffolding which has served its purpose in the development of the facts of the derivation of species. At present most of it-perhaps all of it-unst be taken down, but it may be that from the same base will arise a better constructed theory which will again serve a purpose in the study of organic evolution.

Similar conditions in life tend to develop or encourage analogous adaptations in groups of animals not homologous in structure nor closely related by lines of descent. In many canses these adaptations are so very similar and are so subtle in their paralleism as to deceive even the trained naturalist. In other cases, the convergence and its conseynent analogies are less perfect, and the separate influence of like selection under like environment is casily traceable.

Examples of this sort are seen in the density of the fur of all Arctic animals, whatever the group to which they belong. Another illustration is found in the white winter dress of weasel s, 
rabbits, owls, ptarmigans, and other birds and mammals, this color aiding alike in defense or attack as against the background of snow. Similar convergence of characters is seen in the gray hues of almost all desert animals, in the thorny stems and scant thick foliage of almost all desert plants. In swift streams, fishes of various types (sculpins, darters, gobies, catfish, and minnows) protect themselves from the current by the reduction of the air bladder, by the instinct to lie flat on the bottom, and the instinct to make short quick darts from place to place in the swift waters. To this end also, certain fins are in each case especially increased in size and force.

Convergence of characters is shown in the black colors, soft bodies, and luminous spots, characteristic of different groups of deep-sea fishes. It also appears in the development of eellike forms in groups of fishes which have no affinity with eels, and of snakelike forms among lizards and salamanders, which have no real affinity with snakes. Like conditions of life bring about like structures. We may instance the occurrence of blind fishes of various groups in the different cave areas, these species being derived in all cases from fishes of neighboring regions having well-developed eyes. Thus the blind cave fish of Missouri (Troglichthys ros(e), and those of Indiana and Kentucky (Ambiyopsis spelceus, Typhlichthys subterraneus), are separately derived from the once widespread type of the Dismal Swamp fish (Chologaster cornutus). The blind fishes of Cuba (Stygicola, Lucifuga) are derived from ancestors of a marine cusk (Brotula) now found in the Cuban seas. The blind catfish of Pennsylvania (Gronias nigrilabris) is modified from an existing species (Ameiurus pullus) found in the same region. The blind salamanders of Austria and Texas are derived from former inhabitants of the same regions which possessed well-developed eyes.

Parallelisms of this sort are found in every group of animals and plants. It is generally easy to distinguish analogous variations or results of convergence of characters, by the study of comparative anatomy. Resemblances induced by like selection or by like conditions are usually superficial and do not affect those structures which do not come into direct contact with external conditions. But sometimes even deep-seated characters have been reached and affected by environmental influences. In this case a finer test is found in the study of embryonic development. In general, creatures actually closely 
related in descent have inherited common methods of development. Thus to cmbryology we have looked for the final test as to the real alinities of any given form. But even this test is sometimes delusive, for selection and (nnvironmental influences may affect embryonic development, as they may affect every other chancter or instinct.

Ce:tain writers carry this thought further, and find no real basis for discrimination between homologies and analogies. They would hold that the progrestive inheritance of effects of similar enviromment might in time produce forms not immediately related into at condition of practical identity each with the other.

Professor Hans Gadow observes:

"When Gegenbaur had become the founder of modem comparative anatomy by putting it on the basis of erolution, it became gradually an axiom that homologies determined the degrees of affinity, and now in turn the position of an animal in the system is appealed to for determining whether a given organ is homologous or only analugums. It is a vicious rircle. 'Only analogous' is the usual expression. In reality these cases of analogy, homoplasy, convergence have become of supreme interest in our science. Their solution implies the greatest of problems, and it is only the thoughtless orthodox fanatir who believes that similarity in structure must mean relationship. To him two and two make four, no matter what the twos are composed of."

But most naturalists believe that homology, which involves common descent, and analogy, which rests on similar experiences, are quite distinct elements, and that they can always be distinguished br recognized biological tests.

No one can question the vast influence of extrinsic or environmental influences on the history of a species of animal or plant. In the analysis of such influences we find at wide variety of opinions. According to some writers, these forces are dynamic, shaping the development of the individual, and by heredity determining through the individual the future of the species. Dall uses these striking words:

"The environment stands in relation to the indivilual as the hammer and anvil to the hlacksmith's hot iron. The organism suffers during its entire existence a continuous series of mechanical impacts, none the less real becuuse invisible." 
Others, not questioning the reality of the direct effects of environmental forces on the individual, find no evidence that these impacts are perpetuated in heredity.

Besides direct effects of these outside influences, we have to consider an infinite variety of reactions, which these forces or impacts may set up in the organism. These again have been supposed to be hereditary, for the species changes under them in what seems to be very much the same fashion that the individual does. Use and disuse in the species bring about parallel results to those shown by use and disuse in the individual, and are by some therefore referred to the same cause.

But again there is grave reason to question the fact of the inheritance of such reactions, and to doubt whether the effects of use and disuse in the species rest on the same set of causes as the results of use and disuse in the individual.

There remains the supposition, adopted at least tentatively by a large proportion, probably the majority, of the naturalists of to-day, that the direct effects of environment, as well as the reactions or indirect effects on the individual, are not repeated in heredity, and that the selective influence of environmental causes is the measure of their influence in the transformation of species.

The question of the nature of dynamic forces in evolution is one of the most recent and most interesting phases of the longcontinued discussion of the inheritance of acquired characters.

A vast range of variations are ontogenetic, or dependent on influences affecting directly the life of the individual. These ontogenetic variations are, strictly speaking, individual, appearing as collective only when many individuals have been subjected to the same conditions. They may be divided into environmental variations and functional variations, two categories which cannot always be clearly separated, as variations due to food conditions partake of the nature of both.

More than thirty years ago, Dr. J. A. Allen demonstrated that elimatic influences affect the averages in measurements and in color among birds. For example, in several species of birds, the total length is greater in specimens from the north, while the bills and toes are actually longer in southern specimens. That this condition is due to the influence of climate on development is apparently shown by the fact that numerous species are affected in the same way. It is noticed also that specimens 
from the northeast and the now inwest of the United States are darker in color than those from the interior, and again that red shades are more common in the arid southwest. Similar effects have been recently shown by a study of speciess of wasps. Modifications of this type may he produced at will hy subjecting the larvie and pupa of certain in. sects to artificial heat and cold. The butterflies of the glacial regions and those developed in the ice chest have a pale coloration, and a warm environment deepens the pigment. The woodpeckers and other birds of the rainy forests, northwest and northeast, have always darker and more sooty plumage than those birds of the same type found in more sumny regions.

A typical case is found in the various species of sticklebacks (Fig. 119) constituting the genera Gasterosteus and Pygosteus of the Northern Temperate Zone. In both genera, the marine species are armed for the whole length of the body by a series of about twenty to thirty vertically oblong enameled bony plates.

In brackish waters in Europe, America, and Asia alike, the sticklebacks in all the various species are only partially mailed, having variously from three to fifteen bony plates, these smaller than in the

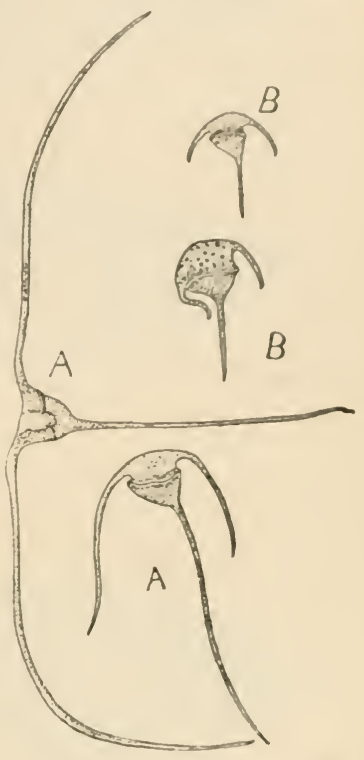

Fig. 11s.-Specimen of Ceratium, eallecterl $(A)$ out of the Guinea Coust stream and $(B)$ out of the South Equatorial stream; note the marked difference in development of the spines. (After Weismann and Chun.) marine forms and covering only the anterior part of the body. In these fishes also, the spines of the fins are less developed than in the marine forms. In strictly fresh waters, sticklebacks of various types are found entirely destitute of bony plates. These marmed fishes have been regarded as distinct species and as distinct subspecies. At present they are usually simply regarded as variant "forms," to which distinctive scientifie names need not be applied. It has not been proved, but it is probably a fact, that the differ- 

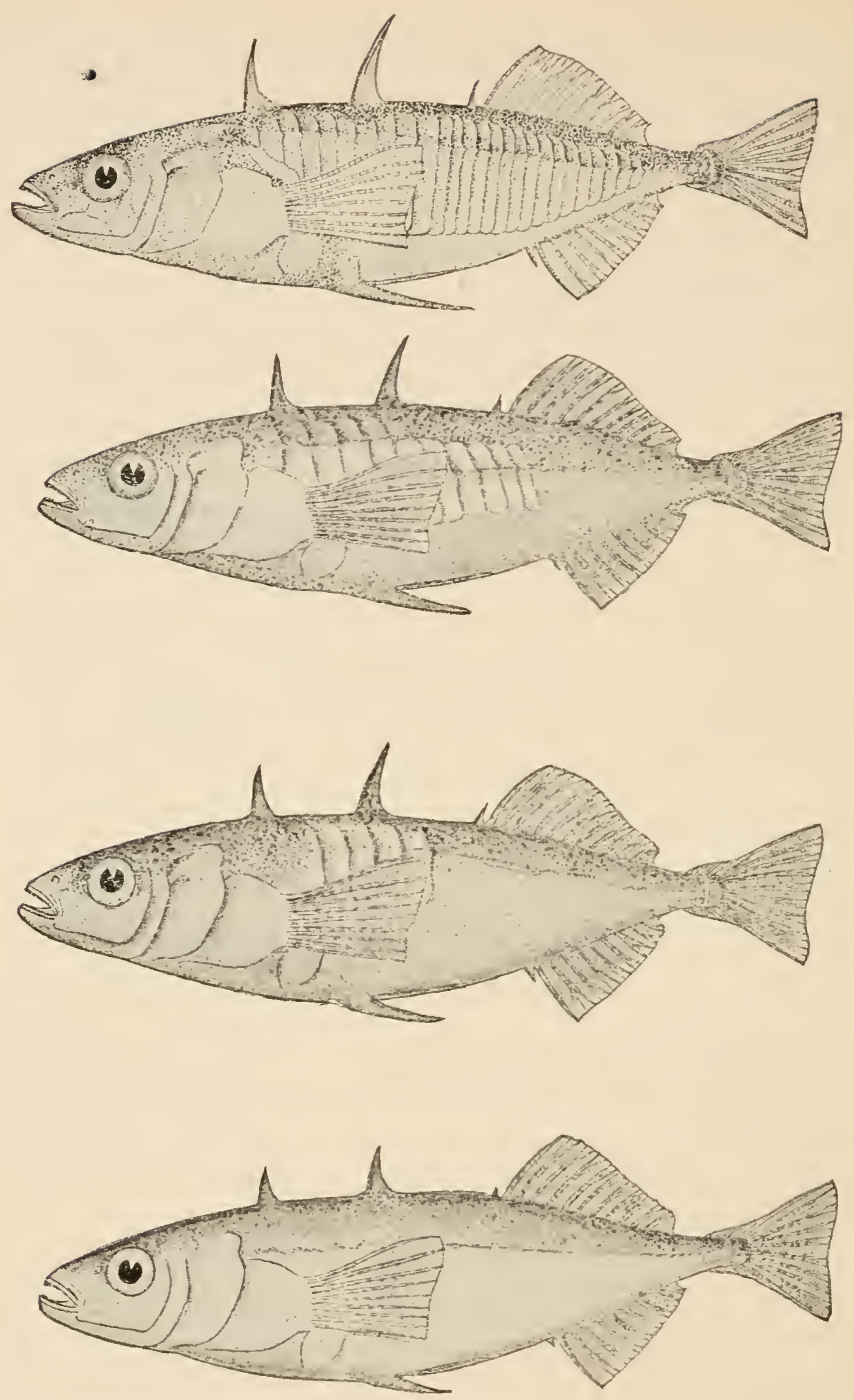

FIG. 119.-Specimens of the stickleback, Gasterostus cataphractus, collected in different kinds of water, and showing marked variations in the number of lateral bony plates and in the size of the dorsal fin rays; at the top, specimens collected in the salt water (note many lateral plates and large dorsal fin rays); next figure below, specimens collected in brackish water; next below, specimens collected in a river mouth; at the bottom, specimens collected in a river, with no lateral plates and small dorsal fin rays. 
ence is one due to the environment of the individual. Those in the sea find adequate salts from which to develop their coats of mail. Those in fresh water do not find this, while those in river mouths and other brackish situations develop armature in intermediate degrees. In the genus Eucalia, a stickleback confined to fresh waters of the Middle Western States, plates are never developed.

The Loch Leven trout, Salmo levenensis, is distinguished from the brook trout of England, Salmo eriox (fario), in its native waters by certain obvious characters. These disappear when the eggs are planted in brooks in England or in ('alifornia, and the species develops as the common English brook trout. But it is conceivable that the obvious or ontogenetic traits of the Loch Leven trout are not the real or phylogenctic distinctions, and that the latter, more subtle, engendered through individual variation, inheritance, selection, and isolation, really exist, although they have escaped the attention of ichthyologists.

After the Loch Leven trout was planted in the Yosemite Park in 1896, it remained for nine years unnoticed. In 190.5 individuals sent to Stanford University were, so far as could be seen, exactly like English brook trout. But it is conceivable that differences in food and water have caused slight ontogenetic distinctions. It is certain that in isolation from all parent stocks they will in time develop larger differences which, after many thousand generations, will be specific or subspecific. At present, these trout are quite unlike the native rainbow trout (Salmo irideus gilberti) of the Yosemite. The ontogenetic characters will perhaps approach those of the latter, but the phylogenetic movement may be in quite another direction.

Another ontogenetic species is the little char or trout (Salvelinus tudes Cope) from Unalaska. In (aptain's Harbor, L'nalaska, the Dolly Varden trout, Salvelinus malma, swarms in myriads, in fresh and salt water alike, reaching in the sea a weight of from six to twelve pounds. A little open brook, which drops into the harbor by an impassable waterfall, contains also an abundance of Dolly Varden trout, mature at six inches and weighing but a few ounces. This is Sulvelinus tudes. In the harbor the trout are gray with lighter gray spots, and fins scarcely rosy. In the brook, the trout are steel blue, with crimson spots and orange fins, striped with white and black. In all visible 
phylogenetic characters, the two forms of trout are one species. We have reason to believe that fry from the bay would grow up as dwarfs in the brook, and that the fry from the brook would be gray giants if developed in the sea.

But it is also supposable that in the complete isolation of the brook fishes, with free interbreeding, there would be some sort of phyiogenetic bond. There may be a genuine subspecies, tudes, characterized not by small size, slender form, and bright colors, but by other traits, which no one has found because no one has looked deeply enough.

In no group of vertebrates are the life characters more plastic than among the trout. The birds have traits far more definitely fixed. Yet differences in external conditions must produce certain results. We should not venture to suggest that the dusky woodpeckers or chickadees of the rainy forests of the northeast and northwest are purely ontogenetic species or that they should be erased from the systematic lists. But it will be a great advance in ornithology when we know what they really are and when we understand the real nature of the small-bodied, largebilled, southern races of other species of birds. It would be worth while to kñow if these are really ontogenetic purely, or if they are phylogenetic through "progressive heredity," the inheritance of acquired characters, such as are produced by the direct effects of climate or as the reaction from climatic influences. Or again may there be a real phylogenetic bond through geographical segregation, its evidences obscured by the more conspicuous traits induced by like experiences? Or are there other influences still more subtle involved in the formation of isohumic or isothermic subspecies?

To sum up, there is no convincing evidence that the cirect influence of environment is a factor in the separation of species, except as its results may be acted upon by natural selection. We have no proof to show that the environment of one generation determines the heredity of the next-and yet perhaps most naturalists feel that the effects of extrinsic influences work their way into the species, although a mechanism by which this might be accomplished is as yet unknown to us. 


\section{CHAPTER XII}

\section{GENERATION, SEX AND ONTOGENY}

"Unter jedem Grab liegt eine Weltgeschichte" (German proverb).

EACH animal, each plant, must have its individual beginning, its "creation," and its individual development from this beginning to a full grown, completely developed condition. For no organism is born fully developed. Even the simplest organisms, the one-celled kinds, whose "creation" is accomplished simply by the splitting in two of a previously existing individual of their kind, are not produced full-fledged. They have at least to increase from half size to full size, that is, to grow, and there are very few if any of them that do not have to effect changes in their body structure during this period of growth; that is, they have to undergo some development. The beginning, then, is always from a previously existing organism-but how could it always have been?-and between this beginning and the normal mature or full-fledged creature there has always to be some development. The beginning is called generation; the development, ontogeny.

We are all so familiar with the fact that a kitten comes into the world only through being born as the offspring of parents of its kind, that we shall likely not appreciate at first the full significance of the statement that all life comes from life; that all organisms are produced by other organisms. Nor shall we at first appreciate the importance of the statement. This is a generalization of modern times. It has always been easy to see that eats and horses and chickens and the other animals we familiarly know give birth to young or new animals of their own kind; or, put conversely, that young or new eats and horses and chickens come into existence only as the offspring of parents of their kind. And in these latter days of microseopes and 
mechanicas aids to observation it is also easy to see that the smaller animals, the microscopic organisms, come into existence only as they are produced by the division of other similar animals, which we may call their parents. But in the days of the earlier naturalists the life of the microscopic organisms, and even that of many of the larger but unfamiliar animals, was shrouded in mystery. And what seem to us ridiculous beliefs were held regarding the origin of new individuals.

The ancients believed that many animals were spontaneously generated. The early naturalists thought that flies arose by spontaneous generation from the decaying matter of dead animals; from a dead horse come myriads of maggots which change into flesh flies. Frogs and many insects were thought to bc generated spontaneously from mud. Eels were thought to arise from the slime rubbed from the skin of fishes. Aristotle, the Greek philosopher, who was the greatest of the ancient naturalists, expresses these beliefs in his books. It was not until the middle of the seventeenth century-Aristotle lived three hundred and fifty years before the Christian erathat these beliefs were attacked and began to be given up. In the beginning of the seventeenth century, William Harvey, an English naturalist, declared that every animal comes from an egg, but he said that the egg might "proceed from parents or arise spontaneously or out of putrefaction." In the middle of the same century Redi proved that the maggots in decaying meat which produce the flesh flies develop from eggs laid on the meat by flies of the same kind. Other zoölogists of this time were active in investigating the origin of new individuals. And all their discoveries tended to weaken the belief in the theory of spontaneous generation.

Finally, the adherents of this theory were forced to restrict their belief in spontaneous generation to the case of a few kinds of animals, like parasites and the animalcules of stagnant water. It was maintained that parasites arose spontaneously from the matter of the living animal in which they lay. Nany parasites have so complicated and extraordinary a life history that it was only after long and careful study that the truth regarding their origin was discovered. But in the case of every parasite whose life history is known, the young are offspring of parents, of other individuals of their kind. No case of spontaneous generation among parasites is known. 
The same is true of the animalcules of stagnant water. If some water in which there are apparently no living organisms, however minute, be allowed to stand for a frw dilys, it will come to be swarming with microscopic plants and animals. Any organic liquid, as a broth or a vegetable infusion exposed for a short time, becomes foul through the presence of innumerablete bacteria, infusoria, and other one-celled animals and plants, or rather through the changes produeed by their life procesces. But it has been ecrtainly proved that these organisms are not spontaneously produced by the water or organic liquid. A few of them enter the water from the air, in which there are always greater or less numbers of spores of microscopic organims. These spores (embryo organisms in the resting stage) germinate quickly when they fall into water or some organic liquid, and the rapid succession of generations soon gives rise to the liosts of bacteria and Protozoa which infest all standing water. If all the active organisms and inactive spores in a glass of water are killed by boiling the water, "sterilizing" it, as it is called. and this sterilized water or organic liquid be put into a sterilized glass, and this glass be so well closed that germs or spores cannot pass from the air without into the sterilized liquid, no living animals will ever appear in it. It is now known that flesh will not decay or liquids ferment except through the presence of living animals or plants. To sum up, we may say that we know of no instance of the spontaneous generation of organisms, and that all the animils whose life history we know are produced from other snimals of the same kind. "All life from life."

The method of simple fission or splitting-binary fission it is often called, because the division is always in two-by which the body of the parent becomes divided into two equal parts -into halves - is the simplest method of multiplication. This is the usual method of Amoba (Fig. 120) and of many other of the simplest animals. In this kind of reproduction it is hardly exact to speak of parent and children. The children, the new Amabe, are simply the parent cut into halves. The parent persists; it does not produce offspring and die. Its whole body continues to live. The new 1 mobe take in and assinilate ford and add new matter to the original matter of the parent boly; then each of them divides in 1 wo. 'The grand parcut's body is now divided into four parts, one fourth of it forming one half 
of each of the bodies of the four grendchildren. The provess of assimilation, growth, and subsequent division takes place again and again and again. Each time there is given to the new $A m \propto b a$ an evel-lessening part of the sctual body substance of the original ancestor. Thus an Amoba never dies a natural
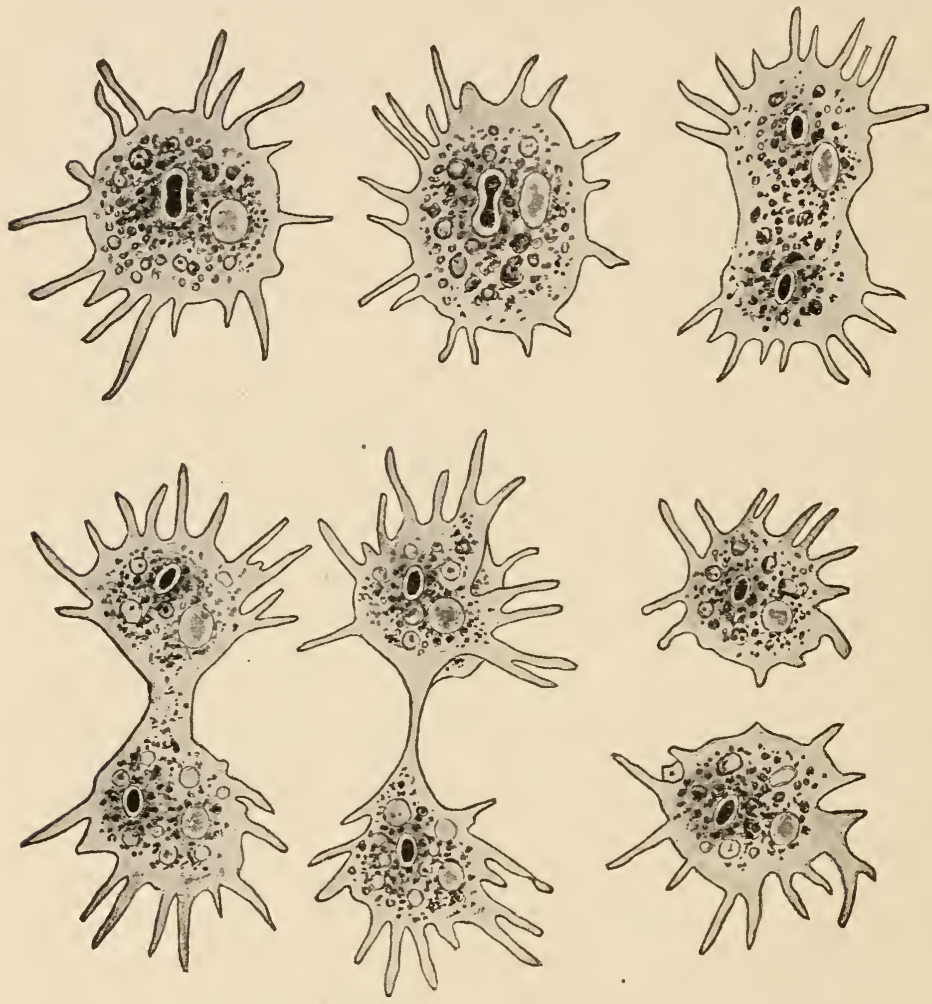

Fig. 120.-A multiplication of Amœba by simple fission.

death, or, as has been said, "no Amoba ever lost an ancestor by death." It may be killed outright, but in that case it leaves no descendants. If it is not killed before it produces new Amœbce it never dies, although it ceases to exist as a single individual. The Amobce and other simple animals which multiply by direct binary fission may be said to be immortal, and the "immortality of the Protozoa" is a phrase which will 
often be met with in the writings of Wrismann and certain other modern philosophical biologists. There is a fallacy, lowever, in the phrasing, because, as a matter of fact, the protoplasm of a given protozoön gradually loses its vitality with continued division until it ultimately is unable to divide further or indeed to perform the other life functions: it dies of old age.

Hardly less simple is generation by budding, which in its simplest character is the breaking off from one individual of a part smaller than a half, often, indeed, only
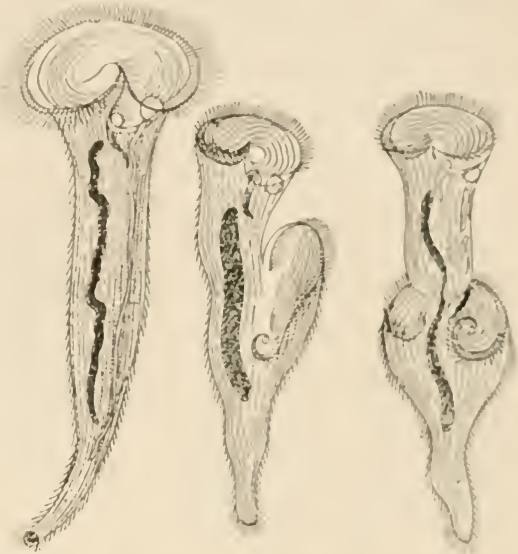

Frg. 121.-Stentor reproducing by fission. (After Stein.)

a very small fractional part, which budded off part has the capacity of growing and developing into a new individual like

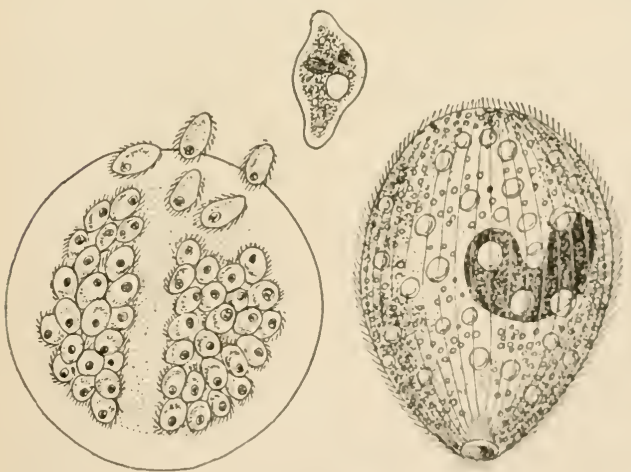

FIG. 122.-Holophrya mullifiliis, an infusorian parasitic on fishes reproducing by sporulation. its parent.

\section{A still other} mode of generation of simple type is that of sporulation, or where the body of one individual subdivides into more than two parts (as in binary fission), these parts, each of which is usually subspherical or ellipsoidal. numbering perhaps many hundreds.

A condition known as parthenogenesis is found among certain of the eomplex animals. Although the species is represented by individuals of both seses, the female can produce 
young from eggs which have not been fertilized. For example, the queen bee lays both fertilized and unfertilized eggs. From the fertilized eggs hatch the workers, which are rudimentary females, and other queens, which are fully developed females; from the unfertilizad eggs hatch only males-the dirones. Many generations of plant lice are produced each year parthenogenetically-that is, by unfertilized females. This subject
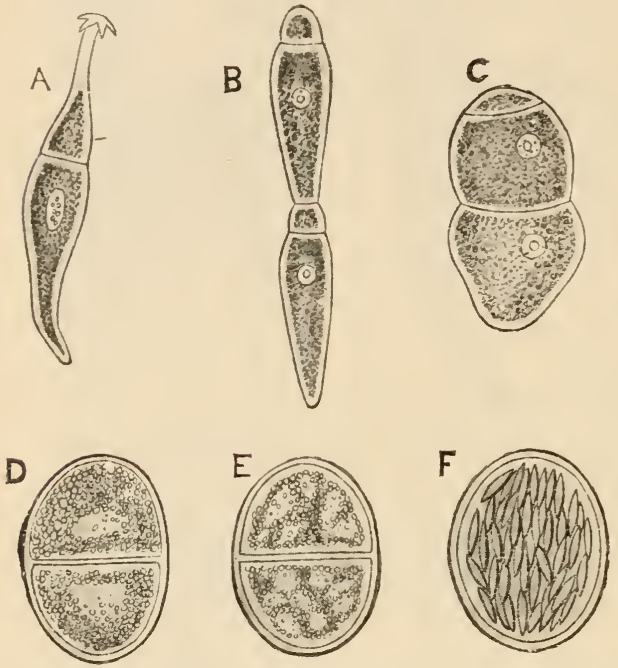

Fīg. 123.-Gregarinidæ. A, A gregarinid, Actinocephalus oligacanthus, from the intestines of an insect (aiter Stein); $B$ and $C$, spore-forming by a gregarinid, Coccidium oviforme, from liver of a guinea-pig (after Leuckart); $D, E$, and $F$, successive stages in conjugation of spore-forming by Gregarina polymorpha. (After Kölliker.)

will be discussed at greater length later in this chapter.

The modes of generation, or reproduction, or multiplication, as this making the beginnings of new individuals may be variously called, so far referred to, may be grouped into a category called asexual generation. In an examination of the lives of the simplest and but slightly complex kinds of animals we find that even among almost the very simplest of organisms another mode of reproduction obtains, at least occasionally, which demands for its carrying out the mutual action of two distinct individuals. The essential thing in this mutual action is the exchange of nuclear material from one of these individuals to the other; with some of the simplest organisms there is a mutual exchange of nuclear material.

Paramocium, for example, reproduces itself for many generations by fission, but a generation finally appears in which a different method of reproduction is followed. Two individuals come together and each exchanges with the other a part of 
its nucleus. Tlan the two individuals separate and cach divides into two. The result of this (onjugation is to give to the new Paramacia produced by the anjugating individuals a body which contains part of the body substance of two distinct individunls. The new I'aramacia are not simply halves of at single parent, they are parts of two parents.

Among the colonial l'rotozoa the first differentiation of the cells or members composing the colony is the differentiation into two kinds of reproductive cells. Reproduction by simple division, without preceling conjugation, cin and does take place, to a certain extent, amone all the colonial Proto\%n. Indeed, this simple method of multiplication, or some modification of it, like budding, persists among many of the (onmplex animals, as the sponges, the polyps, snd even higher and more complex forms. But such a method of single-parent reproduction cannot be used alone by a species for many generations, and those animals which possess the power of multiplicittion in this way always exhibit also the other more complex kind of multiplication, the method of double-parent reproduction. Conjugation takes place between different mombers of a single colony of one of the colonial Protozoa, or leetwern members of different colonies of the same species. Thrse conjugating individuals in the simpler kinds of colonies, like Gonium, are similar; in Pandorina they appear to be slightly different, and in Eudorina and Tolvox the conjugating cells are readily seen to be very different from each other. One lind of cell, which is called the egrg cell, is large, spherical, and inactive, while the other kind, the sperm cell, is small, with oroid head and tapering tail, and free-swimming. In the simpler colonial Protozoa all the cells of the body take part in reproduction, but in Iolvox only certain cells perform this function, and the other 'ells of the body die. Or we may say that the body of Volvox dies after it has produced special reproductive cells which shall fulfill the function of multiplication.

Beginning with the more complex lolvocine, which we may call either the most complex of the one-celled animals or the simplest of the many-celled animals, all the complex animals show this distinct differentiation hetween the repror ductive cells and the cells of the rest of the body. Of course, we find, as soon as we go up at all far in the seale of the animal world, that there is a great deal of differentiation among the 
cells of the body: the cells which have to do with the assimila. tion of food are of one kind; those on which depend the motions of the body are of another kind; those which take oxygen and those which excrete waste matter are of other kinds. But the first of this cell differentiation, as we have already often repeated, is that shown by the reproductive cells; and with the very first of this differentiation between reproductive cells and the other body cells, appears a differentiation of the re-

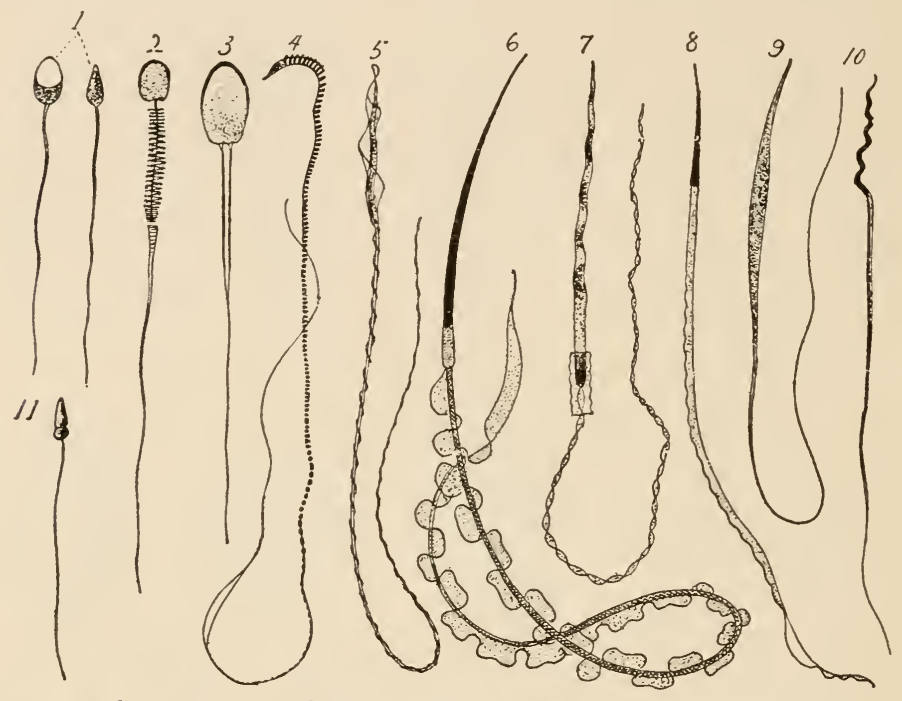

FIG. 124.-Spermatozoa of different animals: 1, Nan; 2, Vesperugo; 3, pig; 4, rat; 5 , finch; 6 , triton; 7 , ray; 8 , beetle; 9 , mole cricket; 10 , snail. (After Ballowitz, Kölliker, and Rath.)

productive cells into two kinds. These two kinds, among all animals, are always essentially similar to the two kinds shown by Tolvox and the simplest of the many-celled animalsnamely, large, inactive, spherical egg cells, and small, active, elongate or "tailed" sperm cells.

In the slightly complex animals one individual produces both egg cells and sperm cells. But in the Siphonophora, or colonial jellyfishes, certain members of the colony produce only sperm cells, and certain other members of the colony produce only egg cells. If the Siphonophora be considered an individual organism and not a colony composed of many individ- 
uals, then, of course, it is like the others of the slightly complex animals in this respect. But as soon as we rise higher in
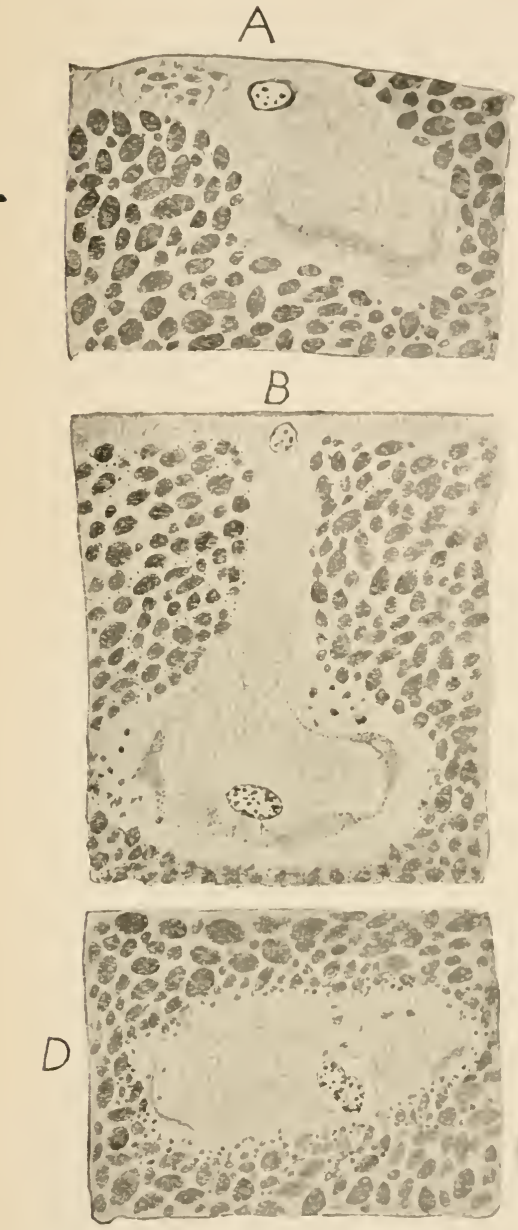
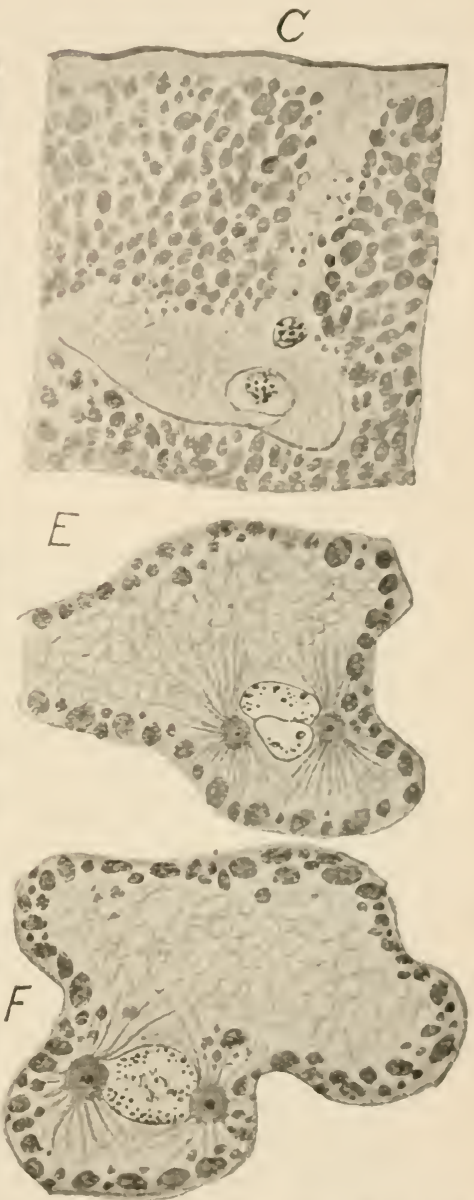

Fra. 125.-Fertilization of Petromyzon fluriatilis: A, sperm nucleus in periphery of the egg plasm; $B$, sperm nucleus in periphery of the egg plasm, and egg nucleus approaching; $C-E$, fusing of the egg and sperm nuclei, and appearnnce of the asters: $F$, cleavage of nucleus. (After Herfort.)

the seale of animal life, as soon as we study the more complex animals, we find that the egg cells and sperm cells are almost 
always produced by different individuạls. Those individuals which produce egg cells are called female, and those which produce sperm cells are called male. There are tro sexes. IIale and female are terms usually applied only to individuals, but it is evidently fair to call the egg cells the female reproductive cells, and the sperm cells the male reproductive cells. A single individual of the simpler kinds of animals produces both male and female cells. But such an individual cannot be said to be either male or female, it is sexless-
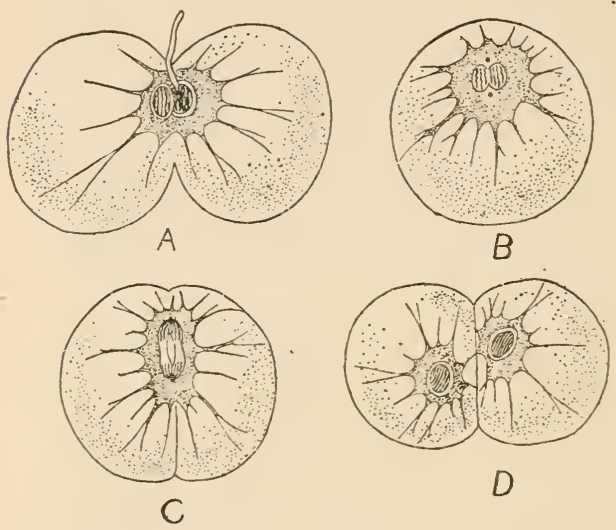

Fig. 126.-Conjugation of Noctiluca, a one-celled animal: $A$, Two individuals just fusing; $B$, the same with cytoplasm wholly fused and nuclei lying closely together; $C$, the two nuclei in closer fusion; $D$, the beginning of fission. (After Ischikawa.) that is, sex is something which appears only after a certain degree of structural and physiological differentiation is reached. It is true that even among many of the higher or complex animals certain species are not represented by male and female individuals, any individual of the species being able to produce both male and female cells. But this is the exception.

Among almost all the complex animals it is necessary that there be a conjugation of male and female reproductive ccils in order that a new individual may be produced. This necessity first appears, we remember, among very simple animals. This intermixing of body substance from two distinct individuals and the development therefrom of the new individual is a phenomenon which takes place through the whole scale of animal life. The object of this intermixing seems to be the production of variation; at least it would seem that variation must result from such a mode of generation. By having the beginnings of an organism's body, the single cell from which this whole body develops, composed of parts of two different individuals, a difference between the offspring and the par- 
ents, although it may be slight and imperceptible, is insured. Sex is a condition of nature which is one, at least, of the causes of variation.

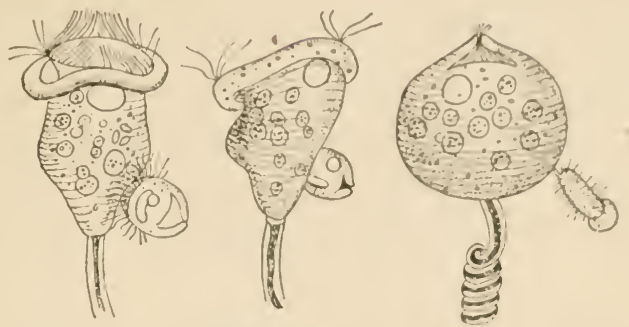

FIG. 127.-Conjugation of the infusorian, Vorticella nebulifera; the smaller intividual at the right may be regarded as the male. (After Weismann.)

As we have seen, almost every species of animal is represented by two kinds of individuals, males and females. In the case of many animals, especially the simpler ones, these two

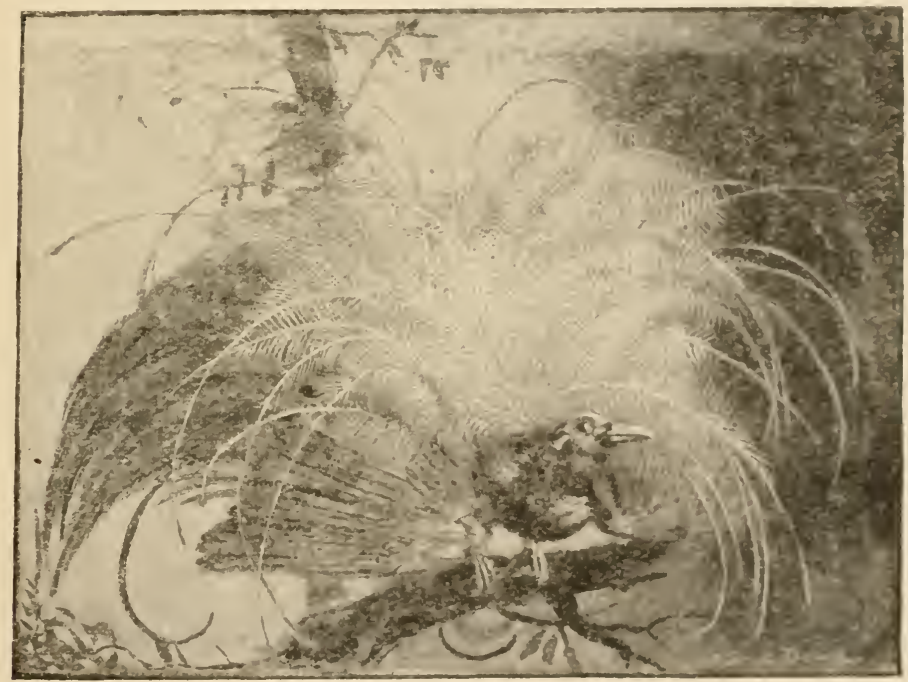

Fig. 125.- Male bird of paradise.

kinds of individuals may not differ in appearance or in structure apart from the organs concerned with multiplication. But with many animals the sexes can be readily distinguished. 
The male and female individuals often show marked differences, especially in external structural characters. We can readily tell the peacock, with its splendidly ornamental tail feathers, from the unadorned peafowl, or the horned ram from the bleating ewe. There is here, plainly, a dimorphism-the existence of two kinds of individuals belonging to a single species. This dimorphism is due to sex, and the condition may be called sex dimorphism. Among some animals this sex dimorphism, or difference between the sexes, is carried to extraordinary ext:emes. This is especially true among polyga-
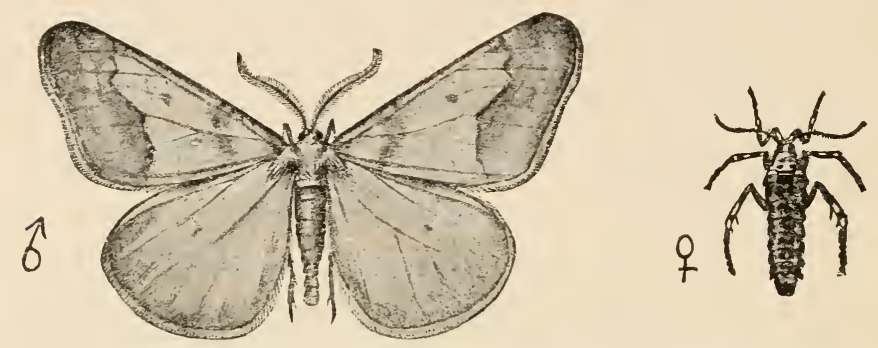

FIG. 129.-Cankerworm moth: the winged male and wingless female.

mous animals, or those in which the males mate with many females, and are forced to fight for their possession. The male bird of paradise, with its gorgeous display of brilliantly colored and fantastically shaped feathers (Fig. 128), seems a wholly different kind of bird from the modest brown female. The male golden and silver pheasants, and allied species with their elaborate plumage, are very unlike the dull-colored females. The great, rough, warlike male fur seal, roaring like a lion, is three times as large as the dainty, soft-furred female, which bleats like a sheep.

Among some of the lower animals the differences between male and female are even greater. The males of the common cankerworm moth (Fig. 129) have four wings; the females are wingless, and several other insect species show this same difference. Among certain species of white ants the females grow to be five or six inches long, while the males do not exceed half an inch in length. In the case of some of the parasitic worms which live in the bodies of other animals the male has an extraordinarily degraded, simple body, much smaller 
than that of the female and differing greatly from it in structure. In some cases even-as, for example, the worm which cutuses "gapes" in chickens-the male lives parasitically on the female, being attached to her body for its whole lifetince, and drawing its nourishment from her blood (Fig. 130).

Some of the complex animals are hermaphroditic-that is, a single individual produces both egg cells and sperm cells. The tapeworm and many allied worms show this condition. This is the normal condition for the simplest animals, as we have already learned, but it is an exceptional condition among the complex animals.

However the beginnings of the new organisms are produced, whether ascxually or bisexually (whether, that is, by simple division, budding, sporulation, or as true but unfertilized eggs, or as eggs with a nucleus made by the fusion of two germinal nuclei from male and female individuals respectively, or from an hermaphroditic individual), this new organism in embryo has a shorter or longer course of development and growth to undergo, before it, in turn, is in condition to produce new individuals of its kind.

Certain phenomena, are familiar to us as recurring inevitably in the life of every animal which we familiarly know. Each individual is born in an immature or young condition; it grows (that is, it increases in size) and develops (that is, changes more or less in structure) and dies. These phenomena occur in the succession of birth, growth, and derelopment, and death. But before any animal appears to us as an independeindividual - that is, outside the body of the mother and outside of an egg (i. e., before birth or hat ihing, as we are aceustomed to eall such appearance) - it has already undererone a longer or shorter period of life. It has been a new living organism hours or days or months, perhaps, before its appearance to 11. This period of life has been passed inside an ererg, or as an cugr. 
or in the egg stage, as it is variously termed. The life of an animal as a distinct organism begins in an egg. And the true life cycle of an organism is its life from egg through birth, growth and development and maturity to the time it produces new organisms in the condition of eggs. The life cycle is from egg to egg. Birth and growth, two of the phenomena readily apparent to us in the life of every animal, are two phenomena

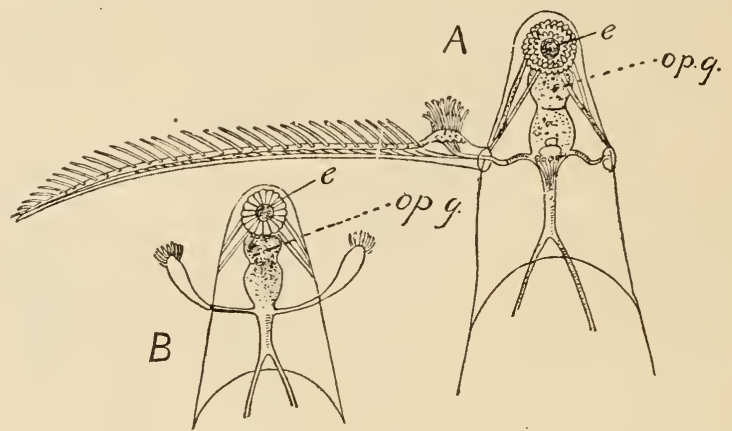

FIG. 131.-Leptodera hyalina, showing sex dimorphism: $A$, Head of male; $B$, head of female.

in the true life cycle. Death is a thrrd inevitable phenomenon in the life of each individual, but it is not a part of the cycle; it is something outside.

The single cell formed by the fusion of two germ cells is called a fertilized egg cell, and its subsequent development results in the formation of a new individual of the same species with its parents. Now, in the development of this cell into a new animal, food is necessary. So with the fertilized egg cell there is, in the case of most animals that lay eggs, a greater cr less amount of food matter-food yolk, it is called-gathered about the germ cell, and both germ cell and food yolk are inclosed in a soft or hard wall. Thus is composed the egg as we know it. The hen's egg is as large as it is because of the great amount of food yolk it contains. The egg of a fish as large as a hen is much smaller than the hen's egg; it contains. less food yolk. Eggs (Fig. 132) may vary also in their external appearance, because of the different kinds of membrane or shells which may inclose and protect them. Thus the frog's eggs are inclosed in a thin membrane and 
imbedded in a soft, jellylike substance; the skate's egg has a tough, dark-brown leathery inclosing wall; the spiral egg of the bullhead shark is leathery and colored like the dark-olive seaweeds among which it lies; and a bird's egg has a hard shell of carbonate of lime. But in each case there is the essential fertilized germ cell; in this the exgs of hen and fish and butterfly and crayfish and worm are alike, however much they may differ in size and external appearance.

There is great variation in the number of young produced by different species of animals. Among the animals we know familiarly, as the mammals, which give birth to young alive,
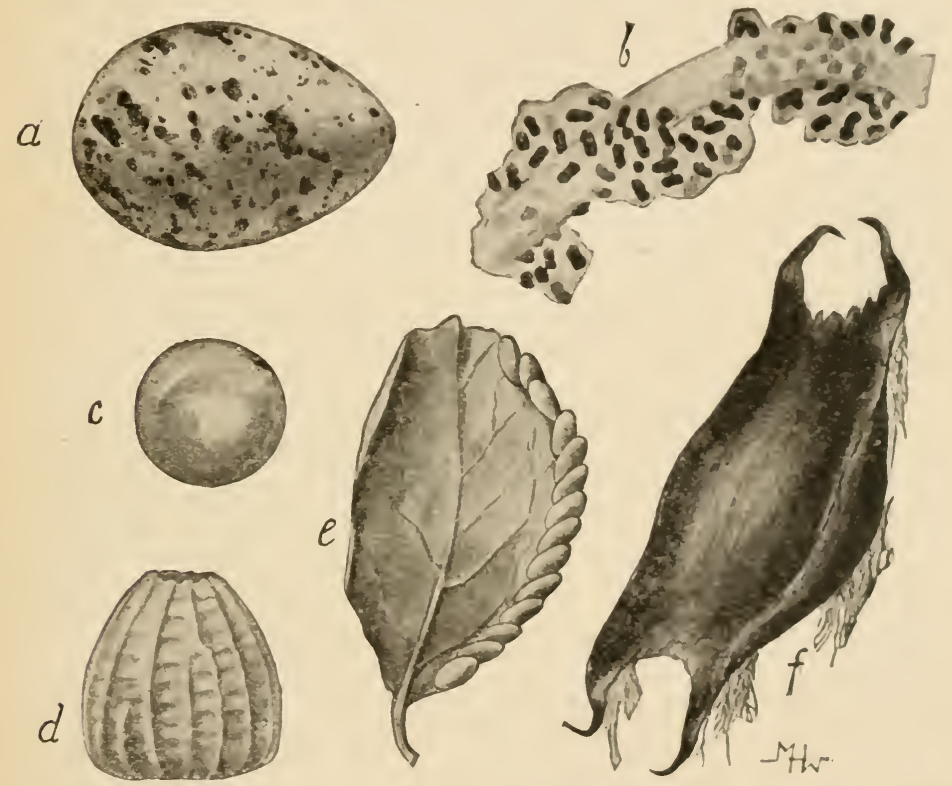

FIG. 132.-Eggs of different animals showing variety in externel appearance: $a$, Ege of bird; $b$, eggs oi toad; c , egg of fish; $d$, egg of butterfly; e, eggs of katydid on leaf; $f$, egg case of skate.

and the birds, which lay egres, it is the general rule that hut few young are produced at a time, and the young are born or egrs are laid only once or perhaps a few tines in a year. The robin lays five or six eggs once or twice a year; a cow may produce a calf each year. Rabbits as jigeons are more 
prolific, each having several broods a year. But when we observe the multiplication of some of the animals whose habits are not so familiar to us, we find that the production of so few young is the exceptional and not the usual habit. A lobster lays ten thousand eggs at a time; a queen bee lays about five

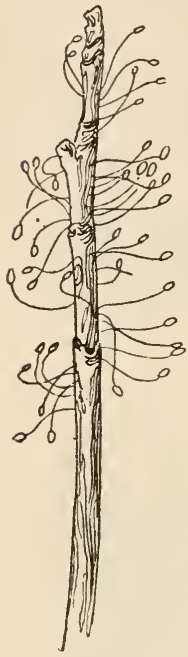

FIG. 133.-Eggs of lace-winged fly, Chrysopa. The eggs are fastened separately, for protection from predaceous insects, on the tips of erect slender pedicles.

million eggs in her life of four or five years. A female termite of a certain species, after it is full grown, does nothing but lie in a cell and lay eggs, producing eighty thousand eggs a day steadily for several months. A large codfish was found on dissection to contain about eight million eggs.

If we search for some reason for this great difference in fertility among different animals, we may find a promising clew by attending to the duration of life of animals, and to the amount of care for the young exercised by the parents. We find it to be the general rule that animals which live many years, and which take care of their young, produce but few young; while animals which live but a short time, and which do not care for their young, are very prolific. The codfish produces its millions of eggs; thousands are eaten by sculpins and other predatory fishes before they ars hatched, and other thousands of the defenseless young fish are eaten long before attaining maturity. Of the great number produced by the parent, a few only reach maturity and produce new young. But the eggs of the robin are hatched and protected, and the helpless fledglings are fed and cared for until able to cope with their natural enemies. In the next year another brood is carefully reared, and so on for the few years of the robin's life.

Under normal conditions in any given locality the number of individuals of a certain species of animal remains about the same. The fish which produces tens of thousands of eggs and the bird which produces half a dozen eggs a year maintain equally well their numbers. In one case a few survive of many born; in the other many (relatively) survive of the few 
born; in both cases the species is effectively maintained. In general, no agency for the perpetuation of the species is so effective as that of care for the young.

Some animals do not lay eggrs, that is, they do not deporit the fertilized egg eell outside of the body, hut allow the development of the new individual to go on inside the body of the mother for a longer or shorter period. The mammals and some other animals have this habit. When such an animal issues from the body of the mother, it is said to be born. When the developing animal issues from an egg which has been deposited outside the body of the mother, it is said to hatch. The $n$ nimal at birth or at time of hatching is not yet fully developed. Only part of its development or period of immaturity is passed within the egg or within the body of the mother. That part of its life thus

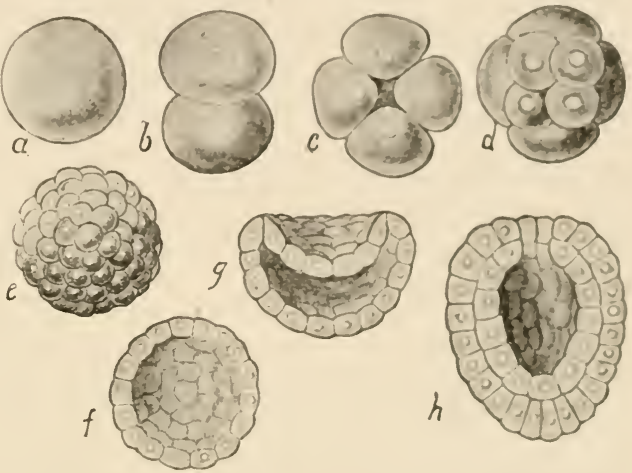

FIG. 134.-First stages in the embryonic development of the pond snail, Lymnarus: $a$, Egg ecll; $b$, first cleavage; $c$, second cleavage; $d$, third cleavage; $e$, after numerous cleavages; $f$, blastula-in section; $g$, gastrula just forming-in section; $h$, gastrula completel-in section. (After Rabl.) passed within the egg or mother's body is called the embryonic life or embryonic stages of development; while that period of deselopment or immaturity from the time of birth or hatching until maturity is reached is called the postembryonic life or postembryonic stages of development.

The embryonic development is from the beginning up to a certain point practically alike, looked at in its larger aspect, for all the many-celled animals. That is, there are certain principal or eonstant characteristies of the begimning development which are present in the development of all many-ecelled animals. The first stage or phenomenon of development is the simple fission of the germ cell into halves (Fig. 134b). These two daughter cells next divide so that there are four cells 
(c); each of these divides, and this division is repeated until a greater or lesser number (varying with the various species or groups of animals) of cells is produced. These cells may not all be of the same size, but in many cases they are, no structural differentiation whatever being apparent among them.

The phenomenon of repeated division of the germ cell is called cleavage, and this cleavage is the first stage of development in the case of all many-celled animals. The germ or embryo in some animals consists now of a mass of few or many undifferentiated primitive cells lying together and usually forming a sphere (Fig. 134,c), or perhaps separated and scattered through the food yolk of the egg. The next stage of development is this: the cleavage cells arrange themselves so as to form a usually hollow sphere or ball, the cells lying side by side to form the outer circumferential wall of this hollow sphere $(f)$. This is called the blastula or blastoderm stage of development, and the embryo itself is called the blastula or blastoderm. This stage also is common to all the many-celled animals. The next stage in embryonic development is formed by the bending inward of a part of the blastoderm cell layer, as shown in $(g)$ (or the splitting off inwardly of celis from a special part of the blastula cell layer). This bending in may produce a small depression or groove; but whatever the shape or extent of the sunken-in part of the blastoderm, it results in distinguishing the blastoderm layer into two parts, a sunken-in or inner portion called the endoblast and the other unmodified portion called the ectoblast. Endo- means within, and the cells of the endoblast often push so far into the original blastoderm cavity as to come into contact with the cells of the ectoblast and thus obliterate this cavity $(h)$. This third well-marked stage in the embryonic development is called the gastrula stage, and it also occurs in the development of all or nearly all manycelled animals.

In the case of a few of the simple many-celled animals the embryo hatches-that is, issues from the egg at the time of or very soon after reaching the gastrula stage. In the higher animals, however, development goes on within the egg or within the body of the mother until the embryo becomes a complex body, composed of many various tissues and organs. Almost all the development may take place within the egg, so that when the young animal hatches there is necessary 
little more than a rapid growth and increase of size to make it a fully developed, mature animal. This is the case with the birds: a chicken just hatched has most of the tissues and organs of a full-grown fowl, and is simply a little hen. But in the case of other animals the young hatehes from the exgr before it has reached such an advanced stage of development; a young starfish or young crab or youmer honeybee just hatched looks very different from its parent. It has yet a great deal of development to undergo before it reaches the structurel condition of a fully developed and fully grown starfish or crab or bee. Thus the development of some animals is almost wholly embryonic development - that is, development within the egg or in the body of the mother-while the development of other animals is largely postembryonic, or larval development, as it is often called. There is no important difference between embryonic and postembryonic development. The development is continuous from exig cell to mature animal, and whether inside or outside of an egre it goes on regularly and uninterruptedly.

The cells which compose the embryo in the cleavage stage and blastoderm stage, and even in the gastrula stage, are apparently all similar; there is little or no differentiation shown among them. But from the gastrula stage on, derclopment includes three important things: the gradual differentiation of cells into various kinds to form the various kinds of animal tissues; the arrangement and grouping of these cells into organs and body parts; and finally the developing of these organs and body parts into the special condition characteristic of the species of animal to which the developing individual helongs. From the primitive undifferentiated cells of the blastoderm, develop)ment leads to the special cell types of muscle tissue, of bone tissue, of nerve tissue; and from the genoralizod condition of the embryo in its early stages, development leads to the specialized condition of the body oi the arlult animal. Development is from the general to the special, as was said years aco by von Baer, the first great student of development.

A starfish, a beetle, a dove, and a horse are all alike in their beginning-that is, the body of each is composed of a single cell, a single structural unit. And they are all alike, or very much alike, through several stares of development: the body of each is first a single cell, then a number of similar un- 
differentiated cells, and then a blastoderm consisting of a single layer of similar undifferentiated cells. But soon in the course of development the embryos begin to differ, and as the young animals get further and further along in the course of their development, they become more and more different until each finally reaches its fully developed mature form, showing all the great structural differences-between the starfish and the dove, the beetle and the horse. That is, all animals begin development apparently alike, but gradually diverge from each other during the course of development.

There are some extremely interesting and significant things about this divergence to which attention should be given. While all animals are apparently alike structurally ${ }^{\mathbf{1}}$ at the beginning of development, so far as we can see, they do not all differ noticeably at the time of the first divergence in development. The first divergence in development is to be noted between two kinds of animals which belong to different great groups or classes. But two animals of different kinds, both belonging to some one great group, do not show differences until later in their development. This can best be understood by an example. All the butterflies and beetles and grasshoppers and flies belong to the great group or class of animals called Insecta, or insects. There are many different kinds of insects, and these kinds can be arranged in subordinate groups (orders), such as the Diptera, or flies, the Lepidoptera, or butterflies and moths, and so on. But all have certain structural characteristics in common, so that they are comprised in one great class-the Insecta. Another great group of animals is known as the Vertebrata, or backboned animals. The class

${ }^{1}$ We can say that they are alike structurally, only when we consider the cell as the unit of animal structure. But, that the egg cells of different animals differ in their fine or ultimate structure, seems certain. For each one of these egg cells is destined to become some one kind of animal, and no other; each is, indeed, an individual in simplest, least developed condition of some one kind of animal, and we must believe that difference in kind of animals depends upon difference in structure in the egg itself. Indeed Wilson, the foremost American student of egg structure, believes himself able to perceive in many eggs a structural differentiation within the egg protoplasm itself, corresponding, in some measure, with the structural differentiation of the embryonic animal as revealed in early developmental stages. 
Vertebrata includes the fishes, the batrachians, the reptiles, the birds, and the mammals, each composing a sulordinate group, but all characterized by the possession of a hacklone, or, more accurately speaking, of a notochord, a backbonclike structure. Now, an insect and a vertebrate diverere very soon in their development from each other; but two insects, such as a beetle and a honeyloee, or any two vertcherates, such as a frog and a pigeon, do not diverege from ealch other so soon. That is, all vertebrate animals diveree in one direction from the other great groups, but all the mombers of the great erroup) keep together for some time longer. Then the subordinate groups of the Vertebrata, such as the fishes, the hirds, and the others, diverge, and still later the different kinds of animals in each of these groups diverge from calch other.

That the course of development of any animal from its beginning to fully dercloped adult form is-in all its esentials -fixed and certain is readily seen. All rabbits dreclop in the same way; every grusshopper geses through the same developmental changes from single egg ('ell to the full-grown, active hopper as every other gr:sshopper of the same kindthat is, development takes place according to cortain natural laws: the laws of animal development. These laws may be roughly stated as follows: All many-celled animals hecrin life as a single coll, the fertilized egg cell; each animal goes through a certain orderly series of developmental changes which, accompanied by growth, leads the animal to change from single cell to the many-celled, complex form characteristic of the species to which the animal belongs: this development is from simple to complex structural condition; the development is the same for all individuals of one species. While all animals begin development similarly, the colirse of derelopment in the different groups soon diverges, the divergence being of the nature of a branching, like that shown in the growth of a tree. In the free tips of the smallest branches we have represented the various species of animals in their fully developed condition, all standing more or less clearly apart from cach ot her. But in tracing back the development of any kind of animal we soon come to a point where it very much resembles or becomes apparently identical with the development of some other kind of animal, and, in addition, the stages pasied through in the developmental course may very much resemble the 
fully developed, mature stages of lower animals. To be sure, any animal at any stage in its existence differs absolutely from any other kind of animal, in that it can develop into only its own kind of animal. There is something inherent in each developing animal that gives it an identity of its own. Although in its young stages it may be hardly distinguishable from some other kind of animal in similar stages, it is sure to come out, when fully developed, an individual of the same kind as its parents were or are. A very young fish and a very young salamander are almost indistinguishably alike, but one is sure to develop into a fish and the other into a salamander. This certainty of an embryo to become an individual of a certain kind is called the law of heredity. Viewèd in the light of development, there must be as great a difference between one egg and another as between one animal and another, for the greater difference is included in the less.

The significance of the developmental phenomena is a matter about which naturalists have yet very much to learn.
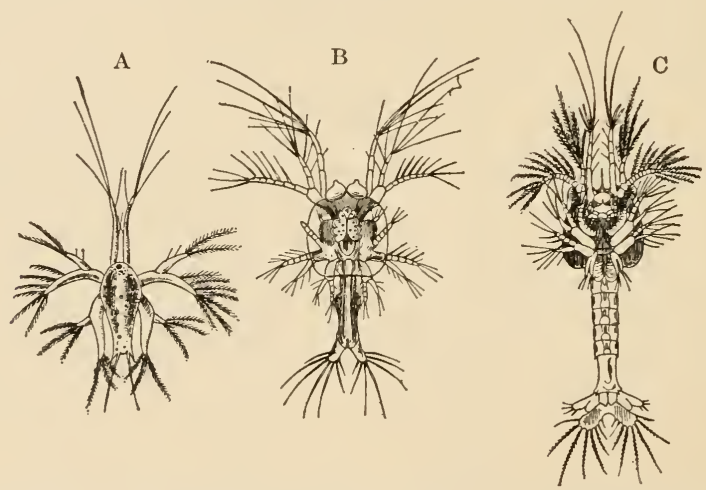

FIG. 135.-Stages in the development of the prawn, Peneus potimirium: $A$, Nauplius larva; $B$, first zoëa stage; $C$, second zoëa stage. (After Fritz Müller.)

$\mathrm{I}^{\prime} \mathrm{c}$ is believed, however, by practically all naturalists that many of the various stages in the development of an animal correspond to or repeat, in many fundamental features at least, the structural condition of the animal's ancestors. Naturalists believe that all backboned or vertebrate animals are related to each other through being descended from a common ancestor, the first or oldest backboned animal. In fact, it is because all 
these backboned animals - the fishes, the batrachians, the reptiles, the birds, and the mammals-have descended from a common ancestor that thery all have a backbone. It is believed that the descendants of the first backloncel animal have in the course of many generations branched off little by little from the original type until there came to exist very real and obvious differences among the backboned animals-
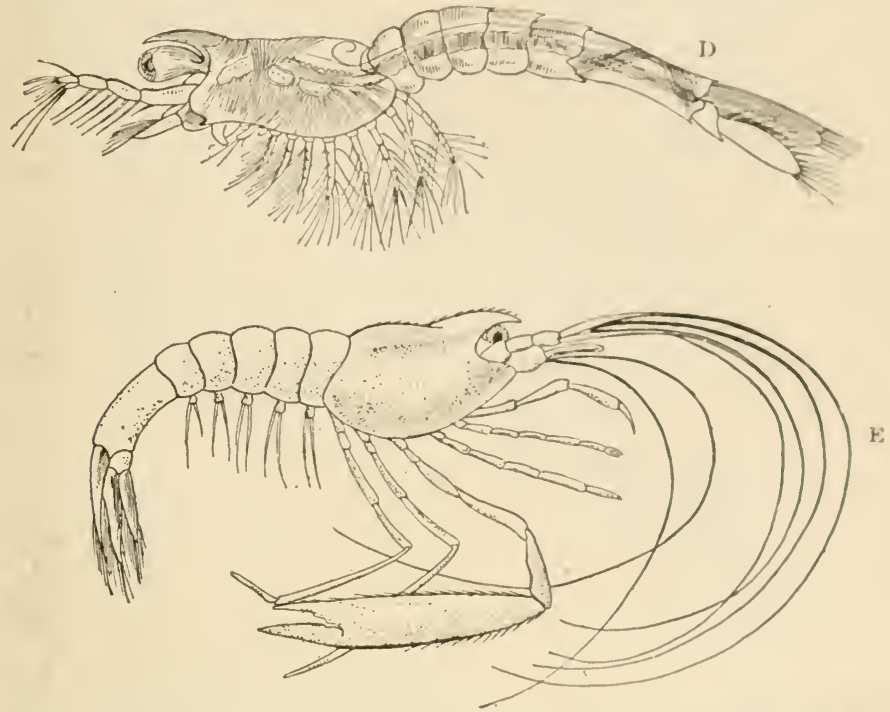

FIG. 136.-Later stages in the development of the prawn, Peneus potimirium: D, Mysis stage; $E$, adult stage.

differences which among the living backboned animals are familiar to all of us. The course of development of an individual animal is believed to be a very rapid and evidently much condensed and changed recapitulation of the history which the species or kind of animal to which the developing individual belongs has passed through in the course of its descent through a long series of gradually changing ancestors. If this is true, then we can readily understand why a fish and a salamander, a tortoise, a hird and a rablit, are all much alike, as they really are, in their earlier stages of development, and gradually come to differ more and more as they pass through later and later developmental stages. A (rab) has a tail in one of its 
developmental stages, so that at that time it looks like and really is like the mature stage of some tailed crustacean like a crayfish. A barnacle, which looks little like a crayfish or prawn in its mature stage, is hardly to be distinguished in its immature life from a young shrimp or prawn. Sacculina, which is a still more degenerate crustacean, is only a sort of feeding sac with rootletlike processes projecting into the body of the host crab on which it lives as a parasite, but the young free-

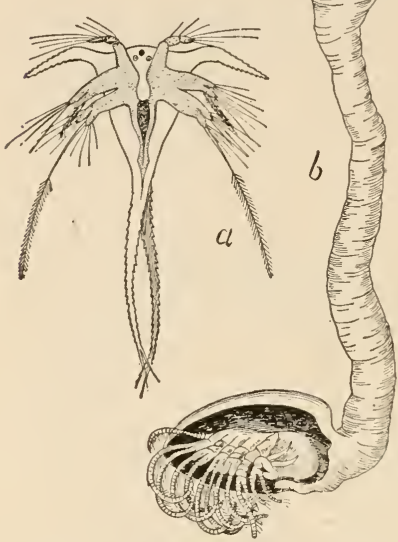

FIG. 137.-Metamorphosis of a barnacle, Lepas: $a$, Larva; $b$, adult. swimming Sacculina is essentially like a barnacle, crayfish, or crab in its young stage.

However, it is obvious that this recapitulation or repetition of ancestral stages is never perfect, and it is often so obscured and modified by interpolated adaptive stages and characters that but little of an animal's ancestry can be learned from a scrutiny of its development. The fascinating biogenetic law of Müller and Haeckel summed up in the phrase, "ontogeny is a recapitulation of phylogeny," must not be too heavily leaned on as a support for any speculations as to the phyletic affinities of any species or group of species of organisms. "Embryology is an ancient manuscript with many of the sheets lost, others displaced, and with spurious passages interpolated by a later hand."

While a young robin when it hatches from the egg or a young kitten at birth resembles its parents, a young starfish or a young crab or a young butterfly when hatched does not at all resemble its parents. And while the young robin after hatching becomes a fully grown robin simply by growing larger and undergoing comparatively slight developmental changes, the young starfish or young butterfly not only grows larger, but undergoes some very striking developmental changes; the body changes very much in appearance. Narked changes in the body of an animal during postembryonic or larval development constitute what is called metamorphic development, 
or the animal is said to undergo or to show metamorphosis in. its development.

This metamorphosis is familiar to all in insects; to zocologicts, it is familiar among numerous other kinds of animals. Fig. 135
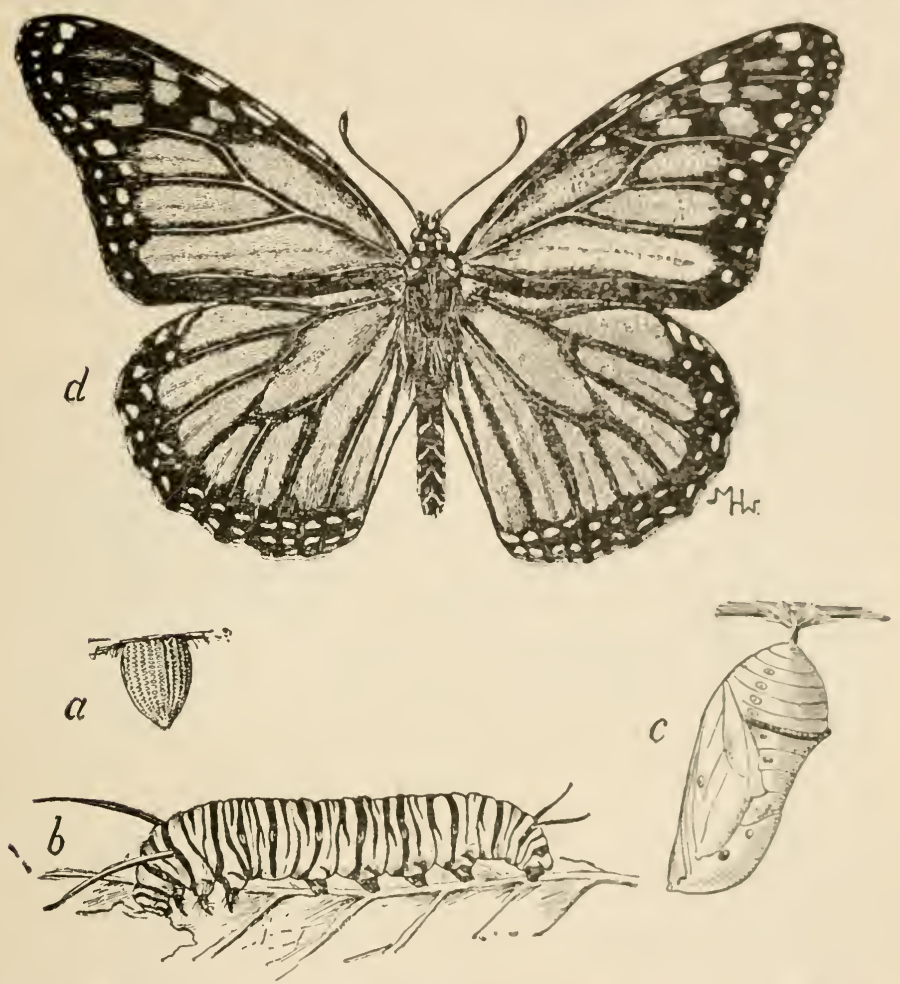

FIG, 138.-Metamorphosis of the Monarch butterfly, A nosin plexippus: $a$, Iigg, b, laru u; $c$, pupa; $d$, imago, or atult.

shows the different stages in the metamorphic derelopment of the common large red-brown milkwerd lutterfly, I nesia plexippus. From the egg hatches a crawling, wormlike larva, wingless, without compound cyes, and with strong jaws and other mouth parts fitter fol biting. This creature developis into the winged butterfly with different eres, different antemes, different mouth parts, different almost ererghing. Ind, hy the intervention of a curious quicsent stage called the prupal 
or chrysalid stage, the changes seem to be made by sudden leaps. Of course, this is not so. It is all done gradually, although there are certain periods in the course of the development when the changing is more rapid and radical than at other times. The changing is masked by the outer covering of larva and pupa, and although it is indeed startlingly radical in its character, it is wholly continuous.

The metamorphosis of frogs and toads also is familiar.

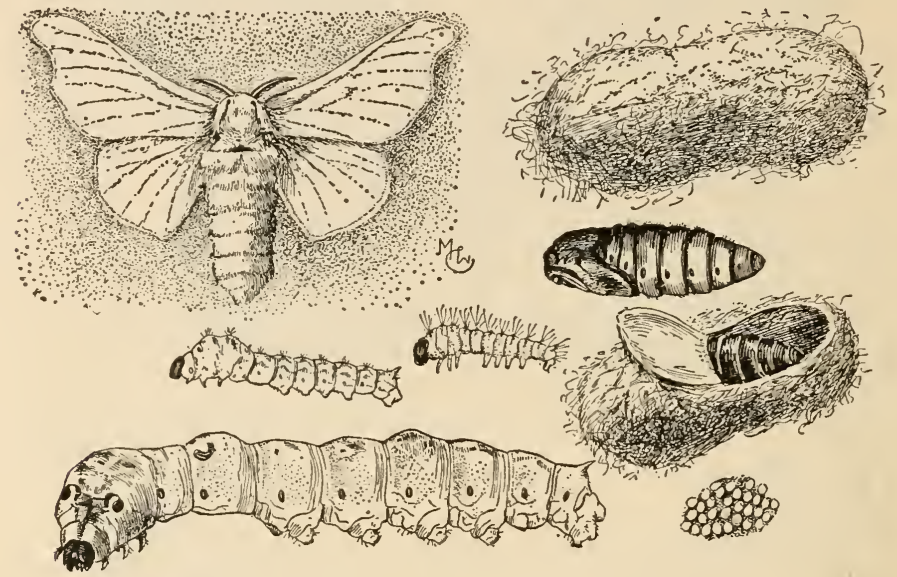

Fic. 139.-Stages in development of silkworm moth.

The eggs of the toad are arranged in long strings or ribbons in a transparent jellylike substance. These jelly ribbons with the small, black, beadlike eggs in them are wound around the stems of submerged plants or sticks near the shores of the pond. From each egg hatches a tiny, wriggling tadpole, differing nearly as much from a full-grown toad as a caterpillar differs fre $n$ a butterfly. The tadpoles feed on the microscopic plants to be found in the water, and swim easily about by means of their long tails. The very young tadpoles remain underneath the surface of the water all the time, breathing the air, which is mixed with the water, by means of gills. But as they become older and larger they come often to the surface of the water. Lungs are developing.inside the body, and the tadpole is beginning to breathe as a land animal, although it still breathes partly by means of gilis, that is, as 
an aquatic animal. Soon it is apparent that although the tadpole is steadily and rapidly growing larger, its tail is growing shorter and smaller instead of longer and larger. At the same time, fore and hind legs bud out and rapidly tahe form and become functional. By the time that the tail grets very short indeed, the young toad is rearly to leave the water and live as a land animal. On land the toad lives, as wo know; on insects and snails and worms. The metamorphosis of the toad is not so striking as that of the butterfly, but if the talpole were inclosed in an unchanging opaque body wall while it was losing its tail and getting its legs, and this wall were to be shed after these changes were made, would not the metamorphosis be nearly as extraordinary as in the case of the

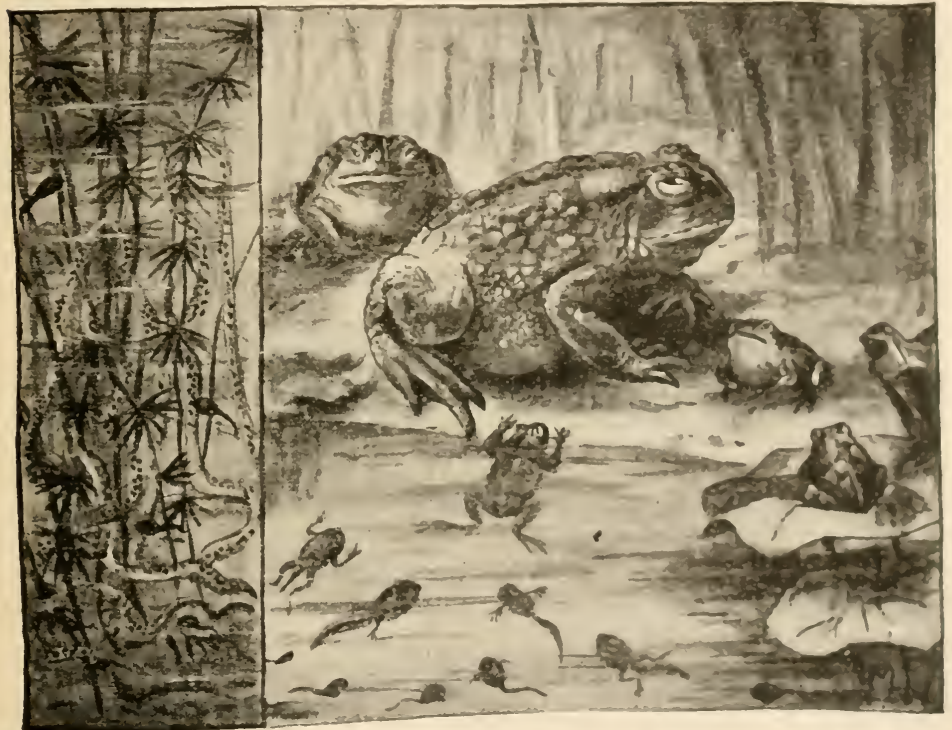

FIG. 140.-Metamorphosis of the toad: At left, strings of egga; in water, various indpole or larval stages; and on the bank, the adult tmals. (Partly after (iane.)

butterfly? But in the metamorphosis of the toad we can see the gradual and continuous character of the change.

Many other animals, besides insects and frogs and toads, undergo metamorphosis. The just-hatched seat urchin does not resemble a fully developed sea urchin at all. It is a minute 
wormlike creature, provided with cilia or vibratile hairs, by means of which it swims freely about. It changes next into a curious bootjack-shaped body called the pluteus stage. In the pluteus a skeleton of lime is formed, and the final true seaurchin body begins to appear inside the pluteus, developing and growing by using up the body substance of the pluteus. Starfishes, which are closely related to sea urchins, show a
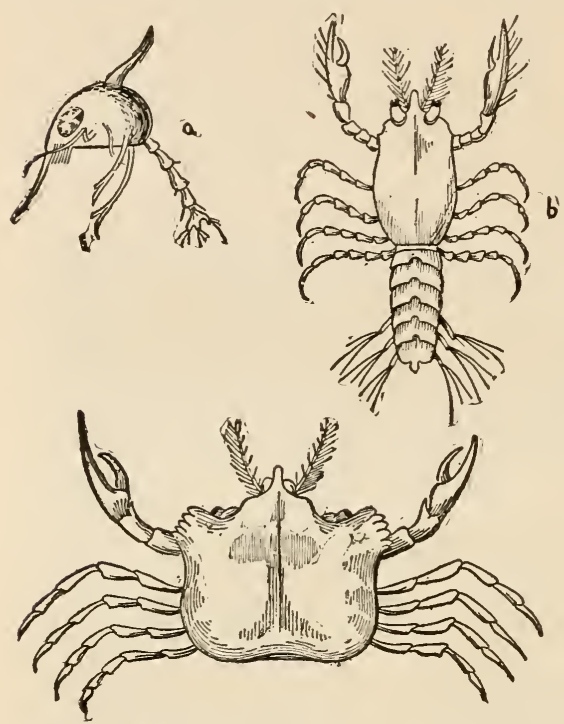

FIG. 141.-Metamorphosis of a crab : $a$, The zoëa stage; $b$, the megalops; $c$, the adult.

similar metamorphosis, except that there is no pluteus stage, the true starfish-shaped body forming within and at the expense of the first larval stage, the ciliated free-swimming stage.

A young crab just issued from the egg (Fig. 141) is a very different appearing creature from the adult or fully developed crab. The body of the crab in its first larval stage is composed of a short, globular portion, furnished with conspicuous long spines and a relatively long, jointed tail. This is called the zoëa stage. The zoëa changes into a stage called the megalops, which has many characteristics of the adult crab condition, but differs especially from it in the possession of a long, segmented tail, and in having the front half of the body longer than wide. The crab in the megalops stage looks very much like a tiny lobster or shrimp. But soon the body widens, the tail is folded underneath, and the final stage is reached.

In many families of fishes the changes which take place in the course of the life cycle are almost as great as in the case of the insect or the toad. In the ladyfish (Albula vulpes) the very young are ribbonlike in form, with small heads and very loose texture of the tissues, the body substance being jelly- 
like and transparent. As the fish grows older the body becomes more compact, and therefore shorter and thicker. After shrinking to the texture of an ordinary fish, its growth in size begins normally, although it hats all the time steadily increased in actual weight. Many hering, eels, and other soft-bodied fishes pass through stages similar to those seen in the lady fish. Another type of development is illustrated in the swordfish. The young has a bony head, bristling with spines. As it grows older the spines disappear, the skin grows moother, and,
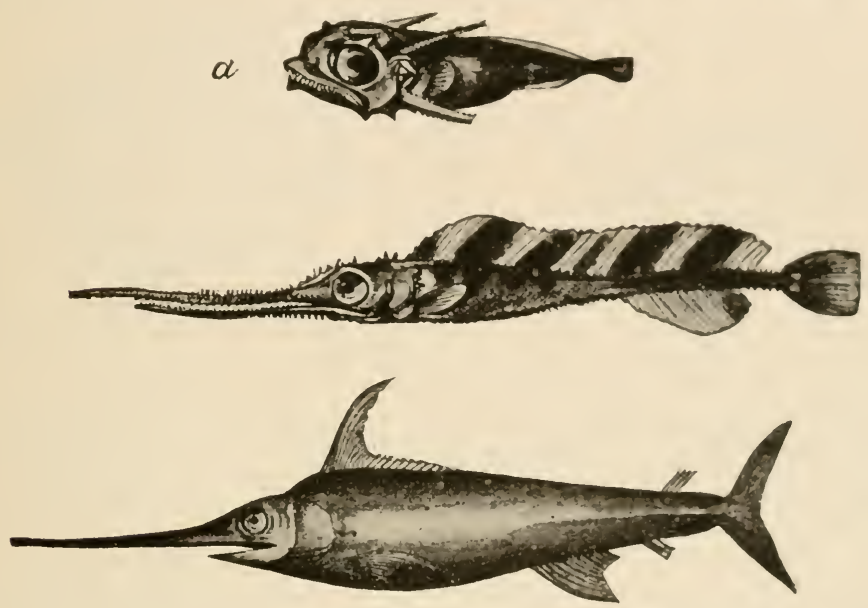

Fig. 142.-Three stages in the development of the swordfish, Xiphias gludius: $a$, Very young; $b$, older; $c$, adult. (After Lütken.)

finally, the bones of the upper jaw grow together, forming a prolonged sword, the teeth are lost and the fins become greatly modified. Fig. 142 shows three of these stages of growth. The flounder or flatfish (Fig. 143) when full grown lies flat on one side when swimming or when resting in the sand on the bettom of the sea. The eyes are both on the upper side of the body, and the lower side is blind and colorless. When the flounder is hatched it is a transparent fish, broad and flat, swimming vertically in the water, with an eye on each side. As its development goes on it rests itself obliquely on the bettom, the eye of the lower side turns upward, and as growth procecels it passes gradually around the forehead, its socket moving with it, until both eyes and sockets are transferred hy the twisting 
of the skull to the upper side. In some related forms, called soles, the small eye passes through the head and not around it, appearing finally in the same socket with the other eye.

Thus in almost all the great groups of animals we find certain kinds which show metamorphosis in their postembryonic development. But metamorphosis is simply development; its striking and extraordinary features are usually due to the fact that the orderly, gradual course of the development is revealed to us only occasionally, with the result of giving
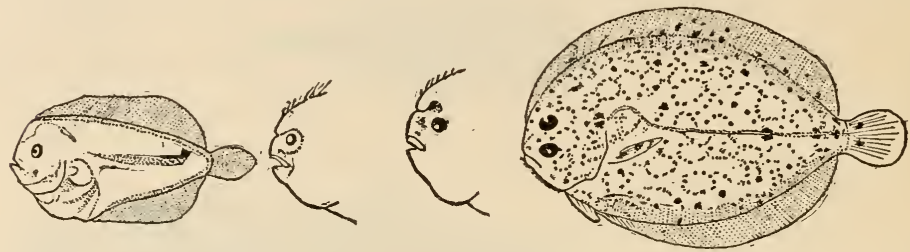

Fig. 143.-Young stages of a flounder, Platophrys podas. The eyes in the young flounder are arranged normally; that is, one on each side of the head. (After Emery.)

the impression that the development is proceeding by leaps and bounds from one strange stage to another.' If metamorphosis is carefully studied it loses its aspect of marvel, although never its great interest.

After an animal has completed its development it has but one thing to do to complete its life cycle, and that is the production of offspring. When it has laid eggs or given birth to young, it has insured the beginning of a new life cycle. Does it now die? Is the business of its life accomplished? There are many animals which die immediately or very soon after laying eggs. Some of the May flies-ephemeral insects which issue as winged adults from ponds or lakes in which they have spent from one to three years as aquatic crawling or swimming larvæ, flutter about for an evening, mate, drop their packets of fertilized eggs into the water, and die before the sunrise-are extreme examples of the numerous kinds of animals whose adult life lasts only long enough for mating and egg-laying. But elephants live for two hundred years. Whales probably live longer. A horse lives about thirty years, and so may a cat or toad. A sea anemone, which was kept in an aquarium, lived sixty-six years. Crayfishes may live twenty years. A queen bee was kept in captivity for fifteen years. Most birds have 
long lives - the small song birds from eight to cighteen years, and the great eagles and vultures up to a himulred years or more. On the other hand, among all the thousands of species of insects, the individuals of very few indeed live more than a year; the adult life of most insects being but a few day's or weeks, or at best months. Even among the higher animals, some are very short-lived. In Japan is a small fish (Salanx) which prob)ably lives but a year, ascending the rivers in numbers when young in the spring, the whole mass of individuals dying in the fall after spawning.

Naturalists have sought to discover the reason for these extraordinary differences in the duration of life of different animals, and while it cannot be said that the reason or reasons. are wholly known, yet the probability is strong that the duration of life is closely connected with, or dependent upen, the conditions attending the production of offspring. It is $n^{\prime}$ t sufficient that an adult animal shall produce simply a single new individual of its kind, or even only a few. It must produce many, or if it produces comparatively few it must devote erreat care to the rearing of these few. if the perpetuation of the species is to be insured. Now, almost all long-lived animals are species which produce but few offspring at a time, and reproduce only at long intervals, while most short-lived animals produce a great many eggs, and these all at one time. IBirds are long-lived animals; as we know, most of them lity egrgs but once a year, and lay only a few eggs each time. Many of the sea birds which swarm in countless numbers on the rocky ocean islets and great sea cliffs lay only a single eggr once each year. And these birds, the guillemots and murres and auks. are especially long-lived. Insects, on the contrary, usually produce many eggs, and all of them in a short time. The May fly, with its one evening's lifetime. lets fall from its body two packets of eggs and then dies. Thus the shortening of the period of reproduction with the production of a great many offspring seem to be always associated with a short adult lifitime; while a long period of reproduction with the production of few offspring at a time and care of the offspring are astociated with a long adult lifetime.

At the end comes death. After the animal has completed its life cycle, after it has done its share toward insuring the perpetuation of its species, it dies. It may meet a violent 
death, may be killed by accident or by enemies, before the life cycle is completed. And this is the fate of the vast majority of animals which are born or hatched. Or death may come before the time for birth or hatching. Of the millions of eggs laid by a fish, each egg a new fish in simplest stage of development, how many or rather how few come to maturity, how few complete the cycle of life!

Of death we know the essential meaning. Life ceases and can never be renewed in the body of the dead animal. It is important that we include the words "can never be renewed," for to say simply that "life ceases," that is, that the performance of the life processes or functions ceases, is not really death. It is easy to distinguish in most cases between life and death, between a live animal and a dead one, yet there are cases of apparent death or a semblance of death which are very puzzling. The test of life is usually taken to be the performance of life functions, the assimilation of food and excretion of waste, the breathing in of oxygen, and breathing out of carbonic-acid gas, movement, feeling, etc. But some animals can actually suspend all of these functions, or at least reduce them to such a minimum that they cannot be perceived by the strictest examination, and yet not be dead; that is, they can renew again the performance of the life processes. Bears and some other animals, among them many insects, spend the winter in a state of deathlike sleep. Perhaps it is but sleep; and yet hibernating insects can be frozen solid and remain frozen for weeks and months, and still retain the power of actively living again in the following spring. Even more remarkable is the case of certain minute animals called Rotatoria and of others called Tardigrada, or bear animalcules. These bear animalcules live in water. If the water dries up, the animalcules dry up too; they shrivel into formless little masses and become desiccated. They are thus simply dried-up bits of organic matter; they are organic dust. Now, if after a long time-years even-one of these organic dust particles, one of these dried-up bear animalcules, is put into water, a strange thing happens. The body swells and stretches out, the skin becomes smooth instead of all wrinkled and folded, and the legs appear in normal shape. The body is again as it was years before, and after a quarter of an hour to several hours (depending on the length of time the animal has lain dormant and dried) slow movements of 
the body parts begin, and soon the animaleule crawls about, begins again its life where it had been interrupted. Various other small animals, such as vinegar cels and certain l'rotozoa, show similar powers. Certainly here is an interesting problem in life and death.

When death comes to one of the animals with which we are familiar, we are accustomed to think of its coming to the whole body at some exact moment of time. As we stand beside a pet which has been fatally injured, we wait until suddenly we say, "It is dead!" As a matter of fact, it is difficult to say when death oceurs. Jong after the hrart cease's to beat, other organs of the body are alive - that is, are able to perform their special functions. The museles can contract for minutes or hours (for a short time in warm-blooded, for a long time in cold-blooded animals) after the animal ceases to breathe and its heart to beat. Even longer live certain cells of the body, especially the amoeboid white blood corpuseles. These cells, much like the Amøba in character, live for days after the animal is, as we say, dead. The cells which line the tracheal tube leading to the lungs bear cilia or fine hairs which they wave back and forth. They continue this movement for days after the heart has ceased beating. Among cold-blooded animals, like snakes and turtles, complete cessation of life functions comes very slowly, even after the body has been literally cut to pieces.

Thus it is essential in defining death to speak of a complete and permanent cessation of the performance of the life processes. 


\section{CHAPTER XIII}

\section{FACTORS IN ONTOGENY AND EXPERIMENTAL DEVELOPMENT}

Many biologists find their greatest triumph in the doctrine that the living body is a "mere machine," but a machine is a collocation of matter and energy working for an end, not a spinning toy, and when the living machine is compared to the products of human art the legitimate deduction is that it is not merely a spinning eddy in a stream of dead matter and mechanical energy, but a little garden in the physical wilderness.

What the distinction (between vital and nonvital) may mean in ultimate analysis, I know no more than Aristotle or Huxley, nor do I believe that anyone will know until we find out.-Brooks.

WHILE in the foregoing chapter there is outlined in some detail the general facts and processes and so-called "laws" of ontogenetic development, we purposely omitted any reference to what is known or guessed concerning the causes and control of this development. Only less wonderful than life itself is the unfolding and changing of a single tiny apparently homogeneous speck of life substance (a fertilized egg cell), into a great myriad-celled, extraordinarily heterogeneous, but perIectly organized fully developed plan'仑 or animal bocy. And only second in point of insistence to man's queries about the whence and whither of life itself are his demands to be informed concerning the causes and control of development. It is indeed strongly felt by most biologists that the study of development, that is, the study of the initiating and guiding factors of development, is more likely to reveal to us the basic factors and mechanism of evolution than any other kind of study. It is plain that evolution, its causes and method, are intimately bound up with the general primary phenomena of life, as 
assimilation, growth, differentiation, adaptation, heredity, variation, etc., and it is also plain that these fundamental life phenomena are to be most effectively studied in their relations to the development of individual organisms.

The most casual analysis of development shows that numerous and various influenees play their parts in determining its course; it satisfies no one any longer to say that the course and character of an animal's development is determined by heredity. No influence or "force" of heredity can make up) in any degree in the ease of the development of a chick, for example, for the absence of a proper temperature. This purely external factor of heat is as indispensable to the development of the new chick creature as is the mysterious inherent capacity of the tiny protoplasmic mass to unfold or change so radically that it (and what it adds to itself) may become a peeping chicken. And temperature is but one of a number of other external factors that contribte to the creation of the new chicken, as indeed the inherent eapacity of the protoplasm of a hen's egg cell to rearrange itself chickwise and no other wise during development is but one among a number of necessary intrinsic factors whose correlated influence or working is part of the developmental mechanism.

The influences or factors which determine the initiation, course, and outcome of development, then, may be roughly classified into intrinsic and extrinsic factors. And ats in our search for rational mechanical explanations of vital phenomena we look on factors as causal, we may use the word "causes" in place of "factors" or "influences" if we like. The intrinsic causes we must believe to be dependent on or incident to the protoplasmic structure of the germ stuff and to be largely the guiding and determining factors in development, while the extrinsic causes are largely such as supply stimulus and energy for the development. Among intrinsic developmental factors are included assimilation, growth, division, differentiation, etc., all constituting what His calls the "law of growth"; under extrinsic factors may be listed heat, light, moisture, food, gravitation, osmosis, etc., composing, according to His, the conditions under" which the "law of growth" operates.

In order to understand just what part each one of the various developmental factors or causes plays, there is necessary a most thorough analytical study of development, and an 
attempt o determine in measurable or quantitative degree just what specific effects each factor produces. Obviously the most reliable way to effect this analysis and this determination of the specific cause and effect relations is to appeal to experiment. But biology has always been looked on as, and until recently has actually been, almost wholly a science of observation. It is now becoming, in part at least, a science of experiment as chemistry and physics have long been (these are now becoming more and more sciences of calculation, that is, exact sciences like mathematics), and this change and advance-for it is truly an advance when a science formerly relying for its facts on observation begins to base its foundations on the results of experiment-is due primarily to the modern interest and work in the problem of developmental causes. The search for a rational, causomechanical explanation of the complex and at first sight wholly baffling phenomena of development has been a great stimulus to the bold questioning of many other vital phenomena heretofore looked on as to be explained only by the assumption of a mystic vital force or capacity wholly beyond and foreign to the physicochemical world of matter and force. Mechanism versus vitalism is one of the greatest present-day battles in biology, and nowhere is the straggle keener or are the mechanists more bold in their position than in the particular field of the processes and factors of development. To the mechanists the play of familiar physicochemical forces through the complex and unique structure of germ plasm and living tissues has for result all the extraordinary outcome of developmental course and outcome; to the vitalists this course and outcome are far too complex and purposeful to be explicable without the assumption of an extraphysicochemical force, with a capacity beyond any single or any combination of several physicochemical forces, which they call vitalism.

There is little need of discussing the great mechanism versus vitalism problem here: it is too difficult a subject, and one as yet too little illuminated by known facts, to introduce into any elementary discussion of evolution matters. But it may not be amiss to call the attention of even the most elementary student of evolution and general bionomics phenomena to the obvious fact, that the moment one indulges a penchant for assuming a mystic, extra-physicochemical force 
to explain a particularly hard problem; one has simply removed his problem from the realm of scientific investigation. It is no longer a problem. It is explained-that is, it is explained for whoever accepts the vitalistic assumption.

The varying behavior of things in the inorganie world, the functions and capacities of these things, depend on the varying physical and chemical make-up of these things acterl upun by the various kinds of energy, such as heat, motion, clectricity, and what not, which we are more or less familiar with as a part of the physicochemical world. Varying energy acting upon, or better, through varying structure: this is the eausomechanical explanation of all the phenomena in the inorganic world. Should we not in any open-minded consideration of the phenomena in the organic world strongly incline to hold to this same explanation until it is definitely proved incompetent. untenable? Answering the question with a hearty "Jes," the mechanists look first of all in their study and analysis of the so-called vital phenomena to the matter of structure of the vital masses and to the play of energy through the masces, to discover, if possible, a tangible clew to the "mysterices" of the life process. In the study of development, then, we strive first to see and to understand the intimate structure of the germ plasm, this protoplasmic stuff with its wondrous endowment of potentiality.

In Chapter III we have already stated summarily what is known of the chemical and physical make-up of protoplasm. What is actually known, by chemical analysis and earnest microscopic peering, of this structural make-up is wholly insufficient to serve as a satisfactory basis of any ("ansomechani(al explanation of protoplasmic properties. Although some of the simpler capacities of protoplasm, as its motion, its taking up of outside substances (feedince), ("tc.. have been to some degree explained by seeing in them direct physicuchemical reactions to external stimuli or conditions. practically nothing has been really aceomplished as yet toward a mechanical explanation of such more complex or unusual capacities as irritability, assimilation, and reproduction. This last function of protoplasm is in a way its most apparently hopelessly inexplicable property. And this is especially so when the reproduction is of the sort peculiar to the germinal protoplasm; that is, where the reproducing protoplasmic mass does 
not simply divide and thus make two masses each capable of the growth and change necessary to make it like the parent mass, but where the parent mass (a fertilized egg cell, or a sexual egg or bud cell) can grow and develop into a highly complex many-celled new organism of type like that from which the parent germ plasm was derived. The special capacities, therefore, of germ plasm have furnished for centuries, and do to-day,

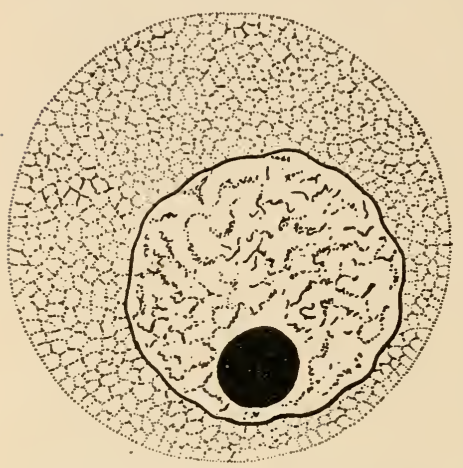

FIg. 144.-Egg cell of a sea urchin, Toxopneustes lividus, showing cytoplasm, nucleus, and nucleolus, and network or alveolar appearance of the protoplasm. (After Wilson.) the great problem of biology (next to that provided by the existence of life itself).

If we cling to a belief that in some way, after all, the explanation of the general protoplasmic and special germ plasm capacities lies in an unusuel combination of structure and play of familiar form of energy through the structure, we are at once forced 'to assume a structural make-up of protoplasm and germ plasm beyond the highest powers of our microscopes to detect. And this assumption actually is made by most biologists. No agreement, however, exists among biologists as to this assumed structure. Biology does not have its atomic theory as chemistry does, to explain the ultramicroscopic make-up of the substances with which it has to deal, but has its atomic theories, a score of fairly well-marked theories as to the ultimate structure of germ plasm having been advanced in the last couple of centuries of biologic study.

Almost all of these theories assume a micromeric structure of protoplasm; a few are antimicromeric. By micromeris is meant simply that the plasm which appears to us as a viscous colloidal substance, somewhat differentiated into denser and less dense parts, appearing as fibrils or grains or alveoles in a ground substance of different density, is assumed to be composed of myriads of minute, ultramicroscopic units of the general nature of combinations of chemical molecules. These unit combinations are given, in the theories of various authors, 
various names, endowed with various particular properties, and attributed, as to their origin, to varying sources.

In the seventeenth century and early part of the eighteenth century, before the time of the microscope, many naturalists and physicians believed that in each germ cell (or, aceording to some, in each egg cell, according to others, in each sperm cell) there existed, preformed and almost complete, at new organism in miniature, and that development was simply the expanding and growing up of this tiny embryo man, or monkey, or chick. Also they were forced to believe, if this first assumption were true, that in each preformed embryo still smaller replicis of their particular kind must exist to be the children of this child, and so on, ad infinitum. Like the nests of Japanese boxes, the outer one encasing a smaller and this still a smaller, and this yet a smaller and so on, the young and future young of any kind of organism were, aceording to this encisement theory of the germ cell structure, nested in the egg and sperm colls of any organism.

But the invention and use of the microscope soon put this theory aside. The germ cells were found to contain no preformed embryo. Indeed, they seemed to the earlier microscopists to be utterly homogeneous little spechs or masses of protoplasm, and the pendulum of speculative explanation tended to swing well away from any preformation theory toward the speedily formulated epigenetic theories, which assumed that all germ cells were practically alike cxeept as to their paternity and maternity, and that the derclopment of these homogeneous specks of protoplasm must be determined chiefly by external conditions and influences.

However, it was obvious that there was no logical or even fair reason for believing that the lack of structural differentiation in the germ plasm revealed by the microscope was a proof of the actual absence of such organization. The first microscope magnified but a few hundred diameters, revealing structure invisible to the madided eye; but later microscopes, magnifying objects a thousind and more diameters, revealed structure and organization which were quite invisible to the lower-powered instruments. And so, although to-day we examine germ plasm with lenses magnifying three thousand times, and yet fail to discover more than threads, rods, grains, or droplets in a viscous 
ground substance, we do not believe at all that this structural differentiation is the ultimate physical make-up of the mysterious substance protoplasm. We readily believe there may exist an ultramicrosropic structure of great complexity.

Buffon suggested that the living stuff is composed ultimatsly of tiny structural units, which he called organic molecules: these molecules are universal and indestructible; they co not increase in number or decrease; when united in groups they form organisms; when an organism dies its organic molecules are freed but not destroyed, and later may help compose other organisms. Bechamp believed in similar living micromeric units called microzymes, created directly by the Supreme Being, indestructible and strewed everywhere in earth, air, and water.

Herbert Spencer postulated the existence of so-called physiological units: living units all of the same structure, active because of their polarity of form and of molecular vibrations, in size and character midway between molecules and cells, small but complex and possessed of a delicate and precise polarity analogous to that of the molecules of crystalline substances, a polarity which gives them the capacity to group themselves into organic parts and wholes. Other theories similar to Spencer's assume a special physicochemical endowment of the chemical molecules in the organic body (Berthold), or a special electrical endowment of the life units (Fol), or a special chemical one (Altmann and Maggi), or, finally, a special vital one (Wiesner).

Darwin proposed a theory to explain how the germ plasm could unfold into the whole body, called the theory of the pangenesis of gemmules. Darwin postulated the existence in the body of a host of life units called gemmules to be found in all the various body cells, capable of rapid self-multiplication and of a migratory movement through the body, the direction and goal of which movement is determined by delicat affinities existing among the various gemmules. When a gemmule enters an undifferentiated or developing cell, as yet gemmuleless, it controls the development of that cell. Thanks to the delicate and precise affinities of the gemmules, they always get to just where they should, to produce harmonious development; but in the germ cells lodge gemmules from all over the body, so the development of these cells results in a new whole body. 
Nägeli, a philosophical botanist, proposed a theory of germplasm structure and behavior which may be called the theory of micelle, nutritive plasm and idioplesm. When the connplex, life-characterizing albuminous substances took their birth in an aqueous liquid, they were precipitated as tiny particles callent micellar, which attracted other micellie to themselves and thus produced aggregates of primitive life stuff, or protophlasm. The micella are all separated from earch other by thin envelopes of water, thus making water an integral part of protoplanm, and making growth by intercalation of new micellic possible, this primitive protoplasm becomes arranged in two ways, resulting in produeing two kinds, one alled nutritive protoplasm, and the other idioplesm or germ phasm, extending all through the nutritive protoplasm as a fine network.

Finally, the most recent micromeric theory of germ-plat-m structure is that of Weismann, the modern champion of nat ural selection. According to him the protoplasin of the mucteus is made up of units called biophors, which are the bearers of the individual characters of the cell; the biophors are complex groups of molecules, capable of assimilating food, growing, and reproducing; the number of biophors is enormous, as it must equal the possibilities of cell variety. The biophors are united into fixed groups called determinants, each determinant containing all the biophors necessary to determine the whole character of any one cell; in each specialized cell there need be but one determinant, but in the germ eells every kind of determinant must be represented.

In connection with the postulation concerning the ultimate make-up of the plasm of the germ cell, Weismann has formulated a theory of germinal selection to aceount for the obvious fact that a certain cumulation of variation of a certain kind or along fixed lines may take place without the aid of natural selection: this variation cumulation often being inderd of a degree too slight to give any opportunity for interference by natural selection. To account for this fact, which has been much used by adverse critics of natural sclection, Weismann assumes a competition of the determinants in the germ cells for food, hence for opportunity to grow, to be vigorous, and to multiply; the initially slightly stronger or more farorahly situated determinants will get the most food, lessening, at the same time, the food supply of others. Now, when the germ cell 
begins development the kind of cells or tissues or organs will be best developed whose determinants happen to be the better fed, stronger ones, while other parts of the body may be made smaller or even not appear at all on account of the starvation of their determinants; also the stronger determinants in the better developed parts of the body will produce by multiplication more and stronger daughter determinants for the germ cells of the new individual than the weak determinants in the ill-developed body parts, and thus this disparity in development of body parts will be passed on, cumulatively, to successive generations: which is nothing more nor less than determinate variation.

All the speculations about the ultimate structure of the germ plasm are interesting, but none of them of course is really convincing. As Delage has well said, the chances are too many to one against the probability of anyone's guessing correctly the actual facts concerning the complex structural detail of the protoplasmic make-up. The structural or inherent factors in ontogeny, then, are to be understood only in so far as obvious results or effects may reveal them. Now there is one set of phenomena in ontogeny, to which we have not as yet called attention, which does seem to throw some light on certain essential features or facts of germ-cell structure which otherwise would not be obvious to us. This set of phenomena is that called mitosis or karyokinesis, and occurs in connection with each division or cleavage of the egg cells, and of their daughter cells or blastomeres. It occurs also in the division or multiplication of cells in all the tissues of the body, and is a phenomenon normal to cell increase anywhere in the body at any time in the life of the organism.

Direct or amitotic cell division is much less common and seems to be restricted to certain kinds of tissues or to certain periods in the history of the life of certain tissues. However, the recent investigations of Child and others show that cell division without mitosis is more common than is usually thought. In this kind of division, the process consists simply of the constriction and equal (or unequal) splitting of the cell body into two parts, the dividing of the nucleus usually being slightly in advance of that of the cytoplasm. Each half of the parent cell has then but to increase in size to become the counterpart of its progenitor. In the mitotic or indirect division, on the 
contrary, the process is more complex. It has been described by F. M. McFarland ${ }^{1}$ as follows:

"One of the earliest results of the study of coll multiplication was the discovery that division of the nucleus precedes the division of the cell body. Furthermore, a careful examination of the different phases of the process offers the strongest proof that the most important feature of this division, an end to which all the other procescess are subsidiary, is the exact halving of a certain muclear substance, the chromatin, between the two daughter cells which result from the division. To gain a clear conception of this process of indirect rell division, called 'mitosis' or 'karyokinesis,' let us consider the changes which take place in typical cell multiplieation. Two parallel serio's of changes occur nearly simultaneously, the one affecting the muclens, the other the cytoplasm. In the so-called 'resting' nucleus-i. e., the nucleus not in active division-the chromatin, as we have seen, exists usually in the form of scattered granules arranged aloner the linin network, and does not color readily with nuclear stains. Is division approaches, these chromatin granules become aggrearated together in certain definite areas, forming usually a convoluted thread or skein, which now readily takes up the nuclear stains which may he used. In some nuelei this skein is in the form of a single long filament, in others the chromatin is divided up from the first into a series of segmerits, a condition which soon follows in the case of a single filatment. By transverse fission the latter breaks up into a series of segments, the 'chromosomes,' the number of which is constunt for each species of animal or plant. Thus in the common mouse there are twenty-four, in the onion sixteen, in the sea urchin eighteen, and in certain sharks thirty-six. The number may be quite small, as, for example, in Ascaris, a cylindrical parasitic worm inhabiting the alimentary canal of the horse. Here the number is cither two or four, depending upon the variety examined. In other forms the number may be so large as to render comting exceedingly difficult or impossible. In all cases, however, one fact is to be esperially noted, viz., the number is always an even one, a striking fact which finds its explanation in the phenomena of fertilization to be discussed later on.

"While the chromatin is collecting into the form of the chromo-

${ }^{1}$ Most of the discussion in the following twenty pages, whether indicated by quotation marks or not, is taken from . Mc Farland's essay on " The Physical Basis of Heredity" in Jordun's "Footnotes to Lvolution" (19022). 
somes the nuclear membrane has disappeared. The chromosomes soon reach their maximum staining capacity, and appear usually as a collection of rods or bands of deeply staining substance lying free in the cytoplasm.

"While this is taking place in the nucleus, another series of changes has been gone through by the centrosome and the cytoplasm immediately surrounding it. We have already indicated the presence of the centrosome as a minute spherical structure lying at one side of the nucleus. This body assumes an ellipsoidal form, constricts transversely into a dumbbell-shaped figure, and divides into two daughter centrosomes, which at first lie side by side but soon move apart. Around each of them is gradually developed a stellate figure composed of a countless number of delicate fibrils radiating out in all directions from the centrosome as a center. This 'aster' or 'astrosphere' is at first small in extent, but grows in size progressively as the two centers move apart, apparently being derived from a rearrangement and modification of the threadlike network of the cytoplasm under the influence of the centrosomes.

"Between these two asters, which lie a short distance apart and at one side of the nucleus, a spindle-shaped system of delicate fibrils may often be made out, stretching from the center of one aster to that of the other. This fusiform figure is termed the 'central spindle.' The two asters, together with the central spindle, form what is termed the 'amphiaster' or the 'achromatic' portion of the karyokinetic figure. The two series of changes in nucleus and cytoplasm, which have thus far gone on apparently independently of each other, now become closely interrelated in that, as the nuclear membrane disappears, a system of fibrils grows out from each astrosphere, which attach themselves to the individual chromosomes. These 'mantle fibers' insert themselves along the chromosomes in such a way that each segment receives a series of fibrils from each pole of the amphiaster, the two series being attached along opposite sides of the chromosomes. Under the influence of these fibers, probably by direct pulling, the chromosomes, now bent into $\mathrm{V}$ - or U-shaped loops, tend to place themselves in a circle around the center of the spindle, transversely to its long axis, and form the 'equatorial plate.'

"'The changes thus far constitute the 'prophases' of the division. The 'metaphases' following these consist primarily in the longitudinal splitting of each chromosome and the moving apart of the halves. This longitudinal splitting of the chromosome into two equivalent parts forms the most important act of the whole cell division, and is 


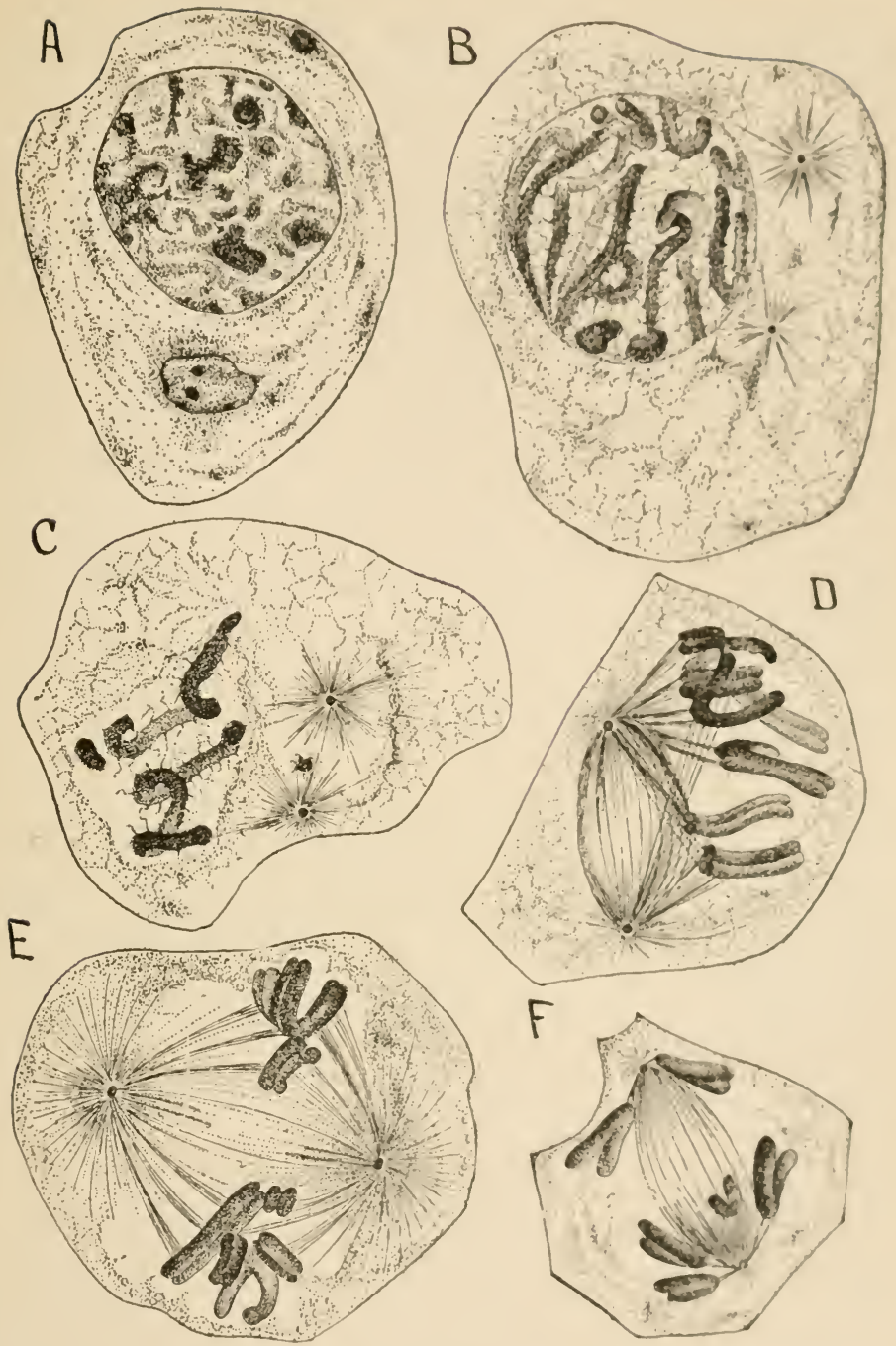

irg. 145.-Cell fission in the salamander: A, Resting nucleus stage, centrusome parfly developed; $B$, skein stage, chromatin vishle as a convoluted haml, the centrosomes having separated; $C$, the nuclear membrane having disalpueared. anul a fow of the chromusomes lying free in the cytoplasm; D). central sumblle complete. the chromosomes on splitting heing drawn to the spumblen: E. metaphase; $F$, an:aphase, the chromosomes being drawn te the pules. (Ifter 1)runer.) 
of the greatest theoretical significance. By it the chromatin substance of the original nucleus is equally distributed between the two daughter nuclei, so that each receives a half of each original chromosome. The elaborate mechanism and consequent expenditure of energy involved in this careful longitudinal division of each chromosome, rather than a simple mass division, such as might be brought about by far less complicated means, indicates clearly that the distribution of the definite organization of the chromatin to the daughter cells is of primary importance, a conclusion which is further strengthened by much evidence too extended to be entered upon here.

"In the 'anaphases' and 'telophases,' which include the closing stages of division, the daughter chromosomes migrate along the fibers of the central spindle toward its poles, perhaps through the direct contraction of the mantle fibers under the influence of the centrosome, though this and many other points regarding the forces at work must be left for future investigation to decide. Arrived at the poles, $\mathrm{V}$-shaped chromosomes become grouped in a star-shaped figure, the 'aster,' their outer ends become again joined together in the form of a tangled skein, the individual chromatin granules separate somewhat along the threads of the linin network, their deeply staining quality is decreased, and a new nuclear membrane develops around each group of chromosomes. Simultaneously with this the cytoplasm constricts across the middle of a somewhat elongated cell, resulting in complete division in the equatorial plane of the spindle, and two separate daughter cells result. Each of these is made up of cytoplasm containing a centrosome and a nucleus, similar in all respects to the parent cell from which it has arisen.

"A simple tabulation of the changes just described is as follows:

\section{Phases of Cell Division by Karyokinesis}
I. Prophases........
(1. Resting nucleus.
2. Skein stage of chromatin.
3. Segmented skein.
6. Segmented daughter skeins.
IV. Telophases........ $\left\{\begin{array}{l}\text { 7. Reconstruction of nucleus. } \\ 8 \text {. Division of cytoplasm. }\end{array}\right.$ 
"It is readily seen that the culnination of the process lies in the splitting of the chromosomes and the separation of their component halves to form the two new daughter nuclei."

The obvious distinction in eapacity of devolopment shown by the various cells which compose an animal's body leads ns to ask whether we can distinguish differences associated with these different potentialities in the fine structure of the refls themselves, and especially in their behavior during the process of multiplication. For the fate or future charactor of any cell must largely depend on the nature of its origin, the character of its inheritance. Now in some cases this difference in potentiality of the undifferentiated dividing cells is plainly shown by differences in the details of the process of division. I conspicuous and important instance of this, and one hearing directly on our subject of the relation of the structure and character of the germ plasm to the fully developed organism, is the distinction, usually easy to make, letween the body or so-called somatic cells and the reproductive or germ cells of any organism.

"Every multicellular" organism arises by a proress of division from a single cell, the fertilized germ or egrg cell, which in turn has been cut off from the cells of a preëxisting indiviclual. Out of the group of cells which result from the continued division of the germ cell and its descendants are differentiated the various tissues and organs of the body through which the vital functions are earried on. Those tistues and organs which perform funetions pertaining directly to the existence of the individual have been termed 'somatic,' and their constituent cells the 'somatic' or body cells, in contradistinction to the reproductive tissues or cells whose function concerns the contimunce of the species. In some forms these groups of cells, the somatic and the reproductive, become isolated from each other quite early in development; in one ease, indeed, the differentiation of reproductive cells from the somatic ones has been traced by Boveri back to the first division of the egg. This case of Ascaris megaluceplatala is so striking and of such fundamental theoretical importance that it must not le passed without notice, for in it we fund marked differences letween the somatic and reproductive cells in their nuclear structure, their relative amount of chromatin, and mode of division. The egg of Ascaris has been the classical object for cytulogical studies on account 
of its small number of chromosomes (two in variety univalens, four $i$. bivalens), their large size, and the diagrammatic clearness of the

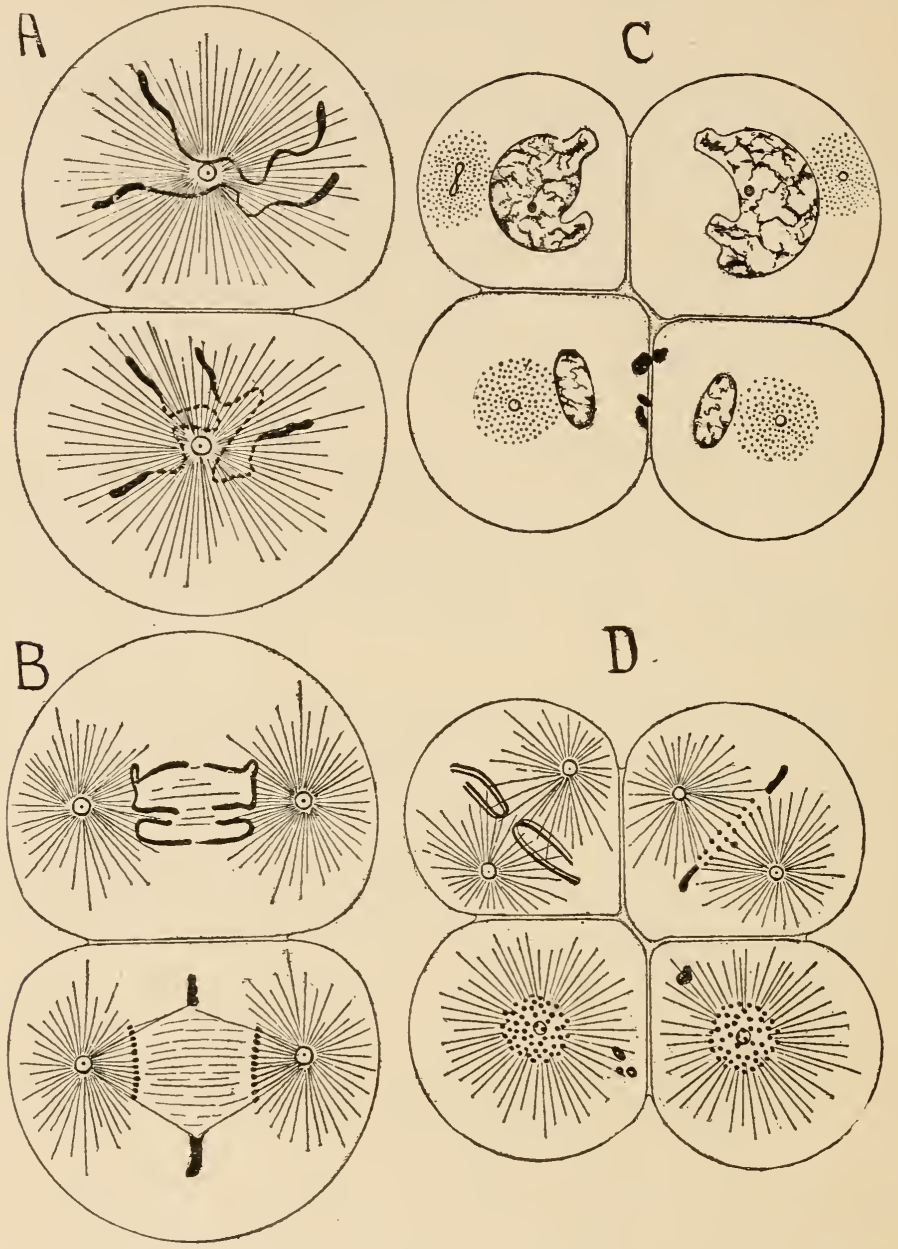

FIG, 146.-Reduction of the chromatin in the cleavage of the egg of Ascaris megalocephala var. univalens. (After Boveri.)

changes which take place in division. In the division of the fertilized egg cell we have two (in univalens) long chromosomes handed over to each daughter cell, As these two cells in turn divide, a striking 
difference is seen in the karyolinetic figures. In Fig. 146, .1, such it two-celled stage is seen from the pole; in $B$, a slighly later stage in side view of the spindle. In the upleer coll of $A$, the division is of the usual form, the two chromosomes split Iongiturlinally, and their two halves travel to opposite poles of the spindle. $(B)$. But in the lower cell this is not the case. The eentral portion of the two chromosomes is broken up into a large number of minute chromatin granules which divide, and, as shown in $B$, form the only portion of the chromosomes drawn up to the poles and entering into the structure of the resting nuclei after the division is complete. The large swollen outer ends of the chromosomes are cust off into the cytoplasm and are eventually" absorbed, playing no further part as nuelear structures. C shows the four-eelled stage, in which a marked difference in the size of the metei of the upper and lower cells is visible. Iying near the margins of the lower eells are the remnants of the ends of the chromosomes which have been east off in the division. In $D$ the four-celled stage is shown with the karyolinetic figures of the next division. In the lower cells the spindles are seen from the pole, the chromatin is juresent in the reduced amount, in the form of small granules. In the upper left-hand cell the two full chromosomes are seen, each split longitudinally, while the upper right-hand cell shows a repetition of the reduction phenomenon-viz., the central portion of the two chromosomes, broken up into granules, alone enters into the spindle figure, the outer ends being cast off into the eytoplasm, where they suffer a sinilar fate to those of the lower cell in the previous division. The next elivision re:uats the process, one cell retaining the two full chromosomes, while all the others have the reduced amount. This takes place for five surersive divisions and then ceases; from the one cell having the two full chromosomes the reproductive tissues devoloy, the others with reduerel ehromatin form the somatic tissues. Thus is areomplisherl a visibhe structural differentiation of the nuclei of the repurenductive cells which distinguishes them sharply from all the somatic tissues in Ascuris. We shall see further on that there is abundint cvidence in favor of the theory that the nucleus-i.e., the chromatin-is the bearer of hereditary influences from one generation to the next, and that the speeific development and functions of each individual coll are dependent upon the specifie changes which take plase in the chromatin of its nucleus. In this light the almost isolated rase of Ascoris possesses a value and interest that camnot he overestimated.

"While in the higher forms of animals and plants we find a sharp differentiation of their tissues into somatic and reproductive or germ 
cells, we must bear in mind that not in all forms is this power of the reproduction of the whole organism so sharply limited to the germ cells alone. The familiar propagation of plants by cuttings, the regeneration of complete animals from small portions of their somatic tissues in many lower forms, and numerous other considerations such as these, show clearly that the difference between the powers of somatic and germinal cells is but one of degree; that while in higher organisms the two seem sharply defined from each other, a series of lower forms may be taken which will show the intermediate steps in this gradual specialization of function.

"In the unicellular organisms we have most interesting examples of the fundamental facts of reproduction, and through an examination of these we may gain an insight into the more complicated processes of the Metazoa. Each of these lowest forms consists of a single cell in which are carried out in a generalized way the complex physiological functions which, in many-celled animals, are divided up among cell groups. In reproduction the animal simply divides into two, the division of the nucleus preceding that of the cytoplasm, and the method is usually a more or less modified karyokinetic one. This mode of multiplication continues in most forms for a certain number of generations, and then the necessity for conjugation-i.e., a temporary or permanent fusion with another individual-sets in. If this conjugation be prevented, the animal soon shows increasing signs of degeneration which result in death. This 'senescence' of the powers of growth and multiplication can only be checked by the admixture of new nuclear substances from an entirely different individual by conjugation. In its simplest terms this process is found in Chilodon, according to Henneguy. Chilodon is a minute fresh-water infusorian, which multiplies for a considerable period of time by transverse division. After a time, however, the physiological necessity for conjugation ensues. The animals having placed themselves side by side in pairs and partly fused together, the nucleus of each individual divides into two portions, one of which passes from each infusor into the other to unite with the half remaining stationary. The two then separate, each having received a half of the nucleus of the other. After thus trading experiences, as it might be termed, a period of renewed vigor and activity for each sets in, manifested in rapid growth and multiplication by division, producing a large number of generations, which continues until weakening vital activities indicate the periodically recurring necessity for conjugation. In general, among the Infusoria we find the same process taking place in regular cyclical order, with 
more or less complicated variations of the phenomena just outlined for Chilodon. In all of them the aim of the conjugation is the same, the exchange of a certain amount of nuclear sulsstance between the two conjugating individuals, and the same physiological effect is reached, a rejuvenescence, as it were, of the two organisms which manifests itself in renewed vigor of growth and multiplication.

"In some of the lowest forms of unicollular life-for example, the Schizomycetes or bacteria and their allies-this necessity for conjugation does not appear to exist, but for the vast majority of forms this cyclical law of development holds good. In the Protozoa no division into somatic and germinal cells is found, both functions being united in the one cell which forms the whole body of the organism. In the Metazoa, however, this differentiation has

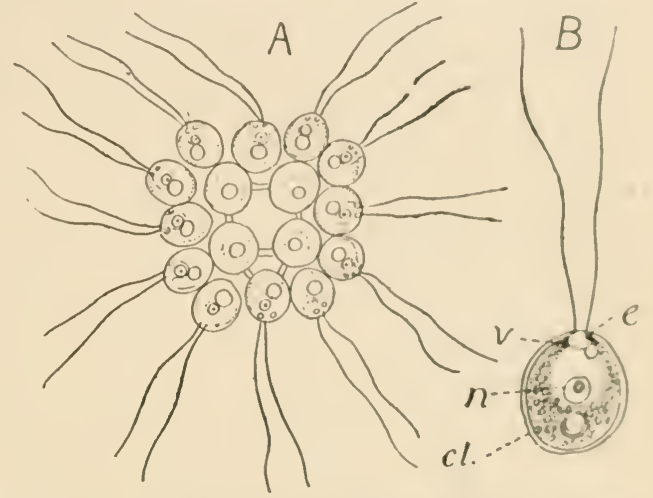

FIG. 147.-Gonium pectorale, a simple colonial Protozoan, composed of sixteen cells holdling together in a single layer or plate: $A$, The whole colony; $B$, a single cell; ${ }^{\circ}$. eye spot; $\mathrm{cl}$, chloroplast; $n$, nucleus; $v$, vacuole. (After Campbell.)

taken place; the germinal cells are set apart for the preservation of the race; the somatic cells carry on their various functions for a time, grow old, die, and disappear, certain of the germ cells alone surviviner in the production of new individuals. On the borderland between the unicellular and the multicellular organisms, however, stand certain colonial forms, which show an exquisitely grated series of stepns, from the conditions of unicellular multiplication to those of the multicellular forms." (McFarland.)

In the many-celled animals the erg is a single cell laden with a large amount of food yolk, and made up of nucleus and cytoplasm as the living elements. For the normal development of this egr, conjugation with anot ker germ cell, derived from a different individual, is usually necessary. This germ cell is the spermatozooid, a minute cell consisting of mucleus and centro- 
some with a small amount of cytoplasm modified primarily into an organ of locomotion, the tail. A physiological division of labor is here met with which admirably meets two diametrically opposed requirements. The one of these demands that the conjugating cells be highty motile, and consequently small, in order that they may be able to come together in the water in which they are usually set free. The second requires that there be furnished a sufficient amount of nutritive material for the nourishment of the embryo until it arrives at a stage of growth in which it can shift for itself. These two necessities have been met by the physiological division of labor between the two conjugating cells. The one, the sperm cell, has become reduced in size with a corresponding gain in motility, the other, the egg cell, has had food yolk stored up in it, and its consequent increased size prevents any more than a very slight degree of independent movement, if any. Different stages of these modifications may be met with among unicellular forms, as illustrated in Pandorina, Eudorina, and Volvox, to which might be added many others. In Pandorina the conjugating cells are of nearly equal size, in Eudorina an intermediate condition is reached, while in Volvox the egg and sperm cells are sharply differentiated in size and motility. Again, in the first two and their allies all of the cells are at first vegetative and afterward reproductive, while in Volvox the definite separation into vegetative or somatic, and reproductive or germinal cells makes its appearance.

We arrive then at the conclusion, from the consideration of these and many other lines of evidence, that the germ cells were primitively exactly alike, and that the differences between them have arisen in the process of differentiation along two separate lines. Furthermore, it is clear that the differences between the two sexes, which become strongly characterized in the higher vertebrates, are all of a purely secondary nature.

In their early development the germ cells are indistinguishable from each other, and both pass through certain stages, preliminary to their union, which are essentially alike. The animal egg is a large, more or less spherical cell, enveloped usually by certain membranes, containing a large nucleus and cytoplasm. The vast bulk of the egg cell, however, is made up of inert food material in the form of yolk granules, which are stored up in it as nourishment for the developing embryo. 


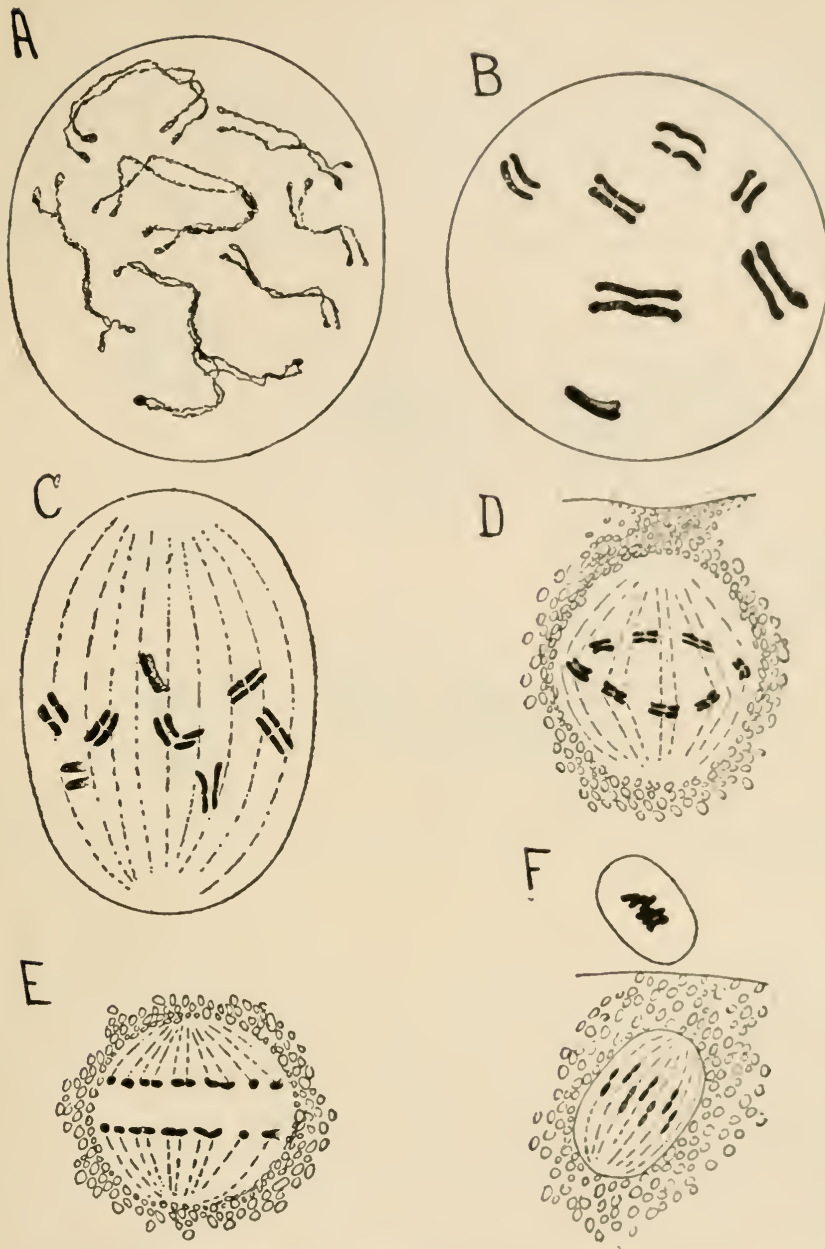

IG. 148.- Maturation of the eqg of Cyclops (the full number of cnromosnmes is not shown): $A$, Chromosomes already split longitudinally; $B$, cliromatin masses with indication of transverse fission to form the tetrads; $C$, the young tetrads arranging themselves on the first polar body spindle; $D$, tetrads in first hody spindie; $E$, separation of the dyads in the same; $F$, position of the dyads in the second polar body spindle, the first polar body being really above the margin of the egg. (After Rückert.) 
The nucleus, or germinal vesicle, is large, and contains a network of chromatin together with one or more conspicuous nucleoli.

There are three periods usually recognized in the development of the egg cell, viz.: (1) The period of multiplication; (2) the period of growth; and (3) the period of maturation. The first period is characterized by a continued series of divisions of the primitive reproductive cell and its descendants, which

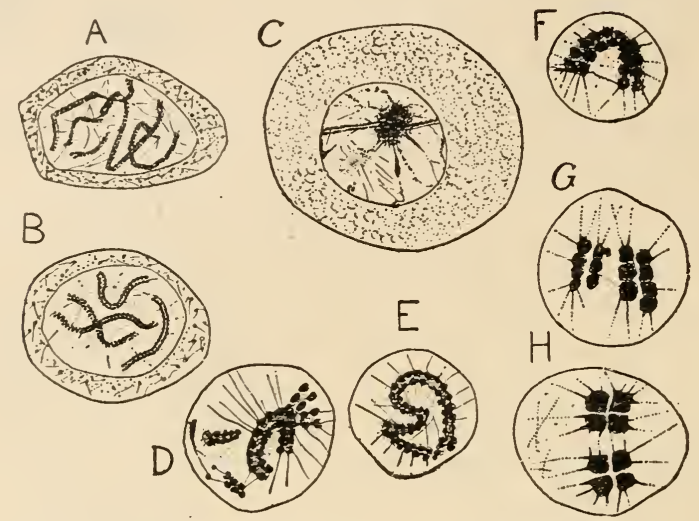

FIG. 149.-Formation of the chromatins and tetrads in the spermatogenesis of Ascaris megalocephala. In $A-C$, the whole cell is shown; in $D-H$, only the nucleus. (After Brauer.)

produces a large number of "ovogonia." Succeeding this is a period of growth in which the ovogonia increase greatly in size, mainly through the production and storing up of food yolk. At the close of this period the germ cell, now termed a "primary ovocyte," enters upon the maturation period, in which it undergoes two divisions in rapid succession, by means of which two minute cells, the polar bodies, are cut off from ns egg. Through these two divisions the number of chromosomes in the egg nucleus is reduced to one half that which is found in the other cells of the body. The first polar body also usually divides, and thus, at the close of the period of maturation, four cells result: one large mature egg cell, ready for the fertilization which initiates the development of the embryo, and three minute polar bodies, which are to be regarded simply as rudimentary eggs. The nuclei of these four cells are exactly 
alike in that they all contsin the same number of chromosomes, i. e., one half the number in the somatic cells of the individual. The difference in size is due simply to the concentration of the food yolk and most of the cytoplasm in one of the cells; the other three degenerate, being sacrificed to the production of an egg cell with the largest possible supply of nutritive substance in it.

In the development of the sperm cell (Figs. 149, 150), we find an exactly parallel series of stages, the end results, however, differing much in size.

The mature spermatozoön is an exceedingly minute cell, consisting typically of a cylindrical or conical "head" containing a nucleus, a short cytoplasmic "middle piece," and a long vibratile "tail," an organ of locomotion differentiated out of the cytoplasm of the cell from which the spermatozoön is de-
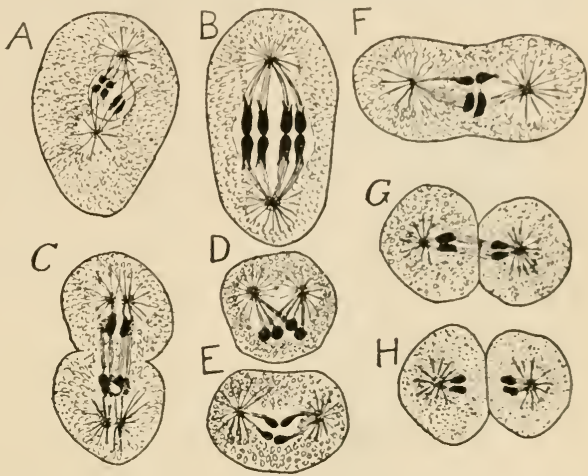

Fig, 150.-First $(A-C)$ and second $(D-H)$ maturation of the spermatocytes of Ascaris megalocephala. (After Brauer.) rived. The stages of multiplication, growth, and maturation are passed through in the development of the spermatozoön in the same order as in the egg development, save that the period of growth does not include the storage of food yolk in the primary spermatocyte, and the two divisions of the maturation stages are equal ones, resulting in the production of four cells of the same size, each of which develops into a complete spermatozoön.

The accompanying diagrams of Fig. 151, taken from Boveri, illustrate clearly the homologies existing between the life histories of the two sorts of germ cells. The earlier stages of ovogonia and spermatogonia are indistinguishable from each other; later in the period of growth the increase in size of an ovocyte marks it off from the minute spelmatocyte, but this distinction is merely one due to nonliving food material, and 
in nowise affects the fundamental identity of the two. In the maturation period the number of chromosomes in the nuclei of both egg and sperm is reduced one half-on the one hand, the ripe egg cell and three rudimentary egg cells (the polar bodies) being formed; on the other, four equal "spermatids" are produced, which develop into four mature spermatozoa. The contrast in size which exists between the two mature reproductive cells is enormous, the spermatozoön in some cases containing less than $\frac{1}{100 \overline{0}} \overline{0}$ (Wilson), and in extreme cases less than $\overline{1000} \overline{0} 0 \overline{0}$ (Hertwig) of the volume of the egg cell.
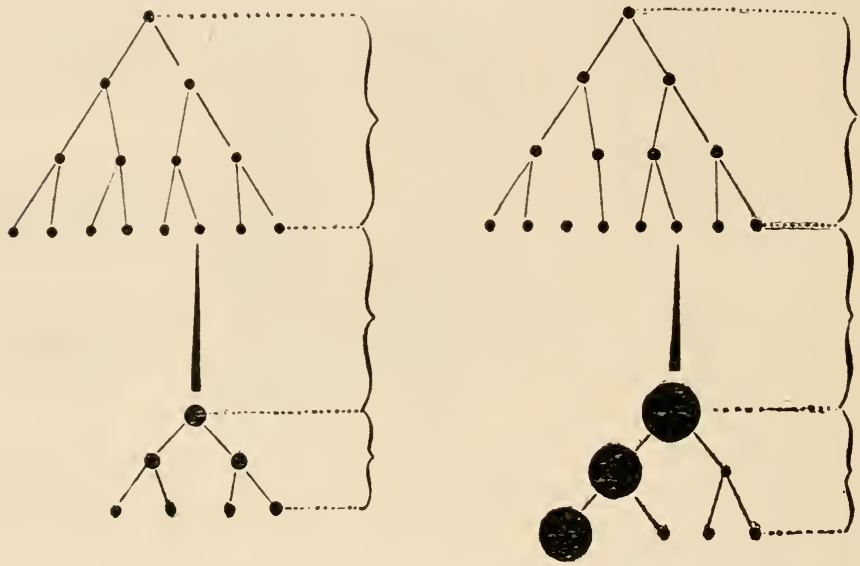

FIG. 151.-At left, diagram illustrating the development of the spermatozoön; at right, diagram illustrating the development of the egg. (After Boveri.)

A discussion of the method by which the reduction of the chromosomes in the germ nuclei is brought about, may profitably be-deferred until the essential features of fertilization have been examined. The phenomena of the fusion of egg and sperm can best be studied in some such form as the sea urchin, in which the egg is very small, and, in some species, quite transparent. As fertilization takes place free in the sea water, the germinal cells being cast out from the parents, it is possible to collect the eggs and sperm separately from mature individuals and bing them together in small dishes of sea water, snd sot such times as may suit one's convenience. Then in the lying egg much of the process may be followed under the 1.... oncope, snd properly prepared sections of the eggs, killed 
by reagents at the various stages, enable conclusions to be drawn as to matters of minute detail.

Fig. 153, A to $F$, presents a series of diagrams, taken from Boveri, illustrating the principal facts in the process of fertilization. In $A$, the egg is represented with its clear nucleus in the center, surrounded by the egg membrane. Clustered around the periphery are a number of spermatozoa endeavoring to find their way into the substance of the egg. On the righthand side in the figure one has penetrated the membrane and is shown passing into the egg cytoplasm, which puts forth a small conical prominence to meet it. As soon as the head of one sperm enters the egg cytoplasm a new membrane is formed around the egg which effectually prevents the entrance of any others. The hea.! ar:d middle piece penetrate into ibe egg, the tail usually remaining imbedrled in the memb:wne, where it soon degenerates. $A$ few moncmis after the sperm has entered, a system of radiations appcars around the middle piece which develops into wn aster surrounding the centrosome of the

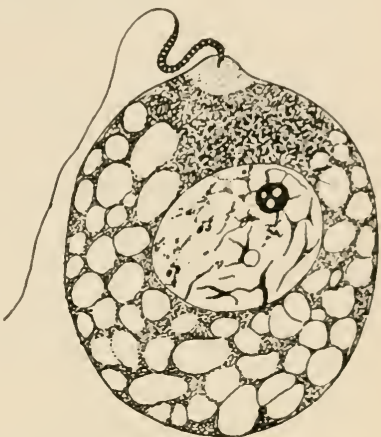

FIG. 152.-Egg of the worm, Myzostoma glabrum, being fertilized by spermatozoön. (After Wheeler.) sperm $(B)$. The sperm nucleus swells up and rapidly increases in size, its chromatin changing from the compact condition in which it is arranged in the sperm head to a reticulate condition $(C)$. The chromatin reticulum of the egg nucleus becomes also more clearly visible. Sperm aster and sperm nucleus now move in toward the egg nucleus, the aster usually preceling. As the nuclei approach, the sperm nucleus increases still more in size until it becomes indistinguishable from the egg nueleus $(C)$. The chromatin network of each now breaks up into a number of chromosomes, one half of the number found in the somatic cells, and the nuclei come into contact, fusing together in some cases. As in the sea urchin, Echinus, the number of chromosomes is eighteen, nine would therefore be found in the germ nuclei; for the sake of clearness and simplicity but two are represented in the diagram, those of the sperm 


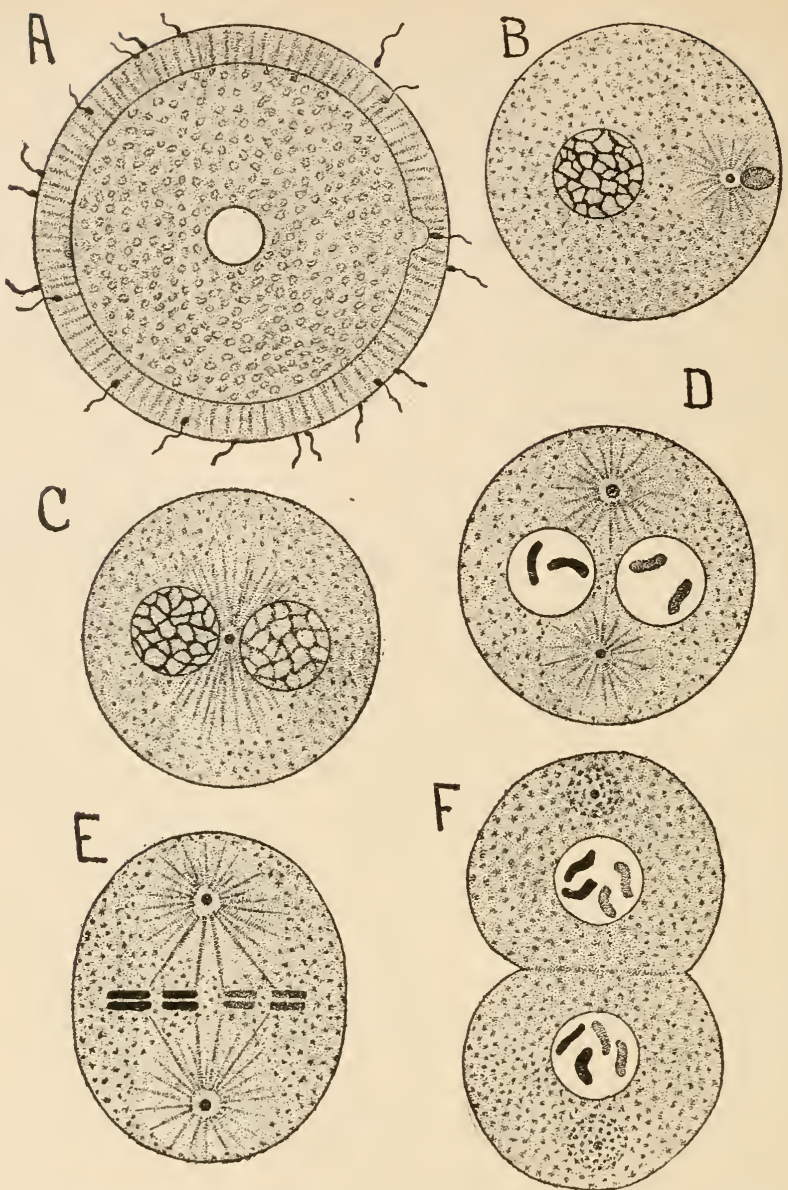

FIG. 153.-Diagrams illustrating the fertilization of the egg: $A$, Egg surrounded by spermatozoa; on the right, one has just penetrated the egg membranes and is entering the egg cytoplasm; egg nucleus in the center. $B$, Egg nucleus with chromatin reticulum on the left; on the right, the sperm nucleus preceded by its centrosome and attraction sphere. $C$, Egg nucleus on the left, sperm nucleus on the right of the center of egg; aster fibrils preceding the fission of the centrosome. $D$, The centrosome has divided, the two attraction spheres separate to form the first cleavage of the spindle; the chromosomes of the egg and sperm nuclei clearly visible and distinguishable (in the figure the egg chromosomes are black, the egg sperm chromosomes shaded). $E$, First cleavage, showing spindle with splitting chromosomes. $F$, Completion of first cleavage, two-celled stage, each nucleus showing four chromosomes, two from the egg and two from the sperm. (After Boveri.) 
nucleus being slightly shaded while those of the egg nucleus are black.

The centrosome divides together with its aster $(D)$, the two daughter centrosomes move apart to opposite poles of the egg, and the typical amphiaster of cell division is formed $(E)$, the nuclear membranes disappearing and the chromosomes being drawn together into the equatorial plate where each splits longitudinally. The halves are drawn by the mantle fibrils toward the opposite poles, and the egg divides transversely into two cells $(F)$. This process of division is repeated continuously in each of the resulting generations of cells, and from the mass of cells thus formed develops the new organism. Each cell in the two-celled stage has received half of its chromosomes from the egg nucleus and half from the sperm, thus containing equal amounts from each parent. The centrosome, which, as we have seen, is to be regarded as the dynamic center of the cell division, comes from the spermatozoön alone; the egg, on the other hand, furnishes the yolk and practically all of the cytoplasm.

After this preliminary outline of the facts of fertilization, we are in a better position to understand the significance of a process which occurs in the development of both egg and sperm cells, namely, the reduction of the chromosornes. The necessity for such a reduction is evident from a moment's reflection. We have seen that the number of chromosomes in the nucleus is a constant and typical one for each animal and plant species so far as known. As fertilization consists in the union of two cells in one, from which the young organism develops, it is plain that, were there no reduction, the number of chromosomes would be doubled in each succeeding generation. However simple this necessity for reduction may appear, the minutiæ of the processes through which it is brought about, and the theoretical significance of these facts, form one of the most involved problems of biology to-day. In a few forms, especially among the lower Crustacea, the facts of the reduction are clear and relatively simple; in other forms they thus far stand in direct contradiction, and, for the present, a comprehensive explanation applicable to all forms must be left to further investigation.

The significance of reduction turns upon the conception of a definite organization and individuality in the chromo- 
somes and the assumption that they represent the physical basis of heredity-i. e., that they influence and determine into what the fertilized egg shall develop. Fifteen years ago Wilhelm Roux showed with convincing clearness that the complicated facts of nuclear division, the careful longitudinal halving of the chromatin thread and its equal distribution between the two daughter cells, can be explained only on the basis that the chromosomes possess different structure in different parts of their extent, and that these structures, representing tendencies in development, are distributed in definite ways to the daughter cells. Were this not the case, a simple direct mass division of nucleus and cytoplasm instead of the

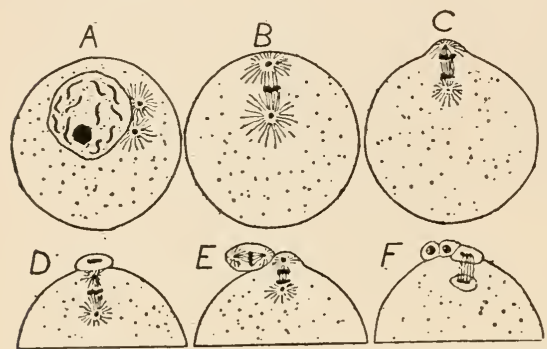

Fig. 154.-Formation of the polar bodies shown diagrammatically. (After Korschelt and Heider.) complicated process of karyokinesis with its consequent much greater expenditure of energy would serve all purposes.

In the light of this probable individuality and morphological olganization of the chromosomes, the method of their reduction in num. ber, preparatory to the fusion of their germ cells, becomes of the greatest significance; to those who may deny this individuality and definite architecture, the phenomena can have no great importance save as concerns a general mass reduction in the amount of the chromatin present in the germ nuclei. It may be assumed as true, in the majority of cases now accurately known, that the reduction takes place somewhere in or near the last two divisions of the germ cells previous to their fusion-that is, in the egg, in the divisions forming the polar bodies, and in the sperm, in the last two divisions of the spermatocyte which produce the four spermatids out of which develop as many mature spermatozoa. The phenomena are exactly homologous in both cases, as has already been pointed out, differing only in the minor details which do no: affect the end result.

Two peculiar features mark these divisions off from all the others which precede and follow them. One of these is the 
absence of an intermediate resting stage between them, the second division following immediately upon the first without the reconstitution of the chromosomes into the skein stages. The second peculiarity lies in the fact that the chromatin (now the individual chromosomes) appears in one half the typical

A
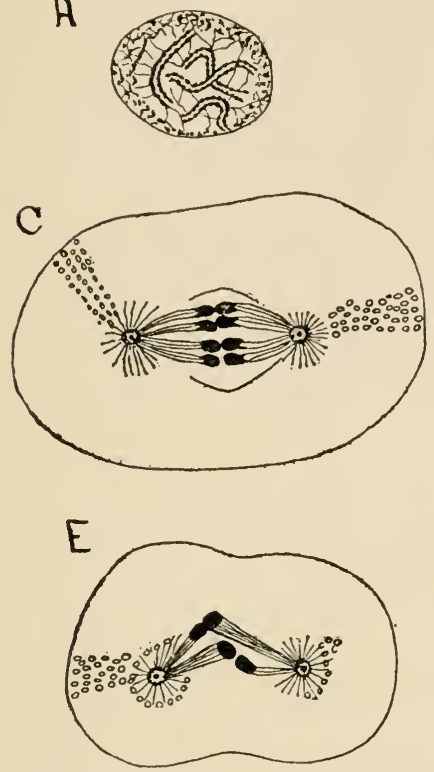

B
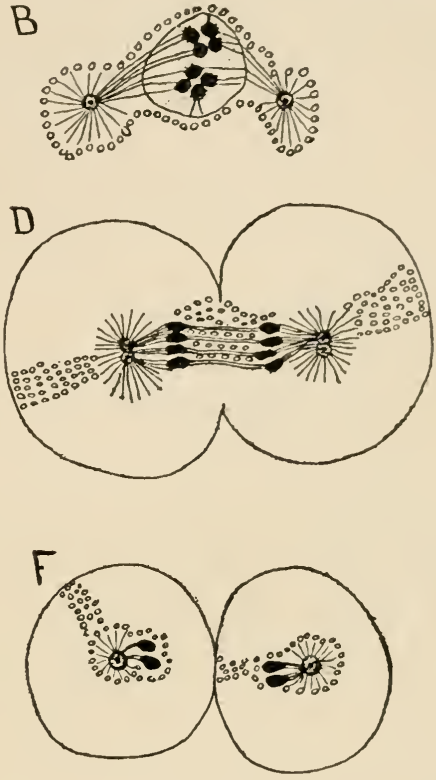

FIG. 155.-Reduction of chromosomes in the spermatogenesis of Ascaris megalocephala var. bivalens: $A$, Nucleus of a spermatogonium, the typical number of chromosomes (4) shown, each split longitudinally preceding the nucleus fission; $B$, young splitting primary spermatocyte, two tetrads present, each with body double from longitudinal splitting of a chromatin thread; $C$, the tetrads in the equatorial stage of fission; $D$, separation of the dyads; $E$, the dyads in succeeding fission of the secondary spermatid; $F$, completion of the fission of the same, each cell (spermatid) contains the reduced number of chromosomes (2). (After Brauer.)

number of the chromosomes in the first division, and is sually arranged in "tetrads," or groups of four rounded, deeply staining bodies connected by linin fibers. These tetrads are always one half the number of the original rod- or threadlike chromosomes. Thus in Fig. 155, A represents a spermatogonium nucleus of Ascaris with the four chromosomes, showing the longitudinal splitting preparatory to division. 
$B$ represents an early spindle stage in the division of the primary spermatocyte, in which not four bandlike chromosomes, but two tetrads, or chromatin groups or four rounded bodies are found. $C$ to $F$ show clearly the further steps in the spermatogenesis. In $C$ the tetrads are grouped in the equatorial plate, and in $D$, in the closing stages of the first division into two spermatocytes, each tetrad has divided into two "dyads," which are drawn to the poles, and the division of the cell body follows. Without an intervening rest stage each spermatocyte now divides again, as in $E$ and $F$, each dyad being separated into halves, so that in the spermatids of $F$ but two chromatin masses are present. Thus the tetrads of the primary spermatocyte are divided up among the four spermatids, so that each of the latter receives one fourth of each tetrad. Since later stages show that the two chromatin masses in each spermatid of $F$ represents two chromosomes, we see that the number of chromosomes has been reduced from the four in $A$ to the two in $F$.

Manifestly the key to the explanation lies in the relations which exist between the four chromosomes of $A$ and the tetrads of $B$. The two divisions consist merely in the distribution of the already separated parts of the tetrads; in the rearrangement of the four chromosomes into the two tetrads lies the possibility of the reduction which is carried out by the following divisions. The problem thus resolves itself into the question, What is the nature of each tetrad? Is it made up of a single chromosome? of two? of four? or have the constituent parts of the original four chromosomes become so completely rearranged and redistributed that their identity as such is completely lost?

Turning for a moment to the lower Crustacea, we find among the Copepods forms admirably suited for the careful following out of the changes taking place in the rearrangement of the chromosomes into the tetrads. To Rückert we owe the clearest account of the process as exhibited in the egg maturation of Cyclops. Here the normal number is twenty-two, or perhaps twenty-four, the minute size rendering counting difficult. Fig. $148, A$ to $F$, taken from Rückert, gives the essential points of the formation of the tetrads and their following divisions, not all the chromosomes being represented. In $A$ the chromatin filament has broken up into one half the usual number of 
segments (chromosomes), and each shows the precocious longitudinal splitting. These segments shorten up into the double rods of $B$, which in $C$ are being arranged in the developing spindle. A comparison of these three figures will show clearly that each chromatin segment has divided both longitudinally and transversely, its parts shortening and arranging themselves in tetrad formation of $D$. The first division following separates the tetrad along the longitudinal plane of its former splitting $(E)$ and the second division along the transverse plane $(F)$.

In Cyclops then, the tetrads are formed by the chromatin thread of the resting nucleus breaking up into one half the usual number of segments, and each of these in turn dividing longitudinally and transversely. A tetrad here is made up of two chromosomes slightly united end to end and split longitudinally. Thus if abcdef . . n represent the unsegmented filament of the resting nucleus, $a-b-c-d-e-f$ would show its breaking up into the normal number of chromosomes which split lengthwise, forming $\frac{a}{a}, \frac{b}{b}, \frac{c}{c}, \frac{d}{d}, \frac{e}{e}, \frac{f}{f}$, in the equatorial plate. In the Cyclops nucleus of Fig. $A$ the filament has separated into the segments $a b$-cd-ef . . . n, each of which has split longitudinally into $\frac{a b}{a b}, \frac{c d}{c d}, \frac{e f}{e f}$, etc., and its transverse division, subsequently becoming more apparent, gives to each tetrad the composition $\frac{a}{a} \frac{b}{b}, \frac{c \mid d}{c \mid}, \frac{e}{d} \frac{f}{e}$, etc. By the first division in the longitudinal plane, each daughter cell receives a half of each chromosome; in tlıe second, however, in the vertical plane, this is not the case, as can be readily seen. This is clearly a qualitative division, and the daughter cells receive unlike chromosomes. This forms the "reducing division" in Weismann's sense, and as such is a most beautiful demonstration of his postulated reduction of the ancestral plasm.

In Ascaris, however, the evidence is just as clear that no reducing division in Weismann's sense takes place, though the actual number of the chromosomes is also reduced.

Boveri has shown for the egg and Brauer for the sperm that the tetrads arise by a double, longitudinal, splitting of the chromatin filament which later breaks into two segments. Thus abcd would again represent the unsegmented filament, 
$a-b-c-d$ the individual chromosomes, and $\frac{a}{a}, \frac{b}{b}, \frac{c}{c}, \frac{d}{d}$, their splitting longitudinally in ordinary division. In the maturation of the egg and in spermatogenesis, lowever, the thread segments into $a b, c d$, and splits twice longitudinally into $\frac{a b}{a b}\left|\frac{a b}{a b}, \frac{c d}{c d}\right| \frac{c d}{c d}$, the two tetrads of $B$ in Fig. 15j. The reduction of chromatin here is only a reduction in mass and not a qualitative one, in Weismann's sense, as in the Crustacea and insects. In Ascaris the actual reduction in number of chromosomes takes place in the nucleus previous to the maturation divisions of the ovocyte and spermatocyte respectively. In Cyclops the formation of the tetrads is merely a pseudo-reduction, the actual reduction taking place in the second division, which gives rise to the mature egg on the one hand, or the spermatids, which develop into the spermatozoa, on the other.

One fundamental fact is clear in these divergent accounts. The number of chromosomes is reduced in both sorts of the germinal cells as a preliminary to their union. Whether there is likewise a qualitative distribution of the chromatin elements remains for future investigation to decide. From the facts of ordinary cell division we have seen that the chromatin of the nucleus is to be regarded as the bearer of hereditary qualities in the cell. The phenomena of fertilization greatly increase this probability. The offspring resembles both of its parents, and the paternal tendencies can be conveyed in the minute spermatozoan head alone, which is constituted almost entirely of chromatin. The scrupulous exactitude with which, in both germ cells, the chromosomes are reduced to one half the normal number preparatory to the union of the pronuclei in fertilization, and the distribution of the paternal and maternal chromatin equally to the resulting cells of cleavage, lenc? - dded weight to the theory.

The development of the fertilized germ cell into the curnplete organism is discussed in the preceding chapter as also is the significance of sex. This significance in the light of actual processes of germ-cell formation, maturation, and fertilization is seen to be very important in relation to the phenomenon of variation, a phenomenon or fact which we have already learned to recognize as the absolutely essential basis of all organic evolution. 

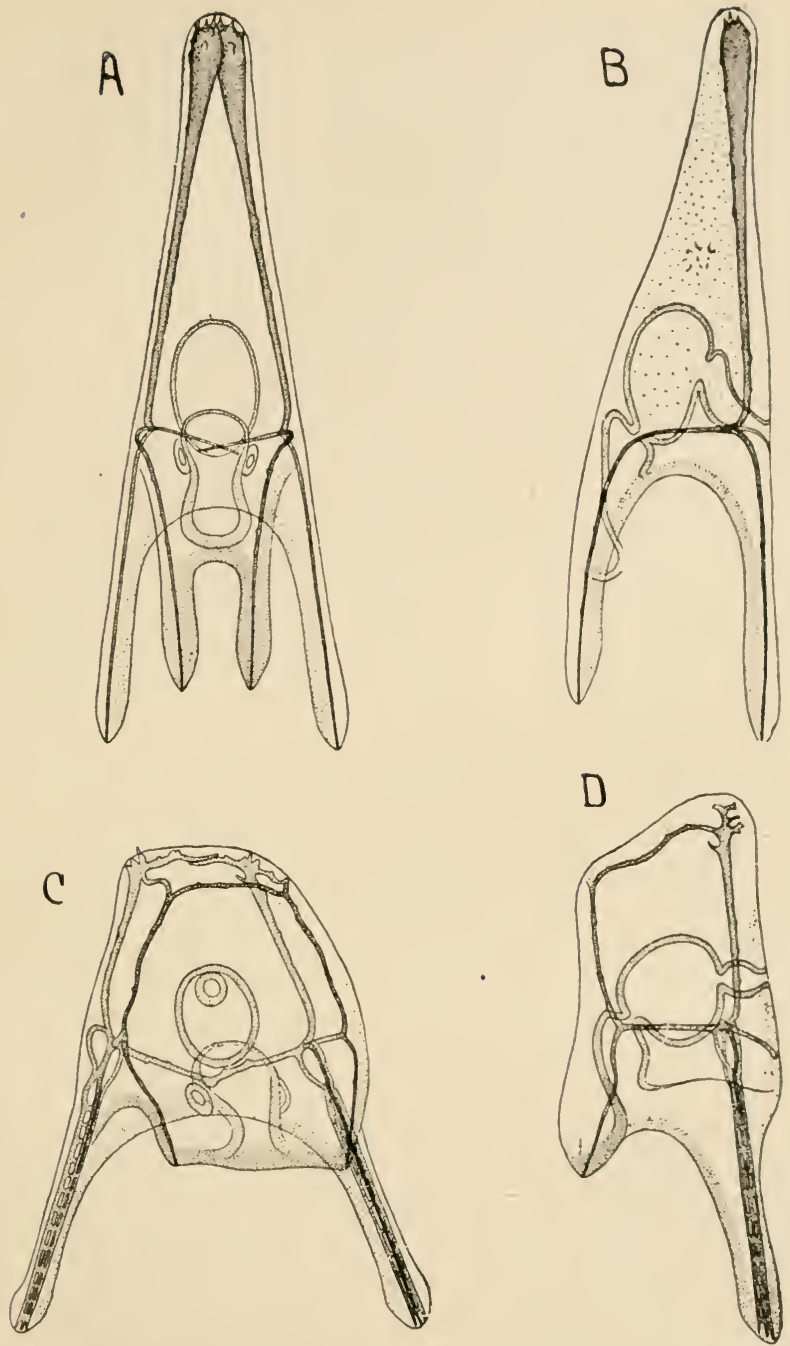

IIG. 150.-A, Normal larva of Echinus microtuberculatus, front view; $B$, the same, side view; $C$, normal larva of Sphorechinus granularis, front view; $D$, the same, side view. (After Boveri.) 
Whether the new individual to be exists in the germ cell as a more or less nearly completely preformed embryo needing only to expand, unfold, and grow to be the fully developed new creature, or whether the fertilized egg cell is a bit of practically undifferentiated protoplasm, endowed with a limited and specific potentiality, but depending for its marvelous outcome chiefly on extrinsic imposed influences-this question has been a matter of contention since the beginning of the study of generation and development.

From our scrutiny of the phenomena of mitosis, it is apparent that, while the germ cell is certainly considerably differentiated as regards its fine structure, on the other hand it as certainly contains no preformed embryo of the individual into which it is to develop, as the old school of preformationists held. But the testimony from mitosis by no means settles the controversy between the modern preformationists and the modern epigenesists. This rages hotly, and furnishes a great incentive to the pushing on of the study of development.

What is most interesting, perhaps, about this present-day embryological study is, perhaps, its method. Where heretofore the study of development has been almost purely descriptive and comparative, as, indeed, all biological study has, the modern embryologist is an experimenter. Experiment, the method of the study of inorganic nature, is being resorted to and relied on for the determination of biological problems, and in particular that one that has for its subject the seeking of the factors and actual causes of individual development. This has been aptly named preformation versus epigenesis. It might also pertinently be called intrinsic versus extrinsic factors or, more broadly, vitalism versus mechanism.

The new phase or mode of the study of development has been variously called developmental mechanics, experimental development, or, more broadly, experimental morphology, because the experimental method has been extended to the study of phenomena not strictly, or at least not usually included : in the immature, or developing stage of the animal's life; the study of regeneration, of reactions to stimuli, and of reflexes and movements in general, has all been illuminated by the decisive results of the substitution of experiment for haphazard observation in nature. And the further extension of experimental and statistical modes of investigation to the 

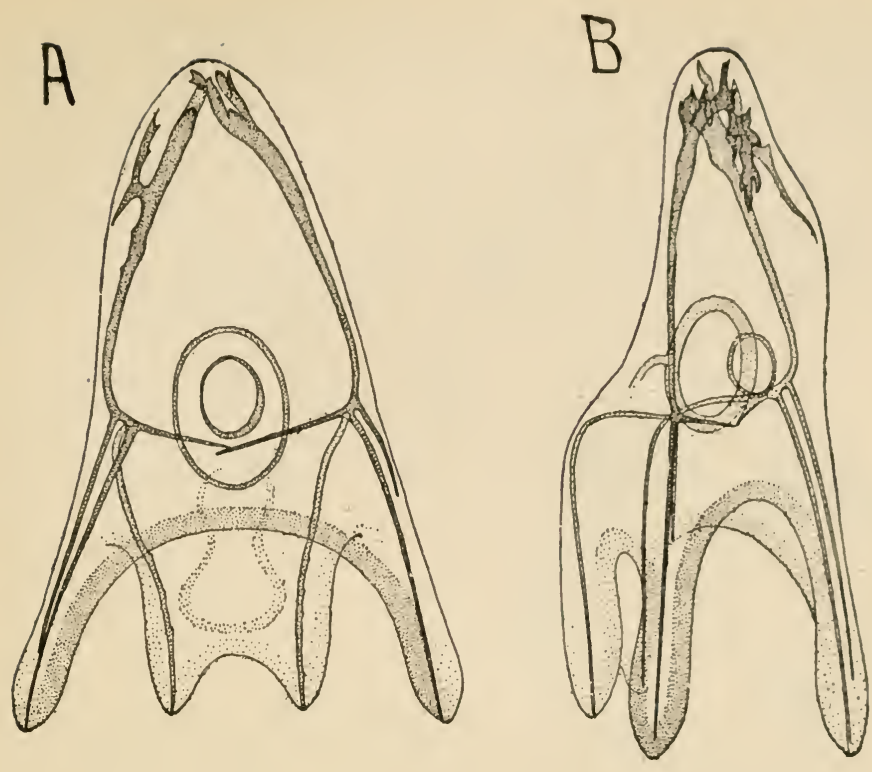

C
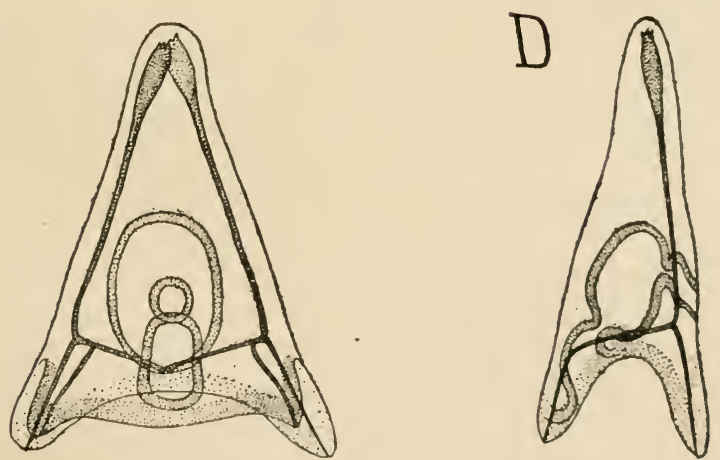

Fig. 157.-A, Hybrid larva (Spharechinus \& and Echinus \&), front view; $B$, the same from side view; $C$, hybrid larva, Spharechinus o (nonnucleated egg formation) and Echinus 5 , of the type; $D$, the same larva in side view. (After Boveri.) 
"grand problems" of heredity and rariation, already well entered upon, bids fair to produce the most rapid and real advance that has yet been made toward the goal of solving some of the mystery which has so far enwrapped these fundamental phenomena of life.

To return to our special problem of preformation or epigenesis, it must be said at the outset that the evidence touching it, which has so far been derived from cxperiment, is distinctly conflicting. For example the frog's exg (which has been a

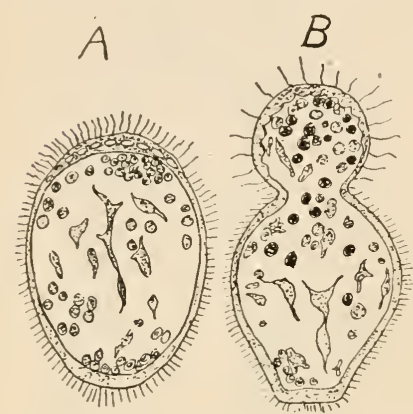

FIG. 158.-Lithium larva of the sea urchin, Spharcchinus granularis: $A$, Elongated blastula; $B$, evaginated gastrula. (After Herbst.) classic Versuchsobject in this study), when treated after its first cleavage so that one of its two blastomeres (daughter cells of the original fertilized egg cell) is killed, develops half a frog, which would indicate that the embryo was Ireformed in the egg cell, or at least that each part of the egg cell had its fate predetermined, so that the loss of part of the egg would produce a loss of a definite part of the embryo.

But in the hands of other investigators diametrically opposed results were got. Hertwig managed to separate entirely the two first cleavage cells and got from each of these half eggs a complete embryo but of dwarfed size, which would indicate that any part of the egg stuff is able to produce any part of the embryo. Other investigators have succeeded in separating blastomeres of later cleaváge stages, and have variously got either miniature but complete embryos from these fractional egg parts, or on the other hand parts of embryos representing apparently the predetermined developmental fate of the various parts of the egg. To list briefly a few of these cases, we may refer to the development of partial embryos from separated (2-16 cell stage) blastomeres of various Ctenophora, and the similar results with the molluses Patella, Dentalium, and Ilyanassa: to the production of defective larvæ by the mutilated eggs of Beroe, also of ascidians and of Echinus to Driesch's distinction between ectoderm and endoderm after 
the first cleavage of Symupta, and the cell lineage studies of zur Strassen on the eggs of 1 scaris in which it was shown that a definite status of outcome for each blastomere was determined after successive early clearages. All these results secm to be

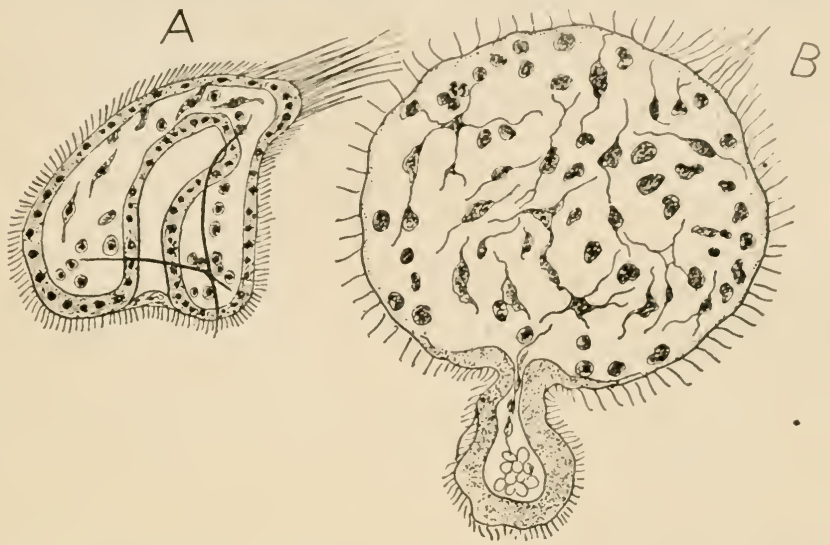

FIg. 159.-A, Normal gastrula of sea urehin, Echinus microtuberculatus; $B$, gastrula of sea urchin, Sphurechinus granularis, from a lithium culture. (After Herbst.)

good evidence for preformation, that is, for a predetermination of the rôle each part of the egg cell is to play in development. Indeed, Wilson is convinced that an obvious structural differentiation (bands, zones, delimited regions) can be seen in the undeveloped eggs of numerous animals, a differentiation corresponding to structural divergence in development.

On the other hand, numerous results of experiment speak just as loudly against preformation or predetermination. Such are Herlitzka's half-sized Triton embryos from the two sepa-
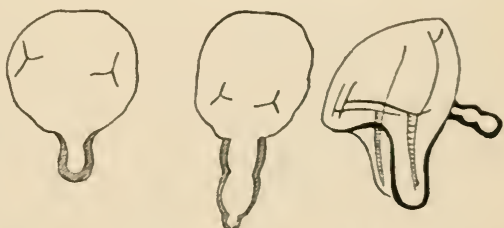

Fig. 160.-Abnormal larval stages of the sea urchin, sphurechinus granularis, produced by heat. (After Driesch.) rated first cleavage cells, Driesch's two half-sized and four quarter-sized sea-urchin plutei from the cells of the first and sccond cleavages, respectively, his eight and sixteen small gastrulie, and thirty-t wo tiny blastulie from the separate blastomeres of the third, fourth, and fifth cleavages respectively; also Zoya's medusa embryos from 
separated blastomeres of the two, four, eight, and even sixteencell stages of developing hydro-medusa eggs. Loeb was able
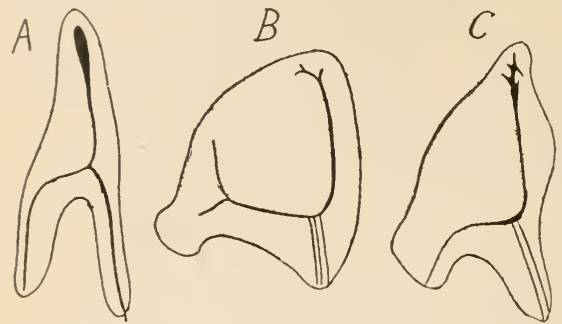

FIG. 161.- $A$, Lateral view of pluteus larva of Echinus; $B$, lateral view of pluteus larva of Sphrrechinus; $C$, hybrid pluteus of the female Sphorechinus and male Echinus. (After Boveri.) to effect the bursting of the membrane of seaurchin eggs and the consequent partial escape or protrusion of parts of the egg plasm forming so-called extra-ovates. Each of these extraovates began development as a distinct blastula, the remainder of the egg forming another blastula (Fig. 163).

Thus we see that experimental work has, so far, not afforded a positive answer to the general query proposed by the preformation versus epigenesis problem. But at the same time it is obvious that the results of the experimental method are of extraordinary interest and of brilliant promise. What seems to be revealed so far, is that the animal egg is certainly not rigidly preformed; that there is no absolute predetermination of the fate in development of each part of the egg stuff, But that normally in most eggs a given part of the egg does have a prospective definitive fate, so that one-half of the egg may
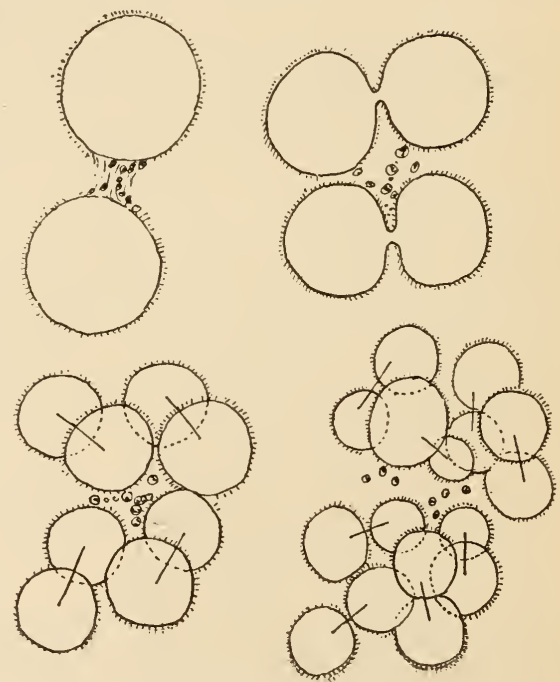

FIG. 162.-Cleavage of Echinus eggs in water free from calcium. Note that the cleavage cells tend to separate entirely. (After Herbst.) be looked on as corresponding to one particular half of the future organism. However, the actual potentiality of any part 
of the egg is not limited by its prospective fate. If accident in nature or ruthless handling in the experimenter's laboratory destroy or remove part of the egg, the remainder has a power of regulation which is in some respects the highest and most important kind of organic adaptation that we know.

The same data derived from the experimental study of development, together with data got from the experimental study of mature and even senescent stages of various organisms, constitute our chief evidence touching the problem of mechanism versus vitalism. This problem may be posed in question form as follows: In how far can so-called vital phenomena be analyzed into physicochemical, or mechanical phenomena? Is life simply an interaction, very complex to be sure, and so far largely unanalyzed and hence not directly referable to specific physicochemical causes, between substances of particular chemical and physical structure and those familiar forms of energy known to us in the physicochemical world, or is it the result or manifestation of an extra physicochemical force and set of conditions?

When the sunflower bends its face always toward the sun, we do not attribute this behavior either to the intelligence or the instinct of the plant. But when young spiderlings or moth caterpillars or green aphids just from the egg move with one accord toward
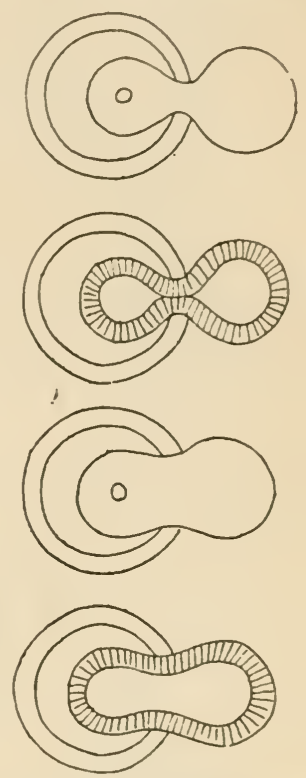

Fig. 163. - Extra-ovates from the eggs of the sea urchin, Arbacia. By diluting the sea water the osmotic pressure bursts the egg membranes so that part of the egg plasm issues and forms an extra-ovate. (After Loeb.) the light side of the glass jar, we do attribute this behavior to animal instinct or to the exercise of a preference or choice. When iron filings rush toward a magnet brought sufficiently near them, we have on our tongues' end the sufficient explaration of this behavior in the single word "magnetism." Now the biological mechanist, observing that in all these cases there is a certain apparent definite relation between a cause 


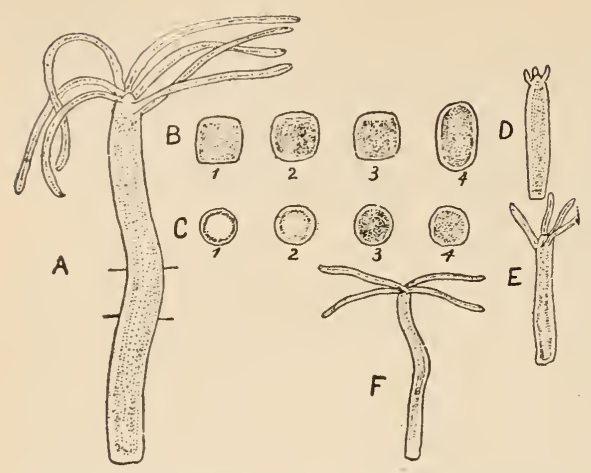

FIG. 164.-Regeneration in Hydra viridis: $A$, Normal hydra (lines show where piece was cut out); $B, 1-4$, changes in a piece of $A$ as seen from side; $C, 1-4$, same as seen from end: $D, E, F$, later changes in same piece. (After Morgan.)

and an effect, presumes to say that all these phenomena may be much more nearly of the same sort than we are accustomed to consider them to be. The biological mechanists believe, in a word, that all vital phenomena will in last analysis prove to be truly physicochemical phenomena; that organisms show in their reactions no new forces or principles, but that their behavior is only an immensely complex interplay of the same forces and activities already known to us in the inorganic world.

And their belief is not wholly without some basis of observed or experimentally proved fact. Nany of the simpler so-called vital phenomena, especially the movements of the simplest
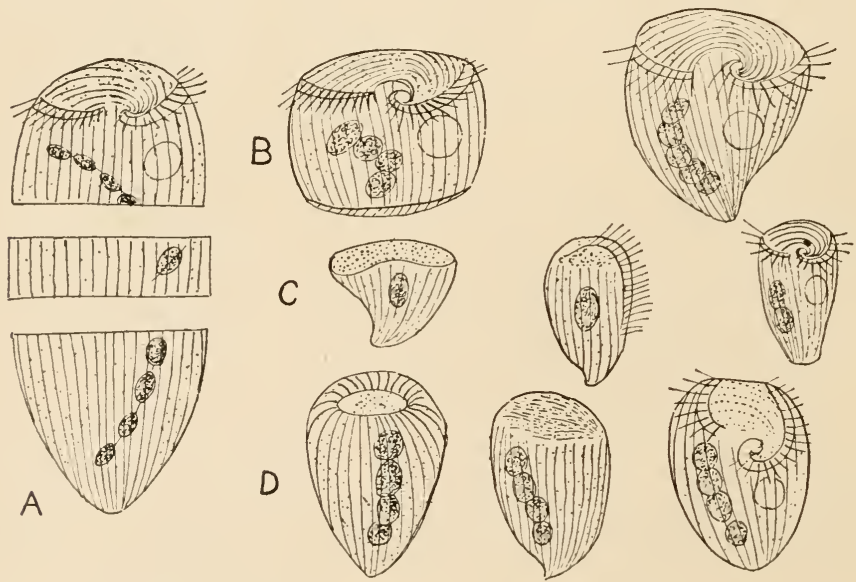

FIG. 165.-Regeneration of Stentor coruleus: $A$, Cut in three pieces; $B$, row showing regeneration of the anterior piece; $C$, regeneration of middle piece; $D$, that of prsterior piece. (After Morgan.) 
and even the unore complex animals, have been shcirn to be suggestively Jike motion reactions in inorganic nature. The mechanists analyze many of the so-called instinctive performances of animals into rigorous taxic and tropic reactions to specific external influences or stimuli. Chemotaxis, phototaxis,
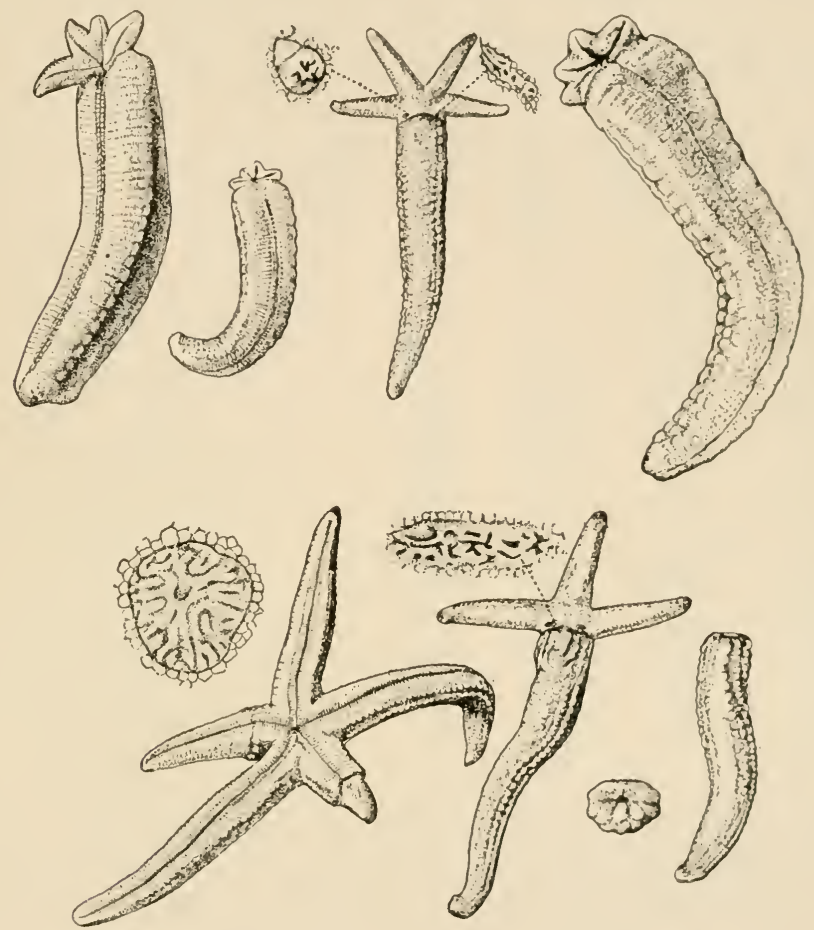

Frg. 166.--Regeneration in nature of starfish, Linckia. The regrnerated specimens shown in the figure were collected as living animals on the ccral reefs of samoa. 'These specimens show the great capacity for regeneration pos essed by this starfish a portion of an arm being capable of regenerating the dis': and all the other arms.

and oxvgenotaxis, heliotropism, geotropism, thigmotropism, etc., are the names applied to the growth or motion reactions of organisms or their parts, conditioned by such external stimuli or control-influences as light, gravitation, contact, the piesence of oxygen or of various other chemical substances. And an account of the ingenious experimentation which has 
been done to test the truth of the mechanical assumptions is a fascinating chapter in the history of modern biological work.

In sum we may say that there has been in recent years a real advance on a basis of experimental work, in the analysis of many vital phenomena long considered mysterious, or at least too complex for human understanding, into simpler components. And that these components are in many cases

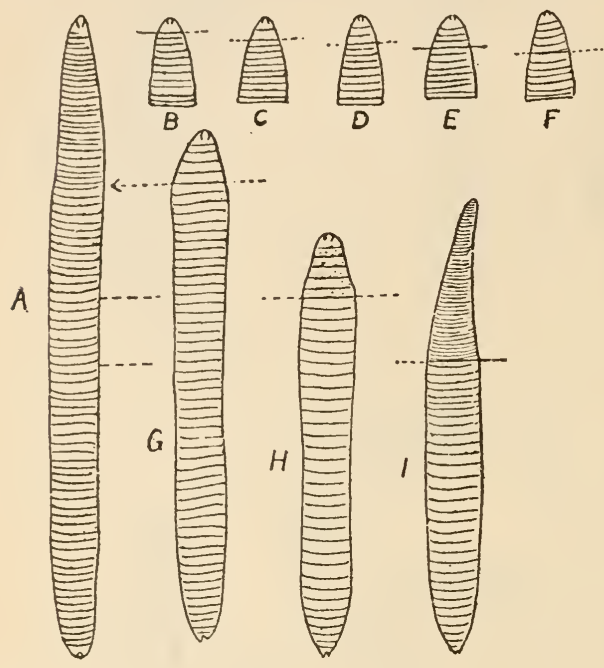

Fig. 167.-Regeneration of the earthworm: $A$, Normal worm; $B-F$, anterior ends of worms which, after the removal of one two, three, four, and five segments, have regenerated the same number; $G$, anterior third cut off, only five head segments regenerated; $H$, worm cut in two in middle, a head-end of five segments regenerated; $I$, worm cut in two behind the middle, a heteromorphic tail regenerated at anterior end. (After Morgan.) no other than reactions and motions familiar to us in inorganic nature. On the other hand it must be said that this advance, in the face of the immense problem presented by vital reactionsthat is, the behavior of organisms - is very small. With all our heart we should welcome all attempts to do away with ideas of mysticism in connection with biological phenomena; the mechanists should have our strong sympathy and our willing support, but to join the more radical of them in their claim that the life mystery

is already solved in terms of physics and chemistry, that there is no longer any vital problem, would be to surrender our judgment to our inclination.

Any discussion, however brief, of experimental work in biology should include a reference, at least, to the striking and suggestive results that have been obtained by the application of the experimental method to the investigation of the problems 
of fertilization and parthenogenesis. Jacques Loeb has been the most active worker in this line and his results are of extreme interest. He has, by various physical or chemical treatment of the unfertilized eggs of various animals, particularly certain Echinoderms, worms and fishes, stimulated these eggs to begin development, which development proceeds either normally or in some degree abnormally along the usual path regularly followed by the species. But in all cases this development falls short of completion and in many cases the death of the embryo occurs at a very early stage. Other investigators have similarly induced a development in parthenogenetic eggs of animal species in which parthenogenetic development does not occur naturally, or at least is very rare.

The significance of these results is by no means wholly clear. Nor do the investigators who have done the work agree among themselves as to the interpretation of the results. Loeb first inclined to the belief that the stimuli which incited the unfertilized egg to development were physical, osmotic changes being looked on as perhaps the immediate stimulus. At present he seems inclined to at-
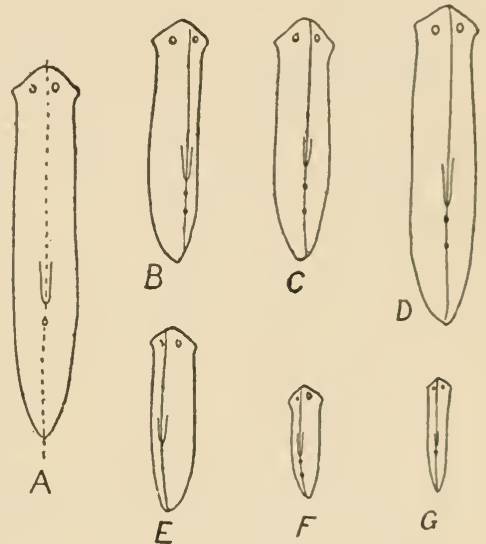

FIG. 168.-Regeneration of the flatworm, Planaria lugubris: A, shows by dotted line where the worm was cut in two lengthwise; $B, C, D$, show how a half that was fed regeneratel; $E, F, G$, show how an unfed half regenerated. (After Morgan.) tribute the stimuli rather to the chemical character of the media which seem to incite the parthenogenetic development. In cither case the physicochemical stimulus is considered to be a substitute for the spermatozoid. That it is a substitute in some degree, is obvious; that it is a complete substitute for it, seems equally obviously not true. The embryos developed by artificial partheogenesis lack at least two fundamentally important attributes which the young of bisexual parentage possess; namely, vigor and the heredity of the father. The lack of vigor is shown by their death before maturity; and the chromosomes 
or other nuclear stuff that is the actual carrier of the paternal heredity are of course actually wanting.

Another phenomenon or group of phenomena, also of much special interest and suggestiveness to students of development, to which the experimental method has been surcessfully applied, is that known as "regeneration." The familiar repro-

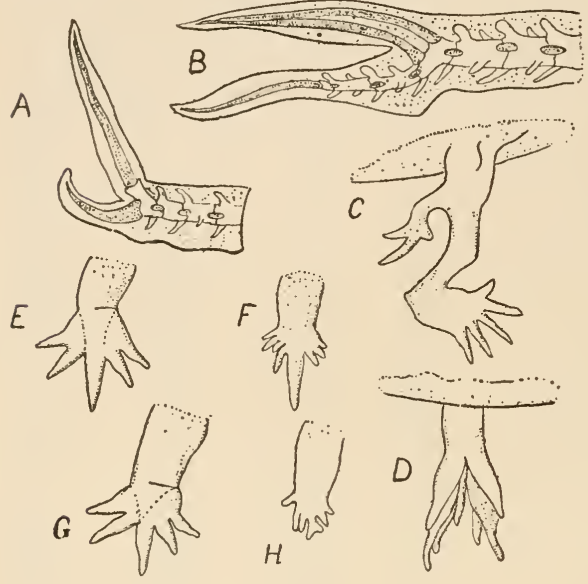

FIG. 169.-Regeneration of the tail and limbs of the lizards, Lacerta agilis and Triton custatus: $A$, Lacerta, new tail arising at place where old tail was broken partly off; $B$, three-tailed form, two tails having a common covering, all these parts being regenerated after old tail was cut off; $C$. Triton, additional leg produced by wounding femur; $D$, double foot produced by tying thread over regenerating stump; $E, F, G$, regenerated feet of Triton after various mutilations. (After Tornier.) duction or growth of new plants from cuttings or buds is paralleled in the animal world by numerous similar cases less familiar but nerertheless long known by naturalists. In 1740, Abbé Trembley made a number of curious experiments with $\mathrm{Hy}$ dra, whose publication in 1744 was the beginning of our knowledge of the phenomena of regeneration in animals. If Hydra, the common little brown or green fresh-water polyp, be cut up into many pieces, each of these pieces has the power to grow into a new complete Hydra body (Fig. 164). We know now that numerous other animals have also this radical capacity for regeneration. Certain protozoans, hydroids, planarian worms, starfishes, etc., can regenerate as freely or nearly so as Hydra (Figs. 165-172). And many other animals representing almost all the great groups of the animal kingdom possess in some degree, at least, the power of regeneration. Some can regenerate only lost or cut appendages, others even less fundamental parts of the body; some can regenerate only in their immature stages; others only in the earliest embryonic stages. But regeneration and "regula- 
tion," as certain phases of regeneration are called, are the property, in some degree probably, of most animals.

The significance of this capacity has been long recognized as of much importance in our conceptions of the germ plasm character and disposition, but no general agreement regarding it has even yet been reached by biologists. More and better understood facts about regeneration are needed. And this need it seems to be the province of experimental biology to supply. By the carry-
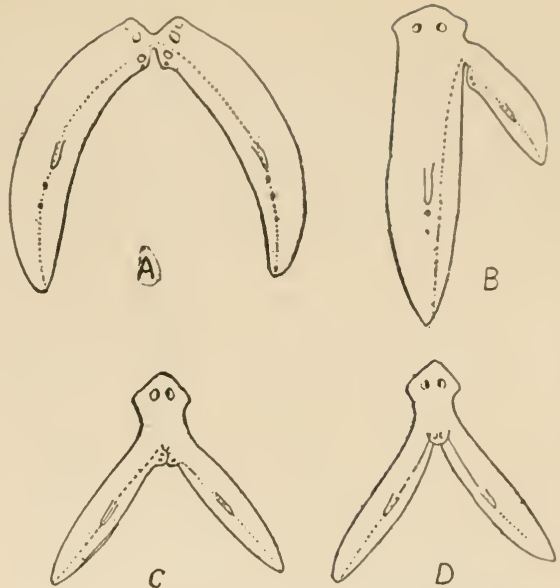

FIG. 170.-Regeneration of the flatworm, Planaria: $A$, Speeimen eut in two as far forward as eyes, regenerating two half-heads; $B$, cut in two at one side of middle line, smaller piece having regenerated a head; $C$, cut partly in two, having regenerated two heads in angle; $D$, another that produced only a single head in the angle. (After Mlorgan.) ing on of ingeniously planned and carefully controlled series

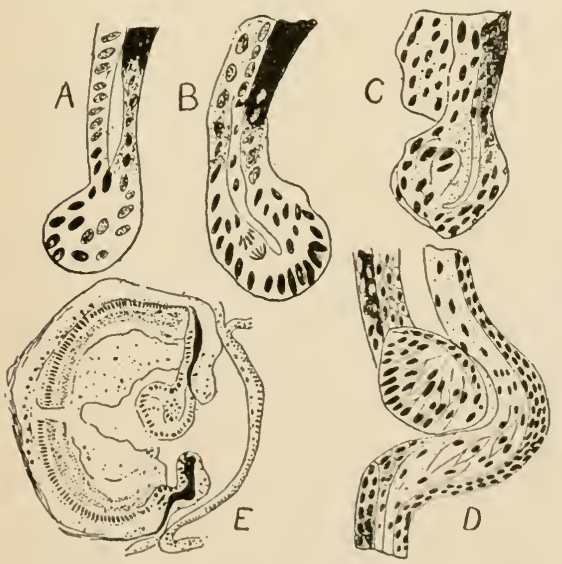

FIG. 171. - Regeneration of the eye of Triton: $A$, Edge of iris with beginning lens; $B, C, D$, later stages of same; $E$, whole eye with regenerating lens. (After Wolff and Fischel) of experiments with regenerating animals, we are acquiring a great mass of important data, and the interpretation and generalization of these data is certain to be accomplished in the near future.

We have space here to call attention to but one of the ways in which an understanding of the phenomena of regeneration will throw light on one of the fundamental problems in develonment. To those biolo- 
gists who believe with Wcismann that there is a sharp distinction between the germ plasm and the somatic or body plasm, and that this germ plasm is limited 10 the germ cells and germ-cell producing tracts, the regeneration of a nearly whole body or even a considerable part of a body from a region which does not include a germ cell presents a serious obstacle. But
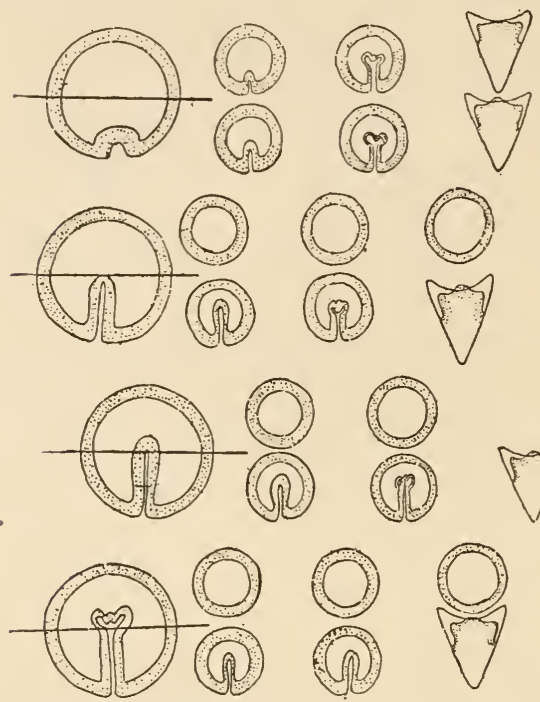

Fig. 172.-Regeneration of the blastula and gastrulæ of sea urchins; line indicates where the blastula or gastrula was cut in half; the smaller figures show results of the regeneration of the two halves of each.

before this obstacle can be considered as one rendering the germ plasm theory absolutely untenable, it is necessary to prove what the regenerated parts are composed of. Are they composed simply of repeated similar cells, all of one tissue type, or do they include other kinds of cells or tissues than those particular kinds from which the regenerated part springs? It is, of course, admitted that many, indeed most cells of the body, can reproduce other cells like themselves. Now is it a fact that regenerated parts are composed of different kinds of cells? As a matter of fact this has been proved to be so by observation and by experiment. Numerous instances are known in which body cells arising originally from one germ layer have produced in the course of regeneration not only cells like themselves, but others which in normal development could only arise from another germ layer. So it is plain that the study of regeneration has already done much to modify our former conceptions of the factors and conditions of development. 


\section{CHAPTER XIV}

\section{PALEONTOLOGY}

This much then we have gained, that we may assert withoti hesitation, that all the more perfect organic natures, such as fishes, amphibious animals, birds, mammals, and man at the head of the list were all formed upon one original type which varies only more or less in parts which are none the less permanent, and which still daily changes and modifies its form by propagation.-Gioethe (1796).

IN a suggestive sentence, Haeckel speaks of our knowledge of the line of descent in the history of any group of animals or plants as being derived from "three ancestral documentsmorphology, embryology, and pa'eontology."

Of these three, paleontology is at once the most certain and the most incomplete. Each fossil animal is a record, absolutely authentic, so far as it goes, admitting of no doubt or question, but for the most part yielding only a very little of the truth. involved in its existence.

For no animal whatever is preserved as a fossil except as the result of an unusual combination of circumstances. Oniy those parts which are themselves hard, calcareous, silicious, or horny, with rare exceptions, can retain their form in the rocks, and even these, shells, teeth, bones, and the like, are often crushed or distorted so that their actual form or nature may be open to question. In addition, only the minutest fraction of the sedimentary rocks of the earth has been laid bare by artificial excavation or by natural erosion, and thus opened to the inspection of man, and the number of fossils actually observed can be only the most trivial fraction of a fraction of the organisms actually existing and preserved.

With all this, the human race has in the past shown a singular lack of insight in the interpretation of animal remains 
found in the stone. As Lyell has graphically shown, it took one hundred and fifty years of dispute and argument to persuade even learned men that shells and teeth in the rocks were actual remains of actual animals, and another hundred and fifty years to demonstrate that the shell-bearing rocks were not masses of débris from Noah's flood. Nothing in the history of science is more tedious than the arguments directed against the first students of fossils, to show that these structures were mere sports of nature, whimsicalities of creation, or freaks developed in the fatty matter (materia pinguis) of the earth by the entangling influence of the revolving stars.

Notwithstanding all these defects in material, and this stupidity of theory, the study of fossils has still gone on, and by its means we are able to delineate with large certainty the line of evolution of most groups of animals, and the nature of faunal relations in the different periods of geological time. If we had not already a theory of evolution by derivation of forms, we should be obliged to invent one in face of the facts of paleontology. In Huxley's words, "fossils are only animals and plants which have been dead rather longer than those which died yesterday."

Fossils are either actual remains of bones or other parts preserved intact in soil or rocks, or else, and more commonly, parts of the animals which have been turned into stone, or of which stony casts have been made. All such remains buried by natural causes are called fossils. The process by which they are sometimes changed from animal substance into stone is called petrifaction.

Fossils may be of three kinds. In the case of recently extinct animals, bones or other parts of the body may become buried in the soil and lie there for a long time without any change of organic into inorganic matter. Thus fossil insects are found with the bodies preserved intact in amber, a fossil resin from some ancient and extinct pine tree. Over eight hundred species of extinct insects are known from amber fossils. The bones of the earliest members of the elephant family, the teeth of extinct sharks, the shells of extinct mollusks and fragments of buried $\operatorname{logs}$, are also often found intact, still composed of their original matter.

In the second kind of fossils the original or organic matter is gone, the organic form and organic structure being preserved 


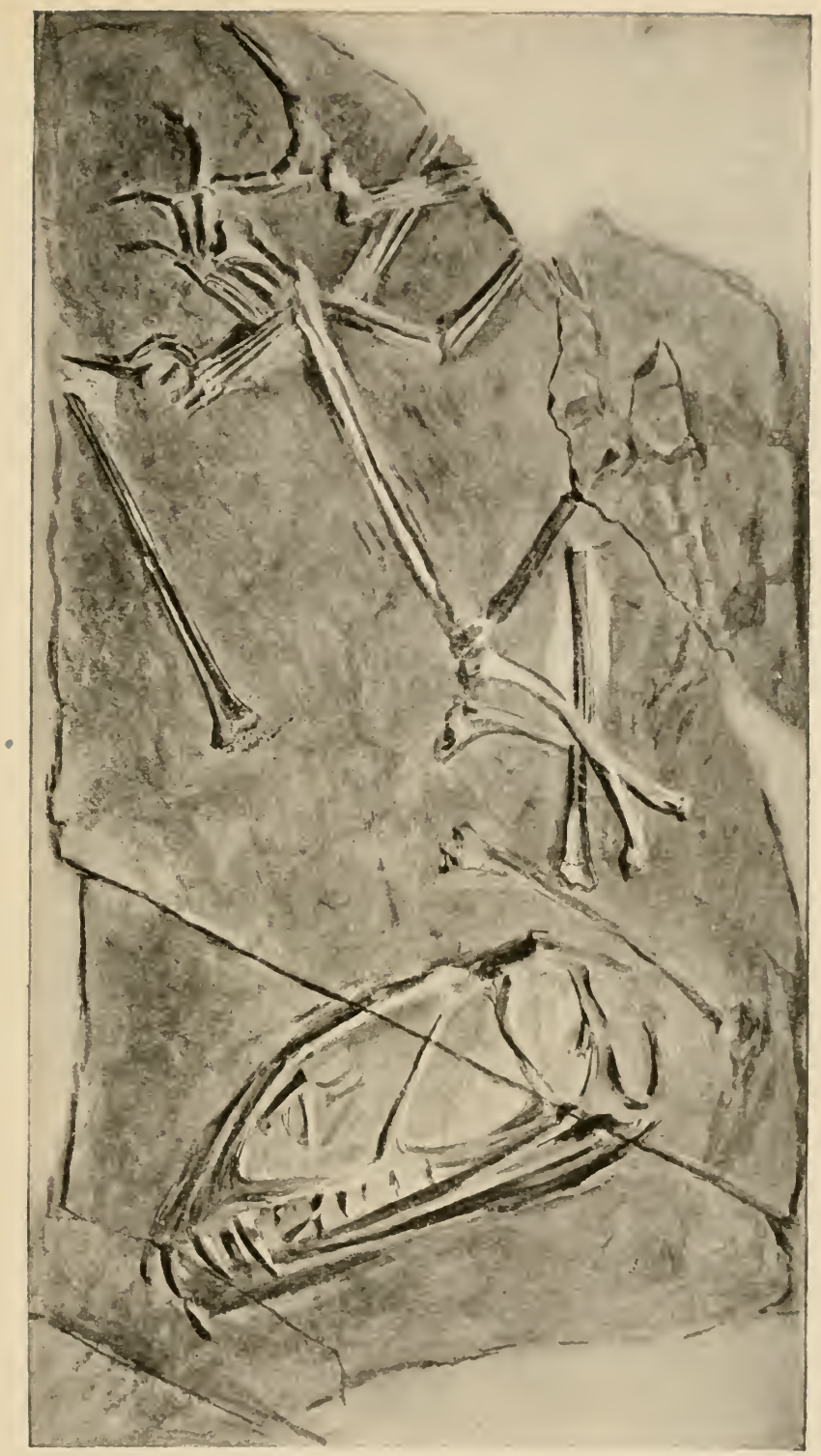

FIg. 173.- Remains of Dimorphodon from the lias of Jyme Rrgis, showing skull, neck, and back, and some of the bones of the skeleton. (After siceley, from a slab in the British Museum.) 
in mineral matter. That is, the organic matter has been slowly and exactly replaced by mineral. As each particle of organic substance passed away by decay, its place was taken by a particle of mineral matter. Such fossils are called petrifactions. This is beautifully shown in the case of petrified wood. We can cut and grind thin a bit of petrified wood, and see in it, with a microscope, the exact details of its original fine cellular structure. This substituted mineral matter may be one of several minerals, but usually it is silica (quartz) or carbonate of lime (limestone) or sulphide of iron (iron pyrites). In the case of animal parts which were originally partly organic and partly inorganic, as bones and teeth and shells, often only the organic matter is replaced by the petrifying mineral, although sometimes the old inorganic matter is also replaced. Finally, sometimes the organic matter and organic structure are both lost, only the original outline of form of the whole part being retained. This occurs when the organic matter imbedded in mud and clay decays away, leaving a hollow which is filled up by some mineral different from the matrix. In this case the fossil is simply a cast of the original organic remains.

Some traces even of the finest organisms occasionally appear.

"Conditions have sometimes permitted even the most delicate structures, such as insects' wings and the impressions of jellyfishes to become retained in the soft mud, which afterwards became solidified. Localities famous the world over for the beauty and delicacy of their fossil remains are the lithographic -stone quarries of Bavaria and certain beds in France" (EASTMAN).

These deposits were perhaps formed in the clear, quiet waters of a coral lagoon.

Examination and study of the rocks of the earth reveal the fact that fossils, or the remains of animals and plants, are found in certain kinds of rocks only. They are not found in lava, because lava comes from volcanoes and rifts in the earth's crust, as a red-hot, viscous liquid, which cools to form a hard rock. No animal or plant caught in a lava stream will leave any trace. Furthermore, fossils are not found in granite, nor in ores of metals, nor in certain other of the common rocks. 
Many rocks are, like lava, of igneous origin; others, like granite, although not originally in melted condition, have been so heated subsequent to their formation, that any traces of animal or plant remains in them have been obliterated. Fossils are found almost exclusively in rocks which have been formed by the slow deposition in water of sand, clay, mud, or lime. The sediment which is carried into a lake or ocean by the streams opening into it sinks slowly to the bottom of the lake or ocean and forms there a layer which gradually hardens under pressure to become rock. This is called sedimentary rock, or stratified rock, because it is composed of sediment, and sectiment always arranges itself in layers or strata. In sedimentary

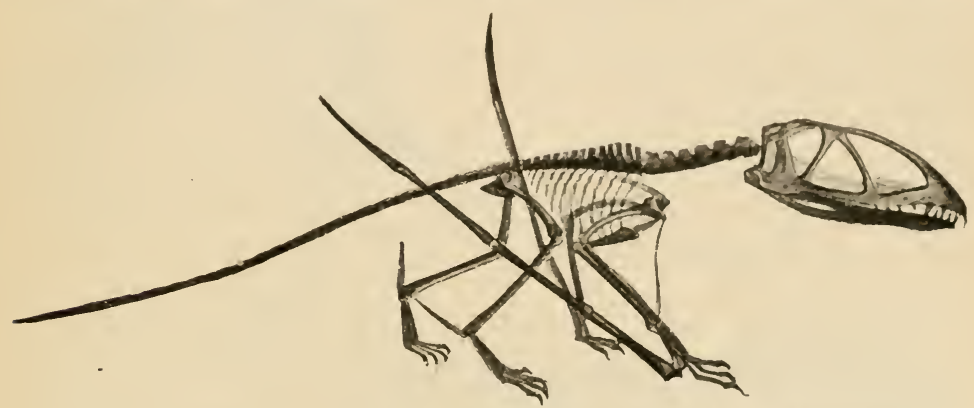

Frg. 174.-Restoration of the skeleton of Dimorphodon macronyx. (After Seeley.)

or stratified rocks fossils are found. The commonest rocks of this sort are limestone, sandstone, and shales. Limestone is formed chiefly of carbonate of lime; sandstone is cemented sand; and shales, or slaty rocks, are formed chiefly of clay.

The formation of sedimentary rocks has been going on since land first rose from the level of the sea; for water has always been wearing away rock and carrying it as sediment into rivers, and rivers have always been carrying the worn-off lime and sand and clay downward to lakes and oceans, at the bottoms of which the particles have been piled up in layers and have formed new rock strata. But geologists have shown that in the course of the earth's history there have been great changes in the position and extent of land and sea. Sea bottoms have been folded or upheaved to form dry land, while regions, once land, have sunk and been covered by lakes and seas. Again, through great foldings in the cooling crust of the earth, which 
resulted in depression at one point and elevation at another, land has become ocean and ocean land. And, in the aln ost unimaginable period of time which has passed since the earth first shrank from its hypothetical condition of nebulous vapor to be a ball of land covered with water, such changes have occurred over and over again. They have, however, mostly taken place slowly and gradually. The principal seat of great

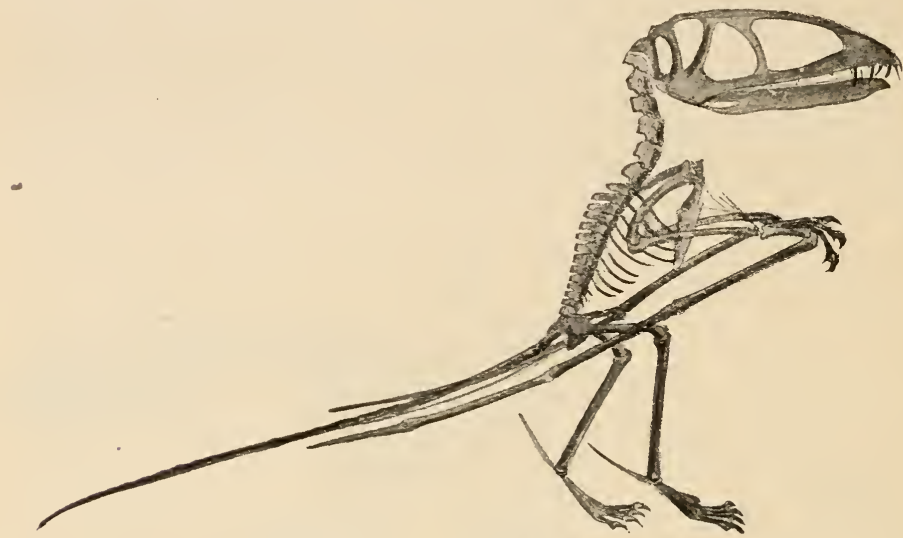

FIG. 175.-Restoration of the skeleton in probable normal position of Dimorphodon macronyx. (After Seeley.)

change is in the regions of mountain chains, which, in most cases, are simply the remains of old folds or wrinkles in the crust of the earth.

When an aquatic animal dies, it sinks to the bottom of the lake or ocean, unless, of course, its flesh is eaten by some other animal. Even then its hard parts will probably find their way to the bottom. There the remains will soon be covered by the always dropping sediment. They are on the way to become fossils. Some land animals also might, after death, get carried by a river to the lake or ocean, and find their way to the bottom, where they, too, will become fossils, or they may die on the banks of the lake or ocean and their bodies may get buried in the soft mud of the shores. Or, again, they are often trodden in the mire about salt springs or submerged in quicksands. It is obvious that aquatic animals are far more likely to be preserved as fossils than land animals. This 
inference is strikingly proved by fossil remains. Of all the thousands and thousands of kinds of extinct insects, mostly land animals, comparatively few specimens are known as fossils. On the other hand, the shell-bearing mollusks and (rustaceans are represented in almost all rock deposits which contain any kind of fossil remains.

It is obvious that any portion of the earth's surface covered by stratified rocks must have been at some time under water, the bottom of a lake or ocean. If now this portion shows a series of layers or strata of different kinds of sedimentary rocks, it is evident that it must have been under water several times, or at least under different conditions. It is also evident that fossils found in this portion of the earth will contain remains of only those animals which were living at the various times this portion of the earth was under water. Of the animals which lived on it when it was land there will be no trace, except, possibly, a few land or fresh-water forms, which might be swept into the sea or might be preserved in the mud of ponds.

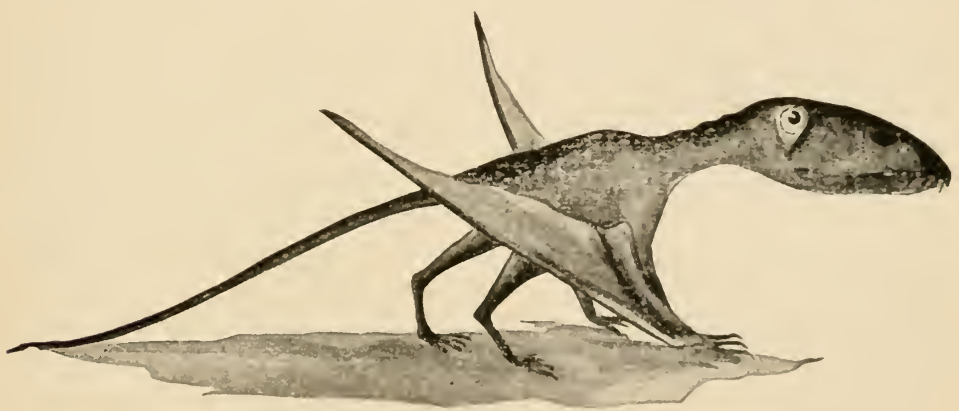

FIG. 176.--Restoration of Dimorphodon macronyx. (After Seeley.)

That is, instead of finding in the stratified rocks of any portion of the earth remains of all the animals which have lived on that portion since the earth began, we shall find, at best, only remains of a few kinds of those animals which have lived on this portion of the earth when it was covered by the ocean or by a great lake.

Thus, the great body of fossil remains of animals reveal only a broken and incomplete history of the animal life of the prast. But the record, so far as it goes, is an absolutely truthful one, 
and when the many deposits of fossils in all parts of the different continents are examined and compared, it is possible to state numerous general truths in regard to past life and the succession of animals in time. The science of extinct life is known! as paleontology.

The study of paleontology has revealed much of the history of the earth and its inhabitants from the first rise of the land from the sea till the present era. This whole stretch of time -how long no one can guess-is divided into eras or ages; these ages usually into lesser divisions called periods, and the periods into shorter lengths of time called epochs. Each epoch is more or less sharply distinguished from every other by the different species of animals and plants which lived while its rocks were being deposited. In the earth's crust, where it has not been distorted by foldings and breaks, the oldest stratified rocks lie at the bottom of the series, and the newest at the top. The fossils found in the lowest or oldest rocks represent, therefore, the oldest or earliest animals, those in the upper or newest rocks the newest or latest animals.

An examination of a whole series of strata and their fossils shows that what we call the most specialized or most highly organized animals did not exist in the earliest epochs of the earth's history, but that the animals of these epochs were all of the simpler or lower kinds. For example, in the earlier stratified rocks there are no fossil remains of the backboned or vertebrate animals. When the vertebrates do appear, through several geological epochs they are fishes only, members of the lowest group of backboned animals. More than this, they represent generalized types of fishes which lack many of the special adaptations to marine life that modern fishes show. For this reason they bear a greater resemblance to the earlier reptiles than do the fishes of to-day; in other words, they were a generalized type, showing the beginnings of characters of their own and other types. It is always through generalized types that great classes of animals approach each other.

In a later epoch the batrachians or amphibians appeared; in a still later period, the reptiles; and last of all, the birds and the mammals, the last being the highest of the backboned animals. The following table gives the names and succession of the various geological periods, and indicates briefly some of the kinds of animals living in each. In each of these di- 


\begin{tabular}{|c|c|c|}
\hline $\begin{array}{l}\text { Eras or } \\
\text { Periods. }\end{array}$ & Ages or Systems. & 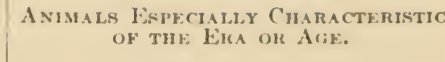 \\
\hline $\begin{array}{l}\text { Cenozoic. } \\
\text { Era of } \\
\text { Mammals. }\end{array}$ & $\begin{array}{l}\text { Quaternary or Pleis- } \\
\text { tocene (age of man } \\
\text { and insects)........ } \\
\text { Tertiary: Pliocene, } \\
\text { Miocene, Eocene... }\end{array}$ & $\begin{array}{l}\text { Man; mammals, mostly of spe- } \\
\text { cies still living. } \\
\text { Mammals abundant; belonging to } \\
\text { mumerous extinct families and } \\
\text { orders. }\end{array}$ \\
\hline $\begin{array}{l}\text { Mesozoic. } \\
\text { Era of } \\
\text { Reptiles. }\end{array}$ & $\begin{array}{l}\text { Cretaceous....... } \\
\text { Jurassic ......... } \\
\text { Triassic ......... }\end{array}$ & $\begin{array}{l}\text { Birdlike rentiles; flying reptiles; } \\
\text { toothed birds; first snakes; bony } \\
\text { fishes abound; sharks again } \\
\text { numerous. } \\
\text { First birds; giant reptiles; anmo- } \\
\text { nites; clams and snails abun- } \\
\text { dant. } \\
\text { First mammals (a marsupial); } \\
\text { sharks reduced to few forms; } \\
\text { bony fishes appear. }\end{array}$ \\
\hline $\begin{array}{c}\text { Paleozoic. } \\
\text { Era of } \\
\text { Invertebrates. }\end{array}$ & 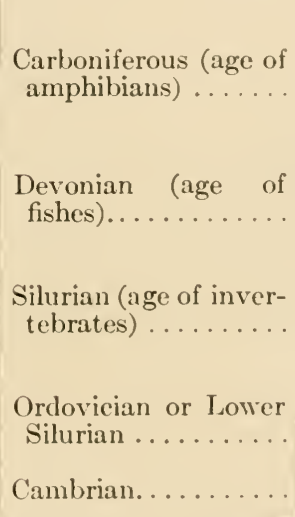 & 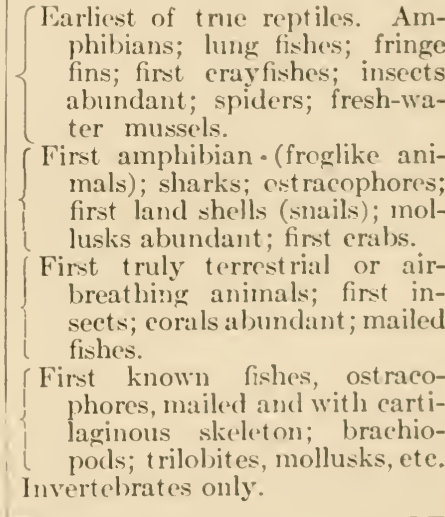 \\
\hline Archean. & $\begin{array}{c}\text { Algonkian. Lauren- } \\
\text { tian............... }\end{array}$ & Simple marine invertebrates. \\
\hline
\end{tabular}

visions of geologieal time some one class of animals wats especially numerous in species, and was evidently the dominant group of animals through that period. The different ages are therefore spoken of in terms of the prevailing life. Thus, the "Silurian Age" is known as the age or era of invertebrates: the "Devonian," as the age of fishes. In the same way we have the "Reptilian Age," the "Mammalian Age," aceording 
to the great class of animals predominating at that time. Of course, in each of the later epochs there lived animals representing the principal classes or groups in all of the preceding ones, as well as the animals of that particular group which may have first appeared in this epoch. or was its dominant group.

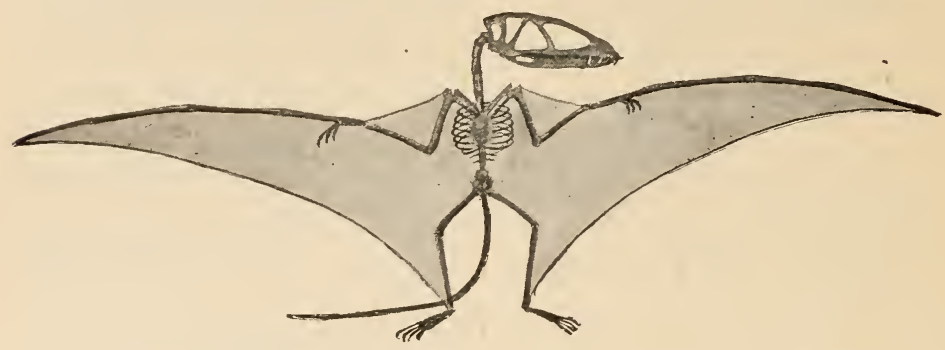

FIG. 177.-Restoration of Dimorphodon macronyx, showing probable wings. (After Seeley.)

In the study of fossils not only is it necessary for us to consider the actual forms and structures and the species they represent, but we should so far as possible reconstruct the conditions under which the organisms were alive, and the threads of genealogy which connect those of one period with those which precede or follow them. By such studies as these we are brought close to a consideration of the method of creation, and to a knowledge not only of the origin of species but to the causes underlying the divergence of the great trunks of animal and plant life.

"In youth," says Dr. A. S. Packard, "the older naturalists of the present generation were taught the doctrine of creation by sudden, cataclysmal, mechanical creative acts, and those to whose lot it fell to come into contact with the ultimate facts and principles of the new biology had to unlearn this view, and gradually to work out a larger, more profound, wider reaching and more philosophic conception of creation."

An early paleontologist, Dr. A. Gaudry, utters these suggestive words:

"We cannot refrain from looking with curious admiration upon the innumerable creatures that have become preserved to us from 
the earth's early days and calling them to life again, and in our imagination we ask these ancient inhabitants of the earth whence they were derived: 'Speak to us and say whether you are isolated remnants disseminated here and there throughout the immensity of the ages, without order more comprehensible to us than the scattering of flowers over the prairie? Or are you in verity linked one to another so that we may yet be able amid the diversity of nature to discover the indications of a plan wherein the Infinite has stamped the impression of His unity?' 'The unraveling of the plan of creation-this is the groal to which our efforts now aspire. Whatever our theories as to it," Gaudry continues, "there is a plan. A day will come when the paleontologists will seize the plan which has presided over the development of life."

This plan is found in the phenomena of organic evolution, the interrelation of the different factors or forees of heredity, variation, adaptation, fecundity, with the conditions of isolation of forms and the relations of enviromment. In the study of these details, we receive great light from the investigation of comparative structure, and the forces and processes of individual development. These are Hacekel's ancestral documents of morphology and embryology, but all theory finds its final verification in its accord with the facts of paleontology, the recorded evidence of succession in time.

Among the general deductions from paleontology are the following:

The various primary groups or branches of the animal kingdom as well as the principal classes are all very old, most of them; the vertebrates excepted, appearing in the carliest known fossiliferous rocks. It is, however, evident that these rocks, Lower Silurian or Ordovician and Cambrian, are very far from the actual beginning of life.

In each group the earliest forms are relatively simple, unspecialized, and as a rule marine. Many of them are embryonic types, that is, forms morphologically comparable to the embryos of forms of later appearance. To such forms, the less appropriate term of "prophetic types" has been applied. Many of the earlier forms are of synthetic types, that is, embracing characters distinetive of different divergent groups. Such synthetic types, where the resemblances are shown to be indicative of real homology, are now re- 
garded as indicative of the actual ancestry, from which the later types have diverged.

The persistence of heredity is the basis of the parallelism between geological and embryonic series. By its influence ancestral traits are repeated in the embryo, even though the characters thus produced give way in later development to further specialization or growth along other lines. This great truth has been stated in these words: "The life history of the individual is an epitome of the life history of the group to which it belongs." This statement is only true when stated very broadly, for there are many exceptions or modifications. The embryonic or larval animal is subject to almost endless secondary changes and adaptations whenever these changes are for the advantage of the animal. In general, the simpler the structure of the animal and the less varied its relations in life, the more perfectly are these ancient phases of heredity preserved in the process of development. In such case, the more perfect is the parallelism between the development of the individual and the succession of forms in geologic time.

It is not always true that the recent representatives of a group are higher in a morphological sense than some or all of the earlier members. They are, however, in all cases farther from the original or parent stock. In many groups there is a progress, seemingly rapid, toward a high degree of specialization followed by the disappearance of the highly organized types, while forms of low development-sometimes even those of primitive character-may remain in abundance. The evolution of the group of Brachiopods is an illustration of this. The group is represented in the Lower Silurian by numerous genera of simple structure, as Lingula, Terebratula and the like. It culminates in the Carboniferous age with complex genera as Spirifer, Productus, Orthis, while the modern representatives Lingulella, Terebratulina, Waldheimia, etc., are little more advanced than the primitive forms. Similar phases have characterized the appearance, culmination, and relative extinction of the trilobites, the cinoids, the ammonites, and other groups. The total extinction of any large group has not usually taken place. Usually a few species have remained, thus giving us a better clew to the life history and development of the group than we should otherwise possess.

One feature shown in many groups of extinct animals has 
never received accurate definition or interpretation. The group may appear in a series of relatively simple forms, showing affinities with some type from which it may have diverged. These early genera will be succeeded in the rocks by others, arranged progressively so as to form a series apparently moving in a certain direction. Each genus successively following in time, will perhaps show a greater and greater emphasis on some one group of characters, a greater and greater specialization in some one direction. Arranging the genera in series, it looks as if there were a definite line of variation shown in their gradual succession. These phenomena have been shown in various groups of reptiles and fishes, and especially well in the evolution of the extinct order of ammonites. These animals, allied to the living nautilus, lived in coiled chambered shells which gradually assumed great complication of form and ornamentation. The extreme of this course of evolution was followed by corresponding progressive degeneration. In some cases, this condition continues to the present time. More frequently, the specialization along the original lines continues to a certain point, to be followed by the progressive degeneration and perhaps the ultimate loss of the very same structures in which the high degree of specialization has prevailed.

To phenomena of this kind, the term determinate variation or orthogenesis has been applied. This phrase secms to involve the theory that the evolution has gone forward toward some predetermined end, or that in some way only variations leading toward this end have existed or at least have been able to maintain themselves. It is possible, however, that the cause may be found in the influence of some phase of environment, which directs the course of natural selection continuously along a certain line. A reversal of selection would be naturally followed by a degeneration of the structures developed to a point beyond the need of the animal.

It is plain that much is to be learned, especially in regard to the relationships existing among living animals, by a study of those of the past. A comparison of certain of the ancient reptiles with the long-tailed Archopteryx (Fig. 17s) and other toothed birds shows that the birds and reptiles were once searcely distinguishable, although now so very different. Birds have feathers, reptiles do not; but there is scarcely any other permanent difference. Fossils show a similar close relation 
between amphibians and fishes. A study of these ancient forms also throws light on many conditions of structure in modern animals, otherwise difficult to understand. An example of this sort is found in the splint bones of the modern horse (see Fig. 179).

It is a fact unquestionable that a species will change on its own grounds little by little with the lapse of time and the slow alteration of conditions of selection. Nations change, languages change, customs change, nothing is secure against the tooth of

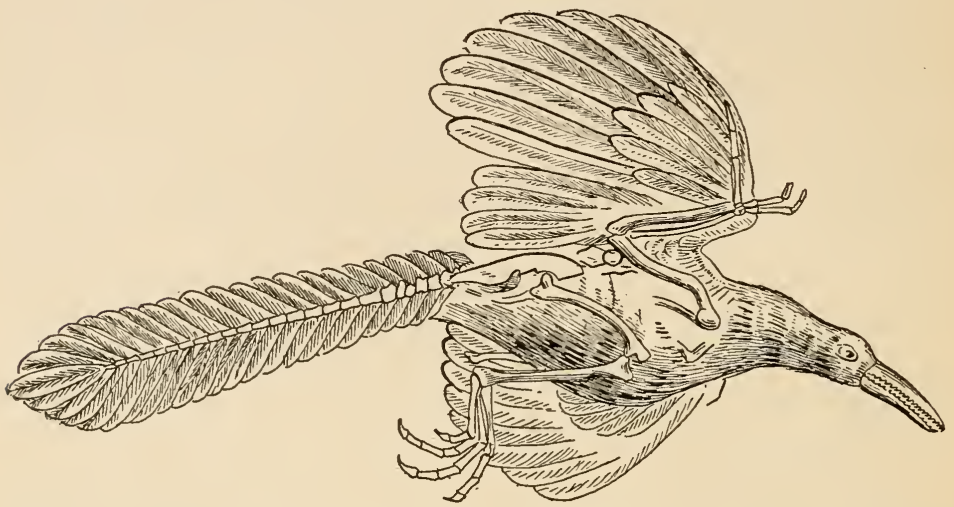

FIG. 178.-Ancient bird with jointed tail, claws on wings, and teeth in jaws, Archcropteryx lithographica, from the Jurassic rocks of Bavaria. (After Nicholson from Owen.)

time. This is in general true, because with time, alteration of environment takes place, events happen, there is an alteration of the stress of life and with this alteration all life may be acted upon.

That time-mutations in all forms of life do take place is beyond question, and some have regarded these slow changes as the chief agency in the formation of species. But the current of life does not flow in straight lines nor in an even current. Species are torn apart by obstacles, as streams are divided by rocks, and the rapidity of their formation is proportioned to the size of the obstacle and the alternations it produces in the flow of life.

We have some basis for the estimate of the duration of a species. When the great glacial Lake Bonneville occupied 
the basin of the Great Salt Lake, the same species of fishes and insects were found in all its tributaries. Now that these streams flow separately into a lifeless lake, the same species of fishes occur in them for the most part without alteration. One species of sucker (Catostomus ardens) and one chub (Lenciscus lineatus) are found unaltered throughout this region and in the Upper Snake River (above Shoshone Falls), into which Lake Bonneville was once drained. Other species are left locally isolated, but one species only (Agosia adobe), a small minnow of the clay bottoms, can be shown to have undergone any alteration. But with the tiger beetles (Cicindelce) a large number of species have been produced by separation.

From the Bay of Panama 374 species of fishes are recorded in the recent monograph of Gilbert and Starks. Of these species, 204 are recorded also from the Gulf of California, while perhaps fifty others are represented in the more northern bay by closely related forms. Comparing the fish faunas separated by the isthmus, we find the closest relation possible so far as families and genera are con-
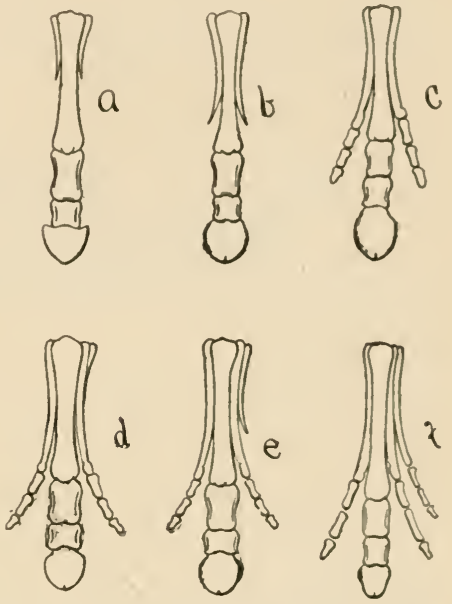

FIG. 179.-Diagrams showing the series of changes in geological time from a horse's foot of four separate toes $(f)$ to one of one toe and a pair of splint bones $(a)$; $a-f$ represent the feet of different horselike animals from modern time backward.

cerned. In this respect the resemblance is far closer than that between Panama and Chile, or Panama and Tahiti, or Panama and southern California. On the Atlantic side, similar conditions obtain, although the number of genera and species is far greater (about 1,200 species) in the West Indies than at Panama. This fact accords with the much larger extent of the West Indies, its varied groups of islands isolated by deep channels, and its near connection to the faunas of Brazil and the United States.

But it is also noteworthy that while the families of fishes 
are almost identical on the two shores of the isthmus of Panama, and the great majority of the genera also, yet the species are almost wholly different.

Taking the enumeration of Gilbert and Starks, we find that cut of 374 species, 43 are found apparently unchanged on both sides of the isthmus; 265 are represented on the Atlantic side by closely related species - in most cases the nearest known relative of the Pacific species-while 64 have no near analogue in the Atlantic. Of the latter group, some find their nearest relative to the northward or southward along the coast, and still others in the islands of Polynesia.

The almost unanimous opinion of recent students of the isthmus faunas finds expression in the following words of Gilbert and Starks ("Fishes of Panama Bay," p. 205):

"The ichthyological evidence is overwhelmingly in favor of a former open communication between the two oceans, which must have become closed at a period sufficiently remote from the present to have permitted the specific differentiation of a very large majority of the forms involved. That this differentiation progressed at widely varying rates in different instances, becomes at once apparent. A small minority (43) of the speciess (11 per cent of the species found on the Pacific side; about 2.5 of the combined fauna) remain wholly unchanged so far as we have been able to determine that point. A larger number have become distinguished from their representatives of the opposite coast by minute, but not 'trivial' differences, which are wholly constant. From such representative forms we pass by imperceptible gradation to species much more widely separated, whose immediate relation in the past we cannot confidently affirm. . . .

"It is obvious, however, that the striking resemblances between the two faunas are shown as well by slightly divergent as well as by identical species, and the evidence in favor of interoceanic connection is not weakened by an increase in the one list at the expense of the other. All evidence concurs in fixing the date of that connection at some time prior to the Pleistocene, probably in the early Miocene. When geological data shall be adequate definitely to determine that date, it will give us the best known measure of the rate of evolution in fishes."

From this discussion, it is probable that even in isolation some species change very slowly, that with similar conditions 
the changes within isolated groups of a species may be parallel, and that the specific changes in different groups may progress with very different degrees of velocity.

The earliest known vertebrate remains are found in rocks of the Ordovician age, approximately of the epoch known as Trenton, at Cañon City, in Colorado. These remains consist of broken bits of bony shields of mailed fishes or fishlike forms known as Ostracophores. With these are fragments of scales, which seem to belong to more specialized forms. It is evident that these remains, as well as the remains of sharks which

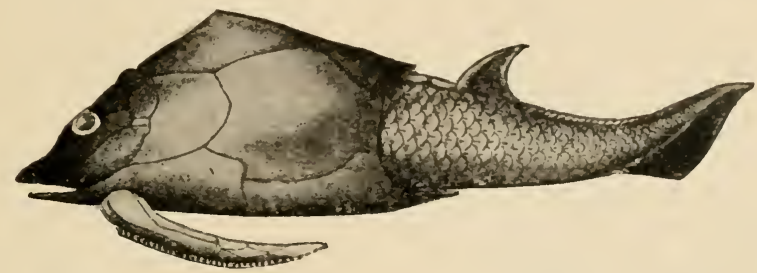

FIg. 180.-An ostracoderm, Pterichyodes milleri, from the lower Devonian of Scotland. The jointed appendage on the head is not a limb. (After Traquair.)

appear later in the Upper Silurian, by no means reveal the actual first existence of vertebrates.

The sharks which appear in the Upper Silurian, although certainly primitive, even as compared with later sharks, are very far from the simplest even of known vertebrates. There seems to be good reason for the view that the vertebrate type of animal, with the nervous cord along the back and the alimentary canal marked by gill slits, was at first soft-bodied and wormlike, in fact, derived from a wormlike ancestry, and that, prior to the Ordovician and Silurian time, it was devoid of hard parts. The early sharks have teeth, and rough skin, fins, and sometimes fin spines, all susceptible of preservation in the rocks, even though the skeleton was soft and cartilaginous. The Ostracophores, some of which, at least, seem to be modified sharks, had no internal hard parts, but were protected by an external coat of mail, perhaps formed of coalescent prickles or scales.

From the sharks were doubtless descended the group of Fringe-fins or Crossopterygians, which were more distinctly fishlike. From these, on the one hand by continuous speciali- 
zation for aquatic life, the true fishes must have been derived. In the more primitive of these the air bladder retains the lunglike structure characteristic of the Fringe-fins. But in the more specialized forms this is reduced to a sac, at first with an open tube, then to a closed sac without tube in the adult, and finally in very many of the true fishes the air sac is altogether lost. On the other hand, in the Amphibia, which were probably also derived from the Crossopterygia, the air bladder is more highly specialized, fitting these animals for life outside the water, and the fins give place to

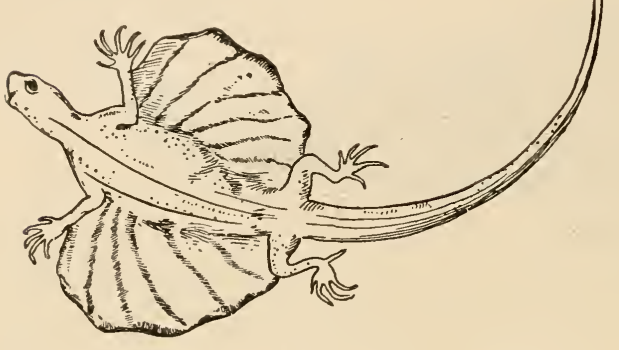

FIG. 181.-The flying dragon (Draco). (After Seeley.) fingers and toes as befitting a terrestrial habit.

The amphibians deposit their eggs in damp places, and the young are hatched while the external gills are still functional.

Among the reptiles, which mark the next stage of adaptation for terrestrial life, the gills are absorbed before the animal leaves the egg. The reptile is therefore no longer confined to the neighborhood of the water for purposes of reproduction.

The bird, derived from the reptile, and at first distinguishable solely by the possession of feathers, loses later various reptilian traits and the group becomes one inhabiting the air.

From the reptiles again are derived the lowest mammals. The Monotremes of Australia lay eggs as reptiles do, these, like reptiles' eggs, being covered with a leathery skin. The higher mammals hatch the eggs within the body, nourish them with milk and, in general, care for them in a degree unknown within the class of reptiles. The traits of external hair, warm blood, double circulation of the blood from and to a two-chambered heart, and other characters of the mammals become fixed with time and the group diverges into a multitude of forms living and extinet, the last, and on the whole the most specialized of the scries being Homo, the genus of man. 
The first traces of man appear in the latei geologic times after the end of the Tertiary. Human bones have been found in caves together with those of the cave-lion, cave-bear, and other extinct animals. In eertain lakes in Switzerland and Austria have been found remains of peculiar dwellings, together with ancient fishing hooks and a variety of implements of stone and bronze. These houses were built on piles in the lakes, and connected with the shore by piers or bridges. The extinct race of men who lived in them is known as Lake-dwellers. Relies of man, especially rough stone tools and flint arrow and axe heads, and skulls and other bones,

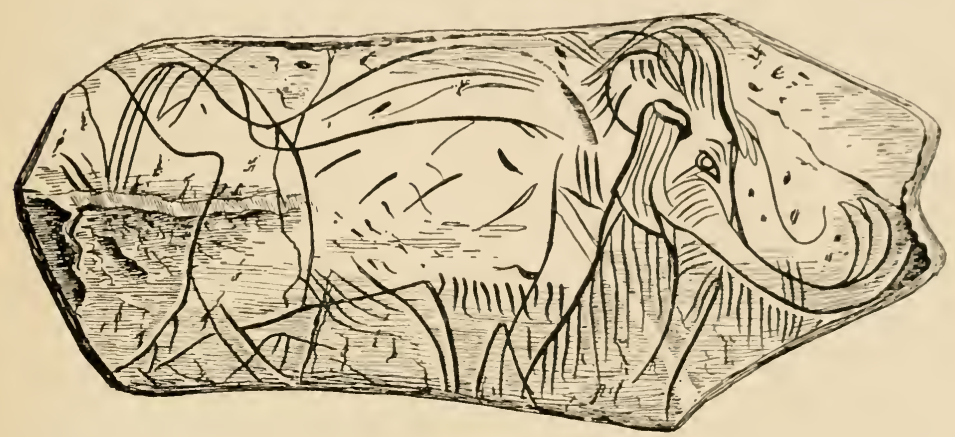

Fig. 182.- Rough drawing of a mammoth on its own ivory, by a contemporary man. (After Le Conte.)

have been found under circumstances which indicate with certainty that man has existed long on the earth. But with these relics very few bones are found. This has been accounted for by supposing that man existed in a few wandering tribes scattered widely over Europe. In Java are found some ancient bones of manlike animals (Pithecanthropus), different, however, from any species or race of men living to-daty, and showing traits which indicate a close relationship with the anthropoid apes.

The time of historic man-i.e., the period which has elapsed since the history of man can be traced from carvings or buildings or writings made by himself-is short indeed compared with that of prehistoric man. Barbarous man writes no history and leaves no record save his tools and his bones. Iron and bronze rust, bones decay, wood disappears. Only stone in- 
plements remain to tell the tale of primitive humanity. These give no exact record of chronology.

So of the actual duration of man's prehistoric existence we can make no estimate. Speaking in terms of the earth's history, man is very recent, the latest of all the animals. In terms of the history of man, he is very ancient. The exact records of human history cover only the smallest fraction of the period of man's existence on earth. 


\section{CHAPTER XV}

\section{GEOGRAPHICAL DISTRIBUTION}

Is not the biological laboratory which leaves out the ocean and the mountains and meadows a monstrous absurdity? Was not the greatest scientific generalization of your times reached independently by two men who were eminent in their familiarity with living beings in their homes?-Brooks.

UNDER the head of "Geographical Distribution" we consider the facts of the diffusion of organisms over the surface of the earth, and the laws by which this diffusion is governed.

The geographical distribution of animals is often known as "zoögeography." In physical geography we may prepare maps of the earth which shall bring into prominence the physical features of its surface. Such maps would show here a sea, here a plateau, here a range of mountains, there a desert, a prairie, a peninsula, or an island. In political geography the maps show the physical features of the earth, as related to the states or powers which claim the allegiance of the people. In zooggcography the realms of the earth are considered in relation to the types or species of animals which inhabit them.

Thus a series of maps of the United States could be drawn which would show the gradual disappearance of the buffalo before the attacks of man. Another might be drawn which would show the present or past distribution of the polar bear, black bear, and grizzly. Still another might show the original range of the wild hares or rabbits of the United States, the white rabbit of the Northeast, the ccttontail of the East and South, the jack rabbit of the plains, the snowshoe rabbit of the Columbia River, the tall jack rabbit of California, the marshhare of the South and the waterhare of the canebrakes, and that of all their relatives. Such a map is very instructive, and 


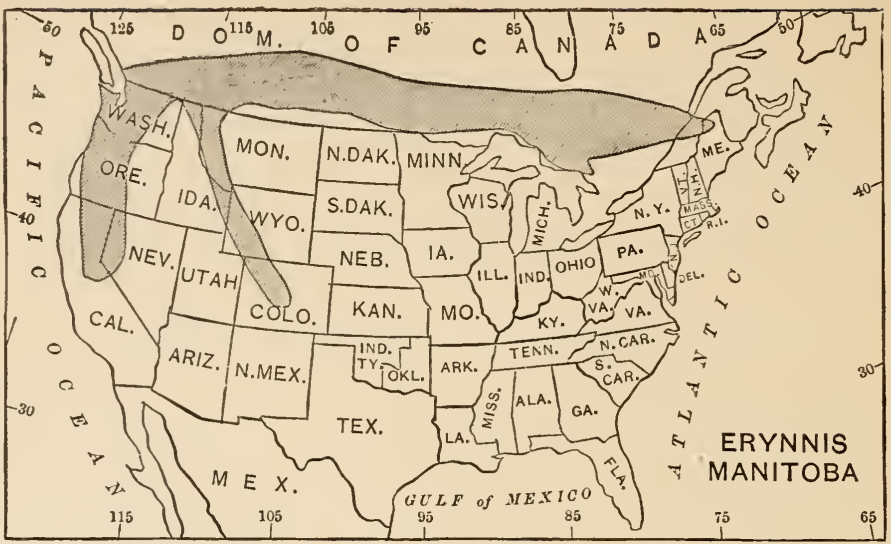

FIG. 183.-Map showing the distribution of the Canadian Skipner butterfly, Erynnis manitoba, in the United States. The butterfly is found in that part of the country shown in the map. This butterfly is subarctic and subalpine in distribution being found only far north or on high mountains, the two southern projecting parts oi its range being in the Rocky Mountains and in the Sierra Nevida Mountains. (After Scudder.)

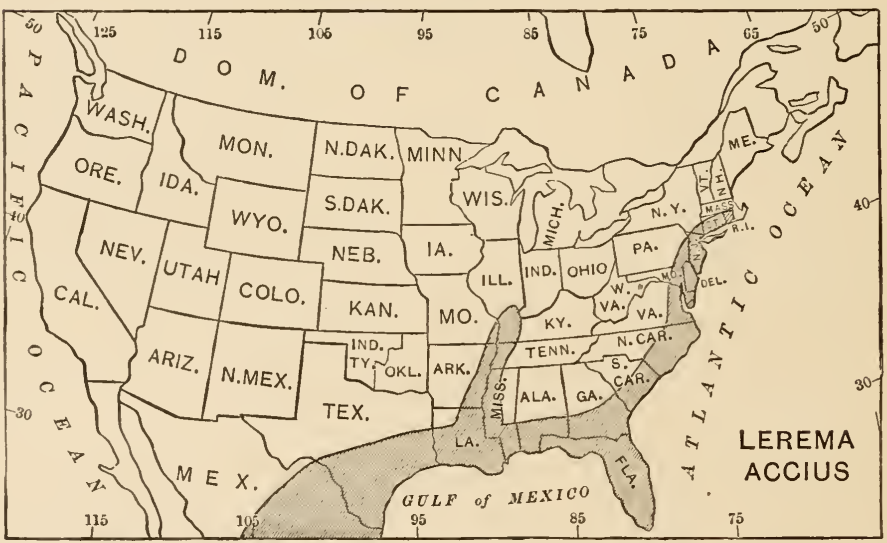

Frg. 184.-Map showing the distribution of the Clouded Skipper butterfly, Lerema accius, in the United States. The butterfly is found in those parts of the country shown in the map by the shading marks-the warm, moist Southern and Eastern parts. (After Scudder.) 
it at once raises a series of questions as to the reasons for each of the facts in geographical distribution, for it is the duty of science to suppose that none of these facts is arbitrary or meaningless. Each fact has some good cause behind it.

It was this phase of the subject, the relation of species to geography, which first attracted the attention of hoth Darwin and Wallace. Both these observers noticed that island life is neither strictly like nor unlike the life of the nearest land, and that the degree of difference varies with the degree of isolation. Both were led from this fact to the theory of derivation, and to lay the greatest stress on the progressive modification resulting from the struggle for existence.

In the voyage of the Beagle Darwin was brought in contact with the singular fauna of the Galapagos Islands, that cluster of volcanic rocks which lies in the open sea about six hundred miles west of the coasts of Ecuador and Peru. The sea birds of these islands are essentially the same as those of the coast of Peru. So with most of the fishes. We can see how this might well be, for both sea birds and fishes can readily pass from the one region to the other. But the land birds, as well as the. reptiles, insects, and plants, are largely peculiar to the islands. Many of these species are found nowhere else. But other species very much like them in all respects are found, and these live along the coast of Peru. In the Galapagos Islands, according to Darwin's notes,

"there are twenty-six land birds; of these, twenty-one, or perhaps twenty-three, are ranked as distinct species, and would be commonly assumed to have been here created; yet the close affinity of the most of these birds to Ameriean species is manifest in every character, in their habits, gestures, and tones of voice. So it is with the other animals and with a large proportion of the plants.

" ... The naturalist, looking at the inhabitants of these volcanic islands in the Pacific, feels that he is standing on American land."

This question naturally arises: If these species have been created as we find them on the Galapagos, why is it that they should all be very similar in type to other animals, living under wholly different conditions, but on the coast not far away? And, again, why are the animals and plants of another cluster of volcanic islands-the Cape Verde Islands-similarly related 
to those of the neighboring coast of Africa, and wholly unlike those of the Galapagos? If the animals were created to match their conditions of life, then those of the Galapagos should be like those of Cape Verde, the two archipelagoes being extremely alike in soil, climate, and physical surroundings. If the species on the islands are products of separate acts of creation, what is there in the nearness of the coasts of Africa or Peru to influence the act of creation so as to cause the island species to be, as it were, echoes of those on shore?

If, on the other hand, we should adopt the obvious suggestion that both these clusters of islands have been colonized by immigrants from the mainland, the fact of uniformity of type is accounted for, but what of the difference of species? If the change of conditions from continent to island causes such great and permanent changes as to form new species from the old, why may not like changes take place on the mainlands as well as on the islands? And if possible on the mainland of South America, what evidence have we that species are permanent anywhere? May they not be constantiy changing? May what we now consider as distinct species be only the present phase in the changing history of the series of forms which constitute the species?

The studies of island life can lead but to one conclusion: These volcanic islands rose from the sea destitute of land life. They were settled by the waifs of wind and of storm, birds blown from the shore by trade winds, lizards and insects carried on drift logs and floating vegetation. Of these waifs few came perhaps in any one year, and few, perhaps, of those who came made the islands their home; yet, as the centuries passed on, suitable inhabitants were found. That this is not fancy we know, for we have the knowledge of specific examples of the very same sort. We know how many animals are carried from their natural homes. One example of this may be seen by those who have approached our eastern shores by sea in the face of a storm. Many land birds-sparrows, warblers, chickadees, and even woodpeckers-are carried out by the wind, a few falling exhausted on the decks of ships, a few others falling on offshore islands, like the Bermudas, the remainder drowning in the sea.

Of the immigrants to the Galapagos the majority doubtless die and leave no sign. A few remain, multiply, and take 


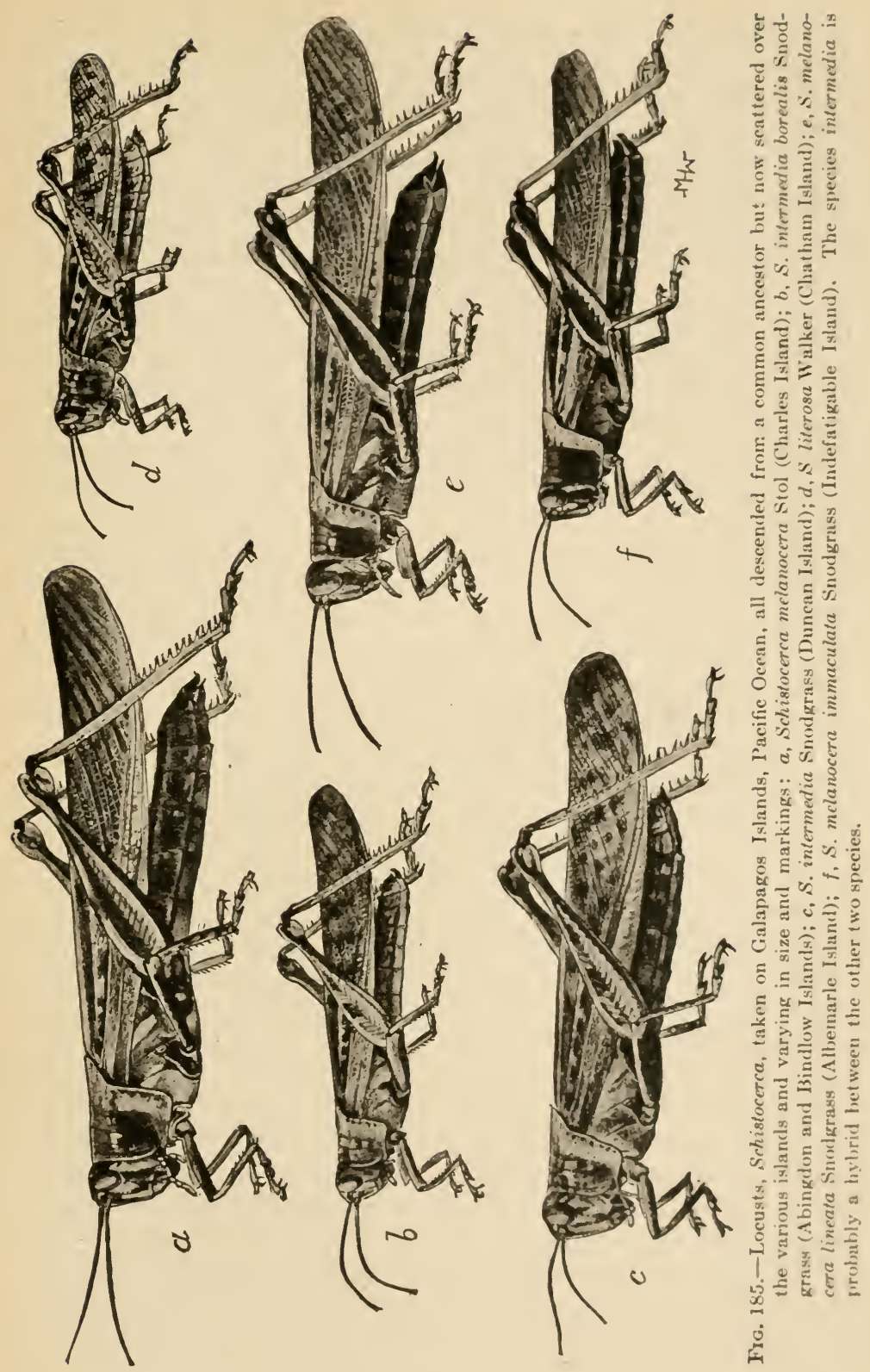


possession, and their descendants are thus native to the islands. But, isolated from the great mass of their species and bred under new surroundings, these island birds come to differ from their parents, and still more from the great mass of the land species of which their ancestors were members. Separated from these, their individuality would manifest itself: They would assume with new environment new friends, new foes, new conditions. They would develop qualities peculiar to themselves-qualities intensified by isolation. Local peculianities disappear with wide association, and are intensified when individuals of similar peculiarities are kept together. Should later migrations of the original species come to the islands, the individuals surviving would in time form new species, or, more likely, mixing with the mass of those already arrived, their special characters would be lost in those of the majority.

The Galapagos, first studied by Darwin, serve to us only as an illustration. The same problems come up, in one guise or another, in all questions of geographical distribution, whether on continent or island. The relation of the fauna of one region to that of another depends on the ease with which barriers may be crossed. Distinctness is in direct proportion to isolation. What is true in this regard of the fauna of any region as a whole, is likewise true of any of its individual species. The degree of resemblance among individuals is in direct proportion to the freedom of their movements, and variations within what we call specific limits is again proportionate to the barriers which prevent equal and perfect diffusion.

The laws governing the distribution of animals are reducible to three very simple propositions. Every species of animal is found in every part of the earth having conditions suitable for its maintenance unless:

(a) Its individuals have been unable to reach this region, through barriers of some sort; or,

(b) Having reached it, the species is unable to maintain itself, through lack of eapacity for adaptation, through severity of competition with other forms, or through destructive condition of environment; or,

(c) Having entered and maintained itself, it has become so altered in the process of adaptation as to become a species distinct from the original type. 
As examples of the first class we may take the absence of kingbirds or meadow lar's or coyotes in Europe, the absence of the lion and tiger in South America, the absence of the civet cat in New York, and that of the bobolink or the Chinese flying fox in California. In each of these cases there is no evident reason why the species in question should not maintain itself if once introduced. The fact that it does not exist is, in general, an evidence that it has never passed the barriers which separate the region in question from its original home.

Tocal illustrations of the same kind may be found in mountainous regions. In the Yosemite Valley in California, for example, the trout ascend the Mereed River to the base of the Vernal fall. They cannot rise above this and so the streams and lakes above this fall are destitute of fish.

Examples of the second class are seen in animals that man has introduced irom one country to another. The nightingale, the starling, and the skylark of Europe have been repeatedly set free in the United States. But none of these colonies has long endured; perhaps from lack of adaptation to the climate, perhaps from severity of competition with other birds, most likely because the few individuals become so widely seattered that they do not find one another at mating time. In other cases the introduced species has been better fitted for the conditions of life than the native forms themselves, and so has gradually crowded out the latter. Both these eases are illustrated among the rats. The black rat (Mus rattus), first introduced into America from Europe about 1544, tended to crowd out the native wild rats (Sigmodon), while the brown rat (Mus decumanus), brought in still later, about 1775, in turn practically exterminated the black rat, its fitness for the conditions of life here being greater than that of the other European species.

Of the third class, or species altered in a new enviromment, examples are numerous, but in most cases the causes involved can only be inferred from their effects. One cliss of illusirations may be taken from island faunas. An island is se off from the mainland by barriers which species of land animals can very rarely cross. On an island a few waifs may maintain themselves, increasing in numbers so as to occupy the territory, but in so doing only those kinds will survive that can fit themselves to the new conditions. Through this process new species 
will be formed, like the parent species in general structure, but having gained new traits adjusted to the new environment.

To processes of this kind, on a larger or smaller scale, the variety in the animal life of the globe must be largely due. Isolation and adaptation through selection probably give the clew to the formation of a very large proportion of the "new species" in any group.

It will be thus seen that geographical distribution is primarily dependent on barriers or checks to the movement of animals. The obstacles met in the spread of animals determine the limits of the species. Each species broadens its range as far as it can. It attempts, unwittingly, of course, through natural processes of increase, to overcome the obstacles of ocean and river, of mountain or plain, of woodland or prairie or desert, of cold or heat, of lack of food, or abundance of enemies-whatever the barriers may be. Were it not for these barriers, each type or species would become cosmopolitan or universal.

Man is preëminently a barrier-crossing animal; hence, in different races or species, man is found in all regions where human life is possible. The different races of men, however, find checks and barriers entirely similar in nature to those experienced by the lower animals, and the race peculiarities are wholly similar to characters acquired by new species under adaptation to changed conditions. The degree of hindrance offered by any barrier differs with the nature of the species trying to surmount it. That which constitutes an impassable obstacle to one form may be a great aid to another. The river which blocks the monkey or the cat is the highway of the fish or the turtle. The waterfall which limits the ascent of the fish is the chosen home of the ouzel. The mountain barrier which the bobolink or the prairie dog does not cross may be the center of distribution of the little chief hare or the Arctic bluebird.

The term fauna is applied to the animals of any region considered collectively. Thus the fauna of Illinois comprises the entire list of animals found naturally in that State. It includes the aboriginal man, the black bear, the fox, and all its animal life down to the Amœba and the microbe of malaria. The relation of the fauna of one region to that of another depends on the ease with which barriers may be crossed. Thus the fauna of Illinois differs little from that of Indiana or Iowa, because the State contains no barriers that animals may not 
readily pass. On the other hand, the famma of Califonia or Colorado differs materially from that of the atjoining regions, because the mountainous country is full of barriers which
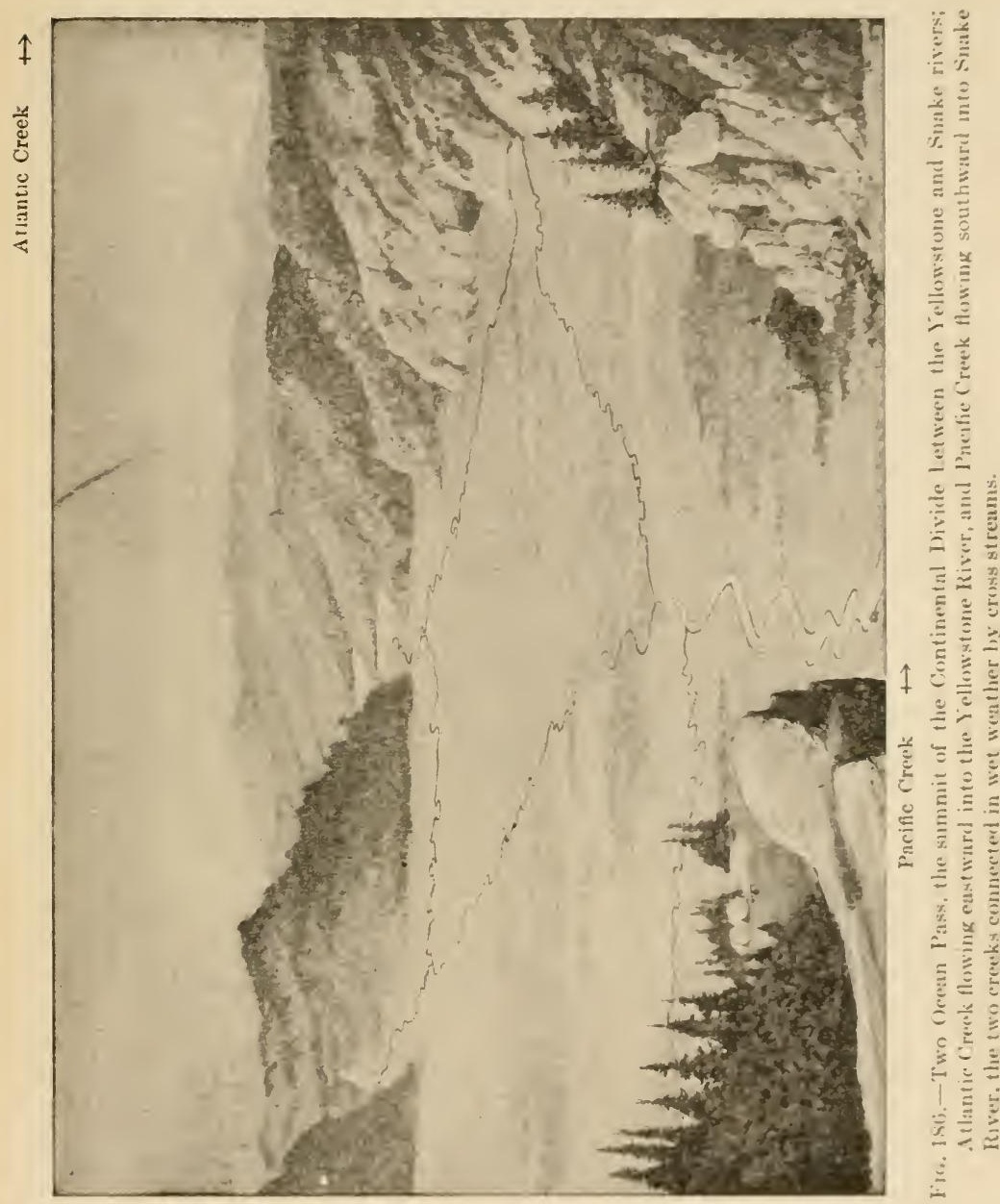

obstruct the diffusion of life. Distinctness is in lirect proportion to isolation. What is true in this regurd of the falmut of any region is likewise true of its individual species. The degree 
of resemplance among individuals is in strict proportion to the freedom of their movements. Variation within the limits of a species is again proportionate to the barriers which prevent equal and free diffusion.

The various divisions or realms into which the land surface of the earth may be divided, on the basis of the character of the animal life, have their boundary in the obstacles offered to the spread of the average animal. In spite of great inequalities in this regard, we may yet roughly divide the land of the globe into seven principal realms or areas of distribution, each limited by barriers, of which the chief are the presence of the sea and the occurrence of frost. There are the Arctic, North Temperate, South American, Indo-African, Patagonian, Lemurian, and Australian realms. Of these the Australian realm alone is sharply defined. Most of the others are surrounded by a broad fringe of debatable ground that forms a transition to some other zone.

The Arctic realm includes all the land area north of the isotherm $32^{\circ}$. Its southern boundary corresponds closely with the northern limit of trees. The fauna of this region is very homogeneous. It is not rich in species, most of the common types of life of warmer regions being excluded by the cold. Among the large animals are the polar bear, the walrus, and certain species of "ice-riding" seals. There are a few species of fishes, mostly trout and sculpins, and a few insects; some of these, as the mosquito, are excessively numerous in individuals. Reptiles are absent from this region and many of its birds migrate southward in the winter, finding in the Arctic their breeding homes only. When we consider the distribution of insects and other small animals of wide diffusion we must add to the Arctic realm all high mountains of other realms whose summits rise above the timber line. The characteristic large animals of the Arctic, as the polar bear or the musk-ox or the reindeer, are not found on the mountain tops because barriers shut them off. But the Alpine flora, even under the equator, may be characteristically arctic, and with the flowers of the north may be found the northern insects on whose presence the flowers depend for their fertilization and which in turn cepend on these for their food. So far as climate is concerned, high altitude is equivalent to high latitude. On certain molintains the different znnes of altitude and the corresponding 
zones of plant and animal life are very sharply defined. Excellent illustrations are found in the San Francisco peaks of Arizona and Mt. Orizaba in Mexico.

The North Temperate or holaretic realm comprises all the land between the northern limit of trees and the southern linit of forests. It includes, therefore, nearly the whole of Europe, most of Asia, and the most of North America. While there are large differences between the fauna of North America and that of Europe and Asia, these differenes are of minor importance, and are scarcely greater in any ease than the difference between the fauna of California and that of our Atlantic coast. The close union of Alaska with Siberia gives the Aretic region an almost continuous land area from Greenland to the westward around to Norway. To the south everywhere in the temperate zone realm, the species increase in number and variety, and the differences between the fauna of North America and that of Europe are due in part to the northward extension in the one and the other of types originating in the tropies.

Especially is this true of eertain of the dominant types of singing birds. The group of wood-warblers, tanagers, Ameriean orioles, vireos, mocking birds, with the fly-catehers and humming birds so characteristic of our forests, are unrepresented in Europe. All of them are apparently immigrants from the neotropical realm where nearly all of them spend the winter. In the same way Central Asia has many immigrants from the Indian realm which lies to the southward. With all these variations there is an essential unity of life over this vast area, and the recognition of North America as a separate (nearetic) realm, which some writers have attempted, seems hardly necessary.

Alfred Russell Wallace refers to this unity of northern life in these words:

"When an Englishman travels on the nearest sea route from Creat Britain to Northern Japan, he passes countries very unlike his own both in aspect and in natural productions. 'The sumny isles of the Mediterranean, the sands and date palms of Egypt, the arid rocks of Aden, the cocoa groves of Ceylon, the tiger-haunted jungles of Malacra and Singapore, the fertile plains and voleanic peaks of Luzon, the forest-clad mountains of Formosa, the bare hills of China pass successively in review, until after a circuivus journey of thirteen thousand 
miles, he finds himself at Hakodate, in Japan. He is now separated from his starting point by an almost endless succession of plains and mountains, arid deserts or icy plateaus; yet, when he visits the interior
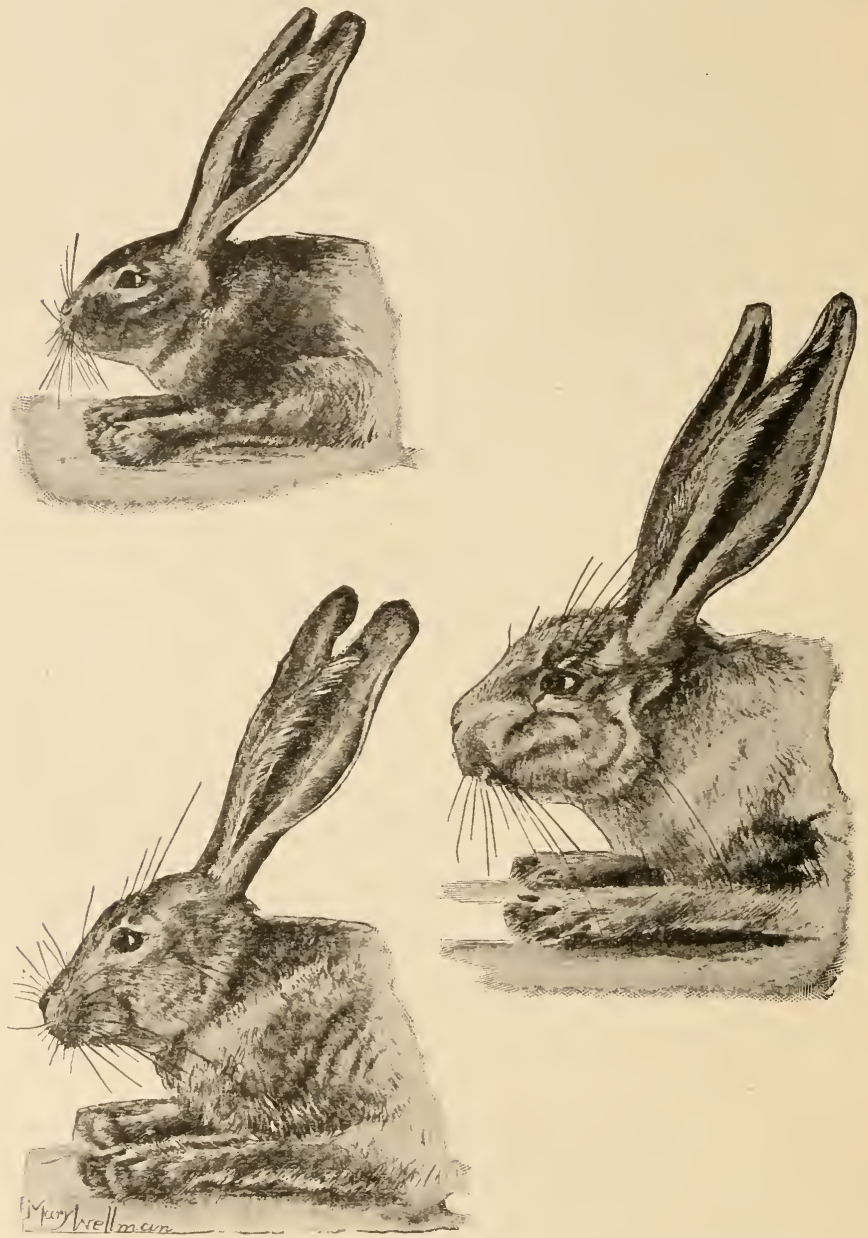

Fic. 187.-Three species of jack rabbits differing in size, color, and markings, but believed to be derived from one stock. The differences have arisen through isolation and adaptation. The upper figure shows the head and fore legs of the black jack rabbit, Lepus insularis, of Espiritu Santo Island, Gulf of California; the lower right-hand figure the Arizona jack rabbit, Lepus alleni, specimen from Fort Lowell, Arizona; and the lower left-hand figure the San Pedro Martir jack rabbit, Lepus martirensis, from San Pedro Martir, Baja California. 
of the country, he sees so many familiar natural objects that he can hardly help faneying he is rlose to his home. He finds the woods and fields tenanted by tits, hedge sparrows, wrens, wagtails, larks, redbreasts, thrushes, buntings, and house sparrows; some absolutely identical with our own feathered friends, others so (doscly resembling them that it requires a practised omithologist to tell the difference. ... There are also, of course, many birds and insects which are quite new and peculiar, but these are by no means so numerous or conspieuous as to remove the general impression of a wonderful resemblance between the productions of such remote islands as IBritain and Yezo." (Island Life.)

A journey to the southward from Britain or Japan or Illinois, or any point within the holaretic realm, would show the successive changes in the character of life though gradual, to be still more rapid. The barrier of frost which keeps the fauna of the tropies from encroaching on the northern regions once crossed, we come to the multitude of animals whose life depends on sunshine, the characteristic forms of the neotropical realm.

The neotropical, or South American realm, includes South America, the West Indies, the hot coast lands (Tierra Caliente) of Mexico, and those parts of Florida and Texas where frost does not occur. Its boundaries through Mexico are not sharply defined, and there is much overlapping of the north temperate realm along its northern limit. Its birds, especially, range widely through the United States in the summer migrations, and a large part of them find in the North their breeding home. Southward, the broad barrier of the two oceans keeps the South American fauna very distinct from that of Australia or Africa. The neotropical fauna is the richest of all in species. The great forests of the Amazon are the treasure houses of the naturalists. Characteristic types among the litrerer animals are the broad-nosed (platyrrhine) monkeys, which in many ways are distinct from the monkeys and apes of the Old World. In many of them the tip of the tail is highly specialized and is used as a hand. The Edentates (armadillos, ant-caters, etc.) are characteristically South American, and there ate many peculiar types of birds, reptiles, fishes, and insects.

The Indo-African or paleotropical realm corresponds to the neotropical realm in position. It includes the great part 
of Africa, merging gradually northward into the north temperate realm through the transition districts which border the Mediterranean. It includes also Arabia, India, and the neighboring islands, all that part of Asia south of the limit of frost. In monkeys, carnivora, ungulates, and reptiles this region is wonderfully rich. In variety of birds, fishes, and insects the neotropical realm exceeds it. The monkeys of this district are all of the narrow-nosed (catarrhine) type, various forms being much more nearly related to man than is the case with the peculiar monkeys of South America. Some of these (anthropoid apes) have much in common with man. To this region belong the elephant, the rhinoceros, and the hippopotamus, as well as the tiger, lion, leopard, giraffe, the wild asses, and horses of various species, besides a large number of ruminant animals not found in other parts of the world. It is, in fact, in the lower mammals and reptiles that its most striking distinctive characters are found. In its fish fauna it has much in common with South America.

The Lemurian realm comprises Madagascar alone. It is an isolated division of the Indo-African realm, but the presence of many species of lemurs-an unspecialized or primitive type of monkey -is held to justify its recognition as a distinct realm. In most other groups of animals the fauna of Madagascar is essentially that of neighboring parts of Africa.

The Patagonian realm includes the south temperate zone of South America. It has much in common with the neotropical realm from which its fauna is mainly derived, but the presence of frost is a barrier which vast numbers of species cannot cross. Beyond the Patagonian realm lies the Antarctic continent. The scanty fauna of this region is little known, and it probably differs from the Patagonian fauna chiefly in the absence of all but the ice-riding species.

The Australian realm comprises Australia and neighboring islands. It is more isolated than any of the others, having been protected by the sea from the invasions of the characteristic animals of the Indo-African and temperate realms. It shows a singular persistence of low or primitive types of vertebrate life, as though in the process of erolution the region had been left a whole geologis age behind. If the competing faunas of Africa and India could have been able to invade Australia, the dominant mammals and birds of that region 
-would not have been left as they are now-marsupials and parrots.

It is only when barriers have shut out competition that simple or unspecialized types abound. The larger the land area and the more varied its surface, the greater is the stress of competition and the more specialized are the characteristic forms. As part of this specialization is in the direction of hardiness and power to persist, the species from the large areas, as a whole, are least easy of extermination. The rapid multiplication of rabbits and foxes in Australia, when introduced by the hand of man, shows what night have taken place in this country had not impassable barriers of ocean shut them out.

Each of these great realms may be indefinitely suldivided into provinces and sections, for there is no end to the possibility of analysis. No farm has exactly the same animals or plants as any other, as finally in ultimate analysis we find that no two animals or plants are exactly alike. Shut off one pair of animals from the others of its species, and its descendants will differ from the parent stock. The difference increases with time and with distance so long as the separation is maintained. Hence new species and new fauna or aggregations of species are produced wherever free diffusion is checked by any kind of barrier.

In like manner, we may divide the ocean into faunal areas or zones, according to the distribution of its animals. For this purpose the fishes probably furnish the best indications, although results very similar are obtained when we consider the mollusks or the crustacea.

The pelagic fishes are those which inhabit the open sea, swimming near the surface, and often in great schools. Nuch forms are usually confined to the warmer waters. They are for the most part predatory fishes, strong swimmers, and many of the species are found in all warm seas. Most species have specal homing waters, to which they repair in the spawning season. To the free-swimming forms of invertebrates and protozoa, found in the open ocean, the name Plankton is applied.

The bassalian fauna, or deep-sea fauna, is composed of species inhabiting great depths (from 2,500 to 25,000 feet) in the sea. At a short distance below the surface the change in temperature from day to night is no longer felt. At a still 
lower depth there is no difference between winter and summer, and still lower none between day and night. The bassalian fishes inhabit a region of great cold and inky darkness. Their bodies are subjected to great pressure, and the conditions of life are practically unvarying. There is, therefore, among them no migration, no seasonal change, no spawning season fixed by outside conditions, and no need of adaptation to varying environment. As a result, all are uniform indigo-black or purple in color, and all show more or less degeneration in those characters associated with ordinary environment. Their bodies are elongate, from the lack of specialization in the vertebræ. The flesh, being held in place by the great pressure of the water, is soft and fragile. The organs of touch are often highly developed. The eye is either excessively large, as if to catch the slightest ray of light, or else it is undeveloped, as if the fish had abandoned the effort to see. In many cases luminous spots or lanterns are developed by which the fish may see to guide its way, and in some forms these shining appendages are highly developed. In one form (Ethoprora) a luminous body covers the end of the nose, like the headlight of an engine. Many of these species have excessively large teeth, and some have been known to swallow animals actually larger than themselves. Those which have lanternlike spots have always large eyes.

The deep-sea fishes, however fantastic, have all near relatives among the shore forms. Most of them are degenerate representatives of well-known types-for example, of eels, cod, smelt, grenadiers, sculpin, and flounders. The deep-sea crustaceans and mollusks are similarly related to shore forms.

The third great subdivision of marine animals is the littoral or. shore group, those living in water of moderate depth, never venturing far into the open sea either at the surface or in the depths. This group shades into both the preceding. The individuals of some of the species are excessively local, remaining their life long in tide pools or coral reefs or piles of rock. Others venture far from home, becoming more or less pelagic. Still others ascend rivers either to spawn (anadromous, as the salmon, shad, and striped bass), or for purposes of feeding, as the robalo, corvina, and other shore fishes of the tropics. Some live among rocks alone, some in seaweed, some on sandy shores, some in the surf, and some only in sheltered lagoons. 
In all seas there are fishes and other marine animals, and each creature haunts the places for which it is fitted.

There is the closest possible analogy between the variations of species of animals or plants in different districts and that of words in different languages. The language of any people is not a unit. It is made up of words which have at variots times and under various eonditions come into it from the speech of other people. The grammar of a language is an expression of the mutual relations of these words. The word as it exists in any one language represents the species. Its cognate or its ancestor in any ether language is a related species. The words used in a given district at any one time constitute its philological fauna. There is a struggle for existence between woids as among animals. For example tlie words begin and commence, shake and agitate, work and operate (kixon and French) are in the English language constintly bonght into competition. The fittest, the one that suits English purposes best, wi!l at last survive. If both have elements of fitness, tle ficld will be divided between them. The silent letters in words tell their past history, as rudimentary organs tell what an arimal's ancestry has been. This analogy, of course, is not perfect in all regards, as the passing of the words from mouth to mouth is not rigidly comparable with the generation of animals.

We may illustrate the formation of species of animals by following any widely used word across Europe. Thus the Greek aster becomes in Iatin and Italian stella: whence the Spanish estrella and the French étoile. In (iermany it becomes Stern, in Danish Stjern; whence the Scottish starn and English star.

In like manner, the name cherry may ie traced from country to country to which it has been taken in cultivation. Its fireck name, kerasos, becomes cerasus, ceresia, ceriso, cereso, cirise, among the Latin nations. This word is shortened to Kirsch and Kers with the people of the North. In England, chorys, cherry, are obviously derived from cérise.

The study of a fauna or a flora as a whole is thus analogous to the study of a living language. The evolution of a language corresponds to the hist ory of the life of some recrion. Ithilologry. systematic zoölogy, and botany are alike intimately related to geography. The parallelism between speech distriets and faunal districts has been many times notor. The spread of a 
language, like the spread of a fauna, is limited by natural barriers. It is the work of civilization to break down these barriers as limiting the distribution of civilized man. The dominant languages cross these barriers with the races of man who use them, and with them go the domesticated animals and plants and the weeds and vermin man has brought unwillingly into relations of domination.

The profitable study of the problems of geographical distribution is possible only on the theory of the derivation of species. If we view all animals and plants as the results of special creations in the regions assigned to them, we have instead of laws only a jumble of arbitrary and meaningless facts. In our experience with the facts of science we have learned that no fact is arbitrary or meaningless. We know no facts which lie beyond the realm of law. We may close with the language of Asa Gray:

"When we gather into ore line the several threads of evidence of this sort we find that they lead in the same direction with the views furnished by other lines of investigation. Slender indeed each thread may be, but they are manifold, and together they bind us firmly to the doctrine of the derivation of species." 


\section{CHAPTER XVI}

\section{ADAPTATIONS}

It is a wise provision of nature that trees shall not grow up into the sky.-Cioetile.

The adaptation of every species of animal and plant to its environment is a matter of everyday observation. Sin perfect is this adaptation in its details that its main facts tend to escape our notice. The animal is fitted to the air it breathes, the water it drinks, the food it finds, the climate it endures, the region which it inhabits. All its organs are fitted to its functions: all its functions to its enviromment. Organs and functions are alike spoken of in a half-figurative waly as concessions to environment. And all structures and powers are in this sense concessions, in another sense, arlaptations. As the loaf is fitted to the pan, or the river to its bed, so is each species fitted to its surroundings. If it were not so fitted, it would not live. But such fitness on the vital side leaves large room for variety in characters not essential to the life of the animal. Thus we ascribe nonessential characters to variation, preserved by heredity and guarded by isolation. Vital or adaptive characters originate in the same way, but these are preserved in heredity and guarded and intensified by selection.

The strife for place in the crowd of animals makes it necessary for each one to adjust itself to the place it holds. Is the individual becomes fitted to its condition, so must he species as a whole. The species is therefore made up of inclividuals that are fitted or may become fitted for the conditions of life. As the stress of existence becomes more severe, the individuals fit to continue the species are chosen more closely. This choice is the automatic work of the conditions of life, but it is none the less effective in its operations, and in the course of centuries 
it may be considered unerring. When conditions change, the perfection of adaptation in a species may be the cause of its extinction. If the need of a special fitness cannot be met, immediately the species will disappear. For example, the native sheep of England have developed a long wool fitted to protect them in a cool, damp climate. Such sheep, transferred to Cuba, died in a short time, leaving no descendants. The warm fleece, so useful in England, rendered them wholly unfit

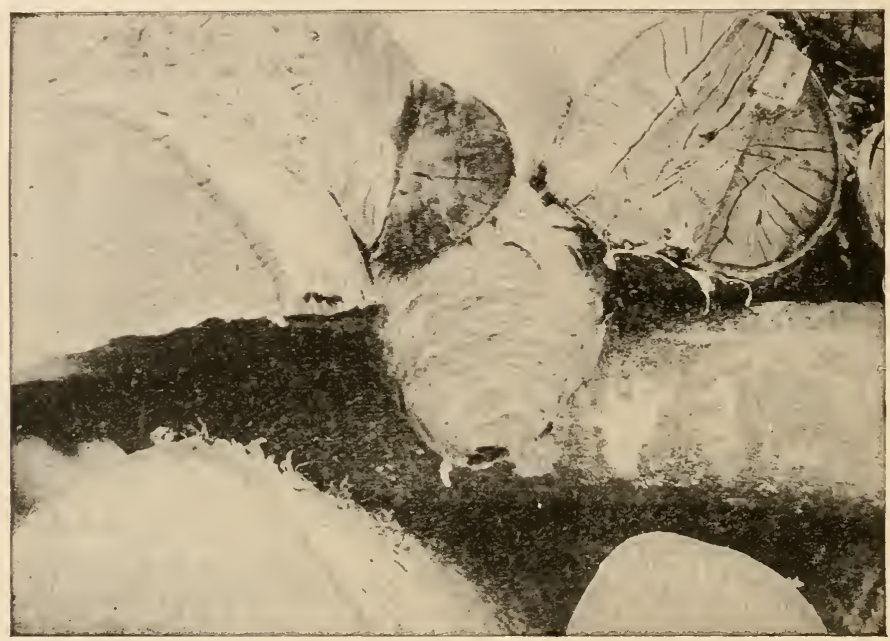

Frg. 188.-Nesi of Vespa, a social wasp. (Photograph by A. L. Melander and C. T. Brues.)

for survival in the tropics. It is one advantage of man, as compared with other forms of life, that so many of his adaptations are external to his structure, and can be cast aside when necessity arises.

The great fact of nature is adaptation. But while general adaptation to widespread conditions is universal, there exist also a multitude and variety of special adaptations fitting organisms to special conditions. These special adaptations arrest our attention to a greater degree than general adaptations because they furnish the element of contrast.

The various types of special adaptations may be roughly civided into five classes as follows: (a) Food-securing; (b) self- 
defense; $(c)$ defense of young; $(d)$ rivalry; $(e)$ adjustment to surroundings.

For the purpose of capture of their prey, most carnivorous animals are provided with strong claws, sharp teeth, hooked beaks, and other structures familiar to us in the lion, tiger, dog, cat, owl, and eagle. Insect-aating mammals have contrivances especially adiapted for the ratehing of insects. The ant-eater, for example, has a long sticky tongue which it thrusts forth from its cylindrical snout deep into the recesses of the ant-hill, bringing it out with its surface covered with ants. Animals which feed on nuts are fitted with strong teeth or beaks for cracking them. Strong teeth are found in those fishes which feed on crabs, or sea urchins. Those mammals like the horse and cow, that feed on plants, have usually broad chisellike incisor teeth for cutting off the foliage, and teeth of very similar form are developed in different groups of plant-eating fishes. Nolar teeth are found when it is necessary that the

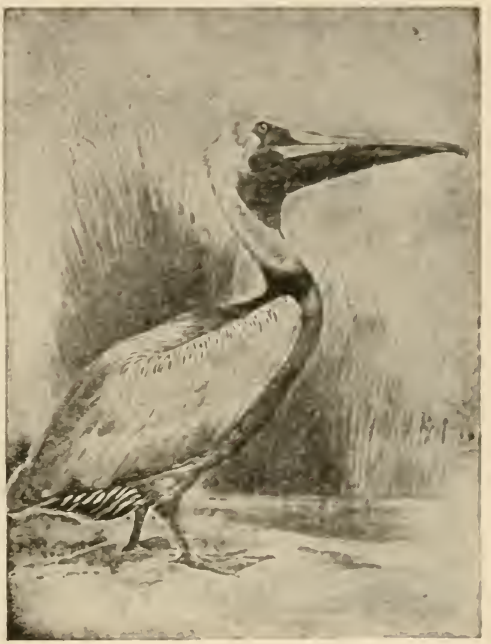

Frg. 189.-The brown pelican, showing gular sac which it uses in catching and holding fishes for its food. food should be crushed or chewed, and the sharp canine teeth gn with a flesh dict. The long neck of the giraffe enables it to browse on the foliage of trees in grassless regions.

Insects like the leaf-beetles and the grasshoppers, that feed on the foliage of plants, have a pair of jaws, broald but sharply edged, for cutting off bits of leaves and stems. Those which take only liquid food, as the butterflies and sucking bugs. have their mouth parts modified to form a slender, hollow sucking beak or proboscis, which can be thrust into a flower nectary, or into the green tissue of plants or the flesh of animals to suck up nectar or plant sap, or blood, according to the special food habits of the insect. The honey-bee has a very 
complicated equipment of mouth parts fitted for taking eithe solid food like pollen, or liquid food jike the nectar of flowers. The mosquito has a "bill" composed of six sharp, slender needles for piercing and lacerating the flesh, and a Isng tubular under lip through which the blood can flow into the mouth. Some predaceous insects, as the praying horse (Fig. 38), have their fore legs developed into formidable grasping organs for seizing and holding their prey.

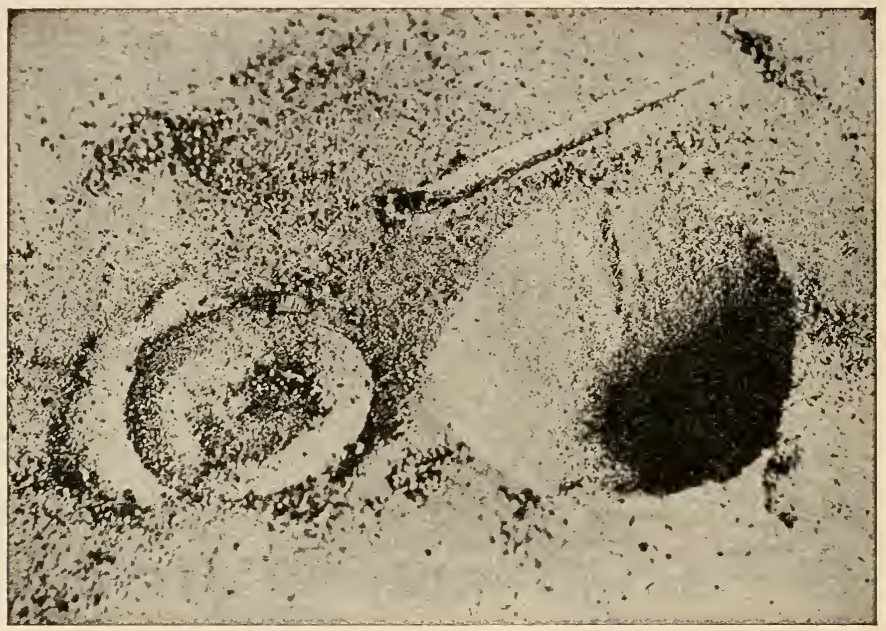

FIG. 190.-Ant-lion larva plowing its way through the sand (ur:yer figure), while another is commencing the excavation of a funnel-shaped pit similar to one on right. (Photograph by A. L. Melander and C. T. Brues.)

For self-protection the higher animals depend largely on the same organs and instincts as for the securing of food. Car. nivorous beasts use tooth and claw in their own defense as well as in securing their prey, but these as well as other animals may protect themselves in other fashions. Many of the higher animals are provided with horns, structures useless in procuring food, but effective as weapons of defense. Others defend themselves by blows with their strong hoofs. Among the reptiles and fishes and even among the mammals, the defensive coat of mail is found in great variety. The turtle, the armadillo, the sturgeon, and gar pike, all these show the value of defensive armature, and bony sinields are developed to a still greater 
degree in various extinct types of fishes. The erab and lobster with claws and carapace are well defended against their enemies, and the hermit crab, with its trick of thrusting its unprotected body within a cast-off shell of a sea snail, finds in this instinct a perfect defense. Insects also, especially beetles, are proterted by their coats of mail. Scales and spines of many sorts serve to defend the bodies of reptiles and fishes, while feathers protect the bodies of birds and hair those of most mammals.

The ways in which animals make themselves disagreeable or dangerous to their captors are almost as varied as the animals themselves. Besides the teeth, claws, and horns of ordinary attack and defense, we find among the mammals many special structures or contrivances which serve for defense through making their possessors unpleasant. The scent glands of the skunk and its relatives serve as examples. The porcupine has the bristles in its fur specialized as quills, barbed and detachable. These quills fill the mouth of an attacking wolf or fox, and serve well the purpose of defense. The hedgehog of Europe, an animal of different nature, being related rather to the mole than to the squirrel, has a similar armature of quills. The armadillo of the tropies has movable shields, and when it withdraws its head (also defended by a bony, shield) it is as well protected as a turtle.

The turtles are all protected by bony shields, and some of them, the box turtles, ma!y close their shields almost hermetically. The snakes broaden their heads, swell their necks, or show their forked tongues to frighten their enemies. Some of 
them are further armed with fangs connected with a venom gland, so that to most animals their bite is deadly. Besides

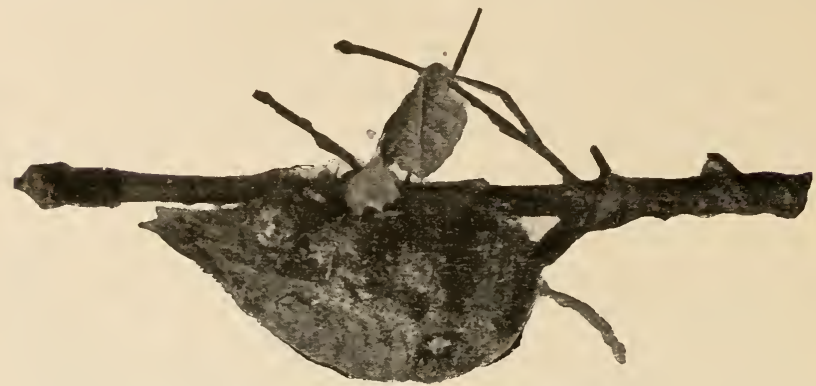

FIG. 192.-Cocoon enclosing a pupa of the great Ceanothus moth, Samia ceanothi, spun by the larva before pupation.

its fangs the rattlesnake has a rattle on the tail made up of a succession of bony clappers, modified vertebræ, and scales, by which intruders are warned of its pre-

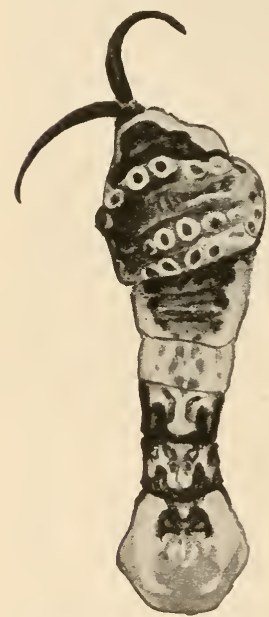

FIG. 193.-Larva of swallowtail butterfly, $P a$ pilio cresphontes, showing osmateria (eversible processes giving off an ill odor) projected. (After photograph by Slingerland.) sence. This sharp and insistent buzz is a warning to animals of other species and perhaps a recognition signal to those of its kind.

Even the fishes have many modes of self-defense through giving pain or injury to animals who would swallow them. The catfish or horned pout when attacked sets immovably the sharp spine of the pectoral fin, inflicting a jagged wound. Pelicans which have swallowed a catfish have been known to die of the wounds inflicted by the fish's spine. In the group of scorpion fishes and toad fishes are certain genera in which these spines are provided with poison glands. These may inflict very severe wounds to other fishes, or even to birds or man. One of this group of poison fishes is the nohi (Emmydrichihys). A group of small fresh-water catfishes, known as the mad toms, have also a poison gland attached to the pectoral spine, and the sting is most exasperating, like the sting 
of the wasp. The sting-rays (Fig. 194), of which there are many species, have a strong jagged spine on the tail, covered with slime, and armed with broad sawlike teeth. This inflicts a dangerous wound, not through the presence of speeific venom, but from the danger of blood poisoning arising from the slime, and the ragered ol unclean cut.

The poisonous alkaloids within the flesh of some fishes (T'etraodon, Balistes, etc.) serve to destroy the enemies of the species while sacrificing the individual. Thess alkaloids, most develo;el in the spawning season, p.oduce a discase, known in man as ciguatera. This is rarely known outside of the tropics.

Many fishes are defended by a coat of mail or a coat of sharp thorns. The globe fishes and porcupine fishes are for the most part defended by spines, but their instinct to swallow air gives them an additional safeguard. When one of these fishes is disturbed it rises to the surface, gulps air until its capacious stomach is filled, and then floats belly upward on

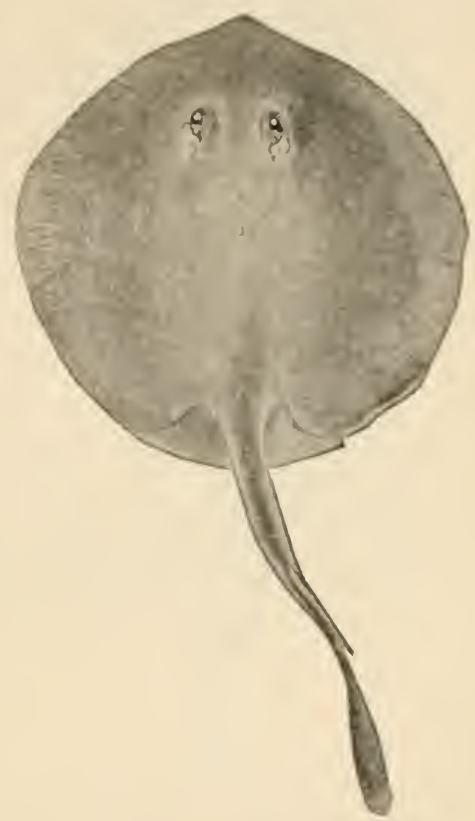

FIG, 194.-Sting-ray, L'rolophus guodei, from l'nnama.

the waicr. It is thus protected from other fishes, though easily taken by man. The torpedo, electric eel, electric catfish, and star-gazer, surprise and st agger their captors by means of electric shocks. In the torpedo or electric ray (Fig. 195), of which species are found on the sandy shores of all warm seas, on either side of the head is a large honeycomblike structure which yields a strong electric shock whenever the live fish is touched. This shock is folt sererely if the fish be stabbed with a knife or metallic spear. The electric eel of the rivers of P'araguay and southern Brazil is said to give serere shocks to 
herds of wild horses driven through the streams, and similar accounts are given of the electric catfish of the Nile. In tropical seas, the tangs or surgeon fishes (Hepatus) are provided with a knifelike spine on the side of the tail, the sharp edge directed forward and slipping into a sheath. This is a formi-

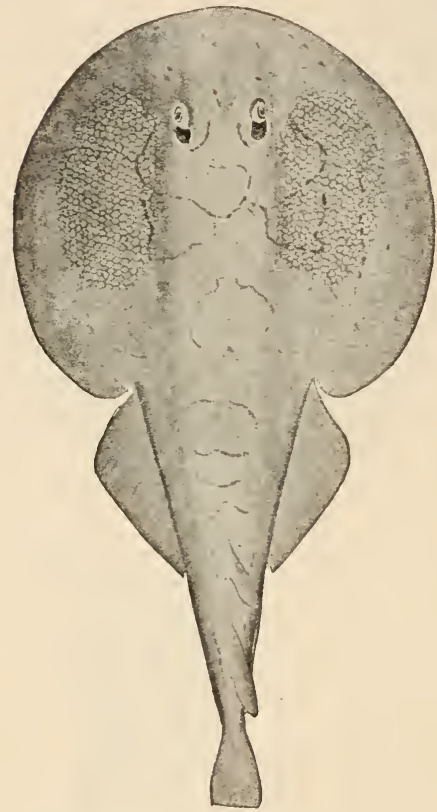

FIG. 195.-Torpedo or electric ray, Narcine brasiliensis, showing electric cells. dable weapon when the fish is alive.

Other fishes defend themselves by spears (swordfish, spearfish, sailfish) or by 'saws (sawfish, sawshark) or by paddles, (paddlefish). Others still, make use of sucking disks of one sort or another (as in the snailfish, the clingfish, and the goby), to cling to the under side of rocks, or as in the Remora to the bodies of swiftmoving sharks. Blind fishes in the caves are adapted to their condition, the eyes being obsolete, while the skin is covered with rows of sensitive papillæ. In similar circumstances salamanders, crayfishes, and insects are also blind. There are also blind gobies which live in the crevices of rocks and still other blind fishes in the great depths of the sea.

Some fishes, like the lancelet, lie buried in the sand all their lives. Others, as the sand darter (Ammocrypta pellucida) and the hinalea (Julis gaimardi), bury themselves in the sand at intervals to escape from their enemies. Some live in the cavities of tunicates or sponges or holothurians or corals or oysters, often passing their whole lives inside the cavity of one animal. Many others hide themselves in the interstices of kelp or seaweeds. Some eels coil themselves in the crevices of rocks or coral masses, striking at their prey like snakes. Some sea-horses cling by their tails to gulfweed or sec-wrack. Many little fishes (Gobiomorus, Carangus, Psenes) cluster under 
the stinging tentacles of the Portuguese man-of-war or under ordinary jellyfishes.

Some fishes called the flying fishes sail through the air with a grasshopperlike motion that closely imitates trus flight. The long pectoral fins, winglike in form, annot, howerer, be flapped by the fish, the muscles serving only to expand or fold them. These fishes live in the open sea or open chinnels, swimming in large schools. The small sperese fly for a fow

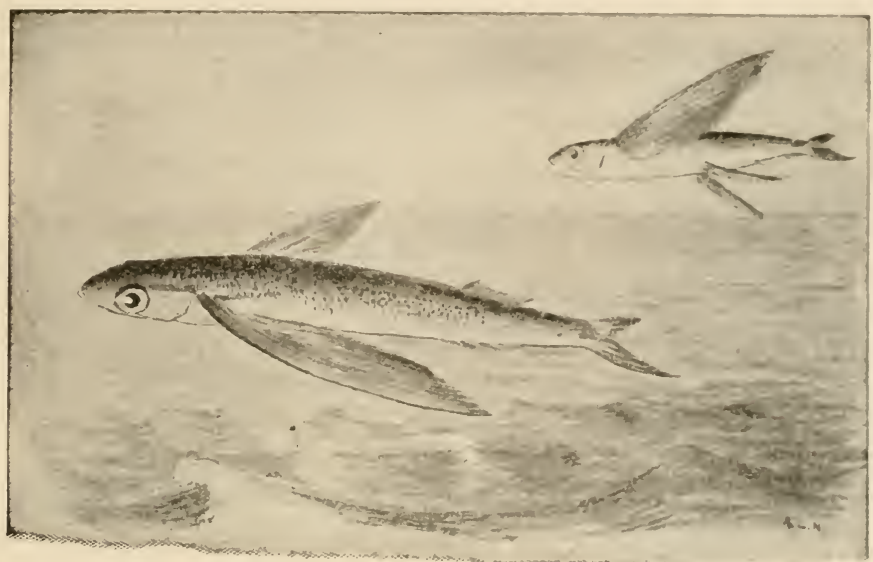

Fig. 196.-Flying fishes: The upper one, a speries of Cypselurus; the lower, of Exocatus. These fishes escape from their encmies by leaping inco the air and sailing or "flying" long distances.

feet only, the large ones for more than an eighth of a mile. These may rise five to twenty feet above the water.

The flight of one of the largest flying fishes (cypsclurus californicus) has been carefully studied by l)r. Charles H. Cilbert and the senior author. The movements of the fish in the water are extremely rapid. The sole motive power is the artion under the water of the strong tail. No force cim be acqinired while the fish is in the air. On rising from the water the movements of the tail are continuous unt the whole body is out of the water. When the talil is in motion the pertorials serm in a state of rapid vibration. This is not produced hy muscular action on the fins themselves. It is the bouly of the fish which vibrates, the pectorals projecting farthest having the groutest amplitude of movement. While the tail is in the water the 
ventral fins are folded. When the action of the tail ceases the pectorals and ventrals are spread out wide and held at rest. They are not used as true wings, but are held out firmly, acting as parachutes, enabling the body to skim through the air. When the fish begins to fall the tail touches the water. As soon as it is in the water it begins its motion, and the body with the pectorals again begins to vibrate. The fish may, by skimming the water, regain motion once or twice, but it finally falls into the water with a splash. While in the air it suggests a large dragon fly. The motion is very swift, at first in a straight line, but is later deflected in a curve, the direction bearing little or no relation to that of the wind. When a vessel passes through a school of these fishes, they spring up before it, moving in all directions, as grasshoppers in a meadow.

Among the insects, the possession of stings is not uncommon. The wasps and bees are familiar examples of stinging insects, but many other kinds, less familiar, are similarly protected. All insects have their bodies covered with a coat of armor, composed of a horny substance called chitin. In some cases, this chitinous coat is rery thick and serves to protect them effectually. This is especially true of the beetles. Some insects are inedible, and are conspicuously colored so as to be readily recognized by insectivorous birds. The birds, knowing by experience that these insects are ill-tasting, avoid them. Others are effectively concealed from their enemies by their close resemblance in color and marking to their surroundings. These protective resemblances are discussed in Chapter XIX.

To the category of structures which may be useful in selfdefense belong the many peculiarities of coloration known as "recognition marks." These are marks, not otherwise helpful, which are supposed to enable members of any one species to recognize its kind among the mass of animal life. To this category belongs the black tip of the weasel's tail, which remains the same whatever the changes in the outer fur. Another example is seen in the white outer feathers of the tail of the meadow lark as well as in certain sparrows and warblers. The white on the skunk's back and tail may serve the same purpose and also as a warning. It is apparently to the skunk's adrantage not to be hidden, for to be seen in the crowd of animals is to be aroided by them. That recognition is the actual 
function of such markings has never been clearly ploved. The songs of birds and the calls of various creatures ma serve also as recognition marks. Fach species knows and heeds its own characteristic song or ery, and it is a source of mutnal protection. The fur-seal pup knows its mother's all, even thongh ten thousand other mothers are calling on the same rookery.

In questions of attack and defense, the neerl of fighting animils of their own kind, as well as animals of oflere races, must be considered. To struggles of species with those of their own kind, the term rivalry may be applied. Actual warfare is confined mainly to males in the lreeding se son, especially in polygamous species. Among those in which the male mates with many females, he must struggle with other males for their possession. In all the groups of vertebrates the sexes are about equal in numbers. Among monogamous animals, which mite for the season or for life, there is less occasion for destruc+ ive rivalry.

Among monogamous birds, or those which pair, the male courts the female of his choice by song and by display of his bright feathers. Accorling to the theory

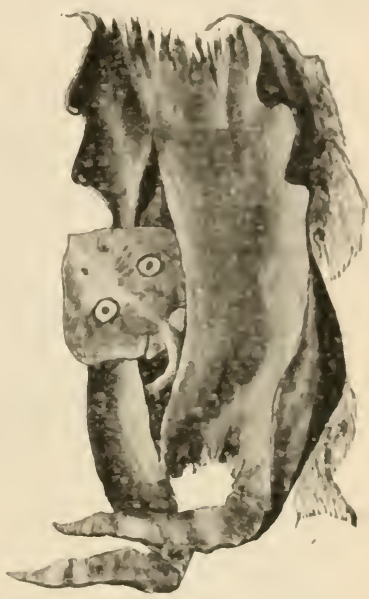

Fig. 197.- Egg case of the California barndoor skate, Raja binoculata, cut open (o show young inside. Joung issues naturally at one end of the skate. of sexual selection, the female consents to be chosen by the one which pleases her. It is assumed that the handsomest, most vivacious, and most musical males are the ones most successful in such (ourtship). With polygamous animals there is intense rivaly among tlec males in the mating season, which in almost all sperest is in the spring. The strongest males survive and reproduce their strength. The most notable adaptation is secu in the superior size of teeth, horns, mane, or spurs. Among the polyegmoms fur seals and sea lions the male is about four times the size of the female. In the polygamous family of deer. buffilo, ant the domestic cattle and sheep, the male is larger and mo:e 
powerfully armed than the female. In the polygamous group to which the hen, turkey, and peacock belong, the males possess the display of plumage, and the structures adapted for fighting, with the will to use them.

The protection of the young is the source of many adaptive siructures as well as of the instincts by which such structures are utilized. In general those animals are highest in development, with the best means of holding their own in the struggle for life, that take best care of their young. Those instincts which lead to home building are all adaptations for preserving

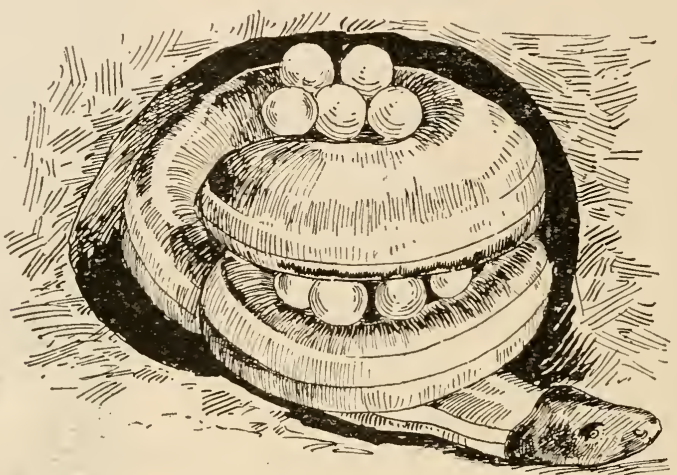

Fig. 198.-The snake, Ichthyophis glutinosus, with egg case carried in coils of the body. (After Goebel and Selenka.)

the young. Among the lower or more coarsely organized birds, such as the chicken, the duck, and the auk, as with the reptiles, the young animal is hatched with well-dereloped muscular system and sense organs, and is capable of running about, and, to some extent, of feeding itself. Birds of this type are known as præcocial, while the name altricial is applied to the more highly organized forms, such as the thrushes, doves, and song birds generally. With these the young are hatched in a wholly helpless condition, with ineffective muscles, deficient senses, and dependent wholly upon the parent. The altricial condition demands the building of a nest, the establishment of a home, and the continued care of one or both of the parents.

The very lowest mammals known, the duck bills (Monotremes) of Australia, lay large eggs in a strong shell like those of a turtle, and these they guard with great jealousy. But 
with almost all mammals the egre is very small and without much food yolk. The egg begins its development within the

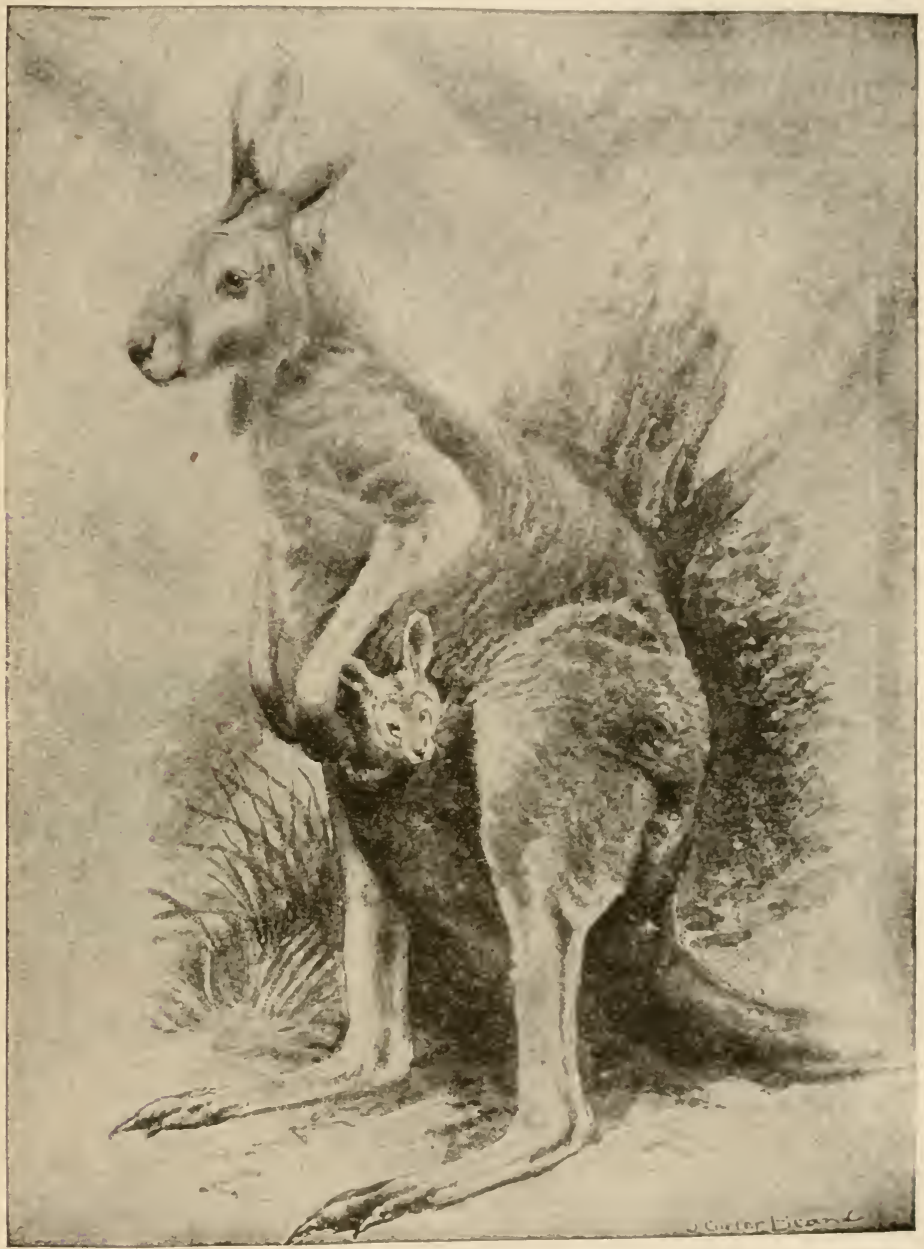

Fir. 199.-Kangaroo, Macropus rufus, with young in pouch.

body. It is nourished by the blood of the mother, and after birth the young is cherished by her, and fed by milk secreted by specialized glands of the skin. All these features are 
adaptations tending toward the preservation of the young. In the Marsupials, which stand next to the Monotremes-the kangaroo, opossum, etc.-the young are born in a very immature state and are at once seized by the mother and thrust into a pouch or fold of skin along the abdomen, where they are

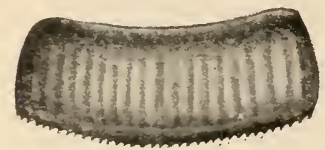

FIG. 200.-Egg case of the cockroach. kept until they are able to take care of themselves (Fig. 199). This is a singular adaptation, but less specialized and less perfect than the condition found in ordinary mammals.

Among the insects, the special provisions for the protection and care of the eggs and the young are widespread and various. The eggs of the common cockroach are laid in small packets inclosed in a firm wall (Fig. 200). The eggs of the great water bugs are carried on the back of the male (Fig. 201): and the spiders lay their eggs in a silken sac or cocoon, and some of the ground or running spiders (Lycosid $($ ), drag this egg sac, attached to the tip of the abdomen, about with them. The young spiders when hatched live for some days inside this sac, feeding on each other. Many insects have long, sharp, piercing ovipositors, by means of which the eggs are thrust into the ground or into the leaves or stems of green plants, or even into the hard wood of tree trunks. Some of the scale insects secrete wax from their bodies and form a large, often beautiful egg case attached to and nearly covering the body in which eggs are deposited. The various gall insects lay their eggs in the soft tissue of plants, and on

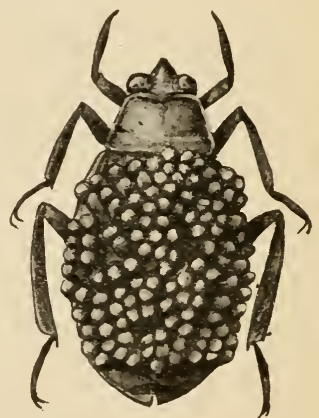

FIG. 201.-Giant waterbug, Serphus, male carrying eggs on its back.

the hatching of the larva an abnormal growth of the plant occurs about the young insect, forming an inclosing gall that serves not only to protect the insect within, but to furnish it with an abundance of plant sap, its food. The young insect remains in the gall until it completes its development and growth, when it gnaws its way out. Such insect galls are especially abundant on oak trees (Figs. 202 and 203).

The movements of migratory fishes are mainly controlled 
by the impulse of reproduction. Some pelagic fishes, especially those of the mackerel and flying fish families, swim long distances to a region favorable for the deposition of spawn. Others pursue for equal distances the schools of herring, menhaden, or other fishes which serve as their prey. Some species are known mainly in the waters they make their breeding homes, as in

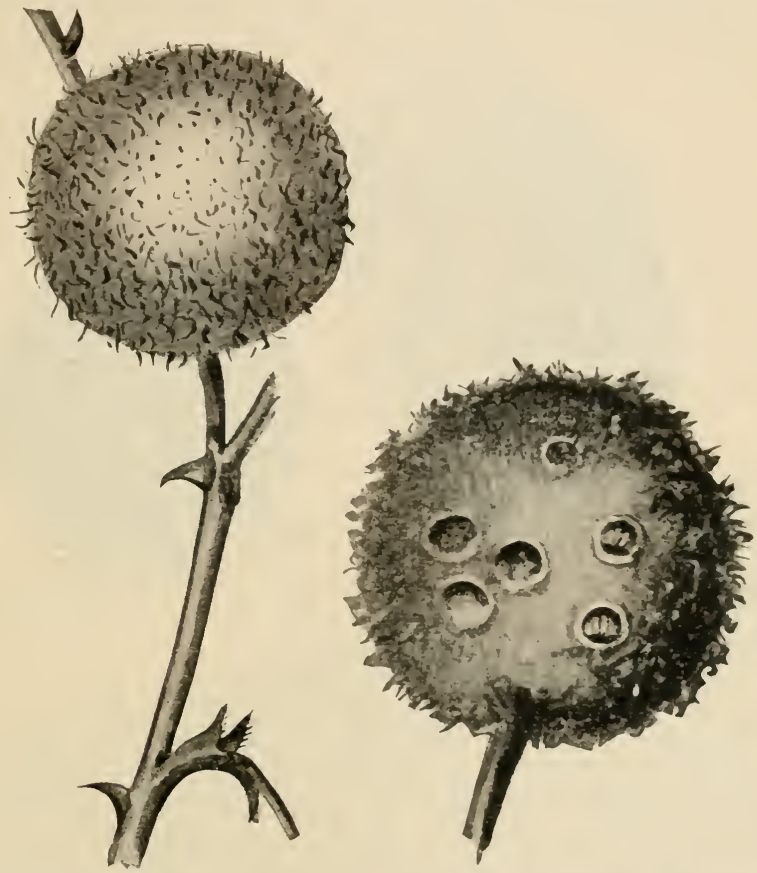

FIG. 202.-Galls on the rose caused by the gall fly, Rhodites rosa. (After Kieffer.)

Cuba, southern California, Hawaii, or Japan, the individuals being seattered at other times through the wide seas.

Many fresh-water fishes, as trout and suckers, forsake the large streams in the spring, ascending the small brooks where their young can be reared in greater safety. Still others, known as anadromous fishes, feed and mature in the sea, but ascend the rivers as the impulse of reproduction grows strong. Among such fishes are the salmon, shad, alewife, sturgeon, and striped bass in American waters. The most remarkable case 
of the anadromous instinct is found in the king salmon or quinnat (Uncorhynchus tschawytscha) of the Pacific Coast. This great fish spawns in November, at the age of four years and with an average weight of twenty-two pounds. In the Columbia River it begins running with the spring freshets in March and April. It spends the whole summer without feeding in the ascent of the river. By the autumn, the individuals

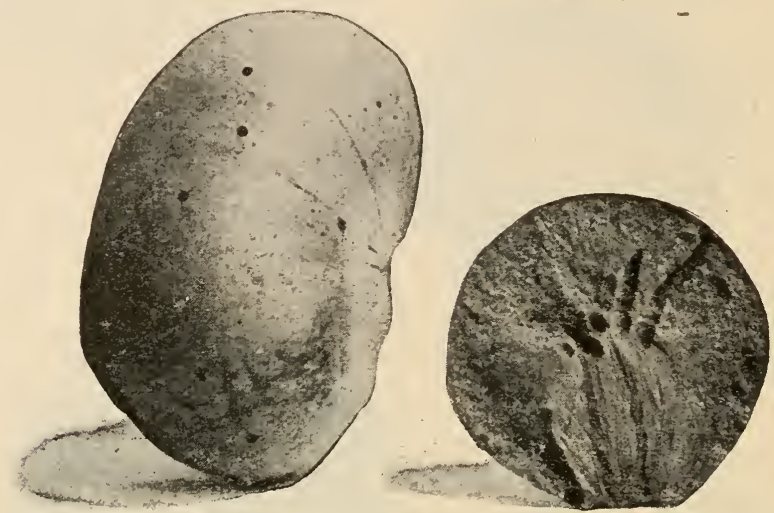

FIg. 203.-Giant gall of the white oak (California) made by the gall fly, Andricus californicus; the gall at the right cut open to show the tunnels made by the insects in escaping from the gall. (From photograph.)

have reached the mountain streams of Idaho, greatly changed in appearance, discolored, worn, and distorted. The male is humpbacked, with sunken scales and greatly enlarged, hooked, bent, or twisted jaws, with enlarged doglike teeth. On reaching the spawning beds, which may be a thousand miles from the sea in the Columbia, over two thousand miles in the Yukon, the female deposits her eggs in the gravel of some shallow brook. The male covers them and scrapes the gravel over them. Then both male and female drift tail foremost helplessly down the stream: none, so far as certainly known, ever survives the reproductive act. The same habits are found in the four other species of salmon in the Pacific, but in most cases the individuals do not start so early nor run so far. The blueback salmon or redfish, however, does not fall far short in these regards. The salmon of the Atlantic has a similar habit, but the distance traveled is everywhere much less, and the hook-jawed males 
drop back down to the sea and survive to repeat the acts of reproduction.

Catadromous fishes, as the true eel (Anguillu), reverse this order, feeding in the rivers and brackish estuaries, apparently finding their usual spawning ground in the sea.

A large part of the life of the animal is a struggrle with the enviromment itself: in this struggrle only those that are adapted, live and leave descendants fitted like themselves. The fur of mammals fits them to their surroundings. As the fur differs so may the habits change. Some animals are active in winter: others, as the bear, and in Northern Japan, the red-faced monkey, hibernate, sleeping in eaves or hollow trees or in burrows, until conditions are favorable for their activity." Most snakes and lizards hibernate in cold weather. In the swampls of Louisiana, in winter, the bottom may often be seen covered with water snakes lying as inert as dead twigs. Lsually, however, hibernation is accompanied by concealment. Some

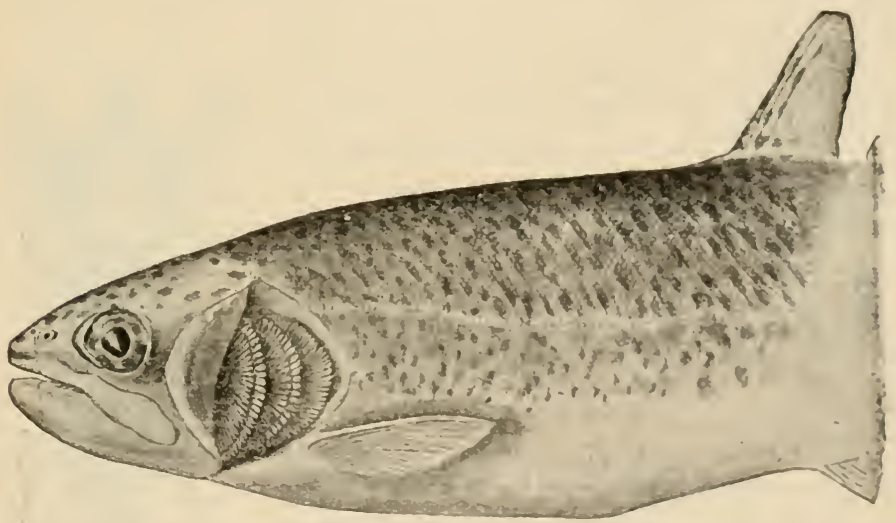

Fig. 204.-Head of rainbow trout, Salmo iridens, with gill cover bent back to show gills, the breathing organs.

animals in hibernation may be frozen alive without apparent injury. The blackfish of the Alaskia swamps, fed to dogs when frozen solid, has been known to revive in the heat of the dog's stomach and to wriggle out and eseape. As animas resist heat and cold by adaptations of structure and habits, so may they resist dryness. Certain fishes hold reservoirs of water above their gills, by means of which they can brenthe during 
short excursions from the water. Still others (mud fishes) retain the primitive lunglike structure of the swim bladder, and are able to breathe air when, in the dry season, the water

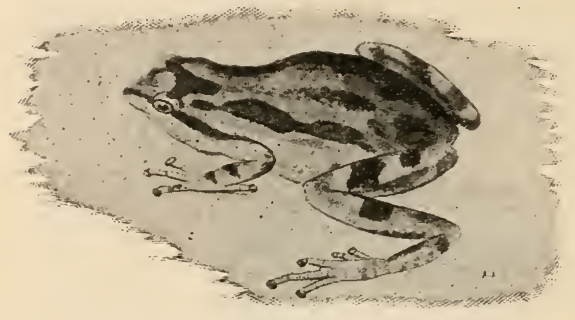

FIG. 205.-Tree toad, Hyla regilla. of the pools is reduced to mud.

Another series of adaptations is concerned with the places chosen by animals for their homes. The fishes that live in the water have special organs for breathing under water (Fig. 204). Many of the South American monkeys have the tip of the tail adapted for clinging to limbs of trees or to the bodies of other monkeys of its own kind. The hooked claws of the bat hold on to rocks, the bricks of chimneys, or to the surface of hollow trees, where the bat sleeps through the day. The tree frogs or tree toads (Fig. 205) have the tips of the toes swollen, forming little pads by which they cling to the bark of trees.

Among other adaptations relating to special surroundings or conditions of life are the great cheek pouches of the pocket gophers, which carry food, as grass-roots and the like, when the gopher excavates its burrow.

Those insects which live underground, making burrows or tunnels in the soil, have their legs or other parts adapted for digging and burrowing. The mole cricket (Figs. 206 and 207) has its legs stout and short, with broad, shovellike feet. Some water beetles and water bugs have one or more of the pairs of legs flattened and broad to serve as oars or paddles for swim-

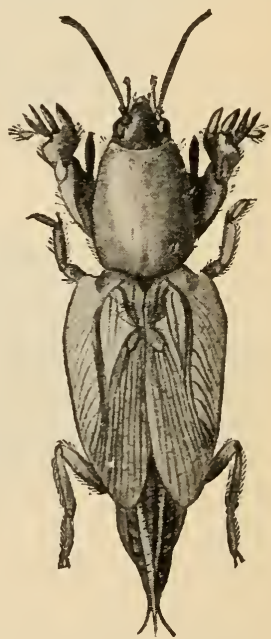

FIG. 206. - The mole cricket, Gryllotalpa, with fore legs modified for digging. ming. The grasshoppers or locusts, which leap, have their hind legs greatly enlarged and elongated, and provided with strong muscles so as to make of them "leaping legs." The 
grubs or larve of beetles which live as "borers" in tree trunks have mere rudiments of legs, or none at all. 'They have great, strong, biting jaws for cutting away the hard wood. They move simply by wriggling along in their burrows or tunnels.

Insects that live in weter either come up to the surface to breathe or take down air underneath their wings, or in some other way, or have gills for b:eathing the air which is mixed with the witer. 'These gills are special adaptive structües which present a great variety of form and appearance. In the young of the May flies they are delicate platelike flaps projecting from the sides of the body. They are kept in constant motion, gently waving back and forth in the water so as to maintain currents to bring fresh water in contact with them. Young mosquitoes do not have gills, but come up to the surface to breathe. The larvæ, or wrigglers, breathe through a special tube at the posterior tip of the body, while the pupx have a pair of hornlike tubes on the back of the head end of the body.

Many fishes, chiefly of the deep seas, develop organs for producing light. These are known as luminous organs, phosphorescent organs, or photophores. These are independently developed in four entirely unrelated groups of fishes. This difference in origin is accompanied by corresponding differences in structure. The best known type is found in the Iniomi, including the lantern fishes and their many relatives.
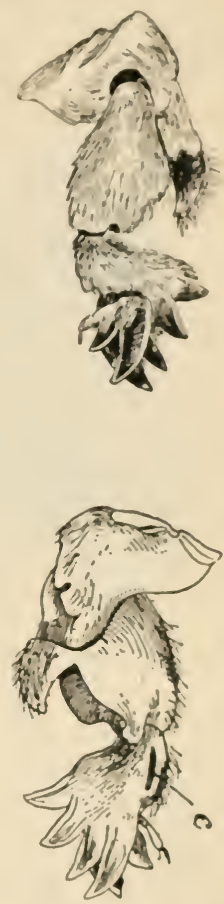

Fig. 207.-Front leg of the mole cricket. showing at e opening of auditory organ. (After Sharp.) They may have luminous spots, differentiated areas, round or oblong, which shine starlike in the dark. These are usually symmetrically placed on the sides of the body. They may have also luminous glands or diffuse areas which are luminous. but which do not show the specialized structure of the phosphorescent spots. These glands of similar nature to the spots are mostly on the hesed or tail. In one gremus, Ethoprora, the luminous snout is compared to the headlight of an engine. 
Entirely different are the p':otoriores in the midshipman or singing fish (Porichthys), a genus of the toad fishes or Batrachoididæ. These species live near the shore and the luminous spots are outgrowths from pores of the lateral line.

In one of the anglers (Corynolophus reinhardti) the complex bait is said to be luminous, and luminous areas occur

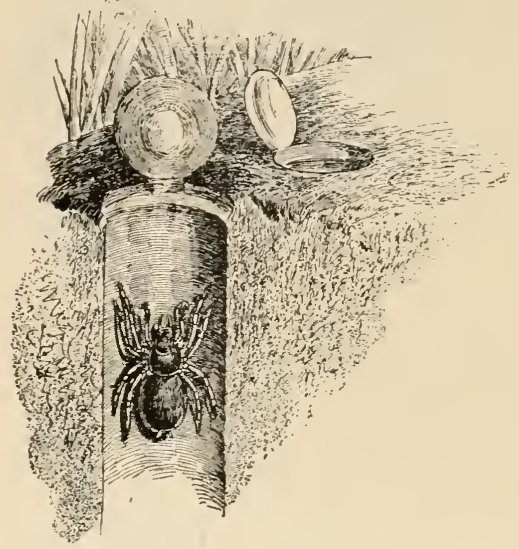

Fig. 208.-Nest of the trapdoor spider. on the belly of a very small shark of the deep seas of Japan (Etmopterus lucifer). Dr.Peter Schmidt of St. Petersburg has a drawing of this shark made at night from its own light.

While among the higher or vertebrate animals, especially the fishes and reptiles, most remarkable cases of adaptations occur, yet the structural changes are for the most part external, usually not affecting fundamentally the development of the internal organs other than the skeleton. The organization of these higher animals is much less plastic than that of the invertebrates. In general, the higher the type the more persistent and unchangeable are those structures not immediately exposed to the influence of the struggle for existence. It is thus the outside of an animal that tells where its ancestors have lived. The inside, suffering little change whatever the surroundings, tells the real nature of the animal 


\section{CHAPTER XVII}

\section{PARASITISM AND DEGENERATION}

Les rauses de l'évolution regressive peuvent se ramenor ì une seule, la limitation des moyens de subsistance, de lii, la lutte pour l'existence entre les organismes ou les socictés. "t entre leu"s parties composantes.-Denoor, Massart, and VANnervelde.

A sPECIAL kind of adaptation is that shown by parasitic animals. The relations of parasitic animals to their hosts appear in many familiar examples, and the results of this parasitic life, or at least the conditions that seem alwats to attend it, namely the degeneration, slight or extreme, of the paratsites, is also familiar to all observers of animal life. The term parasitism, as well as the term degeneration, cannot be very rigidly defined. To prey upon the bodies of other amimals is the common habit of many creatures. If the animals which live in this way are free, chasing or lying in wait for or snaring their prey, we speak of them in general as preclatory animals. But if they attach themselves to the body of their prey or burrow into it, and are carried about by it, live on or in it, then we call them parasites. Ayd the difference in habit between a lion and an intestinal worm is large enough and marked enough to make very elear to us what is meant when we speak of one as predatory and the other as a parasite. But how shall we class the lamprey, that swims about until it finds a fish to which it elings, while sucking away its blood? It lives mostly free, hunting its prey, rlinging to it for a while. and is carried about by it. Closely related to the lampress are the hag fishes (Myxine) marine eellike fishes that attach themsches by a surkerlike mouth to living fishes and gradually scrape and eat their way into the ahdominal cavity of the host. These "hags" or "horers" approach more nearly to the con- 
dition of an internal parasite than any other vertebrate. And what about the flea? In its immature life it lives as a white grub or larva in the dust of cracks and crevices, of floors and cellars and heaps of débris; here it pupates, and finally changes into the active leaping blood-sucking adult which finds its way to the body of some mammal and clings there sucking blood. But it can jump off and hunt other prey; it leaves the host body entirely to lay its eggs, and yet it feeds as a parasite, at least it conforms to the definition of parasite in the essential fact of
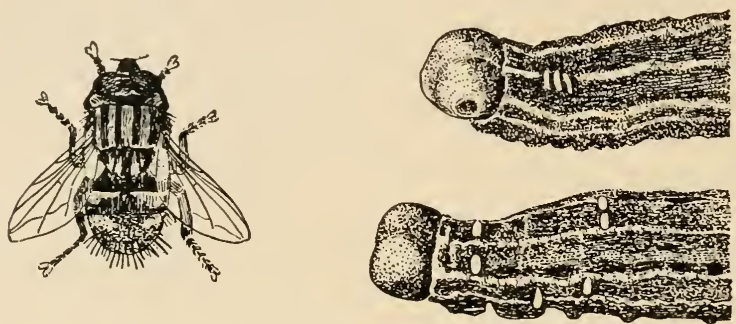

FIG. 209.-At the left, the red-tailed trichina fly, Winthemia, 4-pastulata, the parasite of the army worm, Leucania unipuncta; at the right, the worms upon which the fly has laid eggs. (After Slingerland.)

being carried about on or in the host body, while feeding at the host's expense.

It is of course not particularly important that we distinguish sharply between parasitic and predaceous animals, but as we look on the degeneration of parasitic animals as the result of their special habit of life, we must attempt a sort of classification of the phases or degrees of parasitism, in order to associate with them corresponding categories of degeneration.

The bird lice (Mallophaga), which infest the bodies of all kinds of birds and are found especially abundant on domestic fowls, live upon the outside of the bodies of their hosts, feeding upon the feathers and dermal scales. They are examples of $e x-$ ternal parasites. Other examples are fleas and ticks, and the crustaceans called fish lice and whale lice, which are attached to marine animals. On the other hand, almost all animals are infested by certain parasitic worms which live in the alimentary canal, like the tapeworm, or imbedded in the muscles, like the trichina. These are examples of internal parasites. Such parasites belong mostly to the class of worms, and some 
of them are very injurious, sucking the blond from the tissues of the host, while others feed solely on the partly digested food. There are also parasites that live partly within and partly on the outsicle of the hody, like the Sacculina, which lives on various kinds of crabs. The body of the Sacculina consists of a soft sac which lies on the outside of the crab's body, and of a number of long, slender rootlike processes which penetrate deeply into the crab's body, and take up nourishment from within. The Sacculina is itself a crustacean or crablike creature. The classification of parasites as external and internal is purely arbitrary, but it is often a matter of convenience.

Some parasites live for their whole lifetime on or in the body of the host, as is the case with the bird lice. Their egers are laid on the feathers of the bird host; the young when hat ched remain on the bird during growth and development, and the adults only rarely leave the body, usually never. These may be called permanent parasites. On the other hand, fleas leap off or on a dog apparently as caprice dictates; or, as in other cases, the parasite may pass some definite part of its life as a free nomparasitic organism, attaching itself, after development, to some animal, and remaining there for the rest of its life. These parasites may be called temporary parasites. IBut this grouping or classification, like that of the external and internal parasites, is simply a matter of convenience, and does not indicate at all any blood relationship among the members of any one group.

Some parasites are so specialized in habit and structure that they are wholly unable to go through their life history, or to maintain themselves, except in a single fixed way. They are dependent wholly on one particular kind of host, or on a particular series of hosts, part of their life being passed in one and another part in one or more other so-called intermediate hosts. These parasitic species are called obligate parasites, while. others with less definite, more flexible requirements in regard to their mode of development and life are called facultutive parasites. These latter may indeed be able to go through life as free-living, nomparasitic animals, although, with opportunity, they live parasitically.

In nearly all cases the body of a parasite is simpler in structure than the body of other animals which are closely 
related to the parasite-that is, animals that live parasitically have simpler bodies than animals that live free active lives, competing for food with the other animals about them. This simplicity is not primitive, but results from the loss or atrophy of the structures which the mode of life renders useless. Many - parasites are attached firmly to their host, and do not move about. They have no need of the power of locomotion. They are carried by their host. Such parasites are usually without wings, legs, or other locomotory organs. Because they have given up locomotion they have no need of organs of orientation, those special sense organs like eyes and ears and feelers which serve to guide and direct the moving animal; and most nonlocomotory parasites will be found to have no eyes, nor any of the organs of special sense which are accessory to locomotion and which serve for the detection of food or of enemies. Because these important organs, which depend for their successful activity on a highly organized nervous system, are lacking, the nervous system of parasites is usually very simple and undeveloped. Again, because the parasite usually has for its sustenance the already digested highly nutritious food elaborated by its host, most parasites have a very simple alimentary canal, or even no alimentary canal at all. Finally, as the fixed parasite leads a wholly sedentary and inactive life, the breaking down and rebuilding of tissue in its body go on very slowly and in minimum degree, and there is no need of highly developed respiratory and circulatory organs, so that most fixed parasites have these systems of organs in simple condition. Altogether the body of a fixed, permanent parasite is so simplified and so wanting in all those special structures which characterize the higher, active, complex animals, that it often presents a very different appearance from those animals with which we know it to be nearly related.

The simplicity of parasites does not indicate that they belong to the groups of primitive simple animals. Parasitism is found in the whole range of animal life, from primitive to highest, although the vertebrate animals include very few parasites and these of little specialization of habit. But their simplicity is something that has resulted from their mode of life. It is the result of a change in the body structure which we can often trace in the development of the individual parasite. Many parasites in their young stages are free, active 
animals with a better or more complex body than they possess in their fully developed or adult stage. The simplicity of parasites is the result of degeneration - a degeneration that has been brought about by their adoption of a sedentary, noncompetitive parasitic life. And this simplicity of degeneration, and the simplicity of primitiveness should be sharply distinguished. Animals that are primitively simple have had only simple ancestors; animals that are simple by degeneration often have had highly organized, complex ancestors. And while in the life history or development of a primitively simple animal all the young stages are simpler than the adult, in a degenerate animal the young stages may be, and usually are, more complex and more highly organized than the adult stage.

In the few examples of parasitism (selected from various animal groups) that are described in the following pages all these general statements are illustrated.

In the intestines of crayfishes, centipedes, and several kinds of insects may often be found certain one-celled animals (Protozoa) which are living as parasites. Their food, which they take into their minute body by absorption, is the intes-

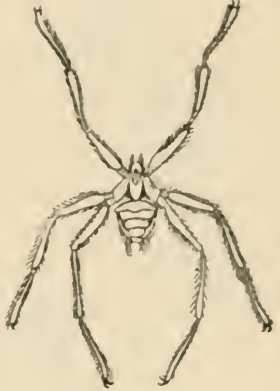

FIG. 210. - The wingless bat-tick, Nycteribia. (After Sharl); much enlarged.) tinal fluid in which they lie. These parasitic Protozoa belong to the genus Gregarina. Because the body of any protozoan is as simple as an animal's body can well be, being composed of but a single cell, degeneration cannot oceur in the cases of these parasites. There are, besides Gregarina, many other parasitic one-celled animals, several kinds living inside the cells of their host's body. Several kinds of these have been proved to be the causal agents of serious human diseases. Conspicuous among these are the minute parasitic Sporozoa which are the actual cause of the malarial and similar fevers that rack the human body in nearly all parts of the world.

In the class of Sporozoa (of the great branch Protozoa or one-celled animals) is an order called Hemosporidia (or Hemocytozoa) comprising numerous kinds of unicellular parasites which live in the blood of vertebrates (with certain inverte- 
brates as intermediatc or alterncte losts). Certain kinds are found in the cold blood of fishes, amphibians, reptiles, and certain others in the warm blood of birds and mammals. The genera Haltcridium and Plasmodium contain certain species that live cxclusively in the blood of birds or mammals for part of their life and in the bodies of certain arthropods for the other part of their life. They produce a series of asexual generations (reproduction by simple division or sporulation) in their vertebrate hosts, and a sexual generation (reproduction

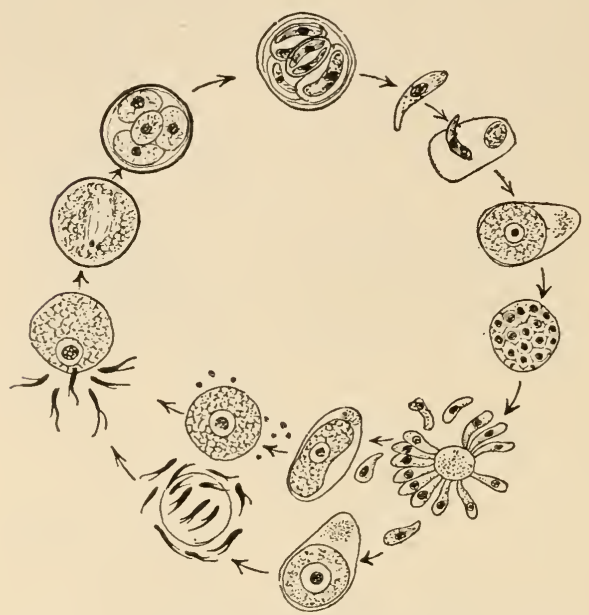

FIg. 211.-The life cycle of Coccidium lithobii, Protozoan parasite of the centipede, Lithobius. (After Schaudinn.)

by the development of a zygote formed by the fusion of two cells, called gametes) in the arthropod host. This arthropod host for all the species so far known of these genera is exclusively the mosquito. Three species of the genus Plasmodium, namely, $P$. vivax, $P$. malario, and $P$. falciparum, are the specific causal agents of the distinct malarial fevers known as tertian, quartan, and tropical fever respectively. (In the literature of "mosquitoes and malaria," the name "Homamoba" will be found to be used synonymously with Plasmodium.)

Laveran, a French surgeon in Algiers, discovered the Plasmodium parasite in the red blood corpuscles of malarial fever patients in 1880, and determined that the disease was actually and solely due to the destructive and toxic effects of the growth and multiplication of the parasite in the blood. Every fortyeight hours in tertian fever (seventy-two hours in quartan) there is completed a whole (asexual) cycle in the life of one of these parasites, including its birth by the division of the body of the mother into several small merozoites, the penetration of 
a red blood corpusele by each of these merozoites, the growth of the parasite in the blood corpuscle at the expense of the corpuscle, the maturing and sporulation (or division into new merozoites) of the parasite, and the final breakdown of the corpuscle and release into the blood plasma of the tiny artive merozoite. Numerous generations of this type are produced in the blood of a patient, but finally a sort of senescence or degeneration of the parasite sets in, and unless there is a fresh infection of the patient from outside, the parasitic host diminishes and finally nearly disappears. If the effects of the parasite have not been too severe during the height of its invasion the patient now recovers.

For the continued multiplication and persistence of the parasitic species a new process or set of conditions is necessary. If a drop of blood drawn from a malarial paticnt is examined under the microscope the parasitic individuals abundantly in evidence in this blood will be seen to manifest a curious behavior within a few minutes. Some of them will move and squirm about with great activity, and extend and retract pseudopodiumlike processes, until finally with grest rapidity a few (usually four to six) delicate threadlike flagella or flagellalike processes will shoot out from the body mass and break away from it. These motile flagella are really gimnctes or sexual cells of one type (the male) while other large ncarly immobile sub-spherical parasite individuals which do not behave as these do are gametes or sexual cells of the other (or female) type. The flagella find and penetrate or fuse with the larger gametes and form a zygote or resting egrg cell.

While the processes just described have been taking place in the blood droplet under our microscope, as a matter of fact this normally takes place in the stomach of a mosquito. For when a mosquito (at least of a certain kind) sucks blood from a malarial patient the blood parasites are of course taken in also and deposited in the stomach where digestion of the blood begins. Now when the zygotes are formed in the mosquito's stomach they do not remain lying in the stomach eavity but move to the wall of the stomach and partially penetrate it. As many as five hundred zygotes have becn found in the stomach walls of a single mosquito. The zygote now increases rapidly in size, becoming a perceptibie nodule on the outer side of the stomach wall, but soon its nucleus and protn- 
plasm begin to break up by repeated division (the parts all being held together, however, in the wall of the zygote), and by the end of the twelfth or fourteenth day the zygote's protoplasm may have become divided into ten thousand minute sporozoites. The zygote wall now breaks down, thus releasing the thousands of active little sporozoites into the general body cavity of the mosquito. This cavity is filled with flowing blood plasm-insects do not have a closed but an almost completely open circulatory system-and swimming about in this plasm the sporozoites soon make their way forward and into the salivary glands of the mosquito. Now when the insect pierces a human being to suck blood, it injects a certain amount of salivary fluid into the wound (presumably to keep the blood from clotting at the puncture) and with this fluid go many of the sporozoites. Thus a new infection of malaria is made. The sporozoites may lie in the salivary glands for several weeks, and so for the whole time from twelve to fourteen days after the mosquito has become infected with the malarial parasite by sucking blood from a malarial patient until the sporozoites in the salivary glands finally die, it is a means of the dissemination of the disease. There can be no malaria without mosquitoes to propagate and disseminate it, and yet no mosquitoes can propagate and disseminate malaria without having access to malarial patients. The only mosquito species in this country which has been proved to be a malaria disseminator is Anopheles maculipennis, a spotted-winged form spread over the whole continent.

In the great branch or phylum of flatworms (Platyhelminthes), that group of animals which of all the principal animal groups is widest in its distribution, perhaps a majority of the species are parasites. Instead of being the exception, the parasitic life is the rule among these worms. Of the three classes into which the flatworms are divided, almost all of the members of two of the classes are parasites. The common tapeworm (Tcenia) (Fig. 212), which lives parasitically in the intestine of man, is a good example of one of these classes. It has the form of a narrow ribbon, which may attain the length of several yards, attached at one end to the wall of the intestine, the remainder hanging freely in the interior. Its body is composed of segments or serially arranged parts, of which there are about eight hundred and fifty altogether. It 
has no mouth nor alimentary canal. It feeds simply by absorbing into its body, through the surface, the nutritious, already digested liquid food in the intestine. There are no eyes nor other special sense organs, nor any organs of locomotion. The body is very degencrate. The life history of the tapeworm is interesting, because of the necessity of two hosts for its completion. The eggis of the tapewoim prass from the intestine with the excreta, and must be taken into the body of some other animal in order to develop. In the case of one of the several species of tapeworms that infest man, this other host must be the pig. In the alimentary canal of the pig the young tapeworm develops and later bores its way through the walls of the canal and becomes imbedded in the muscles. There it lies, until it finds its way into the alimentary canal of man by his eating the flesh of the pig. In the intestine of man the tapeworm continues to develop until it becomes full grown.

In a lake in Yellowstone Park the suckers are infested by one of the flatworms (Ligula) that attains a size of nearly one fourth the size of the fish in whose intestines it lives. If the tapeworm of man attained such a compara-

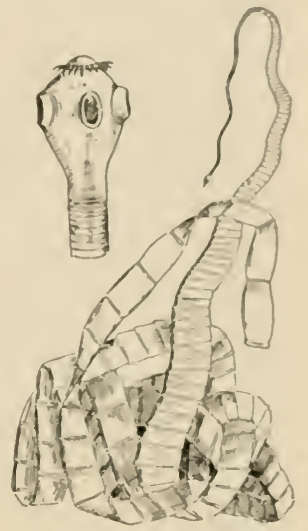

FIG. 212. Tapeworm, Tania solium. In the upper left-hand corner is the nuch enlarged heal. (After I.euckart.) tive size, a man of two hundred pounds' weight would be infested by a parasite of fifty pounds' weiglit.

Another group of animals, many of whose members are parasites, are the roundworms or threadwoms (Nemathelminthes). The free-living roundworms are active, wellorganized animals, but the parasitic kinds all show a greater or less degree of degeneration. One of the most terrible parasites of man is a roundworm (alled Trichinu spiralis (l"ig. 213). It is a minute worm, from one to three millimeters long, which in its adult condition lives in the intestine of man or of the pig or other mammals. The young are born alive and bore through the walls of the intestine. They migrate to the voluntary muscles of the hosts, especially those of the limbs and back, 
and here each worm coils itself up in a muscle fiber and becomes inclosed in a spindle-shaped cyst or cell (Fig. 213). A single muscle may be infested by hundreds of thousands of these minute worms. It has been estimated that fully one hundred million encysted worms may exist in the muscles of a "trichinized" human body. The muscles undergo more or less degeneration, and the death of the host may occur. 'It is necessary,

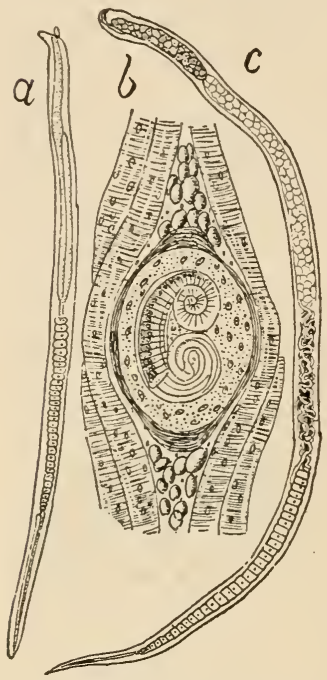

FIG. 213.-Trichina spiralis, the terrible parasite of pork: $a$, Male; $b$, cyst; $c$, female. for the further development of the worms, that the flesh of the host be eaten by another mammal, as the flesh of the pig by man, or the flesh of man by a pig or rat. The Trichince in the alimentary canal of the new host develop into active adult worms and produce new young.

In the Yellowstone Lake the trout are infested by the larvæ or young of a roundworm (Bothriocephalus cordiceps) which reach a length of twenty inches, and which are often found stitched, as it were, through the viscera and the muscles of the fish. The infested trout become feeble and die, or are eaten by the pelicans which fish in this lake. In the alimentary canal of the pelican the worms become adult, and parts of the worms containing eggs escape from the alimentary canal with the excreta. These portions of worms are eaten by the trout, and the eggs give birth to new worms which develop in the bodies of the fish with disastrous effects. It is estimated that for each pelicen in Yellowstone Lake over five million eggs of the parasitic worms are discharged into the lake.

The young of various carnivorous animals are often infested by one of the species of roundworms called "pup worms" (Uncinaria). Recent investigations show that thousands of the young or pup fur seals are destroyed each year by these parasites. The eggs of the worm lie through the winter in the sands of the breeding grounds of the fur seal. The young receive them from the fur of the mother and the worm de- 
velops in the upper intestine. It feerls on the blood of the young seal, which finally dies from anxmiat. On the sand beaches of the seal islands in loring fira there are every year

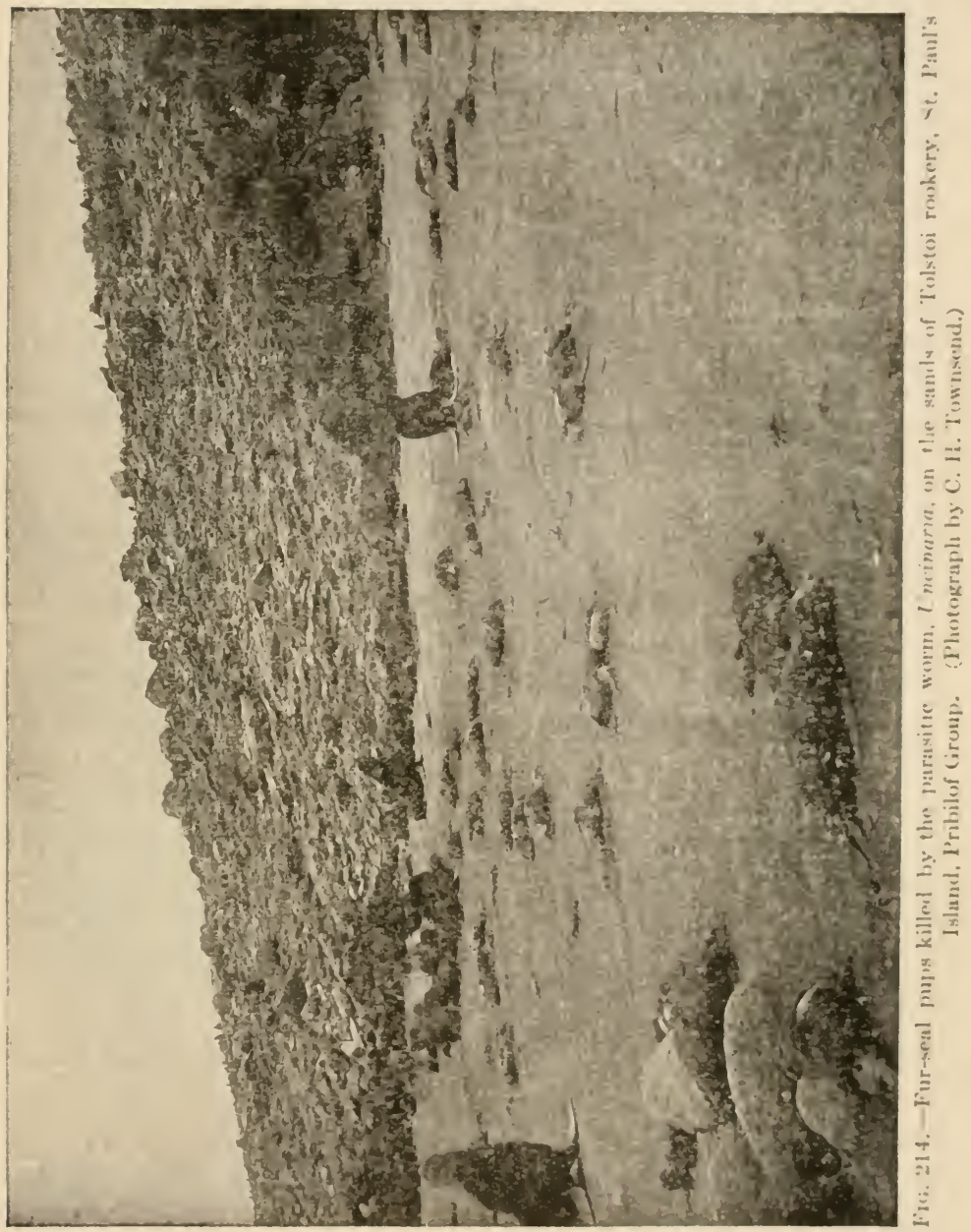

thousands of dead seal puys which lave bren killed by this parasite (Fig. 214). On the rocky ronkeries, the young seals are not affected by this parasite. 
Among the more highly organized animals the results of a parasitic life, in degree of structural degeneration, can be more ieadily seen. A well-known parasite, belonging to the Crustacea - the class of shrimps, crabs, lobsters, and crayfishes-is Sacculina. The young Sacculina (Fig. 215, A) is an active, freeswimming larva much like a young prawn or young crab. But the adult bears absolutely no resemblance to such a typical crustacean as a crayfish or crab. The Sacculina after a short

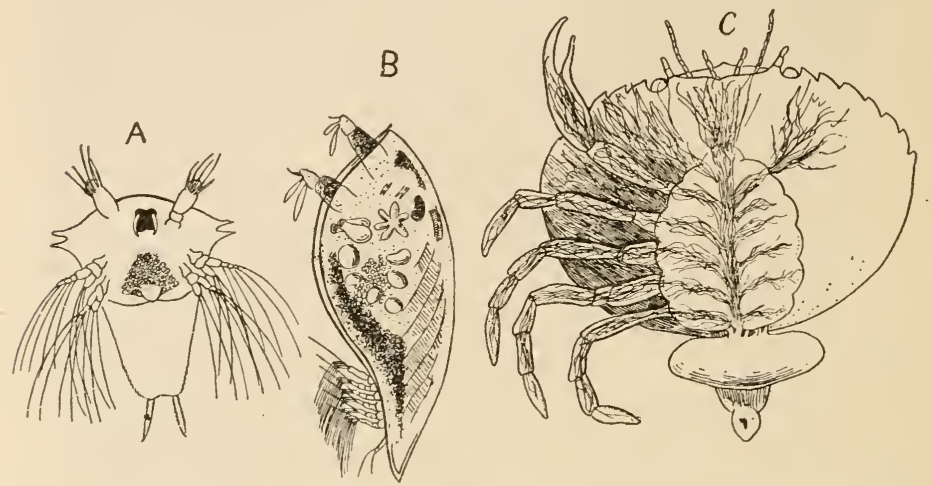

S'IG. 215.-Development of the parasitic crustacean, Sacculina carcinus: $A$, Naplius stage; $B$, cypris stage; $C$, adult attached to its host, the crab, Carcinus manas. (After Hertwig.)

period of independent existence penetrates to the abdomen of a crab, and completes its development while living as a parasite on the crab. In its adult condition (Fig. $215, \mathrm{C}$ ) it is simply a great tumorlike sac, bearing many delicate rootlike suckers which penetrate the body of the crab host and absorb nutriment. The Sacculina has no eyes, no mouth parts, no legs, or other appendages, and hardly any of the usual organs except re. productive organs. Degeneration here is carried very far.

Other parasitic crustacea, as the numerous kinds of fish lice (Fig. 216) which live attached to the gills or to other parts of fish, and derive all their nutriment from the body of the fish, show various degrees of degeneration. With some of these fish lice the female, which looks like a puffed-out worm, is attached to the fish or other aquatic animal, while the male, which is perhaps only a tenth of the size of the female, is permanently attached to the female, living parasitically on her. 
Among the insects there are many kinds that live parasitically for part of their life, and not a few that live as parasites for their whole life. The true sucking lice and the hird lice live for their whole lives as external parasites on the bodies of their host. but they are not fixed-that is, they retain their legs and power of locomotion, although they have lost their wings through degeneration. 'The egrgs of the lice are deposited on the hair of the inammal or bird that serves as host; the young hateh and immediately begin to live as parasites, either sucking the blood or feeding on the hair or feathers of the host. In the order Hymenoptera there are several families, all of whose mem-

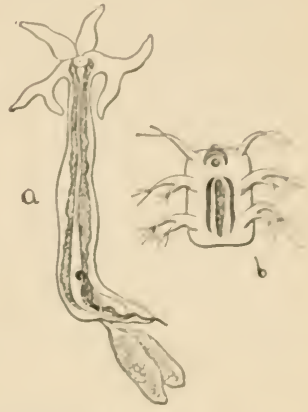

Fig. 216.-The fish louse. Lernacera: $a$. Idult; $b$, larva. bers live during their larval stage as parasites. We may call all these hymenopterous parasites ichneumon flies. The ichneumon flies are parasites of other insects, especially of the

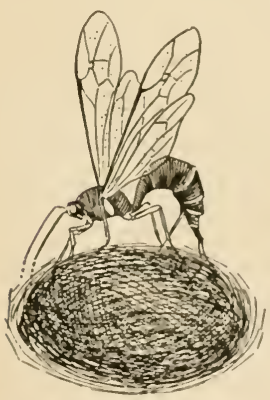

FIG. 217.-The ichneumon fly, Pimpla ccnquisitor, laying eggs in the eocoon of the American tent caterpillar moth. (After Fiske; about natural size.) larvie of beetles and moths and butterflies. In fact, the ichneumon flies do more to keep in check the increase of injurious and destructive caterpillars than do all our artificial remedies for these insect pests. The adult ichnemmon fly is four-winged and lives an active, independent life. It lays its egres either in or on or near some caterpillar or beetle grub. and the young ichnemmon, when hatched. burrows into the body of its host, fereding on its tissues, but not attacking such organs as the heart or nervous granglia, whose injury might mean immediate desth to the host. The eaterpillar lives with the ichneumon grub within it. ustally unt nearly time for its pupation. In many institnces, indeed, it pupates with the parasite still feeding within its body, hut it never comes to maturity. The larval ichneumon fly pupates either within the body of its host (Fig. 218) or in a tiny silken cocoon outside 
of its body. From the cocoons the adult winged ichneumon flies emerge, and after mating find another host on whose body to lay their eggs.

One of the most remarkable ichneumon flies is Thalessa (Fig. 219), which has a very long, slender, flexible ovipositor, or egg-laying organ. An insect known as the pigeon horntail (Tremex columba) (Fig. 220) deposits its eggs, by means of a strong, piercing ovipositor, half an inch deep in the trunk wood of growing trees. The young or larval Tremex is a soft-bodied white grub, which bores deeply into the trunk of the tree, filling up the burrow behind it with small chips. The Thalessa is a parasite of the Tremex, and "when a female Thalessa finds a tree infested by Tremex, she selects a place

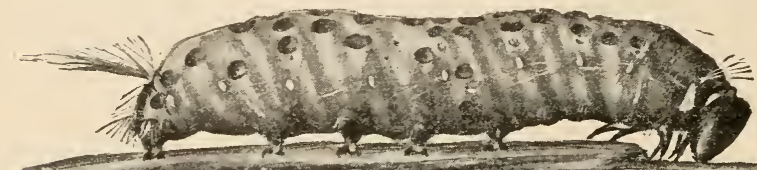

FIG. 218.-Parasitized caterpillar from which the ichneumon fly parasites have issued, showing circular holes of escape in skin.

which she judges is opposite a Tremex burrow, and, elevating her long oripositor in a loop over her back, with its tip on the bark of the tree (Fig. 221), she makes a derrick out of her body and proceeds with great skill and precision to drill a hole into the tree. When the Tremex burrow is reached she deposits an egg in it. The larva that hatches from this egg creeps along this burrow until it reaches its victim, and then fastens itself to the horntail larva, which it destroys by sucking its blood. The larva of Thalessa, when full grown, changes to a plipa within the burrow of its host, and the adult gnaws a hole out through the bark if it does not find the hole already made by the Tremex."

The beetles of the family Stylopidæ present an interesting case of parasitism. The adult males are winged, but the adult females are wingless and grublike. The larval stylopid attaches itself to a wasp or a bee, and. bores into its abdomen. It pupates within the abdomen of the wasp or bee, and lies there with its head projecting slightly from a suture between two of the body rings of its host. 
Almost all of the mites and tirks, animils allierl to the spiders, live parasitically. Mfost of them live as cxtermal parasites, sucking the blood of their host, but some live underneath the skin like the it(rh mites (Fig. 222), which ('illsc', in man, the disease known as the itch.

Among the vertehrate animals there are not many examples of true parasitism. The hagfishes or borers (Myxine, etc.) have beon already mentioned. These are long and cylindrical, eellike creatures, very slimy and very low in structure. The mouth is without jaws, lout forms a sucking disk, by which the hagfish attaches itself to the body of some other fish. By means of the rasping teeth on its tongue, it makes a round hole through the skin, usually at the throat. It then derouis all the muscular substance of the fish, leaving the viscera untouched. When the fish finally dies it is a more hulk of skin, scales, houes, and viscera, nearly all the muscle being gone. Thrm the hagfish slips out and attacks another individual.

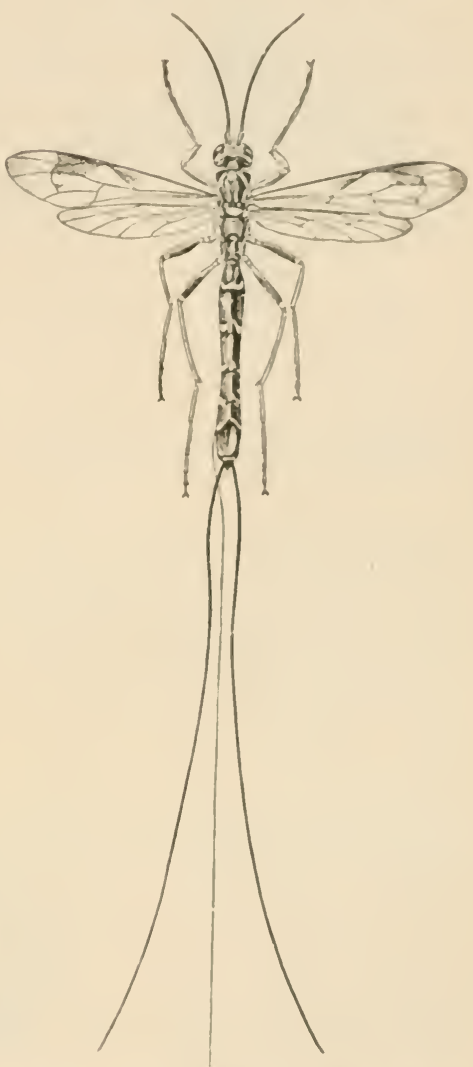

Fis. 219.-The large ichneumon fly, Thalessa, with houg ovunsitur.

The lamprey, another low

fish, in similar fashion ferels lerehlike on the hlood of other fishes, which it oltains hy latcerating the flesh with its rasplike teeth, remaining attitherl hy the roumd surking disk of its mouth.

Certain birds, as the cowbird and the European enclion, hove a parasitic habit, laving their egers in the nests of other 
birds, leaving their young to be hatched and reared by their unwilling hosts. This is, however, not bodily parasitism, such

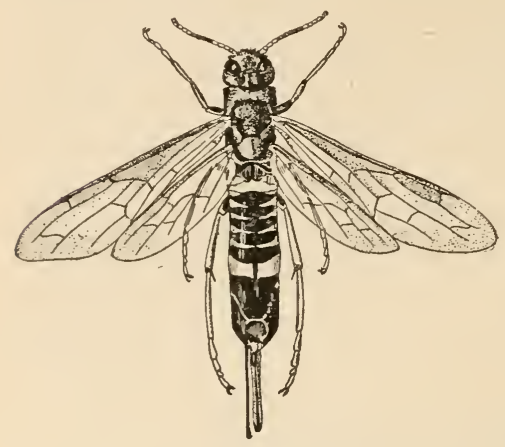

FIG. 220.-The pigeon horn-tail, Tremex columba, with strong bearing ovipositor. as is seen among lower forms.

We may also note that parasitism and consequent structural degeneration are not at all confined to animals. Many plants are parasites and show marked degenerative characteristics. The dodder is a familiar example, clinging to living green plants and thrusting its haustoria or rootlike suckers into their tissue to draw from them already elaborated nutritive sap. Many fungi like the rusts of cereals, the mildew of roses, etc., are parasitic. Numerous plants, too, are parasites, not on other plants, but on animals. Among these are the hosts of bacteria (simplest of the onecelled plants) that swarm in the tissues of all animals, some of which are causal agents of some of the worst of human and animal diseases (as typhoid fever, diphtheria, and cholera in man, anthrax in cattle). There are also many more

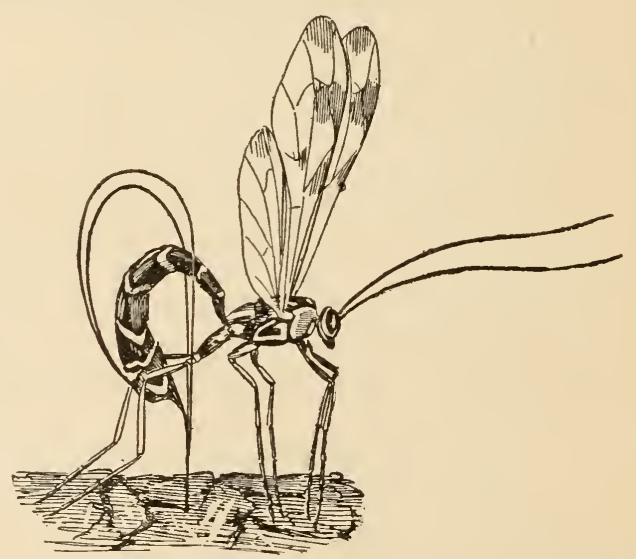

FIG. 221.-Thalessa lunator boring. (After Comstock.) highly organized

fungi like the whole family of Entomophthoræ, and the genus Sporotrichum that live in and on the bodies of insects, often killing them by myriads. One of the great checks to the ravages of the corn and wheat-infesting chinch bug (Blissus 
leucopterus) of the Mississippi Valley is a parasi tic fungus (Sporotrichum globuliferum). In the autumn, house flies may often be seen dead against a windowpane surrounded by a delicate ring or halo of white. This ring is composed of spores of the fungus, Empusa aphidis, which has grown through all the tissues of the fly while alive, finally resulting in its death. The spores are thrown off from tiny fruiting hyphe of the fungus which have grown out through the body wall of the insect. And they serve to inoculate other flies that may come near.

Just as in animals, so in plants; parasitic kinds, especially among the higher groups as the flowering plants, often show marked degeneration. Leaves

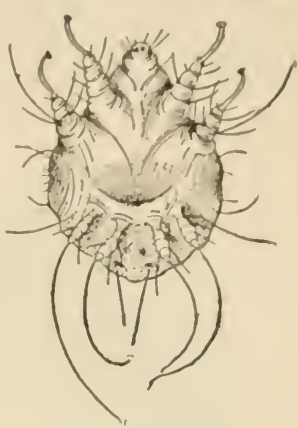

Fig. 222.-The itch mite, Sarcoptes scabci. may be reduced to mere seales, roots are lost, and the waterconducting tissues greatly reduced. This degeneration in plants naturally affeets primarily those parts which in the normal plant are devoted to the gathering and elaboration of inorganic food materials, namely, the leaves and stems and roots.

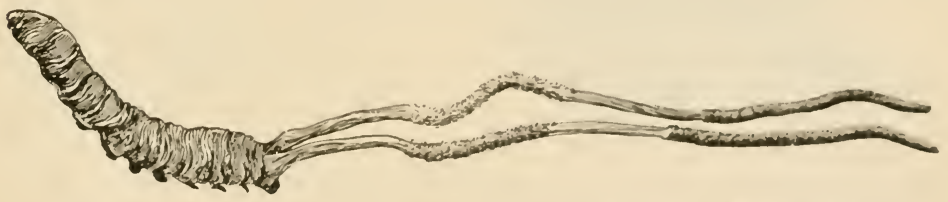

FIg. 223. - The fungus, Cordiceps, growing on a caterpillar. (Natural size.)

The flowers or reproductive organs usually retain, in parasites, all of their high development.

While parasitism is the principal cause of degeneration of animals, other causes may be also concerned. Fixed animals or animals leading inactive or sedentary lives, also become degenerate, even when no parasitism is concerned. The tunicata or soa squirts (Fir. 224) are animals whose simplicity of structure is due to degeneration from the acquisition of a sedentary habit of life.

The young or larval tunieate is a free-swimming active tadpolelike creature with organs much like those of the adult of 
the simplest fishes or fishlike forms. That is, the sea squirt begins life as a primitively simple vertebrate. It possesses in its larval stage a notochord, the delicate structure which precedes the formation of a backbone, extending along the upper part of the body, below the spinal cord. It is found in all young vertebrates, and is characteristic of the branch. The other organs of the

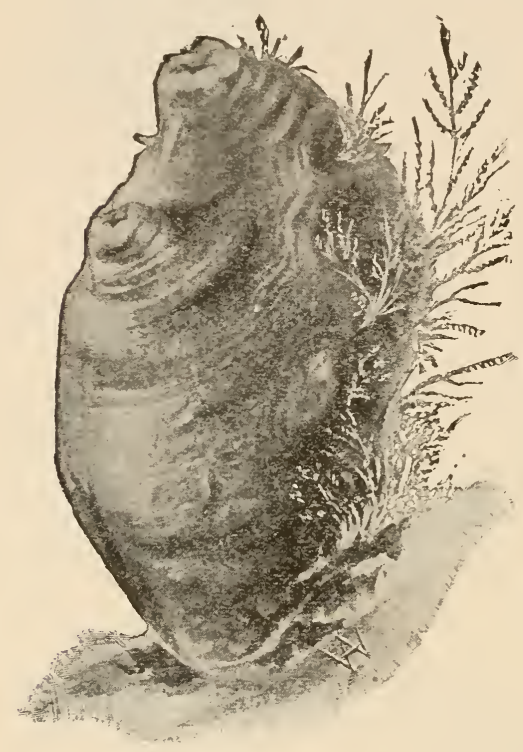

FIG. 224.-The sea squirt or tunicate. young tunicate are all of vertebral type. But the young sea squirt passes a period of active and free life as a little fish, after which it settles down and attaches itsclf to a stone or shell or wooden pier by means of suckers, and remains for the rest of its life fixed. Instead of going on ard developing into a fishlike creature, it loses its notochord, its special sense organs, and other organs; it loses its complexity and high organization and becomes, a "mere rooted bag" with a clouble neck," a thoroughly degenerate animal.

A barnacle is another example of degeneration through quiescence. The barnacles are crustaceans related most nearly to the crabs and shrimps. The young barnacle just from the egg (Fig. 225, f) is a six-legged, free-swimming nauplius, much like $\approx$ young shrimp, with single eye. In its next larval stage it has six pairs of swimming feet, and two large antenne or feelers, and still lives an independent, free-swimming life. When it makes its final change to the adult condition, it attaches itself to some stone or shell, or pile or ship's bottom, loses its feelers, develops a protecting shell, and gives up all power of locomotion. Its swimming feet become changed into grasping organs, and it 
luses most of its outward resemblances to the other members of its class (Fig. 225,e).

Certain insects live sedentary or fixed lives. All the members of the family of scale insects (Coeciclx), in one sex at least, show degeneration that has been caused by quiescence. One of these coceids, called the red orange scale, is very

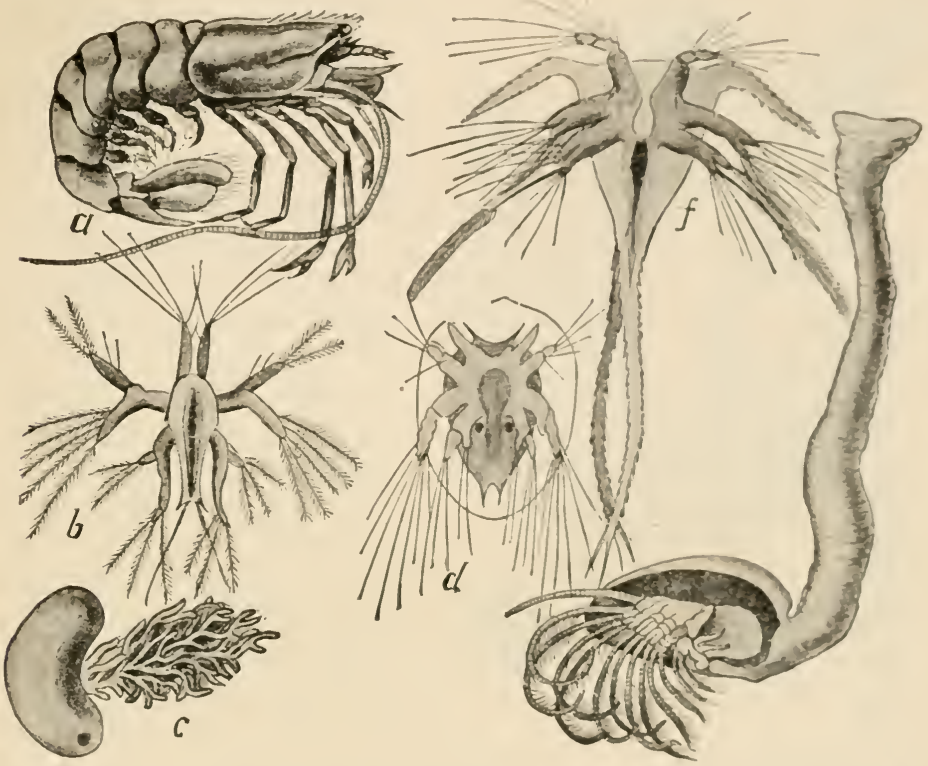

Fig. 225.- Three crustaceans and their larve: $a$, Prawn, Peneus; $b$, Peneus, larva; $c$, Sacculina, parasite ; $d$, larva Sacculina; $e$, barnacle, Lepas, quiescent; f, larva of barnacle. (After Haeckel.)

abundant in Florida and California and in other orange-growing regions. The male is a beautiful, tiny, two-winged midge, but the female is a wingless, footless little sale without eyes or other organs of special sense, and lies motionless under a flat, thin, eireular, redelish scale composed of wax and two or three cast skins of the insect itself. The insect has a long, slender, flexible, sucking beak, which is thrust into the leaf or stem or fruit of the orange on which the "scale hug " lives and through which the insect sucks the orange sap, which is its only" food. It lays eggrs or gives birth to young under its body, under 
the protecting wax scale, and dies. From the eggs hatch active little larval scale bugs with eyes and feelers and six legs. They crawl from under the wax scale and roam about over the orange tree. Finally, they settle down, thrust their sucking beak into the plant tissues, and east their skin. The females lose at this molt their legs and eyes and feelers. Each becomes a

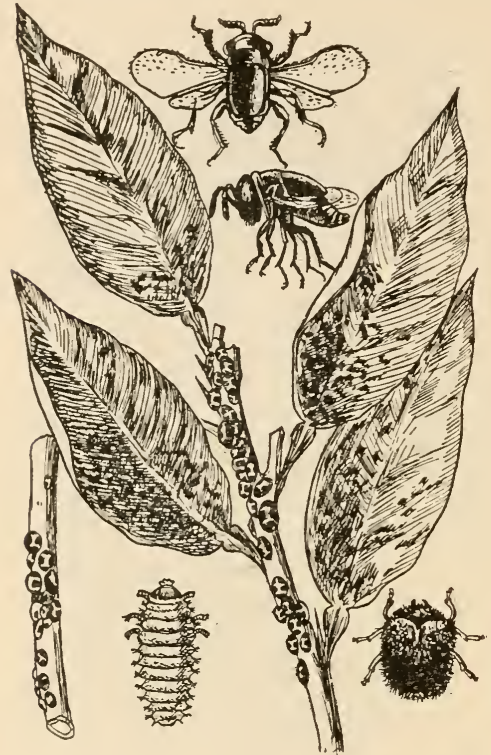

EIG. 226.-The black scale, Lecanium olex; and its parasite, the tiny chalcid fly, Scutellista cyanca; and the ladybird beetle, Rhizobius ventralis. (After Isaacs.) mere motionless sac capable only of sucking up sap and of laying eggs. The young males, however, lose their sucking beak and can no longer take food, but they gain a pair of wings and an additional pair of eyes. They fly about and fertilize the saclike females, which then molt again and secrete the thin wax scale over them.

Throughout the animal kingdom loss of the need of movement is followed by the loss of the power to move, and of all structures related to it.

Loss of certain organs may occur through other causes than parasitism and a fixed life. Many insects live but a short time in their adult stage. May flies live for but a few hours or, at most, a few days. They do not need to take food to sustain life for so short a time, and so their mouth parts have become rudimentary and functionless or are entirely lost. This is true of some moths and numerous other specially shortlived insects. Among the social insects the workers of the termites and of the true ants are wingless, although they are born of winged parents, and are descendants of winged ancestors. The modification of structure dependent upon the division of labor among the individuals of the community has taken the form, in the case of the workers, of a degeneration in the loss of 
the wings. Insects that live in caves are mostly blind: they have lost the eyes, whose function could not be exercised in the darkness of the cave. Certain island-inhabiting insects have lost their wings, flight being attended with too much danger. The strong sea breezes may at any time carry a flying insect off the small island to sea. Probably only those which do not fly much survive, and so by natural selection wingless breeds or species are produced. Finally, we may mention the great modifications of structure, often resulting in the loss of certain organs, which take place to produce protective resemblances (see Chapter XIX). In such cases the body may be modified in color and shape so as to resemble some part of the environment, and thus the animal may be unperceired by its enenies. Many insects have lost their wings through this cause.

When we say that a parasitic or quiescent mode of life learls to or causes degeneration, we have explained the stimulus or the ultimate reason for the degenerative changes, but we have not shown just how parasitism or quiescence act ually produces these changes. Degeneration or the atrophy and disappearance of organs or parts of a body is often said to be due to disuse. That is, the disuse of a part is believed by many nat uralists to be the sufficient cause for its gradual dwindling and final loss. That disuse can so affect parts of a body during the lifetime of an individual is true. A musele unused becomes soft and flabby and small. Whether the effects of such disuse can be inherited, however, is open to serious doubt. Such inheritance must be assumed if disuse is to account for the gradual growing less and final disappearance of an organ in the course of many generations. Some naturalists believe that the results of such disuse can be inherited, but as yet such belief rests on no certain knowledge. If characters acculuired during the lifetime of the individual are subject to inheritance, disise alone may explain degeneration. If not, some other immediate cause, or some other cause along with disilse, must be found.

We are accustomed, perhaps, to think of degeneration as necessarily implying a disadvantage in life. A degenerate animal is considered to be not the erpual of a nondegenerate animal, and this would be true if both kinds of animals hat (1) face the same conditions of life. The hlind, footless, simple, degenerate animal could not cope with the atcive, keen-sighted, highly organized nondegenerate in free competition. But free 
competition is exactly what the degenerate animal has nothing to do with. Certainly the Sacculina lives successfully; it is well adapted for its own peculiar kind of life. For the life of a scale insect, no better type of structure could be devised. A parasite enjoys certain obvious advantages in life, and even extreme degeneration is no drawback, but rather favors it in the advantageousness of its sheltered and easy life. As long as the host is successful in eluding its enemies and avoiding accident and injury, the parasite is safe. It needs to exercise no activity or vigilance of its own; its life is easy as long as its host lives. But the disadvantages of parasitism and degeneration are apparent also. The fate of the parasite is usually bound up with the fate of the host. When the enemy of the host crab prevails, the Sacculina goes down without a chance to struggle in its own defense. But far more important than the disadvantage in such particular or individual cases is the disadvantage of the fact that the parasite cannot adapt itself in any considerable degree to new conditions. It has become so specialized, so greatly modified and changed to adapt itself to the one set of conditions under which it now lives, it has gone so far in its giving up of organs and body parts, that if present conditions should change and new ones come to exist, the parasite could probably not adapt itself to them. The independent, active animal with all its organs and all jts functions intact, holds itself, one may say, ready and able.to adapt itself to any new conditions of life which may gradually come into existence. The parasite has risked everything for the sake of a sure and easy life under the presently existing conditions. Change of conditions means its extinction. 


\section{MUTUAL AID AND COMMUNAL LIFE AMONG ANIMALS}

More ancient than competition is combination. The little fectble fluttering folk of Cood, the spinning insects, the little mire in the meadow, the rat in the cellar, the crane in the marshes or the booming bittern, all these have learned that God's greatest word is together and not alone. He who is striving to make (iod's blessing and bounty possible to most is stepping into line with nature. The selfish man is the isolated man.-Oscar Carltox MicCulloch.

MAN is not the only social animal, nor the only animal species whose individuals live in mutually advantageous relations with each other, and in mutually advantageous relations with individuals of other animal kinds. Just as man lives communally and mutually helpfully with other men, so do the members of a great honeybee or ant community live together: and as we find various other animals as dogs, horses, and doves living under the care and protection of man and returning to him a measure of service in work, companionship, or other helpfulness for his care and feeding, so do we know of hundreds of kinds of other insects that live commensally with ants, each party to this commensal or symbiotic life gaining something from and giving something to the other party of this arrangement. Indeed, the communal life of such insects as the social bees, wasps, and ants is developed along true communisti lines far more specialized than the communism shown by man.

Just as students of human society can trace a scrics of steps from a very primitive living together or communal life among men to the present highly specialized condition, so among various animals we ean find a long series of gradatory conditions of social life from mere gregariousness like that of a band of wolves 
or a herd of bison, to the extremely specialized, interdependent and unified community of the honeybee, or agricultural ant. Before taking up this series of stages in true social or communal development among the lower animals, however, we may profitably give some attention to the conditions of animal association commonly known as commensalism or symbiosis in which individuals of one species are associated to their mutual advantage with individuals of different species.

In the relations of parasite and host, discussed in the last chapter, all the advantages of the association lie with the parasite. The other animal involved, the host, suffers inconvenience, injury, often untimely death. But in commensalism and symbiosis both associating kinds of animals reap advantage, or

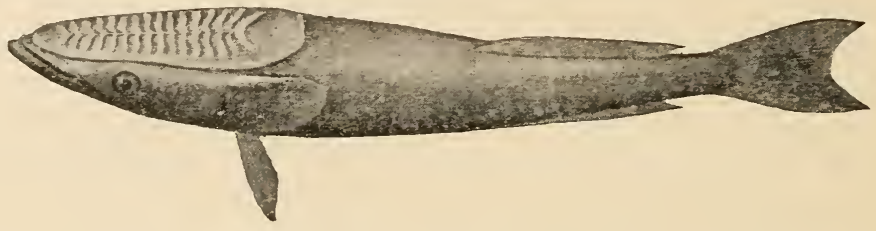

FIG. 227.-Remora Echeneis remora, with dorsal fin modified to be the sucking plate by which the fish attaches itself to a shark.

at least neither suffers in any serious way from the effects of the other's presence. The two kinds live together in harmony and usually to their actual mutual advantage. The term commensalism may be applied to denote a condition of loose and often not obviously equally mutual advantageous association, while symbiosis is used to refer to a more intimate and persistent association with maybe marked coöperation and mutual advantage. A few examples of each are given in the following pages. Of course, no marked line of demarcation can be really drawn between the two conditions, any more than we can establish a sharp distinction between the predatory and parasitic modes of life.

A curious example of commensalism is afforded by the different species of Remoras (Echenididæ) which attach themselves to sharks, barracudas, and other large fishes by means of a sucking disk on the top of the head (Fig. 227). This disk is made by a modification of the dorsal fin. The Remora thus attached to a shark may be carried about for weeks, leaving its host only to secure food. This is done by a sudden dash 
through the water. The Remora injures the shark in no way save, perhaps, by the slight check its presence gives to the shark's speed in swimming.

In the mouth of the menhaden (Brevoortia tyranmus) a small crustacean (Cymothe prugustutor) is almost alwalys present, always resting in the front of the lower jaw. This arrangement is of advantage to the crustacean, but is a matter of indifference to the fish. Iatrobe, who first described this fish, compares the crustacean to the pragustator or foretaster of the Roman tyrants-a slave used in prevention of poisoning.

Whales, similarly, often carry harnacles about with them. These barnacles are permanently attached to the skin of the whale just as they would be to a stone or woolen pile. Many small crustaceans, annelids, mollusks, and other invertebrates burrow into the substance of living sponges, not for the purpose of feeding on them, but for shelter. On the other hand, the little boring sponge (Cliona) burrows in the shells of oysters and other bivalves for protection. These are hardly true cases of even that lesser degree of mutually advantageous associaltion which we are calling commensalism. But some species of sponge "are never found growing except on the backs or legrs of certain erabs." In these cases the sponge, with its many plantlike branches, protects the crab by concealing it from its enemies, while the sponge is benefited by being carried about by the crab to new food supplies. Certain sponges and polyps are always found growing in close association, though what the mutual advantage of this association is has not yet heen found out.

Among the coral reefs in the South Seas there lives an enormous kind of sea anemone or polyp. Individuals of this great polyp measure two feet across the disk when fully expanded. In the interior, the stomach cavity, which communicates freely with the outside hy means of the large mouth opening at the free end of the polyp, there may often be found a small fish (Amphiprion percula). That this fish is purposcly in the gastral eavity of the polyp is proved hy the fact that when it is dishodged it invariably returns to its singular lodging place. The fish is brightly colored, being of a brilliant vermilion hue with three broad white eross hands. The diseoverer of this peculiar habit suggests that there are mutual benefits to fish and polyp from this habit. "The fish being conspicuous, 
is liable to attacks, which it escapes by a rapid retreat into the sea anemone; its enemies in hot pursuit blunder against the outspread tentacles of the anemone and are at once narcotized by the 'thread cells' shot out in innumerable showers from

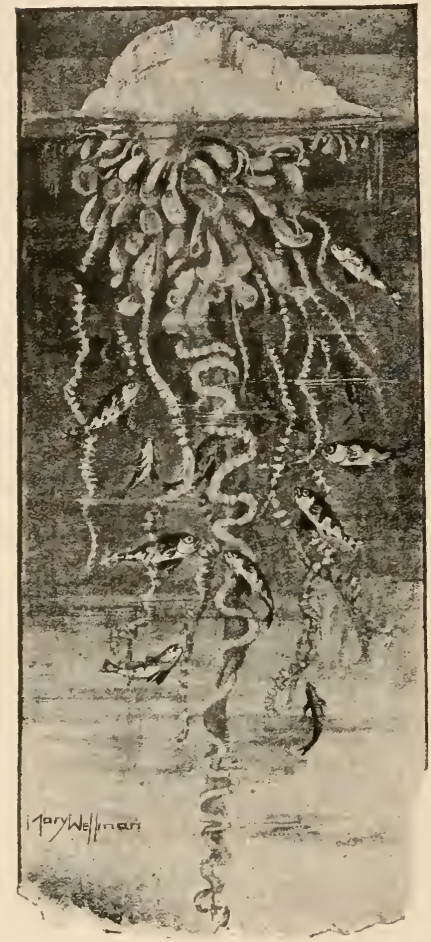

FIg. 228.- The Portuguese man-ofwar, Physalia, with men-of-war fishes, Nomeus gronovii, living in the shelter of the stinging feelers. (Specimens from off Tampa, Fla.) the tentacles, and afterwards drawn into the stomach of the anemone and digested."

Small fish of the genus Nomeus may often be found accompanying the beautiful Portuguese man-of-war (Physalia) as it sails slowly about on the ocean's surface (Fig. 228). These little fish lurk underneath the float and among the various hanging threadlike parts of the Physalia, which are provided with stinging cells. The fish are protected from their enemies by their proximity to these stinging threads. Similarly, several kinds of medusæ are known to harbor or to be accompanied by the young or small adult fishes (Caranx, Psenes).

In the nests of the various species of ants and termites many different kinds of other insects have been found. Some of these are harmful to their hosts, in that they feed on the food stores gathered by the industrious and provident ant, but others appear to feed only on refuse or useless substances in the nest. Some appear to be of help to their hosts by cleaning the nests and by secreting certain fluids much liked by the ants. Over one thousand species of these myrmecophilous (ant-loving) and termitophilous (termite-loving) insects have been recorded by collectors as living habitually in the nests of ants and termites. Many of them (they are mostly small 
beetles and flies) have lost their wings and have had their bodies otherwise considerably modified, usually in such wise that they come greatly, to resemble in external appearance the ants with which they live. The owls and rattlesnakes which live with the prairie dogs in their villages afford another familiar example of commensalism.

Of a more intimate character, and of more obvious and certain mutual advantage, is the well-known rase of the symbiotic association of some of the numerous species of hermit crabs and certain species of sea anemones. The hermit crab always takes for its habitation the shell of another animal, often that of the common whelk. All of the hind part of the crab lies inside the shell, while its head with its great claws project from the opening of the shell. On the surface of the shell near the opening there is often to

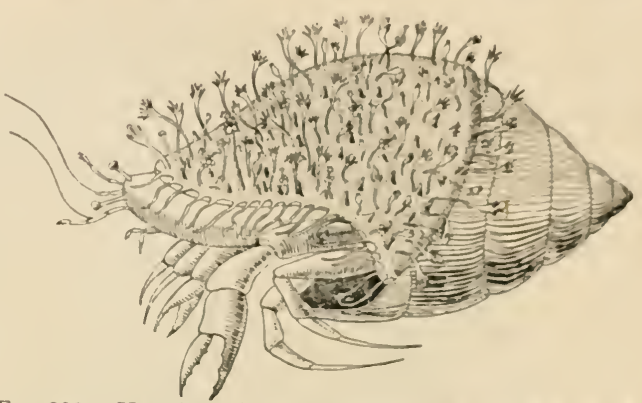

FIg. 229.-Hermit erab within a shell on which is growing a colony of hy.lroi tw, l'ulueoryme carnerz. This colony is composel of several diferent kinds of poly, inclividusals, the stinging ones being situated along the front margin of the shell. (After Weismann.)

be found a hydroid colony (as Fig. 229) or a sea anemone. The last is fastened to the shell with its mouth and tontacles near the crab's head. The sea anemone is carried from place to place by the hermit crab, and in this way is much aided in obtaining food. On the other hand, the crab is protected from its enemics hy the well-armed and dangerous tentacles of the sea anemone. In the tentacles there are many thousand long. slender stinging threads, and the fish or octopus that would olutain the hormit crab for food must first deal with the stinging ancmone. There is no doubt here of the mutual adrantage gatined hy these two widely different but intimately associated rompanions. If the sea ancmone be torn away from the shell inhabited by one of these crabs, the crab will wander about, carefully secking for another anemone. When it finds it, it 
struggles to loosen it from its rock or from whatever it may be growing on, and does not rest until it has torn it loose and placed it on its shell:

There are numerous small crabs called pea crabs (Pinnotheres) which live habitually insid the shells of living mussels. The mussels and the crabs telerate each other, perhaps to their mutual benefit.

The relations between ants and aphids (plant lice) are often referred to in popular natural histories and books about

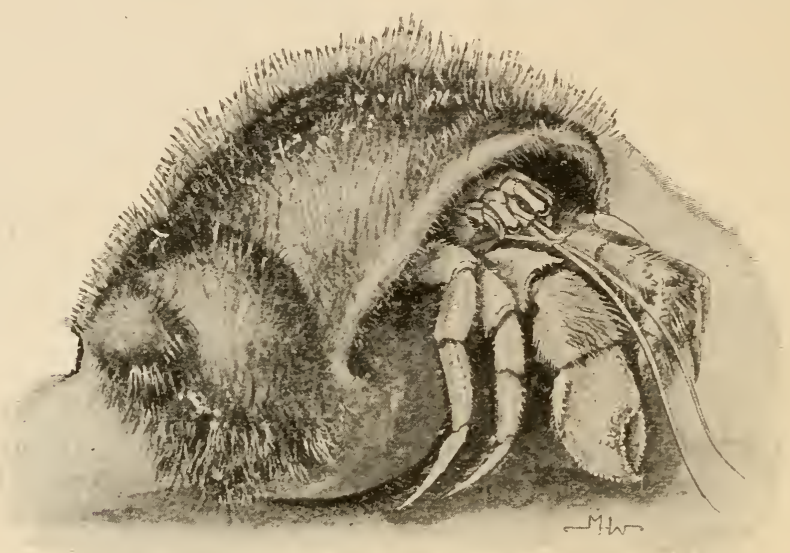

FIG. 230.-The hermit crab, Pagurus bernhardus, in snail shell covered with Hydractinia.

insects as examples of symbiosis of unusual interest. Unfortunately, however, not enough cáreful study has been given to many of these apparently true examples of symbiosis to enable us to be certain of the truth of the alleged care and guarding of the ant-cows, as Linnæus called these aphids, by their milkers, the ants. That ants do swarm about the aphids to lap up the "honey dew" excreted by them is wholly true, and the very presence of the sharp-jawed and pugnacious ants must keep away many enemies of the defenseless plant lice, toothsome morsels for the ladybird beetles, flower-fly larvæ and other predatory insects.

In the case of the interesting relations between the corn root aphid, Aphis maidisradici, of the Mississippi Valley States and the little brown ant, Lasius brunneus, however, we 
have the careful observations of Professor liorbes to rely on. In the Missiswippi Valley, this aphid deposits in autumn its eggs in the gromel in corn fields, often in the galleries of the little brown ant. The following spring before the corn is planted, these raggs hatch. Now, the little brown ant is res pecially fond of the honey dew secereted hy the corn root lice. So when the latter hatch in the spring. before there are corn roots for them to feed on, the ants rarefully place them on the roots of certain kinds of grass and knotweed (Setaria, Polygomum), and there protect them unt il the corn germinates. They are then removerl to the roots of the corn. It is probable that the ants even collect the egress of the aphids in the atumn and carry them into their nests for protection and care.

The studies of Wheeler and others have revealed some interesting eases of the living together of different species of ants. In some cases one of the ant spereics may be living almost wholly at the expense of the other spereses as does the little yellow thief-ant, Solenopisis moleste. Although this ant som(times lives in independent nests, more often it is to be fommel living in association with some latge ant species-it consorts with many different hosts-feeding almost exclusively on the live larve and pupe of the host. The thief-ant is so small and obseurely colored that it seems to live in the nests of its host practically unperceived. The solenopsis nest may be found by the side of the host nest, around it, or partly in it. the tiny Solenopsis galleries ramifying through the nest mass of the host, and often opening bolily into these large galleries. Through their narrower passages, too narrow to be traversed by the hosts, the tiny thief-ants thread their way through the host nest in their burglarious excursions (Fig. 24j).

But there are numerous eases of a less one-sided adrantage in the association of different species. As an example the conditions exhibited by the red-brown ant, Myrmica brevinodes and the smaller Leptothorax emersoni (conditions made known by Wheeler's carcful observations) may be hriefly deseribed (Fig. 246). The little Leptothorux ants live in the Myrmica nests, building one or more chambers with entrances from the Myrmica galleries, so narrow that the large . Myrmecas camnot get through them. When needing food the Leptothorax workers come into the Myrmicn galleries and chambers and, climbing on the backs of the Myrmica workers, proceed 
to lick the face and the back of the head of each host. A Myrmica thus treated, says Wheeler,

"paused, as if spellbound by this shampooing and occasionally folded its antennæ as if in sensuous enjoyment. The Leptothorax after licking the Myrmica's pate, moved its head round to the side and began to lick the cheeks, mandibles, and labium of the Myrmica. Such ardent osculation was not bestowed in vain, for a minute drop of liquidevidently some of the recently imbibed sugar-water-appeared on the Myrmica's lower lip and was promptly lapped up by the Leptothorax. The latter then dismounted, ran to another Myrmica, climbed on its back, and repeated the very same performance. Again it took toll and passed on to still another Myrmica. On looking about in the nest I observed that nearly all the Leptothorax workers were similarly employed."

Wheeler believes that the Leptothorax get food only in this way. They feed their queen and larvæ by regurgitation. The Myrmicas seem not to resent at all the presence of their Leptothorax guests, and indeed may derive some benefit from the constant cleansing licking of their bodies by the shampooers. But the Leptothorax workers are careful to keep their queen and young in a separate chamber, not accessible to their hosts. This is probably the part of wisdom, as the thoughtless habit of eating any conveniently accessible pupæ of another species is widespread among ants.

There are numerous interesting cases of symbiosis in which not different kinds of animals are concerned, but animals and plants. It has long been known that some sea anemones possess certain body cells which contain chlorophyll, that green substance characteristic of the green plants, and only in few cases possessed by animals. When these chlorophyll-bearing sea anemones were first found, it was believed that the chlorophyll cells really belonged to the animal's body, and that this condition broke down one of the chiefest and most readily apparent distinctions between animals and plants. But it is now known that these chlorophyll-bearing cells are microscopic, one-celled plants, green algæ, which live habitually in the bodies of the sea anemone. It is a case of true symbiosis. The algæ, or plants, use as food the carbon dioxide which is given off in the respiratory processes of the sea anemone, and 
the sea anemone breathes in the oxygen given off by the alga in the process of extracting the carbon for food from the carbon dioxide. These algan, or one-celled plants, lie regularly only in the innermost of the three coll layers which compose the wall or body of the sea anemone (lig. 231). They penetrate into and lie in the interior of the colls of this layer, whose special function is that of digestion. They give this innermost layer of cells a distinct green color. Fven rertain amcebalike protczoans have been found to contain individuals of a onccelled alga, Chlorella, in their single-celled bodies, the tiny animal and smaller plants living together truly symbiotically.

Among the higher plants and animals, cases of symbiosis are not rare. There lives in the live-oak trees in the vicinity of Stanford University a certain scale insect, Cerococcus ehrhorni, which differs from the other two or three species of

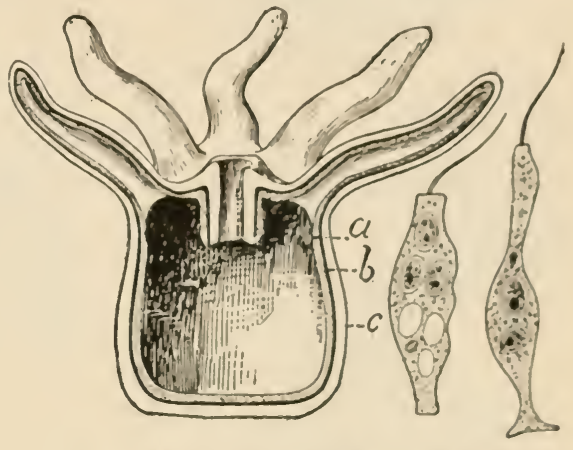

Fig. 231.-Diagrammatic section of sea anemene: $a$, The inner cell layer contains alga cells, the two isolated cells at the right being cells of this layer with contained alg:e; $b$, mildle boly wall layer; $c$, outer body wall layer. (After Hertwik.)

its genus in not having its body covered by a heavy, thick, protecting layer of secreted wax. But it grets the needed protection in another way. It is always corered by a thick feltlike fungus growth, which has been found by investigition to germinate its spores and to find a constant food supply in the "honey dew" excreted by the scale insects. This feltlike covering of fungus, never found to be latcking in the scale insect, serves apparently as a sufficient substitute for the heavy. Waxen mass common to the related species.

The ants show particularly well instances of interesting symbiotic life with plants. Fig. 232, drawn from a specimen sent to us from the Ihilippine Iskunds by the botanist Copeland, shows some details of one such instance. 'The Dischidias are milkweeds of the extreme Orient. 'They twine 
upon trees by means of their flexible siems and branches and are especially noted for possessing appendages in the form of pitchers. These pitcherlike appendages are modified leaves: "he normal Dischidia leaf is orbicular, thick, and fleshy. Each pitcher is the blade of a leaf folded so that the lower surface forms the inner surface of the pitcher. Into these pitchers

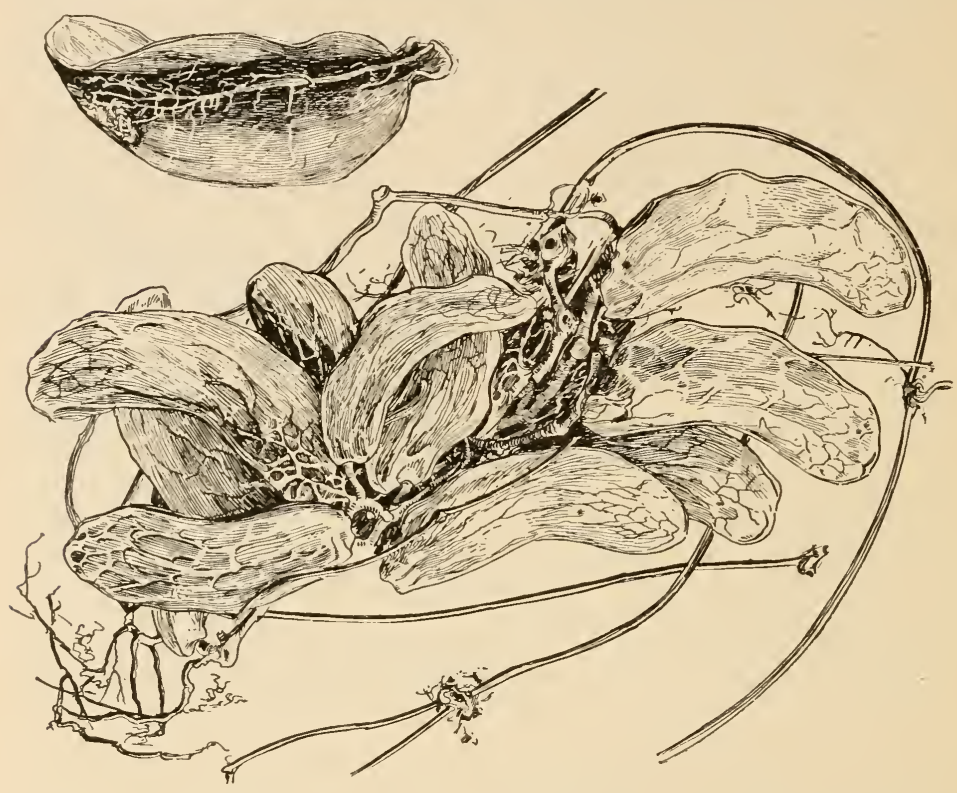

FIG. 232.-Leaves of Dischidia, which contain adventitious roots of the same plant and in which live colonies of small ants. (From specimens from Philippine Islands.)

grow adventitious roots that spring from the leaf peduncle. Also in these pitchers live colonies of ants. As rent for furnishing these comfortable cozy little ant homes, the Dischidia gets, by means of the adventitious roots in the pitcher, food from the excreta and cadavers of the ants. Hundreds of ants with larvæ and pupæ can be found in these Dischidia leaves, and without doubt we have here a mutually advantageous symbiotic adaptation.

From Weismann's chapter on Symbiosis in his "Vorträge über Descendenztheorie," Vol. I, 1902, we translate the follow- 
ing account of the symbiosis of the Aztec ants and the imbauba tree:

"In the forests of South Ameriea grow the imbauba or so-called candelabra trees, species of the genus Cecropia, which well deserve their name, 'eandelabra,' from the curious appearance given them by the outspringing bare branches, each bearing a tuft of fraves at the free end. These leaves are often attacked by the leaf-cutting ants of the genus Ecoloma, which roam ly tens of thousands over the various plants of the forest biting off the leaves, that they may fall to the ground, where they are again seized, bitten into pieces and the pieces earied into the nests of the ants. In the nests they serve as a medium on which grow certain molds or fungi, much liked by the ants. The candelabra tree protects itself from these leaf-robbing enemies by an association with another ant species, Aztcca instabilis, which finds safe dwelling places in the hollow trunk of the tree and a special supply of food in a brownish fluid secreted by it. Along the tree trunk oceur in regular order little pits through which the female Azteca can easily bore into the interior, where she lays her eqges and establishes colonies, so that suon the interior of the whole trunk swarms with ants which rush out whenever the tree is shaken. But this alone would not serve to protect the imbauba from the leaf cutters, for how could the Aztecs dwelling inside the tree know of the presence of the light-footed leaf-cutters without? But this is arranged for by the development on the outside of the tree, at the very points where the danger is greatest, namely, on the petioles of the younger leates, of perouliar little hairy growths from which froject small white grains which are very nutritious and not only eagerly eaten hy ants, hut araruered by them to carry into their nests, presumably as food for their larvar. Thus right where protection is most needed the plant has developed a special organ attractive to the fierce Aztec ants, so that their constant presence at 
these points is an effective protection against the encroachments of the leaf-cutters, as courage and eagerness to fight other ants is already characteristic of the Aztecs. Not all candelabra trees live in symbiosis with ants or possess this special protection against the ravages of the leaf-cutter species. Schimper found in the forests of Brazil several species of Cecropia which never shelter ants in the chambers of the hollow trunk. Now these species do not develop the curious special food-producing organs at the bases of the leaf petioles. These species lack the means of attracting and retaining the ant guests. Only one species of candelabra tree, Cecropia peltata, has developed this arrangement, and it is plainly of no direct use for the tree except through the bringing to it of the protecting ants."

There are, of course, numerous other examples known of the symbiotic association of plants and animals; and if we were to follow the study of symbiosis into the plant kingdom we should find that in one of the large groups of plants, the familiar lichens which grow on rocks and tree trunks and old fences, every member lives symbiotically. A lichen is not a single plant, but is always composed of two plants, an alga (chlorophyll-bearing) and a fungus (without chlorophyll) living together in a most intimate, mutually advantageous association. But we must devote no more space to the consideration of this fascinating subject.

The simplest form of social life, or the living together of several to many individuals of the same species, is shown among those kinds of animals in which many individuals of one species keep together, forming a great band or herd. In this case there is not much division of labor, and the safety of the individual is not wholly bound up in the fate of the herd. Such animals are said to be gregarious in habit. The habit undoubtedly is advantageous in the mutual protection and aid afforded the individuals of the band. This mutual help in the case of many gregarious animals is of a very positive and obvious character. In other cases this gregariousness is reduced to a matter of slight or temporary convenience, possessing but little of the element of mutual aid. The great herds of reindeer in the north, and of the bison or buffalo which once ranged over the Western American plains, are examples of a gregariousness in which mutual protection from enemies, like wolves, seems to be the principal advantage gained. The bands of 
wolves which hunted the buffalo show the advantage of mutual help in aggression as well as in protection. In this banding together of wolves there is active coöperation among individuals to obtain a common food supply. What one wolf camnot dowhat is, tear down a buffalo from the extege of the herd-a domen can do, and all are gainers by the operation.

On the other hand, the vast assembling of sea birds on certain ocean islands and rocks is a condition probably brought about rather by the special suitableness of a few placers for safe breeding than from any special mutual aid afforded; still, these sea birds undoubtedly combine to drive off attacking eagles and hawks. Eagles are usually considered to be strictly solitary in habit (the unit of solitariness being a pair, not an individual); but the (lescription, by a Russian nat uralist, of the hunting habits of the great white-tailed eagle (Haliaëtos albicilla) on the Russian steppes shows that this kind of eagle at least has adopted a gregarious habit, in which mutual help is plainly obvious. This naturalist once saw an eagle high in the air, circling slowly and widely in perfect silence. Suddenly the eagle screamed loudly. "Its cry was soon answered by another eagle, which approached it, and was followed by a third, a fourth, and so on, till nine or ten eagles came together and soon disappeared." The naturalist, following them, soon discovered them gathered about the dead body of a hor:er. The food found by the first was being shared by all. The association of pelicans in fishing is a good eximple of the artvantage of a gregarious and mutually helpful habit. The pelicans sometimes go fishing in great binds, and, after having chosen an appropriate place near the shore, they form a wicle half-sircle facing the shore, and narrow it by paddling toward the land, catching the fish which they inclose in the erernarrowing circle.

The wary Rocky Mountain sheep (Fig. 234) live togrether in small bands, posting sentincls whenever they are feeding or resting, who watch for and give warning of the approach of enemies. The beavers furnish a well-known and very interesting example of mutual help, and they exhibit a truly communal life, although a simple one. They live in "villages" or communities, all helping to build the dam acrosit the stream, which is necessary to form the broad marsh or pool in which the nests or houses are built. P'rairic dogs live in great villages 


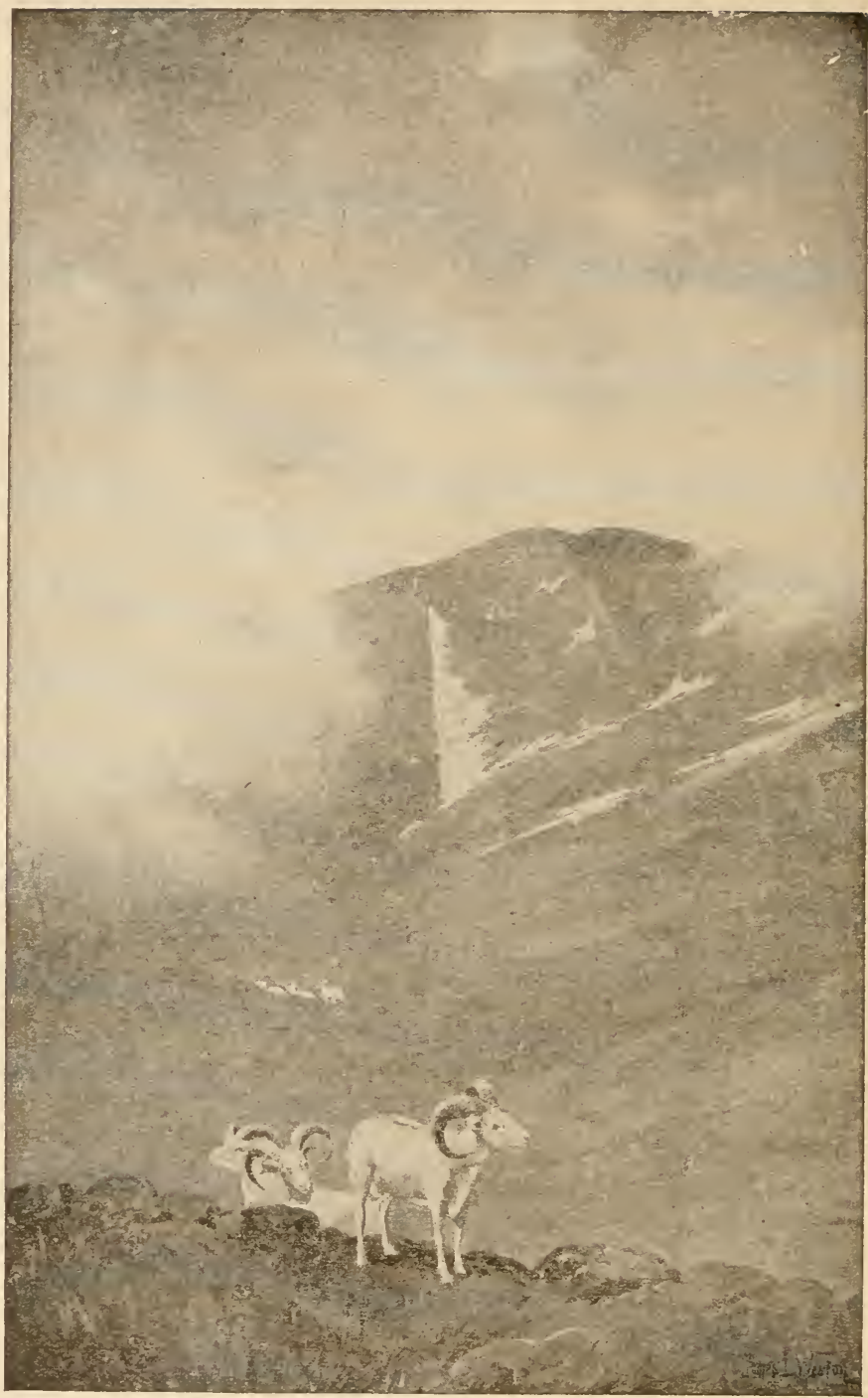

FIG. 234.-Rocky Mountain, or bighorn, sheep. (By permission of the publishers of "Outing.") 
or communities which spread o w many atres. They tall each other by shrill cries of the aploroath of (memies, and they seem to visit each other and to enjoy ateh other" cocioty at great deal, although that they afford atch other mudh ariual active help is not apparent. Birds in migration are grocgatrious, although at other times they may live (omparatively. alone. In their long flights they liepl ingether, often with definite leaders who seem to discovere and decide on the roure

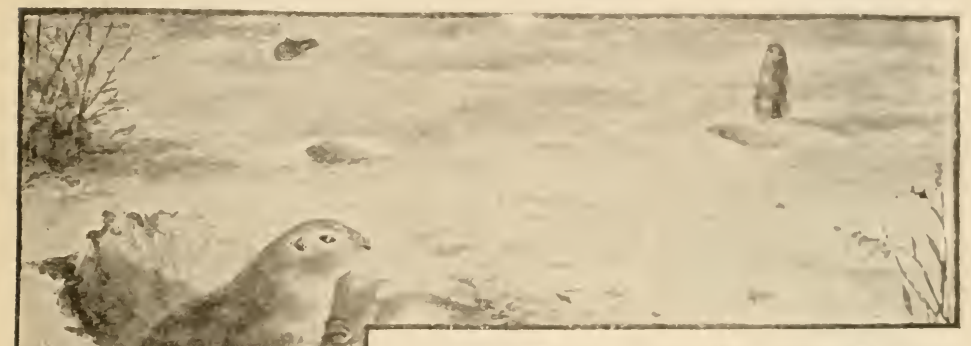

Frg. 23.5. Prative doge. Adapted from photo graph by .lerram.)

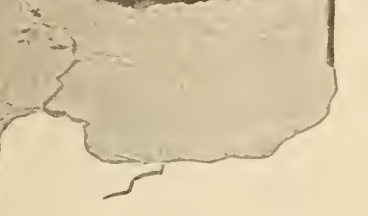

of flight for th:e whole great flock. The wedge-shaped flocks of wild geese flying high and uttring their sharp, metallic call in their southward migrations are well known in many parts of the Enited States. Indeed, the more one studies the labloits of animalis the more examples of social life and mutual help will be found. Probably most animals are in some degree croctarious in halit, and in all cases of gregariousmess there is probahly some degree of mutual aid.

An interesting series of gradations from a strictly solitary through a gregarious to ar piahorately specialized commmal life is shown by the bees. Althourle the humblolue amd the honeybee are so much more familiar to us than of her bee himbs that the communal life exemplified hy them maty have come to seem the wnul kind of here life. yet, ats a matter of fact. there are many more solitary hees than social ones. The eneneral character of the domestic seomomy of the solitary beres is well shown by the interesting little green arpenter bere, combim dupla. Each fomale of this speceies beres ont the pith fromt five or six inches of an chler hranch or ratsuluery ("ame, and 


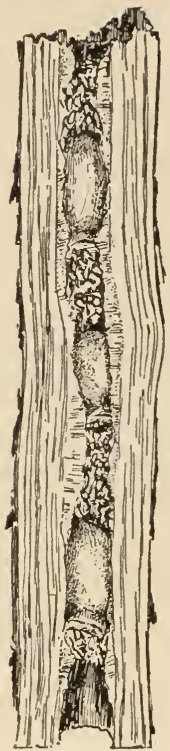

FIG. 236.-Nest of carpenter bee, Ceratina dupla.

divides this space into a few cells by means of transverse partitions (Fig. 236). In each cell she lays an egg, and puts with it enough food -flower pollen-to last the grub or larva through its life. She then waits in an upper cell of the nest until the young bees issue from their cells, when she leads them off, and each begins active life on its own account. The mining bees Andrena, which make little burrows (Fig. 237) in a clay bank, live in large colonies-that is, they make their nest burrows close together in the same clay bank, but each female makes her own burrow, lays her own eggs in it, furnishes it with food-a kind of paste of nectar and pollen-and takes no further care of her young. Nor has she at any time any special interest in her neighbors. But with the smaller mining bees, belonging to the genus Halictus, several females unite in making a common burrow, after which each female makes side passages of her own, extending from the main or public entrance burrow. As a wellknown entomologist has said, Andrena builds villages composed of individual homes, while Halictus makes cities composed of apartment houses. The bumblebee (Fig. 23S), however, establishes a real community with a truly communal life, although a very simple one. The few bumblebees which we see in winter time are queens; all other bumblebees die in the autumn. In the spring a queen selects some deserted nest of a field mouse, or a hole in .the ground, gathers pollen which she molds into

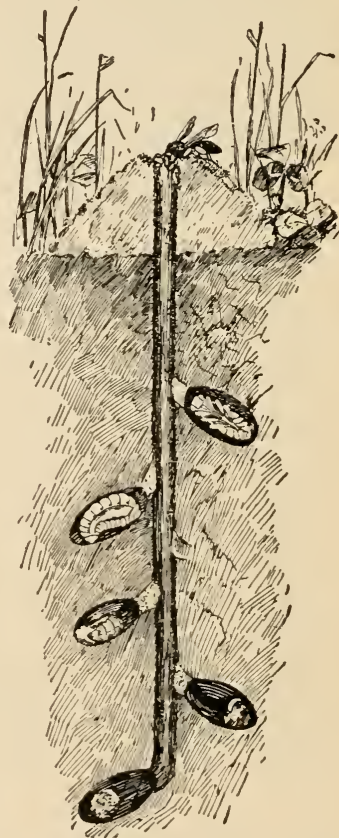

FIG. 237.-Nest of the Andrena, the mining bee. 
MUTUAL AID AND COMMUNAI, IIFE AMON!: ANIMAIS 3\$.)

a rather large irregular mass and puts into the hole, and lays a few eggs on the pollen mass. The young gruls' or larva which soon hatch feed on the pollen, grow, pupate, and issue as workers-winged bees a little smaller than the queen. These workers bring more pollen, enlarge the nest, and make irregular cells in the pollen mass, in each of which the queen lays an egg. She gathers no more pollen, does no more work except that of egg-laying. From these new eggs are produced more workers, and so on until the community may come to be pretty large. Later in the summer males and females are produced and mate. With the approach of winter all the workeis and males die, leaving only the fertilized females, the queens, to live through the winter and found new communities in the spring.

The social wasps-as with the bees,

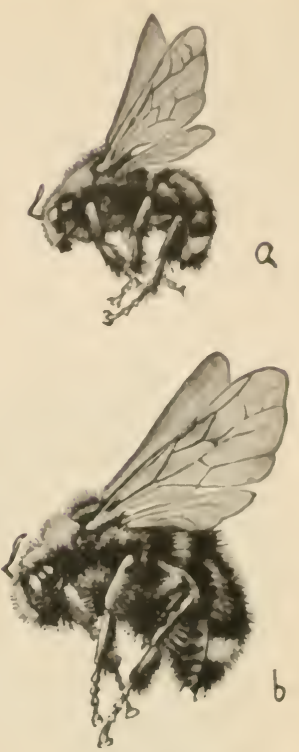

FIG. 23s. - Bumblebers: $a$, Worker; $b$, queen or fertile female.
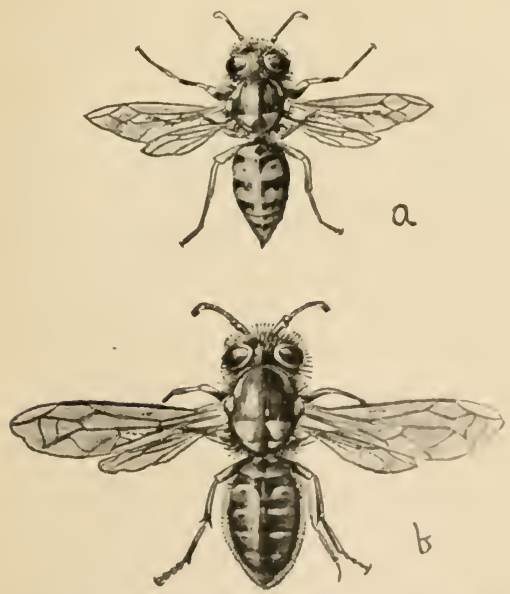

Fra. 239-The yellow jacket, Vespa, a social wanp: $a$, Worker; $b$, queen.

there are many more kinds of solitary wasps than social ones-show a commumal life like that of the bumblebers. The only yellow jackets and hornets that live thromen the winter are fortilized females or queens. Whon spring comes eateh yueen builds al small nest sllspended from a tree hranch. or in a hole in the groumal. which consists of a small comb inclosed in a corering or envelope open at the lower ent. The nest is composed of "wilsp pilper," made by chewing bits of 
weather-beaten wood taken from old fences or outbuildings. In each of the cells the queen lays an egg. She deposits in the cell a small mass of food, consisting of some chewed insects or spiders. From these eggs hatch grubs which eat the food prepared for them, grow, pupate, and issue as worker wasps,
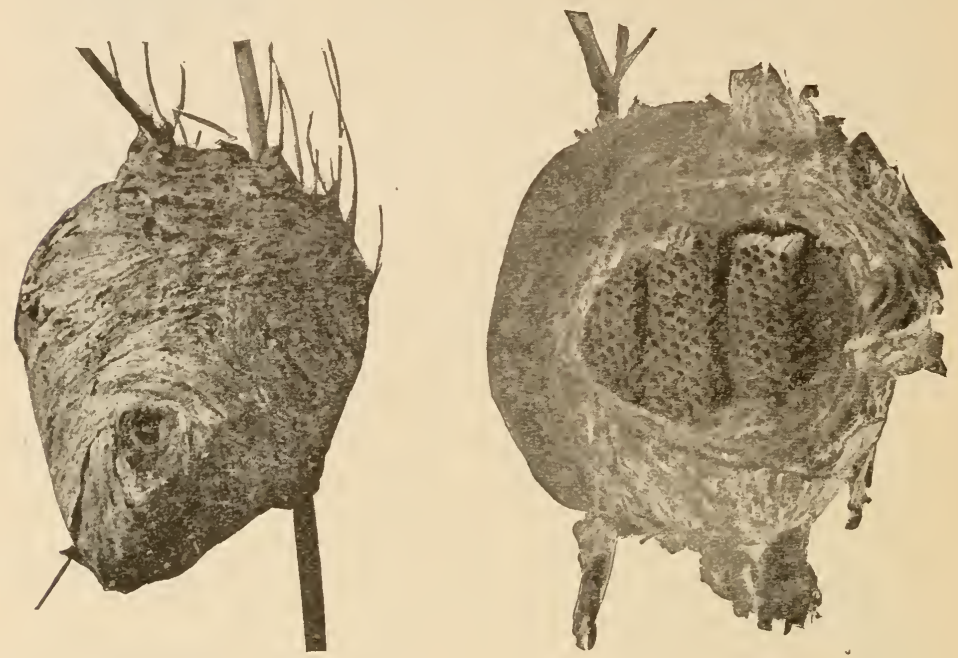

FIG. 240.-At the left, nest of Verpa, a social wasp; at the right, nest of V'espa opened to show combs within. (From photographs.)

winged and slightly smaller than the queen (Fig. 239). The workers enlarge the nest, adding more combs and making many cells, in each of which the queen lays an egg. The workers provision the cell with chewed insects, and other broods of workers are rapidly hatched. The community grows in numbers and the nest grows in size until it comes to be the great ball-like oval mass which we know so well as a hornets' nest (Fig: 240), a thing to be left untouched. When disturbed, the wasps swarm out of the nest and fiercely attack any invading foe in sight. After a number of broods of workers has been produced, broods of males and females appear and mating takes place. In the late fall the males and all of the many workers die, leaving only the new queens to live through the winter.

Honeybees live together, as we know, in large communities. 
We are accustomed to think of honcybees as the inhalitants of beehives, but there were bees before there were hives. The "bee tree" is familiar to many of us. "The bees, in Nature, make their home in the hollow of some dead or deraying trextrunk, and carry on there all the inclustries which charatereries the busy communities in the hives. A honeyloe community comprises three kinds of individuals (Fig. 2-1)-namely, it fertile female or queen, numerous males or drones, and many infertile females or workers. These three kinds of incivivluals differ in external appearance sufliciently to be readily reconnizable. The workers are smaller than the querns and droner, and the last two differ in the shape of the abdomen, or limd body, the abdomen of the queen being longer and more slender than that of the male or drone. In a single community there is one queen, a few hundred drones, and ten to thirty thousand trorkers. The number of drones and workers varies at difierent fimes of the year, being smallest in winter. Wach kind of individual has certain work or business to do for the whole community. The queen lays all the egess from which new hees are born; that is, she is the mother of the ontire communit? The drones or males have simply to aret as royal consonts; upon them depends the fertilization of the erges: The worlins undertake all the food-getting, the care of the young hees, the
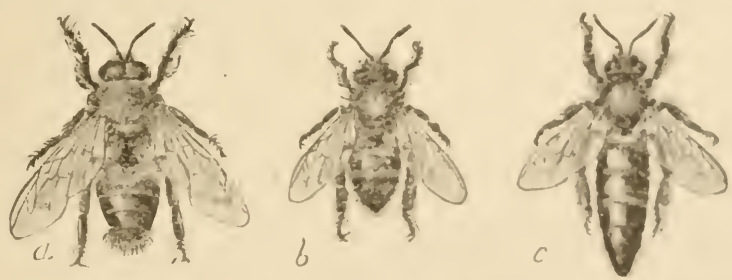

Fig. 2.11. - Honeybee: $a$, I)rone or male; $b$, worker or fomale; $c$, quen or fercile fethale.

comb-building, the honey-making-all the industries with which we are more or less familiar that are carried on in the hive. And all the work done hy the workers is strietly work for the whole eommunity; in no case does the worker bee work for itself alone; it works for itself only in so far ats it is a nomber of the community.

How raried and elaborately perfecterl these industries are may be pereeived from a bricf aceoment of the life history of a 
bee community. The interior of the hollow in the bee tree or of the hive is filled with "comb" - that is, with wax molded into hexagonal cells and supports for these cells. The molding

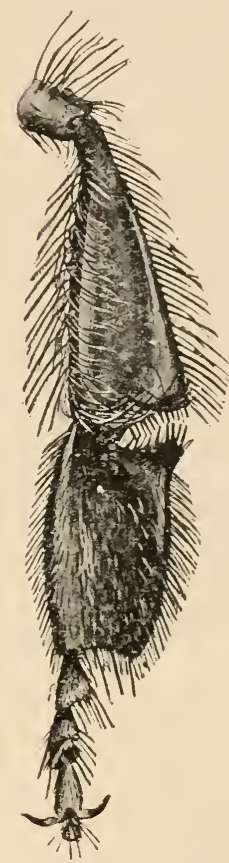

FIG. 242. - Posterior leg of worker honeybee. Concave surface of the upper large joint with the marginal hairs is the pollen basket; the wax shears are the cutting surfaces of the angle between the two large segments of the leg. of these thousands of symmetrical cells is accomplished by the workers by means of their specially modified trowellike mandibles or jaws. The wax itsclf, of which the cells are made, comes from the bodies of tle workers in the form of small liquid drops which exude from the skin on the under side of the abdomen or hinder body rings. These droplets run together, harden ird become flattened, and are removed f:om the wax plates, as the peculiarly modificd parts of the skin which produce the wax are called, by means of the hind legs, which are furnished with scissorlike contrivances for cutting off the wax (Fig. 242). In certain of the cells are stored the pollen and honey, which serve as food for the community. The pollen is gathered by the workers from certain favorite flowers and is carried by them from the flowers to the hive in the "pollen baskets," the slightly concave outer surfaces of one of the segments of the broadened and flattened hind legs. This concave surface is lined on each margin with a row of incurved stiff hairs, which hold the pollen mass securely in place (Fig. 242). The "honey" is the nectar of flowers which has been sucked up by the workers by means of their elaborate lapping and sucking mouth parts and swallowed into a sort of honey sac or stomach, then brought to the hive and regurgitated into the cells. This nectar is at first too watery to be good honey, so the bees have to evaporate some of this water. Many of the workers gather above the cells containing nectar, and buzz-that is, vibrate their wings violently. This creates currents of air which pass over the exposed nectar and increase the evaporation of the water. The violent buzz- 
ing raises the temperature of the bees' bodies, and this warmth given off to the air, also helps make evaporation more rapirl. In addition to bringing in food the workers also bring in, when necessary, "propolis," or the resinous grum of rortain trax. which they use in repairing the hive, as dosing up) aracks and erevices in it.

In many of the cells there will be found, not pollen or honey, but the eggs or the young bees in larval or pupal (ondition (Fig. 243). The queen moves about through the hive. laying eggs. She deposits only one egg in a cell. In three days the egg hatches, and the young bee appears as a helpless soft, white, footless grub or larva. It is cared for by certain of the workers, that may be called nurses. These nurses do not differ structurally from the other workers, but they have the special duty of caring for the helpless young bees. They

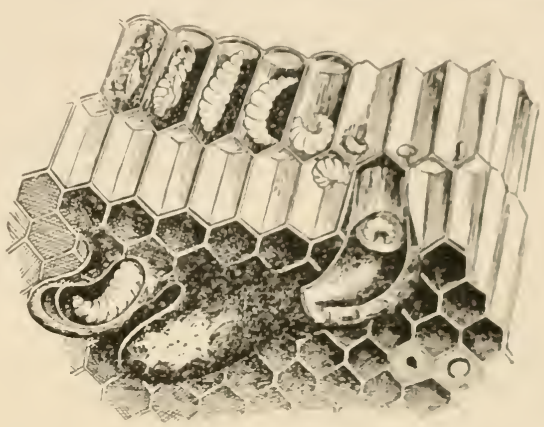

FIg. 243.-Cells containing eggs, larvar, and pupar of the honeybee. The lower, large, irregular cells are the queen cells. (After Benton.) do not go out for pollen or honey, but stay in the hive. They are usually the new bees-i, e., the youngest or most reeently added workers. After they act as nurses for a week or so they talie their places with the food-gathering workers. and other new hees act as nurses. The nurses feed the young or larval bees at first with a highly nutritious food called bee jelly, which the nurses make in their stomach, and regurgitate for the larvar. After the larvin are two or three daysold they are fed with pollen and honey. Finally, a small mass of food is put into the cell, and the cell is "eapped" or covered with wax. Ealch larva, after eating all its food, in two or three days more changes into a pupa, which lies quiescent without eating for thirteen days, when it changes into a full-erown bee. The now here hreaks open the cap of the cell with its jaws, and comes out into the hive, ready to take up its share of the work for the community. In a few cases, however, the life history is different. The murses 
will tear down several cells around some single one, and enlarge this inner one into a great irregular vase-shaped cell. When the egg hatches, the grub or larva is fed bee jelly as long as it remains a larva, never being given ordinary pollen and honey at all. This larva finally pupates, and there issues from the pupa not a worker or drone bee, but a new queen bee. The egg from which the queen is produced is the same as the other eggs, but the worker nurses by feeding the larva only the highly nutritious bee jelly make it certain that the new bee shall become a queen instead of a worker. It is also to be noted that the male bees or drones are hatched from eggs that are not fertilized, the queen having it in her power to lay either fertilized or unfertilized eggs. From the fertilized eggs hatch larvæ which develop into quecns or workers, depending on the manner of their nourishment; from the unfertilized eggs hatch the males.

When several queens appear there is much excitement in the community. Each community has normally a single one, so that when additional queens appear some rearrangement is necessary. This rearrangement comes about first by fighting among the queens until only one of the new queens is left alive. Then the old or mother queen issues from the hive or tree followed by many of the workers. She and her followers fly away together, finally alighting on some tree branch and massing there in a dense swarm. This is the familiar phenomenon of "swarming." The swarm finally finds a new hollow tree, or in the case of the hive bee the swarm is put into a new hive, where the bees build cells, gather food, produce young, and thus found a new community. This swarming is simply an emigration, which results in the wider distribution and in the increase of the number of the species. It is a peculiar but effective mode of distributing and perpetuating the species.

There are many other interesting and suggestive things which might be told of the life in a bee community: how the community protects itself from the dangers of starvation when food is scarce or winter comes on by killing the useless drones and the immature bees in egg and larval stage; how the instinct of home-finding has been so highly developed that the worker bees go miles away for honey and nectar, flying with unerring accuracy back to the hive; of the extraor- 
dinarily nice structural modifications which arlapt the bee so perfectly for its complex and varied businesses; and of the tireless persistence of the workers until they fill exllatusted and dying in the performance of their duties. The community, it is important to note, is a persistent or continnous one. The workers do not live long, the spring hroods usually not over two or three months, and the fall broods not more than six or eight months; but new ones are hatching while the old ones are lying, and the community as a whole always persists. The
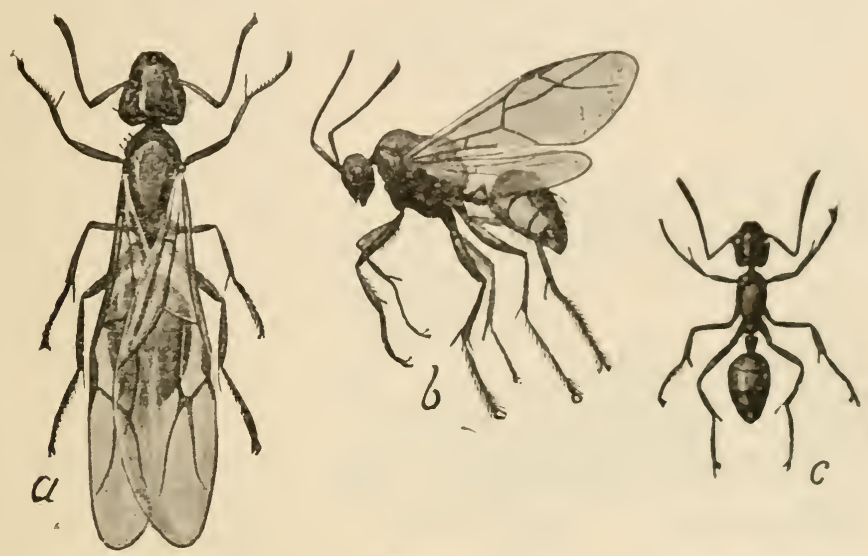

Fig. 244.-Female (a), male (b) and worker (c) of an ant, Camponotus sp.

queen may live several years, perhaps as many as five." She lays about one million eggs a year.

There are many species of ants, two thousand or more, and all of them live in communities and show a truly communal life. There is much variety of habit in the lives of different kinds of ants, and the degree in which the communal or social life is specialized or claborated varies much. But certain general conditions prevail in the life of all the lifferent kinds of individuals-sexually developer males and fenlales that poserss wings, and sexually undeveloped workers that are wingless (Fig. 244). In some kinds the workers show structural differences among themselves, being divided into small workers, large workers, and soldiers. The workers are, as with the

${ }^{3}$ A queen bee has butn licpt alive for fifteen years. 
bees, infertile femaies. Although the life of the ant communities is much less familiar and fully known than that of the bees, it is even more remarkable in its specializations and elaborateness. The ant home, or nest, or formicary, is, with most species, a very elaborate underground, many-storied labyrinth of galleries and chambers. Certain rooms are used for the

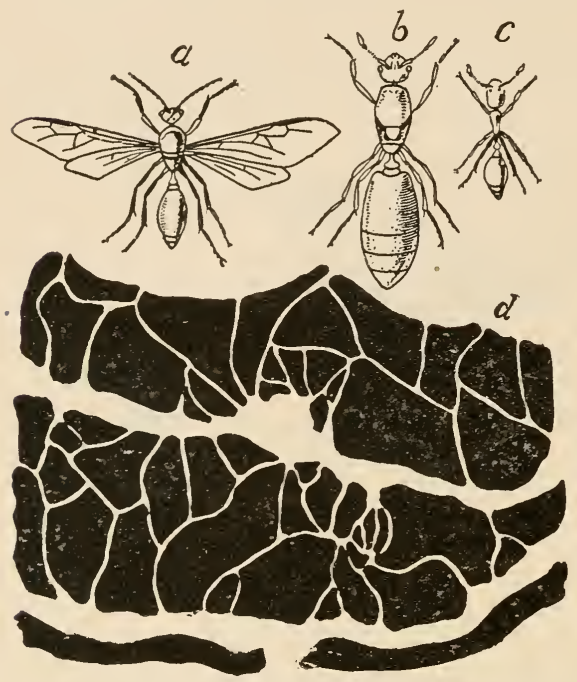

Fi-. 245.-The ant, Solenopsis tugax: $a$, Male; $b$, dealated female; $c$, worker; $d$, portion of nest showing broad galleries of the host ant intersected by the tenuous galleries of Solenopsis, the thief ant. (After Wasmann. See aecount on page 375 .) storage of food; certain others as "nurseries" for the reception and care of the young; and others as "stables" for the ants' cattle, certain plant lice or scale insects which are sometimes collected and cared for by the ants.

The food of ants comprises many kinds of vegetable and animal substances; but the favorite food, or "national dish," as it has been called, is a sweet fluid which is produced by certain small insects, the plant lice (Aphididæ) and scale insects (Coccidæ). These insects live on the sap of plants; rose bushes are especially favored with their presence. The worker ants (and we rarely see any ants but the wingless workers, the winged males and females appearing out of the nest only at mating time) find these honey-secreting insects, and gently touch or stroke them with their feelers (antennæ), when the plant lice allow tiny drops of the honey to issue from the body, which are eagerly drunk by the ants. It is manifestly to the advantage of the ants that the plant lice should thrive; but they are soft-bodied, defenseless insects, and readily fall a prey to the wandering predaceous insects like the ladybirds and aphis lions. So the ants often guard small groups of plant lice, attacking, and driving away the would-be ravagers. When 
the branch on which the plant lice are grets withered and dry, the ants have been observed to earry the plant lice carcfully to a fresh, green branch. On page $37+$ is describenl how the little brown ant Lasius brunneus cares for the com root plant louse. In the arid lands of New Mexico and Arizona the ants rear their scale insects on the roots of eactus. () ther kinds of ants carry plant lice into their nests and provide them with food there. Because the ants obtain food from the plant lice and take care of them, the plant lice are not inaptly called the ants' cattle.

Like the honeybees, the young ants are helpless little grubs or larra, and are cared for and fed by nurses. The so-called ants' eggs, little white, oval masses, which we often see being carried in the mouths of ants in and out of ants' nests, are not eggs, but are the pupæ which are being brought out to enjoy the warmth and light of the sun or being taken back into the nest afterwards.
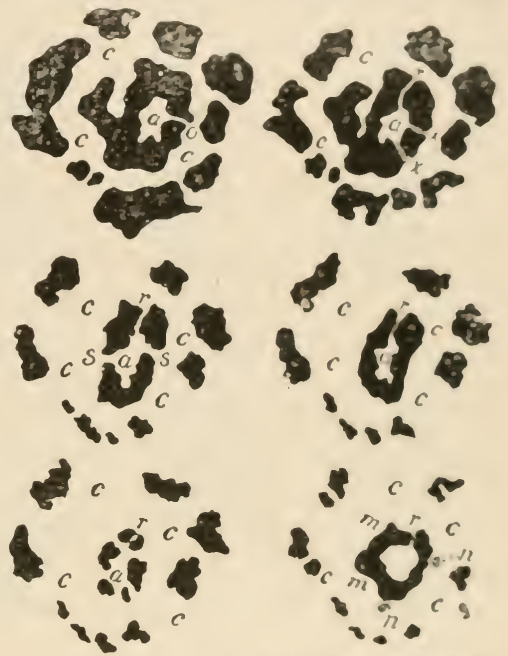

FIa. 246.-Nest of the ant, Ieptothoras emersoni, with the nest of another ant, M/Irmica scabrinodes. (Nee account on puge 375.) (After Wheeler.)

In addition to the workers that build the nest and collect food and care for the plant lice, there is in many species of ants a kind of individuals called soldiers. These are wingless, like the workers, and are also, like the workers, not capable of laying or of fertilizing eggrs. It is the business of the soldiers, as their name suggests, to fight. They protert the community by attacking and driving away predaceous insects, repecially other ants. The ants are among the most warlike of insects. The soldiers of a community of one speciess if ant often sally forth and attack a community of some other speecies. If successful in battle the workers of the victorions community take possession of the food stores of the compuered ame carry them to their own nest. Inteed, they go exen further; they may 
make slaves of the conquered snts. There are numerous species of th so-called slave-making ants. The slave-makers carry.into thes own nest the eggs and larva and pupx of the conquered community, and when these come to maturity they act as slaves of the victors-that is, they collect food, build additions to the nests, and care for the young of the slavemakers. This specialization goes so far in the case of some kinds of ants, like the robber-ant of South America (Eciton), that all of the Eciton woiliers have become soldiers, which ro longer do any work for themselves. The whole community lives, therefo:e, wholly by pillage or by making slaves of other kinds of ants. There are four kinds of individuals in a robberant community-winged males, winged females, and small and large wingless soldiers. There are many more of the small soldiers than of the large, and some naturalists believe that the few latter, which are distinguished by heads and jaws of great size, act as officess! On tlie march the small soldiers are arranged in a long, narrow column, while the large soldiers are scattered along on either side of the column and appear to act is sentinels and directors of the army. The observations made by the European students of ants, Huber. Fo-el, Emery and Wasmann, and by McCook and Wheeler in America, read like fairy tales, and yet are the well-attested actual phenomena of the extremely specialized communal and social life of these animals.

The bumblebees and social wasps show an intermediate condition between the simply gregarious or neighborly mining bees and the highly developed, permanent honeybee and ant communities. Naturalists believe that the highly organized communal life of the honeybees and the ants is a development from some simple condition like that of the bumblebees and social wasps, which in its turn has grown out of a still simpler, more gregarious assembly of the individuals of one species. It is not difficult to see how such a development could in the course of a long time take place.

The termites or white ants (not true ants) are also communal insects. Some species of termites in Africa live in great mounds of earth, often fifteen feet high. The community comprises hundreds of thousands of individuals, which are of as many as eight kinds or castes (Fig. 247) viz., sexually active winged males, sexually active winged females, other fertile males and females 
which are wingless, wingless workers of both sexes not capable of reproduction, and wingless soldiers of both sexes also incapable of reproduction. The production of new individuals is the sole business of the fertile males and fomales; the workers build the nest and collect food, and the soldiers protect the community from the attacks of maranding insects. The egrelaying queen grows to monstrous size in some specie's, being sometimes four or five inches long, while the other individuals of the community are not more than half or three-quarters of an inch long. The great size of the queen is due to the enormous number of eggs in her borly.

ITe have pointed out elsewhere that the complexity of the bodies of the higher animals depends on a specislization or differentistion of parts, due to the assumption of different functions or

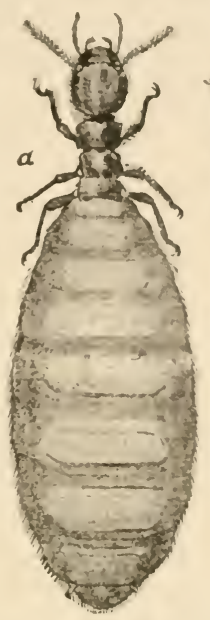

F1g. 247.-Termites: $a$, Queen; $b$, male; $c$, worher: $d$, soldlier.
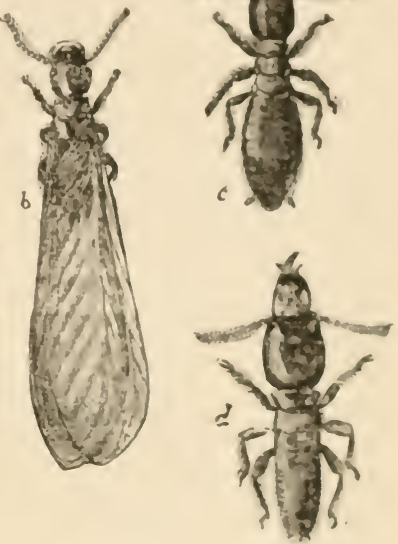
duties by different

parts of the body; that the degree of structural differentiation depends on the degree or extent of division of labor shown in the economy of the animid. It is obvious that the same principle of division of libor with acompanying modification of structure is the hasis of colonial and communal life. It is simply a manifestation of the principle among individuals instead of among organs. The division of the necesiry laters of life among the different zonids of the colonial jollyfinh is plainly the reason for the profomed and striking, hut aluays reasonable and cxplicable, modifications of the typical polyp or medusa body, which is shown by the swimming zooids, the feeding zoodds, the sense zooids, and the others of the colony. And similarly in the case of the termite community, the soldier individuals are different structurally from the worher ir. 
dividuals because of the different work they have to do. And the queen differs from all the others, because of the extraordinary prolificacy demanded of her to maintain the great community.

It is important to note, however, that among those animals that show the most highly organized or specialized communal or social life, the structural differences among the individuals are the least marked, or at least are not the most profound. The three kinds of honeybee individuals differ but little; indeed, as two of the kinds, male and female, are to be found in the case of almost all kinds of animals, whether communal in habit or not, the only unusual structural specialization in the case of the honeybee, is the presence of the worker individual, which differs from the other individuals primarily in the rudimentary condition of the reproductive glands. Finally, in the case of man, with whom the communal or social habit is so all-important as to gain for him the name of "the social animal," there is no differentiation of individuals adapted only for certain kinds of work. Among these highest examples of social animals, the presence of an advanced mental endowment, the specialization of the mental power, the power of reason, have taken the place of and made unnecessary the structural differentiation of individuals. The honeybee workers do different kinds of work: some gather food, some care for the young, and some make wax and build cells, but the individuals are interchangeable; each one knows enough to do these various things. There is a structural differentiation in the matter of only one special work or function, that of reproduction.

With the ants there is, in some cases, a considerable structural divergence among individuals, as in the genus Atta of South America with six kinds of individuals-namely, winged males, winged females, wingless soldiers, and wingless workers of three distinct sizes. In the case of other kinds with quite as highly organized a communal life, there are but three kinds of individuals; the winged males and females and the wingless workers. The workers gather food, build the nest, guard the "cattle" (aphids), make war, and care for the young. Each one knows enough to do all these various distinct things. Its body is not so modified that it is limited to doing but one lind of thing. 
The incresse of intelligence, the development of the power of reasoning, is tlie most potent factor in the development of a highly specialized social lif M Man is the example of the highest development of this sort in the animal kingrlom, but she highest form of social development is mot by any means the most perfectly communal.

The advantages of communal or social life, of coüperation and mutual aid, are real. The animals that have adopted such a life are among the most suceessful of all animals in the struggle for existence. The termite individual is one of the most defenseless, and, for those animels thet prey on inserts, one of the most toothsome luxuries to he found in the insect world. But the termite is one of the most abundant and widespread and sucessfully living insect kinds in all the tropices. Where ants are not, few insects are. The honeyber is a popular type of a successful life. The artifirial protection afforded the honeybee by man may aid in its struegrle for existence, but it gains this protection because of certain foatures of its ("ommunal life, and in Nature the honeylore takes care of itcelf well. The Little Bee People of Kipling's Jungle J Book, who live in great communities in the rocks of Indian hills, can put to rout the largest and fiereest of the jungle animals. Coöperation and mutual aid are among the most important factors which help in the struggle for existence. Its gleat advantages are, however, in some degree balaneed by the fact that mutnal help brings mutual dependence. The community or society can accomplish greater things than the solitary individuals, but coöperation limits freedom, and often sacrifices the individual to the whole. 


\section{CHAPTER XIX}

\section{COLOR AND PATTERN IN ANIMALS}

In spite of the fluency with which so many people talk of the meaning of color in organisms, the subject is as incomplete on the theoretical as on the physiological side. . . . The two deficiencies are related and a little more physiology will arm the theorists with better weapons.-NewBigin.

A conspicuous characteristic of the animal body is its color pattern. Not all kinds of animals attract our attention by their colors: there are even whole groups whose uniform monochrome color scheme is of a sort to relieve them completely from any imputation of flaunting showiness or of bizarre fancies in personal decoration. But consider such a class as the insects: the painted butterflies, the burnished beetles, the flashing dragon flies, the green katydids and brown locusts. All attract attention first by the variety or intensity of their colors and the arrangement of these colors in simple or intricate symmetry of pattern. Even the small and at casual glance, obscure and monochrome insects often reveal, on careful examination; a large degree of color development and ofttimes amazing intricacy and beauty of pattern. So uniformly developed is color pattern among insects, that no thoughtful collector or observer of these animals escapes the self-put question: Why is there such a high degree of specialization of color throughout the insect class? If he be an observer who has taken seriously the teachings of Darwin and the utilitarian school of naturalists, his question becomes couched in this form: What is the use to the insects of all this color and pattern?

For the attitude of any modern student of Nature, confronted by such a phenomenon, is that of the seeker for the significance of the phenomenon. And the key to significance 
in such a case is to be sought in utility. The usefulness of color in animate nature as an inspirer and satisfier of our own asthetic needs and capacities, or of color patterns as means whereby we may distinguish and recognize various sorts of animals and plants, is a usefulness which may be answer enougit to the passing poet on the one hand, and to the old-line I.innxan systematist on the other, but it is, of course, no answer to science. Science demands a usefulness to the color-hearing organisms themselves: and a usefulness large and serious enough to be the sufficient cause for so highly specialized an I amazing a development.

The explanations of some of the color phenomena of animals are obvious: some uses we recognize quickly as certain, some as probable, some as possible. Some colors are obviously there simply because of the chemical make-up of parts of the insect body. That gold is yellow, cinnabar red, and certain copper ores green or blue, are facts which lead us to no special inquiry after significance: at lcast, not after signifieance based on utility. If an insect has part of its body composed of or containing a substance that is by its very chemical and plovical constitution always red or blue or green, we may be conteni with knowing that, and not be too insistent in our demand to the insect to show cause, on a basis of utility, for being partly red or blue or green. And even if this red or blue be disposed with some symmetry, some regularity of repetition, either segmentally or bilaterally, this we may well attribute to the natural segmental and bilaterally symmetrical repetition of similar body parts. Some colon and some color pattern, then, may be explicable on the same basis as the color of a mineral specimen or of a tier of bricks.

But no such explanation will for a moment satisfy us as to the presence of and arrangement of colors in the wings of Lallima, the dead leaf butterfly, or in Phyllium, the groen leaf phasmid, or in the butterfly fish, Chatodom, or in the liehen spider, or in the ehameleon with its changing tints, or in any one of a score of other more or less familiar forms whose color pattern makes, even on the casual obscrorer, an insistent demand for rational explanation.

Certain uses of color secem apparent: the colored eye fleckis or pigment spots of many of the lower animals presumably. serve their possessors as organs by which to distinguish the 
presence or absence of light, by virtue of their capacity to absorb light and thus stimulate the specially sensitive cells composing them. And the pigment or absence of it (dark or light color) in the fur and plumage of certain mammals and birds may perhaps serve to absorb or to reflect the sun's rays so as to help keep warm or cool the animals thus colored. But such explanations of animal colors can obviously apply to but few cases. Very plainly color, and especially pattern, has its significance if anywhere in connection with certain special relations of animals to other animals and to the world generally.

So, ever since the days of Darwin, two general categories of such significance or explanation of color and pattern have been in the minds of naturalists. One of these is the significance attributed to color pattern by the theory of sexual selection; the other is that attributed to it by the general theory or group of theories of protective resemblance, recognition, warning, directive, and mimetic coloration, etc. Of these two general explanations, one has steadily lost ground since Darwinian and early post-Darwinian days, while the other has slowly but steadily gained adherents and has been extended to cover more and more cases of animal ornamentation. Of the theory of sexual selection it must be said that it certainly cannot explain the conditions of secondary sexual differences, including colors and patterns, in many groups of animals, and it has really not been proved to explain them in any single group, although in the case of birds and mammals it seems possible that the theory is applicable: at least no other explanation of equal validity has yet been presented. Of the specialization of color and pattern for the sake of protecting the animal by making it so harmonize or fuse with the usual environment as to be indistinguishable, or by making it simulate with sufficient fidelity some particular part of its surroundings as a green or dead leaf, a twig, the dropping of a bird, a bit of lichen or what not, or by making it mimic some other animal notoriously well defended by sting or fangs or ill-tasting body, so that the otherwise defenseless mimicker is mistaken by its enemies for the defended mimicked kind of animal-of this specialization and utility of color and pattern, evidence for its reality is gradually accumulating to convincing amount. And it is of this sort of color and pattern specialization that the brief discussion to follow will be devoted. 
The green katydid singing in the tree-top or slurubbery is readily known to be there by its musie, hut just which bit of green that we see is katydid, and which is leaf, is a matter to be decided only by unusually discriminating eyes. The alacking locust, beating its black wings in the air, is conspicuous enough; but after it has alighted on the ground it is in vis ible, or, rather, visible but indistinguishable : its gray and brown

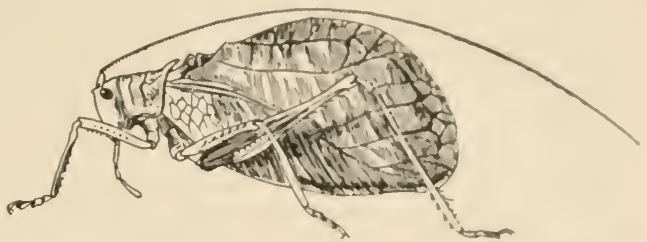

Frg. 248.- Katydid, Cyrtophyllis crepitans, from the Weet Indies, with green body and wings resembling the lonves among which it lives. (After Sharp.) mottled color pattern is simply continuous with that of the soil. The green larve of the P'ierid butterflies lying longitudinally along green grasses simply merge into the color scheme of their cuvironment. The gray moths rest inperceived on the bark of the

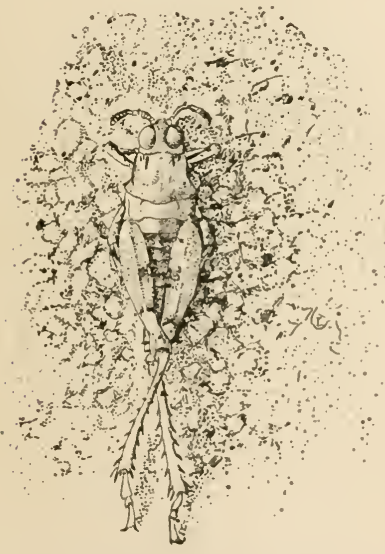

Frg. 249.-Small loeust of the Colorado-Mohave desert on the sand. tree trunk. Hosts of insert kinkl: do really harmonize with the color paitern of their usual anvironment, and hy this correspondenee in shade and marking, are difficult to perceive for what they are. Now if the eyes that survey the green foliage or rum over the uraly kark are those of a preving bird. lizard, or other encmy, it is yuite certain-our reason tolls us so insistently-that this posiseion hy the insect of color and pattern tending to make it indistinguishable from its immediate environment is advantageous to it-atvantageous to the degroe often of saving its life. Now sureh a use of color and pattern is obviously one which can he widespreat through the insect class, and may be, to many speries which lead lives exposed to the attacks of insectivorous animals, of large-even of life and death-importance. And naturalists, 
most of them at least, believe that this kind of usefulness is real, and that it is the principal clew to the chief significance of color and pattern-and this not alone in the case of insects, but of most other animals as well.

From this point of view, namely, that color patterns may be of advantage in the struggle for existence, just as strength, swiftness, and other capacities and conditions are, the specialization and refinement, all the wide modification and variety of colors and patterns are explicable by the hypothesis of their gradual development in time through the natural selection of fortuitous advantageous variations. On this basis, such special instances of resemblance to particular parts of the environment, as that shown by Kallima in its likeness to a dead leaf, and Diapheromera in its simulation of a dry, leafless twig, are simply the logical extremes of such a line of specialization.

But the nature observer may be inclined to ask how such brilliant and bizarre colors as those of the swallowtail butterflies and the tiger-banded caterpillars of $A$ nosia can be included in any category of "protective resemblance" patterns. They are not so included, but are explained ingeniously by an added hypothesis called that of "warning colors," while for the striking similarities of pattern often noted between two unrelated conspicuously colored species still another hypothesis is proposed. In these cases it is not concealment that the color pattern effects, but indeed just the opposite. Since the pioneer studies of Bates and Wallace and Belt, naturalists have been observing and experimenting and pondering these exposing, as well as these concealing, conditions of color and pattern, and they have proposed several theories or hypotheses explanatory of the valious conditions. These hypotheses are plausible; but they are much more than that: they are each more or less well backed up by observation and experiment, and some of them have gained a large acceptance among naturalists. Both the reasoning and observed facts on which these hypotheses rest are based on the usefulness of the colors and patterns to the animals in their relation to the outside world. And the influence of advantage and natural selection is given the chief credit for determining the present-day conditions of these colors and patterns.

Before, however, we take up these hypotheses, defining 
them and looking over some of the evidence arldued for their support, as well as some of the rriticism leveled at them, we may advisedly look to the actual physical causation of color in animals. Whatever the use or significance of color, our understanding of this use must be hased on a knowledge of the method or modes of its actual production.

Color in organisms is produced as color in inorganic nature is. Certain substances have the capacity of sclective ahsoription of light rays, so that when white light falls on them, certain colors (light waves of (ertain length) are absorbed, while certain others (light waves of certain othor lengrtıs) are reflected. An object is red because the substance of which it is (superficially) composed, reflects the red rays and alsocorlos the others. Certain other objects or substances may produce color (be colored) because of their physical rather than their chemicul constitution; their surface may be composed of superposed lamellie, or it may be so striated or scaled that the varions component rays of white light are reflected, refracted, and diffracted in such varying manner (at different angles and from different depths) that complex interference effects are poluced, resulting in the practical extinguishing of certain colo:s (waves of certain length) or the reflection of some at angles so as not to fall on the eye of the observer, and so on. Such colors will change with changes in the angle of observation, and are the so-called metallic or iridescent colors. These two categories of color have been aptly called chemical and physical: chemical color depending on the chemical matic-up of the body, physical on its structural or physical make-up. As a matter of fact we shall find that most animal colors are due to a combination of these two kinds.

(Substances that produce color by virtue of their capacity to absorb certain colors, and reflecet only certain others. we may call, in our discussion of color production, "pigments". and "pigmental" may be used as practically synonymous with "chemical" in referring to colors thus produced, while "structural" may be used as synomymons with "physical" in referring to colors dependent on superficial structural character of the insect body. For colors produced hy the coopperation of both pigment and structure. "combination" or "chemicophysical" may be used as a defining name.)

Now in all animals, color depends on the presence and ar- 
rangement of pigments or on the fine structure of superficial parts, as feathers, scales, skin, etc., or on a combination of the two color-producing conditions. In birds, for example, certain fat pigments called lipochromes (which are either actual reserve food products or are associated with such), are abundantly present in the feathers, bill, feet, etc., producing reds, yellows, browns, etc., and certain other dark melanin pigments are distributed as minute amorphous granules in the cuticular structures or epidermis, producing plain gray, brown, black, and related tints. In addition, the feathers are so constructed that they may, and do in some cases, produce the most brilliant iridescent and metallic colors, as familiarly shown to us by the humming birds, the grackles, etc. Most such metallic colors in birds, however, are produced by a combination of pigment and structure, and not by structure alone. The colors of mammals, of reptiles, of amphibians and of fishes might also be referred to, and as far as they have been studied or analyzed according to their causes, we should find that in mammals the pigmental colors are mostly produced by so-called melanins which seem to be waste products. In the fishes, amphibians and reptiles, the pigments are both lipochromes and melanins, while in all the vertebrate classes there occur cases in which vivid physical or optical color's are produced by cuticular structure. The most extended study of color in animals, however, has been devoted to insect colors. Here we have a pretty clear understanding of all the color-producing agents, and an analysis of all the colors more usually met with, into their proper classes, that is, whether exclusively pigmental, exclusively structural or mixed structural-pigmental. In a raluable paper by Tower, a table of insect colors showing the classification and mode of production of the various colors is given, as follows (see next page):

The only hypothesis that gives to colors and markings a value in the life of animals, at all comparable with the degree of specialization reached by these colors and markings and by the special structures developed to make them possible, is that already referred to as the theory of protective and aggressive resemblances, of warning and directive patterns, and of mimicry. These various uses of color patterns are all concerned with the relation of the animal to its environment: they are means of protecting the animal from its enemies, or of enabling 


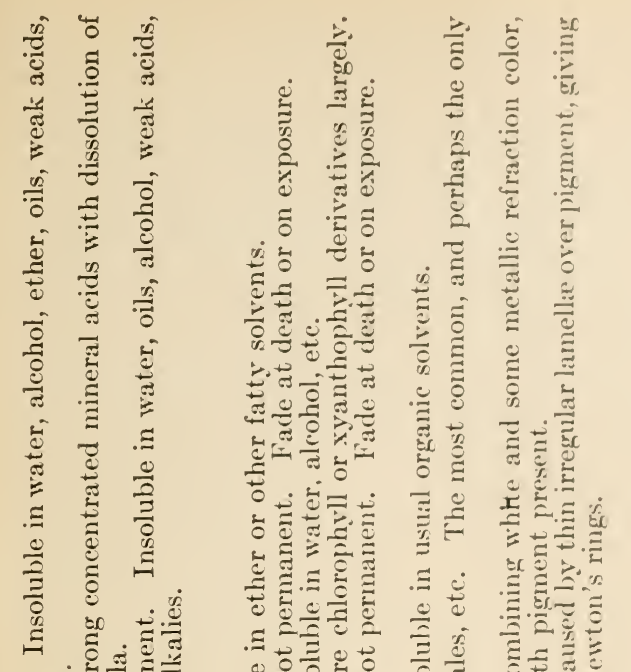

n

。

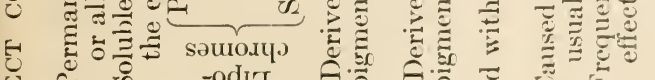

它

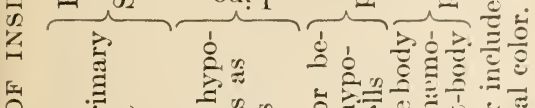

8

(1)
20.
.

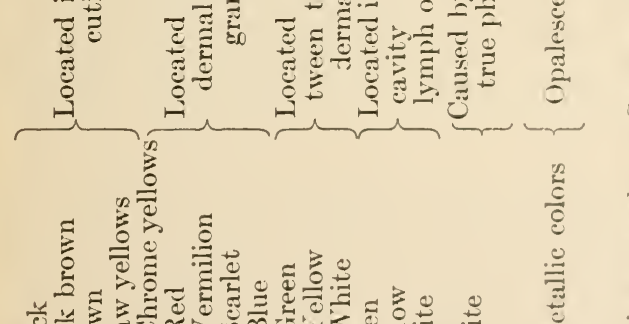

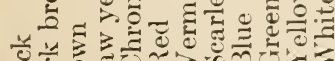
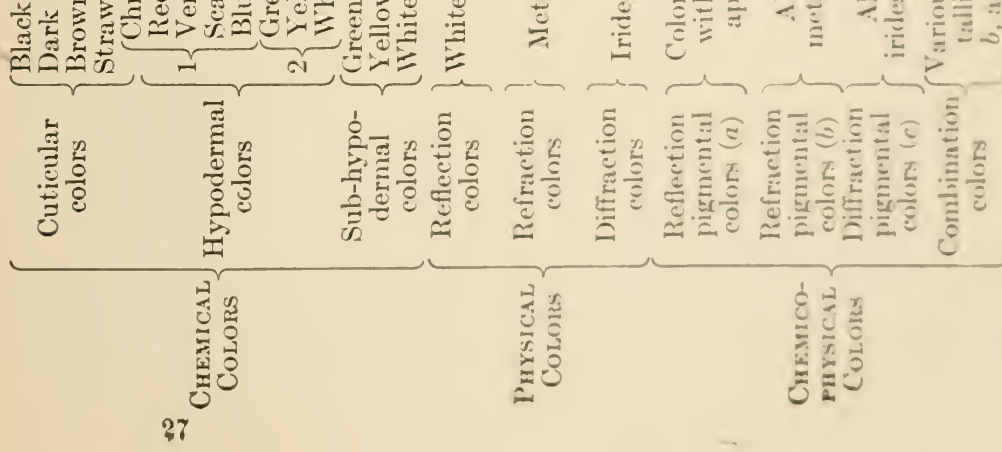
it to capture its prey. They are uses obviously concerned with the "struggle for existence": they are "shifts for a living." For the sake of clearness in discussion these various uses will be rather arbitrarily classified into several categories which in Nature are not so sharply distinguished as the paragraph treatment of them might suggest.

The general harmonizing in color and pattern with the color scheme of the usual environment is a condition which every field student of animals recognizes as widely existing. The green color of foliage-inhabiting forms, as tree frogs and katydids, the mottled gray and tawny of the mammals, birds, lizards, and insects of the deserts, and the white of the hares and foxes and owls and ptarmigan of the arctic and alpine snow-covered wastes, are color tones obviously in harmony with the general color of the environment. In the brooks most fishes are dark olive or greenish above and white below. To the birds and other enemies which look down on them from above, they are colored like the bottom. To their fish enemies which look up from below, their color is like the white light above them, and their forms are not clearly seen. The fishes of the deep sea in perpetual darkness are violet in color below as well as above. Those that live among seaweeds are red, grass-green, or olive like the plants they frequent. The difficulty of distinguishing a quiescent moth from the bark on which it is resting, a green caterpillar or leaf-hopper or meadow grasshopper from the leaf to which it clings, a roadside locust from the soil on which it alights, is a difficulty which has to be reckoned with by every collector.

Now while there are few human collectors of insects, there are hosts of bird and toad and lizard insect-hunters, to say nothing of the many kinds of predaceous insects which use their own cousins for chief food. So that where this difficulty of distingliishing the resting insect from its environment is suffi. cient to postpone success on the part of the insect-hunting bird or lizard, the life of the protectively colored insect is obviously saved, for the time, by its dress. This is a utility of color and pattern than which there can be, from the insect point of view, nothing higher.

One special point should be noted in connection with the general protective resemblance, and that is, that the harmonixing or melting into the environment may often be accomplished 
by a color and pattern not directly imitative of the immediate environmental objects, but of such a kind as to he lost among the light and shadow graclations produced by light shining through leaves, twigs, ete. Thayer has very interestingly shown the possibilities and actual effects of such graulatory or light and shadow patterns among birds, and thus o. plains many cases of bird patterns not apparently very closely imitative, but nerertheless very effertive in making the limel indietinguishable when at rest on its nest or in the hushes or grans of its usual habitat. General protective resemblaner is undoubtedly very widespread among animals, and is not rasily appreciated when the animal is secm in musemus or zoülogical gardens - that is, away from its natural or normal onvironment.

A modification of general eolor resemblance fommd in many. animals, may be called variable protective resemblatnere. C'entain hares and other animals that live in northern latitudes : wholly white during the winter when the snow (overs ryerything; but in summer, when much of the snow melts, revesting the brown and gray rocks and withered leaves, these rementume change color, putting on a grayish and brownish cont of hair. The ptarmigan of the Rocky Mountains (one of the gromer). which lives on the snow and rocks of the high pratis, is alnowet wholly white in winter; but in summer, when most of the snow is melted, its plumage is ehiefly brown. Iocusts of ranious species of the genus Trimerotropis show a variability in color of individuals, ranging through gray, brown, recllish, phumbeous and bluish, and such accompanying valublility in markine as to result in producing much variety of alperarames in a sinerle series of eollected individuals. Ire have noted in collecting these locusts in Colorado and California that this variability of coloration is directly associated with color differences in the soil of the localities in which these loensts live: the revhlinh indivicluals are taken from spots where the soil is reddi-h, the. grayish, where it is sand-colored, and the plumbloms amd hluish from soil formed by decomposing bluish rock. Thu sume variations in color are evident in the horned touls (Phrynosomu). as found on varions eolors of desert soils.

On the eampus of Stanforel l'niversity there is a litule pomet whose shores are covered in some places with hits of humi-h rock, in other places with bits of reddish rock, and in scill 
others with sand. The toad bug (Galgulus) lives abundantly on the banks of this pond. Specimens collected from the blue rocks are bluish in ground color, those from the red rocks are reddish, and those from the sand are sand-colored. But these insects have fixed colors; they cannot, like the chameleon and certain other lizards, or like numerous small fishes and some tree frogs, change color, quickly or slowly, with changes in position-that is, movements from green to brown or to other colored environment. Variable protective resemblance in insects is, as far as known, a variability directly induced, to be sure, by varying environment, but all acquircd during the development of the individual insects, and fixed by the time they reach the adult stage. But changes of color to suit the changing surroundings can be quickly made in the case of some animals. The chameleons of the tropics, whose skin changes color momentarily from green to brown, blackish or golden, is an excellent example of this highly specialized condition. The same change is shown by a small lizard of our Southern States (Anolis), which from its habit is called the Florida chameleon. There is a little fish (Oligocottus) which is common in the tide pools of the bay of Monterey, in California, whose color changes quickly to harmonize with the different colors of the rocks it happens to rest above. Most of the tree frogs show this variable coloring.

The well-known experiments of Trimen, Müller, and Poulton on the pupating larvæ of swallow-tailed butterflies (Papilio), and of Poulton on other butterflies of numerous species with naked chrysalids, show that they take on the color, or a shade resembling it, of the substance surrounding these larvæ. They show also that the result is due to a stimulus of the skin by the enclosing color, and not to a stimulus received through the eyes, and carried to the skin by the nerves. Larvæ just ready to pupate were enclosed in boxes lined with paper of different colors; the chrysalids when formed were found to be colored to harmonize with that particular shade of paper by which they were surrounded while pupating. As these chrysalids in nature hang exposed on bark and in other unsheltered places, without protecting cocoon or cover of any kind, the actual protective value of this harmonious coloration is obvious. It is a familiar fact to entomologists that most butterfly chrysalids and naked pupæ of moths (unless concealed in the ground or elsewhere) 
resemble in color and general external appearance the surface of the object on which they rest. The chrysalids of various Papilios are indeed marvelously faithful imitations of bits of rough bark (Fig. 250).

The larvie (caterpillars) of various moths, particularly Geometrid and Sphingid species, often appear in two color types, one brown and the other green. Poulton has shown by experiment and observation with some of these species that those larræ reared among green leaves and twigs become green, while those on dry branches become brown.

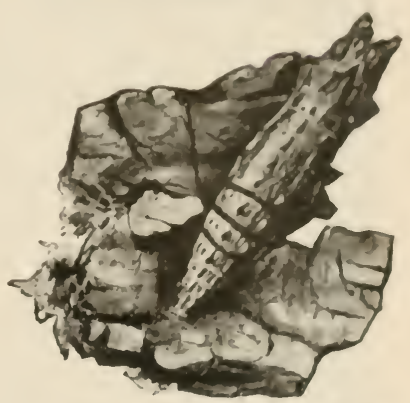

FIG. 250.-Chrysalid of swallowtail butterfly, Papilio, which clunely resembles the bark on which it remts.

This variable protective resemblance, like that of Trimerotropis, Galgulus, and the Papilio chrysalids, also is fixed afte:
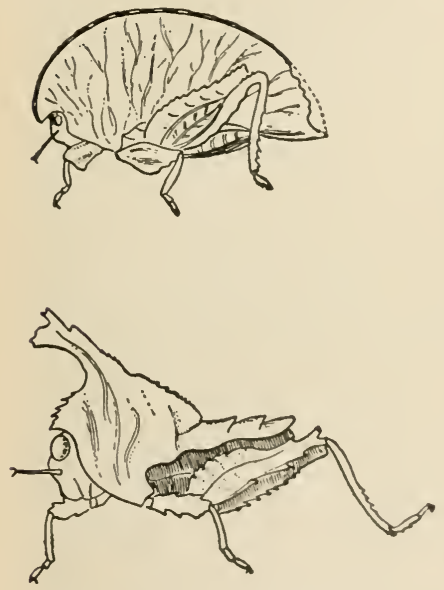

Fig. 251.-Two orthopterous leaf hoppers or membracids: The upper one, Xerophyllum simile: the lower one. Clader nolus humberti:nus. (After Bolivar.) being once acquired.

An interesting example of color harmony which may be classified under the head of variable protective resemblance is that of the larvat of Lycena sp., abundant on the flower heads of the California buckeye, Esculus californicus, that blooms in May. The buds of the buckeye are ereen, or green and rose, or even all rose externally. The quiet sluglike l,yeanid larva lic longitudinally along the buds and their short stems, and are either green with faint rose tinge, especially along the midulle of the hack, or are distinctly rosy all wer. depending strictly upon the

color tone of the particular branch serving as their hahitat. The correspondence in shade of color is strikingly exart: the 


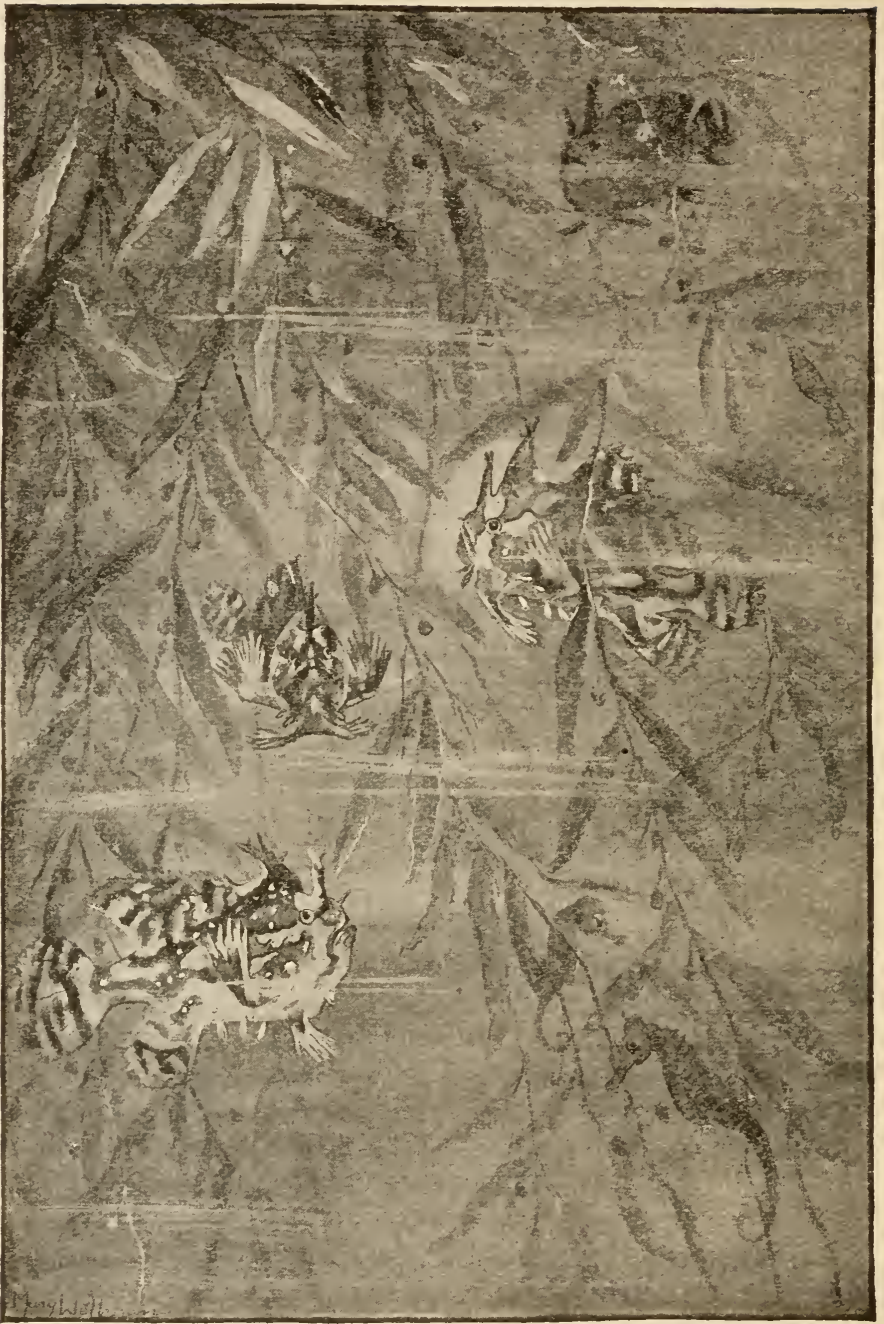

Frg. 252.-The mousefish, Pterophryne histrio, in the Sargassum or Gulf weed. The fishes are marked and colored so as to be nearly indistinguishable from the mass of the Gulf weed. In the lower right-hand corner of the figure are two seahorses, also shaped and marked so as to be concealed. 
utter indistinguishability of the larve is something that needs to be experienced to be fairly ralized.

Far more striking are those catses of protective resemblanc. in which the animal resembles in color and shape, sometimes in extraordinary detail, some particular object or part of its usual enviromment. Certain parts of the Atlantic Ocean are covered with great patches of seawred called the Cinlf weed (Sargassum), and many linds of animals - fishes and other creatures-live upon and among the algxe. No one can fail to note the extraordinary color resemblances which exist between these animals and the weed itself. The gulf weed is of an olive-yellow color, and the crabs and shrimps, a certain flatworm, a certain mollusk, and certain little fishes, all of which live among the Sargassum, are exactly of the same shade of yellow as the weed, and have small white markings on their bodies which are characteristic also of the Sargassum. The mouscfish and the little seahorses, often attached to

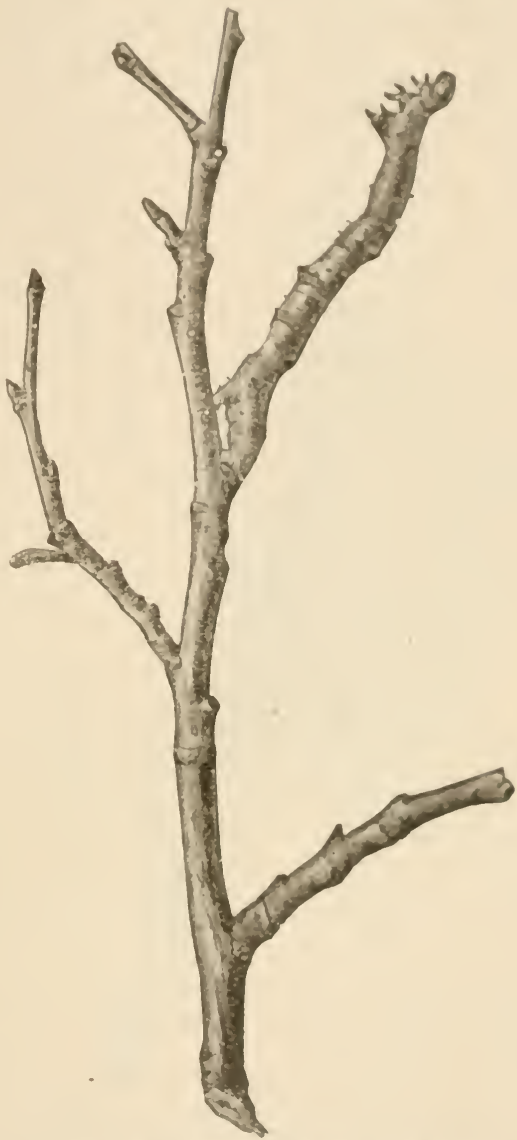

Fig. 253.- - Genmetriil larva on a wranch. (The larva is the upper right-hand projection from the twig.) the Gulf weed, show the same traits of coloration (Fig. 2.:2). The slender grass-green caterpillars of many moths and buterflies resemble very dosely the thin gratsis blades among which they live. The larvax of the greometrid moths, called inchworms 
or spanworms, are twiglike in appearance, and have the habit, when disturbed, of standing out stiffly from the twig or branch upon which they rest, so as to resemble in position as well as in color and markings a short or a broken twig. One of the

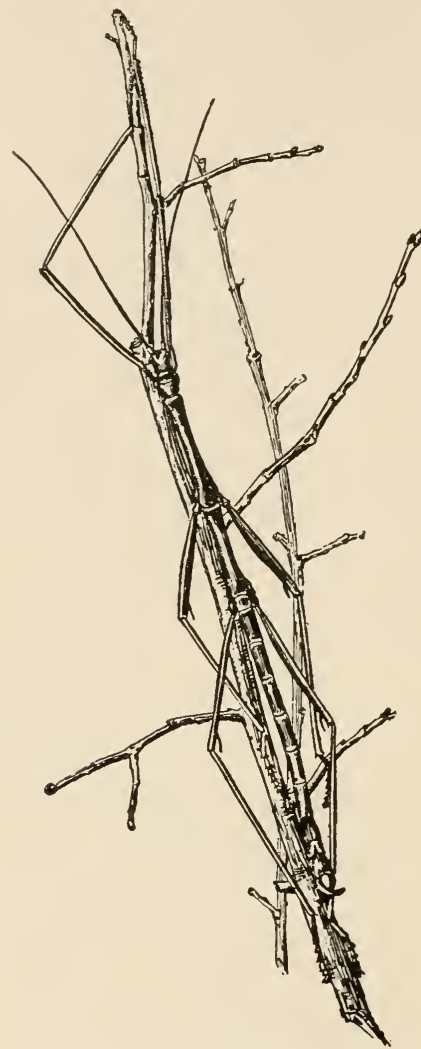

FIG. 254.-The walking-stick insect, Diapheromera femorata, on twig.

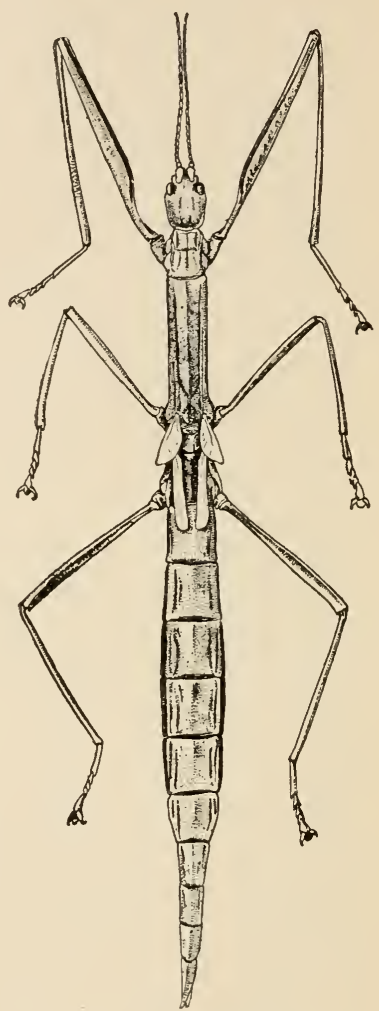

FiG. 255.-A twig-simulating insect from Samoa. (From specimen.)

most striking resemblances of this sort is shown by the large geometrid larva illustrated in Fig. 253, which was found near Ithaca, New York. The body of this caterpillar has a few small, irregular spots or humps, resembling very closely the scars left by fallen buds or twigs. These caterpillars have a special muscular development to enable them to hold themselves rigidly 
for long times in this trying attitule. They also lack the middle proplegs of the body, common to other lepidopncorous larva, the presence of which would temel to destroy the illusinso suecessfully carried out by them. The common walkmg stick (Diapheromera) (Fing. 2ji), with its wingles ereatly. eiongate, dull-colored body, is an cxcellent example of special protective resemblance. It is quite indistingrishalle, when at rest, from the twigs to which it is clinging. Another member of the family of insects to which the walking stick belongs is the famous green-leaf insect (Phyllium) (Fig. 256). It is found in South America and is of a bright green color, with broad leaflike wings and body with markings which imitate the leaf veins, and small irregular yellowish spots which mimic decaying or stained or fungus-covered spots in the leaf.

There are many butterflies that resemble dead leaves. All our common meadow browns (Grapta), brown and reddish butterflies with ragged-edged wings, that appear in the autumn and flutter aimlessly about cx-

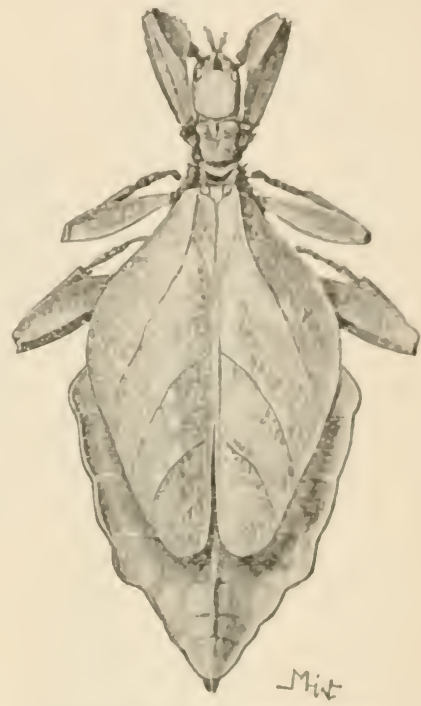

Fig. 256.-The grean-leaf invert, Plyllium. actly like the falling leaves, show this resemblance. But most remarkable of all is a laree butterfly (Kallima) (Fig. 257) of the East Indian region. The upper sides of the wings are dark, with purplish and orange markings, not at all resembling a dead leaf. But the butcerflies when at rest hold their wings together over the back, so that only the under sides of the wings are exposcd. The under sides of Kallima's wings are exalctly the color of a deat and dried leaf, and the wings are so held that all combine to mimic with extraordinary ficlelity a dead leaf still attalled to the twig by a short pedicle or leaf-stalk imitated hy a slort tail on the hind wings, and showing midrils, ohligue vains, and, most remarkable of all, two apparent holes, like those mate 
in leaves by insects, but in the butterfly imitated by two small circular spots free from scales and hence clear and transparent. With the head and feelers concealed beneath the wings, it makes the resemblance wonderfully exact.

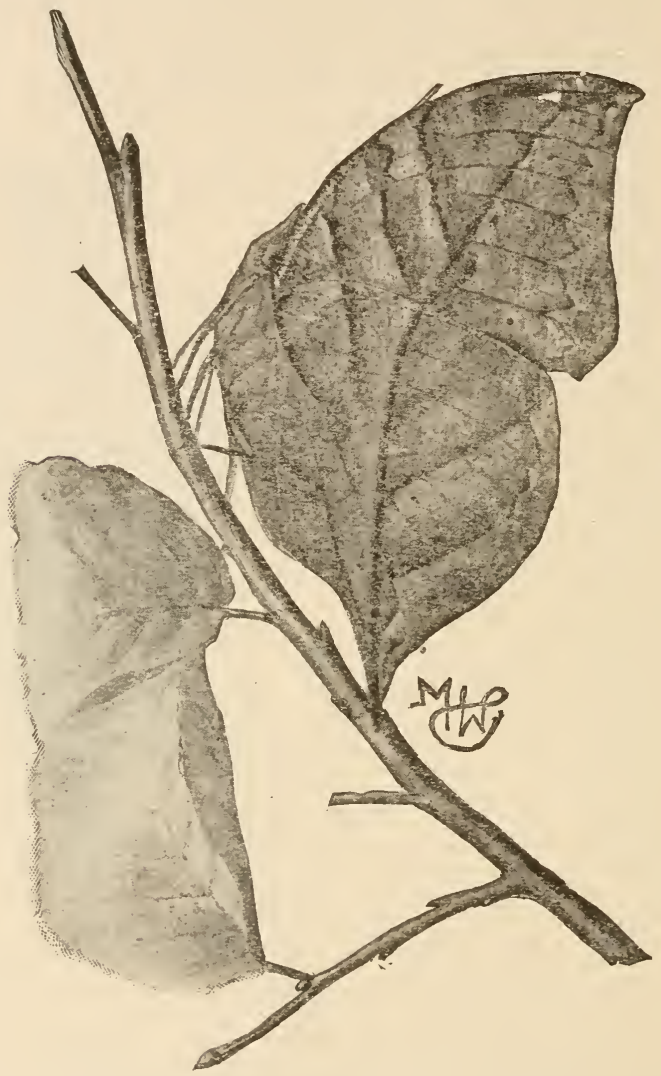

FIG. 257.-Kallima, the "dead-leaf butterfly."

The moths of the genus Cymatophora, and their larra also, mostly harmonize excellently with the gray bark on which they rest, the moths adding to their general simulation the curiou habit of resting, often with folded wings, at an angle of for $\mathrm{fy}^{-}$ five degrees with the tree trunk, head downward, with the curiously blunt and uneven wing tips projecting, so as to imitate 
with great fidelity a short brok(n)off branch or chip of bark. Numerous other moths and eaterpillars resemble bark and habituilly rest on it. Catocala, Schizura, and other genera furnish $\mathrm{cx}^{-}$ amples familiar to the moth collcetor.

here are numerous instance: Ot $s_{1}^{+}$ial protective resemblance among spiders. Many spiders that live habitually on tree trunks resemble bits of bark or small, irregular masses of lichen. A whole family of spiders, which live in flower eups lying in wit for insects, are white and pink and particolored, resembling the, markings of the special flowers frequented by them. This is, of course, a special resemblance not so much for protection as for aggression; the insects coming to visit the flowers are unalyle to distinguish the spiders and fill an easy prey to them.

Any field student of insects,

by paying attention to the matter of ipecial protective resemblance, esn soon make up a striking list of examples. Fumc of these may be more convincing to him than to persons ser-

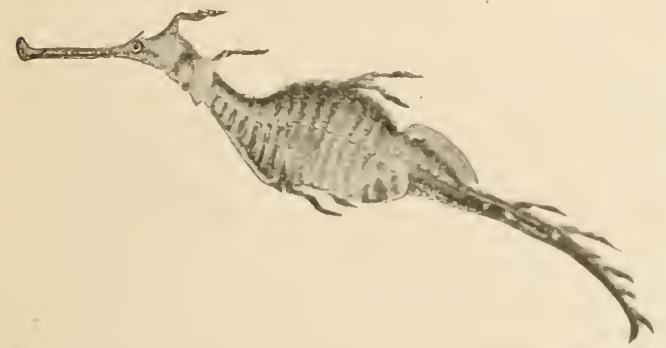

Fra. 259.-A pipefish, Phylloptery/x, which resembles (he sesweed among which it lives. ing his speciment: in the colloretine hoxes, and sume incleal will problalily be cise tioned hy elonet naturaliots. J But mevertheleses no collereter or firld student llas failed to note 
many examples of this clever artifice oi Nature to protect her children.

If the field student may be relied on to note and record a long list of insects colored and marked so as to harmonize well with their general environment or with some specific part of it, he may also be relied on to bring in a list of opposites: a record of bizarre and conspicuous forms, colored with brilliant blues and greens and streaked and spotted in a manner utterly at rariance and in contrast with the foliage or soil or bark or whatever is the usual environment of the insect. The great redbrown monarch butterfly and its black-striped green and yellowish larva, the tiger-banded swallowtails, the black and
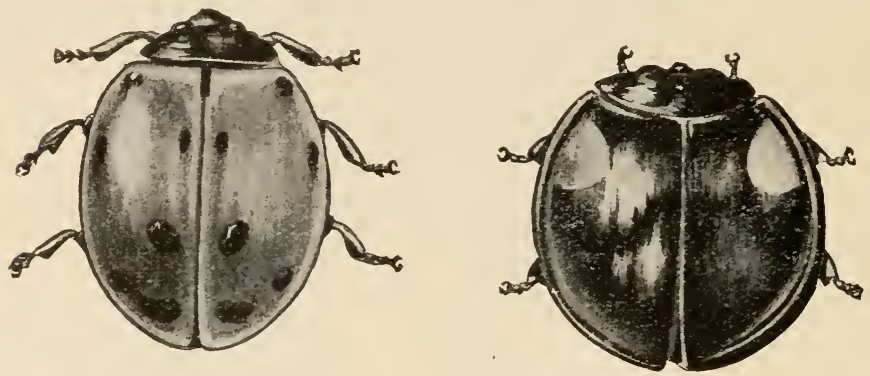

FIG. 260.-Ladybird beetles, conspicuously colored and marked.

yellow wasps and bees, the ladybird beetles with their sharply contrasting colors, the brilliant green blister beetles, the striped and spotted chrysomelids - in all these and many others there can be no talk of protective resemblance. If only such a paradoxical theory as protective conspicuousness could be established, then these colors and markings might well be explained by it.

Exactly such an explanation of brilliant color and contrasting markings is afforded by the theory of warning colors. It has been conclusively shown, by observation and experiment by several naturalists, that many insects are distasteful to birds, lizards, and other predaceous enemies. This is so because the blood lymph or some specially secreted body fluid of these insects contains an acrid or ill-tasting substance so that birds will not, if they can recognize the kind of insect, make any attempt to catch or eat one. This letting alone is un- 
doubtedly the result of previously made trials; that is, it hats been learned by experience. Now it womld obvinusly he of adrantage to those sperices of inserets that are ill-tanting, if their coloring and pattern were so distinclive and (onspiconon as to make them readily known hy hirds, and once learmed easily seen. A distasteful catcrpillar nerels to advortice it: unpalatability so effectively that the swooping birel will reene nize it before making that single sharp-cutting stroke or perk that would be as fatal to a catcrpillar ats heing wholly eaten. Hence the need and the utility of warning colors. And inderel the distasteful insects, as far as recognized, are mostly of conspicuous colors and patterns.

Such warning colors are presumalyly possessed not only iy unpalatable insects, hut also by many that have cortain special means of defense. The wasps and bees, provided with stings dangerous to most of their enemies, are almost all comspicuously marked with yellow and black. Many lungs, woll defonded by sharp beaks, possess a conspicuous (o)lor pattern.

Numerous other animals besides insects also are belicred to have warning colors. The Gila monster (II cloclerma). the only poisonous lizard, differs from most other lizards in beine strikingly patterned with black and brown. Fome of the venomous snakes are conspicuously colored, ats the coral snakes (Elaps) or coralillos of the tropics. The naturalist Bcht, whose observations in Nicaragua have added much to our kuowledge of tropical animals, describes as follows an interesting (xample of warning colors in a species of frog:

"In the woods around Santo Domingo (Nicaragua) there are many frogs. Some are green or brown and initate green or dead linvere and live among foliage. Others are dull carth-colores?, and hicte is holes or under logs. All these come out only at night to fecel, and they are all preyed upon by snakes and birds. In contrast with thea obscurely colored species, another little frog hops about in the dintime. dressed in a bright livery of red and bluse. He camment be miataken for any other, and his flaming breast and hlue storekings show that he diene not court concealment. He is very abundant in the damp wools, and I was convinced he was uneatable so soon as I made his acrubintance and saw the hapyy sense of serurity with which he hopped alout. took a few specimens home with me, and tried my fowls and duch: with them, but none would tomeh them. At list, hy throwing down 
pieces of meat, for which there was a great competition among them, I managed to entice a young duck into snatching up one of the little frogs. Instead of swallowing it, however, it instantly threw it out of its mouth, and went about jerking its head, as if trying to throw off some unpleasant taste."

Certain other insects which are without special means of defense and are not at all formidable or dangerous, are yet so marked or shaped and so behaved as to present a curiously threatening appearance. The large green caterpillars of the sphinx moths have a curious rearing-up habit which seems to

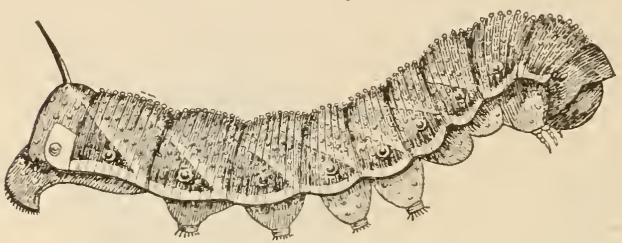

FIG. 261.-A " tobacco-worm," larva of the sphinx moth, Phlegethontius carolina, showing terrifying attitude. simulate threatened attack (Fig. 261). They have, too, a great pointed spine or horn on the back of the posterior tip of the body which has a most formidable appearance, but is, as a matter of fact, not at all a weapon of defense, being quite harmless. Numerous stingless insects, when disturbed, wave about the hind part of the body or curl it over or under, mich as stinging insects do, and seem to be threatening to sting. The striking eye spots of many insects are believed by some entomologists to be of the nature of terrifying markings. Marshall tried feeding baboons a full-grown larva (about seven inches long) of the sphinx moth, Chorocampa osiris. The larva has large strongly colored eye spots and is

"remarkably snakelike, the general coloring somewhat recalling that of the common puff-adder, Bitis arietans. The female baboon ran forward expecting a titbit, but when she saw what I had brought she flicked it out of my hand on to the ground, at the same time jumping back suspiciously: she then approached it very cautiously, and after peering carefully at it at the distance of about a foot she withdrew in alarm, being clearly much impressed by the large blue eyelike markings. The male baboon, which has a much more nervous temperament, had meanwhile remained at a distance surveying the proceedings, so I picked up a caterpillar and brought it towards them, but they 
would not let.me approach, and kejet ruming away round and round their pole, so I threw the insect at theml. 'Their fright was ludicrous to see; with loud (ries they jumped aside and clambered up the pole as fast as they could go, into their box, where they sat peering orer the edge watching the uncanny ubject below." (Mirshill.)

Marshall aise writes concerning the markings on the wines of the mantis, 'Pseudocreobotra wahlbergi:

"They are, I think, almost certainly of a terrifying character. When the insect is irritated, the wings are raiserl over its back in sueh at manner that the tegmina stand side by side, and the marking on them present a very striking resemblance to the crreat yollow eyes of a lirul of prey or some feline animal, which might well deter an insertivorous enemy. It is noticeable that the insect is always carreful to kerp) the wings directed toward the point of attark, and this is oftendone without altering the position of the body."

Still another use is believed by some entomologists to be afferced by such markings as ocelli and other specially conspicuous spots and flecks on the winess of butterflies and mothe, and by such apparently useless parts as the "tails" of the himel wings of the swallowtail, and Lyeanid butterflies, and others. Marshall occupied himself for a long time with collecting hutterflies which had evidently been snapped at by hirds (in some cases the actual attack being observed) and suffered the loss of a part of a wing. Fxamining these specinens when bronght together, Poulton and Marshall noted that the " great majority" [of these injuries to the wings] are inflictert at the anal angle and adjacent hind margin of the hind winge, a comsiderables number at or near the apical angle of the forr wing. and connparatively few between the points." In this fact. compled with the fact that the apieal and hind aneres of the fore and hind wings respectively are precisely those rerions of the winge mont usually specially marked and prolonged as amerular frocenes or tails, Poulton sees a sperial signifieanee in the patterms of these wing parts. He thinks they are "directire marks which temel to divert the attention of an enemy from nore vital parts." It is obvious that a butterfly can very well afford to lose the tip or tail of a wing if that losis will save losing heart or aluloment. Poulton sees a "remarkihle resemblance of the marks and 
structures at the anal angle of the hind wing, under side, in many Lycanidce, to a head with antennæ and eyes," and recalls that this has been independently noticed by many other observers. The movements of the hind wings by which the tails, which appear like antennæ, are made continually to pass and repass each other, add greatly to this resemblance.

Very many species of animals, especially among the vertebaates, possess certain distinctive and striking markings, which

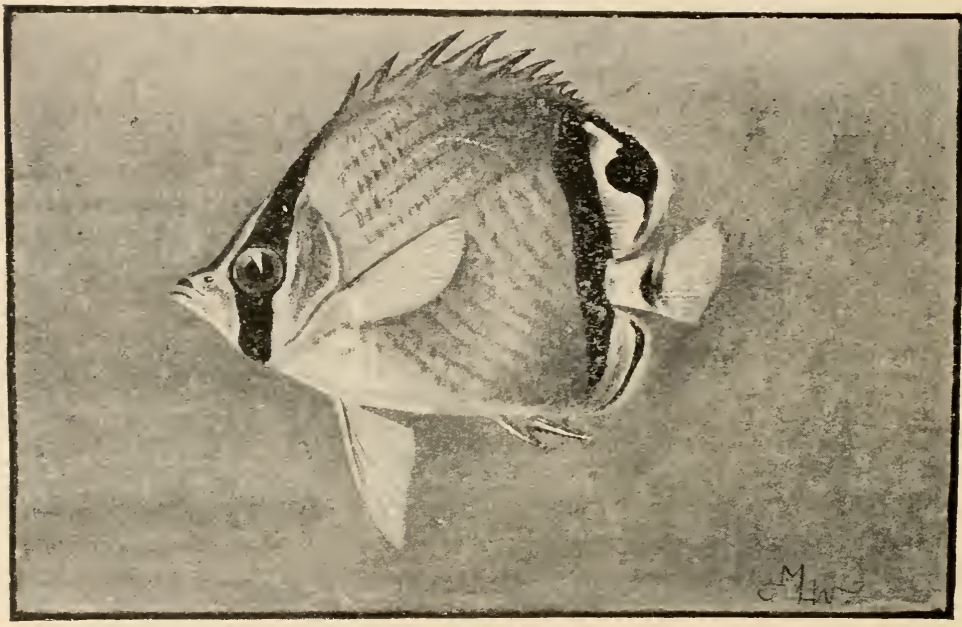

FIG. 262.-The butterfly fish, Chotodon ragabundus, from Samoa. This small fish is most strikingly colored.

have been supposed to serve as recognition marks to other animals of the same species. In this theory, these marks afford a swift means of knowing friends from enemies. Of this nature are the white tufts at the tail of the cottontail rabbit, the black patch of the blacktail deer, the flanks of the Rocky Mountain antelope, the concealed scarlet crest of the kingbird, the fiery shoulder of the redwing blackbird, the blue speculum of the duck, the black bars and eye spots of the butterfly fishes (Chotodon), and the peculiar marks of one form or another on a host of mammals, birds, reptiles, and fishes.

It is very easy to indicate recognition marks. Keeler, among others, has given an elaborate list of the principal cases among American birds, and there is scarcely a species without one or 
more. Nevertheless we are not sure that many, or even any of them, actually serve the purpose of recognition among the animals themselves, however convenient they may be to us who study them. However plausible the theory of recognition marks may seem, it is still not proved to have any objective basis.

Of all the theories accounting for the utility of color and pattern, that of mimicry demands at first thought the larerent degree of credulity. As a matter of fact, however, the observattion and evidence on which it rests are as convincing as are those for almost any of the other forms of protective cclor pattern. Although the word "mimicry" could often have been IIserl aptly in the account of special protective resemblance, it lias been reserved for use in connection with a specific kind of imitation; namely, the initation by an otherwise defenceless insect, one without poison, beak, or sting, and without acrid and distasteful body fluids, of some other specially defencled or inedible kind, so that the mimicker is mistaken for the minicked form and, like this defended or distasteful form, relieved from attack. Many cases of this mimiery may be noted by any field student of entomology.

Buzzing about flowers are to be found various kinds of bees and also various other kinds of inserets thoroughly beelike in appearance, but in reality not bees nor, like them, defenderl by sting. These bee mimickers are mostly flies of varions families (Syrphide, Asilide, Bombyliide), and their resemblance to bees is sufficient to and does constantly deceive collectors. We presume, then, that it equally deceives birds and other insect enemies. Wasps, too, are mimicked by othor insects; the wasplike flies, Conopide, and some of the rlearwinged moths, Sesizde are extremely wasplike in generis seeming.

The distasteful monarch butterfly, I nosia plexippus, willespread and abundant-a suceessul butterfy, whose success undoubtedly largely depends on its inedibility in both larval and imaginal stages-is mimicked with extraordinary ficlelity of detail by the viceroy, Basilarchia archippus (lig. 26:3). The Basilarchias, constituting a genus of numerous species, are with lut two or three exceptions not at all of the color or pattern of Anosia, but in the case of the particular species archippus, not only the red-brown ground color", hut the fine pattern 


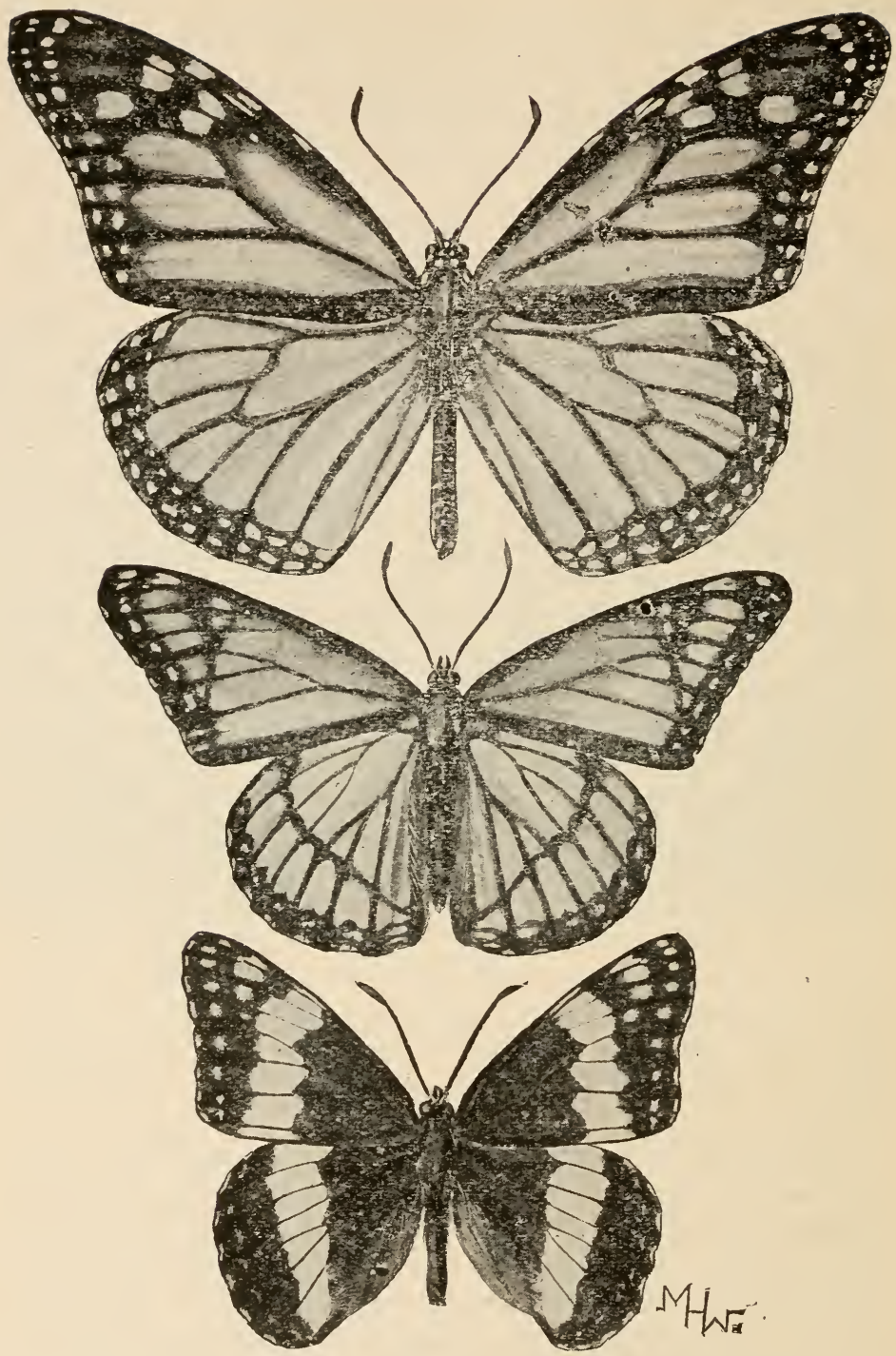

F'IG. 263. - The mimicking of the inedible monarch butterfly by the edible viceroy. The figure at the top is the monarch, Anosia plexippus. The midlde figure is the viceroy, Basilarchia archippus. The lowest figure is another member of the same genus, Basilarchia, to show the usual color patte $n$ of the species of the genus. 
details in black and whitish, eopy faithfully the details in I nosia; only in the addition of a thin blackish line arorose the discal areat of the hind wings does archippus show any noticeable differcucr. The viceroy is believed not to be distastoful to hirds, hut its close mimiery of the distasteful monareh undoubtedly learle to its being constantly mistaken for it hy the hirds and thus left ummolested.

The subject of mimicry has not been studied larecely anume the insects of our country, but in the tropices and subtroppics numerous striking examples of minetid forms have been noted and written about. The members of two larere families of butterflies, the I)anaida and Helioniclar, are distasteful to hirit: and are mimicked by many species of otler hutterfly families, especially the Pieridar, and by the swallowtails, Papilioniclar. Many plates illustrating such cases have been publisherl hy Poulton and Marshall, Haase, Weismann, and others. Shelford, in an extended account of mimicry as exemplified among the insects of Borneo, refers to and illustrates many strikiner examples among the bectles, the Hemiptera, 1)iptera, (1)thoptera. Neuroptera, and motls; distasteful Luciul beetles are clumply mimicked by other beetles, by Hemijtera, and by neothe: distasteful lodybird beetles are mimicled by Hemiptera, Orthoptera, and by otlec beetles; stinging Hymenoptera are mimicked by stingless Hymenoptera, by bectes, flims. hugs. and moths. Poulton and Narshall, in their accomnt of mimicry among South African insects, pulblish many colored plates revealing most striking rescmblanees between insects well defended by inedibility or defensive weapons, and their mimickers. Our space unfortunately prevents any specific consideration of these various interesting cascs.

The special conditions under which minicry cxists have heen seriously studied and are of extreme interest. It is obvious that the inedible or defended mimicled form must be more abundant than the mimicker, so that the experimenting young bird or lizard may have several chances to one of getting an ill tarte or a sting when he attacks an insect of certain type or battern. This requirement of relative abundance of mimicker and mimicked seems actually met, as proved hy abservation. In some cases only females of a specoes indulge in minicry. the males being unmolified. This is cxplidined on the gromel of the particular neresity foj poutection of the cys-liden, heary- 
flying, long-lived, and hence more exposed females, as compared with the lighter, swifter, short-lived males.

It has been found that individuals of a single species may mimic several different species of defended insects, this polymorphism of pattern existing in different localities, or indeed in a single one. Marshall believes that seasonal polychromatism of certain butterfly species is associated with the mimicry of certain defended butterflies of different species, these different species appearing at different times of the year.

It is needless to say that such hypotheses and theories of the utility of color and pattern have been subjected to much criticism, both adverse and favorable. The necessity for limiting results within the working range of efficient causes has been the soundest basis, in our judgment, for the adverse criticism of the theories of special protective resemblance, warning colors, and mimicry. Until recently most of the observations on which the theories are based have been simply observations proving the existence of remarkable similarities in appearance or equally striking contrasts and bizarrerie. The usefulness of these similarities and contrasts had been deduced logically, but not proved experimentally nor by direct observation. In recent years, however, a much sounder basis for these theories has been laid by experimental work. There is now on record a large amount of strong evidence for the validity of the hypothesis of mimicry. Certainly no other hypothesis of equal validity with that of protective resemblance and mimicry has been proposed to explain the numerous striking cases of similarity and the significant conditions of life accompanying the existence of these cases, which have been recorded as the result of much laborious and indefatigable study by certain naturalists.

Plateau and Wheeler have tasted so-called inedible and distasteful insects and found nothing particularly disagreeable about them. But as Poulton suggests, the question is not as to the palate of Plateau and Wheeler nor of any man; it concerns the taste of birds, lizards, etc. Better evidence is that afforded by actual observation of feeding birds and lizards; of experimental offering under natural conditions of alleged distasteful insects to their natural enemies. Marshall's observations and experiments on the point are suggestive and undoubtedly reliable. Much more work of the same kind is needed.

The efficient cause for bringing color and pattern up to such 
a high deg.ee of specialization has been assumed, by nearly all upholders of the use hypotheses, to be natural selection. This agent can account for purposefulness, which is olviously an inherent part of all the hypotheses. And no other suggested agent can. Weismann makes, indeed, of this faet, by inverting the problem, one of the most effective arguments for the potency and "Allmacht" of natural selection. He declares that this existence of special protective resenthlance, warning colors. and mimicry proves the reality of selection. But it must he asked, while admitting the cogeney of much of the argument for natural selection as the efficient canse of high specialization of color and pattern as we have seen it actually to exist, how such a condition as that shown by the mimicking viceroy but terfly has come to be gradually devoloped-gradual development being confessedly selection's only mode of working. ('ould the viceroy have had any protection for itsclf, any advantage at all, until it actually so nearly resembled the inedible monarch is to be mistaken for it? No slight tinge of hrown on the black and white wings (the typical color scheme of the genus), no slight change of marking, would be of any service in making the viceroy a mimic of the monarch. The whole leap from typical Basilarchia to (apparently) typical Anosia had to be made practically at once. On the other hand, is it necessary for Kallima, the simulator of dead leaves, to go so far as it has in its modification? Such minute points of detail are there as will never be noted by bird or lizard. The simple necesity is the effect of a dead leaf; that is all. Kallima certainly does that and more. Kallima goes too far and proves too much. And there are other cases like it. Natural selection alone could never carry the simulation past the point of advantage.

But whatever other factors or agents have played a part in bringing about this specialization of color and pattern, cxemplified by animals showing protective resemblances, warning colors, terrifying manners, and mimiery, naturi I selection has undoubtedly been the chief factor, and the hasis of utility the chief foundation, for the derelopment of the spectialized conditions. 


\section{CHAPTER XX}

\section{REFEEXES, INSTINCT, AND REASON}

We live in a world which is full of misery and ignorance; and the plain duty of each and all of us is to try to make the little corner he can influence somewhat less miserable and somewhat less ignorant than it was before he entered it. To do this effectually it is necessary to be fully possessed of two beliefs-the first, that the oide: of nature is a; ertainable by our faculties to an extent which is practically unlinited; the second, that our volition counts for something as a condition of the course of events.

Each of these beliefs can be verified experimentally as often as we like to try. Each, therefore, stands upon the strongest foundation upon which any belief can rest, and forms one of our highest truths. If we find that the ascertainment of the order of nature is facilitated by using one terminology or one set of symbols rather than another, it is our clear duty to use the former; and no harm can accrue so long as we bear in mind that we are dealing merely with terms and symbols.HuXley.

ALL animals of whatever degree of organization show in life the quality of irritability or response to external stimulus. Contact with external things produces some effect on each of them, and this effect seems to be something more than the mere mechanical effect on the matter of which the animal is composed. In the one-celled animals, the functions of response to external stimulus are not localized. They are the property of any part of the protoplasm of the body. Just as breathing or digestion is a function of the whole cell, so are sensation and response in action. In the higher or many-celled animals each of these functions is specialized and localized. A certain set of cells is set apart for each function, and each organ or series of cells is released from all functions save its own. 
In the more highly organized animals certain colls from the primitive external layer or ectoblast of the anhrye are early set apart to record the relations of the creatture 6 its convirchment. These cells are highly specialized, and while some of them are highly sensitive, others are adapted for carrying cr transmitting the stimuli received by the sensitive cells, and still others have the function of receiving sonse impressions and of translating them into impulses of motion. The nerve cells are receivers of impressions. These are gathered together in nerve masses or ganglia, the largest of these being known ats the brain, the ganglia in general being known as nerve conters. The nerves are of two classes. The one class, called semsory nerves, extends from the skin or other orgen of sensation to the nerve center. The nerves of the other elass, motor nerves, carry impulses to motion.

The brain or other nerve center sits in darkness surrounded by p:otecting tissues or a protecting box of bone. To this ba: in, nerve center, or sensorium eome the ne:ves f ol: all pate of the body that have sensation - the external skin as well as the special organs of sight, hearing, taste, smell. With these eonne nerves bearing sensations of pain, temperature, muscular effort all kinds of sensation which the brain can receive. These nerves are the sole sources of knowledge to any animal o.ganism. Whatever idea its bain may contain must be built up through these nerve impressions. The agrgregate of these impressions constitutes the woild as the organism knows it. All sensition is related to action. If an organism is not to act, it camnot feel, and the intensity of its feeling is related to its power to act.

These impressions brought to the bian by the sensory nerves represent in some degree the facts in the animal's cnvironment. They teach something ats to its food or its safety. The power of locomotion is characte istic of animals. If they move, their actions must depend on the indieations earried to the nerve center from the outsile; if they feed on living orgas. isms, they must seek their food: if, as in many eases, other living organisms prey on thems. 1!ey must bestir themectres to escape. The impulse of hungere on the one hand and of fear on the other are element:1. The semsorium recrives an impression that ford cxists in a contuin direction. At once an impulse to motion is. sent out from it to the muscle necessary t) move the body in that direction. In the higher animals 
these movements are usually more rapid and more exact than with the lower forms. This is because the organs of sense and action, the sense cells, nerve fibers, and muscles are all highly specialized. In the starfish sensation is slight, nervous communication slow, and the muscular response sluggish, but

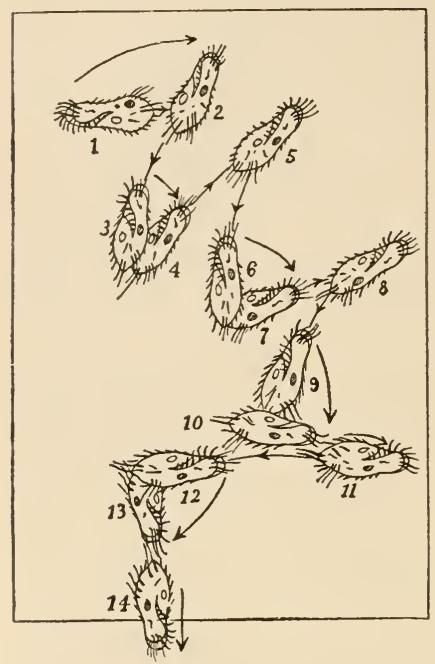

Fig. 264.-Diagram showing how the Protozoan, Oxytricha fallax, reacts to cold; slide is heated at upper end and an Oxytricha beginning at 1 continues to react by turning a little to right and backing and advancing and repeatedly turning a little to right and backing and advancing until position 14 is reached. (After Jennings.)

the method is apparently the same.

But in recent years many biologists have come to believe that much of the behavior of the simplest animals, and some of the actions of the higher, are controlled in a more rigidly mechanical way than the above statements suggest; that, in a word, much of the action, and apparent instinctive or intelligent response of animals to external conditions, is an immediate physicochemical rather than vital phenomenon; that the animal body in its relation to the external world is much more like a passive, senseless, although very complex, machine, stimulated and controlled by external factors and conditions, than like the percipient, determining, purposeful creature that our usual conception of the organism makes it out to be.

Clever experimenters, as Loeb, Lucas, Radl, Bethe, Uexkull, and numerous others, believe themselves justified in explaining a host of the simpler actions or modes of behavior of animals, on a thoroughly mechanical basis, as rigorous, inevitable reactions to the influence or stimulus of light, heat, contact, gravity, galvanism, etc. Phototropism, stereotropism, geotropism, etc., are the names given to these phenomena of response by action and behavior to stimuli of light, contact, and gravity respectively.

Some of these biologists are ready to carry their giving up 
of other than mechanical behavior among animals to ereat lengths. Loeb introduces a paper written in $1 \mathrm{~s}$ (x) on instinct and will in aninals as follows:

"In the biological literature one still fimds anthors who treat the 'instinct' or the 'will' of animals as a cireunstanee which determines motions, so that the scientist. who enters the region of animated nature encounters an entirely new categrory of rauses, such as are said continually to produce before our eyes great effects, without it being pus-ible for an engineer ever to make use of these caures in the phy-iral workl. 'Instinet' and 'will' in animals, as causes which determine movement s, stand upon the same plane as the supermatural powers of theolegians, which are also said to determine motions, lut upon which an engineer could not well rely.

"My investigations on the heliotropism of animals led me to analyze in a few eases the conditions which determine the apprarenty aecidental direction of animal movements which, accordine to trachtional notions, are called voluntary or instinctive. Wherever I have thus far investigated the cause of such 'voluntary' or 'molinctive' movements in animals, I have without exception discovered such eircumstances at work as are known in inanimate nature as determinate movements. By the help of these causes it is possible to contor the 'voluntary' movements of a living animal just as securely and unequirocally as the engineer has been able to control the movenents in inanimate nature. What has been taken for the effect of 'will' or 'instinct' is in reality the effect of light, of gravity, of friction, of chemical forces, etc."

But Jennings, a very careful and industrious student of the behavior of the protozoa, whose studies have bern perhaps more detailed and prolonged than those of any other investigator c $\hat{s}$ the same subject, closes a fascinating volume on his work wi. the following paragraph:

"The present paper may be considered as the sumum, nge up of the general results of sereral years' work ly the anthor on the lechavior of the lowest organisms. This work has shown that in thene ereatures the behavior is not as a rule on the tropism plan-a set, foreed methenl of reacting to each particular agent-hut takes places in a much more flexible, less directly mathinelike way, by the method of trial and error. This method involves many of the fundamental qualities 
which we find in the behavion of higher animals, yet with the simplest possible basis in ways of action; a great portion of the behavior consisting often of but one or two definite movements, movements that are stereotyped in their relation to the environment. This method leads upward, offering at every point opportunity for derelopment, and showing even in the unicellular organisms what must be considered the

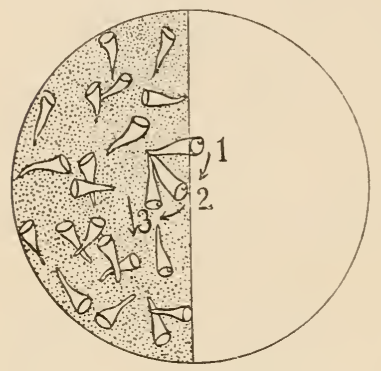

FIg. 265.-Diagram showing how the motile Protozoan, Stentor, reacts to light: A circular space half in light and half in dark; the animalcules collect in dark area; 1, 2, and 3 show the reaction of a specimen which came to the light line. (After Jennings.)

beginnings of intelligence and of many other qualities fornd in higher animals. Tropic action doubtless occurs, but the main basis of behavior is in these organisms the method of trial and error."

Different one-celled animals show differences in method or degree of response to external influences. Most protozoa will discard grains of sand, crystals of acid, or other indigestible objects. Such peculiarities of different forms of life constitute the basis of instinct.

Instinct is automatic obedience to the demands of external conditions. As these conditions vary with each kind of animal, so must the demand vary, and from this arises the great variety actually seen in the instincts of different animals. As the demands of life become complex, so may the instincts become so. The greater the stress of environment, the more perfect the automatism, for impulses to safe action are necessarily adequate to the duty they have to perform. If the instinct were inadequate, the species would have become extinct. The fact that its individuals persist shows that they are provided with the instincts necessary to that end. Instinct differs from other allied forms of response to external conditions in being hereditary and continuous from generation to generation, and in being common to the species and not characteristic of the individual. This sufficiently distinguishes it from reason, but the line betreen instinct and reason and various forms of reflex action cannot be sharply drawn.

Some writers regard instincts as "inherited habit," while others, with apparent justice, doubt if mere habits or voluntary 
actions repeated till they hecome a "sceond nature" over leat re

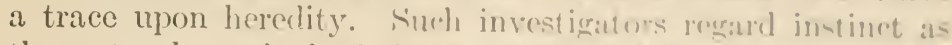
the natural survival of those mothodis of antomatio responser which were most useful to the life of the animal, the individuals having less effoctive methods of roflex aletion having jeri-lecel, leaving no posterity.

An example in point would be the homine instinct of the fur seal. When the aretic winter descends on its home in the Pribilof Islands in 13(')ing sia, these animals take to the open ocean, many of them swimming southward as far as the Santa Barbara Islands in California, more than three thousand miles from home. While on the long swim they never go on shore; but in the spring they return to the northward, finding the little islands nidden in the arctic fogs, often landing on

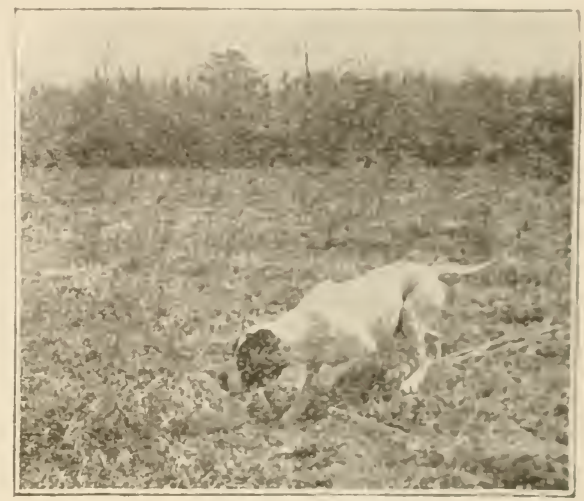

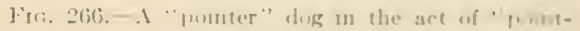

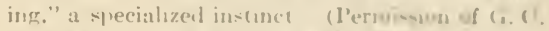
sniclis, publisher of " Recreation. ) the very spot from which they were driven by the ice six months before, and their arrival timed from yoar to your almost to the samo day. The perfection of this hominge instinct is vital to their life. If defective in any individu, l, lec would be lo-e to the herd and would leave no desermbants. Those who neturn hercome parents of the herel. As to the others the rough arat tells no tales. We know that of those that set forth a latge pereentage never come back. To those that retum the buming instinct has proved aclecpuate. This must be so long and lie race exists. The failure of instinct wonld mean the extinction of the species.

The instincts of animals may lo roughly desafied as to their relation to the individual into exoistic and altruistic instimets.

Fenotic instincts ale those which concern ehiefly the individual animal itself. To this cliss belong the instincts of 
feeding, those of self-defense and of strife, the instincts of play, the climatic instincts, and environmental instincts, those which airect the animal's mode of life.

Altruistic instincts are those which relate to parenthood

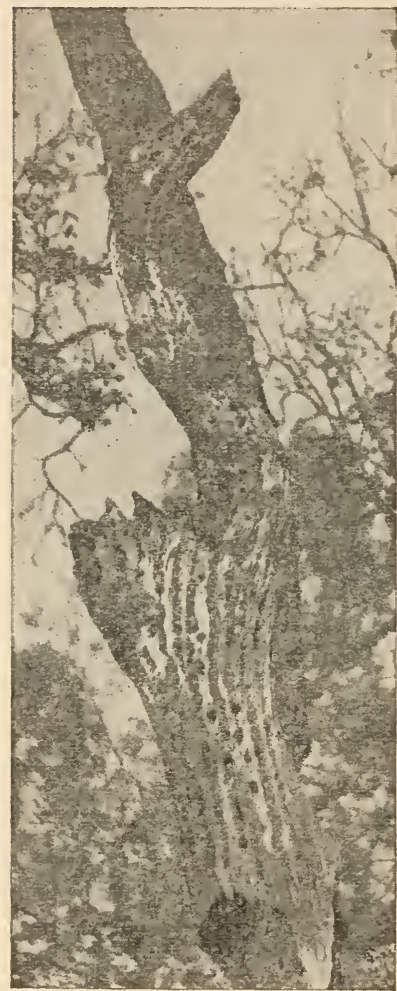

Fig. 267.-Part of branch of oak tree, showing acorns placed in "-cles in the bark by the California woodpecker, Melanerpes formicivorus bairdii. (From photograph taken at Stariford University, California.)

and those which are concerned with the mass of individuals of the same species. The latter may be called the social instincts. In the former class, with the instincts of parenthood, may be included the instincts of courtship, reproduction, home-making, nestbuilding, and care for the young.

The instincts of feeding are primitively simple, growing complex through complex conditions. The protozoan absorbs smaller creatures which contain nutriment. The sea anemone closes its tentacles over its prey. The barnacle waves its feet to bring edible creatures within its mouth. The fish seizes its prey by direct motion. The higher vertebrates in general do the same, but the conditions of life modify this simple action to a very great degree.

In general, animals decide by reflex actions what is suitable food, and by the same processes they reject poisons or unsuitable substances. The dog rejects an apple, while the horse rejects a piece of meat. Either will turn away from the offered stone. Almost all animals reject poisons instantly. Those that fail in this regard in a state of nature die and leave no descendants. The wild vetches or "locoweeds" of the arid regions affect the nerve centers of animals and cause dizziness or death. The native ponies reject these 
instinctively. This may be becanse all ponies wheh hase mot this reflex dislike have been destroyed. The imported horae has no such instinct and is poiconed. Very few animals will eat any poisonous olyeret with which their instinets a re faniliar. unless it be concealed from smond and tatste.

In some calses, very claborate instinces aries in anduction with freding habits. In the case of the C'alifornia woedperekers (Welanerpes formicivorus bairdii) a latre number touncther soluct a live-oak tree for their operations. T!aey first bore its bark full of holes, each large (mough to hold an acorn. 'Thern intos each hole an acoon is thrust (Figs. 26. and ?o.4). () mly one tree in severai square miles maty be selentect, and when tlair work is finished all those interested go alout tineir buninese el-rwhere. At irregular intervils a dezen or so come l...ck with mich clamorous discussion to look at the tres. When the right time comes, they all return, open the acoris one by one, devouring apparently the substance of the nut, and probably also the grubs of beetles which have developed within. Wlarn the muts are ripe, again they return to the sance trese and the same process is repeated. In the tree figured this has herm noticent each year since 1891 .

The instinct of self-defense is even more varied in its manifestations. It may show itself either in the impulse to make war on an intruder or in an impulse to flee from its emmines. Among the flesh-eating mammels and hirels ficresness of demeanor serves both for the securing of food and for protection against enemies. The stealthy movements of the lion, the skulking habits of the wolf, the sly selfishnesti of the for, the blundering good-natured power of the hear, the errectinese of the hyena, are all proverbial, and similar trats in the cagle. owl, hawk, and vulture are scarcely lest matters of common observation.

Herbivorous animals, as a rule, milk little direct revi-tanees to their enemies, depending rather on swiftuess of font, or in some cases on simple insignifiennee. To the litter estater the abundance of mice and mouselike rodents maly he atrilument. for all are the prey of the carnivorous beasts and lirels, and of snakes.

Even young animals of any species show erreat four of their hereditary enemies. The nestlines in a nest of the lmeresm bittern when one woek old slown l mo fear of man, lun when 
two weeks old this fear was very manifest. Young mocking birds will go into spasms at the sight of an owl or a cat, while they pay little attention to a dog or a hen. Monkeys that have

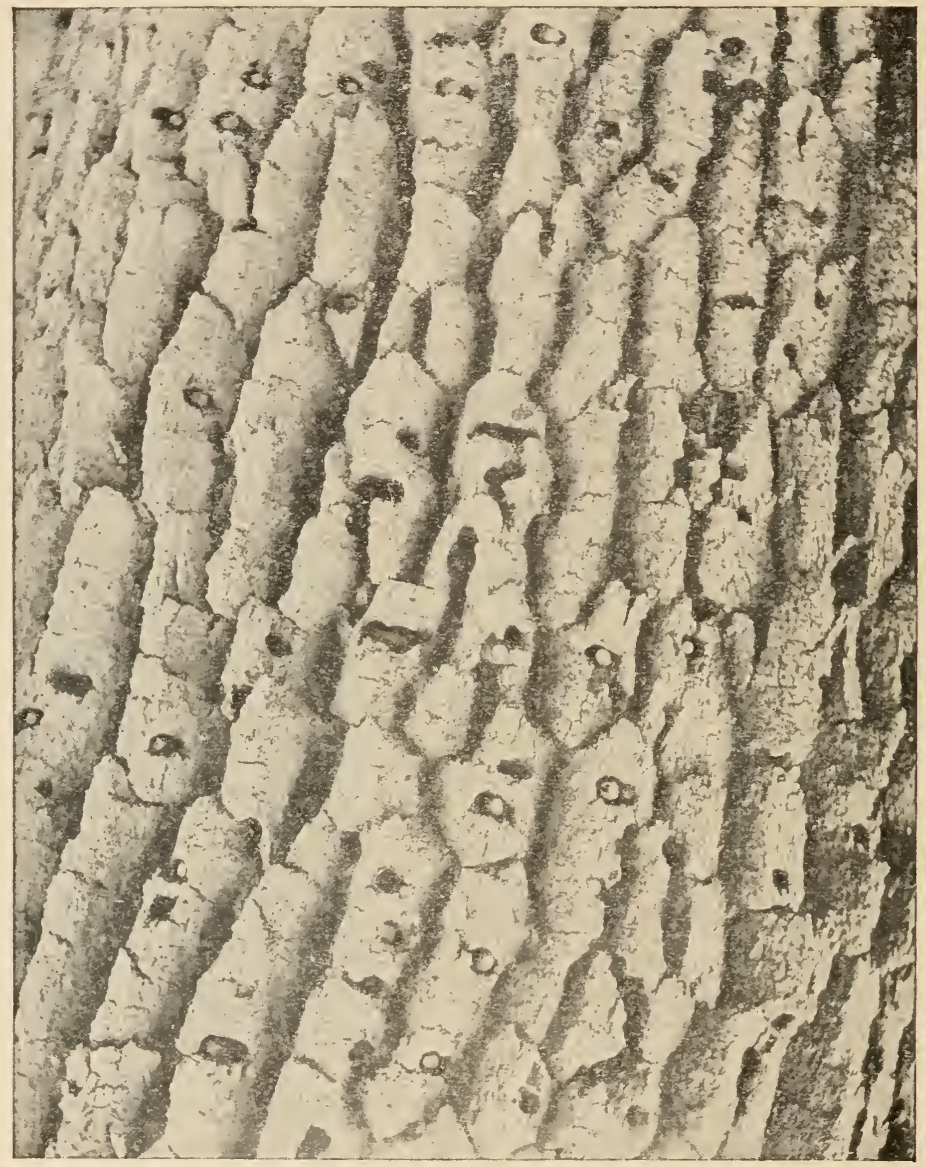

FIG. 268.-Section of bark of the live-oak tree, with acorns placed on it by the California woodpecker, Melanerpes formicivorus bairdii. (From photograph taken at Stanford University, California.)

never seen a snake show almost hysterical fear at first sight of one, and the same kind of feeling is common to most men. A monkey was allowed to open a paper bag which contained a 
live snake. He was staggened hy the right, hut after a while

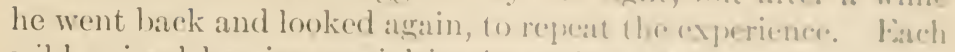
wild animal hats its special instince of re i=tance or methest of kecping off its enemies. The stamping of a sheep, the hiching of a horse, the rumning in a rircle of al hare, and the skulking in a circle of some foxes, are examples of this sort of instinct.

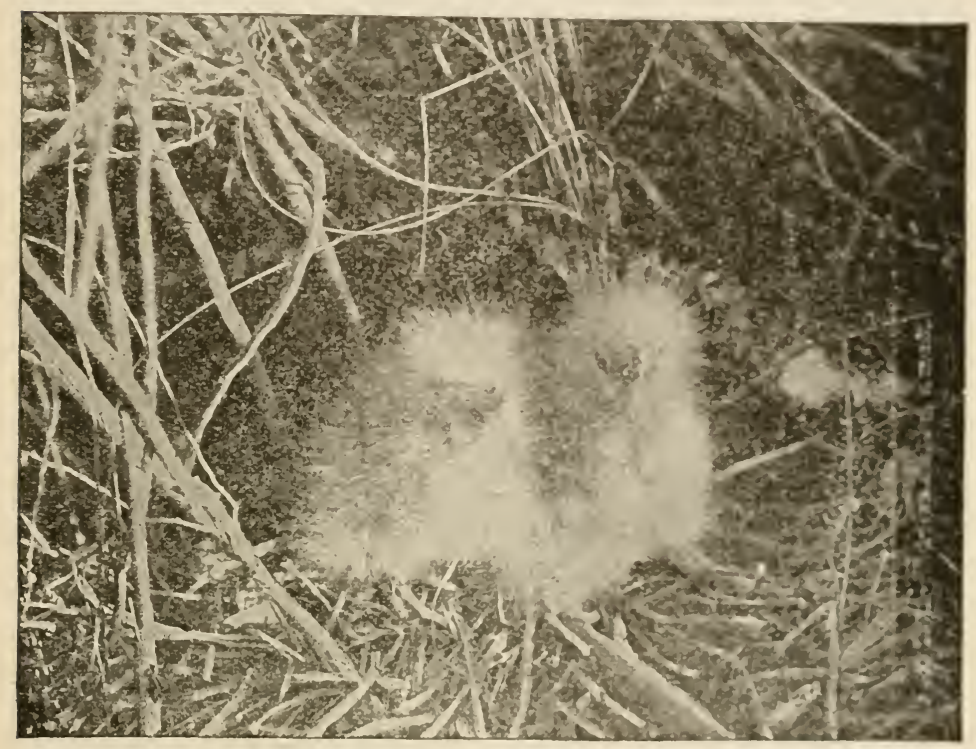

Fig. 269.-Nestlings of the Ameriean bittern, two of a hrom of fuur lirils une week 11 . at which age they showed no fear of man. (Photugraph by L. Y. Ialwor. Merntan, N. Y., May 31, is9s. Permission of Macmillan (o., publi-hers of "B rel I re.")

The play instinet is developed in mumerous animals. To this class belong the wrestlings and mimic fights of young dogs, bear culss, seal pups, and yomen beatsts gromeralls. Cats and kittens play with mice. Sipuimels platy in the trees. l'erhaps it is the play impulse that leats the shrike or huteher hiret to impale small birds and beetles on the thorns alout its nest. a ghastly kind of ormment that sermes fo confer sali-fartion on the bird itself. The talline of the parrots ame their imitations of the sounds they hear serm to be of the nature of plas. The greater their superfluous anergy the more they will talk. Much of the singing of birds, and the crying, calling, and howling 
of other animals, are mere play, although singing primarily belongs to the period of reproduction, and other calls and cries result from social instincts or from the instinct to care for the young.

Climatic instincts are those which arise from the change of

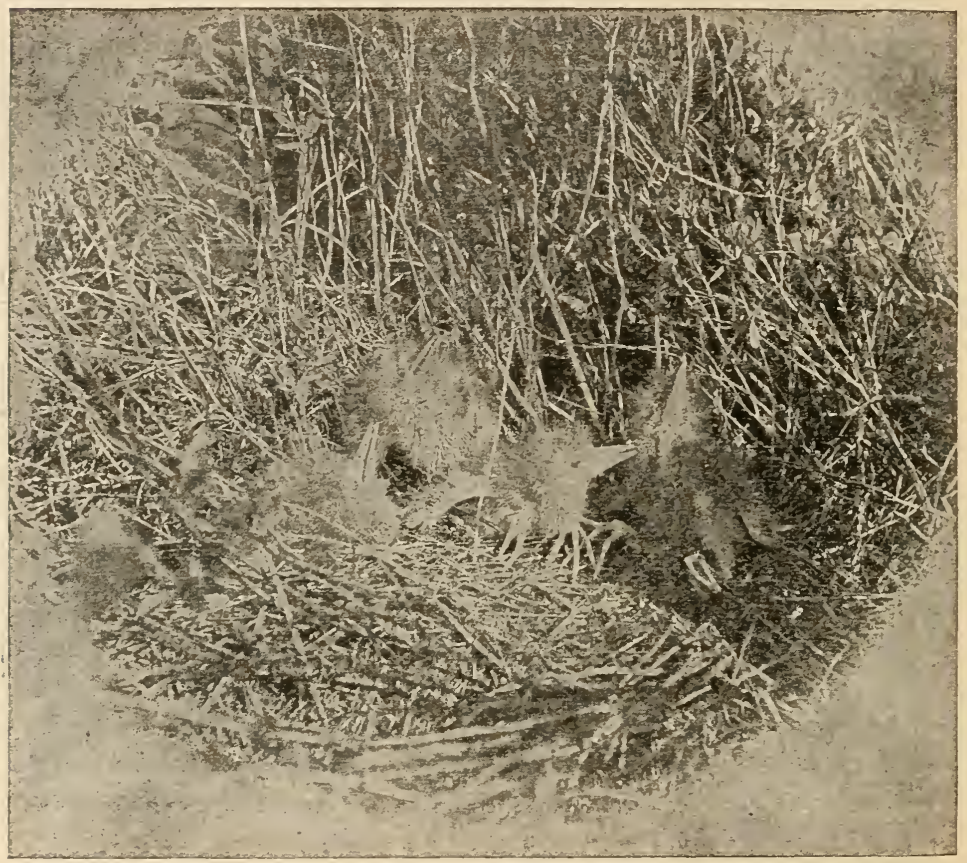

FIG. 270.-Nestlings of American bittern. Four birds, of which two are shown in Fig. 269, two weeks old, at which age they showed marked fear of man. (Photograph by E. N. Tabor, Meridian, N. Y., June 8, 1898. Permission of Macmillan Co., publishers of "Bird Lore.")

the seasons. When the winter comes the fur seal takes its long swim to the southward; the wild geese range themselves in wedge-shaped flocks and fly high and far, calling loudly as they go; the bobolinks straggle away one at a time, flying mostly in the night, and most of the smaller birds in cold countries move away toward the tropics. All these movements spring from the migratory instinct. Another climatic instinct leads the bear to hide in a cave or hollow tree, where he sleeps 
or hibernates till spring. In some cates the climate instinct merges in the homing instinet and the instinet of reproduction. When the birds move north in the spring they sing, mate,

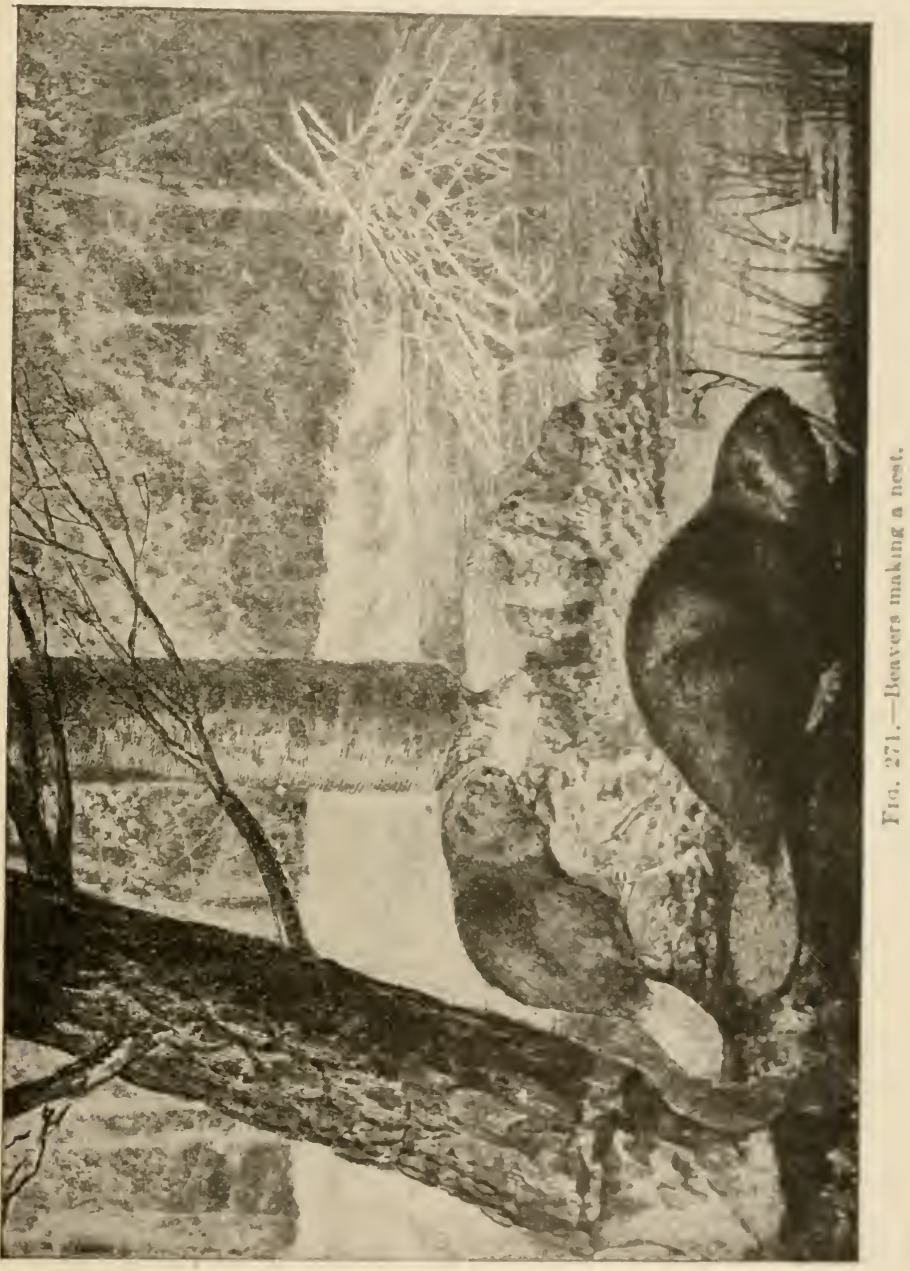

and build their nests. 'The fur' seal gous home to renr its young. The bear exchanges its bed for its lair. amd its firt bunines after waking is to make ready to rear its young. 
Environmental insirncts concern the creature's mode of life. Such are the burrowing instincts of certain rodents, the woodchucks, gophers, and the like. To enumerate the chief phases of such instincts would be difficult, for as all the animals are related to their environment, this relation must show itself in characteristic instincts.

The instincts of courtship relate chiefly to the male, the female being more or less passive. Among the bircls the male in spring

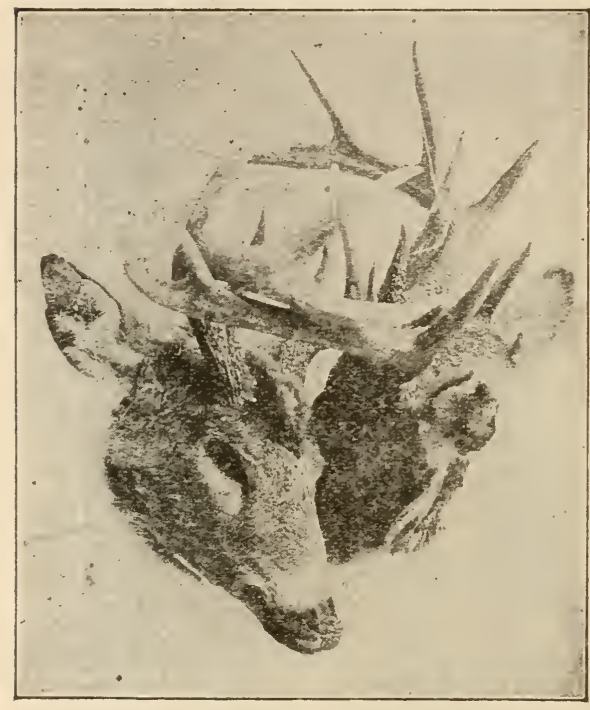

Fig. 272,-Horns of two male deer interlocked while fighting. (Permission of G. O. Shields, publisher of "Recreation.") is in very many species provided with an ornamental plumage which he sheds when the breeding season is over. The scarlet, crimson, orange, blue, black, and lustrous colors of birds are commonly seen only on the males in the breeding season, the young males and the old males in the fall having the plain brown gray or streaky colors of the female. Among the singing birds it is chiefly the male that sings, and his voice and the instinct to use it are commonly lost in great degree when the young are hatched in the nest. Among certain fishes the males are especially brilliantly colored in the breeding time, but there is little evidence of any personal attempts to display these colors before the females.

Among polygamous mammals the male is usually much larger than the female, and his courtship is often a struggle with other males for the possession of the fenile. Among the deer the male, armed with great horns, fight to the death for the possession of the female or for the mastery of the herd. The fur seal has on an average a family of about thirty-two 
female; and for the control of his harem others are realy at all times to dispute the possession. Jint with monogamens animal like the true or hair seal or fos. Where a male male with a - $m$ mele. female, there is no such discrepancy in size amel -4 roneth, and the warlike force of the male is -pent on ont-ide enemies, not or his own speciess.

The movements of many migratory animals aro mainly con-

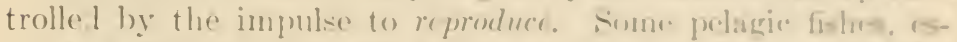
pecially flying fishes and fishes allied to the marherel, suim long distances to a region farorable for a disponition of spawn. Some species are known only in the waters they mak.. their breeding homes, the individuals being seattered thromgh the wide seas at other times. Many fresh-water fisher, as trom, suckers, ete, forsake the large streams in the spring, asending the small brooks where they can rear their yommer in greater safety. Still othews, known as anadromons fiches, fered and mature in the sea, hut aserent the rivers as the impule of reproduction grows strong. Among such species are the salmen, shad, alewife, sturgeon, and swiperl bass in American waters. The most noteworthy easc of the atudromous instinct is found in the king salmon or quimmet of the Pareific const. This great fish spawns in November. In the Columbia River it luegins running in Narch and April, spending the whole suminer in the ascent of the river whthout ferding. By antumn the individuals are greatly chanerel in itplearance, discolurenl, worn, and distorted. On reaching the spawning heds, some of them a thousand miles from the seat, the female deposits her eger in the gravel of some shallow brook. Ifter they are fertilized both male and female drift tail foremost and helploms down the strean, none of them ever surviving to reach the sat. The same habits are found in other species of sillnom of the l'acifie, hut in most cases the individuals of ether species do not start so early or run so far. A few specios of fishes, as the eet, revere this order, feeding in the rivers and brackish creeks, dropping down to the sea to spritur.

The migration of lirds has relation to reproduction an well as to ehanges of weather. As soon as they reneh their summer homes, courtship, mating, nes-bulding, and the care of the young oecupy the attention of erery speecies.

In the animal kinglom one of the great factors in development las been the care of the youmy. Tlis fenure is a prominent 


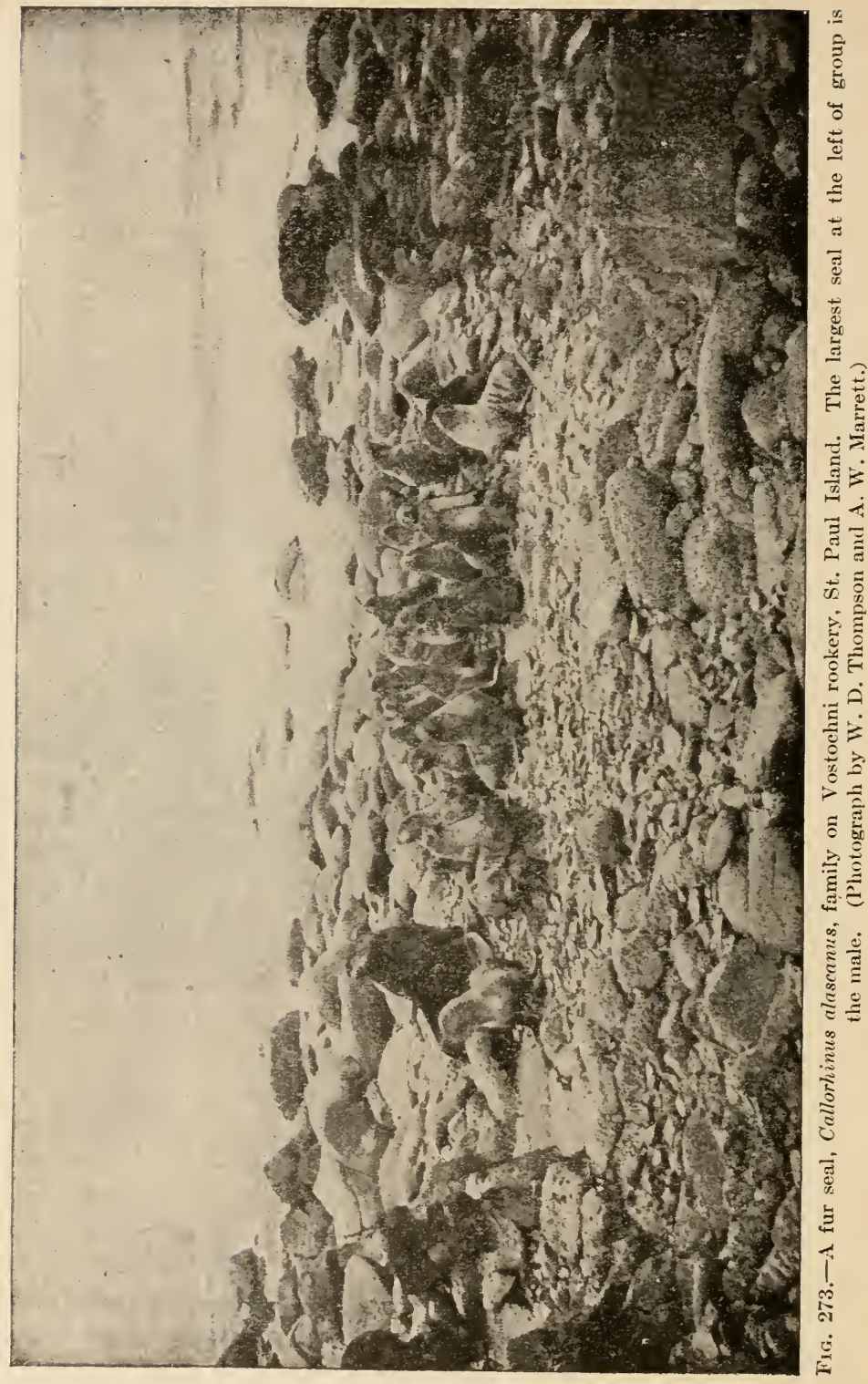


one in the specialization of hirels and mammals, When the

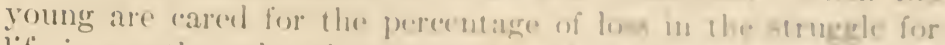

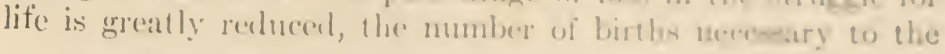

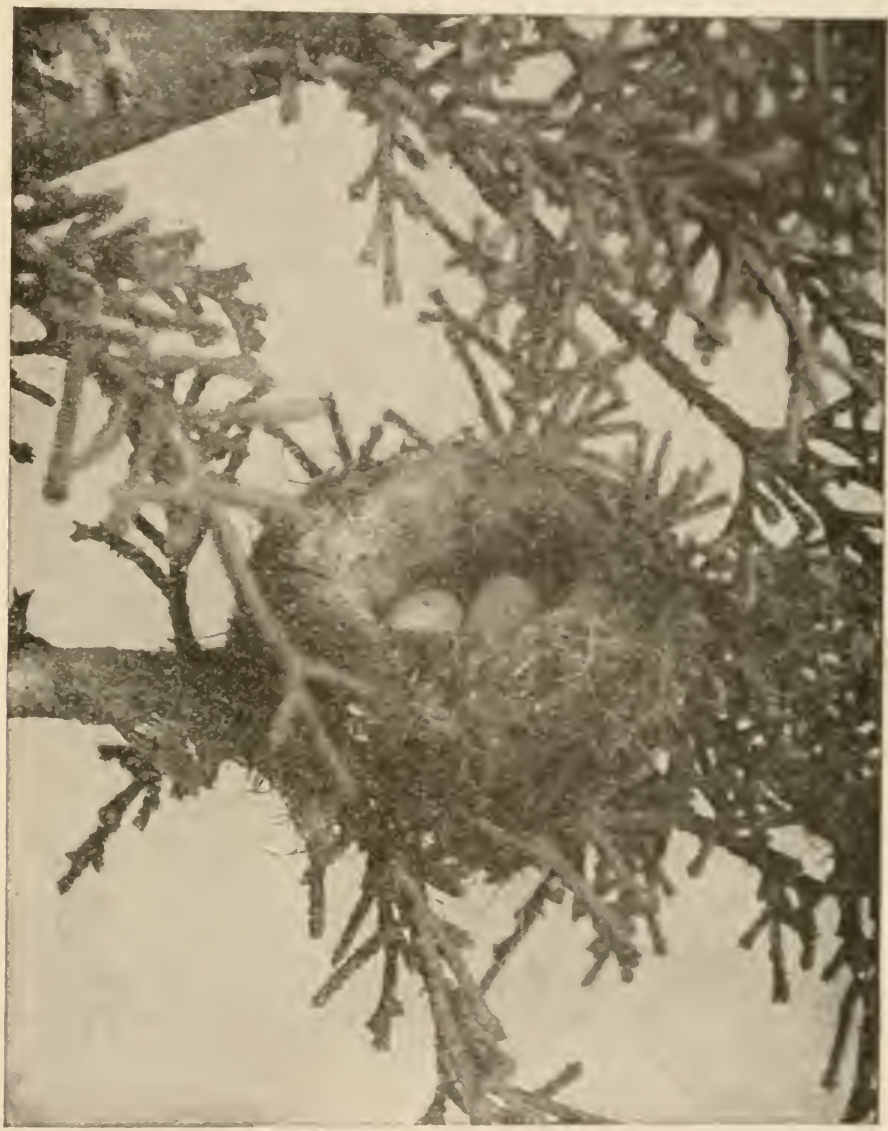

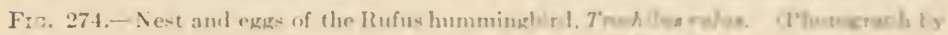

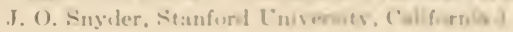

maintenance of the species is much less. and the opportunsties for specialization in other relations of life are nuch genter. In these regards, the nest-ludiling and home-making animals have the adrantage over those that have not these instincts. 
The animals that mate for life have the advantage over polygamous animals, and those whose social or mating habits give

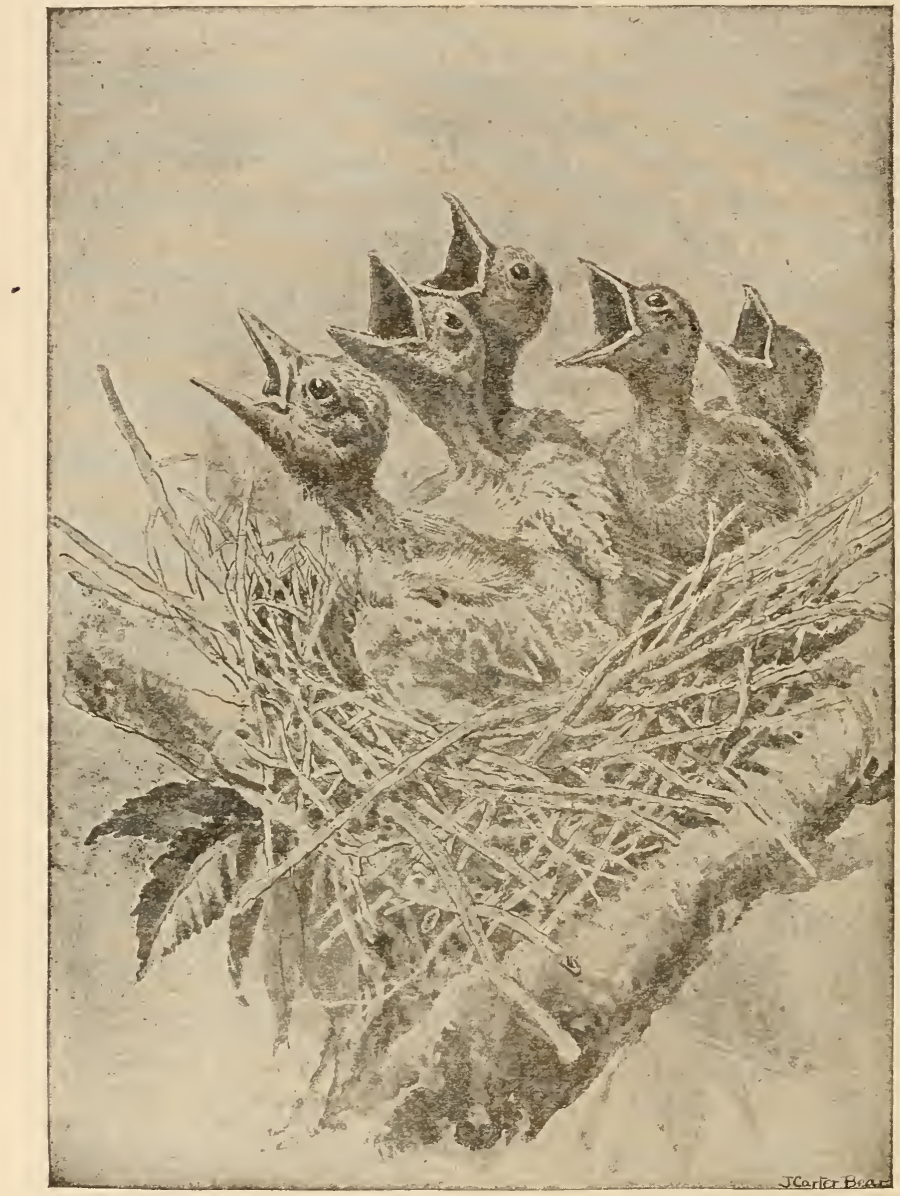

FIG. 275.-Altricial nestlings of the blue jay, Cyanocitta cristata.

rise to a division of labor over those with instincts less highly specialized.

When we study instincts of animals with care and in detail, we find that their regularity is much less than has been supposed. There is as much variation in regard to instinct among 
individuals as there is with reesarel to other characters of the species. Somne power of choim is fouml in almuet esery opera-

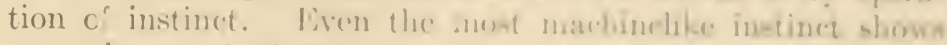
some degree of atclaptablility to new asmlicions. UIt the other hand, in no animal does reason show ande frowlem from

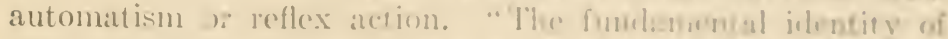

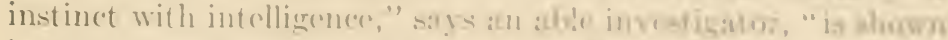
in their dependence 11$] n$ the brain and nerves), and in the ir fe-pundine aluguablity."

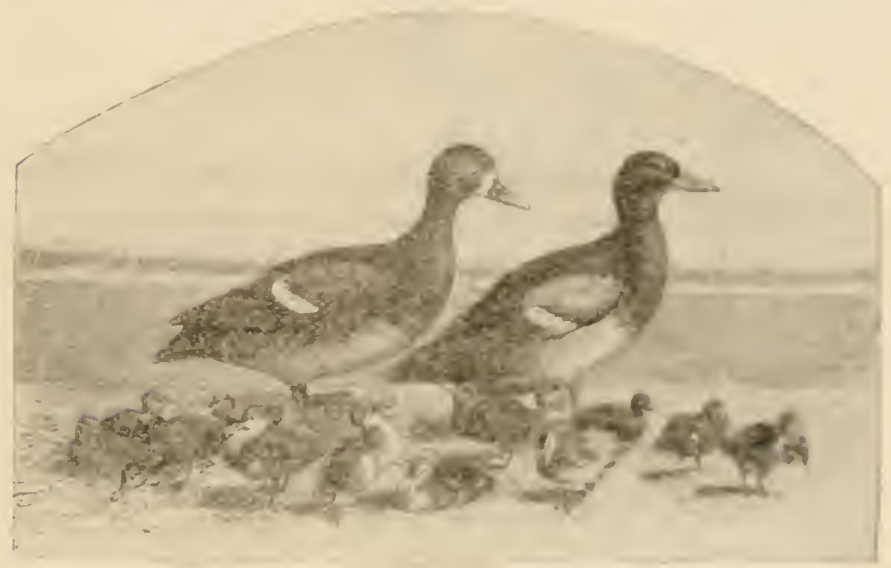

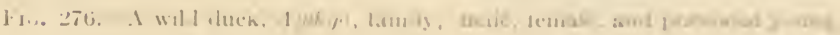

Reason or intellert, as distinguished fonm intimet, is the

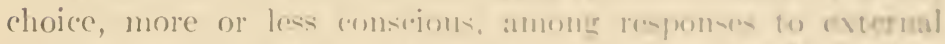
impiesions. Its hasis, lihe that of in-tince in in reftex aneion. Its operations, often repented. leceme similat! methes hy repetition, anci are known as habit. I lablit is a relumars action repeated until it herenges refler. It is mentiblly like instinct in ail its manifentations. The onlt erident differmen

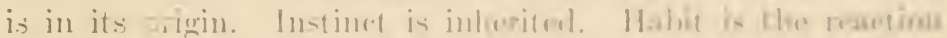

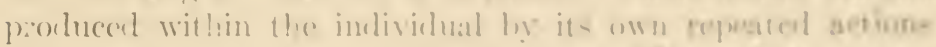
In the vated whitions of life the pure refles action henotors

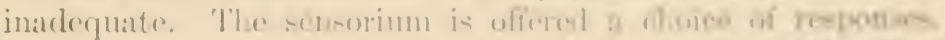

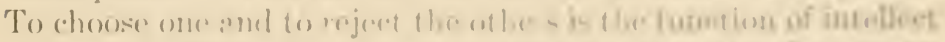

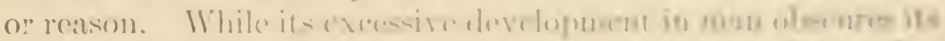

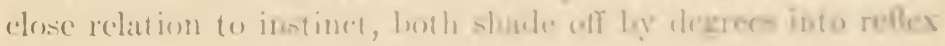


action. Indeed, no sharp line can be drawn between unconscious and subconscious choice of reaction and ordinary intellectual processes.

Most animals have little self-consciousness, and their reasoning powers at best are of a low order; but in kind, at least, the powers are not different from reason in man. A horse reaches

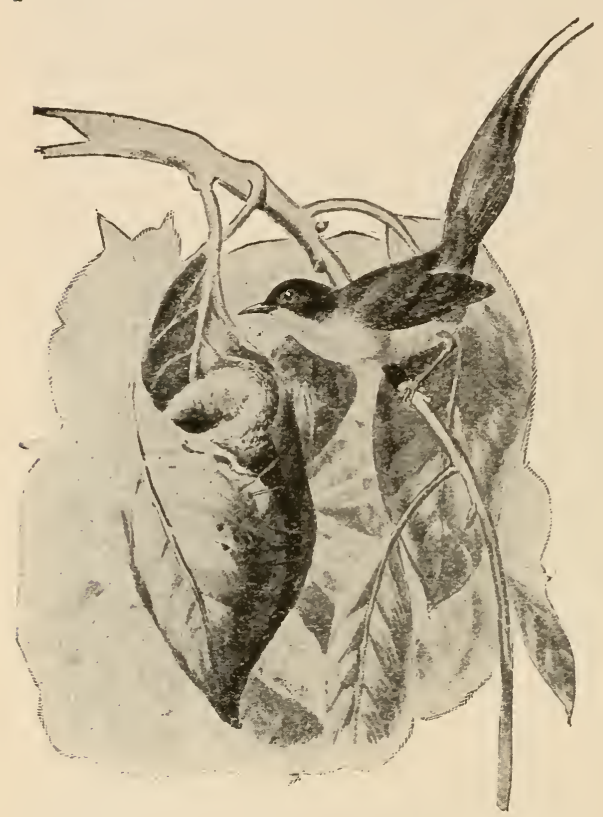

FIG. 277.-Tailor bird, Ornithotomus sutorius, and nest.

over the fence to be company to another. This is instinct. When it lets down the bars with its teeth, that is reason. When a dog finds its way home at night by the sense of smell, this may be instinct; when he drags a stranger to his wounded master, that is reason. When a jack rabbit leaps over a bush to escape a dog, or runs in a circle before a coyote, or when it lies flat in the grass as a round ball of gray, indistinguishable from grass, this is instinct. But the same animal is capable of reasonthat is, of a distinct choice among lines of action. Not long ago a rabbit came bounding across the university campus at Palo Alto. As it passed a corner it suddenly faced two hunting dogs running side by side toward it. It had the choice of turning back, its first instinct, but a dangerous one; of leaping over the dogs, or of lying flat on the ground. It chose none of these, and its choice was instantaneous. It ceased leaping, ran low, and went between the dogs just as they were in the act of seizing it, and the surprise of the dogs, as they stopped and tried to hurry around, was the same feeling that a man would have in like circumstances. 
On the open platins of Mercenl County, Cal., the jack rabthit is the prey of the bald eagle. Not long since at rablit pursued by an eagle was seen to run among the cattle. Leaping from cow to eow, he used these animals as a shelter from the savage bird. When the pursuit was closer, the rabbit- hroke cover for a barbed-wire fence. When the eagle swouperl dewn on it, the rabbit moved a few inches to the right, and the cagle conlil not reach him through the fence. When the eaple cance down on the other side, he moved acruss to the first. And this was continued until the eagle gave up the chase. It is inntince that leads the eagle to swoop on the rabbit. It is instinct again for the rabbit to run away. But to rum along the line of a barbed-wire fence demands some degree of reason. If the next to repeat it arose often in the lifetime of a single rabhit it would become a habit.

The difference between intellect and instinet in lower animals may be illustrated hy the conduct of artain monkers hroughs into relation with new experiences. At one time we had two adult monkeys, "Bob," and "Jocko," belonging to the genuts Macacus. Neither of these possessed the engreating instinct. At the same time we had a haby monkey, " Jono," of the gentse Cercopithecus. Mono had never seen an egg, hut his inl reitod impulses bore a direct relation to feeding on egrgs, ju-t as the heredity of Macacus taught the others how to crace muts or to peel fruit.

To each of these monkeys we gave an egrg, the first that any of them had ever seen. The baby monkey, liono, heing of an egg-eating race, devoured his egr by the operation of instinct or inherited habit. On being given the egg for the first time. he cracked it with his upper teeth, making a hole in it and suched out all the substance. Then holding the exgrshell up to the light and seeing that there was no longer anything in it. Le threw it away. All this he did mechanically, antomatically. and it was just as well done with the first egg he ever saw as with any other he ate. All crgessince offered him he has ireated in the same way.

The monkey Bob took the eagr for some kind of nut. He broke it against his upper teeth and tried to full off the thell. when the inside ran out and foll on the gromel. He lowhed at it for a moment in bewilderment, took both hands and seoupert up the iolk and the sand with which it was mixed and swallowerl 


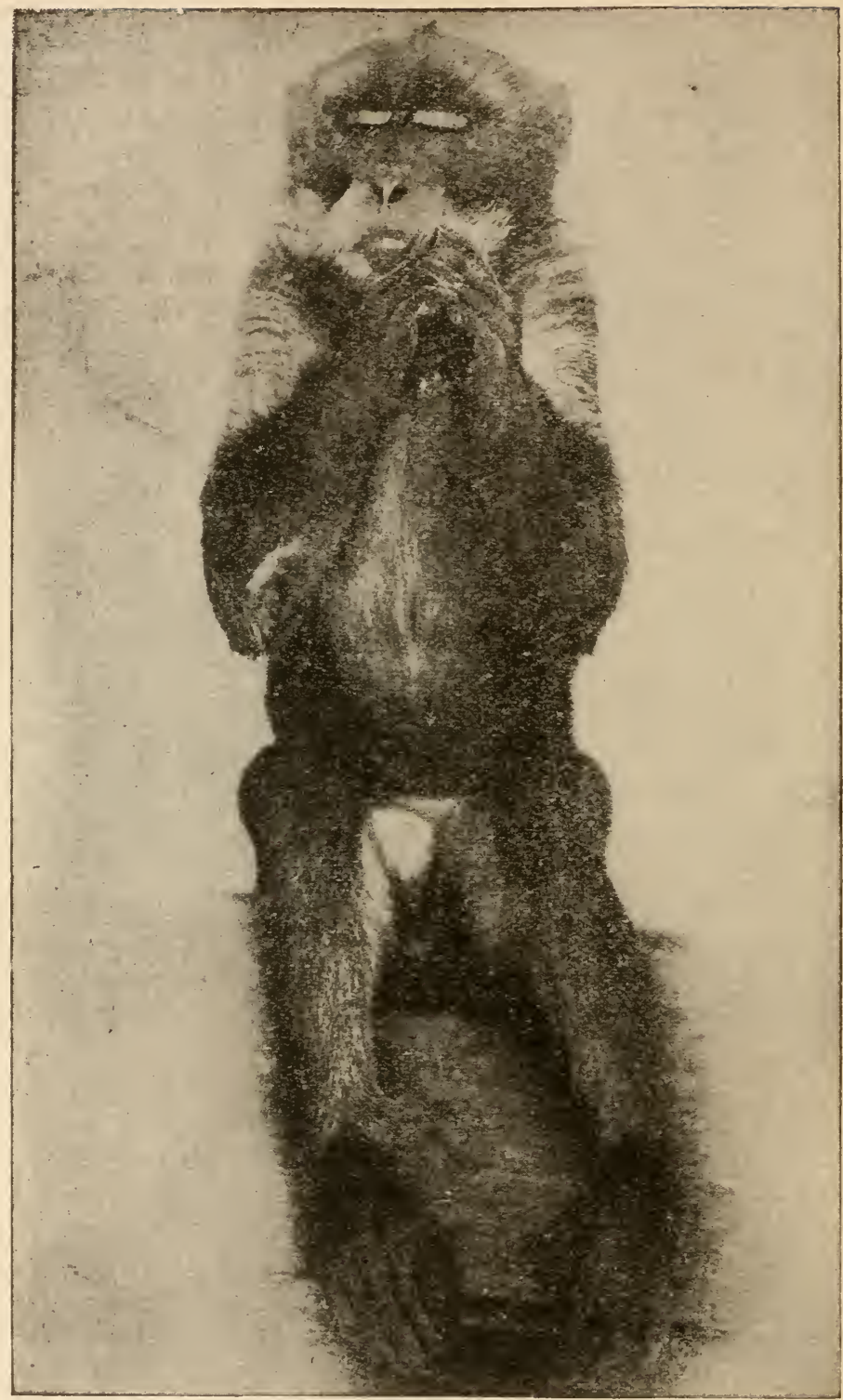

FIG. 278.-A monkey, Cerocopithecus, in a characteristic attitude. 
the whole. Then he stuffol the shell itoelf into his mouth. This act was not instinctive. It wats the work of pure reaton. Evidently his race was not fomiliar with the use of egg- and lial acquired no instincts regarding them. Ho would do it beter next time. Reason is an incfliciont agent at firnt, a weak torl; but when it is trained it beromes an agrent more valuable and more powerful than any instinct.

The monkey Jocko tried to eat the ougr offered him in much the same way that Bob did, but not liking the taste he thesw it away.

The confusion of highly perfereder instinet with intellect is very common in popular discussions. Instinct grows weak and less accurate in its antomatie obedienee as the intellect becomes available in its place. Intellert and inntinet tas well :all other nervous procesies atre outgrowthe from the simplas reflex response to external conditions. But instinct insures as single definite response to the corresponding stimulus. The intellect has a choice of responses. In its lower stages it is vacilloting and ineffective; but ats its development goes on it becomes alert and adequate to the varied conditions of lifo. It grows with the need for improvement. It will therefore become imposible for the complexity of life to ougrow the adequacy of man to adapt himself to its conditions.

diany animals eurrently believed to be of high intelligenese see not so. The fur seal, for example, finds its way back from the long swim of two or three tlousand miles through a fogey and stormy sea, and is never too late or too carly in arrisal. The female fur seal goes two hundreal miles to her feeding grounds in summer, leaving the pup on the shore. After a week or two she returns to find him within a few rods of the rocks where she had left him. Buth mother and young kuow each other by call and hy odor. and neither is ever mistaken though ten thousand other pups and other mothers oreupy the same rookery. But this is not intelligences. It is simply in-tinet, because it has no element of choice in it. Whatever its ancestors were forced to do the fur sial dien to purficetions. Its instincts are perfect als clockwork, and the ureesities of migration must keep them so. But if brought into new conditiens it is dazed and stupid. It camnot choose when different liness of action are presented.

The Bering sea Commision of $14966^{\circ}$ made an experiment 
on the possibility of separating the young male fur seals, or "killables," from the old ones in the same band. The method was to drive them through a wooden chute or runway with two valvelike doors at the end. These animals can be driven like sheep, but to sort them in the way proposed proved impossible. The most experienced males would beat their noses against a closed door, if they had seen a seal before them pass through it. That this door had been shut and another opened beside it passed their comprehension. They could not choose the new direction. In like manner a male fur seal will watch the killing and skinning of his mates with perfect composure. He will sniff at their blood with languid curiosity; so long as it is not his own it does not matter. That his own blood may flow out on the ground in a minute or two he cannot foresee.

Reason arises from the necessity for a choice among actions. It may arise as a clash among instincts which forces on the animal the necessity of choosing. A doe, for example, in a rich pasture has the instinct to feed. It hears the hounds and has the instinct to flee. Its fawn may be with her and it is her instinct to remain and protect it. This may be done in one of several ways. In proportion as the mother chooses wisely will be the fawn's chance of survival. Thus under difficult conditions, reason or choice among actions rises to the aid of the lower animals as well as man.

The word mind is popularly used in two different senses. In the biological sense mind is the sum total of all psychis changes, actions, and reactions. Under the head of psychic functions are included all operations of the nervous system as well as all functions of like nature which may exist in organisms without specialized nerve fibers or nerve cells. As thus defined mind would include all phenomena of irritability, anc even plants have the rudiments of it. The operations of the mind in this sense need not be conscious. With the lower animals almost all of them are automatic and unconscious. With man most of them must be so. All functions of the sensorium, irritability, reflex action, instinct, reason, volition, are alike in essential nature though differing greatly in their degree of specialization.

In another sense the term mind is applied only to conscious reasoning or conscious volition. In this sense it is mainly an attribute of man, the lower animals showing it in 
but slight degree. The discussion as to whether lower animals have minds turns on the definition of mind, and our answer (o) it depends on the definition we adopt.

Most plants are sessile organioms. Each is an organie colony of cells, with the power of motion in parts but not that of locomotion. The plant draws its nourishment from inorganic nature-from air and water. Its life is not conditioned on a search for food, nor on the movement of the body as a whole. Yet the plant searches for food by a movement of the foreting parts. In the process of growth, as darwin hats shown, the tips of the branches and roots are in constant motion. This movement is a spiral squirm. The movement of the tendrils of the growing vine is only an exaggeration of the same action. The course of the squirming rootlet may be deflected from a regular spiral by the presence of water. The moving loranchlets will turn toward the sun. The region of sensation in the plane and the point of growth are identical because this is the only part that needs to move. The tender tip is the plant 's brain. If loeomotion were in question the plint would need to be differently eonstructed. It would demand the mechani-m of the animal. The nerve, brain, and muscle of the plant are all represented by the tender growing cells of the moving tips. The plant is touched by moisture or sunlight. It may be said, in somewhat metaphorical language, that it "thinks" of them. and in so doing the cells that are touched and "think" are turned toward the source of the stimulus. The function of the brain, therefore, in some sense exists in the tree, lunt there is no need in the tree for a specialized sensorium.

The many-celled animals from the lowest to the highest. wear in their organization some relation to locomotion. The animal feeds on living creatures and these it must pursue if it is to thrive. It is not the sensitive nerve tipes which are to move; it is the whole creature. By the division of labor the whole body of the compenud organism camnot be given over to sensation. Hence the development of sense organs different in character: one stimulated by waves of light, another by waves of sound; one sensitive to odor, another to tasto: still others to contact, temperature, muscular strain, and pain. These sense organs must through their nerve fibers report io a sensorium which is distinct from each of them. And in the process of specialization the scnsorium itsel: is subdi- 
vided into higher and lower nerve centers; centers of conscious thought and automatic transfer of impulse into motion. This transfer indicates the real nature of all forms of nerve action. All are processes of transfer of sensation into movement. The sensorium or brain has no knowledge except such as comes to it from the sense organs through the ingoing or sensory nerves. It has no power to act save by its control of the muscles through the outgoing or motor nerves. The mind has no teacher save the senses; no servants save the muscles.

The study of the development of mind in animals and men gives no support to the medieval idea that the mind exists as an entity apart from the organ through which it operates. This "Klavier theory" of the mind, that the ego resides in the brain, playing upon the cells as a musician upon the strings of a piano, finds no warrant in fact. So far as the evidence goes, ve know of no ego, except that which arises from the coördination of the nerve cells. All consciousness is "colonial consciousness," the product of coöperation. It stands related to the action of individual cells much as the content of a poem with the words or letters composing it. Its existence is a phenomenon of coöperation. The "I" in man is the expression of the coworking of the processes and impulses of the brain. The brain is made of individual cells, just as England is made of individual men. To say that England wills a certain deed, or owns a certain territory, or thinks a certain thought is no more a figure of speech than to say that "I will," "I own," or "I think." The "England" is the expression of union of the individual wills and thoughts and ownerships of Englishmen. Similarly, my "ego" is the aggregate resulting from coördination of the elements that make up my body.

That what we really know of human personality tells the whole story of it no one should maintain. It is well, however, not to ascribe to it entities and qualities of which we know nothing. 


\section{CHAPTER XII}

\section{MAN'S PLACE IN! NATURE}

A sacred kinship) I would not foregot

Binds me to all that hreathes: Hough endless strif

The calm and deatluless digrnity of lifo

Unites each bleceling vietims to its foe.

I am the chilk of earth and air and wat.

My lullaby by hoarse silurian storms

IVas ehanted, and thromgh endless dhanging forms

Of tree and bird and beast unceisingly

The toiling ages wrought to fashion me.

Lo! these large ancestors have left a breath

Of their great souls in mine, defying death

And change. I grow and blussom as the tree,

And ever feel deep-delving earthy roots

Binding me daily to the common clay:

Yet with its airy impulse upward shoots

My soul into the realms of liglit and day.

And thou, $O$ seat, stern mother of my suul,

Thy tempests ring in me, thy billows roll!

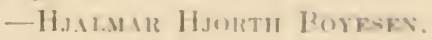

Man betrays his relation to what is below lim, thick-sulled small-bataned, fishy, quadrumatuous quadruped, ill-dieguived, hardly. escaped into biped, and has paid for the new powers hy the low of nome of the old ones. But the lightning which exploder and fashons phome te. maker of planets and sums, is in him. On the one side etemental order, sindstone and granite, rock lederes. jeat long. forest, sen, and shore On the ofher part, thought and the spirit which comporm and derom- 
poses nature. Here they are side by side, god and devil, mind and matter, king and conspirator, belt and spasm riding peacefully together in the eye and brain of every man.-Enerson.

The ape is this rough draft of man. Mankind have their gradations as well as the other productions of the globe. There are a prodigious number of continued links between the most perfect man and the ape.-John WesLeY.

ONE of the most important results of Darwin's studies of the origin of species has been the complete change in the philosophical conception of nıan. We no longer think of the human race as a completed entity in the midst of Nature, but apart
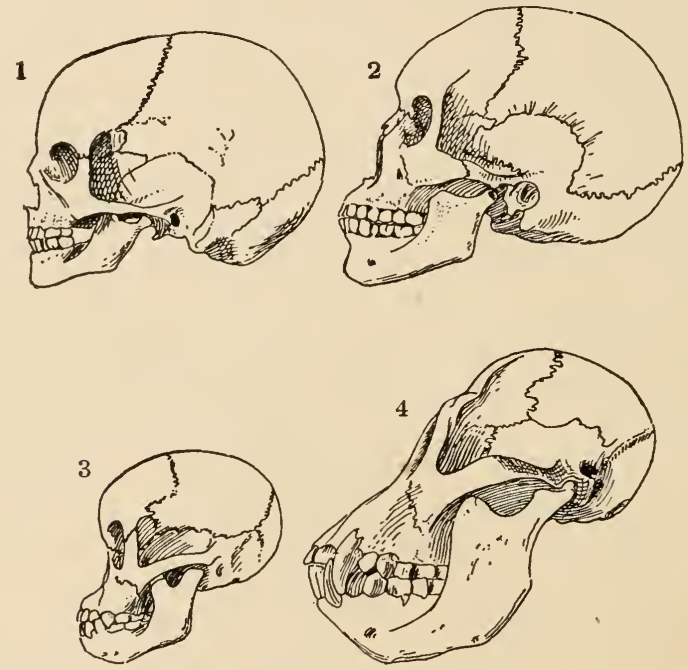

Fig. 279.-Skulls of man and the orang-utan: 1, skull of a seven-ycar-old German child; 2, skull of an Australian from Murray River; 3, skull of young orang-utan; 4, skull of a grown orang-utan. (After Wiedersheim; one-sixth natural size.)

from it, with a different origin, a different motive, a different destiny. Man is like the other species, an inhabitant of the earth, a product of the laws of life; his characters are phases in the long process of change and adaptation to which all organisms are subject. From the point of view of zoölogy, the human race is a group of closely allied species, or subspecies, undoubted- 
ly derived from an common stock, and each species in its ramifications modified by the forees and conditions included under the general heads of variation, heredity, segregation, selertion, and the impact of environment preciscly as species in other groups are affected. It is rlear that if there is an origin of species through natural caluses among the lower animals and plants, there is an origin of species among men. If homology among animals and plants is the stamp of blood relationship, the same rule holds

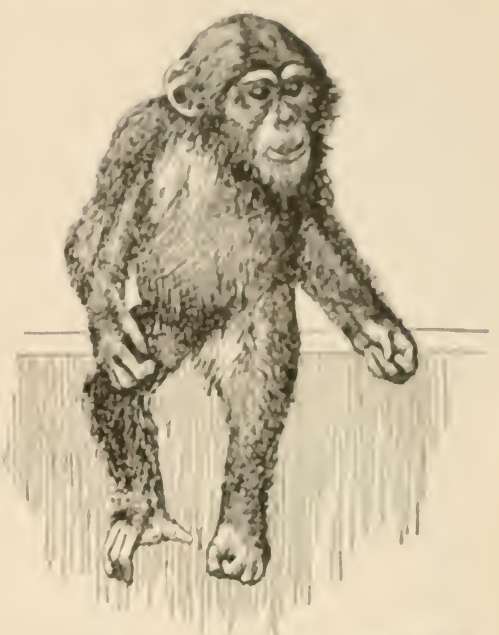

Fis. 2S0. - Vomug chumpatizere I I reen Weltall u. Mensclherl, after photingroph frum life liy Dr. Heck of Berlits.)

with man as well. Jan is connerted with the lower animals by the most perfect of homologies. Theor are tracenale in every bone and muscle, in every blood veseel and glame, in
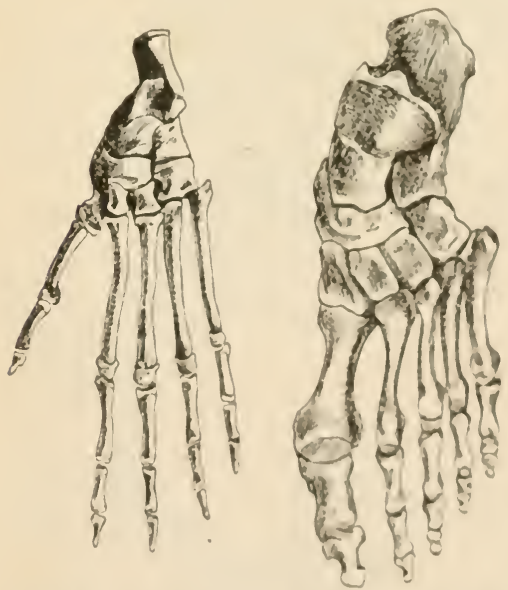

Fis. 2s1.-Foot skeleton of clumptuzen ut left. and of man at right. (After Wielersherum) every phase of structure, even includiner those of the brain amel nersots system. The common horelity of man with other vertebrate animals is as well establi-leet an any fact in phylugems (:an lx.

In working wet the details of the origin of man, we have unere more thr. Hhroe "ancestral doenments" of biologer, romparative amatoms, embriologr. and paleontulogy.

considered structurally, man formes a singlit ganus, Homn, the sole rep. 
resentative among living forms of the Hominidæ, the highest family of the order of Primates. To the species, man, Linnæus gave the scientific name of Homo sapiens, this being regarded by him as the primitive species which has diverged into several geographical varieties or races. Of these, at least three might well be regarded as distinct species. The form called by Linnæus Homo sapiens europceus includes not only the white men of Europe, but allied races of Africa and Asia, as the Moors, the Jews, the Turks, the Arabs, the Hindus and the Ainus of northern Japan. To Homo asiaticus belong
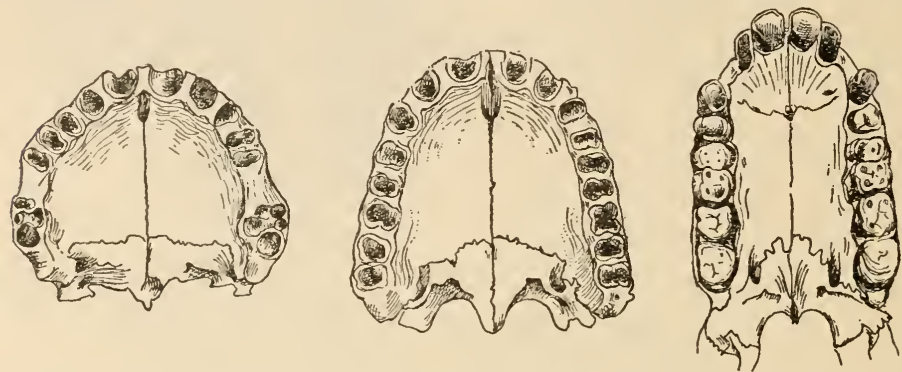

FIG. 282.- Upper teeth of man and the orang-utan: At left, of a Caucasian; in middle, of a negro; at right, of a grown orang-utan. The condition in the negro is between that in the orang-utan and that in the Caucasian. (After Wiedersheim.)

the Mongolian races, probably the Esquimaux and Aleuts of North America, and perhaps the American Indians (Homo americanus), with the Malays, the South Sea Islanders, and the Australians as well. Homo afer of Africa and adjacent islands comprises the kinky-haired negroes and negritos.

Structurally the members of the genus Homo are closely allied to the anthropoid apes. The actual differences in anatomy are very slight. The differences in degree of mental endowment are enormous, but it can be shown that these distinctions are, for the most part, of degree only, associated with the greater size and greater degree of specialization of the brain of man. Homologies of the closest sort exist, involving every element in structure as well as every function of the organism and every known mental attribute. The anthropoid or manlike apes constitute the family of Simiidæ. The principal species are the following, beginning with the lowest or most monkeylike: Hylobates, the gibbons, of several species, notable 
for their very long arms and erect posture; Siamanga synductyle, the siamang; simiu sulyrus, the orang-utan; Pan gerilla, the gorillat, sometimess called Troglodytes yorilla (though the name Troylodyles was first used for the wren); and the (hinpanzees, Anthropitherus niger and calvus. Of these the gorrilla is physically the strongest. It reaches a height of five fert and a weight of 200 pounds. The chimpanzee, smaller and more amiable in disposition. most sngerests man in apprarance, although the gorillar is structurally most like him.

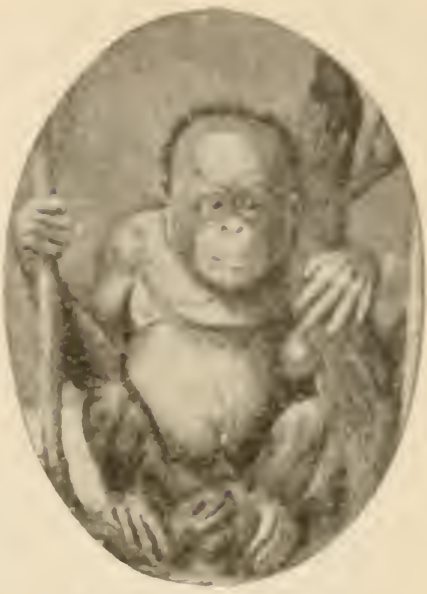

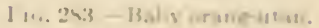

I rimili,

The order of primates has heren barions ly elameified. It is conveniently divided into five principal gronge: (a) the lemure

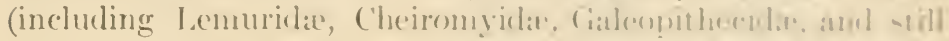

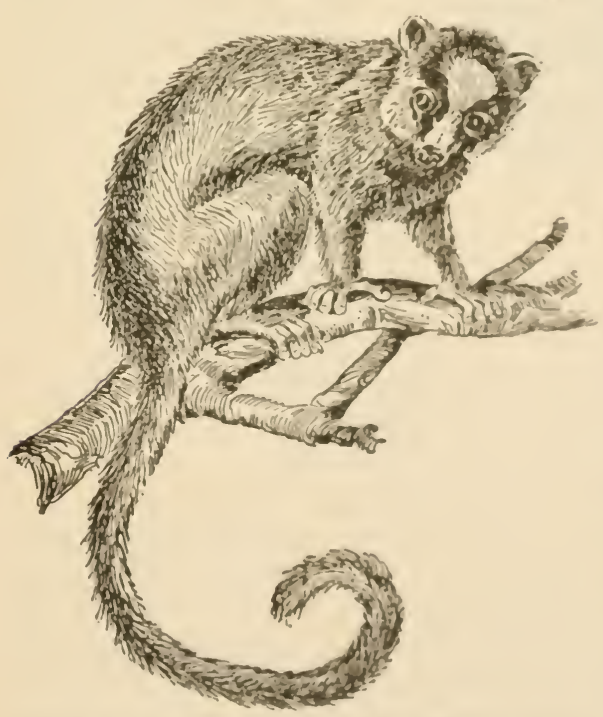

Etc. 2S4.-Lemur, furcifer. (After Ritzema Bus.) more ereneralisal extincet format: (b) the Platerrline or NewWorld monhes s (Coliclar and Aretapitheevilio or Marmoset s: (c) the Ciltarline or (nldIforld monkers am laboure (Creroupitherid: $)$ (d) the anthropoid apes (Finisiles): and (e) mon (Hominalte).

Thie lemurs of Maulagaecar are alue mo-1 primition Lihe otber primsies, they lave flat nails and an opposable 
thumb on each foot. Monkeylike in their feet and in their general habit, yet in appearance they have little to suggest affinity with man. In general make-up, they are superficially comparable rather with weasels, squirrels, and bats.

The New-World monkeys differ widely from the others. Technically they are distinguished by the diverging (platyrrhine) nostrils, and by the retention of the primitively larger

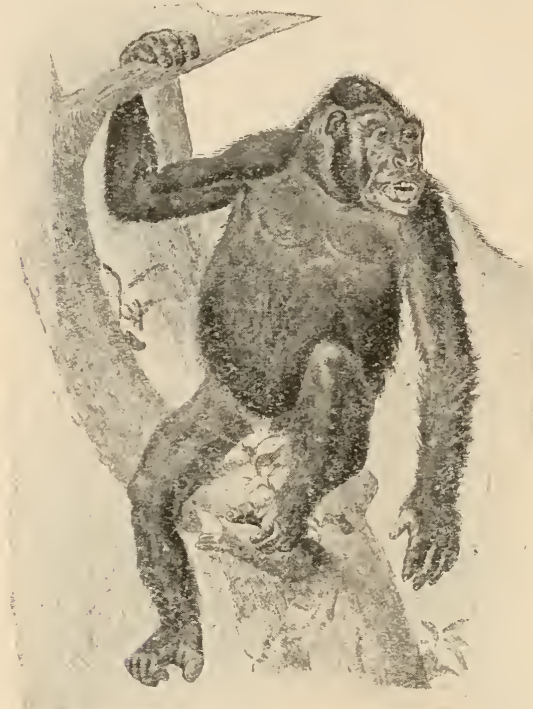

FIG. 285.-Gorilla. number of teeth. Many of them have prehensile tails, and in habit and temper all are very unlike the more hardy and pugnacious monkeys of the Old World. All the Old-World monkeys as well as the apes and man have parallel nostrils, directed downward (catarrhine). Their tails, if present, are not prehensile, and in their habits and temper they approach progressively toward man. Catarrhine monkeys are known to have existed in the Miocene period. The anthropoid apes represent a high degree of advancement within the same group which finds its final extreme in the genus Homo.

Considering structural characters alone, it is readily conceivable that man should have had an anthropoid ancestry, that the anthropoids should have sprung from an Old-World monkey stock, and that the Old-World monkeys in turn are derived from the lemurs. It is not supposable that any living species of man has sprung from any extant species of anthropoid spe. The point of juncture is clearly far back in the earlier Tertiary times, but morphological evidence points to the common origin of primitive man and the known anthropoids. It is, of course, certain that the intermediate forms when known 
will not be strictly man-ilpes, nor :1pe-men, lun rather printion creatures miting the pussibilities of hoth. From that comdition men and atpes have siner diverged and will continue to diverere.

There is no doubt of the truth of Huxley's statement :

"Thus whatever systom or organs lx studierl, the comparison of their modifications in the alpe sericis leads to one aind the same result-that the structural differences which separate man from the gorillit and the chimpanzee are not si)

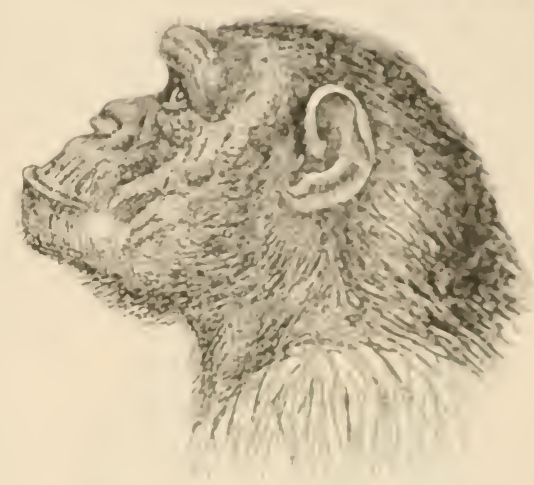

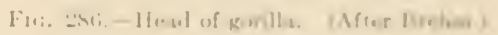
great as those which separate the gerilla from the lone r apre."

In fact, as Hireckel has observerl,

"It is very diffecult to show why man shoull not 1 me law w with

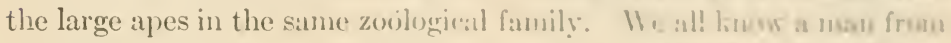

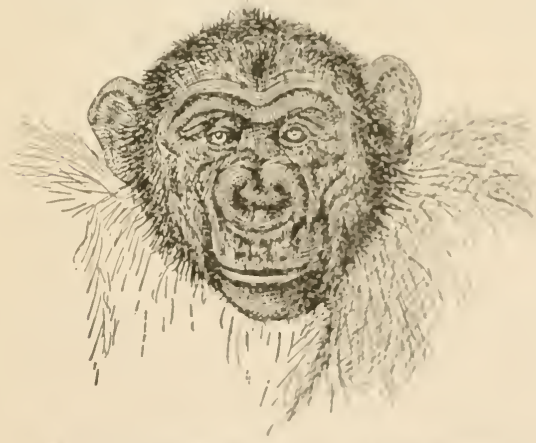

-c. 287.-Face of gorilla. (After Brohm.)

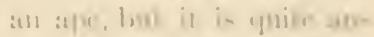
wher thing to find liftion (ruces which are abondite :mol une of dewree unly."

It may la lewally tialdel that man difiers from the apes in the. comblination of the intlowing elaracters: (1) Frect wall : (2) ertremitis differentikent accorelingly. the great toe nut lecing optene

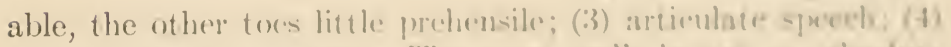
higher reasoning powre. The erect walk is nos an aleofure character. The higher apes walk on their foet. molting the ground at times with their hnuckles. The tailed mowheys 
walk like a bear, four-footed, and resting on the palms of their hands. The muscles in each case are the same, although in man the gastrocnemius and soleus are enlarged, forming the calf of the leg, while the expanded glutæus maximus forms the buttocks. Both buttocks and calf are scantily developed in the apes and monkeys, but the muscles forming them are essentially the same as in man.

The monkeys have been called Quadrumana, four-handed, because the foot like the hand is fitted for grasping, and the

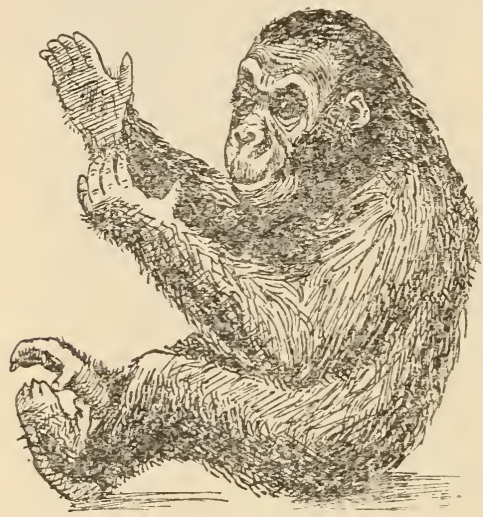

Frg. 288.-A young gorilla of the Leipsig Zoölogical Garden. (From Illustrirte Zeitung, after a photograph.) great toe, like the thumb, is opposable to the other digits. But as Huxley has clearly shown, this modification involves no real change of structure. An examination of the bones and muscles involved at once shows that the hinder limb in apes and monkeys is truly a foot and not a hand. Part by part the hinder foot of the monkey is homologous with the foot of man, not with the hand (Fig. 281). The loss of the power of opposing the great toe, on the part of man, is a result incident to the use of the hinder limbs for walking alone, and not for grasping. In some of the lower races of man the great toe stands apart from the others to a larger extent than in the European races.

In the apes there is a greater degree of mobility of the muscles of the scalp and the ear than in man, but there are very many cases of men who are able to move these muscles freely. The muscles of the tail in man are quite useless, as are also those of the higher apes, in which the coccyx or tail is scarcely more developed than in man.

In man, the wisdom teeth are usually rudimentary, but in the native Australians these teeth are the largest of the series, as is also the case with the apes (Fig. 282).

In structure it is clear that man agrees in all large matters 
with the anthropoid apes, and that be cannot be aejus:lul an order from other primates.

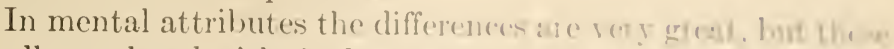

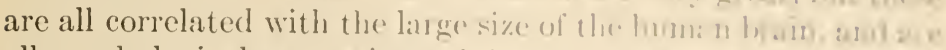

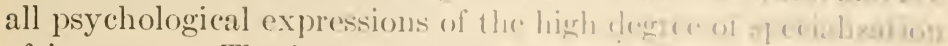

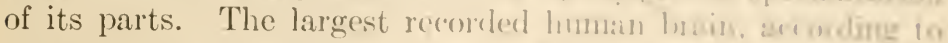
Huxley, has a woight of sixty-five to sixty-in otucres n? smallest of about thirty-two. The luain of the hiphat in ay weighs about twenty ounces.

The immense differences betwern the intellizener of : for and

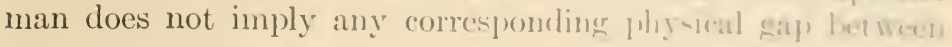
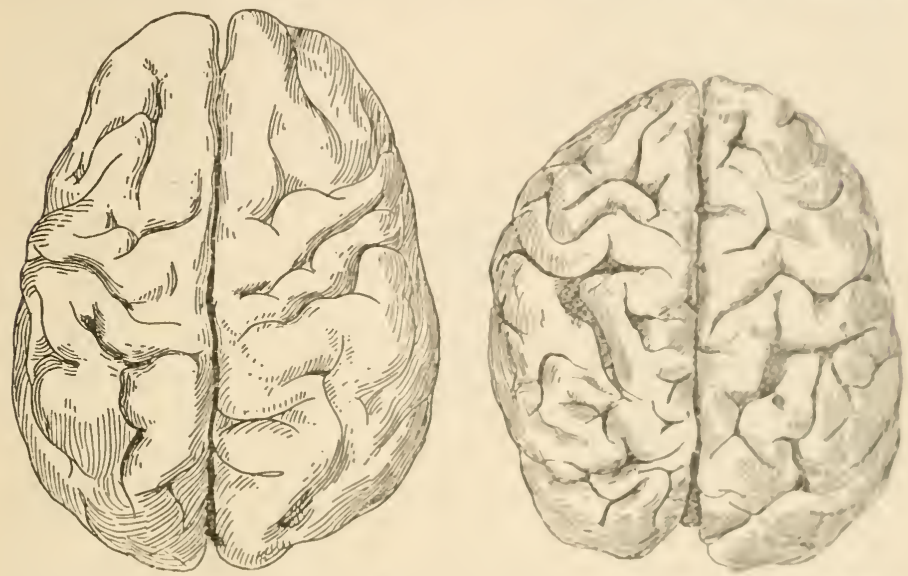

FIG. 289.-Top of brain of a seven-to-eight monthe human en hrs, we hefs, ant a her

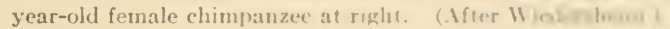

them, or any correspondinger differenes in their lorain. Hustes uses the illustration of a watch which hoch perfint link :at compared with a watch having imperfect mathinerv. The difference is not so much in the struscture of the matele sas in the fineness of the parts and the perforetion of a heir anlionamont-

Believing as I do with ('uvicr that the prasacion of arikubte speech is the grand distincelive character of man whet laer it be aleor

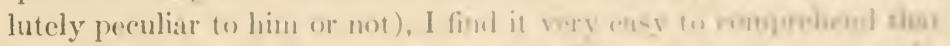

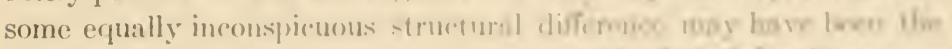

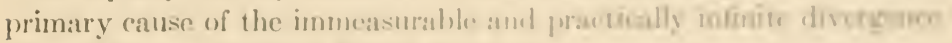
of the Human from the ,imian stirps." 
Huxley further shows that

"the brain is only one condition out of many on which intellectual manifestations depend, the others being, chiefly, the organs of the senses and the motor apparatuses, especially those concerned in prehension and in the production of articulate speech."

Selenka finds that man and the man-apes agree in the manner and relation of the young in the mother-body to that body in that both man and man-apes have but a single disclike placenta, while the other apes have two opposed disc placentas. And Friedenthal finds that while the blood serum of man is poisonous
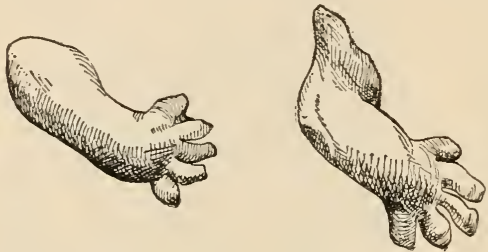

FIG. 290.-Right hand at left, and right foot at right, of a two-months-old human embryo, showing similar position of the first digit (thumb, great toe) in each. (After Wiedersheim.) to, and destroys the red blood corpuscles of all other animals experimented on, these animals, including fishes, amphibians, reptiles, birds, and mammals, among which latter were lemurs and New-World (Ateles and Pithecosciurus) and OldWorld (Cynocephalus, Macacus and Rhesus) monkeys, it does not injure the corpuscles of the man-apes (orang, gibbon, and chimpanzee). This immunity exists only among closely related animals as the horse and donkey, dog and wolf, and hare and rabbit. From which it is evident that man and the man-apes have nearly identical blood.

The second "ancestral document," embryology, emphasizes the common origin of man with that of the higher vertebrates and notably with that of the anthropoids. The embryos of man and apes develop in a fashion precisely parallel. In both, as in all other mammals, the early presence of gill slits furnishes evidence of a descent from a fishlike ancestry. The same evidence is given in the embryonic growth of reptiles and birds. In the development of the human child some simian traits appear, these being wholly or partly lost in the more advanced stages. Among these is the lanugo or general covering of long hairs, more or less developed in certain stages of fœetal growth, but lost entirely before birth. The curving upward of the feet, 
characteristic of early childhood, is a simian trait. According to Jeffreys Wyman, when the fortus is about an inch in length, "the great toe is shorter than the others, and insteat of lrome parallel to them, is projected at an angle from the sile of the foot, thus corresponding with the permanent condition of this part in the Quadrumana."

The great grasping power of young babies in well knous, and this is likewise a simian trait. Dr. Louis Robinson has shown that very young bahies will support their own weight, by holding to a horizontal bar for a period of half a minute to two minutes. In all cases "the thighs are bent nearly at right angles to the body and in no case did the lower limbs hang down and take the attitude of the erect position" (Fig. 291).

The study of embryonic development shows also that the tail in man and ape alike is at a certain stage of development longer than the legs, as in the monkeys and other: lower mammals. In tlis stage, according to Romanes, "the tail admits of being moved by muscles which later on dwindle away.' Sometimes, however, these muscles persist through life.

The vermiform appendix is like-

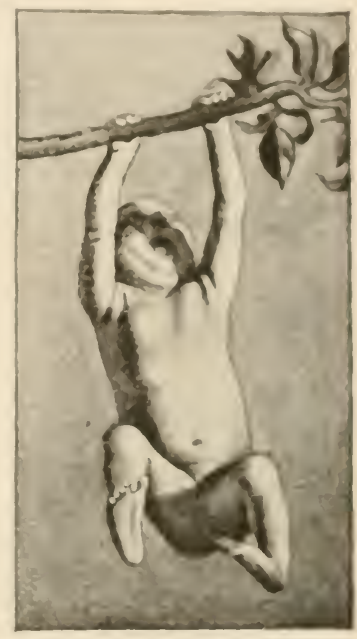

live. 2!)1. - In infant cliem monchs ofl wegureitig is wright for over $(w$, silmates: the atuente of ibe lewer

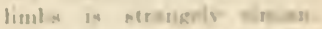
(I roun Risuanes, nfter ad io.

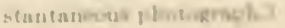
wise more developed in the human embryo than in the adult, a fact which holds in regard io vestigial structures generally. As alrealy sated in (liapter XX (diseussion of restigial structures). Wiecterstum las recorded in man 1 so structural reminiscrences of his dearent from the lower animals. All the farets of this rlase proint to a common origin of man and apes, and an carlier community of origits with other mammals and with other vertetorates, the most primitive traits allying all of them with the flaters.

Palcontology has comparatively litte to offer, but that bisle is decisive. The life hahits of men and monkeys are simpularly 
unfavorable to the preservation of their remains as fossils in rocks. Of the hundreds of species and millions of individuals of the monkey tribes, very few of their remains are known anywhere. Living in thickets and underbrush there is little opportunity for them to be preserved as fossils. With man,
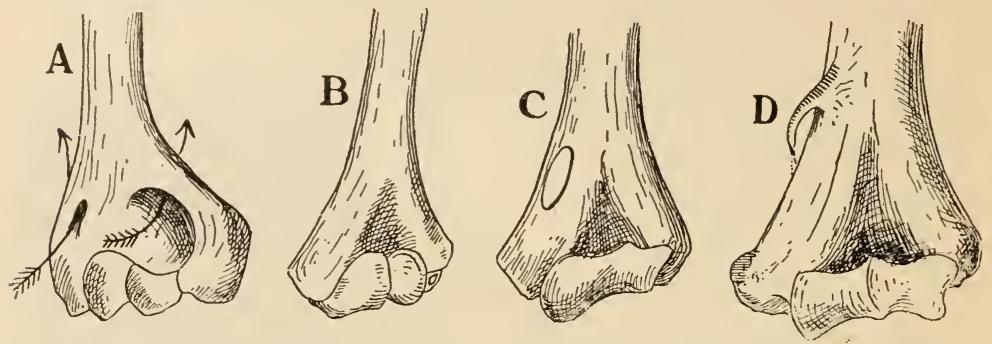

Frg. 292.- End of the humerus of various animals including man, showing position of the humerus canals. $A$, Hatteria; $B$, Lacerta; $C$, eat; $D$, man. (After Wiedersheim.)

the condition is not very different. Implements of stone, bone, bronze, and iron mark stages in the development of primitive tribes. Fossil remains are confined almost wholly to bones buried in quicksand or in the drippings of caves. Of fossil monkeys, several genera have been described. Pan sivalensis is a species of extinct gorilla from the Pliocene of the Punjaub.

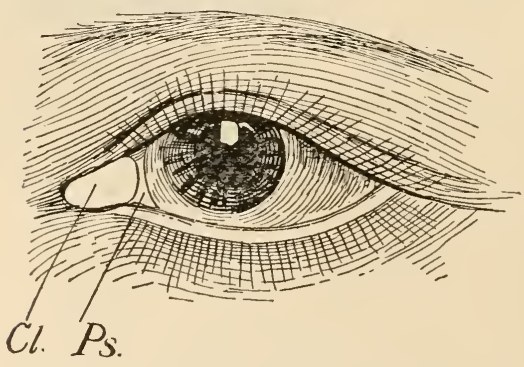

Fig. 293.-The human eye showing, $P s$, arrangement of the third eyelid, Blica semilunaris.
Of all the fossil primates the one of the greatest interest is Pithecanthropus erectus, from the upper Pliocene of Java, lately described by Dr. Eugène $\mathrm{Du}$ Bois. This species has been designated by Haeckel as "the last link" in human genealogy. Its characters have been held to correspond with those of the hypothetical apeman imagined by Haeckel and named Pithecanthropus alaulus, before these remains were found. The generic name of the imaginary ape-man has been transferred to the actual fossil. The discovered relics of this species are scanty enough, consisting of the skullcap, a femur, and two teeth (Figs. 294 and 295). 
In Haeckel's Cambridge lecture, "The Iaut I.ink," the facts concerning this fossil are thus summent up:

"The remains in question rested upon a conglomerate which lies upon a bed of marine marl and sand of Plineme Age. Tourther wibs the bones of Pithecanthropus were found those of ste grodun, Leptahos, Rhinoceros, Sus, Felis, Hy:ena, Hippopot:unus, Tap ir, Blephas, and a gigantic Pangolin. It is remarkable that the first two of these genera are now extinct, and that neither hippopotamus nor hy:ena exists any longer. in the oriental region. If we may judge from these fossil remains, the bones of Pitheeanthropus are not younger than the oldest Pleistocene and prohably belong to the Upper. Pliocene. The teeth are very like those of man. The femur also is very human, but shows some resemblance to that of the gibbons. Its size, however, indicates an animal which stood when erect not less than five feet six inches high. The skulleap is very human, but with very prominent eyebrow ridges, like

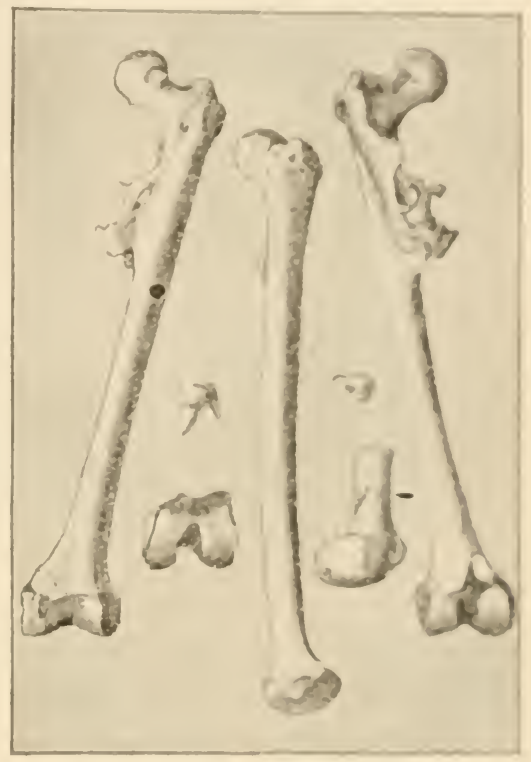

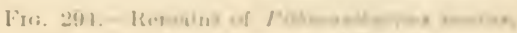
(lie smgle femur shewn in differme dowess (Irom "The Oiven (viurt") those of the famous Neanderthal eranium. It is certainly not that of an idlint. It hal an roliumblel cranial capacity of about $1,000 \mathrm{cec}$, that is 10 say, moch larger then that of the largest ape, which possusies not more than $i x(x)$ cec The crania of female Australians and Vedhlahs mensure not mare than I, ux)

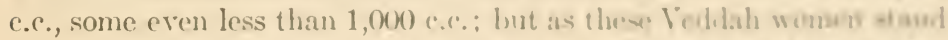
only about four feet nine inches high, the compluted cranial copasiss of the much taller lithecanthropus is comparacively low inded."

The impressions left by the cerelual consolutimas are alm very human, more highly developerd than in the rowme apes. 
It is stated that in the discussion at Leyden, where Dr. $\mathrm{Du}$ Bois's specimens were first exhibited, "three of the twelve experts present held that the fossil remains belonged to a low race of man; three declared them to be those of a manlike ape of great size, the rest maintained that they belonged to an

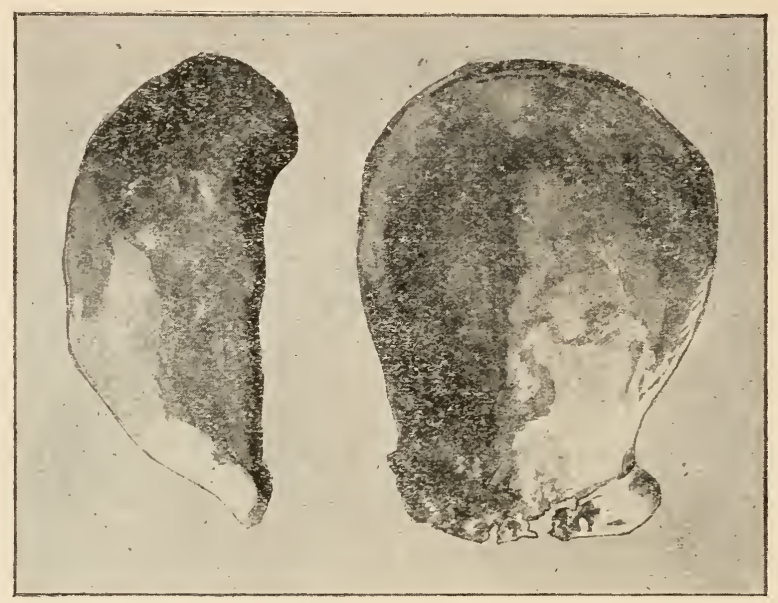

Frg. 295.-Cranium of Pithecanthropus erectus. (From Weltall u. Menschheit.)

intermediate form which directly connected primitive man with the anthropoid apes." (Haeckel.)

Of the several early relics which are distinctly human, the Neanderthal skull, found by Professor Schaffhausen in a limestone cave in the Neanderthal, near Düsseldorf, is the most notable. This skull represents the most primitive and least specialized of any skull type known to be distinctly human. It has therefore been recently named as a distinct species of man, Homo neanderthalensis.

According to Huxley, this type of man, while certainly simple, primitive, and doubtless extremely barbarous is, nevertheless, wholly human. It shows no distinctly pithecoid characters, and it belongs clearly to the genus Homo.

Another skull of great antiquity comes from a cave at Engis in the valley of the Meuse, and is known as the Engis skull. This was found associated with bones of the mammoth and of the woolly rhinoceros. This also is extremely primitive, 
suggesting the skull of an Ethiopian. It is, however, more like that of recent man than is the Noanderthal skull.

The comparison of the different races of men through the methods of the science of ethnology throws much light on the relations of the races to one another, but casts little lightit on he origin of the genus Homo. This study considerably increases the number of primitive rases berond the three stems usually recognized or the four named by Linnatus. The form of the skull, the color of the skin, the character of the hair, omb the traits of language have given rise to the technical nomenclature of numerous more or less well-defined grougs. These

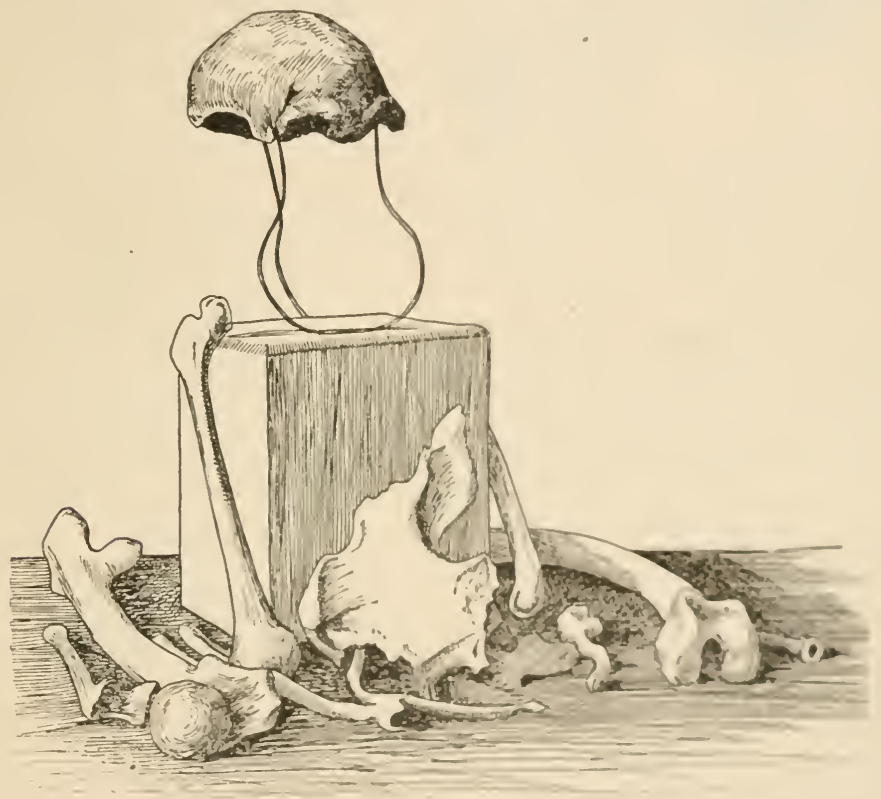

־. 296.-Remains of the Neanlerthal man in the Provincial Muman at Hun.

(From IFellull u. Menachicil)

races of men limited hy gengraplical scuregation rum more or less distinctly parallel to the racese or gengraphical strlepecies within widely distributed speecies of animals. Our huowledge of the origin of man as derived from ethnology is thus summed up by Huxley: "So far as the light is bright it shows lim sub- 
stantially as he is now, and when it grows dim it permits us to see no sign that he was other than he is now."

The gradual development of man from nomadic apes; the gradual effect of the prolonged infancy of his young in the

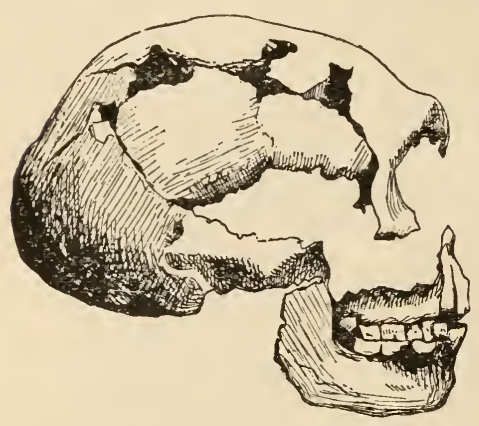

FIG. 297.-Skull of ancient man from Spy in Belgium. (From Weltall $u$. Menschheit; after Professor Fraipont's photograph of the original in the musem at Liège.) holding of the family together; the altruistic transformation of the family into the patriarchal and tribal systems; the gradual increase of the power of choice among instincts, a development which at last places intellect above instinct, the use of fire and the use of tools, the growth of speech and its reaction upon intclligence, the invention of writing, effects of the supremacy of the strong-all these matters afford large range for speculation and some opportunity for direct investigation. But the essential fact, the kinship of man with the lower forms, and his divergence from them through the operation of natural laws, forces and conditions more or less perfectly understood, all this must now be taken as settled by the investigations and discoveries of Darwin and his coworkers and successors.

Assuming that the genealogy of man can be traced through the anthropoids and the Old-World monkeys to the lemurs, how much further can we go? Apparently the lemurs represent an early offshoot

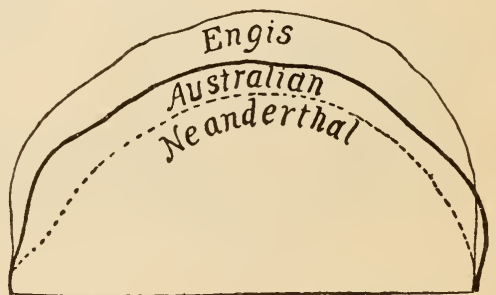

FIG. 298.-Diagrammatic representation of profiles of crania of primitive types of man. (After Lenormant.) from the mammalian stock, the nearest point of juncture being the order of marsupials, now so largely represented in Australia. Certain extinct lemurian genera are more distinctly primitive than any of the living forms, The marsupials are connected with the primitive group 
of reptile-mammals, the Monotremes (Ornithorhynchus, Tachyglossus), now also represented, although scantily, in Auntralia. The Monotremes may be assumed to be derived from repulian stock, perhaps from ancestors of the three-eyed lizards of New Zealand, known as Sphenodon or Hatterit. Behind thene lizards we certainly find the primitive amphibians or mathed frogs and behind these the group of lung-bearing fithres, known as fringefins or erossopterygians. These fishes were originally derived, no doubt, from sharks, and the sharks may have come from wormlike forms through intermediate groups which find their nearest modern homologues in the lamprey and lancelet, and possibly in the wormlike acorn-tongure or balanoglossus, a creature which to a soft wormlike hody anlds the gill slits of a vertebrate and a trace of a primitive backibone or notochord. Hacekel goes on with ennfieleuros to show the derivation of one type of worm from another, of all from allies

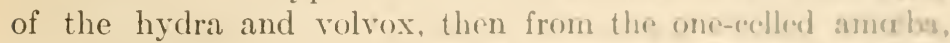
and at last from the still more primitive monera, a mictoseopic bit of protoplasm. I3ut with every step backward the genealogy grows more and more hypothetical. All ants of possibilities open at every turn and positive proof is nectsarily lacking. The gill slits and the primitive notochord of the human embryo leave little doubt that man in common with all other vertebrates had a fishlike ancestry. In the line of this ancestry must have lain the extinct crosispeterygian fishes, but betind this there is room all the way for serious doubt and dpuntroning.

This much is certain, man's placer is in mature. He is part and pareel of nature, and the fores's that still anet on flower atul bird and beast are the forees by which the central entres of the universe, whatever its name or definition, wath day "instantly and constantly renews the work of creation.

Objections have been ratised to the theory of the desame of man from the lower prinates on grounds suppoed to find their sanction in theology. Such objections have mo standug in science. In Darwin's words: "Theology and acience mist ach run its own course and I am not respousible if their mersimgpoint be still af:ur off." In the long rum, theologr, with other forms of philosophy, must aljust itolf to harmonias with ascertained truth. The origin of man is not a quention of prorsonal preference nor one to be deerided ly a majority wate. The only question is as to what is true. "Lingunghed theolu- 
gians," Huxley tells us, "lie about the cradle of every science as the strangled snakes beside that of the infant Hercules." Looking along the history of human thought, we see the attempt to fasten to Christianity each decaying belief in science. Every failing scientific notion has claimed orthodoxy for itself. That the earth is round, that it moves about the sun, that it is old, that granite ever was melted-all these beliefs, now part of our common knowledge, have been declared contrary to religion, and Christian men who knew these things to be true have suffered all manner of evil for their sake. We see the hand of the Almighty in nature everywhere; but everywhere he works with law and order. We have found that even comets have orbits; that valleys were dug out by water, and hills worn down by ice; and all that we have ever known to be done on earth has been done in accordance with law.

Darwin says: "To my mind it accords better with what we know of the laws impressed on matter by the Creator, that the production and extinction of the past and present inhabitants of the world should have been due to secondary causes, like those determining the birth and death of an individual. When I view all beings, not as special creations, but as lineal descendants of some few beings who lived before the first bed of Silurian was deposited, they seem to me to become ennobled. There is grandeur in this view of life, with its several powers having been originally breathed by the Creator into a few forms or into one, and that while this planet has gone cycling on according to the fixed law of gravity, from so simple a beginning, endless forms most beautiful and most wonderful have been and are being evolved."

With the growth of the race has steadily grown a conception of the omnipotence of God. Our ancestors felt, as many races of men still feel, that each household must have a god of its own, for, numerous as the greater gods were, they were busy with priests and kings. Men could hardly believe that the God of their tribe could be the God of the Gentiles also. That He could dwell in the temples not made with hands removed Him from human sight. That there could be two continents was deemed impossible, for one God could not watch them both. That the earth was the central and sole inhabited planet rested on the same limited conception of God. That the beginning of all things was a few thousand years ago is another phase of 
the same limitation of view, as is the idea of the special mechan. ical creation for every form of animal and plant.

A Chinese sage, whose words remain though his name be lost in mists of the ages, has said: "He cannot be concealed: He will appear without showing Himself, effect renovation without moving, and create perfection without acting: It is the law of heaven and earth, whose way is solid, substantial, vast, and unchanging." 



\section{APPENDIX}

ReFerences to general and special treatments of the subjowe included in this book, arranged according to chapters. Thee reformest are eonfined to books and papers published in English (including trans lations of foreign works) and are intended for the assintance of genral readers and elementary students wishing to follow up, in more disul than is offered in this book, the study of any farticular phas of the general subject of Evolution. These references are therefore monty not to original papers, but to manuals, summaries, and diguste of evolution subjects. The list makes no attempt, of course, to inrlude all of even the most general works of reference.

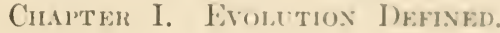

Spencer: Principles of Biology, vol. I, part iii, 157i. Conn: Evolution of To-day, pp. 1-21, 1Scig. Le ('onte: Evolution, Its Nature, Its Evidences, and Its Relation to Religious Thought, 1\%. 3-31, Int. Haeckel: History of Creation, vol. I, ch. i, 1s92. Mar-hall: I)arwinian Theory, pl). 1-24, 1n!9. Willians: (imolugieal Bulugy, pp. 371-354, 1895. liomanes: Darwin and Mfer I)arwin, wh. I, pp. 12-22, 1896. Marshall: Biological Lectures, Mp. 1-26, 1897. Howison: Limits of Erolution, 1)p. 12-15, 1901. Huxley: Darwiniana, 1894.

Chapter II. Variety ani Unity of Iife.

Jordan: Footnotes to Evolution, ch. i and ii, 1902.

Chapter III. Life, Its Physical Basis axi) Simirest Exirkesiov.

Verworn: General Physiology, 1S99. Wilson: (hapters ou Fonlution. pp. 61-79, 1S\$3. Haeckel: History of ('reation, vol. 1, ch. wr: vul. II, ch. xrii and xviii, 1892. Huxley: ()n the Physieal Lasin of Life (ch. iii, in Essays on Method and Results). Mar-hall: Bological Lectures, pp. 11t-191, 1897. Conn: The Methexl of Erolution, eh. ix, 1900. Jordan and Kellogg: Animal life, ch. i, ii, ant iv, 1900. McFarland: The Physical Basis of Heredity, ch, vi in Jordan's Footnotes to Evolution, 1902. Wilson: The Cell in Development and Inheritance, 2d ed, 190-1, Weismann: The Evolution Theory, vol. II, Lect. 36, 1904. 
Chapter IV. The Factors and Mechanism of Evolution.

Darwin: Origin of Species, ch. xv, 1859. Spencer: The Factors of Organic Evolution, pp. 1-37, 1889. Gray: Darwiniana, pp. 9-61, 1889. Conn: The Method of Evolution, 1900. Cope: Primary Factors of Organic Evolution, 1896. Jordan: Footnotes to Evolution, ch. iii and iv, 1902. Weismann: The Evolution Theory, vol. I, Lect. 1, 1904.

\section{Chapter V. Natural Selection and the Struggle for Existence.}

Malthus: Principles of Population. Darwin: Origin of Species, ch. iii and iv, 1859. Wallace: Darwinism, pp. 14-125, 1891. Marshall: Lectures on the Darwinian Theories, pp. 27-52, 1894. Romanes: Darwin and After Darwin, vol. I, pp. 125-294, 1895. Wallace: Natural Selection and Tropical Nature, 1895. Bailey: Survival of the Unlike, pp. 13-54, 1897. Osborn: From the Greeks to Darwin, ch. vi, 1899. Headley: Problems of Evolution, pp. 68-155, 1901. Conn: Method of Evolution, ch. ii and iii, 1901. Morgan: Evolution and Adaptation, ch. iv and v, 1903. Weismann: The Evolution Theory, vol. I, Lects. 2 and 3, 1904. De Vries: Species and Varieties, Their Origin by Mutation, ch. xxviii, 1905. Metcalf: Organic Evolution, 1905. Kellogg: Darwinism To-day, 1907.

\section{Chapter VI. Artificial Selection.}

Darwin: Origin of Species, ch. i, 1859. Darwin: Animals and Plants under Domestication, vols. I and II, 1868. Wallace: Darwinism, ch. iv and vii, 1891. Burbank: New Creations in Fruits and Flowers (catalogues of plant novelties), 1893 and succeeding years. Marshall: Lectures on the Darwinian Theories, pp. 27-36, 1894. Romanes: Darwin and After Darwin, vol. I, pp. 294314, 1896. Bailey: Survival of the Unlike, 1897. De Vries: Species and Varieties, Their Origin by Mutation, 1905. Bailey: Plant Breeding, 4th ed., 1906. Harwood: New Creations in Plant Life, 1906.

\section{Chapter VII. Theories of Species-forming and Descent Control.}

Eimer: Organic Evolution, 1890. Romanes: Darwin and After Darwin, III, 1897. Conn: Method of Evolution, ch. vii and viii, 1900. Packard: Lamarck, His Life and Work, 1901. Morgan: Evolution and Adaptation, 1903. Weismann: The Evolutionary The- 
ory, vol. II, Lects. 32 to 35,1904 . De Vries: Specries and Varuoties, Their Origin by Mutation, 1905. Kellogg: I)arwiniam To-day, 1907.

Chapteir Vili, Geographic Isniation and Sibctmb-yormive.

Wallace: Darwinism, pp. 33S-37.4, 1S91. Romanes: Dorwin sbil After Darwin, I, py. 204-24\$, 1645. Weismann: The Tvolution Theory, vol. II, Lect. 32, 19(0). Jordan: The Origin of syment

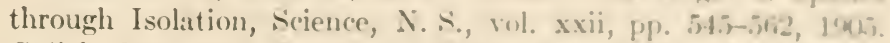
Gulick: Evolution, Racial and Habitudinal, 1905. Montgomery: Analysis of Racial Descent in Animals, 1906.

\section{Chapter IX. Varition a.jo Mutation.}

Darwin: Origin of Species, ch. i, ii, and $v$, 15.59. Darwin: Animals and Plants Under Domestication, vols. I and II, 156s. Wilmin: Chapters on Evolution, pp. 121-142, 1s.5.3. Wallace: J)arwiniem, ch. iii and iv, 1891. Bateson: Materials for the situly of lariation, 1S94. Romanes: Darwin and After I)arwill, vul. I, IH. 50-65, pp. 120-135, 1896. Bumpus: Variations and Mutations of the Introduced Sparrow, in Biologienl Lectures, Hownl's Hall, pp. 1-15, 1596-97. Biometrika: A Journal of Variation, 19x)1to date. Vernon: Variation in I'lants and Animals, 1903. Morgan: Evolution and Adaptation, 1903. Kellogg and Bell : sumbes of Variation in Insects, 1904. Davenport: Statistical Methols, 2d ed., 1904. De Vries: Speries and Varieties and Their Orikin by Mutation, 1905.

\section{Chaiteir X. Hereditr.}

Brooks: Heredity, 1\$\$3. Weismann: Essays upon Meredity, vol. I, Lects. 4 and 6, 1S91; Essays upon Heredity, vol. II, ch. xii, I L Marshall: Biological Lectures, pp. 15!)-191, 14.97. Cialen: Natural Inheritance, 1s99. ('onn: Method of Evolution, H\%. 101-156, 1901. Bateson: Mendel's Principles of Meredity, 1:ma. Redfield: Control of Heredity, 19)2. Milann: The cell in thvelopment and Inheritance, 2ded., 196). Montgomery: Inalyoin of Racial Descent in Animals, 1906. Woods: Herediey in Royalt?, 1906.

Chapter XI. The Inhemitace of Acquiren Curactus.

Weismann: Fssays on Heredity, vol. I, 19x). Spencer-Weismame Contemporary Review, May-December, 1s!3; Aplember-Orto- 
ber, 1595. Cope: Primary Factors in Organic Evolution, pp. 397473, 1896. Marshall: Biological Lectures and Addresses, pp. 91-115, 1897. Hutton: Darwinism and Lamarckism, 1899. Weismann: The Evolution Theory, vol. II, Lects. 23 and 31, 1904. Metcalf: Organic Evolution, pp. 67-82, 1904. Kellogg: Darwinism To-day, ch. x.

\section{Chapter XiI. Generation, Sex, and Ontogeny.}

Marshall: Lectures on the Darwinian Theories, pp. 78-115, 1894. Geddes and Thomson: The Evolution of Sex, 1859. Romanes: Darwin and After Darwin, vol. I, ch. iv, 1896. Marshall: Biological Lectures and Addresses, pp. 259-363, 1897. Jordan and Kellogg: Animal Iife, ch. v, 1900. Morgan: Regeneration, 1901. Weismann: The Evolution Theory, vol. I, Lects. 13 to 16; vol. II, Lects. 27 to 30, 1904. Wilson: The Cell in Development and Inheritance, 2d ed., 1904. Montgomery: Analysis of Racial Descent in Animals, 1906. Morgan : Experimental Zoölogy, 1907.

\section{Chapter XiII. Paleontology.}

Wilsón: Chapters in Evolution, ch. xvi, 1883. Wallace: Darwinism, ch. xiii, 1891. Marshall: Lectures on the Darwinian Theories, pp. 53-77, 1894. Williams: Geological Biology, pp. 1-9, 78-110, 1895. Romanes: Darwin and After Darwin, vol. I, pp. 156-203, 1896. Le Conte: Elements of Geology, part III, 1891. Smith: Evolution of Fossil Cephalopoda, ch. ix, in Jordan's Footnotes to Evolution, 1902. Metcalf : Organic Evolution, pp. 103-111, 1905.

\section{Chapter XIV. Geographical Distribution.}

Wallace: The Geographical Distribution of Animals, 1876. Wallace: Island Life, 1880. Heilprin: Geographical Distribution of Animals, 1887. Wallace: Darwinism, pp. 338-374, 1891. Beddard, Zoögeography, 1895. Romanes: Darwin and After Darwin, vol. I, pp. 204-248, 1895. Jordan: Science Sketches, pp. 83-132. Wallace: The Malay Archipelago, 2d ed., 1869.

\section{Chapter XV. Adaptations.}

Semper: Animal Life, 18s1. Morgan: Evolution and Adaptation, 1903. Weismann: The Evolution Theory, vol. I, Lects. 5 and 7, 1904. Jordan: Guide to the Study of Fishes, vol. I, ch. xi and xii, 1905. Folsom: Entomology, with Reference to Its Biological and Economic Aspects, 1906. 


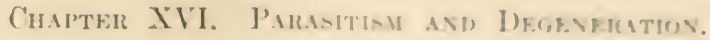

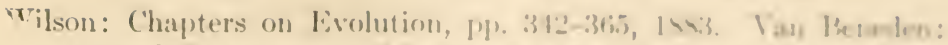

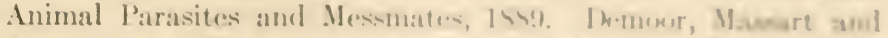
Vandervelde: Evolution by Arophy, 1s?9.

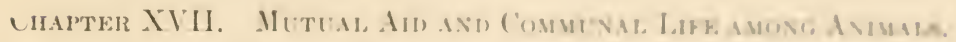

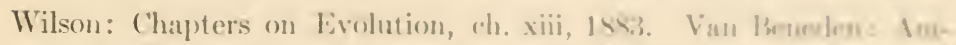

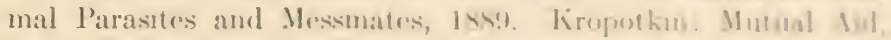
1902. Wrismann: The Evolution Theory, rol. 1, Leet 9, f(x)1. Kelloge: American Inserts, 1). 190-5til, 1!n.i.

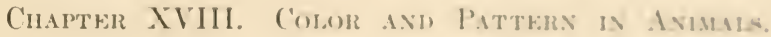

Poulton: The Colors of Animals, Is!ou. Bedelard: Animal culoration, 1895. Wallace: Natural Felection and Tropiceal Nature, ch. v, 1595. Newhigin: Colors in Nature, 14!). Wremann: The Evolutionary Theory, wol. I, Ifets. 4 and 5, 1901. Kelloge: American Insects, (h. xvii, 19().).

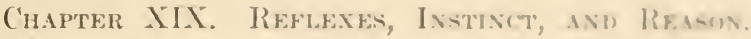

Darwin: Origin of Species, ch. viii, 1859. Morgan: Animal life and

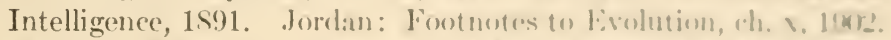
Morgan: Habit and Instinct, 1s!m, Morgan: Aninal Thlinvior. Ioeb: Physiology of the Brain, 1960). Jemuinge: The Buhavior of the Lower Organisms, 1904. Romanes: Mental Fmo lution in Animals, 1SSt. Weismann: The Evolneion Theory, vol. I, Lect. S, 1904. Loch): (ineral l'hysiology; wols. I, II, 1906.

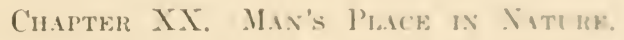

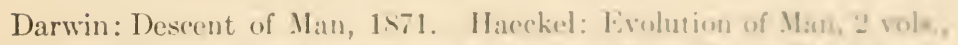
1883. Huxley: Man 's Place in Nature, 1494. Tyler: The II homo and Whither of Man, 1596. C'alelerwood: Frolumion and Man's Place in Nature, 1s96. Revil: The I'resent Frobloson of Man.

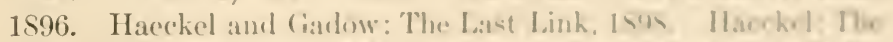

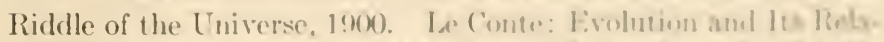

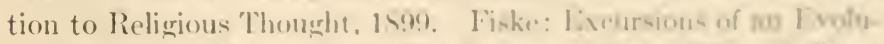

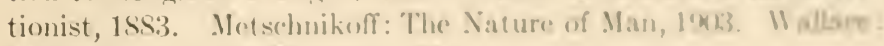
Man's Place in the Universe, 1\%:3. 



\section{N D E X}

Actinocephalus oligacanthus (illus.), 216.

Adaptation, 56, 327; categories of, 328.

Aid, mutual, 369.

Allen, J. A., 136, 206.

Altmann, theory of protoplasmic structure, 250.

Amaryllids, sports of (illus.), 103.

A mblystoma opacum (illus.), 20.

Amitosis, 252.

Amoba eating one-celled plant (illus.), 31; moving (illus.), 30; polypodia, stages of fission (illus.), 31; reproduction of, 213; (illus.), 214.

Amphimixis, 154.

Analogy, between variations in species and in languages, 325; defined, 173; in wings of animals, (illus.), 173.

Anaphase, defined, 256.

Andrena, nest of (illus.), 384.

Andricus californicus, galls produced by (illus.), 342 .

Anemone, sea, with alga in body wall (illus.), 377 .

Anosia plexippus and its mimic (illus.), 422; metamorphosis of (illus.), 235.

Antlion, larva, excavating pit (illus.), 330 .

Ants, castes of (illus.), 391; commensal life with aphids, 37.; communal life of, 391 ; nest of (illus.), 392; (illus.), 393; social parasitism of, 375 ; symbiosis with plants, 377 .
Apes, anthropoiel, elsesifention of 4.51; cars of (illus.), 178.

Aphids, commonal life whto anes, 37.1 .

Appendix vermiformis, of kangarom and man (illus), 17!.

Apple, hybridizerl monsic (illus. 101; secellings of the. Willumes Early (illus.), 10'2.

Aquila chryscielus (illus.). It.

Arbacia, extra-ovates of (illus, , 241: viritis, regeneration in follos. 282.

Archaopterys lithougraphica (illusel. 302.

Ascaris megalocephala, spernator genesis of (illus.), afif; (illas f. 26.5; (illus.). 271; var. unralens, eell division in (llus). 2is.

Ascidian (illus.), 4:; (illus.), 3\%4.

Asters, defined, 254.

Atavism, ltiti.

Australia, rahbit and other plagues of, (i.).

A ythyn, family of (illus.), 443 .

Barnacle (illus), 3i5; metamorphusis of (illus.). 231

Barriers, gerugraphic, 316 ; influencos of giongraphic, 128.

Bascaniun constrictor (1llus), I3

Busslarchiu esrchippuse, munehlug . 1 nosiar (Illus.), 1:2

Bates, II. IT, I0).

Bateson, 117), 111, 1-77, 14, 192

Bat tick, wingless (illus! 3sil

Beavers makime neate (ollus y, bi: 
Bechamp, theory of protoplasmic structure, 250.

Bee, carpenter, nest of (illus.), 384; mining, nest of (illus.), 384; social, 384; solitary, 383.

Beetle, California flower, apparent determinate variation in, 152 ; polygon showing variation in pattern of (illus.), 152; (illus.), 153; (illus.), 154; variation in pattern of, 134 .

Beetle, fore leg of male, of water (illus.), 73; long-horned boring (illus.), 12; (illus.), 41; scarabeid (illus.), 72 .

Bell, R. G., 85, 142, 192.

Belt, Thos., 402, 417.

Berries, Burbank's work with, 93.

Berthold, theory of protoplasmic structure, 250.

Bethe, A., 428.

Bionomies, defined, 1.

Biophors of Weismann, 251.

Bird of paradise, male (illus.), 221.

Bittern, American, young of, showing fear of man (illus.), 436; showing no fear of man (illus.), 435.

Blacksnake (illus.), 43.

Blastoderm, 228.

Blastula, 228.

Blindness, in fishes (illus.), 180.

Blue jay, nestlings of (illus.), 442.

Bones, homologies of, in vertebrate hands (illus.), 169; in vertebrate limbs (illus.), 170, 171, 172.

Boyesen, H. H., 451.

Brewer, Wm., 201.

Brittle stars (illus.), 14.

Brooks, W. K., 1, 57, 165, 197, 244.

Budding, reproduction by, 215.

Buffon, theory of protoplasmic structure, 250.

Bumble bee (illus.), 385; communal life of, 384.

Burbank, L., 80, 90, 91, 195; scientific aspects of his work, 101.

Butterfly fish (illus.), 420; Monarch, metamorphosis of (illus.), 235.

Cactus, hybrid seedlings of (illus.), 98.

Calcolynthus primigenius (illus.), 36 . Callorhinus alascanus, family of (illus.), 440.

Calotarsa insignia, showing secondary sexual characters (illus.), 74.

Camponotus (illus.), 391.

Cankerworm moth, showing sexual dimorphism (illus.), 222.

Carchesium sp. (illus.), 34 .

Cardinalis Virginianus, diagram of variation in, 136.

Castanea vesca, variation in leaves of, 159.

Castle, W., 192.

Caterpillar, parasitized (illus.), 360 . Cattle, British breeds of (illus.), 86 . Cecropia tree, with ants (illus.), 379. Cell, 30; egg, 224; fission of, in salamander (illus.), 255; metotic division of, described, 253.

Cells, different types of (illus.), 29; sex, 218.

Cephalopods (illus.), 40.

Ceratina dupla, nest of (illus.), 384 . Ceratium (illus.), 207.

Cercopithecus (illus.), 446.

Chcetodon vagabundus (illus.), 420.

Characters, illustrations of acquired, 198; inheritance of acquired, 196; secondary sexual, 72.

Chestnut, variation in leaves of (illus.), 159.

Child, C. M., 252.

Child, with six toes on each foot (illus.), 147.

Chimpanzee, foot, skeleton of compared with that of man (illus.), 453; plan of, compared with that of man (illus.), 459. 
Chipmunks of California, classifucattion of, 117; (illus.), 11 s.

Chromosomes, defined, 25:3.

Chrysopa, exgs of (illus.), 22ti.

Cicada, variation in tibial spines of, 13.1; seplendecem, variation in tibial spines of, 136 .

Cladonotus humbertianus (illus.), 409.

Classes of animals, 35.

Classifieation, determined by homologies, 173; of animals, 33.

Cleavage, 228.

Coccidium lithobii, life cycle of (illus.), 352.

Coccidium oriforme (illus.), 216.

Cock, white-crested black Polish (illus.), 81 .

Cockerel, silver-laced Wyandotte (illus.), $s 2$.

Cockroach, egg case of (illus.), 340); showing variation in number of tarsal segments (illus.), 149.

Color, in animals, 395; in organisms, how produced, 403; in protective resemblance, 400 ; in sexual selection, 400; uses of, 399 .

Coloration, directive, $\mathbf{4 1 9}$.

Colors, warning, 416 ; table of insect, 405.

Commensalism, 370 .

Communism, 369, 345; advantages of, 397 ; basis and origin of, 395 .

Conditions, primary, of life, 35.

Conjugation, of noctiluca (illus.), 220; of Vorticella neluelifere (illus.), 221.

Conklin, E. G., 70, 199, 201, 203.

Convergence of characters, 204.

Cope, E. D., 5i), 197.

Cordyceps, growing on a caterpillar (illus.), 363.

Corn, showing results of hybridization, 194.

Correns, E.., 192.

Coues, F., 24, 119

Crab, fideller (illus.), 3s; hermit, commerianal life with pelype (1llus.), 373; (Illus s, 37, w watamorphosin of (illun), 2:35.

Cramer, F., 11.

('ricket, mole (illus), 314; (Illus). 345.

C'rotalus culumanteua (illos.), 16.

Crustaces and their larva (illus.), 3(6i); parasitic, 35s.

('ryptomeria japonica, atavistic variation of (illus.), 160).

Cucumaria sp. (illıs.), 19.

Cueumbers, sea (illus.), 19.

Cuenot, L., 15.5, 191, 192.

Cumningham, J. T., 201.

Cyanocitta cristata, nestlings of (illus.), 4t?.

Cycle of life, 240.

Cyclops, maturation in. 272; maturation of eggs of (illus.), 26i3.

Cypselurus (illus.), 333.5.

Cyrtophyllus crepitans (illus.), 401.

Dill, W., 197, 20:5.

D:arbishire, W., 192.

D):arwin, $(., 9,9,22,45,60,63,67,65$,

$71,7(3,30,137,141,1 ! 6,2=0$,

$311,466,467$, tis.

'Darwinism, defimed, fs.

1):ivenport, ('. B., 192.

Death, 2211.

Decapod, showing extraorlinary rogeneration (illus-), 117.

Deer, head of, showing bariation in horns (illua), 14i, horns of interlesehed fillum tis

Degeneratim, 317; hy quiesmare 363.

Dedage, Y., 2!), 4ti, 25:

Desent, theory of, 10 ; thrmenes al conterol of fors

Determinants of Wrimban 251 .

Development, 2224; discrecine on.

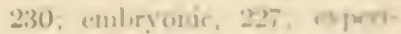
mental. 241: firt staers in embryoutie falmot 2a. of

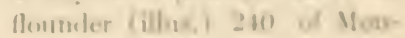


arch butterfly (illus.), 235; of the prawn (illus.), 232; of silkworm moth (illus.), 236; of swordfish (illus.), 239; postembryonic, 234; significance of, 232.

Devilfish (illus.), 40.

De Vries, H. H., 54, 111, 114, 146, 187, 192, 193; work of, on Enotheras, 157.

Diabrotica soror, apparent determinate variation in, 152 ; frequency polygon of variation in (illus.),152; (illus.),153; (illus.), 154; variation in pattern of (illus.), 134.

Diapheromera femorata (illus.), 412. Dickinson, Sidney, 65.

Didelphys virginiana (illus.), 46.

Dimorphism, sexual, 221.

Dimorphodon macronyx, restoration of (illus.), 293; (illus.), 294; (illus.), 295; (illus.), 296; remains of (illus.), 291.

Dischidia, with ant colonies (illus.), 378.

Distribution, geographic, 309 .

Dog, pointer (illus.), 431.

Dogs, prairie (illus.), 383.

Douglas, N., 79.

Draco (illus.), 306.

Dragon, flying (illus.), 306.

Drepanidæ, classification and distribution of, in Hawaii, 124.

Driesch, H., 278, 279.

Du Bois, E., 462, 464.

Dïrigen, 79 .

Dyticus, fore leg of male (illus.), 73.

Eagle, golden (illus.), 44.

Ears of apes and man (illus.), 174.

Earthworm, regeneration of (illus.), 284.

Eastman, C. W., 292.

Echinus, cleavage in calcium-free water (illus.), 280; microtuberculatus, gastrula of (illus.) 279; microtuberculatus, normal larva of (illus.), 275.

Ectoblast, 228.

Egg cell, 224; of sea-urchin (illus.), 248.

Eggs of Chrysopa (illus.), 226; of various animals (illus.), 225.

Eigenmann, C., 179.

Eimer, T., 55, 197.

Embryo, human, foot of, 460 .

Emerson, R. W., 452.

Emery, C., 394.

Encasement theory, 2, 249.

Endoblast, 228.

Epigenesis, 276.

Epigenetic theory, 3.

Eretmoschlys imbricata (illus.), 43.

Ergates sp. (illus.), 41.

Erynnis manitoba, distribution of (illus.), 310.

Eutamia, in California, classification of, 117 .

Evolution, biologic, 6; cosmic, 6; defined, 1; factors of, 48; in philosophy, 2; Lamarckian, 55; mechanism of, 48; orthogenetic, 55; Spencer's definition of, 5; the unknown factors of, 115.

Existence, struggle for, 57, 60 .

Exocotus (illus.), 335.

Extra-ovates of Arbacia (illus.), 281.

Eye, human (illus.), 462; pineal, of horned toad (illus.), 176; pineal, of lizard (illus.), 175.

Factors, extrinsic, in development, 245 ; intrinsic, in development, 245 ; the unknown, of evolution, 115.

Fauna, 316; Bassalian, 323; littoral, 324 ; pelagic, 323 .

Feeding, instincts of, 432 .

Fertilization (illus.), 267; (illus.), 268; of Petromyzon fluviatilis (illus.), 219.

Fishes, adaptations of, 332 ; blind 
(illus.), 1s0, 204; flying (illus.), 335; migrations of, 340 ).

Fish louse (illus.), 359.

Fission, reproduction by, 213; (illus.), 214.

Fittest, survival of, 62.

Flatworm, regeneration of (illus.), 285; (illus.), 286.

Flounder, development of (illus.), 240.

Flower bug, variation in pattern of (illus.), 135.

Flowers, varieties originated by Burbank, 98.

Focke, 192.

Fol, H., theory of protoplasmic structure, 250.

Foot, of horse, evolution of (illus.), 177; of human embryo (illus.), 460 ; of mammals, hology of digits of (illus.), 178.

Forel, A., 394.

Fossils, 17, 290.

Fowls, skulls of (illus.), ss.

Friedenthal, 460.

Frog, male earrying eggs on baek (illus.), 73.

Galls (illus.), 341 ; (illus.), 342 .

Galton, F., 165.

Gasterosteus, 207; cataphractus (illus.), 209.

Gast rula, 228.

Gaudry, A., 298.

Gauss, 141.

Geddes, P., 1.

Gelasimus sp. (illus.), 35 .

Genealogy of animals, 36 .

Generation, 211; spontaneous, 42, 212.

Geography, relation of species to, 311.

Geology, table of ages of, 295 .

Georgine, variation in inflorescence of (illus.), 161.

Geranium, improvement in (illus.), 103 ,
Germ collw, theery of the phrity uf, 191.

(iillbert, ('. II, 31):3.

(iill slits of vertelorates, 179.

Gorthe, II. von, 1, 45, 163, $26 !$.

(iongylus gongyglorides (illum.), 415.

Gonium pretorale (illus.), 34; (illus.), 261.

Gorilla (illus.), 456; face of (illus.), 457 ; head of (illus.), 457; young (illus.), 4iss.

Gray, A., 197, 326.

Gregarina polymorpha (illus.), 216.

Gregarinidar, reproduction in (illus.), 216.

Gregariousness, 380.

Grus americana (illus.), 20.

Grosbeak, cardinal, diagram of variation in, 13ti.

Gryllotal pu (illus.), 3.44; (illus.), 34.5. Gulick, J. T., 1:3.

Hatse, F., 423.

Haeckol, E., 32, 197, 269, 457, 463, $464,46 i, 4 t i 7$.

Hair covering of human embryo (illus.), 174; covering of Piusinn dog-man (illus.), 174.

Hawaii, elassifieation and distribution of Drepanidas of, 124: distribution of land snals of, 123.

Henneguy, I., 260.

Henslow, (;., 124.

Horedity, 53, 16i3: defined, 16i3: laws of. 184; Mendel's law of, 157.

Herlitzka, 279.

H(rmaphroxlitism, 22:3

Hernn, llying (illıs.), 24

Hertwig, 0., 2is.

Heterogenesis, 54; therries of 118: theory of, lixi.

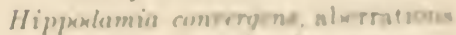
of, 130): variation in pottern of (illua), 132: (illus) 183.

Ihog, wille and domest is (illus ys a a. 
Holophrya multifiliis, reproducing by sporulation (illus.), 215 .

Homologies, defined, 172; of bones in vertebrate hands (illus.), 169; of bones in vertebrate limbs (illus.), 160, 171, 172; of digits of feet of mammals (illus.), 178; of tail of man, 179.

Homo sapiens, 454.

Honey bee (illus.), 387; brood cells of (illus.), 389; communal life of, 387; pollen carrying leg of (illus.), 388; wing, hooks of (illus.), 155; wings of drone, showing variation (illus.), 155; (illus.), 156.

Hooker, Th., 65.

Horse, changes in foot of, in geologic time (illus.), 303; evolution of foot of (illus.), 177; hybrid of, with zebra (illus.), 183.

Horses, trotting, heredity in, 168.

Huber, 394.

Human embryo, head of, showing embryonic hair covering (illus.), 174.

Humerus, end of, of various animals (illus.), 462.

Humming bird, male and female (illus.), 71; Rufus, nest of eggs of (illus.), 441.

Huxley, 7, 25, 26, 64, 197, 309, 426, $457,459,460,468$.

Hyatt, A., 197.

Hybrid colt of horse and zebra (illus.), 183.

Hybridization, 88, 154.

Hydra vulgaris (illus.), 35 .

Hyla regila (illus.), 344 .

Icerya purchasi, 62, 64 .

Ichneumon laying eggs in cocoon (illus.), 359 .

Ichthyophis glutinosus, eggs carried by (illus.), 338 .

Icterus, distribution and classificatinn of American species of,
128; galbula, diagram of varia tion in, 137.

Idioplasm of Nägeli, 251.

Imbauba tree and ants (illus.), 379. Inchworm (illus.), 411.

Inheritance, exceptions to Mendelian, 193; experimental studies of, 192; Galton's law of ancestral, 184; modes of, 181, 186; of acquired characters, 196.

Insects, parasitic, 359 ; special adaptations of, 340 .

Instinct, 426.

Instincts, climatic, 436; environmental, 438; of care of young, 439 ; of courtship, 438 ; of reproduction, 439 ; terrifying, 431 ; variations in, 442 .

Intellect, 443 .

Islands, relation of species to, 312 .

Isolation, 53; biologic, 109; geographic, 54, 117; physiologic, 54; sexual, 54.

Jack rabbits, showing variation (illus.), 320 .

Jennings, H. S., 429.

Kallima (illus.), 414.

Kangaroo (illus.), 339.

Karyokinesis, details of, explained, 253.

Katydid (illus.), 401.

Keeler, C., 420.

Kelvin, Lord, 44.

Korschinsky, H., 111, 114, 156.

Lacerta, diagram showing variation in different species of, 139.

Lacerta agilis, regeneration of (illus.), 286.

Ladybird, Australian (illus.), 62, 64; beetles (illus.), 416; convergent variation in pattern of (illus.), 132; (illus.), 133.

Lamarck, 48, 55, 111, 196; evolutionary principle of, 196. 
Lamarckism, 111.

Lankester, 197.

Laveran, 352.

Laws, of science, 9.

Lecanium oler (illus.), 366).

Lemur furcifer (illus.), 455.

Lepas, metamorphosis of (illus.), 234.

Lepomis megulotis (illus.), 17.

Leptodera hyalina, showing sex dimorphism (illus.), 221.

Leptothorax emersoni, ne'st of (illus.), 393.

Lepus, surecies of, showing differences (illus.), 320).

Lerema accius, distribution of (illus.), 310.

Lernacera (illus.), 359 .

Life, duration of, 240; its physical basis, 25; origin of, 42; simplest expression, 25.

Lilies, Burbank's work with, 100.

Lily, improved seedling with two petals (illus.), 100.

Lina lapponica (illus.), 194 .

Linckia, regeneration of (illus.), 2st.

Linnæus, 14.

Lizard, common (illus.), 1s; pineal eye of, 175; reguneration of (illus.), 2s6; walking (illus.), 22.

Lizards, diagram showing variation in, 139.

Locust, on sand (illus.), 401; redlegged, variation in tibial spiuses of, 133; (illus.), 136; seventernyear, variation in tibial spines of (illus.), 136.

Locusts of Galapagos Islands, showing variation (illus.), 313.

Loeb, J., 280, 42s, 129 .

Loligo pralii (illus.), 40.

Lophortyx californicus (illus.), 15.

Lueas, 428.

Lyell, C., 80.

Macfirland, F. M., 25\%3.

Macropus rufus, 339.
Malaria, parasite problocing, 35:

Malthus, 67, 65, law of 17.7.

Manumeth, drawing of, on isory

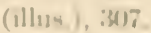

Man, earlint tracem of, :30\%, Mis: enubryology of, Hof, forne, sheler ton of, complaresl wills that of

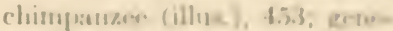

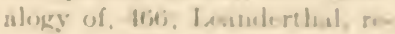
Insius of (1llus), M.5; plaen in nature of, tist; phat: of, compareel with ehimpasaze falluse) 459; protiles of cranis of primitive tyges of (Olles), wot: racess of, 454; linesand doge, hair covering of, 175; shull of, compared with skull of orang-utan, (illus.), 452; from . 4 y, skull of (illus.), 166; st mucture of, 453, tereth of, compared with orangutan (illum.), 451; scetigal structures in, ftil.

Man and apes, ears of (allus), 173

Mantis, prayiug, meting grasoloupper (illus.), 61.

Marshall, fi, 414, 419, 423,424.

Mating, cross, 1 sti.

Maturation in evclope, 272, of egg of (cyclops (illus.), 2t:3; (illus). 265.

Mayer, A., 79.

McCook, 11., 394.

Mecracken, I., 192; exprimental work in luereslity, 1!H.

Mecullewh, O. C. isis

Merbanism, 27t; urous vitalian, 246.

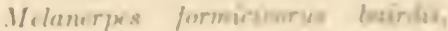
acourse dequesitest in ino ly (illus.), 4:2; (illowel, 134

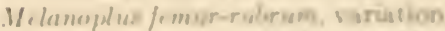
in titisal spiars of ollowis 106.

Mrdisphase, defomed, 254

Mendel, 1; d, 15; expentmese is heredity, 15:

Mercurvalie annos, biviation in lesvers of (ithen) 1.59. 
Merriam, C. H., 117.

Metamorphosis, 235; of barnacle (illus.), 234; of crab (illus.), 238; of Monarch butterfly (illus.), 235; of silkworm moth (illus.), 236; of toad (illus.), 237.

Micellæ of Nägeli, 251.

Microzymes of Bechamp, 250.

Mid-parent of Galton, 165.

Mimicry, 421.

Mind, 448.

Mite, itch (illus.), 363.

Mitosis, 252; details of, described, 253.

Moenkhaus, 89.

Molecules, organic, of Buffon, 250.

Monkey (illus.), 446.

Morgan, 146, 157.

Mousefish (illus.), 410 .

Müller, F., 408.

Mutation, 54, 131, 147, 187; de Vries theory of, 114 .

Mutilations, not inherited, 202.

Myrmecophily, 372.

Myrmica scabrinodes, nest of (illus.), 393.

Myzostoma glabrum, fertilization of egg of (illus.), 267.

Nägeli, 47, 55, 111, 197; theory of protoplasmic structure, 251.

Narcine brasiliensis (illus.), 334.

Neo-Darwinism, 197.

Neo-Lamarckism, 197.

Newbigin, M. I., 398.

New Zealand, plagues of, 65 .

Noctiluca, conjugation of (illus.), 220.

Nomeus, commensal life with Physalia (illus.), 372 .

Number of young, 225 .

Nycteribia (illus.), 351.

Octopus (illus.), 40; punctatus (illus.), 40.

Enothera Lamarckiana, de Vries' work on, 157.
Oncorhynchus tchaytscha, egg-laying of, 59.

Ontogeny, 211, 224; factors in, 244; first stages of (illus.), 227.

Oögenesis, 264.

Opossum (illus.), 46.

Opuntia, hybrid seedlings of (illus.) 98.

Orang-utan baby (illus.), 455; skull of, compared with skull of man (illus.), 452; teeth of, compared with man (illus.), 454 .

Organisms, geologic age of groups of 299 ; simplest, 32.

Organs, vestigial, 174 .

Oriole, Baltimore, diagram of variation in, 137.

Orioles, distribution and classification of American, 128.

Ornithotomus sutorius, nest of (illus.), 444.

Orthogenesis, 113.

Ortmann, A. E., 108.

Osborn, H. F., 115, 203.

Ostracoderm (illus.), 305.

Ostrich, African (illus.), 45.

Ovocyte, defined, 264.

Ovogonium, defined, 264.

Oxytricha fallax, reacting to cold (illus.), 428.

Packard, A. S., 197, 297.

Pagurus bernhardus (illus.), 374 .

Paleontology, 289.

Palo Alto, stock farm of, 103.

Pandorina sp. (illus.), 35.

Pangenesis of gemmules of Darwin 250.

Papilio cresphontes, larva of (illus.) 322; chrysalid of (illus.), 409.

Paramœcium aurelia (illus.), 33; reproduction of, 216.

Parasites, external, 348; facultative, 349 ; internal, 348 ; obligate, 349 ; permanent, 349 ; temporary, 349 .

Parasitism, 347. 
arthenogenesis, 215; artificial, 283; variation in animals produced by, 155 . asteur, 13.

attern, in animals, $39 \mathrm{~s}$.

airson, Karl, 185.

clecanus erythrorhynchus (illus.), 20.

lican, brown (illus.), 329; white (illus.), 20.

cneus potimirium, development of (illus.), 232.

eronea cristana, variation in wing pattern of (illus.), 148.

ctromyzon fluviatilis, fertilization of (illus.), 219.

haneus mexicanus (illus.), 72.

heasant, Argus, male and fomale (illus.), 75 .

hlegethontius carolina, larva of (illus.), 418.

hrynosoma blainevillei, pineal eye of (illus.), 176 .

ayla, of animals, 33 .

hyllium (illus.), 413.

hyllopteryx (illus.), 415.

hysalia, commensal life with $\mathrm{No}$ meus (illus.), 372.

hysiological units of Spencer, 250. iddock (illus.), 39.

igeons, races of (illus.), 87 .

impla conquisitor, laying eggs in cocoon (illus.), 359.

ipa americana (illus.), 43.

ipefish (illus.), 415.

ithecanthropus crectus, 462; remains of (illus), 463; (illus.), 464.

lanaria lugubris, regeneration of (illus.), 285; (illus.), 286.

lants, iiving symbintically with animals, 376; number of, 16 ; parasitic, 362 .

late, L., 77.

lateau, 424.

lum and its parent (illus.), 93; plumeot, types of (illus.), 92; seedlings from (illus.), 92.
Plums, Burbank's work with, 92.

Podocoryne carnea (illus.), 373.

Polar bodies (illus.), 270.

Polyp, fresh water (illus.), 35.

Polyps, commensal life with hermit crab (illus.), 373; (illus.), 374.

Poppies, Burbank's work with (illus.), 99.

Potato, Burlsank, 91, 92.

Poulton, E. B., 405, 419, 423, 424

Prawn (illus.), 365; stages in development of (illus.), 232.

Preformation, 276; theory, 249.

Prenatal influences, 167.

Pressure of atmosphere in relation to animal life, 40.

Primates, 454; classification of, 455 . Primroses, evening, de Vries' work on, 157.

Prophase, defined, 254.

Protista, 32.

Protophyta, 32 .

Protoplasm, chemistry of, 27; physical structure of, 28,247 .

Protozoa, 32; parasitic, 354; reproduction of colonial, 216.

Pterophryne histrio (illus.), 410 .

Pterichthyodes milleri (illus.), 305.

Pygosteus, 207.

Pyrus japonica, seedlings of (illus.), 95.

Quadrumana, 458.

Quail, California (illus.), 15.

Quetelet, 140, 141.

Quince, Japanese, seedlings of (illus.), 95 .

Radl, F., 42S.

Raja binoculata, egg case of (illus.), 337.

Rambur, 13, 14.

Rat, kangaroo (illus.), 13.

Rattlesnake, diamond (illus.), 16.

Realnn, arctic, 318; Australian, 322; holaretic, 319 ; lemurian, 322; 
neo-tropical, 321; paleo-tropical, 321; Patagonian, 322.

Realms, geographic organisms, 318 . Reason, 443.

Recognition marks, 420.

Record, Zoölogical, 14.

Redfield, C., 106.

Reflexes, 426.

Regeneration, 285; of blastula of seaurchin (illus.), 287; of earthworm (illus.), 284; of eye of triton (illus.), 287; of flatworm (illus.), 285; (illus.), 286; of Hydra viridis (illus.), 282; of lizard (illus.), 286; of starfish (illus.), 283; of Stentor cœruleus (illus.), 282.

Remora, commensal life with shark (illus.), 370 .

Reproduction, by budding, 215; by sporulation, 215; excess in, 58. Resemblance, general protective, 406; special protective, 411; variable protective, 407 .

Reversion, 166.

Rhizobius ventralis (illus.), 366 .

Rhodites rosa, galls produced by (illus.), 341.

Robinson, L., 461.

Rocks, sedimentary, how deposited, 293.

Romanes, G., 109, 461.

Roux, W., 70.

Rückert, 272.

Sacculina (illus.), 365; carcinus, parasite of crab (illus.), 358 .

Salamander, blunt-nosed (illus.), 20; cell fission of (illus.), 255 .

Salix auritax purpurea, variation in stamens of (illus.), 160 .

Salmo irideus (illus.), 343.

Salmon, quinnat, egg-laying of, 59 .

Saltation, 54.

Samia ceanothi, cocoon of (illus.), 332.

Sarcoptes scabei (illus.), 363.
Scale, black (illus.), 366; cottony cushion, 62,64 .

Sceloporus undulatus (illus.), 18.

Schaffhausen, 46, 464.

Schistocerca, species of, from Gala pagos Islands, showing variation (illus.), 313.

Schmidt, P., 346.

Scorpion (illus.), 331.

Skulls of two breeds of fowls (illus.), 88.

Scutellista cyanea (illus.), 366.

Sea anemone, anatomy of (illus.), 36.

Seal, fur, family of (illus.), 440; killed by parasitic worm (illus.), 357.

Sea-urchin, egg cell of (illus.), 248; larva of (illus.), 275; regeneration of blastula of (illus.), 287. Segregation, 53.

Selection, artificial, 51, 80; artificial, its relation to evolution, 106; claimed importance of, 50 ; natural, 57; sexual, 51, 57, 71; sexual, criticisms of, 77; sexual, experimental stage of, 79 .

Selenka, 460.

Self-defence, instincts of, 433.

Semper, C., 131.

Separation, 53.

Serpent star (illus.), 14.

Serphus, carrying eggs (illus.), 340 .

Sex, 211, 220; cells, 218; determination of, 170 .

Sexes, numerical relations of, 170 .

Sexual, secondary characters, 72 .

Sheep, artificial selection of, 81; Dorset (illus.), 83; Merino (il.lus.), 85; polled Welsh (illus.), 83; Rocky Mountain (illus.), 382 ; Southdown (illus.), 84 .

Shelford, 423.

Silkworm moth, development of (illus.), 236.

Silkworms, experimental rearing of 150. 
Silva, carmen, 167.

Skate, egg case of barn (loor (illus.), 339.

Slime mold (illus.), 32.

Snails, distribution of land, of Hawaii, 12:3.

Solenopsis fuga, nest of (illus.), 392.

Species, changing with space and time, 18; estimate of duration of, 302 ; number of, 14 ; ontogenetic, 114 .

Species-forming, 117; by saltations, 156 ; various theories of, 108 .

Spencer, Herbert, 5, 196, 197, 19.; definition of evolution, 5 ; theory of protoplasmic structure, 250.

Spermatogenesis of ascaris (illus.), 264.

Spermatozoa (illus.), 218.

Spcrmatozoan, development of (illus.), 266.

Spermatozoid, 261.

Spharechinus Echinus, hybrid larva of (illus.), 277; hybrid pluteus of (illus.), 280.

Sphorechinus granularis, heating larva of (illus.), 279; lithium gastrula of (illus.), 279; lithium larva of (illus.), 278; normal larva of (illus.), 275.

Sphenodon, pineal eye of (illus.), 175 .

Spider, nest of trap door (illus.), 346.

Sponge, simple (illus.), 36.

Sports, 186; examples of race formed from, 161; species arising from, 107.

Sporulation, reproduction by, 215 .

Squid (illus.), 40.

Stamens of willows, variation in (illus.), 160.

Stanford, I ieland, 103.

Starfish, regeneration of (illus.), 283; walking (illus.), 23.

Starks, E. C., 303.

Stentor corruleus (illus.), 2S2; re acting to light (illus.), 430; reproducing by fission (illus.), 215.

Sticklebacks (illus.), 209); ontogonetic variations in, 207 .

Sting-ray (illus.), 333.

Sitructures, convergence of, 204; parallelisms in, 204.

Struggle for cxistence, 57,60 .

Struthio camelus (illus.), 45.

Sunfish, long-eared (illus.), 17.

Survival of the fittest, 62 .

Swift, common (illus.), 18.

Swordfish, development of (illus.), 239.

Symbiosis, 373; of plants and animals, 376.

syngamus trachealis (illus.), 22:3.

Systema Nature, 14.

Tania solium (illus.), 3i5.

Tail of man, hology of, 179 .

Tailor bird, nest of (illus.), 414.

Tapeworm (illus.), 35.5.

Tarsal segments, variation in, corkroach (illus.), 149.

Taxis, 28.2.

Taylor, Bayard, 163.

Teeth of man and orang-utan compared (illus.), 454.

Telegony, 166.

Telophase defined, 256.

Temperature in relation to animal life, 3s.

Termitophily, 372.

Termites, castes of (illus.), 395; communal life of, 3:44.

Terrifying appearances, $41 \mathrm{~s}$.

Thalessa (illus.), 361 ; (illus.), 362.

Theory, transmutation, of lamarck, 111.

Timothy, heads of, improverl by selection (illus.), 91.

To:ad (illus.), 34; horned, pineal (ye of (illus.), 17ti; metamorphosis of (illus.), 237.

Tobucco worm (illus.), 418. 
Toes, variation in number of (illus.), 147.

Torpedo (illus.), 334.

Tower, W. L., 404.

Toxopneustes libidus, egg cell of (illus.), 248.

Toyama, 192.

Trembley, Abbé, 286.

Tremex columba (illus.), 362.

Trial and theory of behavior, 430 .

Trichia favaginea (illus.), 32.

Trichina spiralis (illus.), 356.

Trimen, 408.

Triton, regeneration of eye of (illus.), 287.

Trochilus rufus, nest of eggs of (illus.), 441.

Tropism, 282; theory of bchavior by, 428 .

Trout, ontogenetic variations in, 208; rainbow (illus.), 343.

Tschermak, 192.

Tunicate (illus.), 364 .

Turner, L. J., 39.

Turtle, hawk bill (illus.), 43; with two heads (illus.), 146.

Twig, insect (illus.), 412.

Two Ocean Pass (illus.), 317.

Types of animals (illus.), 31 .

Uexkull, 428.

Uncinaria, parasite of seals (illus.), 357.

Unity, in life, 12, 22.

Urolophus goodi (illus.), 333.

Use and disuse, effects of, 206.

Variation, 131; curves of (illus.), 140; Darwin's laws of, 137; determinate, 150; determinate, apparent example of, 152 ; ontogenetic, in sticklebacks, 207; in parthenogenetic animals, 155; Quetelet's law of, 141; in wings of honeybee (illus.), 155; (illus.), 156.

Variations, acquired, 142; congeni- tal, 142 ; continuous, 146 ; discontinuous, 146; in function, 19; meristic, 148; substantive, 147.

Variety, in life, 12.

Vedalia cardinalis (illus.), 62, 64.

Vegetables originated by Burbank, 98.

Vertebrates, earliest remains of, 305 ; gill slits of, 179 .

Vespa (illus.), 385; germanica, variation in pattern of (illus.), 134. Vespa, nest of (illus.), 328,386 .

Vestigial organs, 174; explanation of, 181 ; vestigial structures in man, 461 .

Vitalism, 276; versus mechanism, 246.

Volvocince, reproduction in, 217.

Von Kölliker, 111, 114, 156.

Vorticella nebulifera, conjugation of (illus.), 221.

Vulpes pennsylvanicus argentatus (illus.), 21.

Wagner, M., 108, 117.

Wallace, A. R., 76, 108, 197, 311, $319,402$.

Walnuts, Burbank's work (illus.), 96; (illus.), 97.

Warblers, yellow, distribution and classification of, 120.

Wasmann, E., 394.

Wasp, social (illus.), 385; variation in pattern of (illus.), 134 .

Wasps, communal life of, 385; social nest of (illus.), 328 .

Water bug, giant (illus.), 340 .

Weismann, A., 68, 154, 197, 198, 423,425 ; theory of protoplasmic structure, 251.

Wesley, J., 452.

Wheeler, W. M., 424.

Wheeler, W. W., 394.

Whitford, C. B., 168.

Whooping cran? (illus.), 20.

Wiedersheim, 175, 461. 
Wiesner, theory of protoplasmic structure, 250.

Willows, variation in stamens of (illus.), 160.

Wilson, E. B., 125, 126, 279.

Wing hooks of honeybee (illus.), 155.

Wings of a drone honeybee, showing variation (illus.), 155; (illus.), 156; of animals, analogies in, 173; variation in pattern of, in Peronea cristena, 145.

II'inthemia 4-pustulata (illus.), 3ts. Woodpecker, Cillifornial, acorns de- posited in tree by (illus) , 432 (illus.), 4.34.

Worms, parasitic, 3.5.4.

Wyman, J., 461.

Xrrophyllum simile (Hlum.), 409 .

Youall, s().

Zebra, hybricl of, with hure, Is.3

Zirphara crispmta (illus.), 39.

Zerogeography, 305.

Zoy:1, 27:1.

Zur st rassen, 0., 279. 






Fin

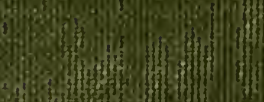

Hot

1030 Q9:3

6)

sisish

10.0

Hol. 